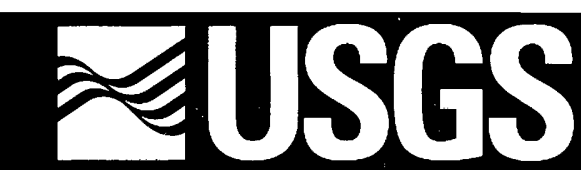

\title{
Quality-Assurance Results for Routine Water Analyses in U.S. Geological Survey Laboratories, Water Year 1998
}

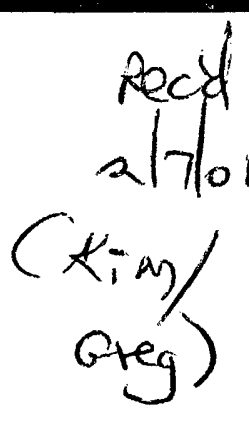

Water-Resources Investigations Report 00-4176

U.\&. Departiment of the linterior

1.8. Geological survey 


\section{Quality-Assurance Results for Routine Water Analyses in U.S. Geological Survey Laboratories, Water Year 1998}

By Amy S. Ludtke, Mark T. Woodworth, and Philip S. Marsh

U.S. GEOLOGICAL. SURVEY

Water-Resources Investigations Report 00-4176 


\section{U.S. DEPARTMENT OF THE INTERIOR \\ BRUCE BABBITT, Secretary}

\section{U.S. GEOLOGICAL SURVEY}

Charles G. Groat, Director

The use of firm, trade, and brand names in this report is for identification purposes only and does not constitute endorsement by the U.S. Geological Survey.

For additional information write to:

Chief, Branch of Quality Systems

U.S. Geological Survey

Water Resources Division

Box 25046, Mail Stop 401

Denver Federal Center

Denver, CO 80225-0046
Copies of this report can be purchased from:

U.S. Geological Survey

Information Services

Box 25286

Federal Center

Denver, CO 80225 


\section{CONTENTS}

Abstract

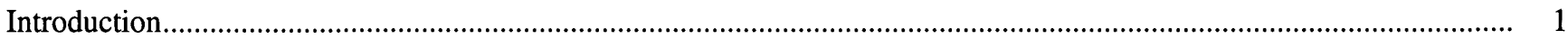

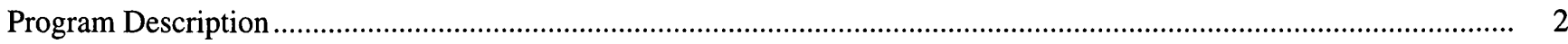

Estimation of Sample Loads ...................................................................................................................

Comparison of Results with the National Water Information System Water-Quality Data Bases ........................... 3

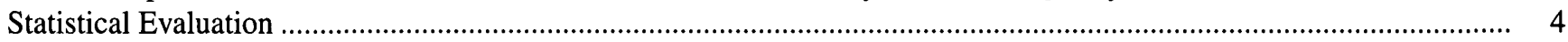

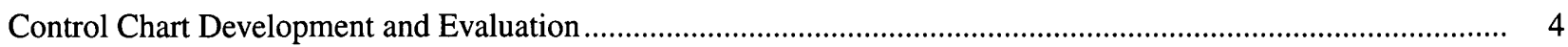

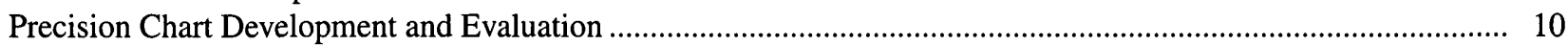

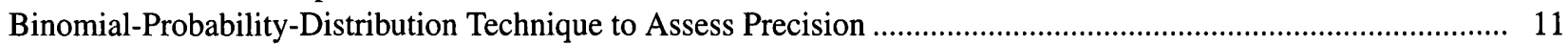

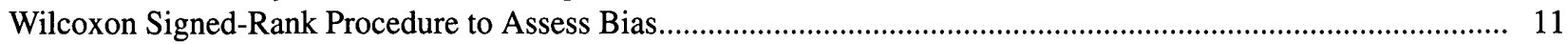

Quality-Assurance Data for Inorganic-Constituent Samples...................................................................................... 16

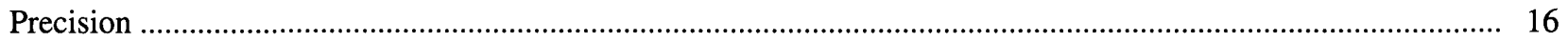

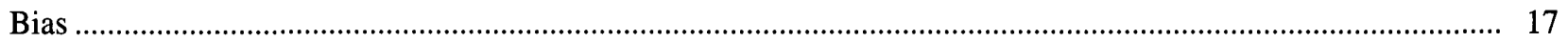

Quality-Assurance Data for Nutrient-Constituent Samples.......................................................................................... 17

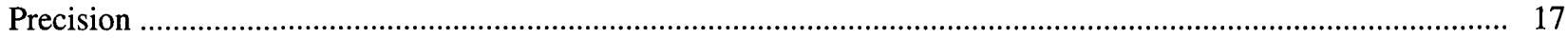

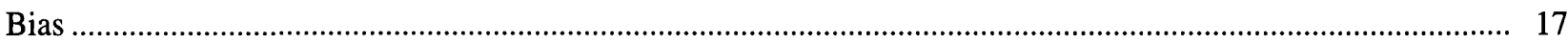

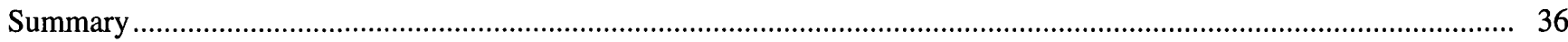

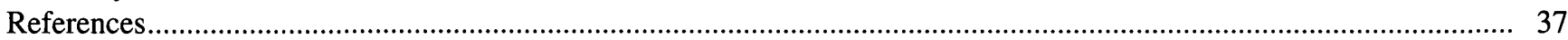

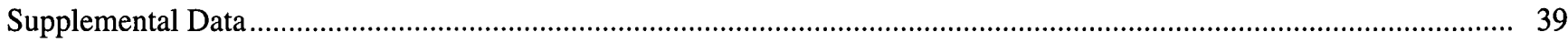

\section{FIGURES}

1-159. Graphs showing:

1. Display of line of relation for ordinary least-squares regression equation derived for sodium................... 5

2. Alkalinity, whole-water recoverable, (electrometric titration) data from the National Water Quality Laboratory...

3. Aluminum, dissolved, (inductively coupled plasma-atomic emission spectrometry) data from the National Water Quality Laboratory.

4. Aluminum, dissolved, (inductively coupled plasma-mass spectrometry) data from the National Water Quality Laboratory

5. Aluminum, whole-water recoverable, (direct current plasma-atomic emission spectrometry) data from the National Water Quality Laboratory...

6. Antimony, dissolved, (hydride generation-atomic absorption spectrophotometry) data from the National Water Quality Laboratory

7. Antimony, dissolved, (inductively coupled plasma-mass spectrometry) data from the National Water Quality Laboratory...

8. Arsenic, dissolved, (hydride generation-atomic absorption spectrophotometry) data from the National Water Quality Laboratory

9. Arsenic, whole-water recoverable, (graphite furnace-atomic absorption spectrophotometry, U.S. Environmental Protection Agency) data from the National Water Quality Laboratory .

10. Arsenic, whole-water recoverable, (hydride generation-atomic absorption spectrophotometry) data from the National Water Quality Laboratory

11. Barium, dissolved, (inductively coupled plasma-atomic emission spectrometry) data from the National Water Quality Laboratory

12. Barium, dissolved, (inductively coupled plasma-mass spectrometry) data from the National Water Quality Laboratory

13. Beryllium, dissolved, (inductively coupled plasma-atomic emission spectrometry) data from the National Water Quality Laboratory.

14. Beryllium, dissolved, (inductively coupled plasma-mass spectrometry) data from the National Water Quality Laboratory

15. Boron, dissolved, (inductively coupled plasma-atomic emission spectrometry) data from the National Water Quality Laboratory 
16. Boron, whole-water recoverable, (direct current plasma-atomic emission spectrometry) data from the National Water Quality Laboratory.

17. Cadmium, dissolved, (graphite furnace-atomic absorption spectrophotometry) data from the National Water Quality Laboratory

18. Cadmium, dissolved, (inductively coupled plasma-atomic emission spectrometry) data from the National Water Quality Laboratory.

19. Cadmium, dissolved, (inductively coupled plasma-mass spectrometry) data from the National Water Quality Laboratory

20. Cadmium, whole-water recoverable, (graphite furnace-atomic absorption spectrophotometry)

data from the National Water Quality Laboratory

21. Calcium, dissolved, (inductively coupled plasma-atomic emission spectrometry) data from the National Water Quality Laboratory

22. Chloride, dissolved, (ion chromatography) data from the National Water Quality Laboratory

23. Chloride, dissolved, (ion chromatography, low level) data from the National Water Quality Laboratory

24. Chromium, dissolved, (graphite furnace-atomic absorption spectrophotometry) data from the National Water Quality Laboratory

25. Chromium, dissolved, (inductively coupled plasma-atomic emission spectrometry) data from the National Water Quality Laboratory

26. Chromium, dissolved, (inductively coupled plasma-mass spectrometry) data from the National Water Quality Laboratory

27. Chromium, whole-water recoverable, (graphite furnace-atomic absorption spectrophotometry) data from the National Water Quality Laboratory

28. Cobalt, dissolved, (graphite furnace-atomic absorption spectrophotometry) data from the National Water Quality Laboratory

29. Cobalt, dissolved, (inductively coupled plasma-atomic emission spectrometry) data from the National Water Quality Laboratory

30. Cobalt, dissolved, (inductively coupled plasma-mass spectrometry) data from the National Water Quality Laboratory....

31. Cobalt, whole-water recoverable, (graphite furnace-atomic absorption spectrophotometry) data from the National Water Quality Laboratory

32. Copper, dissolved, (graphite furnace-atomic absorption spectrophotometry) data from the National Water Quality Laboratory

33. Copper, dissolved, (inductively coupled plasma-atomic emission spectrometry) data from the National Water Quality Laboratory

34. Copper, dissolved, (inductively coupled plasma-mass spectrometry) data from the National Water Quality Laboratory

35. Copper, whole-water recoverable, (graphite furnace-atomic absorption spectrophotometry) data from the National Water Quality Laboratory.

36. Dissolved solids, dissolved, (gravimetric) data from the National Water Quality Laboratory.....

37. Fluoride, dissolved, (ion chromatography, low level) data from the National Water Quality Laboratory

38. Fluoride, dissolved, (ion-selective electrode) data from the National Water Quality Laboratory.

39. Iron, dissolved, (inductively coupled plasma-atomic emission spectrometry) data from the National Water Quality Laboratory

40. Iron, whole-water recoverable, (flame-atomic absorption spectrophotometry) data from the

National Water Quality Laboratory

1. Lead, dissolved, (graphite furnace-atomic absorption spectrophotometry) data from the

National Water Quality Laboratory

42. Lead, dissolved, (inductively coupled plasma-atomic emission spectrometry) data from the National Water Quality Laboratory

43. Lead, dissolved, (inductively coupled plasma-mass spectrometry) data from the National Water Quality Laboratory.

4. Lead, whole-water recoverable, (graphite furnace-atomic absorption spectrophotometry) data from the National Water Quality Laboratory 
45. Lithium, dissolved, (inductively coupled plasma-atomic emission spectrometry) data

from the National Water Quality Laboratory

46. Lithium, whole-water recoverable, (flame-atomic absorption spectrophotometry) data

from the National Water Quality Laboratory

47. Magnesium, dissolved, (inductively coupled plasma-atomic emission spectrometry)

data from the National Water Quality Laboratory.

48. Manganese, dissolved, (inductively coupled plasma-atomic emission spectrometry) data

from the National Water Quality Laboratory .....

49. Manganese, dissolved, (inductively coupled plasma-mass spectrometry) data from the

National Water Quality Laboratory....

50. Manganese, whole-water recoverable, (flame-atomic absorption spectrophotometry)

data from the National Water Quality Laboratory...

51. Mercury, dissolved, (cold vapor-atomic absorption spectrophotometry) data from the National Water Quality Laboratory.....

52. Mercury, whole-water recoverable, (cold vapor-atomic absorption spectrophotometry) data from the National Water Quality Laboratory.

53. Molybdenum, dissolved, (graphite furnace-atomic absorption spectrophotometry) data from the National Water Quality Laboratory .....

54. Molybdenum, dissolved, (inductively coupled plasma-atomic emission spectrometry) data from the National Water Quality Laboratory ....

55. Molybdenum, dissolved, (inductively coupled plasma-mass spectrometry) data from the National Water Quality Laboratory....

56. Molybdenum, whole-water recoverable, (graphite furnace-atomic absorption spectrophotometry) data from the National Water Quality Laboratory.

57. Nickel, dissolved, (graphite furnace-atomic absorption spectrophotometry) data from the National Water Quality Laboratory.....

58. Nickel, dissolved, (inductively coupled plasma-atomic emission spectrometry) data from the National Water Quality Laboratory

59. Nickel, dissolved, (inductively coupled plasma-mass spectrometry) data from the National Water Quality Laboratory.

60. Nickel, whole-water recoverable, (graphite furnace-atomic absorption spectrophotometry) data from the National Water Quality Laboratory...

61. Potassium, dissolved, (flame-atomic absorption spectrophotometry) data from the National Water Quality Laboratory.

62. Potassium, dissolved, (flame-atomic absorption spectrophotometry, low level) data from the National Water Quality Laboratory ....

63. Selenium, dissolved, (hydride generation-atomic absorption spectrophotometry) data from the National Water Quality Laboratory

64. Selenium, whole-water recoverable, (graphite furnace-atomic absorption spectrophotometry, U.S. Environmental Protection Agency) data from the National Water Quality Laboratory.....

65. Selenium, whole-water recoverable, (hydride generation-atomic absorption spectrophotometry) data from the National Water Quality Laboratory...

66. Silica, dissolved, (colorimetric) data from the National Water Quality Laboratory ..

67. Silica, dissolved, (inductively coupled plasma-atomic emission spectrometry) data from the National Water Quality Laboratory

68. Silver, dissolved, (graphite furnace-atomic absorption spectrophotometry) data from the National Water Quality Laboratory..... 107

69. Silver, dissolved, (inductively coupled plasma-atomic emission spectrometry) data from the National Water Quality Laboratory .....

70. Silver, dissolved, (inductively coupled plasma-mass spectrometry) data from the National Water Quality Laboratory....

71. Silver, whole-water recoverable, (graphite furnace-atomic absorption spectrophotometry) data from the National Water Quality Laboratory......

72. Sodium, dissolved, (inductively coupled plasma-atomic emission spectrometry) data from the National Water Quality Laboratory 
73. Specific conductance, whole-water recoverable, (electrometric, low level) data from the National Water Quality Laboratory

74. Strontium, dissolved, (inductively coupled plasma-atomic emission spectrometry) data from

the National Water Quality Laboratory

75. Sulfate, dissolved, (ion chromatography) data from the National Water Quality Laboratory.

76. Vanadium, dissolved, (inductively coupled plasma-atomic emission spectrometry) data from the National Water Quality Laboratory ....

77. Zinc, dissolved, (inductively coupled plasma-atomic emission spectrometry) data from the National Water Quality Laboratory

78. Zinc, dissolved, (inductively coupled plasma-mass spectrometry) data from the National Water Quality Laboratory.....

79. Zinc, whole-water recoverable, (flame-atomic absorption spectrophotometry) data from the National Water Quality Laboratory

80. Ammonia as nitrogen, dissolved, (colorimetric) data from the National Water Quality Laboratory

81. Ammonia as nitrogen, dissolved, (colorimetric, low level) data from the National Water Quality Laboratory

82. Ammonia as nitrogen, dissolved, (U.S. Environmental Protection Agency) data from the National Water Quality Laboratory

83. Ammonia plus organic nitrogen as nitrogen, dissolved, (micro-Kjeldahl digestion, automated segmented flow, colorimetric) data from the National Water Quality Laboratory .....

84. Ammonia plus organic nitrogen as nitrogen, dissolved, (U.S. Environmental Protection Agency) data from the National Water Quality Laboratory.....

85. Ammonia plus organic nitrogen as nitrogen, whole-water recoverable, (micro-Kjeldahl digestion, automated segmented flow, colorimetric) data from the National Water Quality Laboratory......

86. Ammonia plus organic nitrogen as nitrogen, whole-water recoverable, (U.S. Environmental Protection Agency) data from the National Water Quality Laboratory.

87. Nitrate plus nitrite as nitrogen, dissolved, (colorimetric) data from the National Water Quality Laboratory

88. Nitrate plus nitrite as nitrogen, dissolved, (colorimetric, low level) data from the National Water Quality Laboratory.....

89. Orthophosphate as phosphorus, dissolved, (colorimetric) data from the National Water Quality Laboratory

90. Orthophosphate as phosphorus, dissolved, (colorimetric, low level) data from the National Water Quality Laboratory.....

91. Phosphorus, dissolved, (micro-Kjeldahl digestion, automated segmented flow, colorimetric) data from the National Water Quality Laboratory....

92. Phosphorus, dissolved, (colorimetric, low level) data from the National Water Quality Laboratory

93. Phosphorus, dissolved, (U.S. Environmental Protection Agency) data from the National Water Quality Laboratory ......

94. Phosphorus, whole-water recoverable, (micro-Kjeldahl digestion, automated segmented flow, colorimetric) data from the National Water Quality Laboratory

95. Phosphorus, whole-water recoverable, (colorimetric, low level) data from the National Water Quality Laboratory

96. Phosphorus, whole-water recoverable, (U.S. Environmental Protection Agency) data from the National Water Quality Laboratory ......

97. Alkalinity, whole-water recoverable, (electrometric titration) data from the Quality of Water Service Unit laboratory....

98. Aluminum, dissolved, (inductively coupled plasma-atomic emission spectrometry, trace) data from the Quality of Water Service Unit laboratory

99. Aluminum, whole-water recoverable, (graphite furnace-atomic absorption spectrophotometry, U.S. Environmental Protection Agency) data from the Quality of Water Service Unit laboratory.

100. Aluminum, whole-water recoverable, (inductively coupled plasma-atomic emission spectrometry, trace) data from the Quality of Water Service Unit laboratory 
101. Arsenic, dissolved, (graphite furnace-atomic absorption spectrophotometry) data from the Quality of Water Service Unit laboratory...

102. Arsenic, whole-water recoverable, (graphite furnace-atomic absorption spectrophotometry) data from the Quality of Water Service Unit laboratory ....

103. Barium, dissolved, (inductively coupled plasma-atomic emission spectrometry, trace) data from the Quality of Water Service Unit laboratory...

104. Barium, whole-water recoverable, (inductively coupled plasma-atomic emission spectrometry, trace) data from the Quality of Water Service Unit laboratory ...

105. Beryllium, dissolved, (inductively coupled plasma-atomic emission spectrometry, trace) data from the Quality of Water Service Unit laboratory...

106. Beryllium, whole-water recoverable, (inductively coupled plasma-atomic emission spectrometry, trace) data from the Quality of Water Service Unit laboratory .....

107. Boron, dissolved, (inductively coupled plasma-atomic emission spectrometry, trace) data from the Quality of Water Service Unit laboratory.

108. Cadmium, dissolved, (graphite furnace-atomic absorption spectrophotometry) data from the Quality of Water Service Unit laboratory.

109. Cadmium, dissolved, (inductively coupled plasma-atomic emission spectrometry, trace) data from the Quality of Water Service Unit laboratory.....

110. Cadmium, whole-water recoverable, (graphite furnace-atomic absorption spectrophotometry) data from the Quality of Water Service Unit laboratory .....

111. Cadmium, whole-water recoverable, (inductively coupled plasma-atomic emission spectrometry, trace) data from the Quality of Water Service Unit laboratory ....

112. Calcium, dissolved, (inductively coupled plasma-atomic emission spectrometry) data from the Quality of Water Service Unit laboratory.....

113. Calcium, dissolved, (inductively coupled plasma-atomic emission spectrometry, trace) data from the Quality of Water Service Unit laboratory....

114. Chloride, dissolved, (ion chromatography) data from the Quality of Water Service Unit laboratory

115. Chromium, dissolved, (inductively coupled plasma-atomic emission spectrometry, trace) data from the Quality of Water Service Unit laboratory.....

116. Chromium, whole-water recoverable, (graphite furnace-atomic absorption spectrophotometry) data from the Quality of Water Service Unit laboratory ....

117. Chromium, whole-water recoverable, (inductively coupled plasma-atomic emission spectrometry, trace) data from the Quality of Water Service Unit laboratory .....

118. Cobalt, dissolved, (inductively coupled plasma-atomic emission spectrometry, trace) data from the Quality of Water Service Unit laboratory....

119. Copper, dissolved, (graphite furnace-atomic absorption spectrophotometry) data from the Quality of Water Service Unit laboratory.

120. Copper, dissolved, (inductively coupled plasma-atomic emission spectrometry, trace) data from the Quality of Water Service Unit laboratory.....

121. Copper, whole-water recoverable, (graphite furnace-atomic absorption spectrophotometry) data from the Quality of Water Service Unit laboratory.

122. Copper, whole-water recoverable, (inductively coupled plasma-atomic emission spectrometry, trace) data from the Quality of Water Service Unit laboratory .

123. Dissolved solids, dissolved, (gravimetric) data from the Quality of Water Service Unit laboratory

124. Fluoride, dissolved, (ion-selective electrode) data from the Quality of Water Service Unit laboratory

125. Iron, dissolved, (inductively coupled plasma-atomic emission spectrometry, trace) data from the Quality of Water Service Unit laboratory....

126. Iron, whole-water recoverable, (inductively coupled plasma-atomic emission spectrometry, trace) data from the Quality of Water Service Unit laboratory ....

127. Lead, dissolved, (graphite furnace-atomic absorption spectrophotometry) data from the Quality of Water Service Unit laboratory..... 
128. Lead, dissolved, (inductively coupled plasma-atomic emission spectrometry, trace) data from the Quality of Water Service Unit laboratory......

129. Lead, whole-water recoverable, (graphite furnace-atomic absorption spectrophotometry) data from the Quality of Water Service Unit laboratory

130. Lead, whole-water recoverable, (inductively coupled plasma-atomic emission spectrometry, trace) data from the Quality of Water Service Unit laboratory

131. Magnesium, dissolved, (inductively coupled plasma-atomic emission spectrometry) data from the Quality of Water Service Unit laboratory

132. Magnesium, dissolved, (inductively coupled plasma-atomic emission spectrometry, trace) data from the Quality of Water Service Unit laboratory

133. Manganese, dissolved, (inductively coupled plasma-atomic emission spectrometry, trace) data from the Quality of Water Service Unit laboratory.

134. Manganese, whole-water recoverable, (inductively coupled plasma-atomic emission spectrometry, trace) data from the Quality of Water Service Unit laboratory

135. Mercury, whole-water recoverable, (cold vapor-atomic absorption spectrophotometry) data from the Quality of Water Service Unit laboratory

136. Molybdenum, dissolved, (inductively coupled plasma-atomic emission spectrometry, trace) data from the Quality of Water Service Unit laboratory

137. Nickel, dissolved, (inductively coupled plasma-atomic emission spectrometry, trace) data from the Quality of Water Service Unit laboratory

138. Nickel, whole-water recoverable, (graphite furnace-atomic absorption spectrophotometry) data from the Quality of Water Service Unit laboratory.

139. Nickel, whole-water recoverable, (inductively coupled plasma-atomic emission spectrometry, trace) data from the Quality of Water Service Unit laboratory

140. Potassium, dissolved, (flame-atomic absorption spectrophotometry) data from the Quality of Water Service Unit laboratory

141. Selenium, dissolved, (graphite furnace-atomic absorption spectrophotometry) data from the Quality of Water Service Unit laboratory

142. Selenium, whole-water recoverable, (graphite furnace-atomic absorption spectrophotometry) data from the Quality of Water Service Unit laboratory....

143. Silica, dissolved, (inductively coupled plasma-atomic emission spectrometry) data from the Quality of Water Service Unit laboratory

144. Silica, dissolved, (inductively coupled plasma-atomic emission spectrometry, trace) data from the Quality of Water Service Unit laboratory

145. Silver, dissolved, (inductively coupled plasma-atomic emission spectrometry, trace) data from the Quality of Water Service Unit laboratory

146. Sodium, dissolved, (flame-atomic absorption spectrophotometry) data from the Quality of Water Service Unit laboratory

147. Strontium, dissolved, (inductively coupled plasma-atomic emission spectrometry, trace) data from the Quality of Water Service Unit laboratory

148. Strontium, whole-water recoverable, (inductively coupled plasma-atomic emission spectrometry, trace) data from the Quality of Water Service Unit laboratory

149. Sulfate, dissolved, (ion chromatography) data from the Quality of Water Service Unit laboratory

150. Vanadium, dissolved, (inductively coupled plasma-atomic emission spectrometry, trace) data from the Quality of Water Service Unit laboratory

151. Zinc, dissolved, (inductively coupled plasma-atomic emission spectrometry, trace) data from the Quality of Water Service Unit laboratory

152. Zinc, whole-water recoverable, (inductively coupled plasma-atomic emission spectrometry, trace) data from the Quality of Water Service Unit laboratory

153. Ammonia as nitrogen, dissolved, data from the Quality of Water Service Unit laboratory 192

154. Ammonia plus organic nitrogen as nitrogen, dissolved, data from the Quality of Water Service Unit laboratory....

155. Ammonia plus organic nitrogen as nitrogen, whole-water recoverable, data from the Quality of Water Service Unit laboratory 
156. Nitrate plus nitrite as nitrogen, dissolved, data from the Quality of Water Service Unit laboratory

157. Orthophosphate as phosphorus, dissolved, data from the Quality of Water Service Unit laboratory

158. Phosphorus, dissolved, data from the Quality of Water Service Unit laboratory.

159. Phosphorus, whole-water recoverable, data from the Quality of Water Service Unit laboratory

\title{
TABLES
}

1. Ordinary least-squares equations for determining the most probable deviation......

2. Total number of analyses from quality-assurance samples during water year 1998 with the number greater than two and six standard deviations from the most probable value and results of statistical testing for analytical precision in constituent data for the National Water Quality Laboratory....

3. Total number of analyses from quality-assurance samples during water year 1998 with the number greater than two and six standard deviations from the most probable value and results of statistical testing for analytical precision in constituent data for the Quality of Water Service Unit laboratory

4. Results of Wilcoxon signed-rank test for bias in constituent data for the National Water Quality Laboratory

5. Results of Wilcoxon signed-rank test for bias in constituent data for the Quality of Water Service Unit Laboratory.

\section{ABBREVIATIONS}

\author{
Units of Measure \\ C Celsius \\ $\mathrm{mg} / \mathrm{L} \quad$ milligrams per liter \\ $\mu \mathrm{g} / \mathrm{L} \quad$ micrograms per liter \\ $\mu \mathrm{S} / \mathrm{cm} \quad$ microsiemens per centimeter at 25 degrees Celsius
}

\section{Analytical Methods}

ASF micro-Kjeldahl digestion, automated segmented flow, colorimetric

COL colorimetric

CV-AAS cold vapor-atomic absorption spectrophotometry

DCP-AES direct current plasma-atomic emission spectrometry

DIS dissolved

ELEC electrometric

F-AAS flame-atomic absorption spectrophotometry

GF-AAS graphite furnace-atomic absorption spectrophotometry

GRAV gravimetric

HG-AAS hydride generation-atomic absorption spectrophotometry

IC ion chromatography

ICP-AES inductively coupled plasma-atomic emission spectrometry

ICP-AES/T inductively coupled plasma-atomic emission spectrometry, trace

ICP-MS inductively coupled plasma-mass spectrometry

ISE ion-selective electrode

LL low level

LRL laboratory reporting limit

TITR electrometric titration

USEPA U.S. Environmental Protection Agency method

WWR whole-water recoverable 
Others

$\begin{array}{ll}\text { BSP } & \text { Blind Sample Project } \\ F_{\sigma} & \text { regression estimate of F-pseudosigma } \\ \text { LOP } & \text { statistically significant lack of precision } \\ \text { MPV } & \text { most probable value } \\ \text { MRL } & \text { minimum reporting limit } \\ \text { NEG } & \text { negative bias } \\ \text { NSD } & \text { number of standard deviations } \\ \text { NWIS } & \text { National Water Information System } \\ \text { NWQL } & \text { National Water Quality Laboratory } \\ \text { POS } & \text { positive bias } \\ \text { QWSU } & \text { Quality of Water Service Unit } \\ \text { RSD } & \text { relative standard deviation } \\ \text { SRWS } & \text { standard reference water sample } \\ \text { USGS } & \text { U.S. Geological Survey }\end{array}$




\title{
Quality-Assurance Results for Routine Water Analyses in U.S. Geological Survey Laboratories, Water Year 1998
}

\author{
By Amy S. Ludtke, Mark T. Woodworth, and Philip S. Marsh
}

\section{Abstract}

The U.S. Geological Survey operates a quality-assurance program based on the analyses of reference samples for two laboratories: the National Water Quality Laboratory and the Quality of Water Service Unit. Reference samples that contain selected inorganic, nutrient, and lowlevel constituents are prepared and submitted to the laboratory as disguised routine samples. The program goal is to estimate precision and bias for as many analytical methods offered by the participating laboratories as possible. Blind reference samples typically are submitted at a rate of 2 to 5 percent of the annual environmental-sample load for each constituent. The samples are distributed to the laboratories throughout the year. The reference samples are subject to the identical laboratory handling, processing, and analytical procedures as those applied to environmental samples and, therefore, have been used as an independent source to verify bias and precision of laboratory analytical methods and ambient waterquality measurements. The results are stored permanently in the National Water Information System and the Blind Sample Project's data base. During water year 1998, 95 analytical procedures were evaluated at the National Water Quality Laboratory and 63 analytical procedures were evaluated at the Quality of Water Service Unit.

An overall evaluation of the inorganic and low-level constituent data for water year 1998 indicated 77 of 78 analytical procedures at the National Water Quality Laboratory met the criteria for precision. Silver (dissolved, inductively coupled plasma-mass spectrometry) was determined to be imprecise. Five of 78 analytical procedures showed bias throughout the range of reference samples: chromium (dissolved, inductively coupled plasma-atomic emission spectrometry), dissolved solids (dissolved, gravimetric), lithium (dissolved, inductively coupled plasma-atomic emission spectrometry), silver (dissolved, inductively coupled plasma-mass spectrometry), and zinc (dissolved, inductively coupled plasma-mass spectrometry).

At the National Water Quality Laboratory during water year 1998, lack of precision was indicated for 2 of 17 nutrient procedures: ammonia as nitrogen (dissolved, colorimetric) and orthophosphate as phosphorus (dissolved, colorimetric). Bias was indicated throughout the reference sample range for ammonia as nitrogen (dissolved, colorimetric, low level) and nitrate plus nitrite as nitrogen (dissolved, colorimetric, low level).

All analytical procedures tested at the Quality of Water Service Unit during water year 1998 met the criteria for precision. One of the 63 analytical procedures indicated a bias throughout the range of reference samples: aluminum (whole-water recoverable, inductively coupled plasma-atomic emission spectrometry, trace).

\section{INTRODUCTION}

The U.S. Geological Survey (USGS) performs numerous hydrologic investigations that require analyses of water for inorganic, nutrient, and low-level 
constituents. The National Water Quality Laboratory (NWQL) and the Quality of Water Service Unit (QWSU) laboratory are the primary sources of analytical services for many of these hydrologic investigations. The NWQL, which now occupies a new facility in Lakewood, Colorado, was located in Arvada, Colorado, during this reporting period. The QWSU is in Ocala, Florida. The NWQL provides analytical services for all national programs conducted by the USGS and also is used by USGS district offices throughout the Nation for local and regional programs. The QWSU provides analytical services to USGS district offices in the Southeastern United States.

This report describes the results of a qualityassurance program used to monitor the quality of inorganic, nutrient, and low-level analytical procedures at the NWQL and inorganic and nutrient analytical procedures at the QWSU. Previous reports (Peart and Thomas, 1983a, 1983b, 1984; Peart and Sutphin, 1987; Lucey and Peart, 1988, 1989a, 1989b; Lucey, 1989; Maloney and others, 1992, 1993, 1994; Ludtke and others, 1999) document results from February 1981 through September 1997. Some of the previous reports contain quality-assurance information for organic determinations.

The water year used by the USGS is the 12 months from October 1 through September 30 and is identified by the calendar year in which the water year ends. During water year 1998, 95 analytical procedures were evaluated for the NWQL by the Blind Sample Project (BSP). This represents about 85 percent of the inorganic and nutrient analytical procedures offered by the laboratory for water-matrix determinations. The remaining 15 percent of the water-matrix determinations offered were either infrequently requested, so that it was not feasible to include them in the BSP, or the constituents did not have a readily available, stable source of reference material. In addition, the NWQL offers analytical determinations for sample matrices other than water, such as biological tissues and sediments.

The BSP evaluated 63 analytical procedures for the QWSU during water year 1998. This represents about 75 percent of the total number of water-matrix constituents offered for analysis. The remaining 25 percent were considered to be custom determinations that were infrequently requested. In addition, some of the constituents did not have a readily available, stable source of reference material.
Laboratory users who require analyses for water-matrix constituents not offered through the BSP, or any nonwater-matrix determinations, should consider alternative procedures to measure analytical quality. The analytes included in the $1998 \mathrm{NWQL}$ and QWSU BSP are listed below by constituent categories:

Inorganic constituents (NWQL and QWSU BSP's)—alkalinity, aluminum, arsenic, barium, beryllium, boron, cadmium, calcium, chloride, chromium, cobalt, copper, dissolved solids (residue on evaporation at $180^{\circ} \mathrm{C}$ ), fluoride, iron, lead, magnesium, manganese, mercury, molybdenum, nickel, potassium, selenium, silica, silver, sodium, strontium, sulfate, vanadium, and zinc. Constituents included only in the NWQL BSP were antimony, lithium, and specific conductance (low level). The reference materials used by the BSP are not stable for the higher specific conductance concentration range.

Nutrient constituents (NWQL and QWSU BSP's)—ammonia as nitrogen, ammonia plus organic nitrogen as nitrogen, nitrate plus nitrite as nitrogen, orthophosphate as phosphorus, and phosphorus.

\section{PROGRAM DESCRIPTION}

Standard reference water samples (SRWS) (Skougstad and Fishman, 1975; Schroder and others, 1980; Janzer, 1985; Farrar and Chleboun, 1999) are used to prepare samples for the BSP. The SRWS's are used undiluted, diluted with deionized water, or mixed in varying proportions with other SRWS's. This sample-mixing procedure produces a large number of unique samples available for qualityassurance purposes.

Reference samples for the BSP are made to appear as much like environmental samples as possible to reduce the possibility that analysts will recognize them as quality-assurance samples. Analytical request forms are completed to ensure that appropriate analyses have been requested for the samples. For the NWQL program, samples are delivered by BSP personnel directly to the sample login unit of the laboratory. Because of the great number of samples delivered to the NWQL and because the login unit is separated from the analytical operations, there is little chance that the origin of these quality-assurance samples will be detected. Because the QWSU operation is much smaller than the NWQL and the analysts have direct contact with the sample login operations, the samples and forms are sent to selected USGS 
offices that use that laboratory. Throughout the year, these offices send the quality-assurance samples for the BSP to the QWSU with their regular environmental samples.

The BSP samples are subjected to laboratory handling, processing, and analytical procedures identical to processes for the environmental samples. After laboratory analysis, BSP personnel compile and review the analytical results. The resulting data are stored in a National Water Information System (NWIS) data base and the BSP's SAS ${ }^{\circledR}$ data base.

The SRWS's are filtered during preparation; therefore, all constituents in the Blind Reference Samples are in the dissolved phase. Constituents that are designated as whole-water recoverable in this report are from filtered reference samples that have undergone a digestion process (Fishman and Friedman, 1989, p. 87-88) rather than from unfiltered or whole-water samples. Differences that appear in this report between the dissolved (DIS) analyses and the whole-water recoverable (WWR) analyses will be due to the digestion process rather than any difference in the sample phase.

\section{Estimation of Sample Loads}

The number of quality-assurance determinations requested for each analytical procedure is proportional to the number of requests for the procedure from all environmental samples submitted. Because both laboratories have active quality-control programs, the BSP followed the guidelines of Friedman and Erdmann (1982) to set submission of these external qualityassurance samples at a rate of about 2 to 5 percent of the laboratory work for each analytical procedure. The annual workload for each analytical procedure is estimated from sample login records for the previous year. The estimate is determined by taking the difference of the total number of login records for the procedure minus the number of samples submitted by the BSP and the laboratories' quality-control program.

\section{Comparison of Results with the National Water Information System Water-Quality Data Bases}

Analytical results for environmental samples are stored in the USGS National Water Information System (NWIS) data base. The NWIS is a national standardized data-base system that is maintained by each USGS district office nationwide. The NWIS allows users in those offices to enter, review, update, and retrieve analytical results that pertain to the field area the office serves.

The assessments presented in this report are based on analytical results released from the laboratories that have the same level of quality-control review as the data released to each USGS district office. The results presented in the report, however, provide a conservative estimate of the quality of the data stored in individual NWIS data bases because water-quality specialists and project chiefs are expected to scrutinize analytical results for discrepancies, request reruns for questionable results, and update analytical results in the NWIS data base as appropriate.

Factors that need to be considered for interpretation of results stored in NWIS data bases with relation to the results presented in this report include the following:

1. No effort was made to correct nonanalytical errors, even when it was obvious which corrective measures were appropriate. The data are presented as originally produced by the laboratories. Nonanalytical errors include sample login errors, transcription errors by the analyst, datatransmission errors by laboratory instruments, and manual data-entry errors. Therefore, a data reviewer that detects nonanalytical errors can make corrections to improve the quality of the NWIS data base. For example, two samples from different sites are submitted to a laboratory on the same day and are misidentified by the laboratory in a way that the analytical data reported for one actually belongs to the other. A data reviewer familiar with one of the sites or its historical data usually could detect and correct the problem with help from the laboratory.

2. Dilution factors that were incorrectly applied account for some analytical errors. Sample dilutions are routinely made in the laboratory to bring sample concentrations into analytical calibration range. If the dilution factor is not applied or is applied incorrectly, the reported value will be in error. For example, if a nutrient sample has a phosphorus concentration of $1.6 \mathrm{mg} / \mathrm{L}$ and an analysis is reported at $0.16 \mathrm{mg} / \mathrm{L}$, a tenfold dilution may have been used and not applied to the 
final result. These errors are difficult to identify unless historical data for a sampling site are available for comparison.

3. Determinations that exceed control limits, set at \pm 2 standard deviations of the referencesample concentration, are typically submitted for reanalysis by the BSP. The purpose of these rerun requests is to identify reference samples that may be deteriorating or that may have been incorrectly bottled. If the BSP determines that the source of error was deterioration of the sample or a sample mixup that occurred before the sample was delivered to the laboratory, then the data are purged from the quality-assurance data base. The majority of analysis reruns indicate the source of error to be problems associated with laboratory operations, such as analytical errors, internal bottle mixups, or data-transmission errors. If a laboratory problem is indicated by the analysis rerun, the original data remain in the qualityassurance data base. If the quality-control section of the laboratory independently identifies problems with an analytical determination and requires that updated analyses be released, then the quality-assurance data base is updated with the new values.

4. Control charts included in this report may be used to determine analytical conditions at any given time for water year 1998. A chart may show an analytical process to be out of statistical control for a short period of time, but in statistical control for most of the year. The data for the short period may affect the statistical tests for the entire year such that they would indicate analytical imprecision or significant bias. The data for the period when the analytical process was in statistical control can be considered separately to evaluate precision and bias. An interactive quality-assurance data base is available for the retrieval and assessment of blind quality-control sample analytical results. Currently, the BSP data-base system contains more than 190,000 analyses dating from October 1984 to present (2000). New analytical data released from the laboratories are added weekly to the data base. Data retrievals can be customized to document the laboratories' analytical bias and variability relative to the time period, analytical procedures, and concentration ranges of individual water-quality programs. Step-by-step instructions for accessing the BSP data base can be found on the internet at: http://bqs.usgs.gov/bsp/qadatanew.htm.

\section{STATISTICAL EVALUATION}

\section{Control Chart Development and Evaluation}

The SRWS's used in the BSP are analyzed through a round-robin evaluation program described by Farrar and Chleboun (1999). A statistical summary of the round-robin results is prepared for each set of samples. The SRWS Project uses median and F-pseudosigma in the summary reports as a measure of the known value and variability about the known value. The median data reported in the SRWS summaries have been referred to as most probable value (MPV). The F-pseudosigma $\left(F_{\sigma}\right)$ is defined by Hoaglin and others (1983) as:

$$
F_{\sigma}=\frac{\text { data }(\text { Fourth-spread })}{1.349}
$$

where the Fourth-spread is analogous to the interquartile range of the data. In addition, they show that the F-pseudosigma yields an unbiased estimate of standard deviation when the data distribution is Gaussian. However, it is recognized that some of the SRWS Project data sets may not have Gaussian data distributions. For non-Gaussian distributions, the F-pseudosigma is still a good estimate of spread and is not unduly influenced by outliers.

The SRWS Project MPV's are used to estimate the BSP mix concentrations that are based on the proportion of the SRWS's used. Likewise, if deionized water is used in the preparation of a blind sample mix, then a sample concentration of zero is applied to estimate the resultant MPV that is based on the proportion used. The resulting MPV's are used in the BSP to compare with analytical results.

For each SRWS constituent, a regression equation was used to estimate the $F_{\sigma}$ over a continuous range of concentrations. The equations were derived by using ordinary least-squares and regressing the F-pseudosigma against the MPV. The ordinary leastsquares regression equation derived for sodium is displayed in figure 1 . 


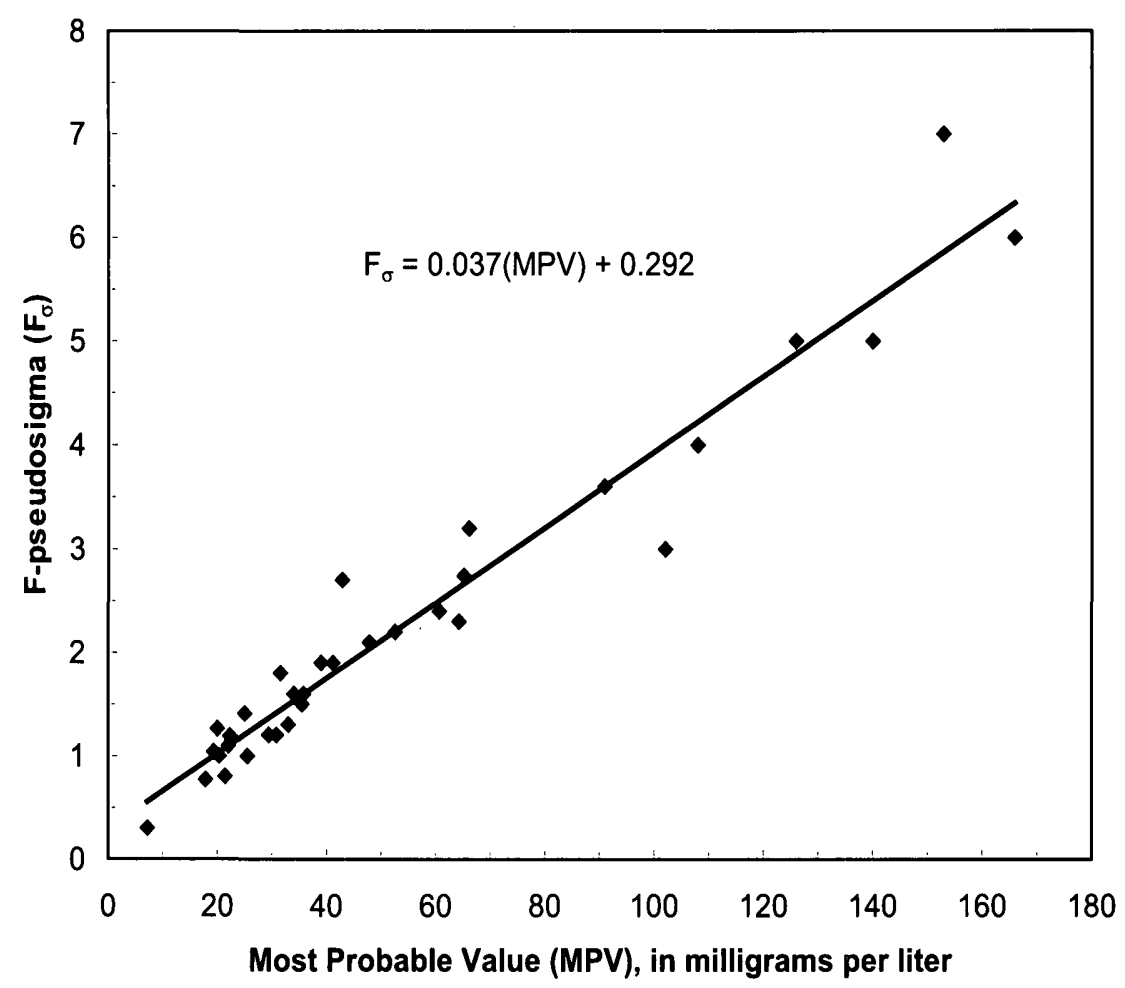

Figure 1. Display of line of relation for ordinary least-squares regression equation derived for sodium.

Helsel and Hirsch (1992) provide a general model for estimation of ordinary least-squares regression:

$$
F_{\sigma_{i}}=\beta_{0}+\beta_{1} M P V_{i}+\varepsilon_{i} \quad i=1,2, \ldots n
$$

where

$$
\begin{aligned}
F_{\sigma_{i}}= & \text { the } i \text { th observation of the response } \\
& \text { variable, } F_{\sigma} ; \\
\beta_{0}= & \text { the intercept; } \\
\beta_{1}= & \text { the slope; } \\
M P V_{i}= & \text { the } i \text { th observation of the explanatory } \\
& \quad \text { variable, Most Probable Value; } \\
\varepsilon_{i}= & \text { the random error or residual for the } \\
& \quad \text { ith observation; and } \\
n= & \text { the number of samples. }
\end{aligned}
$$

The SRWS Project summary data for semiannual round-robin sample studies conducted during the last 7 years were used to derive regression equations for each analyte. The concentration range of SRWS's used to derive the regression equations, the units of measurement, the derived $F_{\sigma}$ equation, the number of samples used to derive the equation, and the p-value indicating the level of significance associated with the derived equation are presented in table 1 . P-values greater than 0.05 indicate there is less than a 5-percent chance that such a relationship would exist. The null hypothesis for the ordinary least-squares regression equation is that no relationship exists between the MPV and the $F_{\sigma}$. The authors set a significance level of 0.05 . Then the null hypothesis was rejected when the probability, or $\mathrm{p}$-value, was less than or equal to 0.05 . Alternatively, when the p-value was less than or equal to 0.05 , there is at least 95-percent chance that there is a linear relationship between the MPV and the $F_{\sigma}$.

The p-value for fluoride (DIS, IC, LL) is greater than 0.05. All of the MPV's and $F_{\sigma}$ 's used in this regression equation were tightly clustered together. The errors contributed by using this regression equation are very minor, due to the samples' low MPV's. For example, the lowest concentration SRWS was $0.04 \mathrm{mg} / \mathrm{L}$ and the highest concentration SRWS was $0.139 \mathrm{mg} / \mathrm{L}$. The $F_{\sigma}$ for each of these samples would be 0.0202 and 0.0207 , respectively. In the case of fluoride (DIS, IC, LL), we can conclude that the $F_{\sigma}$ is close to constant for the narrow range of MPV's analyzed. 
The assessment of whether an analytical measurement meets control specifications is based on the number of standard deviations (NSD) that the measured concentration differs from the MPV. In this report, the term standard deviations will be used when comparing individual determinations to the MPV. The NSD is determined by taking the difference between the analytical result and the MPV and dividing by the $F_{\sigma}$ estimated by the appropriate regression equation using the MPV concentration. Taylor (1987, p. 33-34) provides a general equation that was modified to determine the NSD values for this assessment:

$$
N S D=\frac{X_{q}-M P V}{F_{\sigma}}
$$

where

$$
\begin{aligned}
N S D & =\text { number of standard deviations } \\
X_{q} & =\text { value in question, } \\
M P V & =\text { most probable value, and } \\
F_{\sigma} & =\text { regression estimate of F-pseudosigma. }
\end{aligned}
$$

Analytical results that are within two NSD's of the MPV concentration are considered acceptable; however, there have been instances where the assessment criteria, as defined above, resulted in unrealistic tolerances not related to analytical capability but rather to data-reporting criteria set for computer storage of environmental data. This primarily occurred for results near the reporting limits. The numerical precision for computer storage of environmental data is often much less than that used to calculate the MPV's of the SRWS's. For example, the criteria for NWIS data entry for many metals determined by flame-atomic absorption spectrophotometry (F-AAS) is to report values to the nearest $10 \mu \mathrm{g} / \mathrm{L}$ for determinations below $100 \mu \mathrm{g} / \mathrm{L}$. For the SRWS project roundrobin study, however, laboratories typically report data to the nearest $1 \mu \mathrm{g} / \mathrm{L}$, and the standard deviation for samples with concentrations below $100 \mu \mathrm{g} / \mathrm{L}$ may be only a few micrograms per liter. The regression equations used to estimate $F_{\sigma}$ are based on SRWS data that are reported with more significant figures, especially at lower concentrations.

Table 1. Ordinary least-squares equations for determining the most probable deviation

$\left[F_{\sigma}\right.$, regression estimate of F-pseudosigma; WWR, whole-water recoverable; TITR, electrometric titration; mg/L, milligrams per liter; $\times$, sample most probable value; DIS, dissolved; GF-AAS, graphite furnace-atomic absorption spectrophotometry; $\mu$ g/L, micrograms per liter; ICP-AES, inductively coupled plasma-atomic emission spectrometry; ICP-MS, inductively coupled plasma-mass spectrometry; DCP-AES, direct current

\begin{tabular}{|c|c|c|c|c|c|}
\hline $\begin{array}{l}\text { Constituent and } \\
\text { method of analysis }\end{array}$ & $\begin{array}{c}\text { Concentration } \\
\text { range }\end{array}$ & Unit & $\begin{array}{l}\text { Equation to } \\
\text { determine } \boldsymbol{F}_{\sigma}\end{array}$ & $\begin{array}{l}\text { Number of } \\
\text { samples }\end{array}$ & p-value \\
\hline \multicolumn{6}{|c|}{ Inorganic constituents } \\
\hline Alkalinity (WWR, TITR) & $27.0-234$ & $\mathrm{mg} / \mathrm{L}$ & $F_{\sigma}=0.018 x+0.955$ & 13 & 0.0001 \\
\hline Aluminum (DIS, GF-AAS) & $10.0-317$ & $\mu g / L$ & $F_{\sigma}=0.090 x+6.834$ & 19 & 0.0001 \\
\hline Aluminum (DIS, ICP-AES) & $10.0-317$ & $\mu \mathrm{g} / \mathrm{L}$ & $F_{\sigma}=0.090 x+6.834$ & 19 & 0.0001 \\
\hline Aluminum (DIS, ICP-MS) & $10.0-317$ & $\mu \mathrm{g} / \mathrm{L}$ & $F_{\sigma}=0.090 x+6.834$ & 19 & 0.0001 \\
\hline Aluminum (WWR, DCP-AES) & $10.0-317$ & $\mu \mathrm{g} / \mathrm{L}$ & $F_{\sigma}=0.090 x+6.834$ & 19 & 0.0001 \\
\hline Aluminum (WWR, GF-AAS, USEPA) & $10.0-317$ & $\mu g / L$ & $F_{\sigma}=0.090 x+6.834$ & 19 & 0.0001 \\
\hline Aluminum (WWR, ICP-AES) & $10.0-317$ & $\mu g / L$ & $F_{\sigma}=0.090 x+6.834$ & 19 & 0.0001 \\
\hline Antimony (DIS, HG-AAS) & $0.55-76.3$ & $\mu g / L$ & $F_{\sigma}=0.109 x+0.559$ & 19 & 0.0001 \\
\hline Antimony (DIS, ICP-MS) & $0.55-76.3$ & $\mu \mathrm{g} / \mathrm{L}$ & $F_{\sigma}=0.109 x+0.559$ & 19 & 0.0001 \\
\hline Arsenic (DIS, GF-AAS) & $0.55-56.6$ & $\mu \mathrm{g} / \mathrm{L}$ & $F_{\sigma}=0.090 x+0.427$ & 19 & 0.0001 \\
\hline Arsenic (DIS, HG-AAS) & $0.55-56.6$ & $\mu \mathrm{g} / \mathrm{L}$ & $F_{\sigma}=0.090 x+0.427$ & 19 & 0.0001 \\
\hline Arsenic (WWR, GF-AAS) & $0.55-56.6$ & $\mu g / L$ & $F_{\sigma}=0.090 x+0.427$ & 19 & 0.0001 \\
\hline Arsenic (WWR, GF-AAS, USEPA) & $0.55-56.6$ & $\mu g / L$ & $F_{\sigma}=0.090 x+0.427$ & 19 & 0.0001 \\
\hline Arsenic (WWR, HG-AAS) & $0.55-56.6$ & $\mu g / L$ & $F_{\sigma}=0.090 x+0.427$ & 19 & 0.0001 \\
\hline
\end{tabular}
plasma-atomic emission spectrometry; USEPA, U.S. Environmental Protection Agency; HG-AAS, hydride generation-atomic absorption spectrophotometry; IC, ion chromatography; LL, low level; GRAV, gravimetric; ISE, ion-selective electrode; F-AAS, flame-atomic absorption spectrophotometry; CV-AAS, cold vapor-atomic absorption spectrophotometry; ELEC, electrometric; $\mu \mathrm{S} / \mathrm{cm}$, microsiemens per centimeter at 25 degrees Celsius; COL, colorimetric; ASF, micro-Kjeldahl digestion, automated segmented flow, colorimetric] 
Table 1. Ordinary least-squares equations for determining the most probable deviation—Continued

$\left[F_{\sigma}\right.$, regression estimate of $F$-pseudosigma; WWR, whole-water recoverable; TITR, electrometric titration; mg/L, milligrams per liter; $\times$, sample most probable value; DIS, dissolved; GF-AAS, graphite furnace-atomic absorption spectrophotometry; $\mu \mathrm{g} / \mathrm{L}$, micrograms per liter; ICP-AES, inductively coupled plasma-atomic emission spectrometry; ICP-MS, inductively coupled plasma-mass spectrometry; DCP-AES, direct current plasma-atomic emission spectrometry; USEPA, U.S. Environmental Protection Agency; HG-AAS, hydride generation-atomic absorption spectrophotometry; IC, ion chromatography; LL, low level; GRAV, gravimetric; ISE, ion-selective electrode; F-AAS, flame-atomic absorption spectrophotometry; CV-AAS, cold vapor-atomic absorption spectrophotometry; ELEC, electrometric; $\mu S / \mathrm{cm}$, microsiemens per centimeter at 25 degrees Celsius; COL, colorimetric; ASF, micro-Kjeldahl digestion, automated segmented flow, colorimetric]

\begin{tabular}{|c|c|c|c|c|c|}
\hline $\begin{array}{l}\text { Constituent and } \\
\text { method of analysis }\end{array}$ & $\begin{array}{c}\text { Concentration } \\
\text { range }\end{array}$ & Unit & $\begin{array}{l}\text { Equation to } \\
\text { determine } \boldsymbol{F}_{\sigma}\end{array}$ & $\begin{array}{c}\text { Number of } \\
\text { samples }\end{array}$ & p-value \\
\hline \multicolumn{6}{|c|}{ Inorganic constituents-Continued } \\
\hline Barium (DIS, ICP-AES) & $7.65-507$ & $\mu \mathrm{g} / \mathrm{L}$ & $F_{\sigma}=0.042 \times+1.411$ & 19 & 0.0001 \\
\hline Barium (DIS, ICP-MS) & $7.65-507$ & $\mu \mathrm{g} / \mathrm{L}$ & $F_{\sigma}=0.042 x+1.411$ & 19 & 0.0001 \\
\hline Barium (WWR, ICP-AES) & $7.65-507$ & $\mu \mathrm{g} / \mathrm{L}$ & $F_{\sigma}=0.042 x+1.411$ & 19 & 0.0001 \\
\hline Beryllium (DIS, ICP-AES) & $0.12-59.0$ & $\mu g / L$ & $F_{\sigma}=0.042 x+0.482$ & 18 & 0.0001 \\
\hline Beryllium (DIS, ICP-MS) & $0.12-59.0$ & $\mu \mathrm{g} / \mathrm{L}$ & $F_{\sigma}=0.042 x+0.482$ & 18 & 0.0001 \\
\hline Beryllium (WWR, ICP-AES) & $0.12-59.0$ & $\mu \mathrm{g} / \mathrm{L}$ & $F_{\sigma}=0.042 x+0.482$ & 18 & 0.0001 \\
\hline Boron (DIS, ICP-AES) & $0.18-297$ & $\mu \mathrm{g} / \mathrm{L}$ & $F_{\sigma}=0.060 x+6.207$ & 33 & 0.0001 \\
\hline Boron (WWR, DCP-AES) & $0.18-297$ & $\mu \mathrm{g} / \mathrm{L}$ & $F_{\sigma}=0.060 x+6.207$ & 33 & 0.0001 \\
\hline Cadmium (DIS, GF-AAS) & $0.34-50.5$ & $\mu g / L$ & $F_{\sigma}=0.060 x+0.350$ & 19 & 0.0001 \\
\hline Cadmium (DIS, ICP-AES) & $0.34-50.5$ & $\mu g / L$ & $F_{\sigma}=0.060 x+0.350$ & 19 & 0.0001 \\
\hline Cadmium (DIS, ICP-MS) & $0.34-50.5$ & $\mu \mathrm{g} / \mathrm{L}$ & $F_{\sigma}=0.060 x+0.350$ & 19 & 0.0001 \\
\hline Cadmium (WWR, GF-AAS) & $0.34-50.5$ & $\mu g / L$ & $F_{\sigma}=0.060 x+0.350$ & 19 & 0.0001 \\
\hline Cadmium (WWR, ICP-AES) & $0.34-50.5$ & $\mu g / L$ & $F_{\sigma}=0.060 x+0.350$ & 19 & 0.0001 \\
\hline Calcium (DIS, ICP-AES) & $4.60-154$ & $\mathrm{mg} / \mathrm{L}$ & $F_{\sigma}=0.054 \times-0.187$ & 33 & 0.0001 \\
\hline Chloride (DIS, IC) & $7.60-208$ & $\mathrm{mg} / \mathrm{L}$ & $F_{\sigma}=0.030 x+0.355$ & 14 & 0.0001 \\
\hline Chloride (DIS, IC, LL) & $0.14-7.79$ & $\mathrm{mg} / \mathrm{L}$ & $F_{\sigma}=0.040 x+0.164$ & 12 & 0.0001 \\
\hline Chromium (DIS, GF-AAS) & $0.68-79.0$ & $\mu g / L$ & $F_{\sigma}=0.059 x+0.754$ & 18 & 0.0001 \\
\hline Chromium (DIS, ICP-AES) & $0.68-79.0$ & $\mu g / L$ & $F_{\sigma}=0.059 x+0.754$ & .18 & 0.0001 \\
\hline Chromium (DIS, ICP-MS) & $0.68-79.0$ & $\mu g / L$ & $F_{\sigma}=0.059 x+0.754$ & 18 & 0.0001 \\
\hline Chromium (WWR, GF-AAS) & $0.68-79.0$ & $\mu g / L$ & $F_{\sigma}=0.059 \times+0.754$ & 18 & 0.0001 \\
\hline Chromium (WWR, ICP-AES) & $0.68-79.0$ & $\mu \mathrm{g} / \mathrm{L}$ & $F_{\sigma}=0.059 x+0.754$ & 18 & 0.0001 \\
\hline Cobalt (DIS, GF-AAS) & $0.40-40.0$ & $\mu \mathrm{g} / \mathrm{L}$ & $F_{\sigma}=0.048 x+0.734$ & 17 & 0.0003 \\
\hline Cobalt (DIS, ICP-AES) & $0.40-40.0$ & $\mu g / L$ & $F_{\sigma}=0.048 x+0.734$ & 17 & 0.0003 \\
\hline Cobalt (DIS, ICP-MS) & $0.40-40.0$ & $\mu g / L$ & $F_{\sigma}=0.048 x+0.734$ & 17 & 0.0003 \\
\hline Cobalt (WWR, GF-AAS) & $0.40-40.0$ & $\mu \mathrm{g} / \mathrm{L}$ & $F_{\sigma}=0.048 x+0.734$ & 17 & 0.0003 \\
\hline Copper (DIS, GF-AAS) & $1.90-85.3$ & $\mu \mathrm{g} / \mathrm{L}$ & $F_{\sigma}=0.050 x+1.067$ & 19 & 0.0001 \\
\hline Copper (DIS, ICP-AES) & $1.90-85.3$ & $\mu g / L$ & $F_{\sigma}=0.050 x+1.067$ & 19 & 0.0001 \\
\hline Copper (DIS, ICP-MS) & $1.90-85.3$ & $\mu g / L$ & $F_{\sigma}=0.050 x+1.067$ & 19 & 0.0001 \\
\hline Copper (WWR, GF-AAS) & $1.90-85.3$ & $\mu g / L$ & $F_{\sigma}=0.050 x+1.067$ & 19 & 0.0001 \\
\hline Copper (WWR, ICP-AES) & $1.90-85.3$ & $\mu g / L$ & $F_{\sigma}=0.050 x+1.067$ & 19 & 0.0001 \\
\hline Dissolved solids (DIS, GRAV) & $88.0-1309$ & $\mathrm{mg} / \mathrm{L}$ & $F_{\sigma}=0.017 x+7.610$ & 13 & 0.0001 \\
\hline Fluoride (DIS, IC, LL) & $0.028-0.14$ & $\mathrm{mg} / \mathrm{L}$ & $F_{\sigma}=0.005 x+0.020$ & 9 & 0.953 \\
\hline Fluoride (DIS, ISE) & $0.23-1.23$ & $\mathrm{mg} / \mathrm{L}$ & $F_{\sigma}=0.061 \times+0.012$ & 12 & 0.0001 \\
\hline Iron (DIS, ICP-AES) & $4.30-1175$ & $\mu g / L$ & $F_{\sigma}=0.045 x+4.886$ & 17 & 0.0001 \\
\hline Iron (WWR, F-AAS) & $4.30-1175$ & $\mu g / L$ & $F_{\sigma}=0.045 x+4.886$ & 17 & 0.0001 \\
\hline Iron (WWR, ICP-AES) & $4.30-1175$ & $\mu g / L$ & $F_{\sigma}=0.045 x+4.886$ & 17 & 0.0001 \\
\hline Lead (DIS, GF-AAS) & $1.00-103$ & $\mu g / L$ & $F_{\sigma}=0.066 x+0.822$ & 19 & 0.0001 \\
\hline
\end{tabular}


Table 1. Ordinary least-squares equations for determining the most probable deviation-Continued

$\left[F_{\sigma}\right.$, regression estimate of F-pseudosigma; WWR, whole-water recoverable; TITR, electrometric titration; mg/L, milligrams per liter; $\times$, sample most probable value; DIS, dissolved; GF-AAS, graphite furnace-atomic absorption spectrophotometry; $\mu \mathrm{g} / \mathrm{L}$, micrograms per liter; ICP-AES, inductively coupled plasma-atomic emission spectrometry; ICP-MS, inductively coupled plasma-mass spectrometry; DCP-AES, direct current plasma-atomic emission spectrometry; USEPA, U.S. Environmental Protection Agency; HG-AAS, hydride generation-atomic absorption spectrophotometry; IC, ion chromatography; LL, low level; GRAV, gravimetric; ISE, ion-selective electrode; F-AAS, flame-atomic absorption spectrophotometry; CV-AAS, cold vapor-atomic absorption spectrophotometry; ELEC, electrometric; $\mu \mathrm{S} / \mathrm{cm}$, microsiemens per centimeter at 25 degrees Celsius; COL, colorimetric; ASF, micro-Kjeldahl digestion, automated segmented flow, colorimetric]

\begin{tabular}{|c|c|c|c|c|c|}
\hline $\begin{array}{l}\text { Constituent and } \\
\text { method of analysis }\end{array}$ & $\begin{array}{c}\text { Concentration } \\
\text { range }\end{array}$ & Unit & $\begin{array}{l}\text { Equation to } \\
\text { determine } F_{\sigma}\end{array}$ & $\begin{array}{l}\text { Number of } \\
\text { samples }\end{array}$ & p-value \\
\hline \multicolumn{6}{|c|}{ Inorganic constituents-Continued } \\
\hline Lead (DIS, ICP-AES) & $1.00-103$ & $\mu g / L$ & $F_{\sigma}=0.066 x+0.822$ & 19 & 0.0001 \\
\hline Lead (DIS, ICP-MS) & $1.00-103$ & $\mu g / L$ & $F_{\sigma}=0.066 x+0.822$ & 19 & 0.0001 \\
\hline Lead (WWR, GF-AAS) & $1.00-103$ & $\mu g / L$ & $F_{\sigma}=0.066 x+0.822$ & 19 & 0.0001 \\
\hline Lead (WWR, ICP-AES) & $1.00-103$ & $\mu \mathrm{g} / \mathrm{L}$ & $F_{\sigma}=0.066 x+0.822$ & 19 & 0.0001 \\
\hline Lithium (DIS, ICP-AES) & $8.70-132$ & $\mu g / L$ & $F_{\sigma}=0.081 x+0.364$ & 19 & 0.0001 \\
\hline Lithium (WWR, F-AAS) & $8.70-132$ & $\mu g / L$ & $F_{\sigma}=0.081 \times+0.364$ & 19 & 0.0001 \\
\hline Magnesium (DIS, ICP-AES) & $0.78-58.4$ & $\mathrm{mg} / \mathrm{L}$ & $F_{\sigma}=0.044 \times-0.003$ & 33 & 0.0001 \\
\hline Manganese (DIS, ICP-AES) & $2.40-455$ & $\mu g / L$ & $F_{\sigma}=0.047 x+0.990$ & 19 & 0.0001 \\
\hline Manganese (DIS, ICP-MS) & $2.40-455$ & $\mu \mathrm{g} / \mathrm{L}$ & $F_{\sigma}=0.047 x+0.990$ & 19 & 0.0001 \\
\hline Manganese (WWR, F-AAS) & $2.40-455$ & $\mu g / L$ & $F_{\sigma}=0.047 x+0.990$ & 19 & 0.0001 \\
\hline Manganese (WWR, ICP-AES) & $2.40-455$ & $\mu g / L$ & $F_{\sigma}=0.047 x+0.990$ & 19 & 0.0001 \\
\hline Mercury (DIS, CV-AAS) & $0.34-5.04$ & $\mu g / L$ & $F_{\sigma}=0.110 x+0.075$ & 16 & 0.0001 \\
\hline Mercury (WWR, CV-AAS) & $0.34-5.04$ & $\mu g / L$ & $F_{\sigma}=0.110 x+0.075$ & 16 & 0.0001 \\
\hline Molybdenum (DIS, GF-AAS) & $1.25-112$ & $\mu g / L$ & $F_{\sigma}=0.081 \times+0.735$ & 18 & 0.0001 \\
\hline Molybdenum (DIS, ICP-AES) & $1.25-112$ & $\mu g / L$ & $F_{\sigma}=0.081 \times+0.735$ & 18 & 0.0001 \\
\hline Molybdenum (DIS, ICP-MS) & $1.25-112$ & $\mu g / L$ & $F_{\sigma}=0.081 \times+0.735$ & 18 & 0.0001 \\
\hline Molybdenum (WWR, GF-AAS) & $1.25-112$ & $\mu g / L$ & $F_{\sigma}=0.081 \times+0.735$ & 18 & 0.0001 \\
\hline Nickel (DIS, GF-AAS) & $1.70-71.0$ & $\mu \mathrm{g} / \mathrm{L}$ & $F_{\sigma}=0.057 x+1.14$ & 19 & 0.0001 \\
\hline Nickel (DIS, ICP-AES) & $1.70-71.0$ & $\mu g / L$ & $F_{\sigma}=0.057 x+1.14$ & 19 & 0.0001 \\
\hline Nickel (DIS, ICP-MS) & $1.70-71.0$ & $\mu g / L$ & $F_{\sigma}=0.057 x+1.14$ & 19 & 0.0001 \\
\hline Nickel (WWR, GF-AAS) & $1.70-71.0$ & $\mu g / L$ & $F_{\sigma}=0.057 x+1.14$ & 19 & 0.0001 \\
\hline Nickel (WWR, ICP-AES) & $1.70-71.0$ & $\mu g / L$ & $F_{\sigma}=0.057 x+1.14$ & 19 & 0.0001 \\
\hline Potassium (DIS, F-AAS) & $0.45-13.9$ & $\mathrm{mg} / \mathrm{L}$ & $F_{\sigma}=0.067 x+0.022$ & 33 & 0.0001 \\
\hline Potassium (DIS, F-AAS, LL) & $0.057-0.55$ & $\mathrm{mg} / \mathrm{L}$ & $F_{\sigma}=0.064 x+0.017$ & 12 & 0.0024 \\
\hline Selenium (DIS, GF-AAS) & $2.10-21.4$ & $\mu g / L$ & $F_{\sigma}=0.160 x+0.191$ & 17 & 0.0001 \\
\hline Selenium (DIS, HG-AAS) & $2.10-21.4$ & $\mu g / L$ & $F_{\sigma}=0.160 x+0.191$ & 17 & 0.0001 \\
\hline Selenium (WWR, GF-AAS) & $2.10-21.4$ & $\mu g / L$ & $F_{\sigma}=0.160 x+0.191$ & 17 & 0.0001 \\
\hline Selenium (WWR, GF-AAS, USEPA) & $2.10-21.4$ & $\mu g / L$ & $F_{\sigma}=0.160 x+0.191$ & 17 & 0.0001 \\
\hline Selenium (WWR, HG-AAS) & $2.10-21.4$ & $\mu g / L$ & $F_{\sigma}=0.160 x+0.191$ & 17 & 0.0001 \\
\hline Silica (DIS, COL) & $2.46-24.0$ & $\mathrm{mg} / \mathrm{L}$ & $F_{\sigma}=0.061 \times+0.007$ & 32 & 0.0001 \\
\hline Silica (DIS, ICP-AES) & $2.46-24.0$ & $\mathrm{mg} / \mathrm{L}$ & $F_{\sigma}=0.061 \times+0.007$ & 32 & 0.0001 \\
\hline Silver (DIS, GF-AAS) & $0.90-19.8$ & $\mu \mathrm{g} / \mathrm{L}$ & $F_{\sigma}=0.049 \times+0.568$ & 16 & 0.0043 \\
\hline Silver (DIS, GF-AAS, LL) & $0.90-19.8$ & $\mu g / L$ & $F_{\sigma}=0.049 \times+0.568$ & 16 & 0.0043 \\
\hline Silver (DIS, ICP-AES) & $0.90-19.8$ & $\mu g / L$ & $F_{\sigma}=0.049 \times+0.568$ & 16 & 0.0043 \\
\hline Silver (DIS, ICP-MS) & $0.90-19.8$ & $\mu g / L$ & $F_{\sigma}=0.049 \times+0.568$ & 16 & 0.0043 \\
\hline Silver (WWR, GF-AAS) & $0.90-19.8$ & $\mu g / L$ & $F_{\sigma}=0.049 x+0.568$ & 16 & 0.0043 \\
\hline Sodium (DIS, F-AAS) & $7.19-166$ & $\mathrm{mg} / \mathrm{L}$ & $F_{\sigma}=0.037 x+0.292$ & 33 & 0.0001 \\
\hline
\end{tabular}


Table 1. Ordinary least-squares equations for determining the most probable deviation-Continued

$\left[F_{\sigma}\right.$, regression estimate of F-pseudosigma; WWR, whole-water recoverable; TITR, electrometric titration; mg/L, milligrams per liter; $\times$, sample most probable value; DIS, dissolved; GF-AAS, graphite furnace-atomic absorption spectrophotometry; $\mu$ g/L, micrograms per liter; ICP-AES, inductively coupled plasma-atomic emission spectrometry; ICP-MS, inductively coupled plasma-mass spectrometry; DCP-AES, direct current plasma-atomic emission spectrometry; USEPA, U.S. Environmental Protection Agency; HG-AAS, hydride generation-atomic absorption spectrophotometry; IC, ion chromatography; LL, low level; GRAV, gravimetric; ISE, ion-selective electrode; F-AAS, flame-atomic absorption spectrophotometry; CV-AAS, cold vapor-atomic absorption spectrophotometry; ELEC, electrometric; $\mu \mathrm{S} / \mathrm{cm}$, microsiemens per centimeter at 25 degrees Celsius; COL, colorimetric; ASF, micro-Kjeldahl digestion, automated segmented flow, colorimetric]

\begin{tabular}{|c|c|c|c|c|c|}
\hline $\begin{array}{l}\text { Constituent and } \\
\text { method of analysis }\end{array}$ & $\begin{array}{c}\text { Concentration } \\
\text { range }\end{array}$ & Unit & $\begin{array}{l}\text { Equation to } \\
\text { determine } F_{\sigma}\end{array}$ & $\begin{array}{l}\text { Number of } \\
\text { samples }\end{array}$ & p-value \\
\hline \multicolumn{6}{|c|}{ Inorganic constituents-Continued } \\
\hline Sodium (DIS, F-AAS, LL) & $0.117-4.40$ & $\mathrm{mg} / \mathrm{L}$ & $F_{\sigma}=0.047 x+0.023$ & 12 & 0.0001 \\
\hline Sodium (DIS, ICP-AES) & $7.19-166$ & $\mathrm{mg} / \mathrm{L}$ & $F_{\sigma}=0.037 x+0.292$ & 33 & 0.0001 \\
\hline Specific conductance (WWR, ELEC, LL) & $7.000-44.1$ & $\mu \mathrm{S} / \mathrm{cm}$ & $F_{\sigma}=0.049 x+0.460$ & 13 & 0.0127 \\
\hline Strontium (DIS, ICP-AES) & $31.9-1669$ & $\mu g / L$ & $F_{\sigma}=0.054 \times-0.870$ & 33 & 0.0001 \\
\hline Strontium (WWR, ICP-AES) & $31.9-1669$ & $\mu g / L$ & $F_{\sigma}=0.054 \times-0.870$ & 33 & 0.0001 \\
\hline Sulfate (DIS, IC) & $6.06-621$ & $\mathrm{mg} / \mathrm{L}$ & $F_{\sigma}=0.036 x+0.631$ & 14 & 0.0001 \\
\hline Vanadium (DIS, COL) & $1.00-52.8$ & $\mu g / L$ & $F_{\sigma}=0.047 x+1.343$ & 29 & 0.0001 \\
\hline Vanadium (DIS, ICP-AES) & $1.00-52.8$ & $\mu g / L$ & $F_{\sigma}=0.047 x+1.343$ & 29 & 0.0001 \\
\hline Zinc (DIS, ICP-AES) & $5.80-381$ & $\mu \mathrm{g} / \mathrm{L}$ & $F_{\sigma}=0.046 x+2.448$ & 19 & 0.0001 \\
\hline Zinc (DIS, ICP-MS) & $5.80-381$ & $\mu g / L$ & $F_{\sigma}=0.046 x+2.448$ & 19 & 0.0001 \\
\hline Zinc (WWR, F-AAS) & $5.80-381$ & $\mu g / L$ & $F_{\sigma}=0.046 x+2.448$ & 19 & 0.0001 \\
\hline Zinc (WWR, ICP-AES) & $5.80-381$ & $\mu g / L$ & $F_{\sigma}=0.046 x+2.448$ & 19 & 0.0001 \\
\hline \multicolumn{6}{|c|}{ Nutrient constituents } \\
\hline Ammonia as nitrogen (DIS) & $0.024-1.33$ & $\mathrm{mg} / \mathrm{L}$ & $F_{\sigma}=0.060 x+0.012$ & 25 & 0.0004 \\
\hline Ammonia as nitrogen (DIS, COL) & $0.024-1.33$ & $\mathrm{mg} / \mathrm{L}$ & $F_{\sigma}=0.060 x+0.012$ & 25 & 0.0004 \\
\hline Ammonia as nitrogen (DIS, COL, LL) & $0.024-1.33$ & $\mathrm{mg} / \mathrm{L}$ & $F_{\sigma}=0.060 x+0.012$ & 25 & 0.0004 \\
\hline Ammonia as nitrogen (DIS, USEPA) & $0.024-1.33$ & $\mathrm{mg} / \mathrm{L}$ & $F_{\sigma}=0.060 x+0.012$ & 25 & 0.0004 \\
\hline Ammonia plus organic nitrogen as nitrogen (DIS) & $0.118-2.37$ & $\mathrm{mg} / \mathrm{L}$ & $F_{\sigma}=0.052 x+0.113$ & 27 & 0.0069 \\
\hline Ammonia plus organic nitrogen as nitrogen (DIS, ASF) & $0.118-2.37$ & $\mathrm{mg} / \mathrm{L}$ & $F_{\sigma}=0.052 x+0.113$ & 27 & 0.0069 \\
\hline Ammonia plus organic nitrogen as nitrogen (DIS, USEPA) & $0.118-2.37$ & $\mathrm{mg} / \mathrm{L}$ & $F_{\sigma}=0.052 x+0.113$ & 27 & 0.0069 \\
\hline Ammonia plus organic nitrogen as nitrogen (WWR) & $0.118-2.37$ & $\mathrm{mg} / \mathrm{L}$ & $F_{\sigma}=0.052 x+0.113$ & 27 & 0.0069 \\
\hline Ammonia plus organic nitrogen as nitrogen (WWR, ASF) & $0.118-2.37$ & $\mathrm{mg} / \mathrm{L}$ & $F_{\sigma}=0.052 x+0.113$ & 27 & 0.0069 \\
\hline Ammonia plus organic nitrogèn as nitrogen (WWR, USEPA) & $0.118-2.37$ & $\mathrm{mg} / \mathrm{L}$ & $F_{\sigma}=0.052 x+0.113$ & 27 & 0.0069 \\
\hline Nitrate plus nitrite as nitrogen (DIS) & $0.073-1.93$ & $\mathrm{mg} / \mathrm{L}$ & $F_{\sigma}=0.042 x+0.015$ & 25 & 0.0003 \\
\hline Nitrate plus nitrite as nitrogen (DIS, COL) & $0.073-1.93$ & $\mathrm{mg} / \mathrm{L}$ & $F_{\sigma}=0.042 x+0.015$ & 25 & 0.0003 \\
\hline Nitrate plus nitrite as nitrogen (DIS, COL, LL) & $0.073-1.93$ & $\mathrm{mg} / \mathrm{L}$ & $F_{\sigma}=0.042 x+0.015$ & 25 & 0.0003 \\
\hline Orthophosphate as phosphorus (DIS) & $0.052-1.59$ & $\mathrm{mg} / \mathrm{L}$ & $F_{\sigma}=0.040 x+0.006$ & 24 & 0.0004 \\
\hline Orthophosphate as phosphorus (DIS, COL) & $0.052-1.59$ & $\mathrm{mg} / \mathrm{L}$ & $F_{\sigma}=0.040 x+0.006$ & 24 & 0.0004 \\
\hline Orthophosphate as phosphorus (DIS, COL, LL) & $0.052-1.59$ & $\mathrm{mg} / \mathrm{L}$ & $F_{\sigma}=0.040 x+0.006$ & 24 & 0.0004 \\
\hline Phosphorus (DIS) & $0.060-1.63$ & $\mathrm{mg} / \mathrm{L}$ & $F_{\sigma}=0.035 x+0.009$ & 27 & 0.0001 \\
\hline Phosphorus (DIS, ASF) & $0.060-1.63$ & $\mathrm{mg} / \mathrm{L}$ & $F_{\sigma}=0.035 x+0.009$ & 27 & 0.0001 \\
\hline Phosphorus (DIS, COL, LL) & $0.060-1.63$ & $\mathrm{mg} / \mathrm{L}$ & $F_{\sigma}=0.035 x+0.009$ & 27 & 0.0001 \\
\hline Phosphorus (DIS, USEPA) & $0.060-1.63$ & $\mathrm{mg} / \mathrm{L}$ & $F_{\sigma}=0.035 x+0.009$ & 27 & 0.0001 \\
\hline Phosphorus (WWR) & $0.060-1.63$ & $\mathrm{mg} / \mathrm{L}$ & $F_{\sigma}=0.035 x+0.009$ & 27 & 0.0001 \\
\hline Phosphorus (WWR, ASF) & $0.060-1.63$ & $\mathrm{mg} / \mathrm{L}$ & $F_{\sigma}=0.035 x+0.009$ & 27 & 0.0001 \\
\hline Phosphorus (WWR, COL, LL) & $0.060-1.63$ & $\mathrm{mg} / \mathrm{L}$ & $F_{\sigma}=0.035 x+0.009$ & 27 & 0.0001 \\
\hline Phosphorus (WWR, USEPA) & $0.060-1.63$ & $\mathrm{mg} / \mathrm{L}$ & $F_{\sigma}=0.035 x+0.009$ & 27 & 0.0001 \\
\hline
\end{tabular}


The rounding differences between the SRWS summary results and the NWIS computer-storage criteria make the assessments at lower sample concentrations less sensitive. As a means to make the assessments more sensitive at lower concentration ranges, a correction factor has been applied to allow at least one reportable value to be within one standard deviation of the MPV. The correction is accomplished by setting a minimum $F_{\sigma}$ at three-fourths of the minimum reporting limit. For example, a sample may be assigned an MPV for manganese of $13.7 \mu \mathrm{g} / \mathrm{L}$; however, the laboratories can only report environmental data for manganese (WWR, F-AAS) to the nearest $10 \mu \mathrm{g} / \mathrm{L}$ in the NWIS data base. For the reference sample in question, a reported value of 10 or 20 would generally be expected. The regression equation for manganese $\left(F_{\sigma}=0.047 \mathrm{MPV}+0.990\right)$ provides an estimate that reported $F_{\sigma}$ values within $\pm 1.63 \mu \mathrm{g} / \mathrm{L}$ of a sample with an MPV of $13.7 \mu \mathrm{g} / \mathrm{L}$ will be considered within one standard deviation. The laboratories' closest reportable values, 10 and $20 \mu \mathrm{g} / \mathrm{L}$, would be -2.27 and +3.87 standard deviations, respectively, from the MPV. When a minimum $F_{\sigma}$ value of $7.5 \mu \mathrm{g} / \mathrm{L}$ is assigned (three-fourths of the reporting limit), then values reported at 10 and $20 \mu \mathrm{g} / \mathrm{L}$ would be -0.49 and +0.84 standard deviations from the MPV, respectively.

BSP mixes that had MPV concentrations less than the laboratory reporting limit (LRL) were removed from the BSP data base. The BSP mixes are not designed to quality ensure the laboratories for false positives or for how well the laboratory reports samples less than the LRL.

For each constituent, the NSD values were plotted against the date that the samples were logged into the laboratory to prepare control charts. The results for each constituent are presented as control charts, as shown in part A of figures 2 through 96 for the NWQL and figures 97 through 159 for the QWSU in the "Supplemental Data" section of this report.

Control charts for inorganic-constituent reference samples are presented in figures 2 through 79 for the NWQL and figures 97 through 152 for the QWSU. Control charts for nutrient constituents are shown in figures 80 through 96 for the NWQL and figures 153 through 159 for the QWSU. The data on control charts have been separated into quartiles on the basis of environmental sample concentrations. All environmental data released during water year 1998 by the NWQL and QWSU were obtained and used to determine the quartiles. The quartiles and their associated concentration ranges are identified in the figure explanation. The MPV's of the reference materials were examined to determine which quartile group they represented. A different symbol was used to represent data points in each of the quartile ranges. For reference samples with MPV's in quartile 1 (up through 25 percent), the ( $O$ ) symbol has been used; reference samples in quartile 2 ( 25.1 through 50 percent) are represented by the $(\Delta)$ symbol; quartile 3 (50.1 through 75 percent) by the (•) symbol; and quartile 4 (75.1 through 100 percent) by the $(x)$ symbol.

Points on the control charts that are greater than 6 standard deviations or less than -6 standard deviations have been rounded to 6 and -6 , respectively, and are plotted at the top or bottom edge of the figure.

\section{Precision Chart Development and Evaluation}

Replicate determinations of reference samples were used to estimate precision. For each sample mixture having at least three determinations for water year 1998, the mean, standard deviation, and relative standard deviation (RSD) were calculated for each constituent. Taylor (1987, p. 20) defines RSD as the coefficient of variation multiplied by 100 (percent). The equation to represent this is:

$$
R S D=\frac{\sigma}{X} \times 100
$$

where

$$
\begin{aligned}
R S D= & \text { relative standard deviation } \\
\sigma= & \text { standard deviation, and } \\
X= & \text { mean of replicate values reported by the } \\
& \text { laboratory. }
\end{aligned}
$$

The RSD provides an estimate of error relative to the mean of replicate values reported by the laboratory for each reference sample.

The RSD data are presented graphically as precision data charts in part B of figures 2 through 96 for the NWQL and figures 97 through 159 for the QWSU in the "Supplemental Data" section of this report. These charts were prepared by plotting the RSD for inorganic, nutrient, and low-level constituents against the mean concentration of the reference samples reported by the individual laboratories. These charts allow a data reviewer to estimate precision at any concentration shown for a constituent. For example, figure 80B shows precision data for dissolved ammonia determinations from the NWQL. 
This plot shows a distribution of approximately 19 to 4 percent RSD for concentrations that range from 0.23 to $1.29 \mathrm{mg} / \mathrm{L}$.

Precision is dependent upon the analyte of interest, the concentration range, the number of determinations, the method of determination, and the analyzing laboratory. A precision of 2 to 5 percent RSD is typical for chloride; whereas mercury's precision may vary from 10 to 40 percent RSD. Therefore, a data reviewer needs to be cognizant of the many variables contributing to a determination's precision and only compare for similar determinations.

To allow the precision charts to be used to estimate expected error of analytical results, outliers were rejected from the data set. Outliers are a rare occurrence in the data reported by the laboratories, accounting for less than 0.5 percent of all data. Outliers produce erroneous results in the use of parametric statistics such as RSD. Taylor (1987, p. 33-34) suggested NSD $\geq|4|$ as a criterion for rejection of data for a large sample set and NSD $\geq|6|$ for smaller data sets or when the standard deviation is not well established. In this report, an outlier was defined as a value greater than or equal to 6 standard deviations from the MPV. There were 48 outliers deleted from the entire data set of 11,056 analyses for the RSD procedure. Table 2 for the NWQL and table 3 for the QWSU present the total number of determinations for each constituent processed during the water year, the number of determinations that lie outside the \pm 2 standard deviation limits, and the number of determinations that lie outside the \pm 6 standard deviation limits.

The precision chart data for inorganic, nutrient, and low-level constituents have been separated into groups that are based on environmental-sample data quartiles in the same manner as explained previously in this report for the development of the control charts.

\section{Binomial-Probability-Distribution Technique to Assess Precision}

Measures of precision were determined from the control chart data by applying binomialprobability-distribution procedures described by Friedman, Bradford, and Peart (1983) and by Peart and Thomas (1983a). The precision evaluation is based on whether or not an analytical method could produce results within \pm 2 standard deviations of the MPV. The binomial equation identifies the maximum number of determinations that could exceed the control limit at a 0.01 significance level. A comparison is then made between the number of analytical determinations that exceed control limits and the results of the binomial-probability-distribution equation for the total number of analytical determinations.

$$
P(x)=\sum_{i-x}^{N} \frac{N !}{i !(N-i) !}(0.05)^{i}(0.95)^{N-i}
$$

where

$$
\begin{aligned}
& P(x)=\text { probability of having } x \text { or more points } \\
& \text { greater than two standard deviations, } \\
& N \text { = number of successive points, and } \\
& i=\text { number of points greater than two standard } \\
& \text { deviations. }
\end{aligned}
$$

Analytical procedures exhibit imprecision if they have more determinations outside the control limits than the result predicted by the binomial equation. The binomial-probability-distribution procedure to measure precision allows tracking of annual variations in the precision of analytical measurements. The binomial test can be used to evaluate analytical results for short periods that appear to indicate imprecision, but the test loses power as fewer total analytical determinations are used in the evaluation.

\section{Wilcoxon Signed-Rank Procedure to Assess Bias}

The Wilcoxon signed-rank test (Helsel and Hirsch, 1992) was used to determine whether the median difference between the laboratory determinations and the MPV of the reference samples equaled zero. An assessment of bias was made for each analyte and mix combination that had three or more observations. The null hypothesis for the bias assessment was defined as that the median difference between the laboratory determinations and the MPV equaled zero. A bias condition was assigned if the p-value of the test was less than 0.05 and the median difference was greater than the nearest reporting unit used for the analyte concentration in the mix. When the analyte concentration fell below the minimum reporting limit, bias was not stated. Whether bias is negative or positive was determined on the basis of the sign of the median difference. Data users are urged to consider the concentration level and review the magnitude of bias, which is based on the median differences, to evaluate whether a bias is of any practical concern for their particular situation. 
Table 2. Total number of analyses from quality-assurance samples during water year 1998 with the number greater than two and six standard deviations from the most probable value and results of statistical testing for analytical precision in constituent data for the National Water Quality Laboratory

[ $>2 \mathrm{SD}$, number of analyses greater than 2 or less than -2 standard deviations from the most probable value; $>6 \mathrm{SD}$, number of analyses greater than 6 or less than -6 standard deviations from the most probable value; WWR, whole-water recoverable; TITR, electrometric titration; --, acceptable results; DIS, dissolved; ICP-AES, inductively coupled plasma-atomic emission spectrometry; ICP-MS, inductively coupled plasma-mass spectrometry; DCP-AES, direct current plasma-atomic emission spectrometry; HG-AAS, hydride generation-atomic absorption spectrophotometry; GF-AAS, graphite furnace-atomic absorption spectrophotometry; USEPA, U.S. Environmental Protection Agency; IC, ion chromatography; LL, low level; GRAV, gravimetric; ISE, ionselective electrode; F-AAS, flame-atomic absorption spectrophotometry; CV-AAS, cold vapor-atomic absorption spectrophotometry; LOP, statistically significant lack of precision; ELEC, electrometric; COL, colorimetric; ASF, micro-Kjeldahl digestion, automated segmented flow, colorimetric]

\begin{tabular}{|c|c|c|c|c|c|}
\hline \multirow{2}{*}{$\begin{array}{l}\text { Constituent and } \\
\text { method of analysis }\end{array}$} & \multicolumn{3}{|c|}{ Number of analyses } & \multirow{2}{*}{ p-value } & \multirow{2}{*}{$\begin{array}{c}\text { Results } \\
\text { from } 1998\end{array}$} \\
\hline & Total & >2SD & $>6 \mathrm{SD}$ & & \\
\hline \multicolumn{6}{|c|}{ Inorganic constituents } \\
\hline Alkalinity (WWR,TITR) & 241 & 1 & 0 & 1.00000 & -- \\
\hline Aluminum (DIS, ICP-AES) & 31 & 0 & 0 & 0.79609 & -- \\
\hline Aluminum (DIS, ICP-MS) & 96 & 0 & 0 & 0.99273 & -- \\
\hline Aluminum (WWR, DCP-AES) & 37 & 5 & 1 & 0.03593 & -- \\
\hline Antimony (DIS, HG-AAS) & 12 & 1 & 0 & 0.45964 & -- \\
\hline Antimony (DIS, ICP-MS) & 96 & 0 & 0 & 0.99273 & -- \\
\hline Arsenic (DIS, HG-AAS) & 72 & 1 & 0 & 0.97511 & -- \\
\hline Arsenic (WWR, GF-AAS, USEPA) & 8 & 0 & 0 & 0.33658 & -- \\
\hline Arsenic (WWR, HG-AAS) & 41 & 0 & 0 & 0.87791 & -- \\
\hline Barium (DIS, ICP-AES) & 97 & 0 & 0 & 0.99309 & -- \\
\hline Barium (DIS, ICP-MS) & 96 & 0 & 0 & 0.99273 & -- \\
\hline Beryllium (DIS, ICP-AES) & 73 & 0 & 0 & 0.97635 & -- \\
\hline Beryllium (DIS, ICP-MS) & 96 & 0 & 0 & 0.99273 & -- \\
\hline Boron (DIS, ICP-AES) & 161 & 0 & 0 & 0.99974 & -- \\
\hline Boron (WWR, DCP-AES) & 12 & 1 & 0 & 0.45964 & - \\
\hline Cadmium (DIS, GF-AAS) & 48 & 1 & 0 & 0.91474 & -- \\
\hline Cadmium (DIS, ICP-AES) & 62 & 2 & 0 & 0.82275 & - \\
\hline Cadmium (DIS, ICP-MS) & 96 & 0 & 0 & 0.99273 & -- \\
\hline Cadmium (WWR, GF-AAS) & 73 & 2 & 1 & 0.88549 & -- \\
\hline Calcium (DIS, ICP-AES) & 241 & 0 & 0 & 1.00000 & -- \\
\hline Chloride (DIS, IC) & 241 & 4 & 0 & 0.99816 & -- \\
\hline Chloride (DIS, IC, LL) & 12 & 1 & 1 & 0.45964 & -- \\
\hline Chromium (DIS, GF-AAS) & 48 & 1 & 0 & 0.91474 & -- \\
\hline Chromium (DIS, ICP-AES) & 59 & 0 & 0 & 0.95151 & -- \\
\hline Chromium (DIS, ICP-MS) & 96 & 0 & 0 & 0.99273 & -- \\
\hline Chromium (WWR, GF-AAS) & 49 & 0 & 0 & 0.91901 & - \\
\hline Cobalt (DIS, GF-AAS) & 8 & 0 & 0 & 0.33658 & -- \\
\hline Cobalt (DIS, ICP-AES) & 29 & 3 & 0 & 0.17512 & - \\
\hline Cobalt (DIS, ICP-MS) & 64 & 0 & 0 & 0.96248 & -- \\
\hline Cobalt (WWR, GF-AAS) & 25 & 0 & 0 & 0.72261 & -- \\
\hline Copper (DIS, GF-AAS) & 37 & 0 & 0 & 0.85011 & -- \\
\hline Copper (DIS, ICP-AES) & 49 & 0 & 0 & 0.91901 & -- \\
\hline Copper (DIS, ICP-MS) & 64 & 0 & 0 & 0.96248 & -- \\
\hline Copper (WWR, GF-AAS) & 54 & 2 & 1 & 0.75921 & -- \\
\hline Dissolved Solids (DIS, GRAV) & 239 & 4 & 0 & 0.99801 & -- \\
\hline Fluoride (DIS, IC, LL) & 13 & 1 & 1 & 0.48666 & -- \\
\hline Fluoride (DIS, ISE) & 236 & 3 & 0 & 0.99950 & -- \\
\hline Iron (DIS, ICP-AES) & 191 & 0 & 0 & 0.99994 & -- \\
\hline
\end{tabular}


Table 2. Total number of analyses from quality-assurance samples during water year 1998 with the number greater than two and six standard deviations from the most probable value and results of statistical testing for analytical precision in constituent data for the National Water Quality Laboratory-Continued

[ $>2 S D$, number of analyses greater than 2 or less than -2 standard deviations from the most probable value; $>6 S D$, number of analyses greater than 6 or less than -6 standard deviations from the most probable value; WWR, whole-water recoverable; TITR, electrometric titration; --, acceptable results; DIS, dissolved; ICP-AES, inductively coupled plasma-atomic emission spectrometry; ICP-MS, inductively coupled plasma-mass spectrometry; DCP-AES, direct current plasma-atomic emission spectrometry; HG-AAS, hydride generation-atomic absorption spectrophotometry; GF-AAS, graphite furnace-atomic absorption spectrophotometry; USEPA, U.S. Environmental Protection Agency; IC, ion chromatography; LL, low level; GRAV, gravimetric; ISE, ionselective electrode; F-AAS, flame-atomic absorption spectrophotometry; CV-AAS, cold vapor-atomic absorption spectrophotometry; LOP, statistically significant lack of precision; ELEC, electrometric; COL, colorimetric; ASF, micro-Kjeldahl digestion, automated segmented flow, colorimetric]

\begin{tabular}{|c|c|c|c|c|c|}
\hline \multirow{2}{*}{$\begin{array}{c}\text { Constituent and } \\
\text { method of analysis }\end{array}$} & \multicolumn{3}{|c|}{ Number of analyses } & \multirow{2}{*}{ p-value } & \multirow{2}{*}{$\begin{array}{c}\text { Results } \\
\text { from } 1998\end{array}$} \\
\hline & Total & $>2 S D$ & $>6 S D$ & & \\
\hline \multicolumn{6}{|c|}{ Inorganic constituents-Continued } \\
\hline Iron (WWR, F-AAS) & 73 & 3 & 0 & 0.71332 & -- \\
\hline Lead (DIS, GF-AAS) & 48 & 1 & 1 & 0.91474 & -- \\
\hline Lead (DIS, ICP-AES) & 10 & 3 & 0 & 0.01150 & -- \\
\hline Lead (DIS, ICP-MS) & 96 & 0 & 0 & 0.99273 & -- \\
\hline Lead (WWR, GF-AAS) & 73 & 2 & 0 & 0.88549 & -- \\
\hline Lithium (DIS, ICP-AES) & 97 & 0 & 0 & 0.99309 & -- \\
\hline Lithium (WWR, F-AAS) & 13 & 0 & 0 & 0.48666 & -- \\
\hline Magnesium (DIS, ICP-AES) & 241 & 2 & 0 & 0.99994 & -- \\
\hline Manganese (DIS, ICP-AES) & 191 & 0 & 0 & 0.99994 & -- \\
\hline Manganese (DIS, ICP-MS) & 96 & 0 & 0 & 0.99273 & -- \\
\hline Manganese (WWR, F-AAS) & 43 & 0 & 0 & 0.88982 & -- \\
\hline Mercury (DIS, CV-AAS) & 48 & 3 & 0 & 0.43295 & -- \\
\hline Mercury (WWR, CV-AAS) & 48 & 6 & 3 & 0.03171 & -- \\
\hline Molybdenum (DIS, GF-AAS) & 12 & 0 & 0 & 0.45964 & -- \\
\hline Molybdenum (DIS, ICP-AES) & 16 & 2 & 0 & 0.18924 & -- \\
\hline Molybdenum (DIS, ICP-MS) & 96 & 0 & 0 & 0.99273 & -- \\
\hline Molybdenum (WWR, GF-AAS) & 24 & 1 & 1 & 0.70801 & -- \\
\hline Nickel (DIS, GF-AAS) & 24 & 1 & 0 & 0.70801 & -- \\
\hline Nickel (DIS, ICP-AES) & 33 & 1 & 0 & 0.81597 & -- \\
\hline Nickel (DIS, ICP-MS) & 96 & 0 & 0 & 0.99273 & -- \\
\hline Nickel (WWR, GF-AAS) & 49 & 2 & 1 & 0.71012 & -- \\
\hline Potassium (DIS, F-AAS) & 241 & 6 & 2 & 0.98243 & -- \\
\hline Potassium (DIS, F-AA, LL) & 13 & 0 & 0 & 0.48666 & -- \\
\hline Selenium (DIS, HG-AAS) & 108 & 2 & 0 & 0.97375 & -- \\
\hline Selenium (WWR, GF-AAS, USEPA) & 8 & 0 & 0 & 0.33658 & -- \\
\hline Selenium (WWR, HG-AAS) & 41 & 0 & 0 & 0.87791 & -- \\
\hline Silica (DIS, COL) & 120 & 4 & 2 & 0.85559 & -- \\
\hline Silica (DIS, ICP-AES) & 240 & 0 & 0 & 1.00000 & -- \\
\hline Silver (DIS, GF-AAS) & 16 & 0 & 0 & 0.55987 & -- \\
\hline Silver (DIS, ICP-AES) & 30 & 2 & 0 & 0.44646 & -- \\
\hline Silver (DIS, ICP-MS) & 64 & 11 & 0 & 0.00031 & LOP \\
\hline Silver (WWR, GF-AAS) & 33 & 4 & 1 & 0.08081 & -- \\
\hline Sodium (DIS, ICP-AES) & 241 & 0 & 0 & 1.00000 & -- \\
\hline Specific Conductance (WWR, ELEC, LL) & 13 & 1 & 0 & 0.48666 & -- \\
\hline Strontium (DIS, ICP-AES) & 97 & 0 & 0 & 0.99309 & -- \\
\hline Sulfate (DIS, IC) & 241 & 1 & 0 & 1.00000 & -- \\
\hline Vanadium (DIS, ICP-AES) & 52 & 0 & 0 & 0.93056 & -- \\
\hline Zinc (DIS, ICP-AES) & 53 & 4 & 0 & 0.27287 & -- \\
\hline Zinc (DIS, ICP-MS) & 96 & 0 & 0 & 0.99273 & -- \\
\hline Zinc (WWR, F-AAS) & 73 & 1 & 0 & 0.97635 & -- \\
\hline
\end{tabular}


Table 2. Total number of analyses from quality-assurance samples during water year 1998 with the number greater than two and six standard deviations from the most probable value and results of statistical testing for analytical precision in constituent data for the National Water Quality Laboratory-Continued

[ $>2 \mathrm{SD}$, number of analyses greater than 2 or less than -2 standard deviations from the most probable value; $>6 \mathrm{SD}$, number of analyses greater than 6 or less than -6 standard deviations from the most probable value; WWR, whole-water recoverable; TITR, electrometric titration; --, acceptable results; DIS, dissolved; ICP-AES, inductively coupled plasma-atomic emission spectrometry; ICP-MS, inductively coupled plasma-mass spectrometry; DCP-AES, direct current plasma-atomic emission spectrometry; HG-AAS, hydride generation-atomic absorption spectrophotometry; GF-AAS, graphite furnace-atomic absorption spectrophotometry; USEPA, U.S. Environmental Protection Agency; IC, ion chromatography; LL, low level; GRAV, gravimetric; ISE, ionselective electrode; F-AAS, flame-atomic absorption spectrophotometry; CV-AAS, cold vapor-atomic absorption spectrophotometry; LOP, statistically significant lack of precision; ELEC, electrometric; COL, colorimetric; ASF, micro-Kjeldahl digestion, automated segmented flow, colorimetric]

\begin{tabular}{|c|c|c|c|c|c|}
\hline \multirow{2}{*}{$\begin{array}{l}\text { Constituent and } \\
\text { method of analysis }\end{array}$} & \multicolumn{3}{|c|}{ Number of analyses } & \multirow{2}{*}{ p-value } & \multirow{2}{*}{$\begin{array}{l}\text { Results } \\
\text { from } 1998\end{array}$} \\
\hline & Total & >2SD & $>6 S D$ & & \\
\hline \multicolumn{6}{|c|}{ Nutrient constituents } \\
\hline Ammonia as nitrogen (DIS, COL) & 333 & 30 & 2 & 0.00153 & LOP \\
\hline Ammonia as nitrogen (DIS, COL, LL) & 66 & 1 & 1 & 0.96613 & -- \\
\hline Ammonia as nitrogen (DIS, USEPA) & 17 & 1 & 0 & 0.58188 & -. \\
\hline Ammonia plus organic nitrogen as nitrogen (DIS, ASF) & 334 & 5 & 1 & 0.99982 & -- \\
\hline Ammonia plus organic nitrogen as nitrogen (DIS, USEPA) & 34 & 0 & 0 & 0.82518 & -- \\
\hline Ammonia plus organic nitrogen as nitrogen (WWR, ASF) & 226 & 1 & 0 & 0.99999 & -- \\
\hline Ammonia plus organic nitrogen as nitrogen (WWR, USEPA) & 34 & 1 & 0 & 0.82518 & -- \\
\hline Nitrate plus nitrite as nitrogen (DIS, COL) & 334 & 21 & 3 & 0.16875 & -- \\
\hline Nitrate plus nitrite as nitrogen (DIS, COL, LL) & 66 & 2 & 1 & 0.84850 & -- \\
\hline Orthophosphate as phosphorus (DIS, COL) & 332 & 52 & 8 & 0.00000 & LOP \\
\hline Orthophosphate as phosphorus (DIS, COL, LL) & 66 & 3 & 3 & 0.64727 & -- \\
\hline Phosphorus (DIS, ASF) & 334 & 21 & 2 & 0.16875 & -- \\
\hline Phosphorus (DIS, COL, LL) & 33 & 4 & 2 & 0.08081 & -- \\
\hline Phosphorus (DIS, USEPA) & 34 & 1 & 0 & 0.82518 & -- \\
\hline Phosphorus (WWR, ASF) & 226 & 3 & 0 & 0.99923 & -- \\
\hline Phosphorus (WWR, COL, LL) & 65 & 5 & 3 & 0.22479 & -- \\
\hline Phosphorus (WWR, USEPA) & 34 & 0 & 0 & 0.82518 & -- \\
\hline
\end{tabular}

Table 3. Total number of analyses from quality-assurance samples during water year 1998 with the number greater than two and six standard deviations from the most probable value and results of statistical testing for analytical precision in constituent data for the Quality of Water Service Unit laboratory

[ $>2 \mathrm{SD}$, number of analyses greater than 2 or less than -2 standard deviations from the most probable value; $>6 \mathrm{SD}$, number of analyses greater than 6 or less than -6 standard deviations from the most probable value; WWR, whole-water recoverable; TITR, electrometric titration; --, acceptable results; DIS, dissolved; ICP-AES/T, inductively coupled plasma-atomic emission spectrometry, trace; GF-AAS, graphite furnace-atomic absorption spectrophotometry; USEPA, U.S. Environmental Protection Agency; ICP-AES, inductively coupled plasma-atomic emission spectrometry; IC, ion chromatography; GRAV, gravimetric; ISE, ion-selective electrode; CV-AAS, cold vapor-atomic absorption spectrophotometry; F-AAS, flame-atomic absorption spectrophotometry]

\begin{tabular}{|c|c|c|c|c|c|}
\hline \multirow{2}{*}{$\begin{array}{l}\text { Constituent and } \\
\text { method of analysis }\end{array}$} & \multicolumn{3}{|c|}{ Number of analyses } & \multirow{2}{*}{ p-value } & \multirow{2}{*}{$\begin{array}{c}\text { Results } \\
\text { from } 1998\end{array}$} \\
\hline & Total & $>2 S D$ & $>6 \mathrm{SD}$ & & \\
\hline \multicolumn{6}{|c|}{ Inorganic constituents } \\
\hline Alkalinity (WWR, TITR) & 65 & 1 & 1 & 0.96435 & -- \\
\hline Aluminum (DIS, ICP-AES/T) & 24 & 0 & 0 & 0.70801 & -- \\
\hline Aluminum (WWR, GF-AAS, USEPA) & 11 & 1 & 0 & 0.43120 & -- \\
\hline Aluminum (WWR, ICP-AES/T) & 24 & 0 & 0 & 0.70801 & -- \\
\hline Arsenic (DIS, GF-AAS) & 12 & 0 & 0 & 0.45964 & -- \\
\hline Arsenic (WWR, GF-AAS) & 8 & 0 & 0 & 0.33658 & -- \\
\hline Barium (DIS, ICP-AES/T) & 10 & 0 & 0 & 0.40126 & -- \\
\hline Barium (WWR, ICP-AES/T) & 12 & 0 & 0 & 0.45964 & -- \\
\hline
\end{tabular}


Table 3. Total number of analyses from quality-assurance samples during water year 1998 with the number greater than two and six standard deviations from the most probable value and results of statistical testing for analytical precision in constituent data for the Quality of Water Service Unit laboratory-Continued

[ $>2 \mathrm{SD}$, number of analyses greater than 2 or less than -2 standard deviations from the most probable value; $>6 \mathrm{SD}$, number of analyses greater than 6 or less than -6 standard deviations from the most probable value; WWR, whole-water recoverable; TITR, electrometric titration; --, acceptable results; DIS, dissolved; ICP-AES/T, inductively coupled plasma-atomic emission spectrometry, trace; GF-AAS, graphite furnace-atomic absorption spectrophotometry; USEPA, U.S. Environmental Protection Agency; ICP-AES, inductively coupled plasma-atomic emission spectrometry; IC, ion chromatography; GRAV, gravimetric; ISE, ion-selective electrode; CV-AAS, cold vapor-atomic absorption spectrophotometry; F-AAS, flame-atomic absorption spectrophotometry]

\begin{tabular}{|c|c|c|c|c|c|}
\hline \multirow{2}{*}{$\begin{array}{l}\text { Constituent and } \\
\text { method of analysis }\end{array}$} & \multicolumn{3}{|c|}{ Number of analyses } & \multirow{2}{*}{ p-value } & \multirow{2}{*}{$\begin{array}{c}\text { Results } \\
\text { from } 1998\end{array}$} \\
\hline & Total & >2SD & $>6 S D$ & & \\
\hline \multicolumn{6}{|c|}{ Inorganic constituents-Continued } \\
\hline Beryllium (DIS, ICP-AES/T) & 10 & 0 & 0 & 0.40126 & -- \\
\hline Beryllium (WWR, ICP-AES/T) & 12 & 0 & 0 & 0.45964 & -- \\
\hline Boron (DIS, ICP-AES/T) & 10 & 0 & 0 & 0.40126 & -- \\
\hline Cadmium (DIS, GF-AAS) & 11 & 0 & 0 & 0.43120 & -- \\
\hline Cadmium (DIS, ICP-AES/T) & 10 & 0 & 0 & 0.40126 & -- \\
\hline Cadmium (WWR, GF-AAS) & 11 & 0 & 0 & 0.43120 & -- \\
\hline Cadmium (WWR, ICP-AES/T) & 11 & 1 & 0 & 0.43120 & -- \\
\hline Calcium (DIS, ICP-AES) & 90 & 2 & 0 & 0.94327 & -- \\
\hline Calcium (DIS, ICP-AES/T) & 34 & 0 & 0 & 0.82518 & -- \\
\hline Chloride (DIS, IC) & 89 & 0 & 0 & 0.98959 & -- \\
\hline Chromium (DIS, ICP-AES/T) & 10 & 0 & 0 & 0.40126 & -- \\
\hline Chromium (WWR, GF-AAS) & 11 & 1 & 0 & 0.43120 & -- \\
\hline Chromium (WWR, ICP-AES/T) & 10 & 1 & 0 & 0.40126 & -- \\
\hline Cobalt (DIS, ICP-AES/T) & 8 & 0 & 0 & 0.33658 & -- \\
\hline Copper (DIS, GF-AAS) & 11 & 0 & 0 & 0.43120 & -- \\
\hline Copper (DIS, ICP-AES/T) & 8 & 0 & 0 & 0.33658 & -- \\
\hline Copper (WWR, GF-AAS) & 9 & 0 & 0 & 0.36975 & -- \\
\hline Copper (WWR, ICP-AES/T) & 12 & 0 & 0 & 0.45964 & -- \\
\hline Dissolved Solids (DIS, GRAV) & 65 & 2 & 0 & 0.84240 & -- \\
\hline Fluoride (DIS, ISE) & 76 & 0 & 0 & 0.97972 & -- \\
\hline Iron (DIS, ICP-AES/T) & 44 & 1 & 1 & 0.89533 & -- \\
\hline Iron (WWR, ICP-AES/T) & 45 & 2 & 0 & 0.66504 & -- \\
\hline Lead (DIS, GF-AAS) & 10 & 0 & 0 & 0.40126 & -- \\
\hline Lead (DIS, ICP-AES/T) & 10 & 0 & 0 & 0.40126 & -- \\
\hline Lead (WWR, GF-AAS) & 11 & 2 & 1 & 0.10189 & -- \\
\hline Lead (WWR, ICP-AES/T) & 11 & 0 & 0 & 0.43120 & -- \\
\hline Magnesium (DIS, ICP-AES) & 90 & 0 & 0 & 0.99011 & -- \\
\hline Magnesium (DIS, ICP-AES/T) & 34 & 1 & 0 & 0.82518 & -- \\
\hline Manganese (DIS, ICP-AES/T) & 44 & 0 & 0 & 0.89533 & -- \\
\hline Manganese (WWR, ICP-AES/T) & 35 & 2 & 0 & 0.52797 & -- \\
\hline Mercury (WWR, CV-AAS) & 21 & 0 & 0 & 0.65944 & -- \\
\hline Molybdenum (DIS, ICP-AES/T) & 10 & 0 & 0 & 0.40126 & -- \\
\hline Nickel (DIS, ICP-AES/T) & 10 & 0 & 0 & 0.40126 & -- \\
\hline Nickel (WWR, GF-AAS) & 11 & 0 & 0 & 0.43120 & -- \\
\hline Nickel (WWR, ICP-AES/T) & 12 & 0 & 0 & 0.45964 & -- \\
\hline Potassium (DIS, F-AAS) & 90 & 0 & 0 & 0.99011 & -- \\
\hline Selenium (DIS, GF-AAS) & 11 & 0 & 0 & 0.43120 & -- \\
\hline Selenium (WWR, GF-AAS) & 8 & 0 & 0 & 0.33658 & -- \\
\hline Silica (DIS, ICP-AES) & 66 & 0 & 0 & 0.96613 & - \\
\hline Silica (DIS, ICP-AES/T) & 34 & 0 & 0 & 0.82518 & -- \\
\hline
\end{tabular}


Table 3. Total number of analyses from quality-assurance samples during water year 1998 with the number greater than two and six standard deviations from the most probable value and results of statistical testing for analytical precision in constituent data for the Quality of Water Service Unit laboratory-Continued

[ $>2 \mathrm{SD}$, number of analyses greater than 2 or less than -2 standard deviations from the most probable value; $>6 \mathrm{SD}$, number of analyses greater than 6 or less than -6 standard deviations from the most probable value; WWR, whole-water recoverable; TITR, electrometric titration; --, acceptable results; DIS, dissolved; ICP-AES/T, inductively coupled plasma-atomic emission spectrometry, trace; GF-AAS, graphite furnace-atomic absorption spectrophotometry; USEPA, U.S. Environmental Protection Agency; ICP-AES, inductively coupled plasma-atomic emission spectrometry; IC, ion chromatography; GRAV, gravimetric; ISE, ion-selective electrode; CV-AAS, cold vapor-atomic absorption spectrophotometry; F-AAS, flame-atomic absorption spectrophotometry]

\begin{tabular}{|c|c|c|c|c|c|}
\hline \multirow{2}{*}{$\begin{array}{l}\text { Constituent and } \\
\text { method of analysis }\end{array}$} & \multicolumn{3}{|c|}{ Number of analyses } & \multirow{2}{*}{ p-value } & \multirow{2}{*}{$\begin{array}{c}\text { Results } \\
\text { from } 1998\end{array}$} \\
\hline & Total & $>2 S D$ & $>6 S D$ & & \\
\hline \multicolumn{6}{|c|}{ Inorganic constituents-Continued } \\
\hline Silver (DIS, ICP-AES/T) & 8 & 0 & 0 & 0.33658 & -- \\
\hline Sodium (DIS, F-AAS) & 90 & 0 & 0 & 0.99011 & -- \\
\hline Strontium (DIS, ICP-AES/T) & 20 & 0 & 0 & 0.64151 & -- \\
\hline Strontium (WWR, ICP-AES/T) & 12 & 1 & 0 & 0.45964 & -- \\
\hline Sulfate (DIS, IC) & 89 & 0 & 0 & 0.98959 & -- \\
\hline Vanadium (DIS, ICP-AES/T) & 10 & 0 & 0 & 0.40126 & -- \\
\hline Zinc (DIS, ICP-AES/T) & 10 & 0 & 0 & 0.40126 & -- \\
\hline Zinc (WWR, ICP-AES/T) & 22 & 0 & 0 & 0.67647 & -- \\
\hline \multicolumn{6}{|c|}{ Nutrient constituents } \\
\hline Ammonia as nitrogen (DIS) & 39 & 2 & 1 & 0.58705 & - \\
\hline Ammonia plus organic nitrogen as nitrogen (DIS) & 41 & 0 & 0 & 0.87791 & -- \\
\hline Ammonia plus organic nitrogen as nitrogen (WWR) & 64 & 0 & 0 & 0.96248 & -- \\
\hline Nitrate plus nitrite as nitrogen (DIS) & 39 & 1 & 0 & 0.86472 & -- \\
\hline Orthophosphate as phosphorus (DIS) & 39 & 1 & 0 & 0.86472 & -- \\
\hline Phosphorus as phosphorus (DIS) & 41 & 1 & 0 & 0.87791 & -- \\
\hline Phosphorus as phosphorus (WWR) & 64 & 3 & 1 & 0.62653 & -- \\
\hline
\end{tabular}

There are two important factors to consider when analyzing analytical results for bias: the first is the number of observations in the subsample, and the second is the magnitude of the bias. If there are few observations in the subsample, the median difference has to be large to attain a p-value that indicates a biased condition. On the other hand, if there are many observations, a small median difference may result in a $p$-value that indicates bias.

The second factor used for the bias assessment is the bias magnitude. The magnitude of the bias is defined as the difference in concentration between the reported values from the laboratory and the MPV. The magnitude must be greater than one reporting unit for that MPV for the results to be considered biased. For example, 32 aluminum (DIS, ICP-MS) determinations of a sample having an MPV of $11.1 \mu \mathrm{g} / \mathrm{L}$ resulted in a median difference of $0.3 \mu \mathrm{g} / \mathrm{L}$ from the MPV. It is important to consider that at a concentration of $11.1 \mu \mathrm{g} / \mathrm{L}$, a laboratory would typically report data only to the nearest $1 \mu \mathrm{g} / \mathrm{L}$. The signed-rank test provided a p-value of 0.00247 , which is considerably less than the 0.05 value. If the reporting unit was not considered, this result would have been considered biased negative, even though the laboratory was reporting the sample to the best of its reporting ability. Because the median difference of $0.3 \mu \mathrm{g} / \mathrm{L}$ is less than the reporting level of $1 \mu \mathrm{g} / \mathrm{L}$, the magnitude of the bias is less than the implied accuracy of the analysis; therefore, analytical bias that is based strictly on the p-value has no practical meaning.

\section{QUALITY-ASSURANCE DATA FOR INORGANIC-CONSTITUENT SAMPLES}

\section{Precision}

The results of the binomial-probabilitydistribution test for analytical precision for each inorganic constituent are presented in table 2 for the NWQL and in table 3 for the QWSU. These tables show either acceptable results (indicated by --) or a 
statistically significant lack of precision (LOP) at a significance level of 0.01 for each constituent. The NWQL data from water year 1998 for silver (DIS, ICP-MS) indicated lack of precision. There were no inorganic methods at the QWSU that indicated imprecision.

\section{Bias}

Analytical bias for the inorganic analyses are presented in table 4 for the NWQL and in table 5 for the QWSU. These tables show the results of the Wilcoxon signed-rank test for each reference sample mix by constituent. The following discussion presents an evaluation of those analytes that show strong evidence of bias through part or all of the concentration range of reference samples submitted by the BSP. Strong evidence of bias was considered to be greater than 50 percent of the samples found to have a positive or negative bias. Frequently only one or two of the reference mixes for a constituent indicated analytical bias. In many of these cases, the median bias was only slightly greater than the reporting unit, or the data for other reference samples in the same analytical range did not indicate analytical bias.

At the NWQL, positive analytical bias was indicated throughout the range of reference samples for chromium (DIS, ICP-AES), dissolved solids (DIS, GRAV), lithium (DIS, ICP-AES), and zinc (DIS, ICP-MS). Negative analytical bias throughout the reference sample range was indicated for silver (DIS, ICP-MS). This bias was caused by mix biases in the two samples submitted. Manganese (DIS, ICP-AES) showed a negative bias only on those mixes greater than $25 \mu \mathrm{g} / \mathrm{L}$.

At the QWSU, positive bias was indicated throughout the range of reference samples for aluminum (WWR, ICP-AES/T). This bias was determined to be an artifact of the digestion process. Positive bias was indicated on the majority of sample mixes submitted for alkalinity (WWR, TITR) and dissolved solids (DIS, GRAV).

The statistical power of the Wilcoxon signedranks tests for analytical bias from QWSU is dependent on sample size. Tests on analytical data from the QWSU are less powerful than the same tests used at the NWQL due to the smaller sample sizes associated with the QWSU data.

\section{QUALITY-ASSURANCE DATA FOR NUTRIENT-CONSTITUENT SAMPLES}

\section{Precision}

The results of the binomial-probabilitydistribution test for analytical precision for each nutrient constituent are presented in table 2 for the NWQL and table 3 for the QWSU. These tables show either acceptable results (indicated by --) or a statistically significant lack of precision (LOP) at a significance level of 0.01 for each constituent. NWQL data from water year 1998 for ammonia as nitrogen (DIS, $\mathrm{COL}$ ) and orthophosphate as phosphorus (DIS, COL) indicated lack of precision. The ammonia as nitrogen (DIS, COL) method experienced a period of imprecision from October 1997 to mid-January 1998. Beginning in October 1997, new analytical software was installed, and the baseline correction factor was calculated incorrectly, skewing the analytical results (J. Vasquez, U.S. Geological Survey, National Water Quality Laboratory, written commun., March 1998). All seven nutrient procedures at the QWSU displayed acceptable precision for water year 1998.

\section{Bias}

Analytical bias for the nutrient analyses are presented in table 4 for the NWQL and in table 5 for the QWSU. These tables show the results of the Wilcoxon signed-rank test for each reference sample mix by constituent. The following discussion presents an evaluation of those analytes that showed strong evidence of bias through part or all of the range of reference samples submitted by the BSP. Strong evidence of bias was indicated if more than 50 percent of the samples had a positive or negative bias. Frequently, one or two of the reference mixes for a constituent indicated analytical bias. In many of these cases, the median bias was only slightly greater or less than the reporting unit, or data for other reference samples in the same analytical range did not indicate analytical bias.

At the NWQL, two mixes submitted for ammonia as nitrogen (DIS, COL, LL) and nitrate plus nitrite as nitrogen (DIS, COL, LL) showed a negative bias. There were no nutrient procedures at the QWSU that indicated a significant bias. 
Table 4. Results of Wilcoxon signed-rank test for bias in constituent data for the National Water Quality Laboratory

[Most probable value, Median bias, and Nearest reporting unit reported in same units as Minimum Reporting Limit; WWR, whole-water recoverable; TITR, electrometric titration; mg/L, milligrams per liter; POS, positive bias; --, acceptable results; DIS, dissolved; ICP-AES, inductively coupled plasma-atomic emission spectrometry; $\mu \mathrm{g} / \mathrm{L}$, micrograms per liter; NEG, negative bias; ICP-MS, inductively coupled plasma-mass spectrometry; DCP-AES, direct current plasma-atomic emission spectrometry; HG-AAS, hydride generation-atomic absorption spectrophotometry; GF-AAS, graphite furnace-atomic absorption spectrophotometry; USEPA, U.S. Environmental Protection Agency; IC, ion chromatography; LL, low level; GRAV, gravimetric; ISE, ion-selective electrode; F-AAS, flame-atomic absorption spectrophotometry; CV-AAS, cold vapor-atomic absorption spectrophotometry; ELEC, electrometric; $\mu$ S/cm, microsiemens per centimeter at 25 degrees Celsius; COL, colorimetric; ASF, micro-Kjeldahl digestion, automated segmented flow, colorimetric]

\begin{tabular}{|c|c|c|c|c|c|c|}
\hline $\begin{array}{l}\text { Constituent and } \\
\text { method of analysis }\end{array}$ & $\begin{array}{c}\text { Most } \\
\text { probable value }\end{array}$ & $\begin{array}{l}\text { Number of } \\
\text { determinations }\end{array}$ & $\begin{array}{c}\text { Median } \\
\text { bias }\end{array}$ & $\begin{array}{c}\text { Nearest } \\
\text { reporting } \\
\text { unit }\end{array}$ & p-value & Bias \\
\hline \multicolumn{7}{|c|}{ Inorganic constituents } \\
\hline \multirow{10}{*}{$\begin{array}{l}\text { Alkalinity (WWR,TITR) Minimum Reporting } \\
\text { Limit } 1 \mathrm{mg} / \mathrm{L}\end{array}$} & 9.08 & 22 & 1.29 & 0.1 & 0.00000 & POS \\
\hline & 18.2 & 30 & 1.0 & 1 & 0.00000 & -- \\
\hline & 55.7 & 16 & -0.1 & 1 & 0.27444 & -- \\
\hline & 75.2 & 24 & -0.2 & 1 & 0.03664 & -- \\
\hline & 76.0 & 27 & 2.5 & 1 & 0.00000 & POS \\
\hline & 88.5 & 18 & 0.0 & 1 & 0.94080 & -- \\
\hline & 94.2 & 30 & 0.4 & 1 & 0.00036 & -- \\
\hline & 107.5 & 34 & 2.0 & 1 & 0.00000 & POS \\
\hline & 114.0 & 26 & 2.7 & 1 & 0.00000 & POS \\
\hline & 129.7 & 14 & 2.8 & 1 & 0.00012 & POS \\
\hline \multirow{5}{*}{$\begin{array}{l}\text { Aluminum (DIS, ICP-AES) Minimum Reporting } \\
\text { Limit } 10 \mu \mathrm{g} / \mathrm{L}\end{array}$} & 7.63 & 3 & 3.95 & 0.1 & 0.25000 & -- \\
\hline & 26.30 & 4 & 1.68 & 0.1 & 0.12500 & -- \\
\hline & 26.45 & 12 & 0.19 & 0.1 & 0.73340 & -- \\
\hline & 28.48 & 8 & -1.95 & 0.1 & 0.03906 & NEG \\
\hline & 33.48 & 4 & 0.91 & 0.1 & 0.37500 & -- \\
\hline \multirow{3}{*}{$\begin{array}{l}\text { Aluminum (DIS, ICP-MS) Minimum Reporting } \\
\text { Limit } 1 \mu \mathrm{g} / \mathrm{L}\end{array}$} & 7.6 & 32 & 0.4 & 1 & 0.00000 & -- \\
\hline & 11.1 & 32 & 0.3 & 1 & 0.00247 & -- \\
\hline & 44.9 & 32 & -2.5 & 1 & 0.00000 & NEG \\
\hline \multirow{6}{*}{$\begin{array}{l}\text { Aluminum (WWR, DCP-AES) Minimum } \\
\text { Reporting Limit } 10 \mu \mathrm{g} / \mathrm{L}\end{array}$} & 26 & 4 & 8 & 10 & 0.62500 & -- \\
\hline & 26 & 4 & 5 & 10 & 0.87500 & -- \\
\hline & 28 & 8 & -1 & 10 & 0.72656 & -- \\
\hline & 33 & 4 & 12 & 10 & 0.37500 & -- \\
\hline & 45 & 8 & -2 & 10 & 0.71094 & -- \\
\hline & 45 & 8 & 8 & 10 & 0.01563 & -- \\
\hline \multirow{3}{*}{$\begin{array}{l}\text { Antimony (DIS, HG-AAS) Minimum Reporting } \\
\text { Limit } 1 \mu \mathrm{g} / \mathrm{L}\end{array}$} & 12.4 & 4 & 0.5 & 1 & 0.25000 & -- \\
\hline & 14.7 & 4 & 0.2 & 1 & 0.87500 & -- \\
\hline & 16.1 & 4 & 0.0 & 1 & 0.87500 & -- \\
\hline \multirow{3}{*}{$\begin{array}{l}\text { Antimony (DIS, ICP-MS) Minimum Reporting } \\
\quad \text { Limit } 1 \mu \mathrm{g} / \mathrm{L}\end{array}$} & 3.9 & 32 & 0.4 & 1 & 0.00000 & -- \\
\hline & 8.3 & 32 & 0.4 & 1 & 0.00000 & -- \\
\hline & 12.7 & 32 & 0.9 & 1 & 0.00000 & -- \\
\hline \multirow{7}{*}{$\begin{array}{l}\text { Arsenic (DIS, HG-AAS) Minimum Reporting } \\
\quad \text { Limit } 1 \mu \mathrm{g} / \mathrm{L}\end{array}$} & 1.8 & 8 & 0.2 & 1 & 0.00781 & -- \\
\hline & 3.1 & 12 & 0.3 & 1 & 0.05127 & -- \\
\hline & 7.6 & 21 & 0.4 & 1 & 0.69287 & -- \\
\hline & 7.9 & 4 & 1.1 & 1 & 0.12500 & -- \\
\hline & 11.4 & 8 & 0.6 & 1 & 0.35938 & -- \\
\hline & 12.5 & 14 & 0.0 & 1 & 0.11133 & -- \\
\hline & 13.9 & 4 & -0.9 & 1 & 0.62500 & -- \\
\hline \multirow{2}{*}{$\begin{array}{l}\text { Arsenic (WWR, GF-AAS, USEPA) Minimum } \\
\text { Reporting Limit } 1 \mu \mathrm{g} / \mathrm{L}\end{array}$} & 7.6 & 4 & -0.5 & 1 & 0.12500 & -- \\
\hline & 11.4 & 4 & 0.1 & 1 & 1.00000 & -- \\
\hline
\end{tabular}


Table 4. Results of Wilcoxon signed-rank test for bias in constituent data for the National Water Quality Laboratory-Continued

[Most probable value, Median bias, and Nearest reporting unit reported in same units as Minimum Reporting Limit; WWR, whole-water recoverable; TITR, electrometric titration; $\mathrm{mg} / \mathrm{L}$, milligrams per liter; POS, positive bias; --, acceptable results; DIS, dissolved; ICP-AES, inductively coupled plasma-atomic emission spectrometry; $\mu \mathrm{g} / \mathrm{L}$, micrograms per liter; NEG, negative bias; ICP-MS, inductively coupled plasma-mass spectrometry; DCP-AES, direct current plasma-atomic emission spectrometry; HG-AAS, hydride generation-atomic absorption spectrophotometry; GF-AAS, graphite furnace-atomic absorption spectrophotometry; USEPA, U.S. Environmental Protection Agency; IC, ion chromatography; LL, low level; GRAV, gravimetric; ISE, ion-selective electrode; F-AAS, flame-atomic absorption spectrophotometry; CV-AAS, cold vapor-atomic absorption spectrophotometry; ELEC, electrometric; $\mu \mathrm{S} / \mathrm{cm}$, microsiemens per centimeter at 25 degrees Celsius; COL, colorimetric; ASF, micro-Kjeldahl digestion, automated segmented flow, colorimetric]

\begin{tabular}{|c|c|c|c|c|c|c|}
\hline $\begin{array}{l}\text { Constituent and } \\
\text { method of analysis }\end{array}$ & $\begin{array}{c}\text { Most } \\
\text { probable value }\end{array}$ & $\begin{array}{l}\text { Number of } \\
\text { determinations }\end{array}$ & $\begin{array}{l}\text { Median } \\
\text { bias }\end{array}$ & $\begin{array}{l}\text { Nearest } \\
\text { reporting } \\
\text { unit }\end{array}$ & p-value & Bias \\
\hline \multicolumn{7}{|c|}{ Inorganic constituents-Continued } \\
\hline \multirow{5}{*}{$\begin{array}{l}\text { Arsenic (WWR, HG-AAS) Minimum Reporting } \\
\quad \text { Limit } 1 \mu \mathrm{g} / \mathrm{L}\end{array}$} & 1.8 & 8 & 0.2 & 1 & 0.00781 & - \\
\hline & 7.6 & 8 & 0.4 & 1 & 0.32031 & -- \\
\hline & 7.7 & 8 & 0.3 & 1 & 0.53125 & -- \\
\hline & 11.4 & 8 & 0.6 & 1 & 0.01563 & -- \\
\hline & 12.5 & 8 & 1.0 & 1 & 0.13281 & -- \\
\hline \multirow{6}{*}{$\begin{array}{l}\text { Barium (DIS, ICP-AES) Minimum Reporting } \\
\quad \text { Limit } 1 \mu \mathrm{g} / \mathrm{L}\end{array}$} & 32.5 & 8 & -0.9 & 1 & 0.10938 & - \\
\hline & 40.6 & 26 & -0.3 & 1 & 0.81470 & -- \\
\hline & 41.0 & 8 & 0.0 & 1 & 0.84375 & -- \\
\hline & 59.5 & 22 & 0.3 & 1 & 0.39316 & -- \\
\hline & 59.8 & 24 & 0.1 & 1 & 0.59798 & - \\
\hline & 61.4 & 8 & 1.6 & 1 & 0.02344 & POS \\
\hline \multirow{3}{*}{$\begin{array}{l}\text { Barium (DIS, ICP-MS) Minimum Reporting } \\
\text { Limit } 1 \mu \mathrm{g} / \mathrm{L}\end{array}$} & 16.3 & 32 & 0.1 & 1 & 0.63431 & -- \\
\hline & 41.0 & 32 & 0.8 & 1 & 0.00004 & - \\
\hline & 59.5 & 32 & 1.2 & 1 & 0.00000 & POS \\
\hline \multirow{3}{*}{$\begin{array}{l}\text { Beryllium (DIS, ICP-AES) Minimum Reporting } \\
\quad \text { Limit } 1 \mu \mathrm{g} / \mathrm{L}\end{array}$} & 6.43 & 24 & 0.02 & 0.1 & 0.73957 & -- \\
\hline & 8.77 & 22 & 0.03 & 0.1 & 0.06501 & -- \\
\hline & 9.57 & 26 & 0.0 & 0.1 & 0.76710 & -- \\
\hline \multirow{3}{*}{$\begin{array}{l}\text { Beryllium (DIS, ICP-MS) Minimum Reporting } \\
\quad \text { Limit } 1 \mu \mathrm{g} / \mathrm{L}\end{array}$} & 1.3 & 32 & 0.0 & 1 & 0.07286 & -- \\
\hline & 4.3 & 32 & 0.0 & 1 & 0.18195 & -- \\
\hline & 8.8 & 32 & 0.0 & 1 & 0.67354 & -- \\
\hline \multirow{9}{*}{$\begin{array}{l}\text { Boron (DIS, ICP-AES) Minimum Reporting } \\
\quad \text { Limit } 16 \mu \mathrm{g} / \mathrm{L}\end{array}$} & 5.00 & 5 & -0.59 & 0.1 & 0.75000 & -- \\
\hline & 17.90 & 16 & -1.90 & 0.1 & 0.00134 & NEG \\
\hline & 20.70 & 8 & 0.23 & 0.1 & 0.74219 & -- \\
\hline & 25.80 & 8 & 1.03 & 0.1 & 0.38281 & - \\
\hline & 37.65 & 18 & 1.50 & 0.1 & 0.36339 & -- \\
\hline & 100.0 & 27 & 2.9 & 1 & 0.00000 & POS \\
\hline & 105.0 & 30 & -0.6 & 1 & 0.23505 & -- \\
\hline & 116.9 & 34 & 0.7 & 1 & 0.02109 & -- \\
\hline & 158.4 & 14 & 3.1 & 1 & 0.00037 & POS \\
\hline \multirow{3}{*}{$\begin{array}{l}\text { Boron (WWR,DCP-AES) Minimum Reporting } \\
\text { Limit } 10 \mu \mathrm{g} / \mathrm{L}\end{array}$} & 25 & 4 & -6 & 10 & 0.37500 & -- \\
\hline & 26 & 4 & 2 & 10 & 1.00000 & $\cdots$ \\
\hline & 38 & 4 & -5 & 10 & 0.62500 & - \\
\hline \multirow{6}{*}{$\begin{array}{l}\text { Cadmium (DIS, GF-AAS) Minimum Reporting } \\
\quad \text { Limit } 1 \mu \mathrm{g} / \mathrm{L}\end{array}$} & 1.7 & 8 & 0.1 & 1 & 0.12500 & - \\
\hline & 3.4 & 8 & 0.0 & 1 & 0.90625 & -- \\
\hline & 7.0 & 8 & 0.0 & 1 & 0.57031 & -- \\
\hline & 7.2 & 8 & 0.1 & 1 & 0.56250 & - \\
\hline & 9.6 & 8 & 0.0 & 1 & 0.57031 & - \\
\hline & 14.3 & 8 & 0.5 & 1 & 0.46094 & -. \\
\hline
\end{tabular}


Table 4. Results of Wilcoxon signed-rank test for bias in constituent data for the National Water Quality Laboratory-Continued

[Most probable value, Median bias, and Nearest reporting unit reported in same units as Minimum Reporting Limit; WWR, whole-water recoverable; TITR, electrometric titration; mg/L, milligrams per liter; POS, positive bias; --, acceptable results; DIS, dissolved; ICP-AES, inductively coupled plasma-atomic emission spectrometry; $\mu \mathrm{g} / \mathrm{L}$, micrograms per liter; NEG, negative bias; ICP-MS, inductively coupled plasma-mass spectrometry; DCP-AES, direct current plasma-atomic emission spectrometry; HG-AAS, hydride generation-atomic absorption spectrophotometry; GF-AAS, graphite furnace-atomic absorption spectrophotometry; USEPA, U.S. Environmental Protection Agency; IC, ion chromatography; LL, low level; GRAV, gravimetric; ISE, ion-selective electrode; F-AAS, flame-atomic absorption spectrophotometry; CV-AAS, cold vapor-atomic absorption spectrophotometry; ELEC, electrometric; $\mu \mathrm{S} / \mathrm{cm}$, microsiemens per centimeter at 25 degrees Celsius; COL, colorimetric; ASF, micro-Kjeldahl digestion, automated segmented flow, colorimetric]

\begin{tabular}{|c|c|c|c|c|c|c|}
\hline $\begin{array}{l}\text { Constituent and } \\
\text { method of analysis }\end{array}$ & $\begin{array}{c}\text { Most } \\
\text { probable value }\end{array}$ & $\begin{array}{l}\text { Number of } \\
\text { determinations }\end{array}$ & $\begin{array}{l}\text { Median } \\
\text { bias }\end{array}$ & $\begin{array}{c}\text { Nearest } \\
\text { reporting } \\
\text { unit }\end{array}$ & p-value & Bias \\
\hline \multicolumn{7}{|c|}{ Inorganic constituents-Continued } \\
\hline \multirow{3}{*}{$\begin{array}{l}\text { Cadmium (DIS, ICP-AES) Minimum Reporting } \\
\text { Limit } 8 \mu \mathrm{g} / \mathrm{L}\end{array}$} & 7.0 & 13 & 1.9 & 1 & 0.00439 & POS \\
\hline & 8.4 & 26 & -0.4 & 1 & 0.89085 & -- \\
\hline & 14.2 & 22 & -0.6 & 1 & 0.43919 & -- \\
\hline \multirow{3}{*}{$\begin{array}{l}\text { Cadmium (DIS, ICP-MS) Minimum Reporting } \\
\quad \text { Limit } 1 \mu \mathrm{g} / \mathrm{L}\end{array}$} & 1.7 & 32 & 0.0 & 1 & 0.11706 & -- \\
\hline & 9.6 & 32 & 0.1 & 1 & 0.23892 & -- \\
\hline & 14.2 & 32 & -0.2 & 1 & 0.00137 & -- \\
\hline \multirow{7}{*}{$\begin{array}{l}\text { Cadmium (WWR, GF-AAS) Minimum Reporting } \\
\text { Limit } 1 \mu \mathrm{g} / \mathrm{L}\end{array}$} & 1.7 & 10 & 0.0 & 1 & 0.81250 & -- \\
\hline & 3.4 & 16 & -0.1 & 1 & 0.25708 & -- \\
\hline & 7.0 & 14 & -0.1 & 1 & 0.51135 & -- \\
\hline & 8.4 & 8 & -0.3 & 1 & 0.08594 & -- \\
\hline & 9.6 & 8 & -0.3 & 1 & 0.14844 & -- \\
\hline & 14.2 & 8 & -0.1 & 1 & 0.38281 & -- \\
\hline & 14.3 & 8 & -0.8 & 1 & 0.19531 & -- \\
\hline \multirow{12}{*}{$\begin{array}{l}\text { Calcium (DIS, ICP-AES) Minimum Reporting } \\
\text { Limit } 0.02 \mathrm{mg} / \mathrm{L}\end{array}$} & 3.33 & 22 & -0.01 & 0.1 & 0.30971 & -- \\
\hline & 9.53 & 14 & -0.06 & 0.1 & 0.46313 & -- \\
\hline & 25.1 & 16 & -0.2 & 1 & 0.10458 & -- \\
\hline & 37.0 & 24 & -1.1 & 1 & 0.00034 & NEG \\
\hline & 40.5 & 26 & 0.3 & 1 & 0.04089 & -- \\
\hline & 41.2 & 24 & 0.4 & 1 & 0.06609 & -- \\
\hline & 42.2 & 22 & 0.3 & 1 & 0.07849 & -- \\
\hline & 44.2 & 16 & 0.6 & 1 & 0.23120 & -- \\
\hline & 45.9 & 18 & -0.2 & 1 & 0.52261 & -- \\
\hline & 47.1 & 26 & -0.9 & 1 & 0.00056 & -- \\
\hline & 52.2 & 18 & -1.3 & 1 & 0.00560 & NEG \\
\hline & 58.1 & 14 & -1.3 & 1 & 0.01660 & NEG \\
\hline \multirow{10}{*}{$\begin{array}{l}\text { Chloride (DIS, IC) Minimum Reporting Limit } \\
0.1 \mathrm{mg} / \mathrm{L}\end{array}$} & 8.35 & 21 & 0.29 & 0.1 & 0.00011 & POS \\
\hline & 16.7 & 30 & 0.1 & 1 & 0.36890 & -- \\
\hline & 29.6 & 24 & 0.7 & 1 & 0.00321 & -- \\
\hline & 31.5 & 16 & 0.9 & 1 & 0.01550 & -- \\
\hline & 45.4 & 18 & 0.3 & 1 & 0.26453 & -- \\
\hline & 46.0 & 27 & 0.2 & 1 & 0.15293 & -- \\
\hline & 62.7 & 30 & 2.2 & 1 & 0.00000 & POS \\
\hline & 69.0 & 26 & 1.6 & 1 & 0.00013 & POS \\
\hline & 78.5 & 34 & 0.2 & 1 & 0.22678 & -- \\
\hline & 85.3 & 14 & 0.6 & 1 & 0.50159 & -- \\
\hline \multirow{3}{*}{$\begin{array}{l}\text { Chloride (DIS, IC, LL) Minimum Reporting Limit } \\
0.01 \mathrm{mg} / \mathrm{L}\end{array}$} & 1.20 & 5 & 0.02 & 0.1 & 0.06250 & -- \\
\hline & 1.30 & 4 & -0.01 & 0.1 & 0.87500 & - \\
\hline & 7.79 & 3 & 0.34 & 0.1 & 1.00000 & -- \\
\hline
\end{tabular}


Table 4. Results of Wilcoxon signed-rank test for bias in constituent data for the National Water Quality Laboratory—Continued

[Most probable value, Median bias, and Nearest reporting unit reported in same units as Minimum Reporting Limit; WWR, whole-water recoverable; TITR, electrometric titration; mg/L, milligrams per liter; POS, positive bias; --, acceptable results; DIS, dissolved; ICP-AES, inductively coupled plasma-atomic emission spectrometry; $\mu \mathrm{g} / \mathrm{L}$, micrograms per liter; NEG, negative bias; ICP-MS, inductively coupled plasma-mass spectrometry; DCP-AES, direct current plasma-atomic emission spectrometry; HG-AAS, hydride generation-atomic absorption spectrophotometry; GF-AAS, graphite furnace-atomic absorption spectrophotometry; USEPA, U.S. Environmental Protection Agency; IC, ion chromatography; LL, low level; GRAV, gravimetric; ISE, ion-selective electrode; F-AAS, flame-atomic absorption spectrophotometry; CV-AAS, cold vapor-atomic absorption spectrophotometry; ELEC, electrometric; $\mu \mathrm{S} / \mathrm{cm}$, microsiemens per centimeter at 25 degrees Celsius; COL, colorimetric; ASF, micro-Kjeldahl digestion, automated segmented flow, colorimetric]

\begin{tabular}{|c|c|c|c|c|c|c|}
\hline $\begin{array}{l}\text { Constituent and } \\
\text { method of analysis }\end{array}$ & $\begin{array}{c}\text { Most } \\
\text { probable value }\end{array}$ & $\begin{array}{c}\text { Number of } \\
\text { determinations }\end{array}$ & $\begin{array}{l}\text { Median } \\
\text { bias }\end{array}$ & $\begin{array}{c}\text { Nearest } \\
\text { reporting } \\
\text { unit }\end{array}$ & p-value & Bias \\
\hline \multicolumn{7}{|c|}{ Inorganic constituents-Continued } \\
\hline \multirow{5}{*}{$\begin{array}{l}\text { Chromium (DIS, GF-AAS) Minimum Reporting } \\
\text { Limit } 1 \mu \mathrm{g} / \mathrm{L}\end{array}$} & 4.85 & 10 & 0.15 & 0.1 & 0.61133 & -- \\
\hline & 9.70 & 16 & 0.35 & 0.1 & 0.00012 & POS \\
\hline & 16.5 & 6 & 1.5 & 1 & 0.06250 & -- \\
\hline & 18.5 & 8 & 0.3 & 1 & 0.32813 & -- \\
\hline & 27.8 & 8 & -0.4 & 1 & 0.66406 & -- \\
\hline \multirow{3}{*}{$\begin{array}{l}\text { Chromium (DIS, ICP-AES) Minimum Reporting } \\
\quad \text { Limit } 14 \mu \mathrm{g} / \mathrm{L}\end{array}$} & 11.5 & 12 & 3.5 & 1 & 0.00146 & POS \\
\hline & 16.5 & 24 & 1.3 & 1 & 0.00074 & POS \\
\hline & 26.2 & 22 & 1.6 & 1 & 0.00019 & POS \\
\hline \multirow{3}{*}{$\begin{array}{l}\text { Chromium (DIS, ICP-MS) Minimum Reporting } \\
\text { Limit } 1 \mu \mathrm{g} / \mathrm{L}\end{array}$} & 4.9 & 32 & 0.0 & 1 & 0.88591 & -- \\
\hline & 18.5 & 32 & -0.2 & 1 & 0.00024 & -- \\
\hline & 26.2 & 32 & -1.1 & 1 & 0.00000 & NEG \\
\hline \multirow{6}{*}{$\begin{array}{l}\text { Chromium (WWR, GF-AAS) Minimum } \\
\text { Reporting Limit } 1 \mu \mathrm{g} / \mathrm{L}\end{array}$} & 9.70 & 8 & -0.05 & 0.1 & 0.67188 & -- \\
\hline & 11.5 & 8 & -0.1 & 1 & 0.52344 & -- \\
\hline & 16.5 & 8 & -0.6 & 1 & 0.38281 & -- \\
\hline & 18.5 & 8 & -0.4 & 1 & 0.14844 & -- \\
\hline & 26.2 & 8 & -1.3 & 1 & 0.25000 & -- \\
\hline & 27.8 & 8 & -0.9 & 1 & 0.10938 & -- \\
\hline $\begin{array}{l}\text { Cobalt (DIS, GF-AAS) Minimum Reporting } \\
\quad \text { Limit } 1 \mu \mathrm{g} / \mathrm{L}\end{array}$ & 8.5 & 6 & 0.4 & 1 & 0.18750 & -- \\
\hline \multirow{2}{*}{$\begin{array}{l}\text { Cobalt (DIS, ICP-AES) Minimum Reporting } \\
\text { Limit } 12 \mu \mathrm{g} / \mathrm{L}\end{array}$} & 8.4 & 6 & 1.1 & 1 & 0.31250 & -- \\
\hline & 13.5 & 22 & 0.5 & 1 & 0.08154 & -- \\
\hline \multirow{2}{*}{$\begin{array}{l}\text { Cobalt (DIS, ICP-MS) Minimum Reporting Limit } \\
\quad 1 \mu \mathrm{g} / \mathrm{L}\end{array}$} & 8.5 & 32 & 0.0 & 1 & 0.26020 & -- \\
\hline & 13.5 & 32 & -0.1 & 1 & 0.00982 & -- \\
\hline \multirow{3}{*}{$\begin{array}{l}\text { Cobalt (WWR, GF-AAS) Minimum Reporting } \\
\text { Limit } 1 \mu \mathrm{g} / \mathrm{L}\end{array}$} & 2.0 & 8 & 0.0 & 1 & 0.64063 & -- \\
\hline & 8.4 & 8 & 0.5 & 1 & 0.31250 & -- \\
\hline & 13.5 & 8 & 0.5 & 1 & 0.07813 & -- \\
\hline \multirow{5}{*}{$\begin{array}{l}\text { Copper (DIS, GF-AAS) Minimum Reporting } \\
\text { Limit } 1 \mu \mathrm{g} / \mathrm{L}\end{array}$} & 0.95 & 5 & 0.05 & 0.1 & 0.06250 & -- \\
\hline & 4.7 & 8 & 0.1 & 1 & 0.46094 & -- \\
\hline & 7.5 & 8 & 1.0 & 1 & 0.01563 & -- \\
\hline & 11.2 & 8 & 0.7 & 1 & 0.03125 & -- \\
\hline & 16.7 & 8 & 0.4 & 1 & 0.05469 & -- \\
\hline \multirow{2}{*}{$\begin{array}{l}\text { Copper (DIS, ICP-AES) Minimum Reporting } \\
\text { Limit } 10 \mu \mathrm{g} / \mathrm{L}\end{array}$} & 12 & 26 & 0 & 10 & 0.14029 & -- \\
\hline & 17 & 22 & 0 & 10 & 0.53920 & -- \\
\hline \multirow{2}{*}{$\begin{array}{l}\text { Copper (DIS, ICP-MS) Minimum Reporting } \\
\quad \text { Limit } 1 \mu \mathrm{g} / \mathrm{L}\end{array}$} & 11.2 & 32 & 0.3 & 1 & 0.00002 & -- \\
\hline & 16.7 & 32 & 0.0 & 1 & 0.21890 & -- \\
\hline \multirow{6}{*}{$\begin{array}{l}\text { Copper (WWR, GF-AAS) Minimum Reporting } \\
\text { Limit } 1 \mu \mathrm{g} / \mathrm{L}\end{array}$} & 0.95 & 7 & 0.15 & 0.1 & 0.01563 & POS \\
\hline & 4.7 & 14 & -0.2 & 1 & 0.13135 & -- \\
\hline & 11.2 & 8 & 0.0 & 1 & 0.58594 & -- \\
\hline & 12.0 & 8 & -0.1 & 1 & 0.78125 & -- \\
\hline & 16.7 & 8 & 0.1 & 1 & 0.92188 & -- \\
\hline & 16.7 & 8 & 0.8 & 1 & 0.07813 & -- \\
\hline
\end{tabular}


Table 4. Results of Wilcoxon signed-rank test for bias in constituent data for the National Water Quality Laboratory-Continued

[Most probable value, Median bias, and Nearest reporting unit reported in same units as Minimum Reporting Limit; WWR, whole-water recoverable; TITR, electrometric titration; $\mathrm{mg} / \mathrm{L}$, milligrams per liter; POS, positive bias; --, acceptable results; DIS, dissolved; ICP-AES, inductively coupled plasma-atomic emission spectrometry; $\mu \mathrm{g} / \mathrm{L}$, micrograms per liter; NEG, negative bias; ICP-MS, inductively coupled plasma-mass spectrometry; DCP-AES, direct current plasma-atomic emission spectrometry; HG-AAS, hydride generation-atomic absorption spectrophotometry; GF-AAS, graphite furnace-atomic absorption spectrophotometry; USEPA, U.S. Environmental Protection Agency; IC, ion chromatography; LL, low level; GRAV, gravimetric; ISE, ion-selective electrode; F-AAS, flame-atomic absorption spectrophotometry; CV-AAS, cold vapor-atomic absorption spectrophotometry; ELEC, electrometric; $\mu \mathrm{S} / \mathrm{cm}, \mathrm{microsiemens}$ per centimeter at 25 degrees Celsius; COL, colorimetric; ASF, micro-Kjeldahl digestion, automated segmented flow, colorimetric]

\begin{tabular}{|c|c|c|c|c|c|c|}
\hline $\begin{array}{l}\text { Constituent and } \\
\text { method of analysis }\end{array}$ & $\begin{array}{c}\text { Most } \\
\text { probable value }\end{array}$ & $\begin{array}{c}\text { Number of } \\
\text { determinations }\end{array}$ & $\begin{array}{l}\text { Median } \\
\text { bias }\end{array}$ & $\begin{array}{l}\text { Nearest } \\
\text { reporting } \\
\text { unit }\end{array}$ & p-value & Bias \\
\hline \multicolumn{7}{|c|}{ Inorganic constituents-Continued } \\
\hline \multirow{10}{*}{$\begin{array}{l}\text { Dissolved Solids (DIS, GRAV) Minimum } \\
\text { Reporting Limit } 10 \mathrm{mg} / \mathrm{L}\end{array}$} & 37.8 & 22 & 3.3 & 1 & 0.01783 & POS \\
\hline & 75.5 & 29 & 2.5 & 1 & 0.01583 & POS \\
\hline & 208.8 & 16 & 3.3 & 1 & 0.00015 & POS \\
\hline & 266.5 & 24 & 4.0 & 1 & 0.01043 & POS \\
\hline & 284.0 & 27 & 5.0 & 1 & 0.00000 & POS \\
\hline & 359.5 & 30 & 4.5 & 1 & 0.00021 & POS \\
\hline & 376.0 & 17 & 9.0 & 1 & 0.00002 & POS \\
\hline & 426.0 & 26 & 3.5 & 1 & 0.00583 & POS \\
\hline & 469.0 & 34 & 6.0 & 1 & 0.00102 & POS \\
\hline & 518.5 & 14 & 7.5 & 1 & 0.01270 & POS \\
\hline \multirow{3}{*}{$\begin{array}{l}\text { Fluoride (DIS, IC, LL) Minimum Reporting Limit } \\
0.01 \mathrm{mg} / \mathrm{L}\end{array}$} & 0.040 & 4 & 0.004 & 0.01 & 0.87500 & -- \\
\hline & 0.110 & 5 & 0.005 & 0.01 & 0.81250 & -- \\
\hline & 0.139 & 4 & 0.017 & 0.01 & 0.12500 & -- \\
\hline \multirow{10}{*}{$\begin{array}{l}\text { Fluoride (DIS, ISE) Minimum Reporting Limit } \\
0.1 \mathrm{mg} / \mathrm{L}\end{array}$} & 0.18 & 21 & 0.02 & 0.1 & 0.00155 & -- \\
\hline & 0.36 & 29 & 0.03 & 0.1 & 0.00000 & -- \\
\hline & 0.52 & 27 & 0.03 & 0.1 & 0.00114 & -- \\
\hline & 0.55 & 18 & 0.02 & 0.1 & 0.02003 & -- \\
\hline & 0.63 & 24 & 0.05 & 0.1 & 0.00001 & -- \\
\hline & 0.67 & 15 & 0.04 & 0.1 & 0.00012 & -- \\
\hline & 0.78 & 24 & 0.04 & 0.1 & 0.00001 & -- \\
\hline & 0.80 & 34 & 0.04 & 0.1 & 0.00000 & -- \\
\hline & 0.88 & 30 & 0.05 & 0.1 & 0.00000 & -- \\
\hline & 0.92 & 14 & 0.05 & 0.1 & 0.00403 & -- \\
\hline \multirow{9}{*}{$\begin{array}{l}\text { Iron (DIS, ICP-AES) Minimum Reporting Limit } \\
\quad 10 \mu \mathrm{g} / \mathrm{L}\end{array}$} & 17.8 & 31 & 1.0 & 1 & 0.12334 & -- \\
\hline & 35.5 & 16 & 2.5 & 1 & 0.03354 & POS \\
\hline & 39.3 & 24 & -3.0 & 1 & 0.00000 & NEG \\
\hline & 54.3 & 26 & -1.5 & 1 & 0.00119 & NEG \\
\hline & 55.1 & 37 & -2.0 & 1 & 0.00018 & NEG \\
\hline & 111 & 8 & -3 & 10 & 0.00781 & -- \\
\hline & 147 & 18 & -2 & 10 & 0.10838 & -- \\
\hline & 162 & 22 & -5 & 10 & 0.00219 & -- \\
\hline & 167 & 8 & 2 & 10 & 0.25000 & -- \\
\hline \multirow{7}{*}{$\begin{array}{l}\text { Iron (WWR, F-AAS) Minimum Reporting Limit } \\
\quad 10 \mu \mathrm{g} / \mathrm{L}\end{array}$} & 18 & 10 & 4 & 10 & 0.07617 & -- \\
\hline & 36 & 16 & 5 & 10 & 0.00113 & -- \\
\hline & 54 & 8 & -2 & 10 & 1.00000 & -- \\
\hline & 55 & 14 & 3 & 10 & 0.26050 & -- \\
\hline & 111 & 8 & -6 & 10 & 0.10938 & -- \\
\hline & 162 & 8 & -9 & 10 & 0.01563 & -- \\
\hline & 167 & 8 & -2 & 10 & 0.48438 & -- \\
\hline
\end{tabular}


Table 4. Results of Wilcoxon signed-rank test for bias in constituent data for the National Water Quality Laboratory-Continued

[Most probable value, Median bias, and Nearest reporting unit reported in same units as Minimum Reporting Limit; WWR, whole-water recoverable; TITR, electrometric titration; mg/L, milligrams per liter; POS, positive bias; --, acceptable results; DIS, dissolved; ICP-AES, inductively coupled plasma-atomic emission spectrometry; $\mu \mathrm{g} / \mathrm{L}$, micrograms per liter; NEG, negative bias; ICP-MS, inductively coupled plasma-mass spectrometry; DCP-AES, direct current plasma-atomic emission spectrometry; HG-AAS, hydride generation-atomic absorption spectrophotometry; GF-AAS, graphite furnace-atomic absorption spectrophotometry; USEPA, U.S. Environmental Protection Agency; IC, ion chromatography; LL, low level; GRAV, gravimetric; ISE, ion-selective electrode; F-AAS, flame-atomic absorption spectrophotometry; CV-AAS, cold vapor-atomic absorption spectrophotometry; ELEC, electrometric; $\mu \mathrm{S} / \mathrm{cm}$, microsiemens per centimeter at 25 degrees Celsius; COL, colorimetric; ASF, micro-Kjeldahl digestion, automated segmented flow, colorimetric]

\begin{tabular}{|c|c|c|c|c|c|c|}
\hline $\begin{array}{l}\text { Constituent and } \\
\text { method of analysis }\end{array}$ & $\begin{array}{l}\text { Most } \\
\text { probable value }\end{array}$ & $\begin{array}{l}\text { Number of } \\
\text { determinations }\end{array}$ & $\begin{array}{l}\text { Median } \\
\text { bias }\end{array}$ & $\begin{array}{c}\text { Nearest } \\
\text { reporting } \\
\text { unit }\end{array}$ & p-value & Bias \\
\hline \multicolumn{7}{|c|}{ Inorganic constituents-Continued } \\
\hline \multirow{6}{*}{$\begin{array}{l}\text { Lead (DIS, GF-AAS) Minimum Reporting Limit } \\
\quad 1 \mu \mathrm{g} / \mathrm{L}\end{array}$} & 1.6 & 8 & 0.1 & 1 & 0.55469 & -- \\
\hline & 3.2 & 8 & -0.3 & 1 & 0.10156 & -- \\
\hline & 5.4 & 8 & -0.1 & 1 & 0.08594 & -- \\
\hline & 5.8 & 8 & -0.1 & 1 & 0.07031 & -- \\
\hline & 41.7 & 8 & 0.8 & 1 & 0.05469 & -- \\
\hline & 62.6 & 8 & 3.2 & 1 & 0.00781 & POS \\
\hline $\begin{array}{l}\text { Lead (DIS, ICP-AES) Minimum Reporting Limit } \\
\qquad 100 \mu \mathrm{g} / \mathrm{L}\end{array}$ & 48 & 5 & 2 & 10 & 0.81250 & -- \\
\hline \multirow{3}{*}{$\begin{array}{l}\text { Lead (DIS, ICP-MS) Minimum Reporting Limit } \\
\quad 1 \mu \mathrm{g} / \mathrm{L}\end{array}$} & 1.6 & 32 & 0.0 & 1 & 0.88342 & -- \\
\hline & 41.7 & 32 & 0.0 & 1 & 0.89829 & -- \\
\hline & 48.1 & 32 & -0.3 & 1 & 0.21900 & -- \\
\hline \multirow{7}{*}{$\begin{array}{l}\text { Lead (WWR, GF-AAS) Minimum Reporting } \\
\text { Limit } 1 \mu \mathrm{g} / \mathrm{L}\end{array}$} & 1.6 & 10 & 0.1 & 1 & 0.48242 & -- \\
\hline & 3.2 & 16 & 0.1 & 1 & 0.40942 & -- \\
\hline & 5.8 & 14 & -0.1 & 1 & 0.89050 & -- \\
\hline & 8.6 & 8 & 0.2 & 1 & 0.29688 & -- \\
\hline & 41.7 & 8 & -0.2 & 1 & 0.77344 & -- \\
\hline & 48.1 & 8 & -0.3 & 1 & 0.94531 & -- \\
\hline & 62.6 & 8 & 3.4 & 1 & 0.07813 & -- \\
\hline \multirow{6}{*}{$\begin{array}{l}\text { Lithium (DIS, ICP-AES) Minimum Reporting } \\
\quad \text { Limit } 6 \mu \mathrm{g} / \mathrm{L}\end{array}$} & 4.4 & 8 & 1.5 & 1 & 0.01563 & POS \\
\hline & 9.0 & 8 & 1.1 & 1 & 0.00781 & POS \\
\hline & 11.2 & 24 & 2.0 & 1 & 0.00000 & POS \\
\hline & 13.5 & 8 & 1.4 & 1 & 0.00781 & POS \\
\hline & 22.7 & 22 & 1.4 & 1 & 0.00000 & POS \\
\hline & 23.0 & 26 & 1.9 & 1 & 0.00000 & POS \\
\hline \multirow{2}{*}{$\begin{array}{l}\text { Lithium (WWR, F-AAS) Minimum Reporting } \\
\text { Limit } 10 \mu \mathrm{g} / \mathrm{L}\end{array}$} & 23 & 7 & 0 & 10 & 0.89063 & -- \\
\hline & 23 & 4 & 0 & 10 & 1.00000 & -- \\
\hline \multirow{12}{*}{$\begin{array}{l}\text { Magnesium (DIS, ICP-AES) Minimum Reporting } \\
\text { Limit } 0.01 \mathrm{mg} / \mathrm{L}\end{array}$} & 0.925 & 22 & -0.010 & 0.01 & 0.05983 & - \\
\hline & 2.53 & 14 & 0.01 & 0.1 & 0.79517 & -- \\
\hline & 7.43 & 16 & -0.24 & 0.1 & 0.00006 & NEG \\
\hline & 9.34 & 26 & -0.10 & 0.1 & 0.00537 & NEG \\
\hline & 9.54 & 22 & -0.10 & 0.1 & 0.25841 & -- \\
\hline & 10.1 & 16 & 0.1 & 1 & 0.77225 & -- \\
\hline & 10.1 & 24 & 0.0 & 1 & 0.40287 & -- \\
\hline & 10.3 & 18 & 0.0 & 1 & 0.31165 & -- \\
\hline & 11.2 & 24 & -0.5 & 1 & 0.00000 & -- \\
\hline & 11.5 & 26 & -0.2 & 1 & 0.00010 & -- \\
\hline & 13.9 & 14 & -0.2 & 1 & 0.01294 & -- \\
\hline & 14.2 & 18 & -0.3 & 1 & 0.00001 & -- \\
\hline
\end{tabular}


Table 4. Results of Wilcoxon signed-rank test for bias in constituent data for the National Water Quality Laboratory-Continued

[Most probable value, Median bias, and Nearest reporting unit reported in same units as Minimum Reporting Limit; WWR, whole-water recoverable; TITR, electrometric titration; $\mathrm{mg} / \mathrm{L}$, milligrams per liter; POS, positive bias; --, acceptable results; DIS, dissolved; ICP-AES, inductively coupled plasma-atomic emission spectrometry; $\mu \mathrm{g} / \mathrm{L}$, micrograms per liter; NEG, negative bias; ICP-MS, inductively coupled plasma-mass spectrometry; DCP-AES, direct current plasma-atomic emission spectrometry; HG-AAS, hydride generation-atomic absorption spectrophotometry; GF-AAS, graphite furnace-atomic absorption spectrophotometry; USEPA, U.S. Environmental Protection Agency; IC, ion chromatography; LL, low level; GRAV, gravimetric; ISE, ion-selective electrode; F-AAS, flame-atomic absorption spectrophotometry; CV-AAS, cold vapor-atomic absorption spectrophotometry; ELEC, electrometric; $\mu \mathrm{S} / \mathrm{cm}$, microsiemens per centimeter at 25 degrees Celsius; COL, colorimetric; ASF, micro-Kjeldahl digestion, automated segmented flow, colorimetric]

\begin{tabular}{|c|c|c|c|c|c|c|}
\hline $\begin{array}{l}\text { Constituent and } \\
\text { method of analysis }\end{array}$ & $\begin{array}{c}\text { Most } \\
\text { probable value }\end{array}$ & $\begin{array}{c}\text { Number of } \\
\text { determinations }\end{array}$ & $\begin{array}{l}\text { Median } \\
\text { bias }\end{array}$ & $\begin{array}{c}\text { Nearest } \\
\text { reporting } \\
\text { unit }\end{array}$ & p-value & Bias \\
\hline \multicolumn{7}{|c|}{ Inorganic constituents-Continued } \\
\hline \multirow{9}{*}{$\begin{array}{l}\text { Manganese (DIS, ICP-AES) Minimum Reporting } \\
\quad \text { Limit } 4 \mu \mathrm{g} / \mathrm{L}\end{array}$} & 9.1 & 8 & -0.2 & 1 & 0.14844 & -- \\
\hline & 11.7 & 26 & -0.1 & 1 & 0.39137 & -- \\
\hline & 13.7 & 8 & 0.5 & 1 & 0.03906 & -- \\
\hline & 19.6 & 22 & -0.1 & 1 & 0.93754 & -- \\
\hline & 24.5 & 31 & -0.9 & 1 & 0.00000 & -- \\
\hline & 49.0 & 16 & -1.4 & 1 & 0.00003 & NEG \\
\hline & 50.2 & 24 & -2.2 & 1 & 0.00000 & NEG \\
\hline & 58.1 & 18 & -1.6 & 1 & 0.00033 & NEG \\
\hline & 74.1 & 37 & -2.1 & 1 & 0.00000 & NEG \\
\hline \multirow{3}{*}{$\begin{array}{l}\text { Manganese (DIS, ICP-MS) Minimum Reporting } \\
\quad \text { Limit } 1 \mu \mathrm{g} / \mathrm{L}\end{array}$} & 9.1 & 32 & -0.1 & 1 & 0.00112 & -- \\
\hline & 19.6 & 32 & -0.7 & 1 & 0.00000 & -- \\
\hline & 24.5 & 32 & -1.2 & 1 & 0.00000 & NEG \\
\hline \multirow{5}{*}{$\begin{array}{l}\text { Manganese (WWR, F-AAS) Minimum Reporting } \\
\text { Limit } 10 \mu \mathrm{g} / \mathrm{L}\end{array}$} & 12 & 8 & 2 & 10 & 0.02344 & -- \\
\hline & 14 & 8 & 1 & 10 & 0.06250 & -- \\
\hline & 20 & 8 & -1 & 10 & 1.00000 & -- \\
\hline & 49 & 8 & -5 & 10 & 0.01563 & -- \\
\hline & 74 & 8 & -3 & 10 & 0.04688 & -- \\
\hline \multirow{4}{*}{$\begin{array}{l}\text { Mercury (DIS, CV-AAS) Minimum Reporting } \\
\quad \text { Limit } 0.1 \mu \mathrm{g} / \mathrm{L}\end{array}$} & 0.26 & 8 & -0.04 & 0.1 & 0.00781 & -- \\
\hline & 0.76 & 16 & 0.08 & 0.1 & 0.39642 & -- \\
\hline & 0.93 & 8 & 0.08 & 0.1 & 0.93750 & -- \\
\hline & 3.32 & 16 & 0.20 & 0.1 & 0.06357 & -- \\
\hline \multirow{4}{*}{$\begin{array}{l}\text { Mercury (WWR, CV-AAS) Minimum Reporting } \\
\text { Limit } 0.1 \mu \mathrm{g} / \mathrm{L}\end{array}$} & 0.26 & 8 & -0.06 & 0.1 & 0.10938 & - \\
\hline & 0.76 & 8 & 0.00 & 0.1 & 0.82031 & -- \\
\hline & 0.93 & 15 & 0.02 & 0.1 & 0.55054 & -- \\
\hline & 3.32 & 16 & 0.02 & 0.1 & 0.55283 & -- \\
\hline \multirow{2}{*}{$\begin{array}{l}\text { Molybdenum (DIS, GF-AAS) Minimum } \\
\quad \text { Reporting Limit } 1 \mu \mathrm{g} / \mathrm{L}\end{array}$} & 2.22 & 5 & 0.58 & 0.1 & 0.62500 & -- \\
\hline & 11.9 & 5 & 0.5 & 1 & 0.12500 & -- \\
\hline \multirow{3}{*}{$\begin{array}{l}\text { Molybdenum (DIS, ICP-AES) Minimum } \\
\text { Reporting Limit } 60 \mu \mathrm{g} / \mathrm{L}\end{array}$} & 10 & 6 & 0 & 10 & 0.43750 & -- \\
\hline & 12 & 4 & 0 & 10 & 0.62500 & -- \\
\hline & 23 & 5 & -11 & 10 & 0.62500 & -- \\
\hline \multirow{3}{*}{$\begin{array}{l}\text { Molybdenum (DIS, ICP-MS) Minimum } \\
\text { Reporting Limit } 1 \mu \mathrm{g} / \mathrm{L}\end{array}$} & 2.2 & 32 & 0.1 & 1 & 0.00001 & -- \\
\hline & 18.1 & 32 & 0.6 & 1 & 0.00000 & -- \\
\hline & 22.7 & 32 & 0.4 & 1 & 0.00002 & -- \\
\hline \multirow{3}{*}{$\begin{array}{l}\text { Molybdenum (WWR, GF-AAS) Minimum } \\
\text { Reporting Limit } 1 \mu \mathrm{g} / \mathrm{L}\end{array}$} & 10.4 & 8 & -0.8 & 1 & 0.03906 & -- \\
\hline & 12.1 & 8 & -0.9 & 1 & 0.05469 & -- \\
\hline & 22.7 & 8 & 0.3 & 1 & 0.94531 & -- \\
\hline
\end{tabular}


Table 4. Results of Wilcoxon signed-rank test for bias in constituent data for the National Water Quality Laboratory—Continued

[Most probable value, Median bias, and Nearest reporting unit reported in same units as Minimum Reporting Limit; WWR, whole-water recoverable; TITR, electrometric titration; $\mathrm{mg} / \mathrm{L}$, milligrams per liter; POS, positive bias; --, acceptable results; DIS, dissolved; ICP-AES, inductively coupled plasma-atomic emission spectrometry; $\mu \mathrm{g} / \mathrm{L}$, micrograms per liter; NEG, negative bias; ICP-MS, inductively coupled plasma-mass spectrometry; DCP-AES, direct current plasma-atomic emission spectrometry; HG-AAS, hydride generation-atomic absorption spectrophotometry; GF-AAS, graphite furnace-atomic absorption spectrophotometry; USEPA, U.S. Environmental Protection Agency; IC, ion chromatography; LL, low level; GRAV, gravimetric; ISE, ion-selective electrode; F-AAS, flame-atomic absorption spectrophotometry; CV-AAS, cold vapor-atomic absorption spectrophotometry; ELEC, electrometric; $\mu \mathrm{S} / \mathrm{cm}$, microsiemens per centimeter at 25 degrees Celsius; COL, colorimetric; ASF, micro-Kjeldahl digestion, automated segmented flow, colorimetric]

\begin{tabular}{|c|c|c|c|c|c|c|}
\hline $\begin{array}{l}\text { Constituent and } \\
\text { method of analysis }\end{array}$ & $\begin{array}{c}\text { Most } \\
\text { probable value }\end{array}$ & $\begin{array}{c}\text { Number of } \\
\text { determinations }\end{array}$ & $\begin{array}{l}\text { Median } \\
\text { bias }\end{array}$ & $\begin{array}{c}\text { Nearest } \\
\text { reporting } \\
\text { unit }\end{array}$ & p-value & Bias \\
\hline \multicolumn{7}{|c|}{ Inorganic constituents-Continued } \\
\hline \multirow{4}{*}{$\begin{array}{l}\text { Nickel (DIS, GF-AAS) Minimum Reporting } \\
\quad \text { Limit } 1 \mu \mathrm{g} / \mathrm{L}\end{array}$} & 3.8 & 5 & 0.4 & 1 & 0.06250 & -- \\
\hline & 7.5 & 4 & 0.5 & 1 & 0.25000 & -- \\
\hline & 14.1 & 5 & 0.9 & 1 & 0.06250 & -- \\
\hline & 35.5 & 6 & 2.0 & 1 & 0.03125 & POS \\
\hline \multirow{3}{*}{$\begin{array}{l}\text { Nickel (DIS, ICP-AES) Minimum Reporting } \\
\quad \text { Limit } 40 \mu \mathrm{g} / \mathrm{L}\end{array}$} & 12 & 4 & 4 & 10 & 0.02500 & -- \\
\hline & 15 & 6 & 2 & 10 & 0.56250 & -- \\
\hline & 41 & 22 & 1 & 10 & 0.03200 & -- \\
\hline \multirow{3}{*}{$\begin{array}{l}\text { Nickel (DIS, ICP-MS) Minimum Reporting Limit } \\
\quad 1 \mu \mathrm{g} / \mathrm{L}\end{array}$} & 3.8 & 32 & 0.3 & 1 & 0.00000 & -- \\
\hline & 35.5 & 32 & -0.4 & 1 & 0.01415 & -- \\
\hline & 41.0 & 32 & -1.1 & 1 & 0.00000 & NEG \\
\hline \multirow{6}{*}{$\begin{array}{l}\text { Nickel (WWR, GF-AAS) Minimum Reporting } \\
\text { Limit } 1 \mu \mathrm{g} / \mathrm{L}\end{array}$} & 7.5 & 8 & 0.7 & 1 & 0.00781 & -- \\
\hline & 12.1 & 8 & 0.5 & 1 & 0.00781 & -- \\
\hline & 14.5 & 8 & 0.6 & 1 & 0.10938 & -- \\
\hline & 35.5 & 8 & 2.2 & 1 & 0.00781 & POS \\
\hline & 41 & 8 & 1.9 & 1 & 0.01563 & POS \\
\hline & 53.3 & 8 & 4.0 & 1 & 0.05469 & -- \\
\hline \multirow{10}{*}{$\begin{array}{l}\text { Potassium (DIS, F-AAS) Minimum Reporting } \\
\quad \text { Limit } 0.1 \mathrm{mg} / \mathrm{L}\end{array}$} & 0.46 & 22 & -0.02 & 0.1 & 0.00000 & -- \\
\hline & 0.91 & 30 & -0.03 & 0.1 & 0.00217 & -- \\
\hline & 2.01 & 16 & -0.03 & 0.1 & 0.29694 & -- \\
\hline & 2.20 & 24 & -0.04 & 0.1 & 0.41355 & -- \\
\hline & 2.49 & 18 & -0.04 & 0.1 & 0.47470 & -- \\
\hline & 3.27 & 27 & -0.01 & 0.1 & 0.36439 & -- \\
\hline & 4.18 & 30 & -0.05 & 0.1 & 0.20736 & -- \\
\hline & 4.47 & 34 & -0.05 & 0.1 & 0.36349 & -- \\
\hline & 4.90 & 26 & 0.02 & 0.1 & 0.83387 & -- \\
\hline & 5.50 & 14 & 0.12 & 0.1 & 0.03406 & POS \\
\hline \multirow{3}{*}{$\begin{array}{l}\text { Potassium (DIS, F-AAS, LL) Minimum Reporting } \\
\text { Limit } 0.01 \mathrm{mg} / \mathrm{L}\end{array}$} & 0.118 & 5 & 0.001 & 0.01 & 0.37500 & -- \\
\hline & 0.146 & 4 & 0.003 & 0.01 & 0.25000 & -- \\
\hline & 0.550 & 4 & 0.008 & 0.01 & 0.12500 & -- \\
\hline \multirow{8}{*}{$\begin{array}{l}\text { Selenium (DIS, HG-AAS) Minimum Reporting } \\
\quad \text { Limit } 1 \mu \mathrm{g} / \mathrm{L}\end{array}$} & 2.2 & 31 & -0.9 & 1 & 0.00000 & -- \\
\hline & 3.1 & 12 & -0.5 & 1 & 0.00049 & -- \\
\hline & 4.8 & 8 & -0.2 & 1 & 0.46094 & -- \\
\hline & 5.5 & 4 & -0.8 & 1 & 0.25000 & -- \\
\hline & 7.2 & 8 & 0.3 & 1 & 0.25000 & -- \\
\hline & 7.5 & 22 & -0.1 & 1 & 0.88780 & -- \\
\hline & 9.7 & 4 & 0.6 & 1 & 0.37500 & -- \\
\hline & 9.9 & 19 & 0.6 & 1 & 0.91347 & -- \\
\hline
\end{tabular}


Table 4. Results of Wilcoxon signed-rank test for bias in constituent data for the National Water Quality Laboratory—Continued

[Most probable value, Median bias, and Nearest reporting unit reported in same units as Minimum Reporting Limit; WWR, whole-water recoverable; TITR, electrometric titration; mg/L, milligrams per liter; POS, positive bias; --, acceptable results; DIS, dissolved; ICP-AES, inductively coupled plasma-atomic emission spectrometry; $\mu \mathrm{g} / \mathrm{L}$, micrograms per liter; NEG, negative bias; ICP-MS, inductively coupled plasma-mass spectrometry; DCP-AES, direct current plasma-atomic emission spectrometry; HG-AAS, hydride generation-atomic absorption spectrophotometry; GF-AAS, graphite furnace-atomic absorption spectrophotometry; USEPA, U.S. Environmental Protection Agency; IC, ion chromatography; LL, low level; GRAV, gravimetric; ISE, ion-selective electrode; F-AAS, flame-atomic absorption spectrophotometry; CV-AAS, cold vapor-atomic absorption spectrophotometry; ELEC, electrometric; $\mu \mathrm{S} / \mathrm{cm}, \mathrm{microsiemens}$ per centimeter at 25 degrees Celsius; COL, colorimetric; ASF, micro-Kjeldahl digestion, automated segmented flow, colorimetric]

\begin{tabular}{|c|c|c|c|c|c|c|}
\hline $\begin{array}{l}\text { Constituent and } \\
\text { method of analysis }\end{array}$ & $\begin{array}{c}\text { Most } \\
\text { probable value }\end{array}$ & $\begin{array}{l}\text { Number of } \\
\text { determinations }\end{array}$ & $\begin{array}{l}\text { Median } \\
\text { bias }\end{array}$ & $\begin{array}{c}\text { Nearest } \\
\text { reporting } \\
\text { unit }\end{array}$ & p-value & Bias \\
\hline \multicolumn{7}{|c|}{ Inorganic constituents-Continued } \\
\hline \multirow{2}{*}{$\begin{array}{l}\text { Selenium (WWR, GF-AAS, USEPA) Minimum } \\
\text { Reporting Limit } 1 \mu \mathrm{g} / \mathrm{L}\end{array}$} & 4.8 & 4 & 0.5 & 1 & 0.12500 & -- \\
\hline & 7.2 & 4 & 0.6 & 1 & 0.12500 & -- \\
\hline \multirow{5}{*}{$\begin{array}{l}\text { Selenium (WWR, HG-AAS) Minimum Reporting } \\
\quad \text { Limit } 1 \mu \mathrm{g} / \mathrm{L}\end{array}$} & 2.2 & 8 & -0.9 & 1 & 0.00781 & -- \\
\hline & 4.8 & 8 & 0.0 & 1 & 0.74219 & -- \\
\hline & 7.2 & 8 & -0.1 & 1 & 0.74219 & -- \\
\hline & 7.5 & 8 & 0.0 & 1 & 1.00000 & -- \\
\hline & 9.9 & 8 & 0.0 & 1 & 0.54688 & -- \\
\hline \multirow{6}{*}{$\begin{array}{l}\text { Silica (DIS, COL) Minimum Reporting Limit } \\
0.1 \mathrm{mg} / \mathrm{L}\end{array}$} & 2.24 & 22 & -0.04 & 0.1 & 0.35836 & -- \\
\hline & 6.35 & 18 & -0.21 & 0.1 & 0.00011 & NEG \\
\hline & 8.15 & 24 & 0.04 & 0.1 & 0.83553 & -- \\
\hline & 8.54 & 16 & 0.15 & 0.1 & 0.19281 & -- \\
\hline & 9.75 & 25 & -0.22 & 0.1 & 0.02308 & NEG \\
\hline & 11.1 & 14 & -0.4 & 1 & 0.01343 & -- \\
\hline \multirow{10}{*}{$\begin{array}{l}\text { Silica (DIS, ICP-AES) Minimum Reporting Limit } \\
\quad 0.1 \mathrm{mg} / \mathrm{L}\end{array}$} & 1.74 & 14 & -0.07 & 0.1 & 0.00012 & -- \\
\hline & 4.47 & 30 & -0.16 & 0.1 & 0.00000 & NEG \\
\hline & 6.50 & 26 & -0.22 & 0.1 & 0.00000 & NEG \\
\hline & 7.55 & 24 & -0.06 & 0.1 & 0.00119 & -- \\
\hline & 8.14 & 16 & -0.05 & 0.1 & 0.85034 & -- \\
\hline & 9.17 & 34 & -0.35 & 0.1 & 0.00000 & NEG \\
\hline & 10.3 & 26 & -0.1 & 1 & 0.00035 & -- \\
\hline & 11.0 & 29 & -0.3 & 1 & 0.00000 & -- \\
\hline & 15.2 & 18 & -0.4 & 1 & 0.00026 & -- \\
\hline & 17.4 & 22 & -0.6 & 1 & 0.00001 & -- \\
\hline \multirow{2}{*}{$\begin{array}{l}\text { Silver (DIS, GF-AAS) Minimum Reporting Limit } \\
\quad 1 \mu \mathrm{g} / \mathrm{L}\end{array}$} & 9.9 & 8 & -1.1 & 1 & 0.00781 & NEG \\
\hline & 14.9 & 8 & -0.1 & 1 & 0.29688 & -- \\
\hline \multirow{2}{*}{$\begin{array}{l}\text { Silver (DIS, ICP-AES) Minimum Reporting Limit } \\
\quad 4 \mu \mathrm{g} / \mathrm{L}\end{array}$} & 4.9 & 14 & -0.1 & 1 & 0.38208 & -- \\
\hline & 13.7 & 14 & -2.6 & 1 & 0.00012 & NEG \\
\hline \multirow{2}{*}{$\begin{array}{l}\text { Silver (DIS, ICP-MS) Minimum Reporting Limit } \\
1 \mu \mathrm{g} / \mathrm{L}\end{array}$} & 9.9 & 32 & -1.3 & 1 & 0.00000 & NEG \\
\hline & 13.7 & 32 & -2.3 & 1 & 0.00000 & NEG \\
\hline \multirow{4}{*}{$\begin{array}{l}\text { Silver (WWR, GF-AAS) Minimum Reporting } \\
\quad \text { Limit } 1 \mu \mathrm{g} / \mathrm{L}\end{array}$} & 4.9 & 8 & -0.1 & 1 & 0.28906 & -- \\
\hline & 9.9 & 8 & -1.2 & 1 & 0.00781 & NEG \\
\hline & 13.7 & 8 & -2.1 & 1 & 0.00781 & NEG \\
\hline & 14.9 & 8 & 0.3 & 1 & 0.14844 & -- \\
\hline \multirow{12}{*}{$\begin{array}{l}\text { Sodium (DIS, ICP-AES) Minimum Reporting } \\
\text { Limit } 0.2 \mathrm{mg} / \mathrm{L}\end{array}$} & 5.50 & 14 & -0.05 & 0.1 & 0.42627 & -- \\
\hline & 7.90 & 22 & -0.05 & 0.1 & 0.02980 & -- \\
\hline & 28.0 & 18 & 0.1 & 1 & 0.21214 & -- \\
\hline & 33.5 & 16 & 0.2 & 1 & 0.70572 & -- \\
\hline & 35.4 & 24 & 0.2 & 1 & 0.93384 & -- \\
\hline & 37.6 & 22 & 0.0 & 1 & 0.40216 & -- \\
\hline & 39.2 & 24 & -0.1 & 1 & 0.40287 & -- \\
\hline & 49.9 & 18 & 0.1 & 1 & 0.29869 & -- \\
\hline & 56.5 & 16 & 1.0 & 1 & 0.05066 & -- \\
\hline & 66.1 & 26 & 0.1 & 1 & 0.97050 & -- \\
\hline & 81.0 & 26 & -0.7 & 1 & 0.03564 & -- \\
\hline & 96.2 & 14 & -0.7 & 1 & 0.13525 & -- \\
\hline
\end{tabular}


Table 4. Results of Wilcoxon signed-rank test for bias in constituent data for the National Water Quality Laboratory-Continued

[Most probable value, Median bias, and Nearest reporting unit reported in same units as Minimum Reporting Limit; WWR, whole-water recoverable; TITR, electrometric titration; mg/L, milligrams per liter; POS, positive bias; --, acceptable results; DIS, dissolved; ICP-AES, inductively coupled plasma-atomic emission spectrometry; $\mu \mathrm{g} / \mathrm{L}$, micrograms per liter; NEG, negative bias; ICP-MS, inductively coupled plasma-mass spectrometry; DCP-AES, direct current plasma-atomic emission spectrometry; HG-AAS, hydride generation-atomic absorption spectrophotometry; GF-AAS, graphite furnace-atomic absorption spectrophotometry; USEPA, U.S. Environmental Protection Agency; IC, ion chromatography; LL, low level; GRAV, gravimetric; ISE, ion-selective electrode; F-AAS, flame-atomic absorption spectrophotometry; CV-AAS, cold vapor-atomic absorption spectrophotometry; ELEC, electrometric; $\mu \mathrm{S} / \mathrm{cm}$, microsiemens per centimeter at 25 degrees Celsius; COL, colorimetric; ASF, micro-Kjeldahl digestion, automated segmented flow, colorimetric]

\begin{tabular}{|c|c|c|c|c|c|c|}
\hline $\begin{array}{l}\text { Constituent and } \\
\text { method of analysis }\end{array}$ & $\begin{array}{c}\text { Most } \\
\text { probable value }\end{array}$ & $\begin{array}{l}\text { Number of } \\
\text { determinations }\end{array}$ & $\begin{array}{l}\text { Median } \\
\text { bias }\end{array}$ & $\begin{array}{c}\text { Nearest } \\
\text { reporting } \\
\text { unit }\end{array}$ & p-value & Bias \\
\hline \multicolumn{7}{|c|}{ Inorganic constituents-Continued } \\
\hline \multirow{3}{*}{$\begin{array}{l}\text { Specific Conductance (WWR, ELEC, LL) } \\
\text { Minimum Reporting Limit } 0.5 \mu \mathrm{S} / \mathrm{cm}\end{array}$} & 13.3 & 5 & -0.5 & 1 & 0.43750 & -- \\
\hline & 20.9 & 4 & 0.0 & 1 & 1.00000 & -- \\
\hline & 36.1 & 4 & 1.3 & 1 & 0.25000 & -- \\
\hline \multirow{6}{*}{$\begin{array}{l}\text { Strontium (DIS, ICP-AES) Minimum Reporting } \\
\quad \text { Limit } 1 \mu \mathrm{g} / \mathrm{L}\end{array}$} & 115 & 8 & -1 & 10 & 0.31250 & -- \\
\hline & 153 & 8 & -2 & 10 & 0.25000 & -- \\
\hline & 230 & 8 & 7 & 10 & 0.03906 & -- \\
\hline & 255 & 22 & -1 & 10 & 0.56038 & -- \\
\hline & 273 & 24 & 3 & 10 & 0.00634 & -- \\
\hline & 302 & 26 & 4 & 10 & 0.01828 & -- \\
\hline \multirow{8}{*}{$\begin{array}{l}\text { Sulfate (DIS, IC) Minimum Reporting Limit } \\
0.1 \mathrm{mg} / \mathrm{L}\end{array}$} & 7.00 & 21 & -0.41 & 0.1 & 0.00000 & NEG \\
\hline & 14.0 & 30 & -0.9 & 1 & 0.00000 & -- \\
\hline & 58.5 & 16 & -1.2 & 1 & 0.00015 & NEG \\
\hline & 75.0 & 27 & -0.4 & 1 & 0.00218 & -- \\
\hline & 89.0 & 54 & -0.6 & 1 & 0.00862 & -- \\
\hline & 113 & 26 & 0 & 10 & 0.60359 & -- \\
\hline & 114 & 52 & -1 & 10 & 0.00014 & -- \\
\hline & 132 & 14 & -1 & 10 & 0.17261 & - \\
\hline \multirow{3}{*}{$\begin{array}{l}\text { Vanadium (DIS, ICP-AES) Minimum Reporting } \\
\quad \text { Limit } 10 \mu \mathrm{g} / \mathrm{L}\end{array}$} & 8.4 & 5 & -0.3 & 1 & 1.00000 & -- \\
\hline & 11.8 & 24 & 0.1 & 1 & 0.78181 & -- \\
\hline & 20.9 & 22 & 0.4 & 1 & 0.23168 & - \\
\hline \multirow{4}{*}{$\begin{array}{l}\text { Zinc (DIS, ICP-AES) Minimum Reporting Limit } \\
\quad 20 \mu \mathrm{g} / \mathrm{L}\end{array}$} & 10.5 & 4 & 2.0 & 1 & 0.12500 & -- \\
\hline & 15.0 & 15 & 6.7 & 1 & 0.00085 & POS \\
\hline & 24.8 & 8 & 3.1 & 1 & 0.05469 & -- \\
\hline & 39.9 & 24 & 0.8 & 1 & 0.59798 & - \\
\hline \multirow{3}{*}{$\begin{array}{l}\text { Zinc (DIS, ICP-MS) Minimum Reporting Limit } \\
1 \mu \mathrm{g} / \mathrm{L}\end{array}$} & 10.0 & 32 & 1.7 & 1 & 0.00000 & POS \\
\hline & 12.4 & 32 & 1.4 & 1 & 0.00000 & POS \\
\hline & 15.0 & 32 & 2.5 & 1 & 0.00000 & POS \\
\hline \multirow{6}{*}{$\begin{array}{l}\text { Zinc (WWR, F-AAS) Minimum Reporting Limit } \\
10 \mu \mathrm{g} / \mathrm{L}\end{array}$} & 10 & 8 & 3 & 10 & 0.01563 & -- \\
\hline & 11 & 8 & 2 & 10 & 0.00781 & -- \\
\hline & 12 & 8 & 3 & 10 & 0.00195 & -- \\
\hline & 15 & 16 & 4 & 10 & 0.00360 & -- \\
\hline & 25 & 16 & 0 & 10 & 0.31619 & - \\
\hline & 40 & 14 & 2 & 10 & 0.01953 & -- \\
\hline \multicolumn{7}{|c|}{ Nutrient Constituents } \\
\hline \multirow{5}{*}{$\begin{array}{l}\text { Ammonia as nitrogen (DIS, COL) Minimum } \\
\text { Reporting Limit } 0.02 \mathrm{mg} / \mathrm{L}\end{array}$} & 0.210 & 60 & 0.026 & 0.01 & 0.00001 & POS \\
\hline & 0.240 & 54 & -0.012 & 0.01 & 0.06591 & -- \\
\hline & 0.498 & 60 & 0.004 & 0.01 & 0.41528 & -- \\
\hline & 0.620 & 62 & 0.054 & 0.01 & 0.00000 & POS \\
\hline & 1.24 & 96 & 0.05 & 0.1 & 0.00000 & -- \\
\hline
\end{tabular}


Table 4. Results of Wilcoxon signed-rank test for bias in constituent data for the National Water Quality Laboratory-Continued

[Most probable value, Median bias, and Nearest reporting unit reported in same units as Minimum Reporting Limit; WWR, whole-water recoverable; TITR, electrometric titration; mg/L, milligrams per liter; POS, positive bias; --, acceptable results; DIS, dissolved; ICP-AES, inductively coupled plasma-atomic emission spectrometry; $\mu \mathrm{g} / \mathrm{L}$, micrograms per liter; NEG, negative bias; ICP-MS, inductively coupled plasma-mass spectrometry; DCP-AES, direct current plasma-atomic emission spectrometry; HG-AAS, hydride generation-atomic absorption spectrophotometry; GF-AAS, graphite furnace-atomic absorption spectrophotometry; USEPA, U.S. Environmental Protection Agency; IC, ion chromatography; LL, low level; GRAV, gravimetric; ISE, ion-selective electrode; F-AAS, flame-atomic absorption spectrophotometry; CV-AAS, cold vapor-atomic absorption spectrophotometry; ELEC, electrometric; $\mu \mathrm{S} / \mathrm{cm}$, microsiemens per centimeter at 25 degrees Celsius; COL, colorimetric; ASF, micro-Kjeldahl digestion, automated segmented flow, colorimetric]

\begin{tabular}{|c|c|c|c|c|c|c|}
\hline $\begin{array}{l}\text { Constituent and } \\
\text { method of analysis }\end{array}$ & $\begin{array}{c}\text { Most } \\
\text { probable value }\end{array}$ & $\begin{array}{c}\text { Number of } \\
\text { determinations }\end{array}$ & $\begin{array}{l}\text { Median } \\
\text { bias }\end{array}$ & $\begin{array}{l}\text { Nearest } \\
\text { reporting } \\
\text { unit }\end{array}$ & p-value & Bias \\
\hline \multicolumn{7}{|c|}{ Nutrient constituents-Continued } \\
\hline \multirow{2}{*}{$\begin{array}{l}\text { Ammonia as nitrogen (DIS, COL, LL) Minimum } \\
\text { Reporting Limit } 0.002 \mathrm{mg} / \mathrm{L}\end{array}$} & 0.2100 & 36 & -0.0140 & 0.001 & 0.00000 & NEG \\
\hline & 0.2400 & 30 & -0.0130 & 0.001 & 0.00000 & NEG \\
\hline \multirow{4}{*}{$\begin{array}{l}\text { Ammonia as nitrogen (DIS, USEPA) Minimum } \\
\text { Reporting Limit } 0.02 \mathrm{mg} / \mathrm{L}\end{array}$} & 0.210 & 3 & -0.022 & 0.01 & 0.25000 & -- \\
\hline & 0.240 & 3 & -0.035 & 0.01 & 0.25000 & -- \\
\hline & 0.498 & 6 & 0.002 & 0.01 & 1.00000 & -- \\
\hline & 0.620 & 5 & -0.036 & 0.01 & 0.12500 & -- \\
\hline \multirow{5}{*}{$\begin{array}{l}\text { Ammonia plus organic nitrogen as nitrogen (DIS, } \\
\text { ASF) Minimum Reporting Limit } 0.1 \mathrm{mg} / \mathrm{L}\end{array}$} & 0.29 & 60 & -0.06 & 0.1 & 0.00000 & -- \\
\hline & 0.30 & 59 & -0.03 & 0.1 & 0.00047 & -- \\
\hline & 0.75 & 60 & -0.04 & 0.1 & 0.00000 & -- \\
\hline & 0.86 & 95 & 0.00 & 0.1 & 0.38038 & -- \\
\hline & 0.91 & 59 & 0.02 & 0.1 & 0.03868 & -- \\
\hline \multirow{4}{*}{$\begin{array}{l}\text { Ammonia plus organic nitrogen as nitrogen (DIS, } \\
\text { USEPA) Minimum Reporting Limit } 0.1 \mathrm{mg} / \mathrm{L}\end{array}$} & 0.285 & 9 & -0.045 & 0.01 & 0.12500 & -. \\
\hline & 0.300 & 7 & -0.024 & 0.01 & 0.17188 & -- \\
\hline & 0.750 & 9 & -0.012 & 0.01 & 0.44531 & -- \\
\hline & 0.910 & 9 & 0.022 & 0.01 & 0.64063 & -- \\
\hline \multirow{4}{*}{$\begin{array}{l}\text { Ammonia plus organic nitrogen as nitrogen } \\
\text { (WWR, ASF) Minimum Reporting Limit } \\
0.1 \mathrm{mg} / \mathrm{L}\end{array}$} & 0.29 & 60 & -0.07 & 0.1 & 0.00000 & -- \\
\hline & 0.30 & 46 & -0.02 & 0.1 & 0.00833 & -- \\
\hline & 0.75 & 60 & -0.04 & 0.1 & 0.00000 & -- \\
\hline & 0.91 & 59 & 0.00 & 0.1 & 0.69543 & -- \\
\hline \multirow{4}{*}{$\begin{array}{l}\text { Ammonia plus organic nitrogen as nitrogen } \\
\text { (WWR, USEPA) Minimum Reporting Limit } \\
0.1 \mathrm{mg} / \mathrm{L}\end{array}$} & 0.29 & 9 & -0.07 & 0.1 & 0.00781 & -- \\
\hline & 0.30 & 7 & 0.00 & 0.1 & 0.81250 & -- \\
\hline & 0.75 & 9 & -0.03 & 0.1 & 0.16406 & -- \\
\hline & 0.91 & 9 & 0.01 & 0.1 & 0.91016 & -- \\
\hline \multirow{5}{*}{$\begin{array}{l}\text { Nitrate plus nitrite as nitrogen (DIS, COL) } \\
\text { Minimum Reporting Limit } 0.05 \mathrm{mg} / \mathrm{L}\end{array}$} & 0.220 & 60 & -0.004 & 0.01 & 0.10353 & -- \\
\hline & 0.443 & 54 & -0.008 & 0.01 & 0.11066 & -- \\
\hline & 0.747 & 60 & -0.037 & 0.01 & 0.00000 & NEG \\
\hline & 1.01 & 62 & -0.02 & 0.1 & 0.00016 & -- \\
\hline & 1.04 & 96 & 0.03 & 0.1 & 0.00011 & -- \\
\hline \multirow{2}{*}{$\begin{array}{l}\text { Nitrate plus nitrite as nitrogen (DIS, COL, LL) } \\
\text { Minimum Reporting Limit } 0.005 \mathrm{mg} / \mathrm{L}\end{array}$} & 0.220 & 36 & -0.013 & 0.01 & 0.00000 & NEG \\
\hline & 0.443 & 30 & -0.011 & 0.01 & 0.00000 & NEG \\
\hline \multirow{5}{*}{$\begin{array}{l}\text { Orthophosphate as phosphorus (DIS, COL) } \\
\text { Minimum Reporting Limit } 0.01 \mathrm{mg} / \mathrm{L}\end{array}$} & 0.195 & 60 & 0.005 & 0.01 & 0.05772 & -- \\
\hline & 0.580 & 54 & 0.054 & 0.01 & 0.00000 & POS \\
\hline & 0.658 & 59 & -0.032 & 0.01 & 0.00000 & NEG \\
\hline & 0.758 & 62 & 0.001 & 0.01 & 0.98840 & -- \\
\hline & 1.01 & 96 & 0.00 & 0.1 & 0.42110 & -- \\
\hline \multirow{2}{*}{$\begin{array}{l}\text { Orthophosphate as phosphorus (DIS, COL, LL) } \\
\text { Minimum Reporting Limit } 0.001 \mathrm{mg} / \mathrm{L}\end{array}$} & 0.195 & 36 & 0.004 & 0.01 & 0.10731 & -- \\
\hline & 0.580 & 30 & 0.007 & 0.01 & 0.00005 & -- \\
\hline
\end{tabular}


Table 4. Results of Wilcoxon signed-rank test for bias in constituent data for the National Water Quality Laboratory-Continued

[Most probable value, Median bias, and Nearest reporting unit reported in same units as Minimum Reporting Limit; WWR, whole-water recoverable; TITR, electrometric titration; $\mathrm{mg} / \mathrm{L}$, milligrams per liter; POS, positive bias; --, acceptable results; DIS, dissolved; ICP-AES, inductively coupled plasma-atomic emission spectrometry; $\mu \mathrm{g} / \mathrm{L}$, micrograms per liter; NEG, negative bias; ICP-MS, inductively coupled plasma-mass spectrometry; DCP-AES, direct current plasma-atomic emission spectrometry; HG-AAS, hydride generation-atomic absorption spectrophotometry; GF-AAS, graphite furnace-atomic absorption spectrophotometry; USEPA, U.S. Environmental Protection Agency; IC, ion chromatography; LL, low level; GRAV, gravimetric; ISE, ion-selective electrode; F-AAS, flame-atomic absorption spectrophotometry; CV-AAS, cold vapor-atomic absorption spectrophotometry; ELEC, electrometric; $\mu \mathrm{S} / \mathrm{cm}, \mathrm{microsiemens}$ per centimeter at 25 degrees Celsius; COL, colorimetric; ASF, micro-Kjeldahl digestion, automated segmented flow, colorimetric]

\begin{tabular}{|c|c|c|c|c|c|c|}
\hline $\begin{array}{l}\text { Constituent and } \\
\text { method of analysis }\end{array}$ & $\begin{array}{c}\text { Most } \\
\text { probable value }\end{array}$ & $\begin{array}{c}\text { Number of } \\
\text { determinations }\end{array}$ & $\begin{array}{c}\text { Median } \\
\text { bias }\end{array}$ & $\begin{array}{c}\text { Nearest } \\
\text { reporting } \\
\text { unit }\end{array}$ & p-value & Bias \\
\hline \multicolumn{7}{|c|}{ Nutrient constituents-Continued } \\
\hline \multirow{5}{*}{$\begin{array}{l}\text { Phosphorus (DIS, ASF) Minimum Reporting } \\
\text { Limit } 0.05 \mathrm{mg} / \mathrm{L}\end{array}$} & 0.201 & 60 & -0.002 & 0.01 & 0.88725 & -- \\
\hline & 0.602 & 60 & 0.003 & 0.01 & 0.31645 & -- \\
\hline & 0.715 & 60 & 0.008 & 0.01 & 0.00240 & -- \\
\hline & 0.766 & 59 & 0.025 & 0.01 & 0.00020 & POS \\
\hline & 1.01 & 95 & 0.02 & 0.1 & 0.00003 & -- \\
\hline \multirow{2}{*}{$\begin{array}{l}\text { Phosphorus (DIS, COL, LL) Minimum Reporting } \\
\text { Limit } 0.001 \mathrm{mg} / \mathrm{L}\end{array}$} & 0.201 & 18 & 0.007 & 0.01 & 0.35216 & -- \\
\hline & 0.602 & 15 & 0.014 & 0.01 & 0.11029 & -- \\
\hline \multirow{4}{*}{$\begin{array}{l}\text { Phosphorus (DIS, USEPA) Minimum Reporting } \\
\text { Limit } 0.05 \mathrm{mg} / \mathrm{L}\end{array}$} & 0.201 & 9 & -0.008 & 0.01 & 0.58594 & -- \\
\hline & 0.602 & 7 & 0.002 & 0.01 & 1.00000 & -- \\
\hline & 0.715 & 9 & 0.018 & 0.01 & 0.73438 & -- \\
\hline & 0.766 & 9 & 0.022 & 0.01 & 0.12500 & -- \\
\hline \multirow{4}{*}{$\begin{array}{l}\text { Phosphorus (WWR, ASF) Minimum Reporting } \\
\text { Limit } 0.05 \mathrm{mg} / \mathrm{L}\end{array}$} & 0.201 & 60 & 0.003 & 0.01 & 0.32082 & -- \\
\hline & 0.602 & 46 & 0.000 & 0.01 & 0.54222 & -- \\
\hline & 0.715 & 60 & 0.007 & 0.01 & 0.12027 & -- \\
\hline & 0.766 & 60 & 0.028 & 0.01 & 0.00000 & POS \\
\hline \multirow{2}{*}{$\begin{array}{l}\text { Phosphorus (WWR, COL, LL) Minimum } \\
\text { Reporting Limit } 0.001 \mathrm{mg} / \mathrm{L}\end{array}$} & 0.201 & 35 & 0.007 & 0.01 & 0.00239 & - \\
\hline & 0.602 & 30 & 0.019 & 0.01 & 0.17542 & -- \\
\hline \multirow{4}{*}{$\begin{array}{l}\text { Phosphorus (WWR, USEPA) Minimum Reporting } \\
\text { Limit } 0.05 \mathrm{mg} / \mathrm{L}\end{array}$} & 0.201 & 9 & 0.012 & 0.01 & 0.37500 & -- \\
\hline & 0.602 & 7 & -0.006 & 0.01 & 0.81250 & -- \\
\hline & 0.715 & 9 & 0.007 & 0.01 & 0.67188 & -- \\
\hline & 0.766 & 9 & 0.040 & 0.01 & 0.03906 & POS \\
\hline
\end{tabular}

Table 5. Results of Wilcoxon signed-rank test for bias in constituent data for the Quality of Water Service Unit laboratory

[Most probable value, Median bias, and Nearest reporting unit reported in same units as Minimum Reporting Limit; WWR, whole-water recoverable; TITR, electrometric titration; mg/L, milligrams per liter; POS, positive bias; --, acceptable results; DIS, dissolved; ICP-AES/T, inductively coupled plasma-atomic emission spectrometry, trace; $\mu \mathrm{g} / \mathrm{L}$, micrograms per liter; GF-AAS, graphite furnace-atomic absorption spectrophotometry; USEPA, U.S. Environmental Protection Agency; ICP-AES, inductively coupled plasma-atomic emission spectrometry; NEG, negative bias; IC, ion chromatography; GRAV, gravimetric; ISE, ion-selective electrode; CV-AAS, cold vapor-atomic absorption spectrophotometry; F-AAS, flame-atomic absorption spectrophotometry]

\begin{tabular}{|c|c|c|c|c|c|c|}
\hline $\begin{array}{l}\text { Constituent and } \\
\text { method of analysis }\end{array}$ & $\begin{array}{c}\text { Most } \\
\text { probable value }\end{array}$ & $\begin{array}{l}\text { Number of } \\
\text { determinations }\end{array}$ & $\begin{array}{l}\text { Median } \\
\text { bias }\end{array}$ & $\begin{array}{c}\text { Nearest } \\
\text { reporting } \\
\text { unit }\end{array}$ & p-value & Bias \\
\hline \multicolumn{7}{|c|}{ Inorganic constituents } \\
\hline \multirow{6}{*}{$\begin{array}{l}\text { Alkalinity (WWR, TITR) Minimum Reporting } \\
\text { Limit } 1 \mathrm{mg} / \mathrm{L}\end{array}$} & 55.7 & 11 & 1.3 & 1 & 0.00098 & POS \\
\hline & 76.0 & 6 & 3.0 & 1 & 0.03125 & POS \\
\hline & 88.5 & 12 & -0.5 & 1 & 0.17529 & -- \\
\hline & 94.2 & 12 & 0.9 & 1 & 0.02246 & -- \\
\hline & 107.5 & 12 & 1.6 & 1 & 0.00049 & POS \\
\hline & 129.7 & 12 & 2.3 & 1 & 0.02588 & POS \\
\hline
\end{tabular}


Table 5. Results of Wilcoxon signed-rank test for bias in constituent data for the Quality of Water Service Unit laboratory-Continued

[Most probable value, Median bias, and Nearest reporting unit reported in same units as Minimum Reporting Limit; WWR, whole-water recoverable; TITR, electrometric titration; mg/L, milligrams per liter; POS, positive bias; --, acceptable results; DIS, dissolved; ICP-AES/T, inductively coupled plasma-atomic emission spectrometry, trace; $\mu \mathrm{g} / \mathrm{L}$, micrograms per liter; GF-AAS, graphite furnace-atomic absorption spectrophotometry; USEPA, U.S. Environmental Protection Agency; ICP-AES, inductively coupled plasma-atomic emission spectrometry; NEG, negative bias; IC, ion chromatography; GRAV, gravimetric; ISE, ion-selective electrode; CV-AAS, cold vapor-atomic absorption spectrophotometry; F-AAS, flame-atomic absorption spectrophotometry]

\begin{tabular}{|c|c|c|c|c|c|c|}
\hline $\begin{array}{l}\text { Constituent and } \\
\text { method of analysis }\end{array}$ & $\begin{array}{c}\text { Most } \\
\text { probable value }\end{array}$ & $\begin{array}{c}\text { Number of } \\
\text { determinations }\end{array}$ & $\begin{array}{l}\text { Median } \\
\text { bias }\end{array}$ & $\begin{array}{c}\text { Nearest } \\
\text { reporting } \\
\text { unit }\end{array}$ & p-value & Bias \\
\hline \multicolumn{7}{|c|}{ Inorganic constituents-Continued } \\
\hline \multirow{3}{*}{$\begin{array}{l}\text { Aluminum (DIS, ICP-AES/T) Minimum Reporting } \\
\text { Limit } 3 \mu \mathrm{g} / \mathrm{L}\end{array}$} & 28.5 & 8 & -0.5 & 1 & 0.74219 & -- \\
\hline & 44.9 & 8 & 0.7 & 1 & 0.08594 & -- \\
\hline & 45.0 & 8 & 6.0 & 1 & 0.00781 & POS \\
\hline \multirow{3}{*}{$\begin{array}{l}\text { Aluminum (WWR, GF-AAS, USEPA) Minimum } \\
\text { Reporting Limit } 2 \mu \mathrm{g} / \mathrm{L}\end{array}$} & 28 & 4 & 2 & 10 & 0.12500 & -- \\
\hline & 45 & 4 & 5 & 10 & 0.25000 & -- \\
\hline & 45 & 3 & 5 & 10 & 0.25000 & -- \\
\hline \multirow{3}{*}{$\begin{array}{l}\text { Aluminum (WWR, ICP-AES/T) Minimum } \\
\text { Reporting Limit } 3 \mu \mathrm{g} / \mathrm{L}\end{array}$} & 28.5 & 8 & 5.0 & 1 & 0.03906 & POS \\
\hline & 44.9 & 8 & 2.2 & 1 & 0.00781 & POS \\
\hline & 45.0 & 8 & 15.0 & 1 & 0.00781 & POS \\
\hline \multirow{3}{*}{$\begin{array}{l}\text { Arsenic (DIS, GF-AAS) Minimum Reporting Limit } \\
\quad 1 \mu \mathrm{g} / \mathrm{L}\end{array}$} & 1.84 & 5 & -0.54 & 0.1 & 0.12500 & -- \\
\hline & 7.72 & 3 & 0.29 & 0.1 & 0.25000 & -- \\
\hline & 12.5 & 4 & 0.0 & 1 & 0.87500 & -- \\
\hline \multirow{2}{*}{$\begin{array}{l}\text { Arsenic (WWR, GF-AAS) Minimum Reporting } \\
\text { Limit } 1 \mu \mathrm{g} / \mathrm{L}\end{array}$} & 7.60 & 4 & -0.10 & 0.1 & 1.00000 & -- \\
\hline & 11.4 & 4 & -1.3 & 1 & 0.37500 & -- \\
\hline \multirow{2}{*}{$\begin{array}{l}\text { Barium (DIS, ICP-AES/T) Minimum Reporting } \\
\quad \text { Limit } 0.2 \mu \mathrm{g} / \mathrm{L}\end{array}$} & 54.5 & 4 & -0.5 & 1 & 0.62500 & -- \\
\hline & 73.5 & 4 & 0.1 & 1 & 0.87500 & -- \\
\hline \multirow{3}{*}{$\begin{array}{l}\text { Barium (WWR, ICP-AES/T) Minimum Reporting } \\
\text { Limit } 0.2 \mu \mathrm{g} / \mathrm{L}\end{array}$} & 54.5 & 4 & -1.5 & 1 & 0.12500 & -- \\
\hline & 70.7 & 4 & -1.7 & 1 & 0.25000 & -- \\
\hline & 73.5 & 4 & -2.0 & 1 & 0.12500 & -- \\
\hline \multirow{2}{*}{$\begin{array}{l}\text { Beryllium (DIS, ICP-AES/T) Minimum Reporting } \\
\quad \text { Limit } 0.5 \mu \mathrm{g} / \mathrm{L}\end{array}$} & 6.85 & 4 & -0.05 & 0.1 & 0.50000 & -- \\
\hline & 7.65 & 4 & -0.05 & 0.1 & 0.12500 & -- \\
\hline \multirow{3}{*}{$\begin{array}{l}\text { Beryllium (WWR, ICP-AES/T) Minimum } \\
\text { Reporting Limit } 0.5 \mu \mathrm{g} / \mathrm{L}\end{array}$} & 6.85 & 4 & -0.30 & 0.1 & 0.12500 & -- \\
\hline & 7.65 & 4 & -0.25 & 0.1 & 0.12500 & -- \\
\hline & 8.64 & 4 & -0.19 & 0.1 & 0.12500 & -- \\
\hline \multirow{2}{*}{$\begin{array}{l}\text { Boron (DIS, ICP-AES/T) Minimum Reporting } \\
\text { Limit } 3 \mu \mathrm{g} / \mathrm{L}\end{array}$} & 25.3 & 4 & -0.3 & 1 & 1.00000 & -- \\
\hline & 25.8 & 4 & -0.8 & 1 & 0.25000 & -- \\
\hline \multirow{3}{*}{$\begin{array}{l}\text { Cadmium (DIS, GF-AAS) Minimum Reporting } \\
\text { Limit } 1 \mu \mathrm{g} / \mathrm{L}\end{array}$} & 6.98 & 4 & 0.08 & 0.1 & 0.62500 & -- \\
\hline & 8.42 & 3 & 0.19 & 0.1 & 0.25000 & -- \\
\hline & 14.2 & 4 & -0.2 & 1 & 1.00000 & -- \\
\hline \multirow{2}{*}{$\begin{array}{l}\text { Cadmium (DIS, ICP-AES/T) Minimum Reporting } \\
\text { Limit } 0.5 \mu \mathrm{g} / \mathrm{L}\end{array}$} & 7.15 & 4 & -0.05 & 0.1 & 0.50000 & -- \\
\hline & 13.0 & 4 & 0.1 & 1 & 1.00000 & -- \\
\hline \multirow{3}{*}{$\begin{array}{l}\text { Cadmium (WWR, GF-AAS) Minimum Reporting } \\
\text { Limit } 1 \mu \mathrm{g} / \mathrm{L}\end{array}$} & 3.40 & 3 & 0.10 & 0.1 & 0.75000 & -- \\
\hline & 9.55 & 4 & -0.50 & 0.1 & 0.12500 & -- \\
\hline & 14.3 & 4 & -0.8 & 1 & 0.37500 & -- \\
\hline \multirow{3}{*}{$\begin{array}{l}\text { Cadmium (WWR, ICP-AES/T) Minimum } \\
\text { Reporting Limit } 0.5 \mu \mathrm{g} / \mathrm{L}\end{array}$} & 6.98 & 4 & -0.38 & 0.1 & 0.12500 & -- \\
\hline & 8.42 & 3 & -0.22 & 0.1 & 1.00000 & -- \\
\hline & 14.2 & 4 & -1.2 & 1 & 0.12500 & -- \\
\hline
\end{tabular}


Table 5. Results of Wilcoxon signed-rank test for bias in constituent data for the Quality of Water Service Unit laboratory-Continued

[Most probable value, Median bias, and Nearest reporting unit reported in same units as Minimum Reporting Limit; WWR, whole-water recoverable; TITR, electrometric titration; $\mathrm{mg} / \mathrm{L}$, milligrams per liter; POS, positive bias; --, acceptable results; DIS, dissolved; ICP-AES/T, inductively coupled plasma-atomic emission spectrometry, trace; $\mu \mathrm{g} / \mathrm{L}$, micrograms per liter; GF-AAS, graphite furnace-atomic absorption spectrophotometry; USEPA, U.S. Environmental Protection Agency; ICP-AES, inductively coupled plasma-atomic emission spectrometry; NEG, negative bias; IC, ion chromatography; GRAV, gravimetric; ISE, ion-selective electrode; CV-AAS, cold vapor-atomic absorption spectrophotometry; F-AAS, flame-atomic absorption spectrophotometry]

\begin{tabular}{|c|c|c|c|c|c|c|}
\hline $\begin{array}{l}\text { Constituent and } \\
\text { method of analysis }\end{array}$ & $\begin{array}{c}\text { Most } \\
\text { probable value }\end{array}$ & $\begin{array}{c}\text { Number of } \\
\text { determinations }\end{array}$ & $\begin{array}{l}\text { Median } \\
\text { bias }\end{array}$ & $\begin{array}{l}\text { Nearest } \\
\text { reporting } \\
\text { unit }\end{array}$ & p-value & Bias \\
\hline \multicolumn{7}{|c|}{ Inorganic constituents-Continued } \\
\hline \multirow{9}{*}{$\begin{array}{l}\text { Calcium (DIS, ICP-AES) Minimum Reporting } \\
\text { Limit } 0.02 \mathrm{mg} / \mathrm{L}\end{array}$} & 9.53 & 8 & -0.08 & 0.1 & 0.35156 & -- \\
\hline & 25.1 & 11 & -1.1 & 1 & 0.00098 & NEG \\
\hline & 31.4 & 7 & -0.4 & 1 & 0.85938 & -- \\
\hline & 38.1 & 12 & -1.1 & 1 & 0.00049 & NEG \\
\hline & 44.2 & 8 & 0.8 & 1 & 0.25000 & -- \\
\hline & 45.9 & 8 & 0.1 & 1 & 0.13281 & -- \\
\hline & 52.2 & 12 & -1.2 & 1 & 0.00391 & NEG \\
\hline & 53.3 & 12 & -0.3 & 1 & 0.01123 & -- \\
\hline & 58.1 & 12 & -1.1 & 1 & 0.00049 & NEG \\
\hline \multirow{5}{*}{$\begin{array}{l}\text { Calcium (DIS, ICP-AES/T) Minimum Reporting } \\
\quad \text { Limit } 0.02 \mathrm{mg} / \mathrm{L}\end{array}$} & 40.5 & 8 & 0.5 & 1 & 0.06250 & -- \\
\hline & 41.2 & 8 & 0.9 & 1 & 0.09375 & -- \\
\hline & 42.2 & 8 & 0.8 & 1 & 0.01563 & -- \\
\hline & 44.2 & 4 & -0.2 & 1 & 1.00000 & -- \\
\hline & 45.9 & 4 & 0.1 & 1 & 0.12500 & -- \\
\hline \multirow{9}{*}{$\begin{array}{l}\text { Chloride (DIS, IC) Minimum Reporting Limit } \\
0.1 \mathrm{mg} / \mathrm{L}\end{array}$} & 8.35 & 8 & 0.05 & 0.1 & 0.00781 & -- \\
\hline & 29.6 & 7 & 0.4 & 1 & 0.01563 & -- \\
\hline & 31.5 & 11 & 0.5 & 1 & 0.00098 & -- \\
\hline & 45.4 & 12 & -0.4 & 1 & 0.12500 & -- \\
\hline & 46.0 & 7 & 1.0 & 1 & 0.03125 & -- \\
\hline & 62.7 & 12 & 2.3 & 1 & 0.00049 & POS \\
\hline & 69.0 & 8 & 0.5 & 1 & 0.25000 & -- \\
\hline & 78.5 & 12 & 1.5 & 1 & 0.00293 & POS \\
\hline & 85.3 & 12 & 1.8 & 1 & 0.00488 & POS \\
\hline \multirow{2}{*}{$\begin{array}{l}\text { Chromium (DIS, ICP-AES/T) Minimum Reporting } \\
\text { Limit } 1 \mu \mathrm{g} / \mathrm{L}\end{array}$} & 13.6 & 4 & -0.6 & 1 & 0.12500 & -- \\
\hline & 28.2 & 4 & -0.7 & 1 & 0.12500 & -- \\
\hline \multirow{3}{*}{$\begin{array}{l}\text { Chromium (WWR, GF-AAS) Minimum Reporting } \\
\text { Limit } 1 \mu \mathrm{g} / \mathrm{L}\end{array}$} & 9.70 & 3 & 0.30 & 0.1 & 0.75000 & -- \\
\hline & 18.5 & 4 & -0.5 & 1 & 0.50000 & -- \\
\hline & 27.8 & 4 & -0.8 & 1 & 0.62500 & -- \\
\hline \multirow{2}{*}{$\begin{array}{l}\text { Chromium (WWR, ICP-AES/T) Minimum } \\
\text { Reporting Limit } 1 \mu \mathrm{g} / \mathrm{L}\end{array}$} & 9.70 & 4 & -0.20 & 0.1 & 0.25000 & -- \\
\hline & 27.8 & 4 & -1.8 & 1 & 0.12500 & -- \\
\hline \multirow{2}{*}{$\begin{array}{l}\text { Cobalt (DIS, ICP-AES/T) Minimum Reporting } \\
\quad \text { Limit } 1 \mu \mathrm{g} / \mathrm{L}\end{array}$} & 3.55 & 4 & 0.05 & 0.1 & 0.75000 & -- \\
\hline & 8.70 & 4 & -0.05 & 0.1 & 0.75000 & -- \\
\hline \multirow{3}{*}{$\begin{array}{l}\text { Copper (DIS, GF-AAS) Minimum Reporting Limit } \\
1 \mu \mathrm{g} / \mathrm{L}\end{array}$} & 4.68 & 4 & -0.13 & 0.1 & 0.50000 & -- \\
\hline & 12.0 & 3 & 0.0 & 1 & 1.00000 & -- \\
\hline & 16.7 & 4 & 0.4 & 1 & 0.12500 & -- \\
\hline \multirow{2}{*}{$\begin{array}{l}\text { Copper (DIS, ICP-AES/T) Minimum Reporting } \\
\text { Limit } 1 \mu \mathrm{g} / \mathrm{L}\end{array}$} & 7.45 & 4 & 0.90 & 0.1 & 0.12500 & -- \\
\hline & 12.1 & 4 & 0.4 & 1 & 0.62500 & -- \\
\hline \multirow{2}{*}{$\begin{array}{l}\text { Copper (WWR, GF-AAS) Minimum Reporting } \\
\text { Limit } 1 \mu \mathrm{g} / \mathrm{L}\end{array}$} & 11.2 & 4 & 0.9 & 1 & 0.25000 & -- \\
\hline & 16.7 & 4 & -0.2 & 1 & 0.62500 & -- \\
\hline
\end{tabular}


Table 5. Results of Wilcoxon signed-rank test for bias in constituent data for the Quality of Water Service Unit laboratory-Continued

[Most probable value, Median bias, and Nearest reporting unit reported in same units as Minimum Reporting Limit; WWR, whole-water recoverable; TITR, electrometric titration; mg/L, milligrams per liter; POS, positive bias; --, acceptable results; DIS, dissolved; ICP-AES/T, inductively coupled plasma-atomic emission spectrometry, trace; $\mu \mathrm{g} / \mathrm{L}$, micrograms per liter; GF-AAS, graphite furnace-atomic absorption spectrophotometry; USEPA, U.S. Environmental Protection Agency; ICP-AES, inductively coupled plasma-atomic emission spectrometry; NEG, negative bias; IC, ion chromatography; GRAV, gravimetric; ISE, ion-selective electrode; CV-AAS, cold vapor-atomic absorption spectrophotometry; F-AAS, flame-atomic absorption spectrophotometry]

\begin{tabular}{|c|c|c|c|c|c|c|}
\hline $\begin{array}{l}\text { Constituent and } \\
\text { method of analysis }\end{array}$ & $\begin{array}{l}\text { Most } \\
\text { probable value }\end{array}$ & $\begin{array}{l}\text { Number of } \\
\text { determinations }\end{array}$ & $\begin{array}{l}\text { Median } \\
\text { bias }\end{array}$ & $\begin{array}{c}\text { Nearest } \\
\text { reporting } \\
\text { unit }\end{array}$ & p-value & Bias \\
\hline \multicolumn{7}{|c|}{ Inorganic constituents-Continued } \\
\hline \multirow{3}{*}{$\begin{array}{l}\text { Copper (WWR, ICP-AES/T) Minimum Reporting } \\
\text { Limit } 1 \mu \mathrm{g} / \mathrm{L}\end{array}$} & 7.45 & 4 & -0.20 & 0.1 & 0.62500 & -- \\
\hline & 12.1 & 4 & -1.1 & 1 & 0.12500 & -- \\
\hline & 19.5 & 4 & 0.5 & 1 & 0.75000 & -- \\
\hline \multirow{6}{*}{$\begin{array}{l}\text { Dissolved Solids (DIS, GRAV) Minimum } \\
\text { Reporting Limit } 1 \mathrm{mg} / \mathrm{L}\end{array}$} & 208.8 & 11 & 5.3 & 1 & 0.00977 & POS \\
\hline & 284.0 & 6 & 7.0 & 1 & 0.03125 & POS \\
\hline & 359.5 & 12 & 7.5 & 1 & 0.01123 & POS \\
\hline & 376.0 & 12 & 12.0 & 1 & 0.00391 & POS \\
\hline & 469.0 & 12 & 7.0 & 1 & 0.06055 & -- \\
\hline & 518.5 & 12 & 10.5 & 1 & 0.00049 & POS \\
\hline \multirow{8}{*}{$\begin{array}{l}\text { Fluoride (DIS, ISE) Minimum Reporting Limit } \\
0.1 \mathrm{mg} / \mathrm{L}\end{array}$} & 0.180 & 4 & 0.015 & 0.01 & 0.25000 & -- \\
\hline & 0.520 & 7 & 0.010 & 0.01 & 0.56250 & -- \\
\hline & 0.546 & 12 & 0.004 & 0.01 & 0.71924 & -- \\
\hline & 0.673 & 11 & 0.017 & 0.01 & 0.00781 & POS \\
\hline & 0.780 & 4 & 0.000 & 0.01 & 1.00000 & -- \\
\hline & 0.800 & 12 & 0.000 & 0.01 & 0.50000 & -- \\
\hline & 0.880 & 12 & 0.020 & 0.01 & 0.00098 & POS \\
\hline & 0.920 & 12 & -0.010 & 0.01 & 0.17188 & -- \\
\hline \multirow{7}{*}{$\begin{array}{l}\text { Iron (DIS, ICP-AES/T) Minimum Reporting Limit } \\
\quad 1 \mu \mathrm{g} / \mathrm{L}\end{array}$} & 35.5 & 4 & 4.5 & 1 & 0.25000 & -- \\
\hline & 39.3 & 4 & 0.8 & 1 & 0.12500 & -- \\
\hline & 54.3 & 8 & -3.8 & 1 & 0.72656 & -- \\
\hline & 55.1 & 8 & -5.1 & 1 & 0.00781 & NEG \\
\hline & 146.5 & 4 & -4.5 & 1 & 0.37500 & -- \\
\hline & 161.5 & 8 & -1.5 & 1 & 0.00781 & NEG \\
\hline & 166.5 & 4 & -6.5 & 1 & 0.12500 & -- \\
\hline \multirow{6}{*}{$\begin{array}{l}\text { Iron (WWR, ICP-AES/T) Minimum Reporting } \\
\quad \text { Limit } 1 \mu \mathrm{g} / \mathrm{L}\end{array}$} & 35.5 & 7 & 4.5 & 1 & 0.01563 & POS \\
\hline & 54.3 & 8 & 2.3 & 1 & 0.03125 & POS \\
\hline & 55.1 & 8 & -0.6 & 1 & 0.42188 & -- \\
\hline & 111.0 & 6 & -1.0 & 1 & 0.40625 & -- \\
\hline & 161.5 & 8 & -1.5 & 1 & 0.00781 & NEG \\
\hline & 166.5 & 8 & -6.5 & 1 & 0.19531 & -- \\
\hline \multirow{2}{*}{$\begin{array}{l}\text { Lead (DIS, GF-AAS) Minimum Reporting Limit } \\
\quad 1 \mu \mathrm{g} / \mathrm{L}\end{array}$} & 3.2 & 4 & -0.2 & 1 & 0.12500 & -- \\
\hline & 62.6 & 4 & 1.5 & 1 & 0.62500 & -- \\
\hline \multirow{2}{*}{$\begin{array}{l}\text { Lead (DIS, ICP-AES/T) Minimum Reporting Limit } \\
\quad 1 \mu \mathrm{g} / \mathrm{L}\end{array}$} & 5.39 & 4 & -0.29 & 0.1 & 0.12500 & -- \\
\hline & 44.9 & 4 & 0.2 & 1 & 0.75000 & -- \\
\hline \multirow{3}{*}{$\begin{array}{l}\text { Lead (WWR, GF-AAS) Minimum Reporting Limit } \\
\quad 1 \mu \mathrm{g} / \mathrm{L}\end{array}$} & 3.2 & 3 & -0.2 & 1 & 0.25000 & -- \\
\hline & 41.7 & 4 & -1.2 & 1 & 0.25000 & -- \\
\hline & 62.6 & 4 & -7.1 & 1 & 0.37500 & -- \\
\hline \multirow{3}{*}{$\begin{array}{l}\text { Lead (WWR, ICP-AES/T) Minimum Reporting } \\
\quad \text { Limit } 1 \mu \mathrm{g} / \mathrm{L}\end{array}$} & 5.84 & 4 & -0.24 & 0.1 & 0.62500 & -- \\
\hline & 8.59 & 3 & -0.49 & 0.1 & 0.75000 & - \\
\hline & 48.1 & 4 & -2.6 & 1 & 0.12500 & -- \\
\hline
\end{tabular}


Table 5. Results of Wilcoxon signed-rank test for bias in constituent data for the Quality of Water Service Unit laboratory-Continued

[Most probable value, Median bias, and Nearest reporting unit reported in same units as Minimum Reporting Limit; WWR, whole-water recoverable; TITR, electrometric titration; mg/L, milligrams per liter; POS, positive bias; --, acceptable results; DIS, dissolved; ICP-AES/T, inductively coupled plasma-atomic emission spectrometry, trace; $\mu \mathrm{g} / \mathrm{L}$, micrograms per liter; GF-AAS, graphite furnace-atomic absorption spectrophotometry; USEPA, U.S. Environmental Protection Agency; ICP-AES, inductively coupled plasma-atomic emission spectrometry; NEG, negative bias; IC, ion chromatography; GRAV, gravimetric; ISE, ion-selective electrode; CV-AAS, cold vapor-atomic absorption spectrophotometry; F-AAS, flame-atomic absorption spectrophotometry]

\begin{tabular}{|c|c|c|c|c|c|c|}
\hline $\begin{array}{l}\text { Constituent and } \\
\text { method of analysis }\end{array}$ & $\begin{array}{c}\text { Most } \\
\text { probable value }\end{array}$ & $\begin{array}{c}\text { Number of } \\
\text { determinations }\end{array}$ & $\begin{array}{c}\text { Median } \\
\text { bias }\end{array}$ & $\begin{array}{l}\text { Nearest } \\
\text { reporting } \\
\text { unit }\end{array}$ & p-value & Bias \\
\hline \multicolumn{7}{|c|}{ Inorganic constituents-Continued } \\
\hline \multirow{9}{*}{$\begin{array}{l}\text { Magnesium (DIS, ICP-AES) Minimum Reporting } \\
\text { Limit } 0.01 \mathrm{mg} / \mathrm{L}\end{array}$} & 2.53 & 8 & 0.08 & 0.1 & 0.03125 & -- \\
\hline & 7.43 & 11 & -0.23 & 0.1 & 0.00098 & NEG \\
\hline & 7.65 & 7 & -0.05 & 0.1 & 0.18750 & -- \\
\hline & 9.50 & 12 & -0.20 & 0.1 & 0.00098 & NEG \\
\hline & 10.1 & 8 & -0.1 & 1 & 0.00781 & -- \\
\hline & 10.3 & 8 & -0.3 & 1 & 0.23438 & -- \\
\hline & 12.5 & 12 & -0.5 & 1 & 0.00049 & -- \\
\hline & 13.9 & 12 & 0.1 & 1 & 0.84277 & -- \\
\hline & 14.2 & 12 & -0.2 & 1 & 0.00049 & -- \\
\hline \multirow{5}{*}{$\begin{array}{l}\text { Magnesium (DIS, ICP-AES/T) Minimum } \\
\text { Reporting Limit } 0.001 \mathrm{mg} / \mathrm{L}\end{array}$} & 9.34 & 8 & -0.14 & 0.1 & 0.03906 & NEG \\
\hline & 9.54 & 8 & 0.01 & 0.1 & 0.50781 & -- \\
\hline & 10.1 & 4 & -0.1 & 1 & 0.12500 & -- \\
\hline & 10.1 & 8 & -0.1 & 1 & 0.00781 & -- \\
\hline & 10.3 & 4 & -0.3 & 1 & 0.12500 & -- \\
\hline \multirow{7}{*}{$\begin{array}{l}\text { Manganese (DIS, ICP-AES/T) Minimum Reporting } \\
\text { Limit } 0.2 \mu \mathrm{g} / \mathrm{L}\end{array}$} & 11.7 & 8 & 0.4 & 1 & 0.00781 & -- \\
\hline & 13.7 & 4 & 0.4 & 1 & 0.12500 & -- \\
\hline & 19.6 & 8 & 0.5 & 1 & 0.00781 & -- \\
\hline & 49.0 & 4 & 0.0 & 1 & & -- \\
\hline & 50.2 & 4 & -1.2 & 1 & 0.12500 & -- \\
\hline & 58.1 & 4 & -0.1 & 1 & 0.62500 & -- \\
\hline & 74.1 & 8 & -1.1 & 1 & 0.02344 & NEG \\
\hline \multirow{6}{*}{$\begin{array}{l}\text { Manganese (WWR, ICP-AES/T) Minimum } \\
\text { Reporting Limit } 0.2 \mu \mathrm{g} / \mathrm{L}\end{array}$} & 9.10 & 4 & 0.10 & 0.1 & 0.50000 & -- \\
\hline & 11.7 & 8 & -0.7 & 1 & 0.29688 & -- \\
\hline & 13.7 & 4 & -0.2 & 1 & 0.62500 & -- \\
\hline & 19.6 & 8 & -0.1 & 1 & 0.28125 & -- \\
\hline & 49.0 & 3 & -1.0 & 1 & 1.00000 & -- \\
\hline & 74.1 & 8 & -4.1 & 1 & 0.00781 & NEG \\
\hline \multirow{3}{*}{$\begin{array}{l}\text { Mercury (WWR, CV-AAS) Minimum Reporting } \\
\text { Limit } 0.1 \mu \mathrm{g} / \mathrm{L}\end{array}$} & 0.26 & 4 & -0.01 & 0.1 & 0.50000 & -- \\
\hline & 0.76 & 8 & 0.09 & 0.1 & 0.06250 & -- \\
\hline & 3.32 & 7 & 0.29 & 0.1 & 0.01563 & POS \\
\hline \multirow{2}{*}{$\begin{array}{l}\text { Molybdenum (DIS, ICP-AES/T) Minimum } \\
\text { Reporting Limit } 2 \mu \mathrm{g} / \mathrm{L}\end{array}$} & 11.9 & 4 & 0.1 & 1 & 0.62500 & -- \\
\hline & 22.5 & 4 & 1.0 & 1 & 0.12500 & -- \\
\hline \multirow{2}{*}{$\begin{array}{l}\text { Nickel (DIS, ICP-AES/T) Minimum Reporting } \\
\quad \text { Limit } 1 \mu \mathrm{g} / \mathrm{L}\end{array}$} & 14.1 & 4 & 0.5 & 1 & 0.50000 & -- \\
\hline & 43.0 & 4 & 0.0 & 1 & 1.00000 & -- \\
\hline \multirow{3}{*}{$\begin{array}{l}\text { Nickel (WWR, GF-AAS) Minimum Reporting } \\
\text { Limit } 1 \mu \mathrm{g} / \mathrm{L}\end{array}$} & 7.50 & 3 & 0.20 & 0.1 & 0.75000 & -- \\
\hline & 35.5 & 4 & -1.5 & 1 & 0.50000 & -- \\
\hline & 53.3 & 4 & -3.8 & 1 & 0.12500 & -- \\
\hline \multirow{3}{*}{$\begin{array}{l}\text { Nickel (WWR, ICP-AES/T) Minimum Reporting } \\
\quad \text { Limit } 1 \mu \mathrm{g} / \mathrm{L}\end{array}$} & 14.1 & 4 & -0.1 & 1 & 0.62500 & -- \\
\hline & 43.0 & 4 & -1.0 & 1 & 0.12500 & -- \\
\hline & 56.0 & 4 & -1.5 & 1 & 0.37500 & -- \\
\hline
\end{tabular}


Table 5. Results of Wilcoxon signed-rank test for bias in constituent data for the Quality of Water Service Unit laboratory-Continued

[Most probable value, Median bias, and Nearest reporting unit reported in same units as Minimum Reporting Limit; WWR, whole-water recoverable; TITR, electrometric titration; mg/L, milligrams per liter; POS, positive bias; --, acceptable results; DIS, dissolved; ICP-AES/T, inductively coupled plasma-atomic emission spectrometry, trace; $\mu \mathrm{g} / \mathrm{L}$, micrograms per liter; GF-AAS, graphite furnace-atomic absorption spectrophotometry; USEPA, U.S. Environmental Protection Agency; ICP-AES, inductively coupled plasma-atomic emission spectrometry; NEG, negative bias; IC, ion chromatography; GRAV, gravimetric; ISE, ion-selective electrode; CV-AAS, cold vapor-atomic absorption spectrophotometry; F-AAS, flame-atomic absorption spectrophotometry]

\begin{tabular}{|c|c|c|c|c|c|c|}
\hline $\begin{array}{l}\text { Constituent and } \\
\text { method of analysis }\end{array}$ & $\begin{array}{c}\text { Most } \\
\text { probable value }\end{array}$ & $\begin{array}{c}\text { Number of } \\
\text { determinations }\end{array}$ & $\begin{array}{l}\text { Median } \\
\text { bias }\end{array}$ & $\begin{array}{c}\text { Nearest } \\
\text { reporting } \\
\text { unit }\end{array}$ & p-value & Bias \\
\hline \multicolumn{7}{|c|}{ Inorganic constituents-Continued } \\
\hline \multirow{9}{*}{$\begin{array}{l}\text { Potassium (DIS, F-AAS) Minimum Reporting } \\
\quad \text { Limit } 0.1 \mathrm{mg} / \mathrm{L}\end{array}$} & 0.30 & 8 & 0.00 & 0.1 & 0.00781 & -- \\
\hline & 1.85 & 8 & -0.05 & 0.1 & 0.23438 & -- \\
\hline & 1.96 & 8 & -0.06 & 0.1 & 0.00781 & -- \\
\hline & 2.01 & 11 & -0.01 & 0.1 & 0.68164 & -- \\
\hline & 2.49 & 12 & 0.01 & 0.1 & 0.59912 & -- \\
\hline & 3.27 & 7 & 0.04 & 0.1 & 0.48438 & - \\
\hline & 4.18 & 12 & 0.03 & 0.1 & 0.11084 & -- \\
\hline & 4.47 & 12 & -0.07 & 0.1 & 0.01904 & -- \\
\hline & 5.50 & 12 & -0.10 & 0.1 & 0.02002 & -- \\
\hline \multirow{3}{*}{$\begin{array}{l}\text { Selenium (DIS, GF-AAS) Minimum Reporting } \\
\quad \text { Limit } 1 \mu \mathrm{g} / \mathrm{L}\end{array}$} & 2.18 & 4 & -0.98 & 0.1 & 0.12500 & -- \\
\hline & 7.47 & 3 & -0.57 & 0.1 & 0.25000 & -- \\
\hline & 9.87 & 4 & -0.42 & 0.1 & 1.00000 & -- \\
\hline \multirow{2}{*}{$\begin{array}{l}\text { Selenium (WWR, GF-AAS) Minimum Reporting } \\
\text { Limit } 1 \mu \mathrm{g} / \mathrm{L}\end{array}$} & 4.82 & 4 & 0.79 & 0.1 & 0.12500 & -- \\
\hline & 7.22 & 4 & 0.23 & 0.1 & 0.37500 & -- \\
\hline \multirow{6}{*}{$\begin{array}{l}\text { Silica (DIS, ICP-AES) Minimum Reporting Limit } \\
0.01 \mathrm{mg} / \mathrm{L}\end{array}$} & 6.35 & 12 & -0.05 & 0.1 & 0.91162 & -- \\
\hline & 6.50 & 7 & -0.10 & 0.1 & 0.06250 & -- \\
\hline & 8.54 & 11 & -0.04 & 0.1 & 0.81055 & -- \\
\hline & 9.17 & 12 & -0.12 & 0.1 & 0.01123 & NEG \\
\hline & 11.0 & 12 & 0.0 & 1 & 0.00049 & -- \\
\hline & 11.1 & 12 & -0.1 & 1 & 0.00049 & -- \\
\hline \multirow{5}{*}{$\begin{array}{l}\text { Silica (DIS, ICP-AES/T) Minimum Reporting } \\
\text { Limit } 0.01 \mathrm{mg} / \mathrm{L}\end{array}$} & 7.55 & 8 & 0.25 & 0.1 & 0.00781 & POS \\
\hline & 8.14 & 4 & 0.17 & 0.1 & 0.12500 & -- \\
\hline & 10.3 & 8 & 0.2 & 1 & 0.28125 & -- \\
\hline & 15.2 & 4 & -0.2 & 1 & 1.00000 & -- \\
\hline & 17.4 & 8 & -0.4 & 1 & 0.64844 & -- \\
\hline \multirow{2}{*}{$\begin{array}{l}\text { Silver (DIS, ICP-AES/T) Minimum Reporting } \\
\quad \text { Limit } 1 \mu \mathrm{g} / \mathrm{L}\end{array}$} & 1.28 & 4 & 0.27 & 0.1 & 0.12500 & -- \\
\hline & 10.1 & 4 & -0.6 & 1 & 0.12500 & -. \\
\hline \multirow{9}{*}{$\begin{array}{l}\text { Sodium (DIS, F-AAS) Minimum Reporting Limit } \\
\quad 0.1 \mathrm{mg} / \mathrm{L}\end{array}$} & 5.50 & 8 & 0.15 & 0.1 & 0.37500 & -- \\
\hline & 28.0 & 8 & 0.0 & 1 & 0.62500 & -- \\
\hline & 33.5 & 11 & -0.5 & 1 & 0.66309 & -- \\
\hline & 49.9 & 12 & 0.1 & 1 & 0.09180 & -- \\
\hline & 54.0 & 7 & 0.0 & 1 & 0.75000 & -- \\
\hline & 56.4 & 8 & 0.1 & 1 & 0.78906 & -- \\
\hline & 69.8 & 12 & -0.8 & 1 & 0.09766 & -- \\
\hline & 84.4 & 12 & 0.7 & 1 & 0.55078 & -- \\
\hline & 96.2 & 12 & -0.2 & 1 & 0.06055 & -- \\
\hline \multirow{4}{*}{$\begin{array}{l}\text { Strontium (DIS, ICP-AES/T) Minimum Reporting } \\
\quad \text { Limit } 0.5 \mu \mathrm{g} / \mathrm{L}\end{array}$} & 115 & 4 & 0 & 10 & 1.00000 & -. \\
\hline & 330 & 4 & 1 & 10 & 0.12500 & -- \\
\hline & 268 & 4 & 2 & 10 & 1.00000 & -- \\
\hline & 316 & 4 & -1 & 10 & 0.50000 & -- \\
\hline
\end{tabular}


Table 5. Results of Wilcoxon signed-rank test for bias in constituent data for the Quality of Water Service Unit laboratory-Continued

[Most probable value, Median bias, and Nearest reporting unit reported in same units as Minimum Reporting Limit; WWR, whole-water recoverable; TITR, electrometric titration; mg/L, milligrams per liter; POS, positive bias; --, acceptable results; DIS, dissolved; ICP-AES/T, inductively coupled plasma-atomic emission spectrometry, trace; $\mu \mathrm{g} / \mathrm{L}$, micrograms per liter; GF-AAS, graphite furnace-atomic absorption spectrophotometry; USEPA, U.S. Environmental Protection Agency; ICP-AES, inductively coupled plasma-atomic emission spectrometry; NEG, negative bias; IC, ion chromatography; GRAV, gravimetric; ISE, ion-selective electrode; CV-AAS, cold vapor-atomic absorption spectrophotometry; F-AAS, flame-atomic absorption spectrophotometry]

\begin{tabular}{|c|c|c|c|c|c|c|}
\hline $\begin{array}{l}\text { Constituent and } \\
\text { method of analysis }\end{array}$ & $\begin{array}{c}\text { Most } \\
\text { probable value }\end{array}$ & $\begin{array}{c}\text { Number of } \\
\text { determinations }\end{array}$ & $\begin{array}{c}\text { Median } \\
\text { bias }\end{array}$ & $\begin{array}{c}\text { Nearest } \\
\text { reporting } \\
\text { unit }\end{array}$ & p-value & Bias \\
\hline \multicolumn{7}{|c|}{ Inorganic constituents-Continued } \\
\hline \multirow{3}{*}{$\begin{array}{l}\text { Strontium (WWR, ICP-AES/T) Minimum } \\
\text { Reporting Limit } 0.5 \mu \mathrm{g} / \mathrm{L}\end{array}$} & 268 & 4 & -8 & 10 & 0.12500 & -- \\
\hline & 280 & 4 & -10 & 10 & 0.12500 & -- \\
\hline & 316 & 4 & -6 & 10 & 0.12500 & -- \\
\hline \multirow{7}{*}{$\begin{array}{l}\text { Sulfate (DIS, IC) Minimum Reporting Limit } \\
\quad 0.2 \mathrm{mg} / \mathrm{L}\end{array}$} & 7.00 & 8 & -0.20 & 0.1 & 0.01563 & NEG \\
\hline & 58.5 & 11 & 0.5 & 1 & 0.06543 & -- \\
\hline & 75.0 & 7 & 1.0 & 1 & 0.01563 & -- \\
\hline & 89.0 & 19 & 1.0 & 1 & 0.00046 & -- \\
\hline & 113 & 8 & -3 & 10 & 0.64844 & -- \\
\hline & 114 & 24 & 6 & 10 & 0.00279 & -- \\
\hline & 132 & 12 & -2 & 10 & 0.67041 & -- \\
\hline \multirow{2}{*}{$\begin{array}{l}\text { Vanadium (DIS, ICP-AES/T) Minimum Reporting } \\
\text { Limit } 1 \mu \mathrm{g} / \mathrm{L}\end{array}$} & 9.5 & 4 & -0.5 & 1 & 0.12500 & -- \\
\hline & 22.0 & 4 & -0.5 & 1 & 0.50000 & -- \\
\hline \multirow{2}{*}{$\begin{array}{l}\text { Zinc (DIS, ICP-AES/T) Minimum Reporting Limit } \\
\quad 1 \mu \mathrm{g} / \mathrm{L}\end{array}$} & 30.3 & 4 & -0.8 & 1 & 0.37500 & -- \\
\hline & 34.8 & 4 & 2.3 & 1 & 0.12500 & -- \\
\hline \multirow{6}{*}{$\begin{array}{l}\text { Zinc (WWR, ICP-AES/T) Minimum Reporting } \\
\text { Limit } 1 \mu \mathrm{g} / \mathrm{L}\end{array}$} & 10.0 & 4 & 1.5 & 1 & 0.12500 & -- \\
\hline & 15.0 & 4 & 1.5 & 1 & 0.62500 & -- \\
\hline & 17.5 & 4 & 3.0 & 1 & 0.12500 & -- \\
\hline & 24.8 & 3 & -0.8 & 1 & 1.00000 & -- \\
\hline & 30.3 & 4 & -0.3 & 1 & 1.00000 & -- \\
\hline & 34.8 & 3 & 1.3 & 1 & 0.25000 & -- \\
\hline \multicolumn{7}{|c|}{ Nutrient constituents } \\
\hline \multirow{5}{*}{$\begin{array}{l}\text { Ammonia as nitrogen (DIS) Minimum Reporting } \\
\text { Limit } 0.01 \mathrm{mg} / \mathrm{L}\end{array}$} & 0.210 & 6 & 0.010 & 0.01 & 0.06250 & -- \\
\hline & 0.240 & 5 & 0.010 & 0.01 & 0.12500 & -- \\
\hline & 0.498 & 4 & 0.052 & 0.01 & 0.12500 & -- \\
\hline & 0.620 & 4 & 0.060 & 0.01 & 0.12500 & -- \\
\hline & 1.24 & 20 & 0.06 & 0.1 & 0.00340 & -- \\
\hline \multirow{5}{*}{$\begin{array}{l}\text { Ammonia plus organic nitrogen as nitrogen (DIS) } \\
\text { Minimum Reporting Limit } 0.2 \mathrm{mg} / \mathrm{L}\end{array}$} & 0.285 & 6 & -0.085 & 0.01 & 0.03125 & NEG \\
\hline & 0.300 & 5 & -0.040 & 0.01 & 0.43750 & -- \\
\hline & 0.750 & 4 & 0.045 & 0.01 & 0.12500 & -- \\
\hline & 0.864 & 22 & -0.014 & 0.01 & 0.45803 & -- \\
\hline & 0.910 & 4 & -0.085 & 0.01 & 0.12500 & -- \\
\hline \multirow{4}{*}{$\begin{array}{l}\text { Ammonia plus organic nitrogen as nitrogen } \\
\text { (WWR) Minimum Reporting Limit } 0.2 \mathrm{mg} / \mathrm{L}\end{array}$} & 0.285 & 14 & -0.075 & 0.01 & 0.00061 & NEG \\
\hline & 0.300 & 13 & 0.000 & 0.01 & 0.27148 & -- \\
\hline & 0.750 & 17 & 0.010 & 0.01 & 0.66849 & -- \\
\hline & 0.910 & 20 & -0.070 & 0.01 & 0.00373 & NEG \\
\hline \multirow{5}{*}{$\begin{array}{l}\text { Nitrate plus nitrite as nitrogen (DIS) Minimum } \\
\text { Reporting Limit } 0.02 \mathrm{mg} / \mathrm{L}\end{array}$} & 0.220 & 6 & 0.000 & 0.01 & 1.00000 & -- \\
\hline & 0.443 & 5 & 0.017 & 0.01 & 0.06250 & -- \\
\hline & 0.747 & 4 & -0.052 & 0.01 & 0.12500 & -- \\
\hline & 1.01 & 4 & -0.05 & 0.1 & 0.12500 & -- \\
\hline & 1.04 & 20 & -0.04 & 0.1 & 0.58840 & -- \\
\hline
\end{tabular}


Table 5. Results of Wilcoxon signed-rank test for bias in constituent data for the Quality of Water Service Unit laboratory-Continued

[Most probable value, Median bias, and Nearest reporting unit reported in same units as Minimum Reporting Limit; WWR, whole-water recoverable; TITR, electrometric titration; mg/L, milligrams per liter; POS, positive bias; --, acceptable results; DIS, dissolved; ICP-AES/T, inductively coupled plasma-atomic emission spectrometry, trace; $\mu \mathrm{g} / \mathrm{L}$, micrograms per liter; GF-AAS, graphite furnace-atomic absorption spectrophotometry; USEPA, U.S. Environmental Protection Agency; ICP-AES, inductively coupled plasma-atomic emission spectrometry; NEG, negative bias; IC, ion chromatography; GRAV, gravimetric; ISE, ion-selective electrode; CV-AAS, cold vapor-atomic absorption spectrophotometry; F-AAS, flame-atomic absorption spectrophotometry]

\begin{tabular}{|c|c|c|c|c|c|c|}
\hline $\begin{array}{l}\text { Constituent and } \\
\text { method of analysis }\end{array}$ & $\begin{array}{c}\text { Most } \\
\text { probable value }\end{array}$ & $\begin{array}{c}\text { Number of } \\
\text { determinations }\end{array}$ & $\begin{array}{l}\text { Median } \\
\text { bias }\end{array}$ & $\begin{array}{l}\text { Nearest } \\
\text { reporting } \\
\text { unit }\end{array}$ & p-value & Bias \\
\hline \multicolumn{7}{|c|}{ Nutrient constituents-Continued } \\
\hline \multirow{5}{*}{$\begin{array}{l}\text { Orthophosphate as phosphorus (DIS) Minimum } \\
\text { Reporting Limit } 0.01 \mathrm{mg} / \mathrm{L}\end{array}$} & 0.195 & 6 & -0.005 & 0.01 & 0.15625 & -- \\
\hline & 0.580 & 5 & 0.030 & 0.01 & 0.12500 & -- \\
\hline & 0.658 & 4 & -0.013 & 0.01 & 0.62500 & -- \\
\hline & 0.758 & 4 & -0.008 & 0.01 & 0.62500 & -- \\
\hline & 1.01 & 20 & -0.01 & 0.1 & 0.00968 & -- \\
\hline \multirow{5}{*}{$\begin{array}{l}\text { Phosphorus as phosphorus (DIS) Minimum } \\
\text { Reporting Limit } 0.02 \mathrm{mg} / \mathrm{L}\end{array}$} & 0.201 & 6 & -0.021 & 0.01 & 0.03125 & NEG \\
\hline & 0.602 & 5 & -0.022 & 0.01 & 0.37500 & -- \\
\hline & 0.715 & 4 & -0.010 & 0.01 & 0.87500 & -- \\
\hline & 0.766 & 4 & -0.006 & 0.01 & 0.12500 & -- \\
\hline & 1.01 & 22 & -0.01 & 0.1 & 0.00003 & -- \\
\hline \multirow{4}{*}{$\begin{array}{l}\text { Phosphorus as phosphorus (WWR) Minimum } \\
\text { Reporting Limit } 0.02 \mathrm{mg} / \mathrm{L}\end{array}$} & 0.201 & 14 & -0.021 & 0.01 & 0.00012 & NEG \\
\hline & 0.602 & 13 & -0.002 & 0.01 & 0.49341 & -- \\
\hline & 0.715 & 17 & -0.005 & 0.01 & 0.61668 & -- \\
\hline & 0.766 & 20 & 0.004 & 0.01 & 0.51160 & -- \\
\hline
\end{tabular}

\section{SUMMARY}

A quality-assurance program was operated during water year 1998 to evaluate the quality of analytical work for inorganic, nutrient, and lowlevel constituents at two USGS laboratories. Reference water samples with established most probable values were disguised and submitted as routine environmental water samples to the National Water Quality Laboratory in Arvada, Colorado, and the Quality of Water Service Unit laboratory in Ocala, Florida. Reference samples were submitted at a rate of 2 to 5 percent of the laboratory work for each analytical procedure. Resulting analytical data were stored in National Water Information System and the Blind Sample Project's data base.

For each constituent, control charts were prepared on the basis of the difference between the analytical results and the most probable values of the reference samples. To allow the data for all reference mixes to be plotted on the same chart, the difference from the above calculations was divided by each sample's F-pseudosigma, which was determined from a linear-regression technique. Replicate sample determinations allowed the preparation of precision charts for each constituent. Data for inorganic, nutrient, and low-level constituent samples were then evaluated statistically for precision by using a binomialprobability-distribution test. The Wilcoxon signedrank test was used in the bias assessment for each constituent by quantifying the median difference between the reported values and the most probable values.

An overall evaluation of the National Water Quality Laboratory inorganic and low-level constituent data for water year 1998 indicated imprecision for silver (dissolved, inductively coupled plasma-mass spectrometry). The evaluation also indicated bias throughout the range of reference samples for chromium (dissolved, inductively coupled plasma-atomic emission spectrometry), dissolved solids (dissolved, 
gravimetric), lithium (dissolved, inductively coupled plasma-atomic emission spectrometry), silver (dissolved, inductively coupled plasma-mass spectrometry), and zinc (dissolved, inductively coupled plasma-mass spectrometry).

Statistical evaluation of the National Water Quality Laboratory nutrient methods indicated a lack of precision for ammonia (dissolved, colorimetric) and orthophosphate as phosphorus (dissolved, colorimetric). Bias was indicated throughout the reference sample range for ammonia as nitrogen (dissolved, colorimetric, low level) and nitrate plus nitrite as nitrogen (dissolved, colorimetric, low level).

An overall evaluation of the Quality of Water Service Unit data for water year 1998 indicated no imprecision. Bias throughout the reference sample range was indicated for aluminum (whole-water recoverable, inductively coupled plasma-atomic emission spectrometry, trace).

\section{REFERENCES}

Farrar, J.W., and Chleboun, K.M., 1999, Results of the U.S. Geological Survey's analytical evaluation program for standard reference samples distributed in March 1999: U.S. Geological Survey Open-File Report 99-259, $166 \mathrm{p}$.

Fishman, M.J., and Friedman, L.C., 1989, Methods for determination of inorganic substances in water and fluvial sediments: Techniques of Water-Resources Investigations of the U.S. Geological Survey, book 5, chap. A1, $545 \mathrm{p}$.

Friedman, L.C., Bradford, W.L., and Peart, D.B., 1983, Application of binomial distributions to quality assurance of quantitative chemical analyses: Journal of Environmental Science and Health, v. A18, no. 4, p. 561-570.

Friedman, L.C., and Erdmann, D.E., 1982, Quality assurance practices for the chemical and biological analyses of water and sediments: U.S. Geological Survey Techniques of Water-Resources Investigations, book 5 , chap. A6, $181 \mathrm{p}$.

Helsel, D.R., and Hirsch, R.M., 1992, Statistical methods in water resources-Studies in environmental science, v. 49: Amsterdam, The Netherlands, Elsevier Science Publishers, $522 \mathrm{p}$.
Hoaglin, D.C., Mosteller, Frederick, and Tukey, J.W. 1983, Understanding robust and exploratory data analysis: New York, John Wiley, 447 p.

Janzer, V.J., 1985, The use of natural waters as U.S. Geological Survey reference samples, in Taylor, J.K., and Stanley, T.W., eds., Quality assurance for environmental measurements, ASTM STP 867: Philadelphia, American Society for Testing and Materials, p. 319-333.

Lucey, K.J., 1989, Quality-assurance data for routine water analysis in the National Water Quality Laboratory of the U.S. Geological Survey for water year 1988: U.S. Geological Survey Water-Resources Investigations Report 89-4166, 96 p.

Lucey, K.J., and Peart, D.B., 1988, Quality-assurance data for routine water analysis in the laboratories of the U.S. Geological Survey for water year 1985: U.S. Geological Survey Water-Resources Investigations Report 88-4109, 121 p.

1989a, Quality-assurance data for routine water analysis in the laboratories of the U.S. Geological Survey for water year 1986: U.S. Geological Survey Water-Resources Investigations Report 89-4009, $145 \mathrm{p}$.

1989b, Quality-assurance data for routine water analysis in the laboratories of the U.S. Geological Survey for water year 1987: U.S. Geological Survey Water-Resources Investigations Report 89-4049, 90 p.

Ludtke, A.S., Woodworth, M.T., and Marsh, P.S., 1999, Quality-assurance data for routine water analysis in U.S. Geological Survey laboratories, water year 1997: U.S. Geological Survey Water-Resources Investigations Report 99-4057, $186 \mathrm{p}$.

Maloney, T.J., Ludtke, A.S, and Krizman, T.L., 1992, Quality-assurance data for routine water analysis in the National Water Quality Laboratory of the U.S. Geological Survey for water year 1989: U.S. Geological Survey Water-Resources Investigations Report 92-4075, 99 p. 1993, Quality-assurance data for the routine water analysis in the laboratories of the U.S. Geological Survey for water year 1990: U.S. Geological Survey Water-Resources Investigations Report 93-4082, $145 \mathrm{p}$.

1994, Quality-assurance results for routine water analysis in U.S. Geological Survey laboratories, water year 1991: U.S. Geological Survey Water-Resources Investigations Report 94-4046, 144 p. 
Peart, D.B., and Sutphin, H.B. 1987, Quality-assurance data for routine water analysis in the laboratories of the U.S. Geological Survey for water year 1984: U.S. Geological Survey Water-Resources Investigations Report 87-4077, 125 p.

Peart, D.B., and Thomas, Nancy, 1983a, Quality-assurance data for routine water analysis in the laboratories of the U.S. Geological Survey 1981 annual report: U.S. Geological Survey Water-Resources Investigations Report 83-4090, 112 p.

1983b, Quality-assurance data for routine water analysis in the laboratories of the U.S. Geological Survey for water year 1982: U.S. Geological Survey Water-Resources Investigations Report 83-4264, $112 \mathrm{p}$.
1984, Quality-assurance data for routine water analysis in the laboratories of the U.S. Geological Survey for water year 1983: U.S. Geological Survey WaterResources Investigations Report 84-4234, 112 p.

Schroder, L.J., Fishman, M.J., Friedman, L.C., and Darlington, G.W., 1980, The use of standard reference water samples by the U.S. Geological Survey: U.S. Geological Survey Open-File Report 80-738, 11 p.

Skougstad, M.W., and Fishman, M.J., 1975, Standard reference water samples: American Water Works Association Water Quality Technology Conference, Dallas, 1974, Proceedings, p. XIX-1-XIX-6.

Taylor, J.K., 1987, Quality assurance of chemical measurements: Chelsea, Mich., Lewis Publishers, 328 p. 
SUPPLEMENTAL DATA 


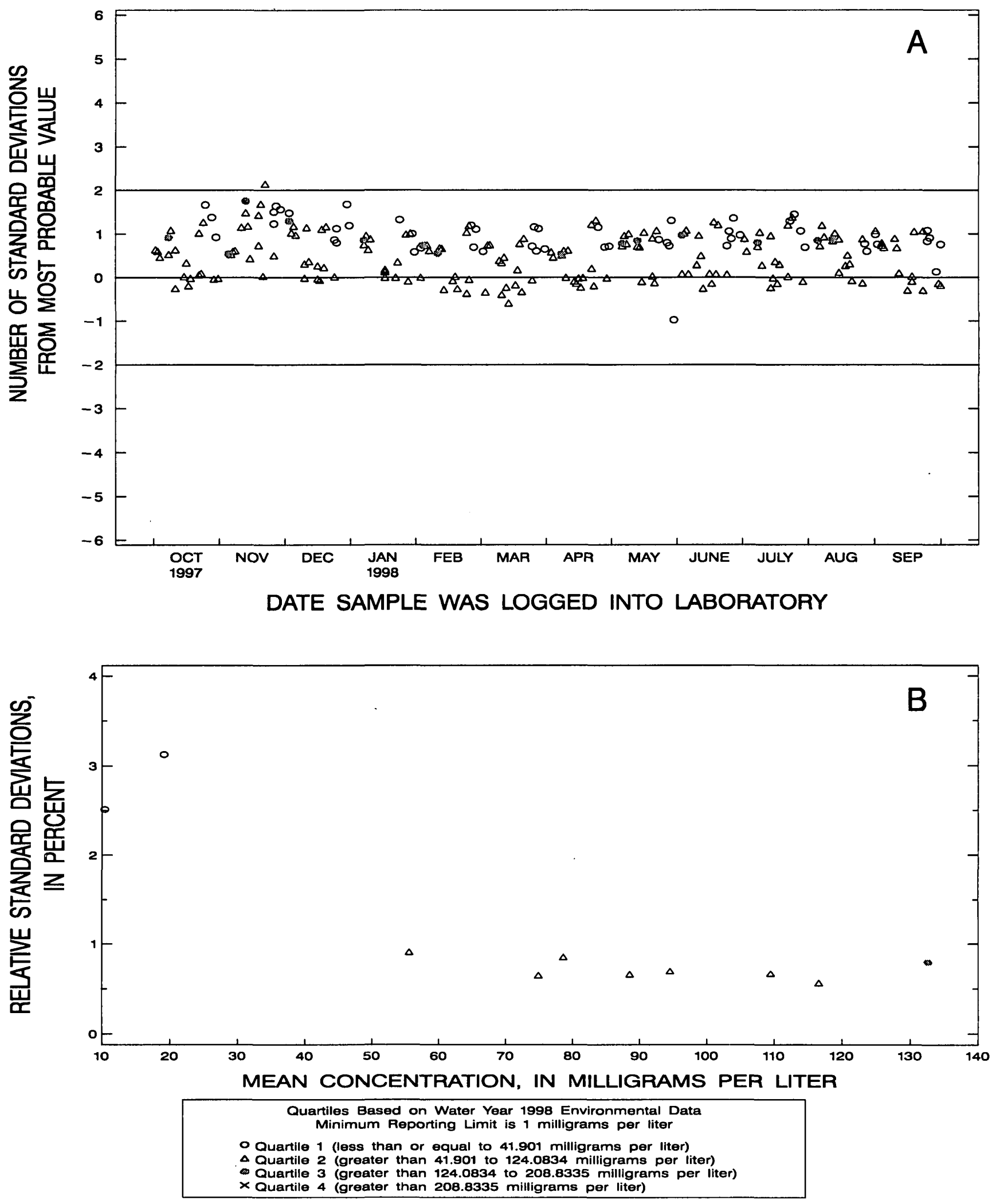

Figure 2. Alkalinity, whole-water recoverable, (electrometric titration) data from the National Water Quality Laboratory. 

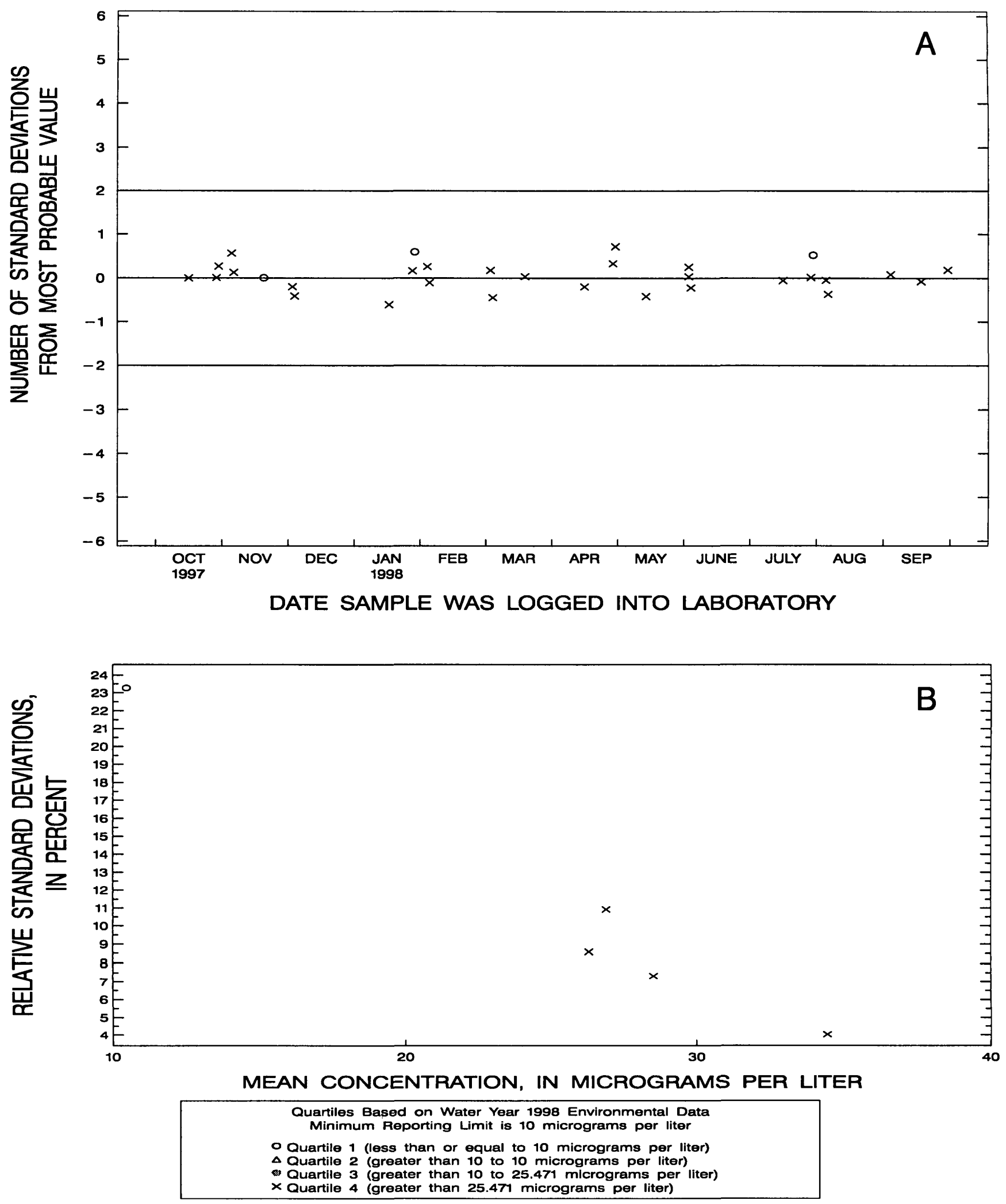

Figure 3. Aluminum, dissolved, (inductively coupled plasma-atomic emission spectrometry) data from the National Water Quality Laboratory. 

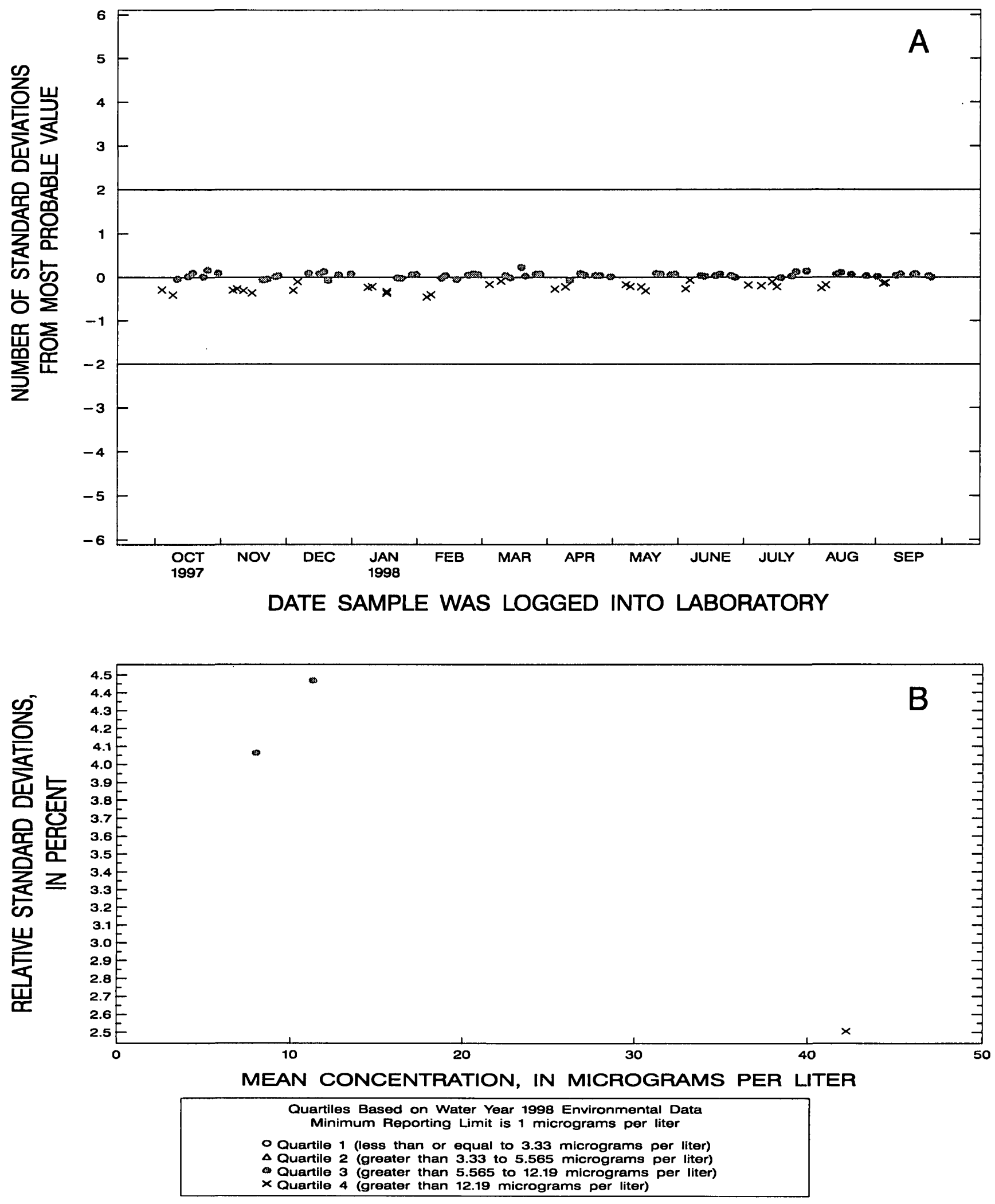

Figure 4. Aluminum, dissolved, (inductively coupled plasma-mass spectrometry) data from the National Water Quality Laboratory. 

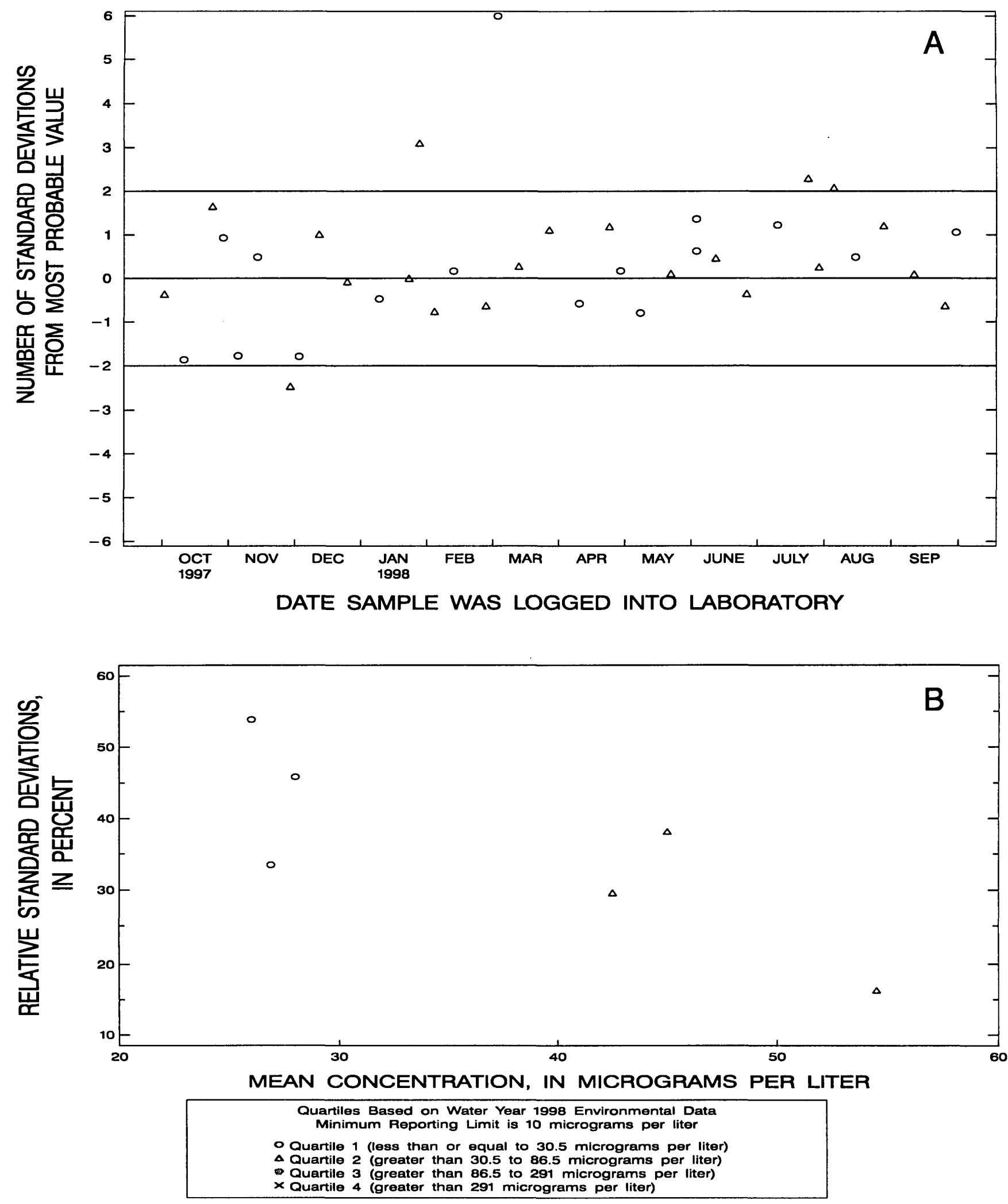

Figure 5. Aluminum, whole-water recoverable, (direct current plasma-atomic emission spectrometry) data from the National Water Quality Laboratory. 


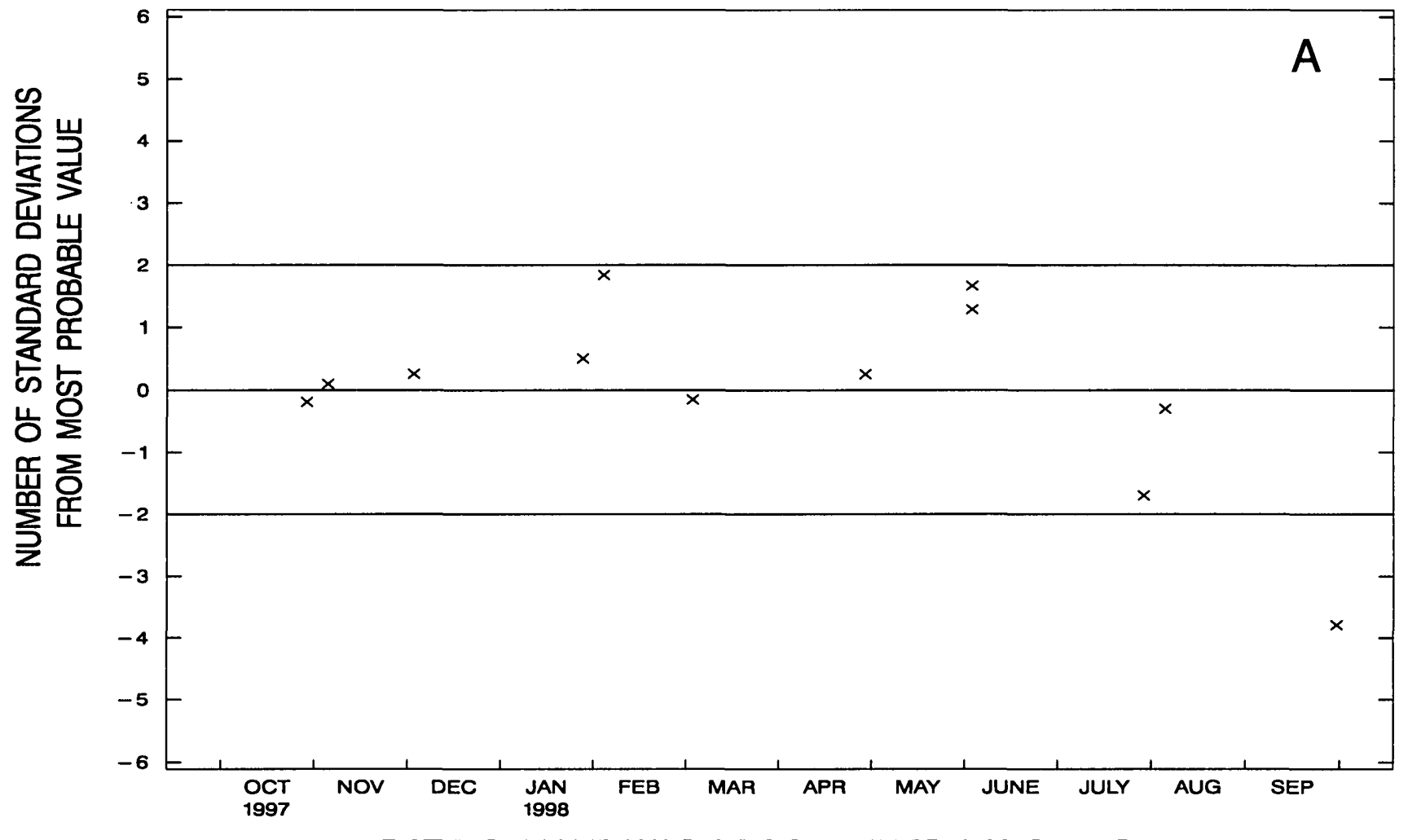

DATE SAMPLE WAS LOGGED INTO LABORATORY

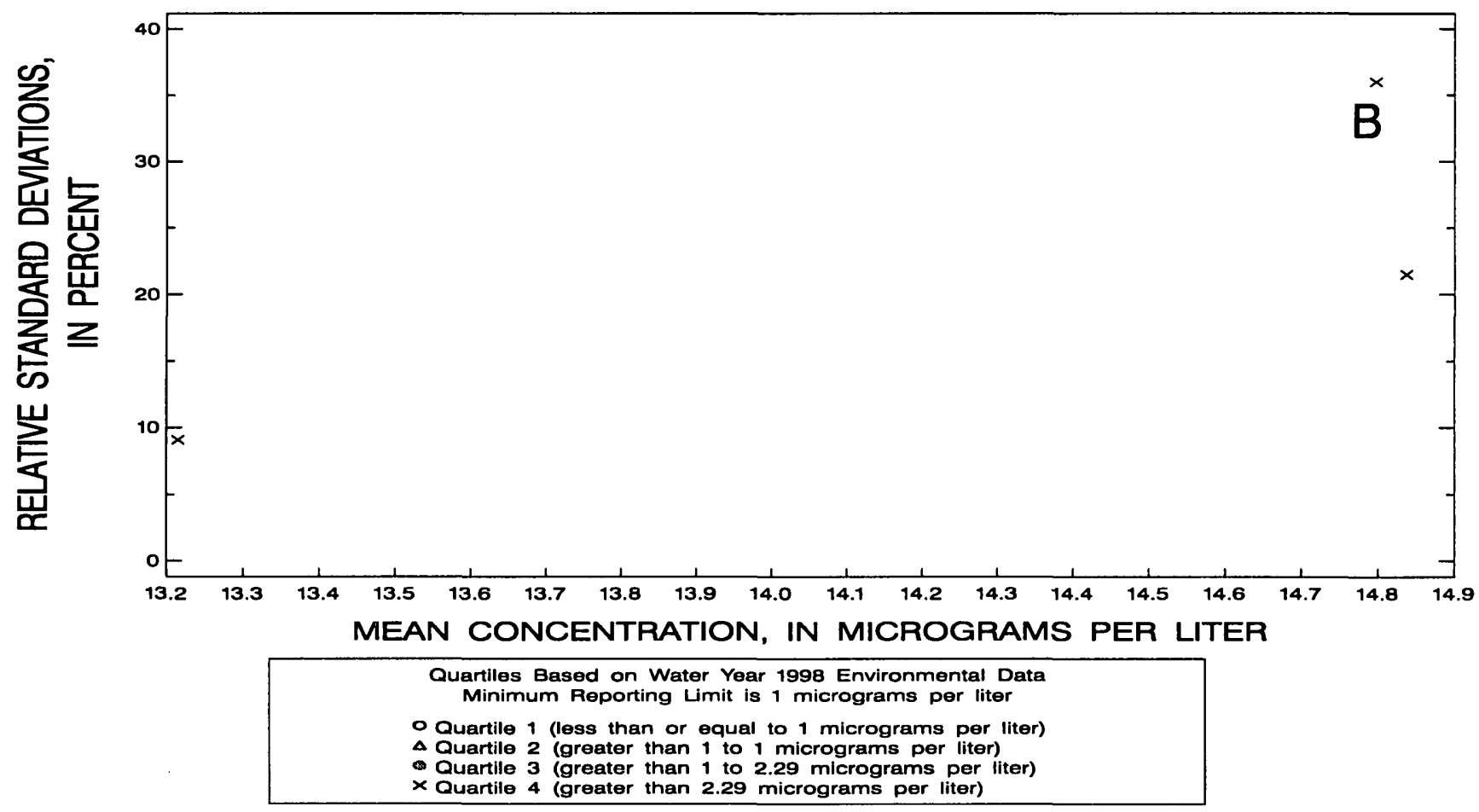

Figure 6. Antimony, dissolved, (hydride generation-atomic absorption spectrophotometry) data from the National Water Quality Laboratory. 

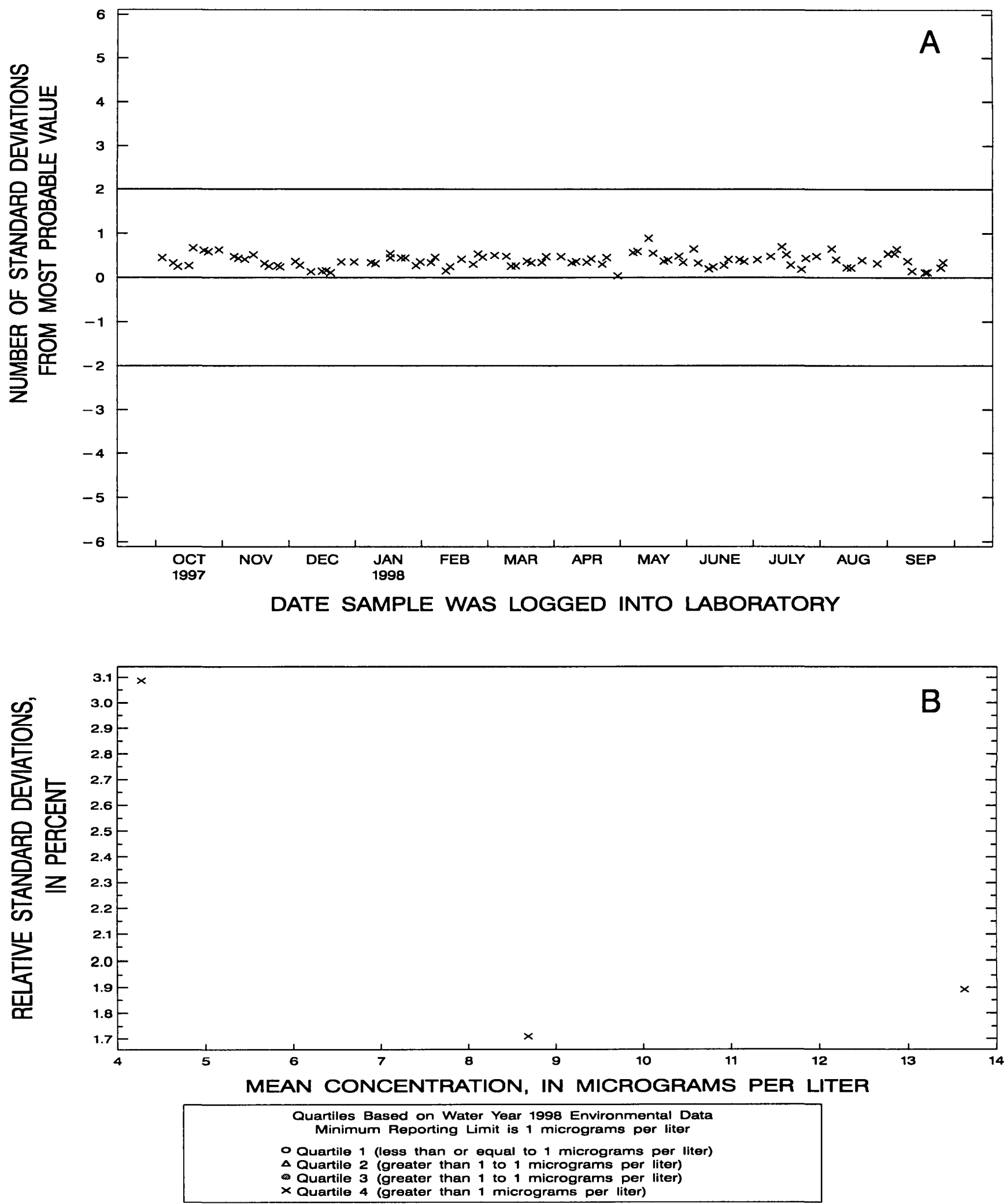

Figure 7. Antimony, dissolved, (inductively coupled plasma-mass spectrometry) data from the National Water Quality Laboratory. 

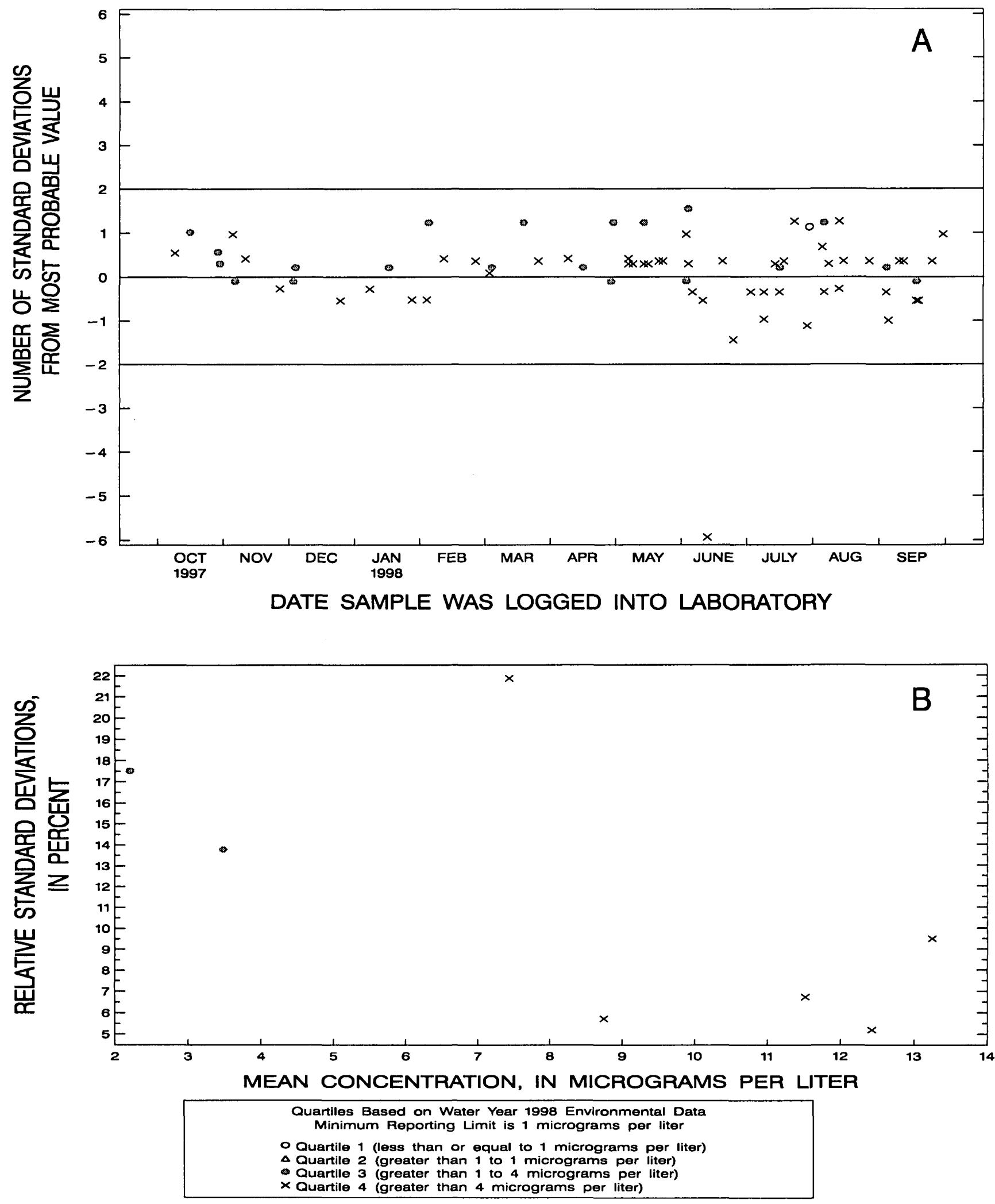

Figure 8. Arsenic, dissolved, (hydride generation-atomic absorption spectrophotometry) data from the National Water Quality Laboratory. 

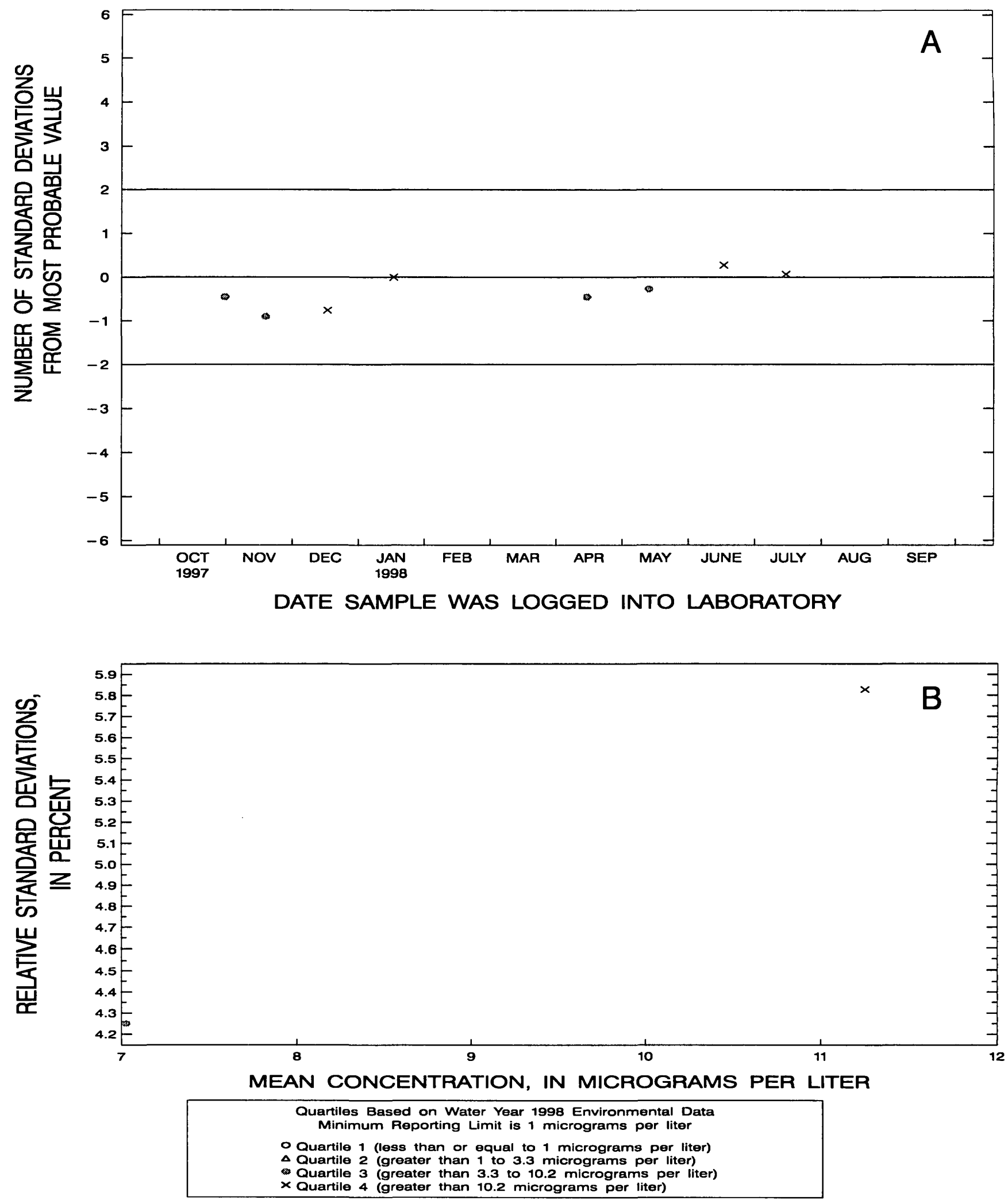

Figure 9. Arsenic, whole-water recoverable, (graphite furnace-atomic absorption spectrophotometry, U.S. Environmental Protection Agency) data from the National Water Quality Laboratory. 

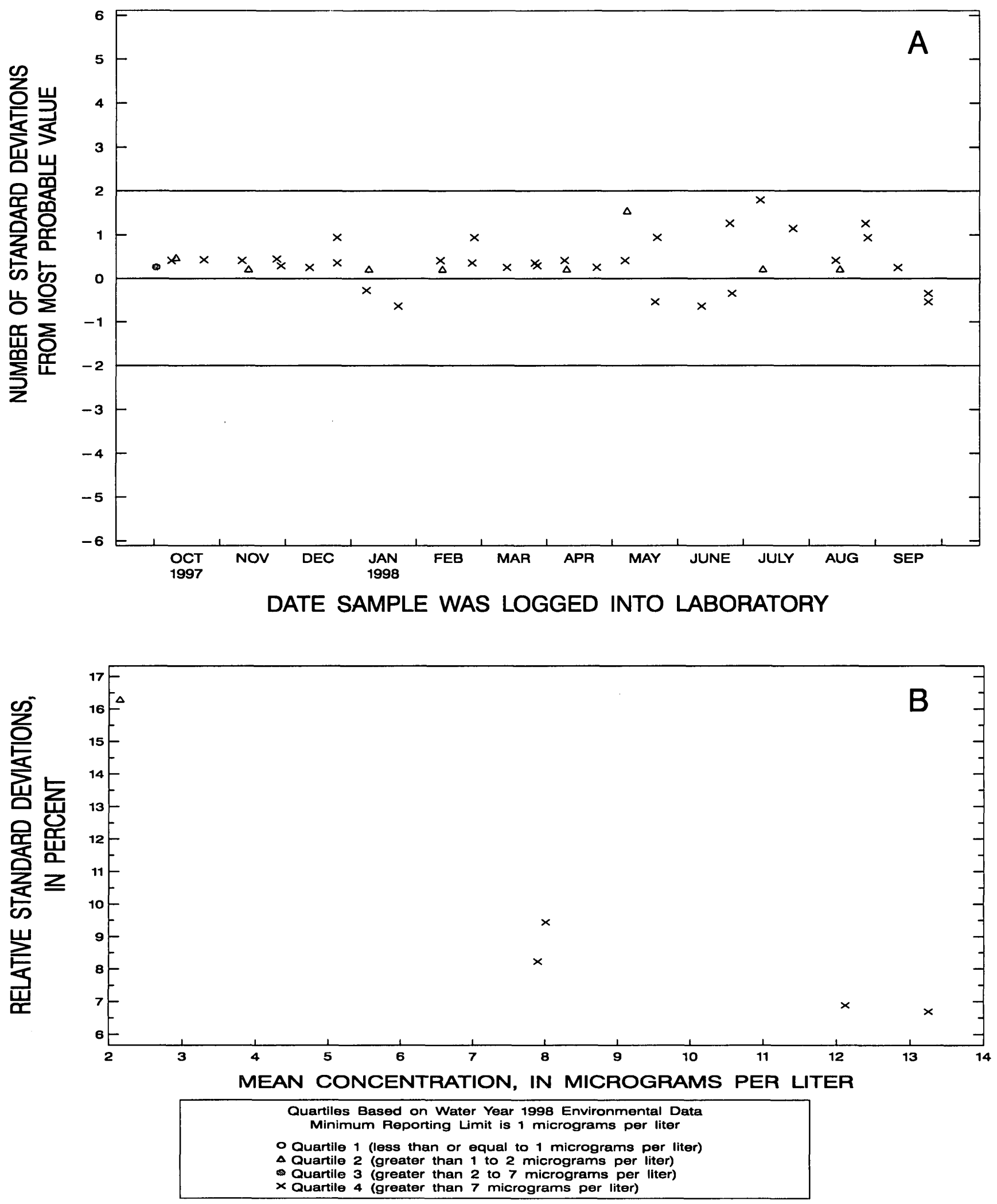

Figure 10. Arsenic, whole-water recoverable, (hydride generation-atomic absorption spectrophotometry) data from the National Water Quality Laboratory. 

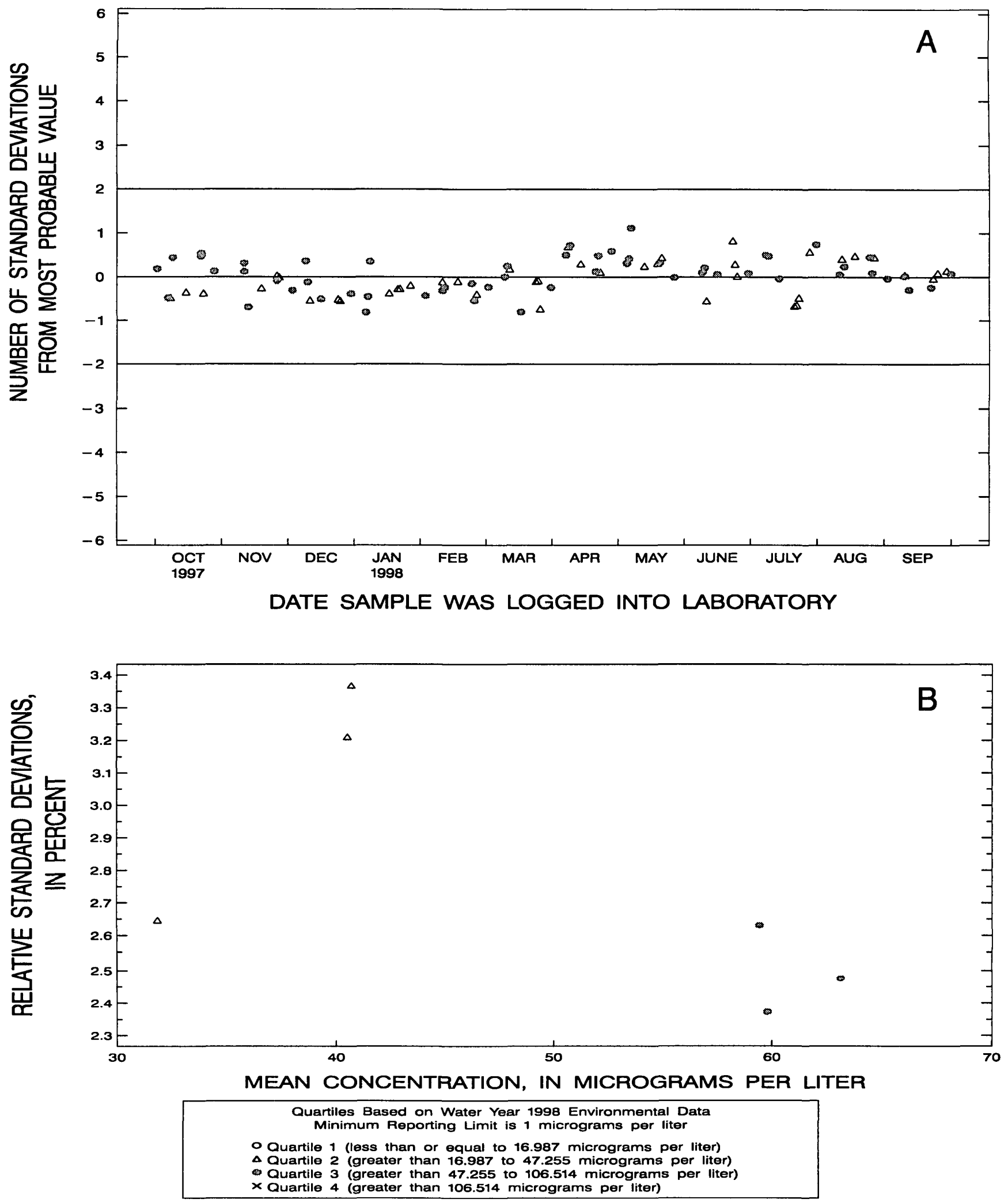

Figure 11. Barium, dissolved, (inductively coupled plasma-atomic emission spectrometry) data from the National Water Quality Laboratory. 

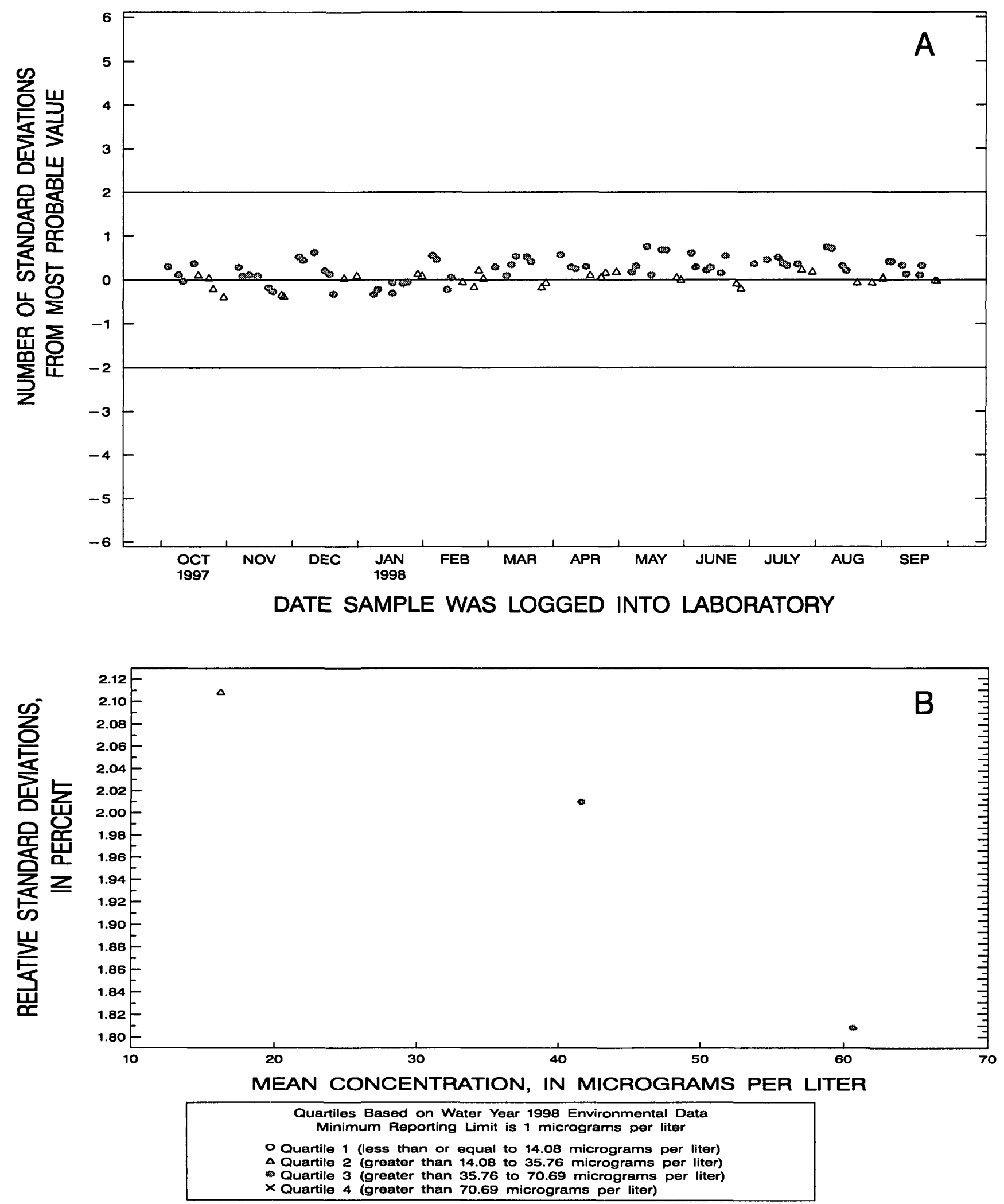

Figure 12. Barium, dissolved, (inductively coupled plasma-mass spectrometry) data from the National Water Quality Laboratory. 

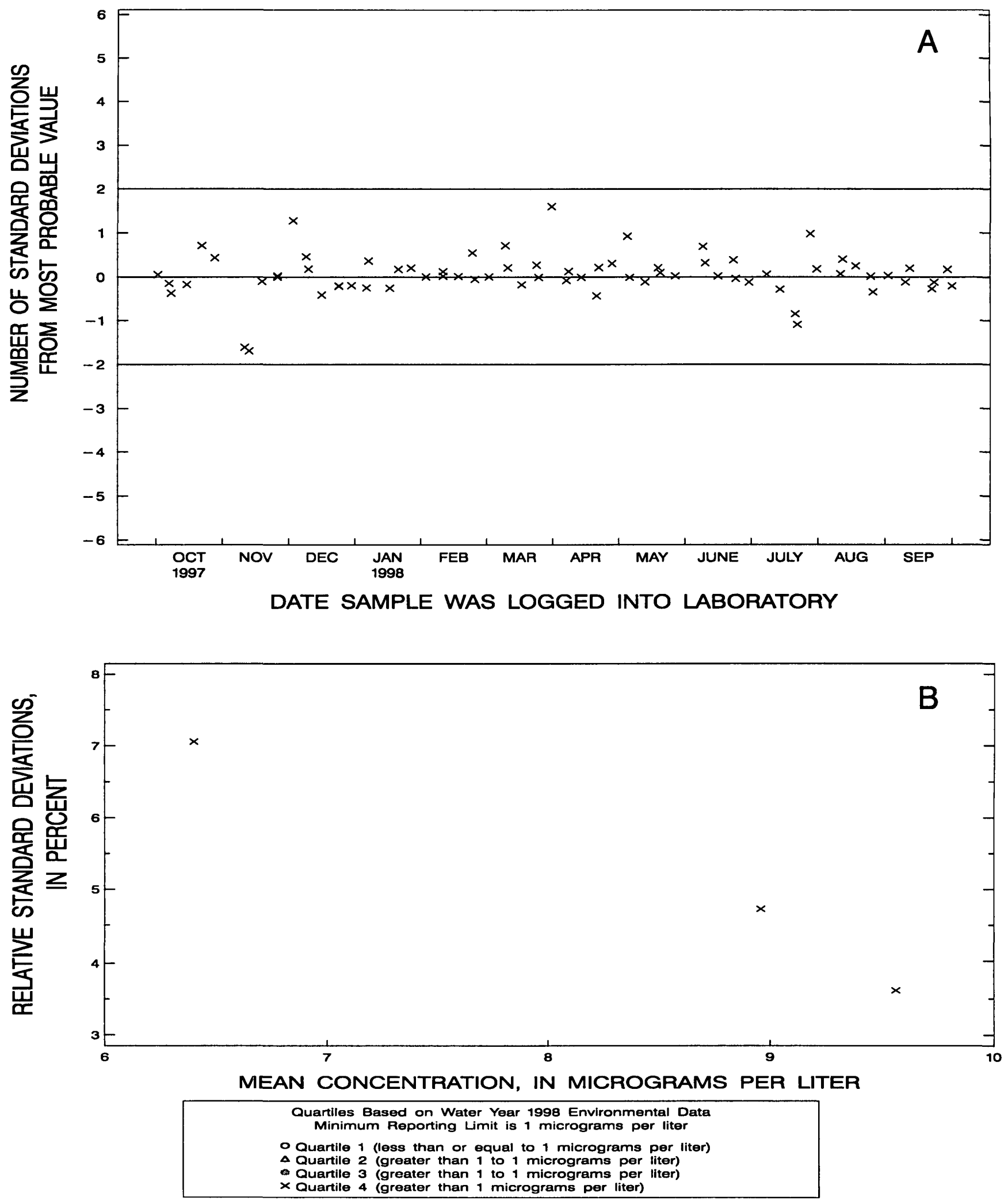

Figure 13. Beryllium, dissolved, (inductively coupled plasma-atomic emission spectrometry) data from the National Water Quality Laboratory. 

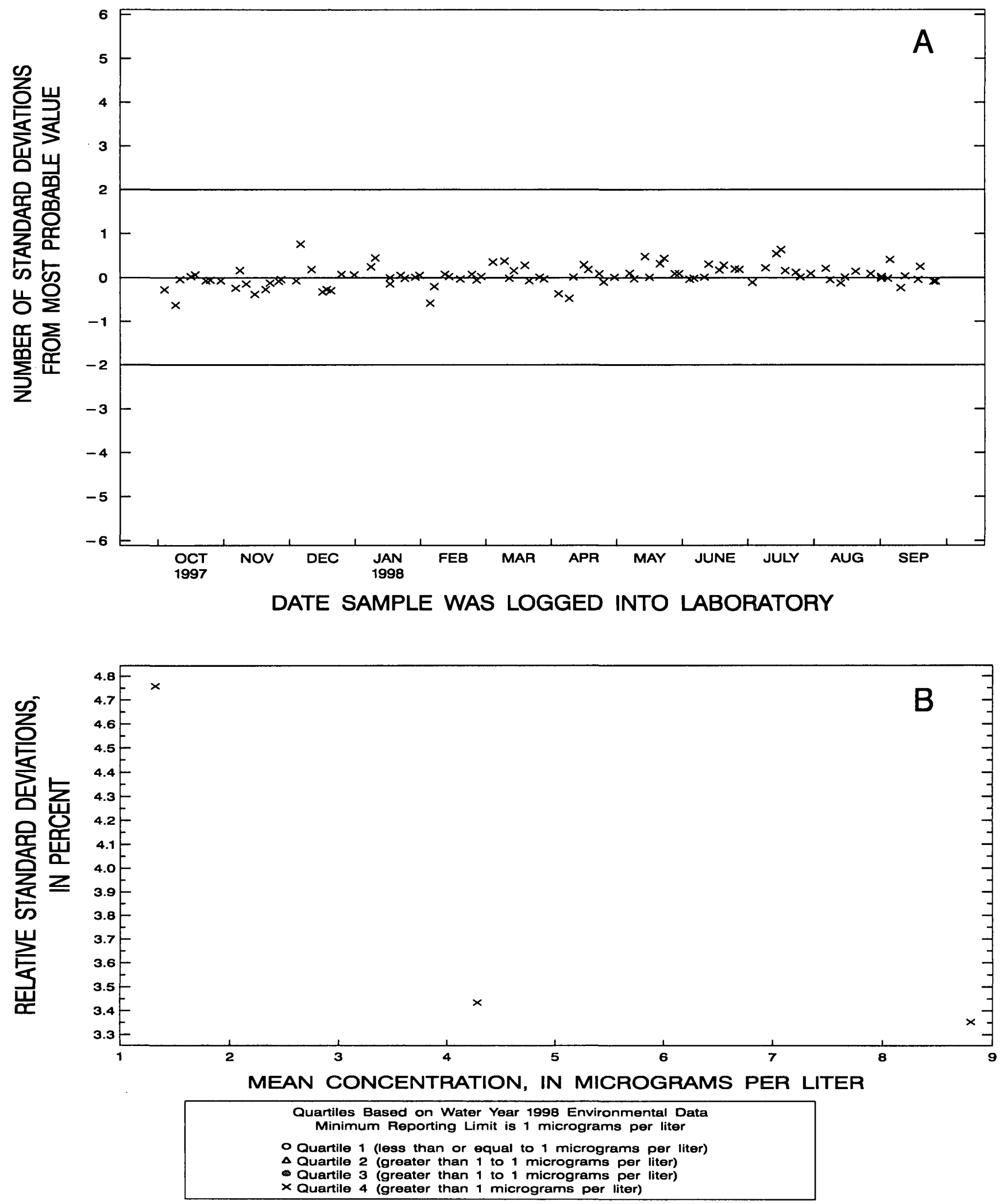

Figure 14. Beryllium, dissolved, (inductively coupled plasma-mass spectrometry) data from the National Water Quality Laboratory. 

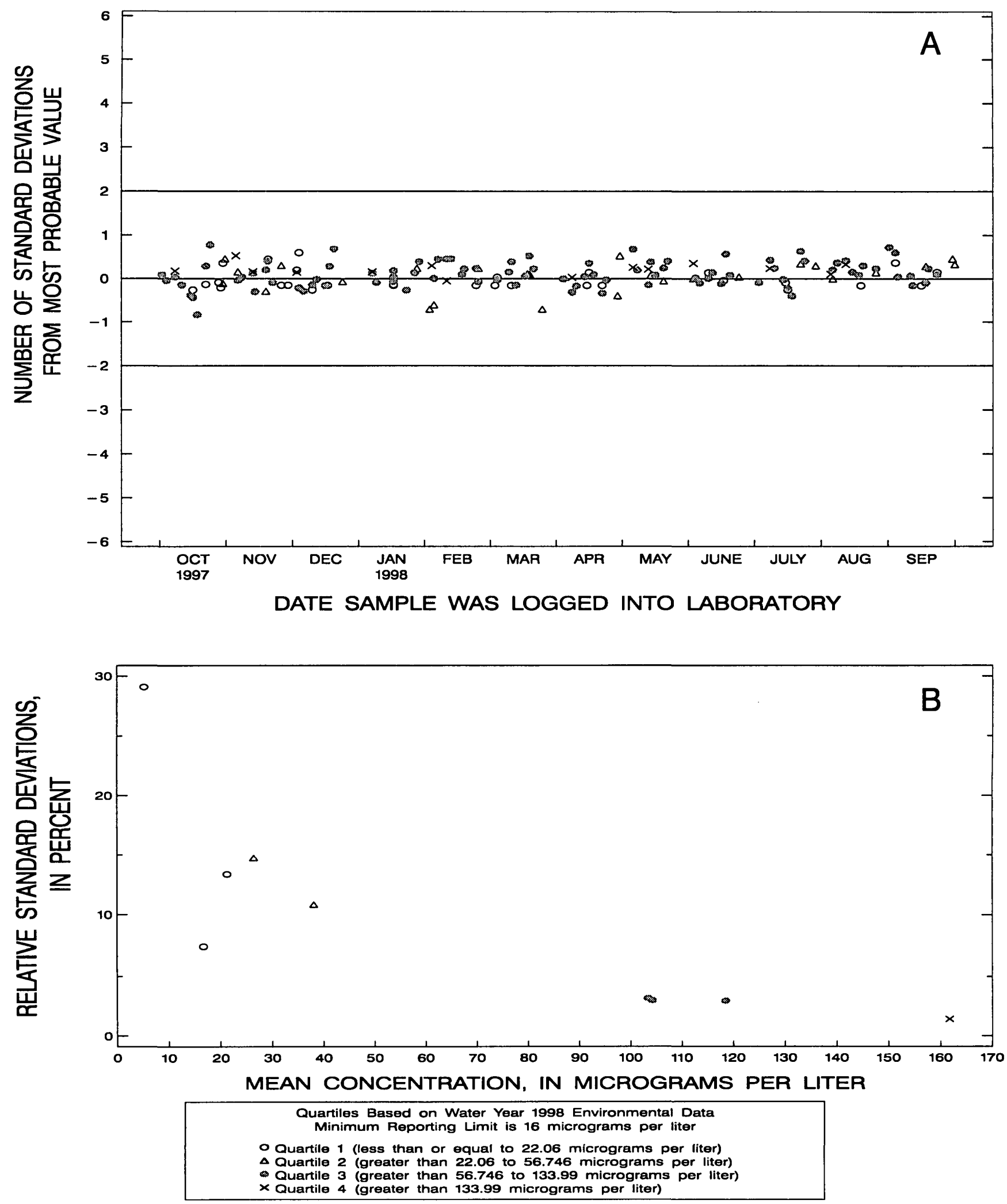

Figure 15. Boron, dissolved, (inductively coupled plasma-atomic emission spectrometry) data from the National Water Quality Laboratory. 

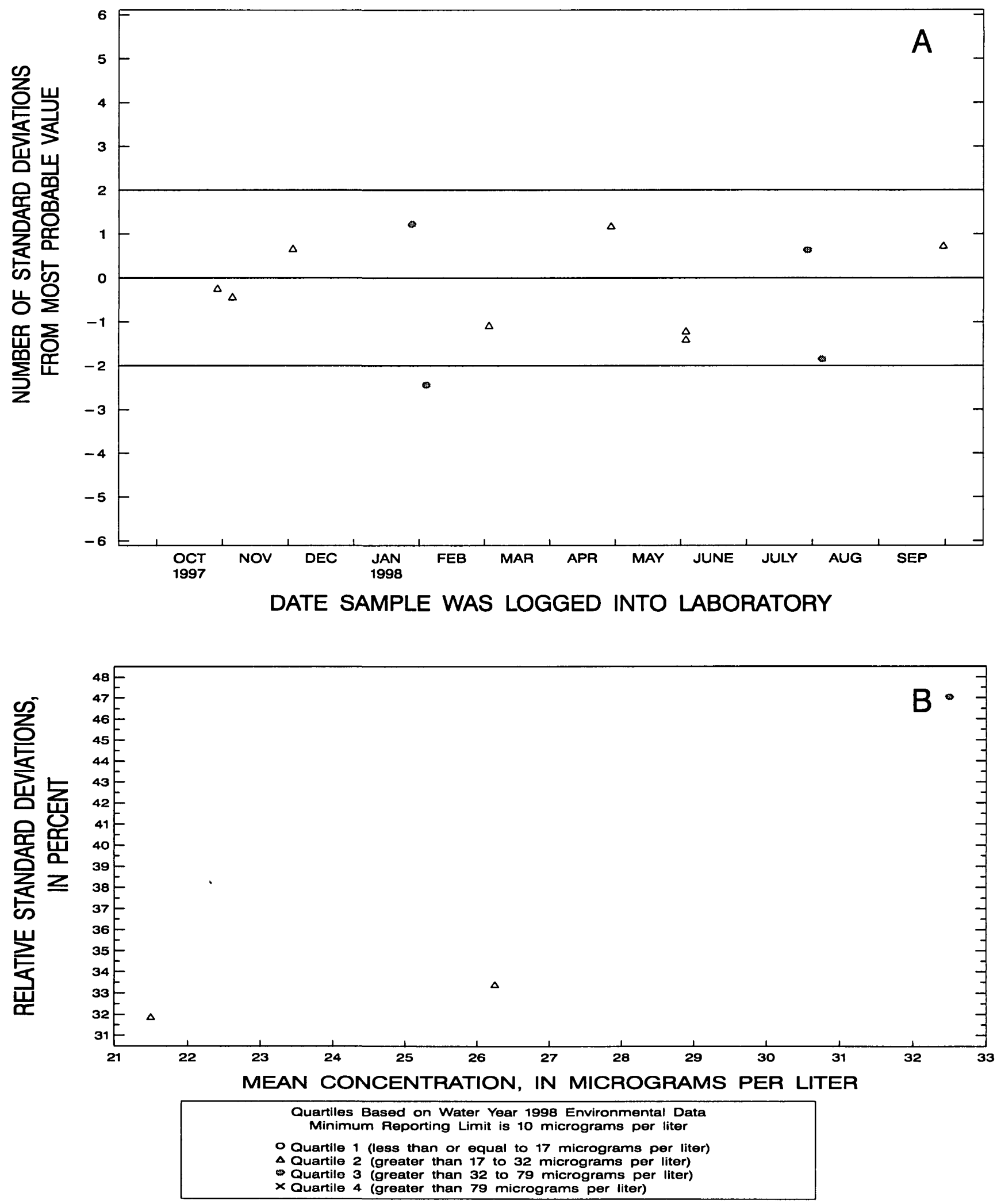

Figure 16. Boron, whole-water recoverable, (direct current plasma-atomic emission spectrometry) data from the National Water Quality Laboratory. 

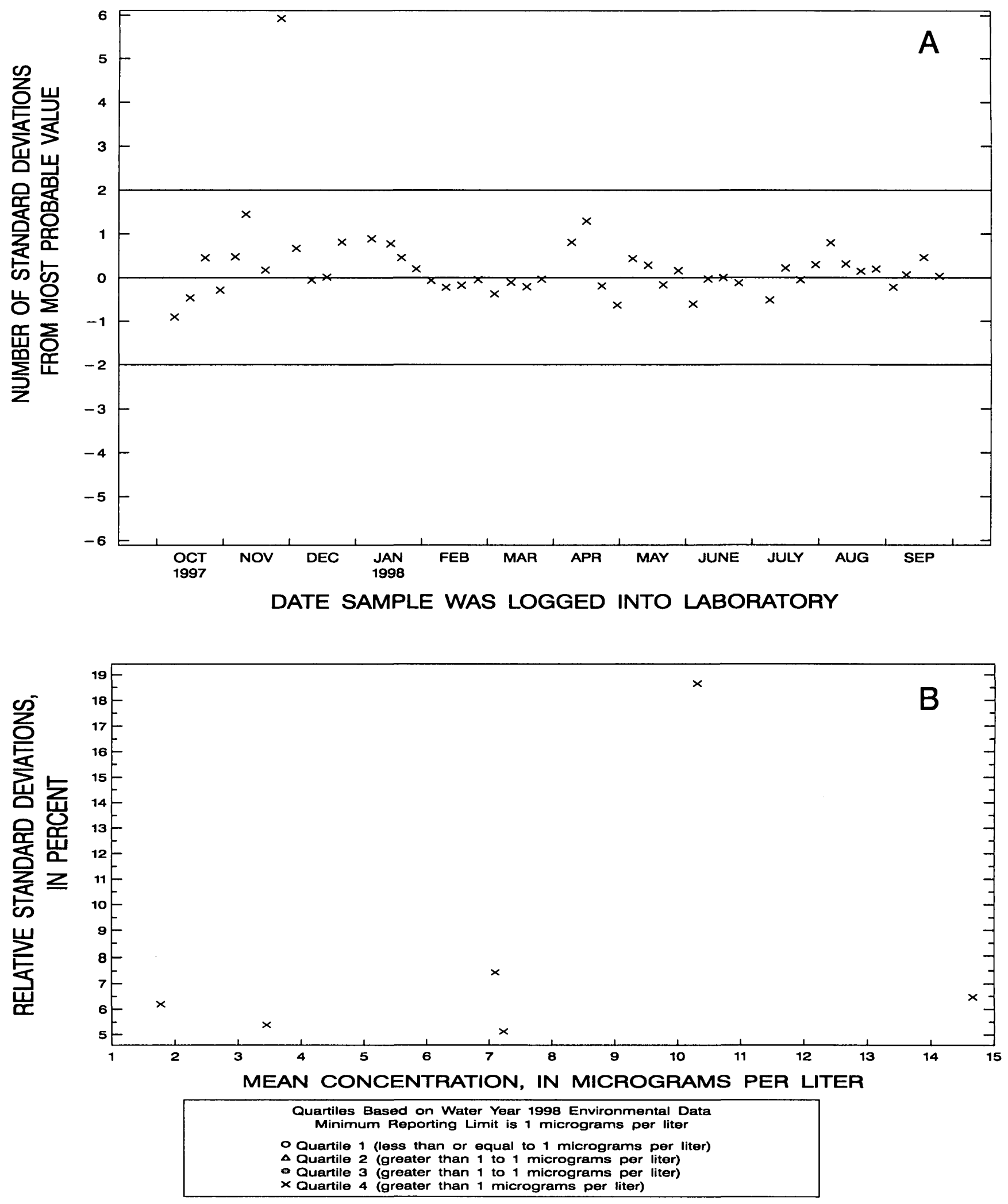

Figure 17. Cadmium, dissolved, (graphite furnace-atomic absorption spectrophotometry) data from the National Water Quality Laboratory. 

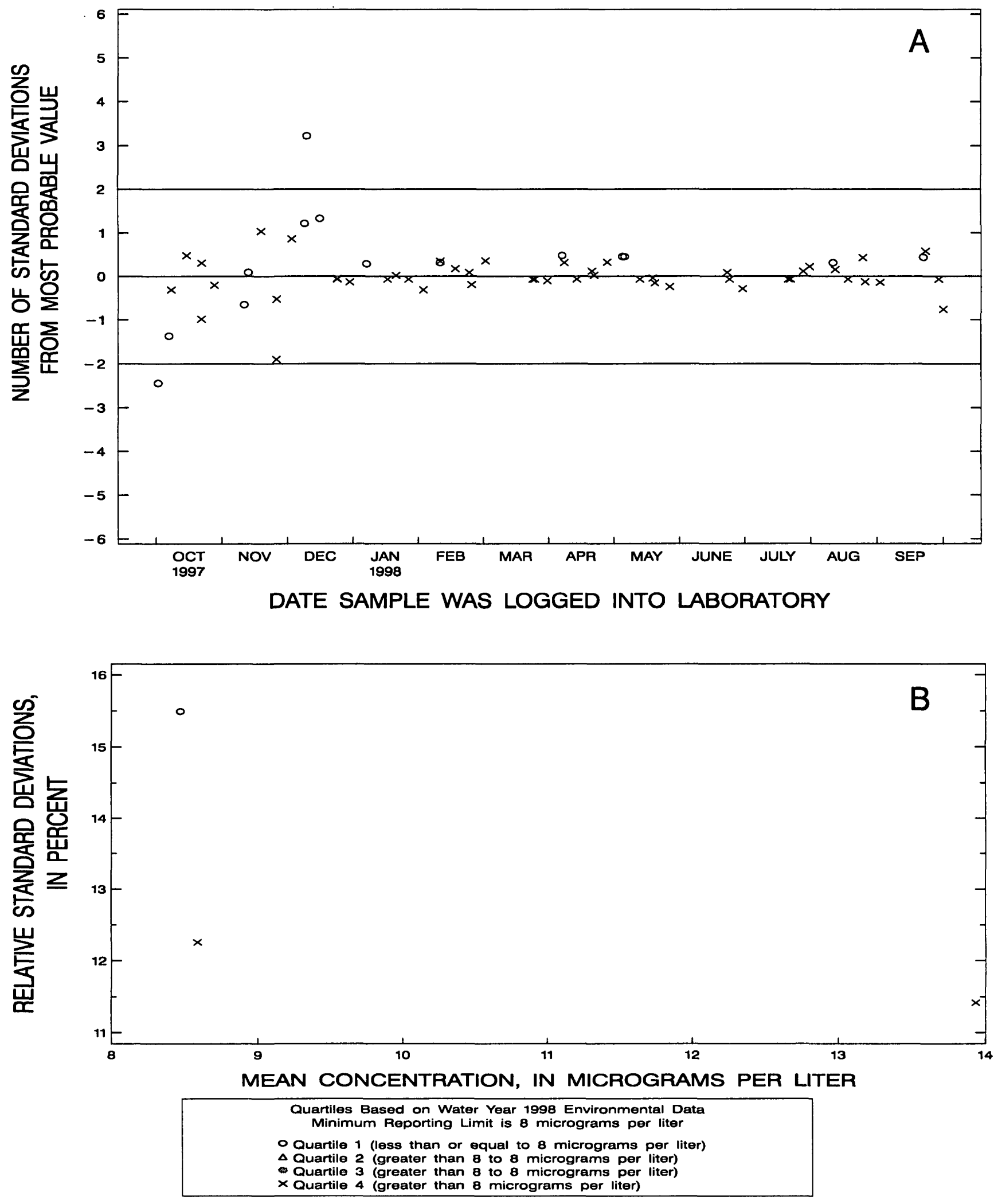

Figure 18. Cadmium, dissolved, (inductively coupled plasma-atomic emission spectrometry) data from the National Water Quality Laboratory. 

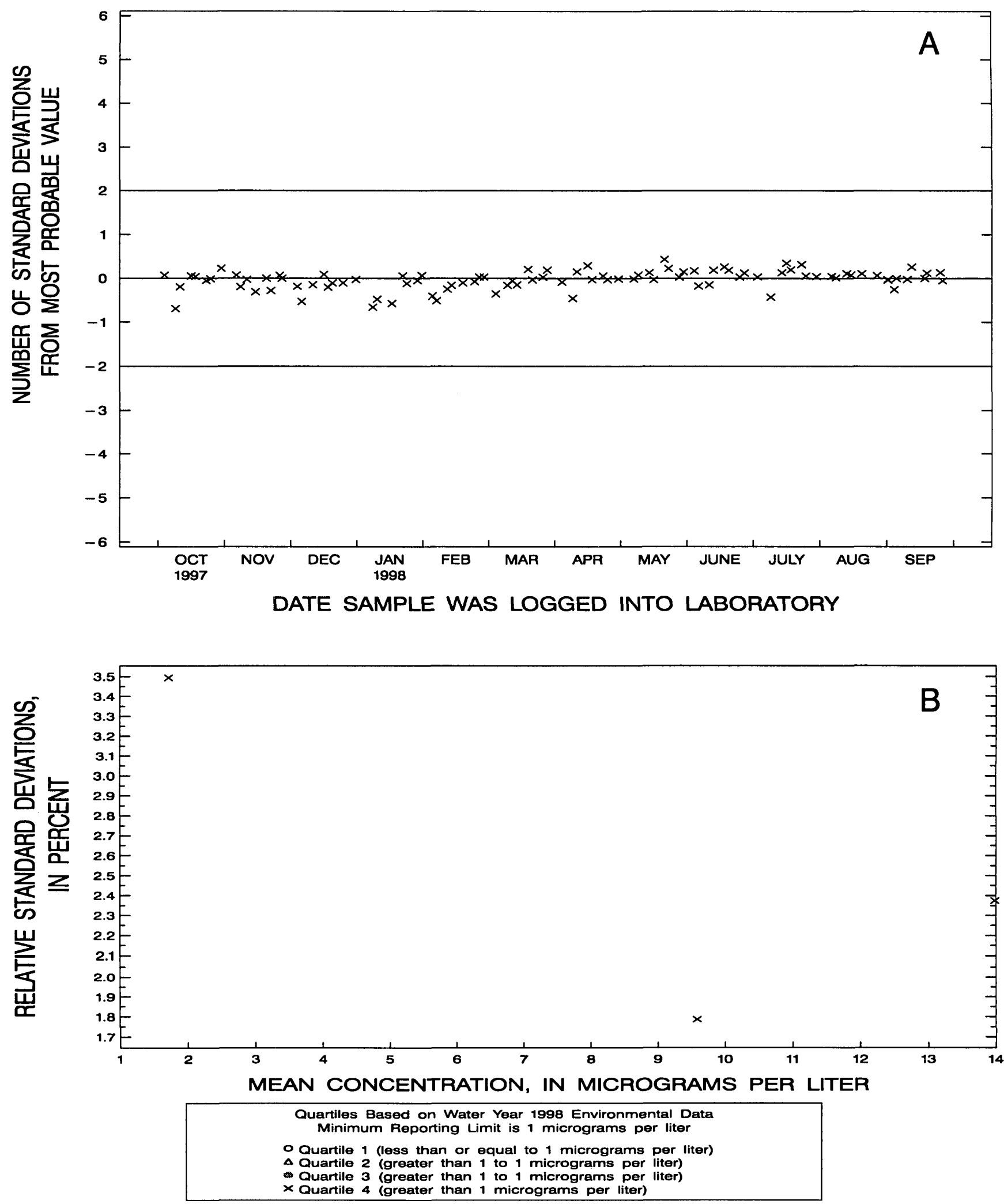

Figure 19. Cadmium, dissolved, (inductively coupled plasma-mass spectrometry) data from the National Water Quality Laboratory. 

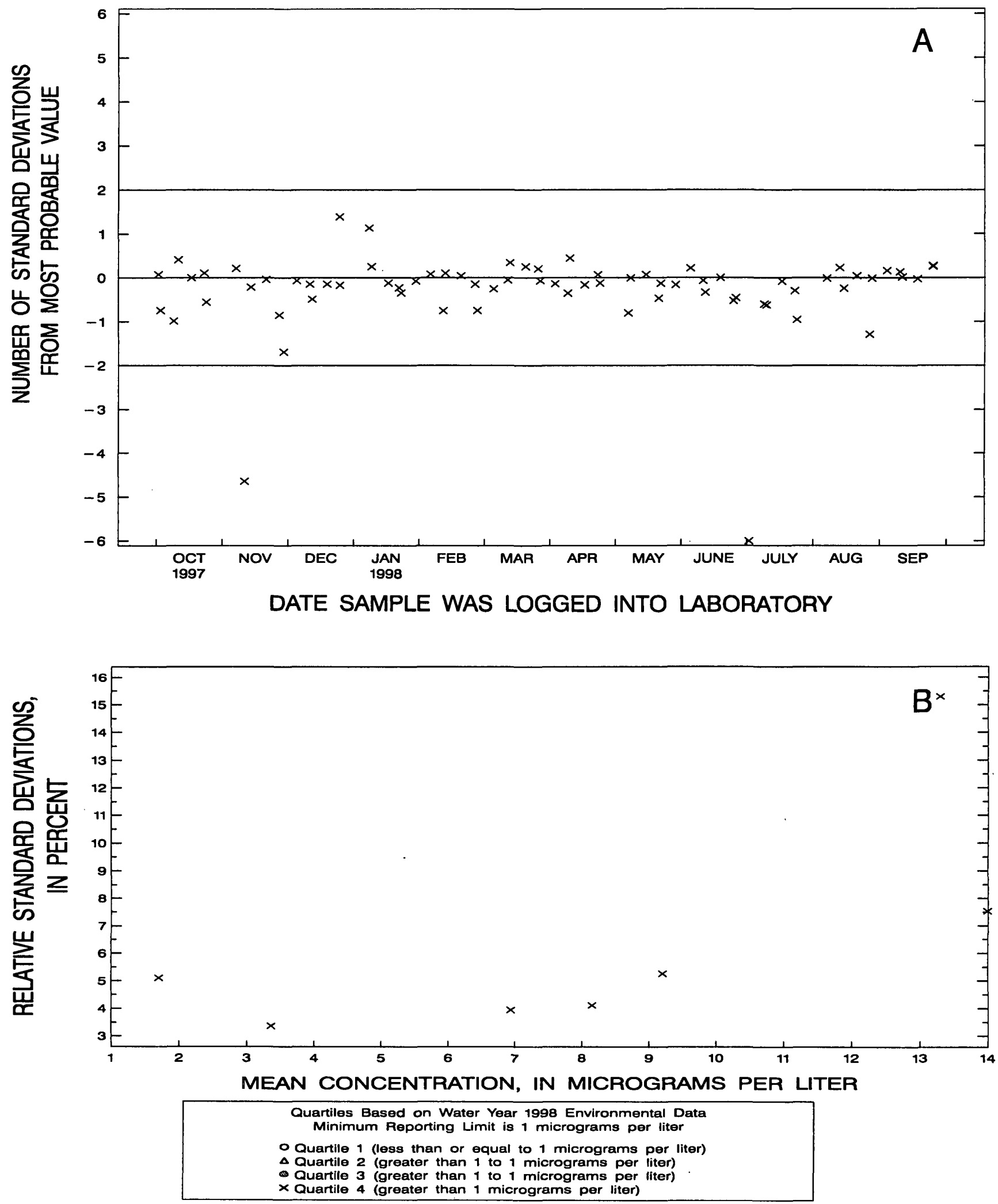

Figure 20. Cadmium, whole-water recoverable, (graphite furnace-atomic absorption spectrophotometry) data from the National Water Quality Laboratory. 

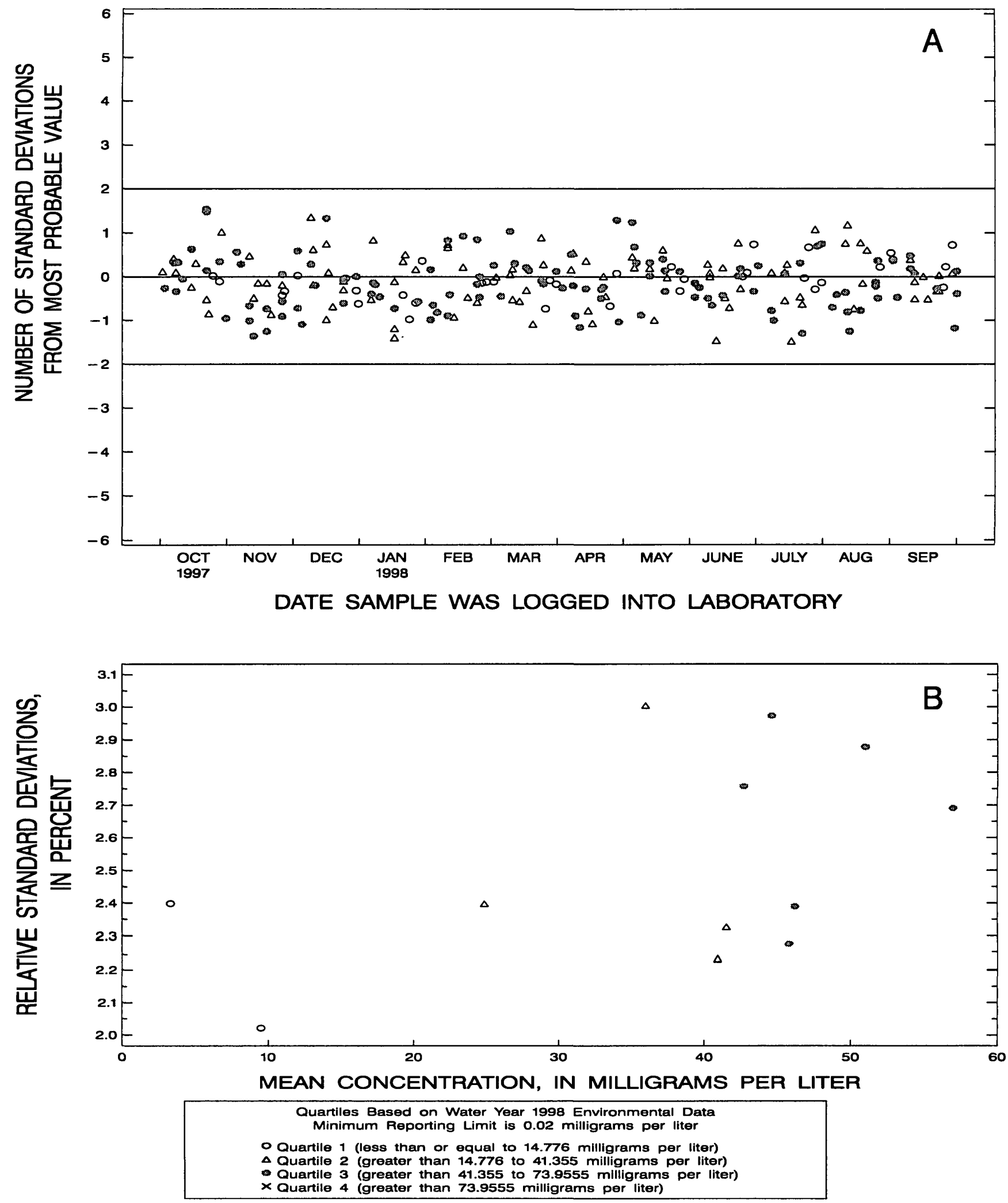

Figure 21. Calcium, dissolved, (inductively coupled plasma-atomic emission spectrometry) data from the National Water Quality Laboratory. 

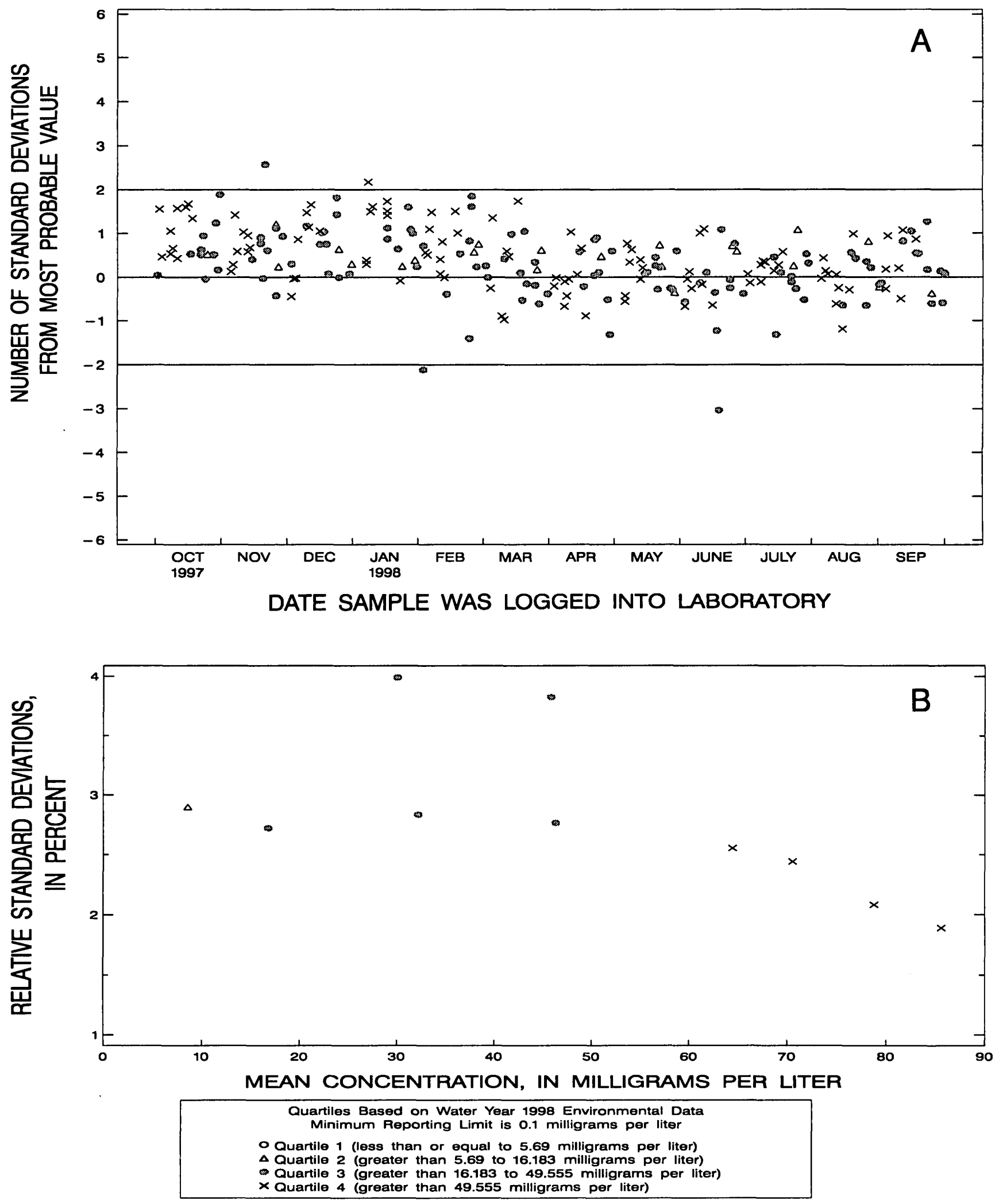

Figure 22. Chloride, dissolved, (ion chromatography) data from the National Water Quality Laboratory. 

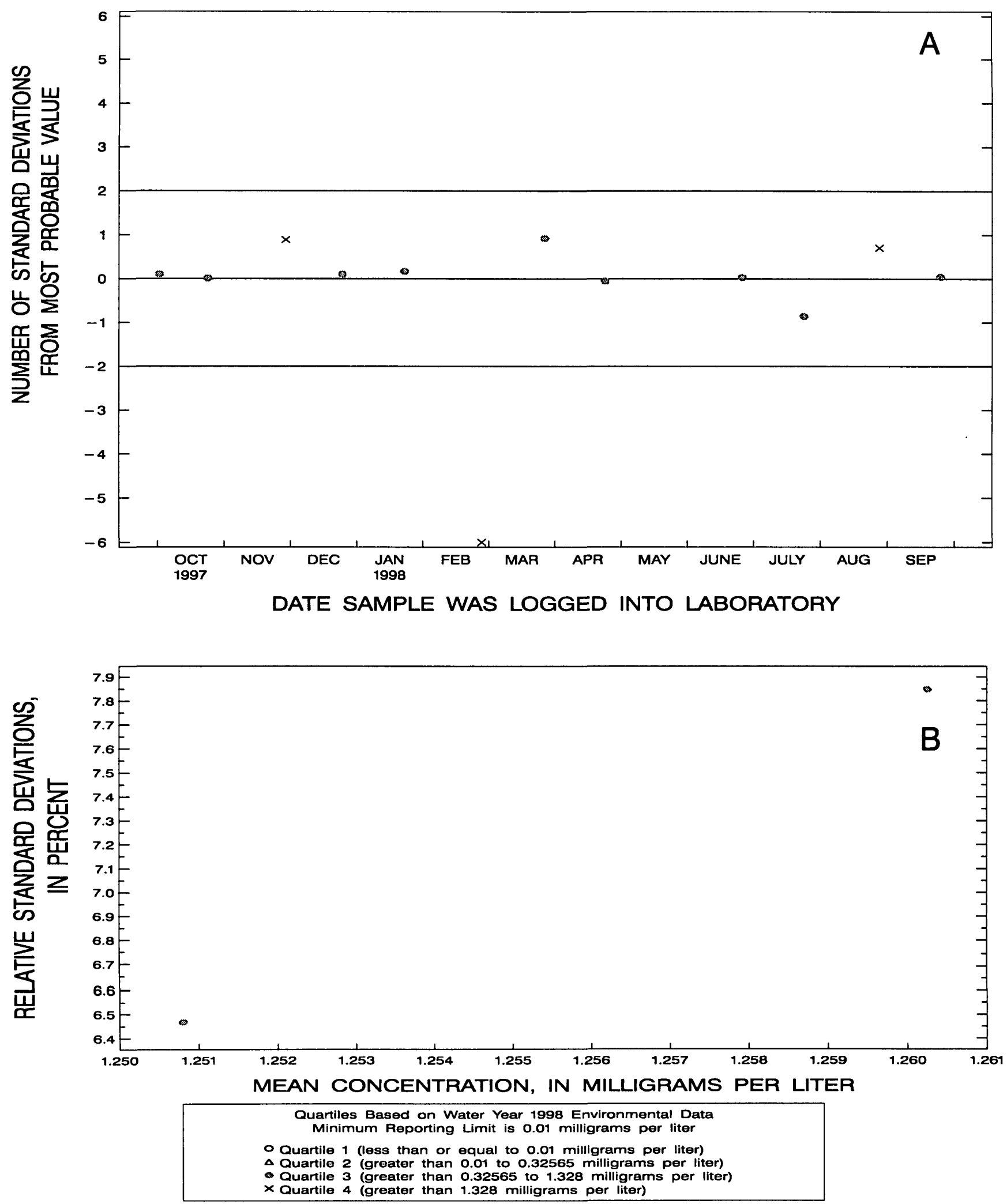

Figure 23. Chloride, dissolved, (ion chromatography, low level) data from the National Water Quality Laboratory. 

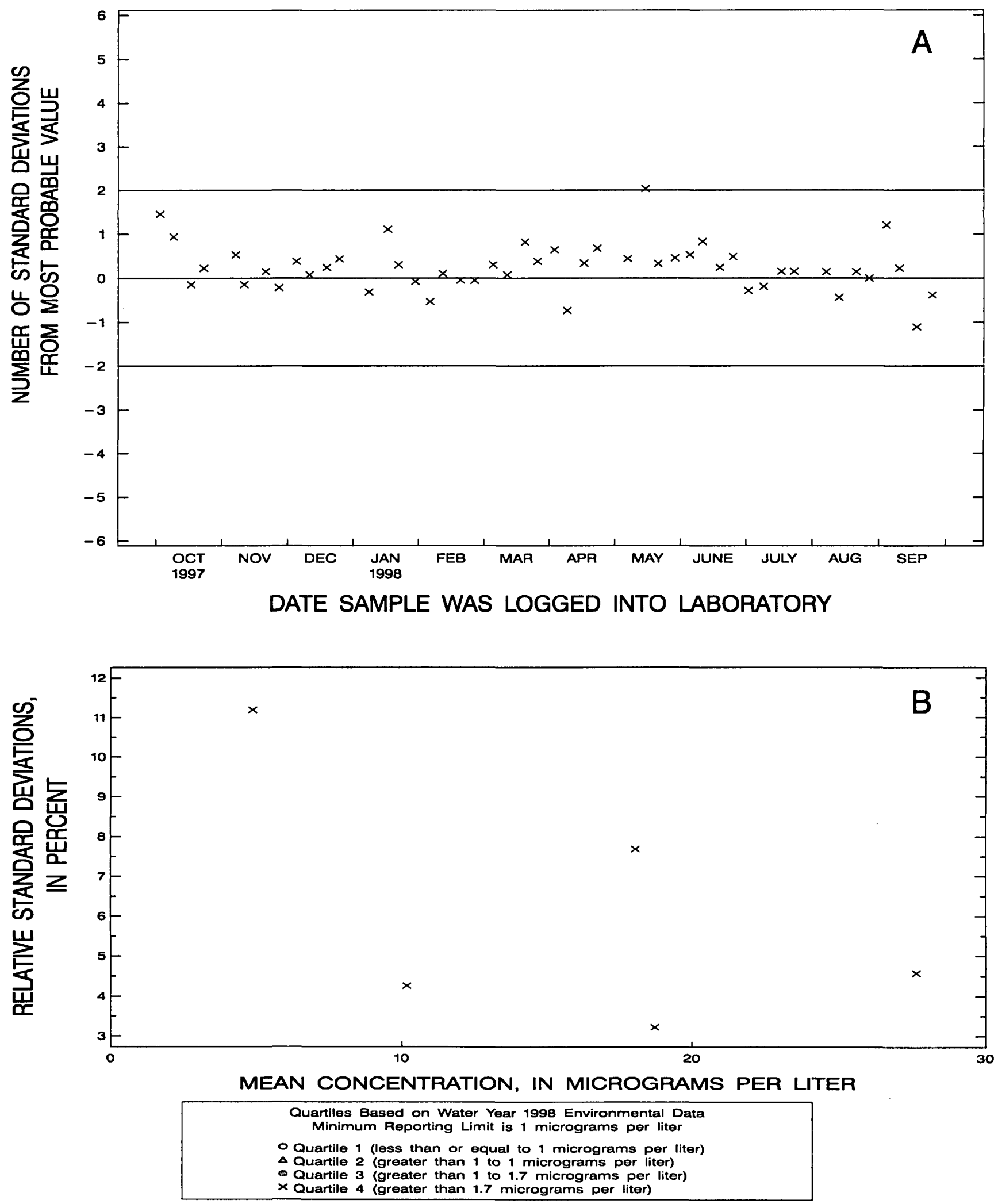

Figure 24. Chromium, dissolved, (graphite furnace-atomic absorption spectrophotometry) data from the National Water Quality Laboratory. 

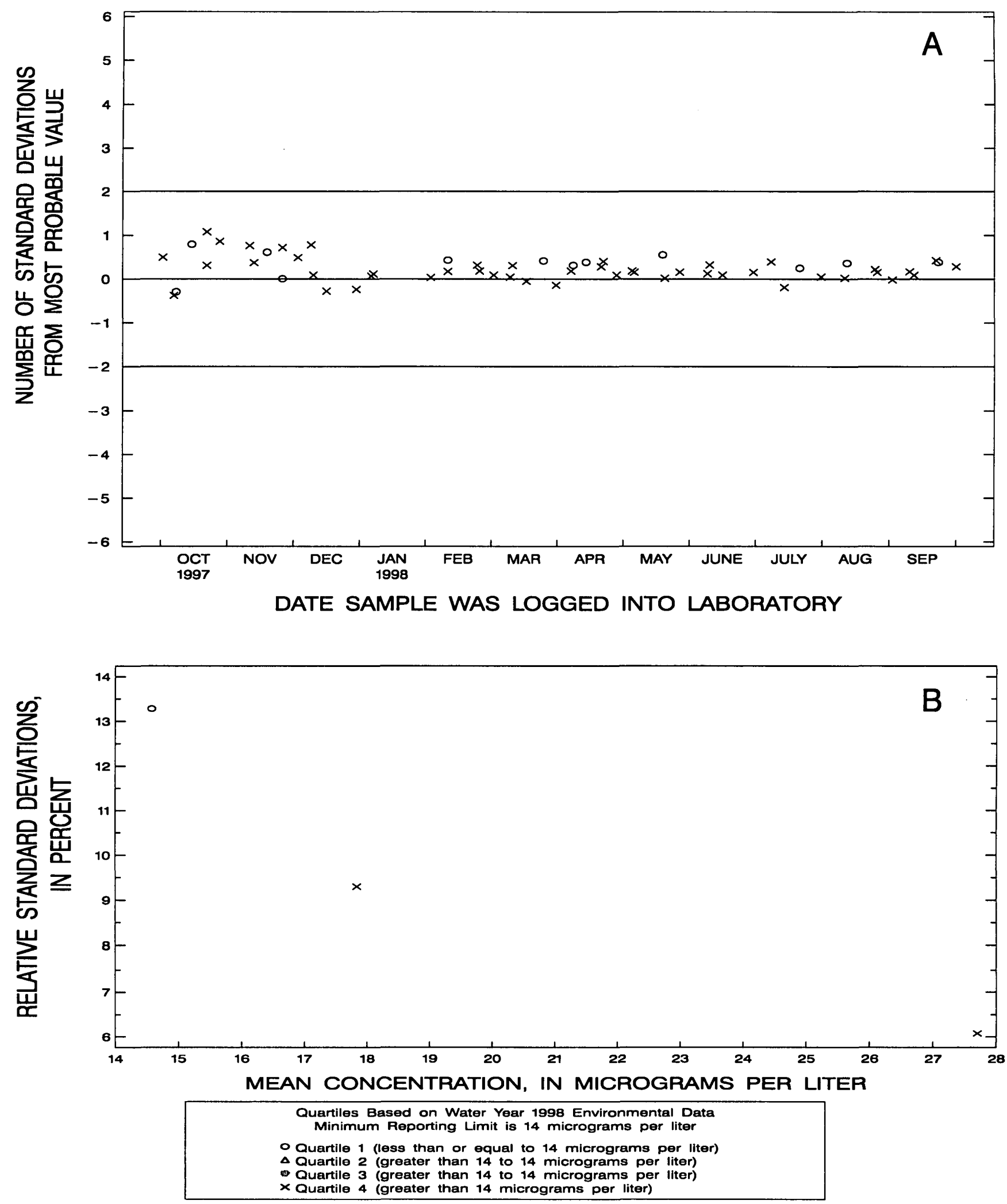

Figure 25. Chromium, dissolved, (inductively coupled plasma-atomic emission spectrometry) data from the National Water Quality Laboratory. 

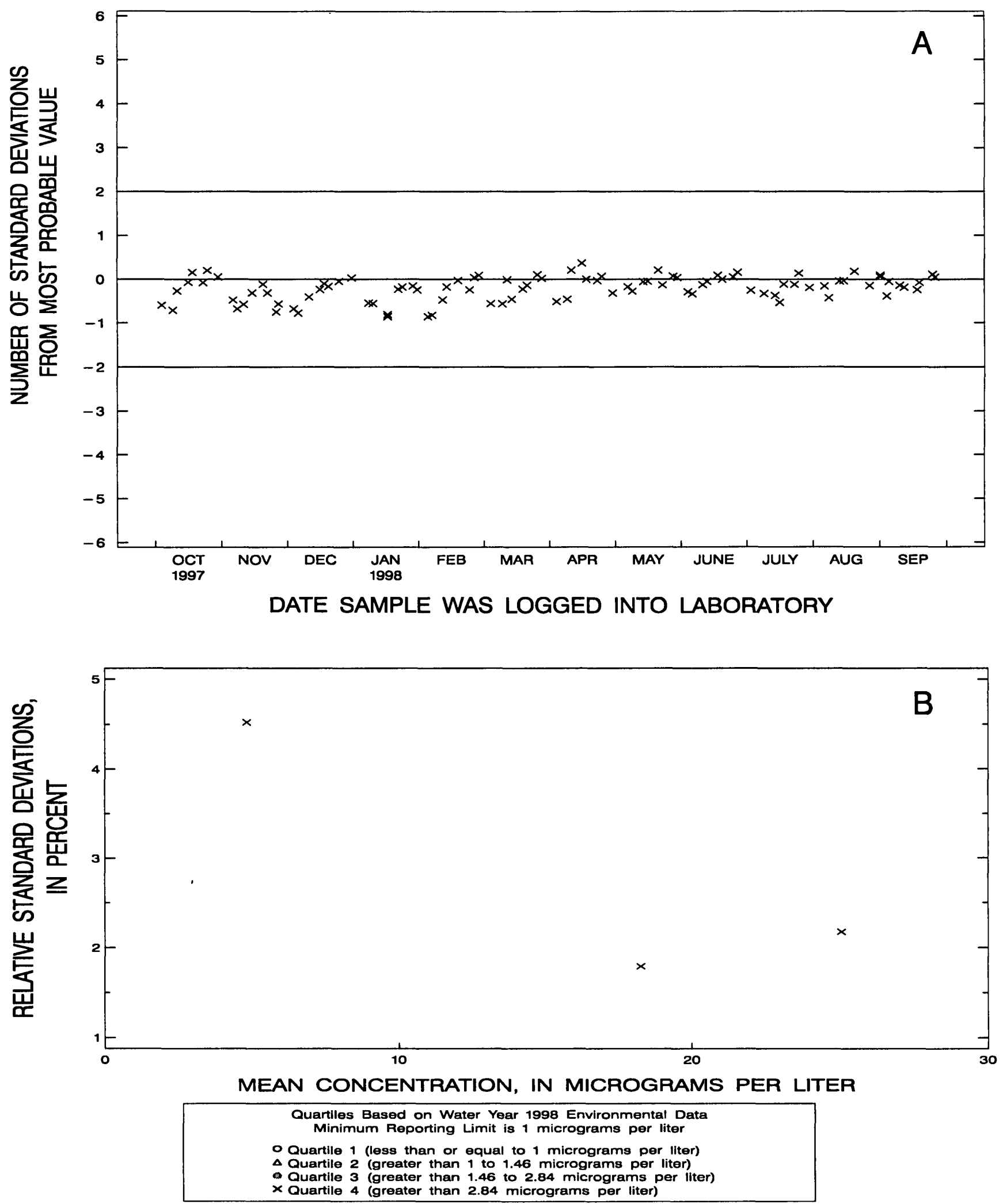

Figure 26. Chromium, dissolved, (inductively coupled plasma-mass spectrometry) data from the National Water Quality Laboratory. 

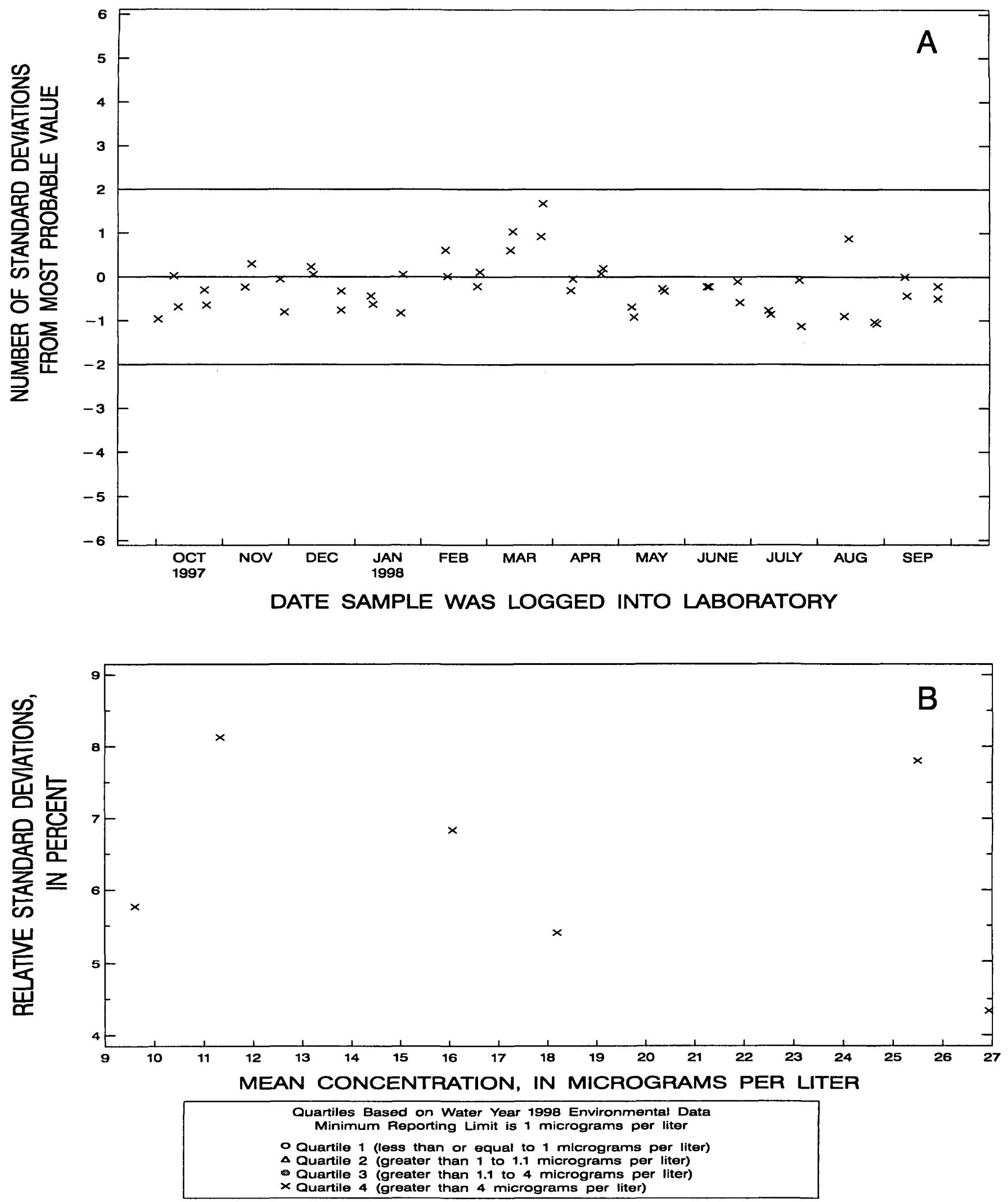

Figure 27. Chromium, whole-water recoverable, (graphite furnace-atomic absorption spectrophotometry) data from the National Water Quality Laboratory. 

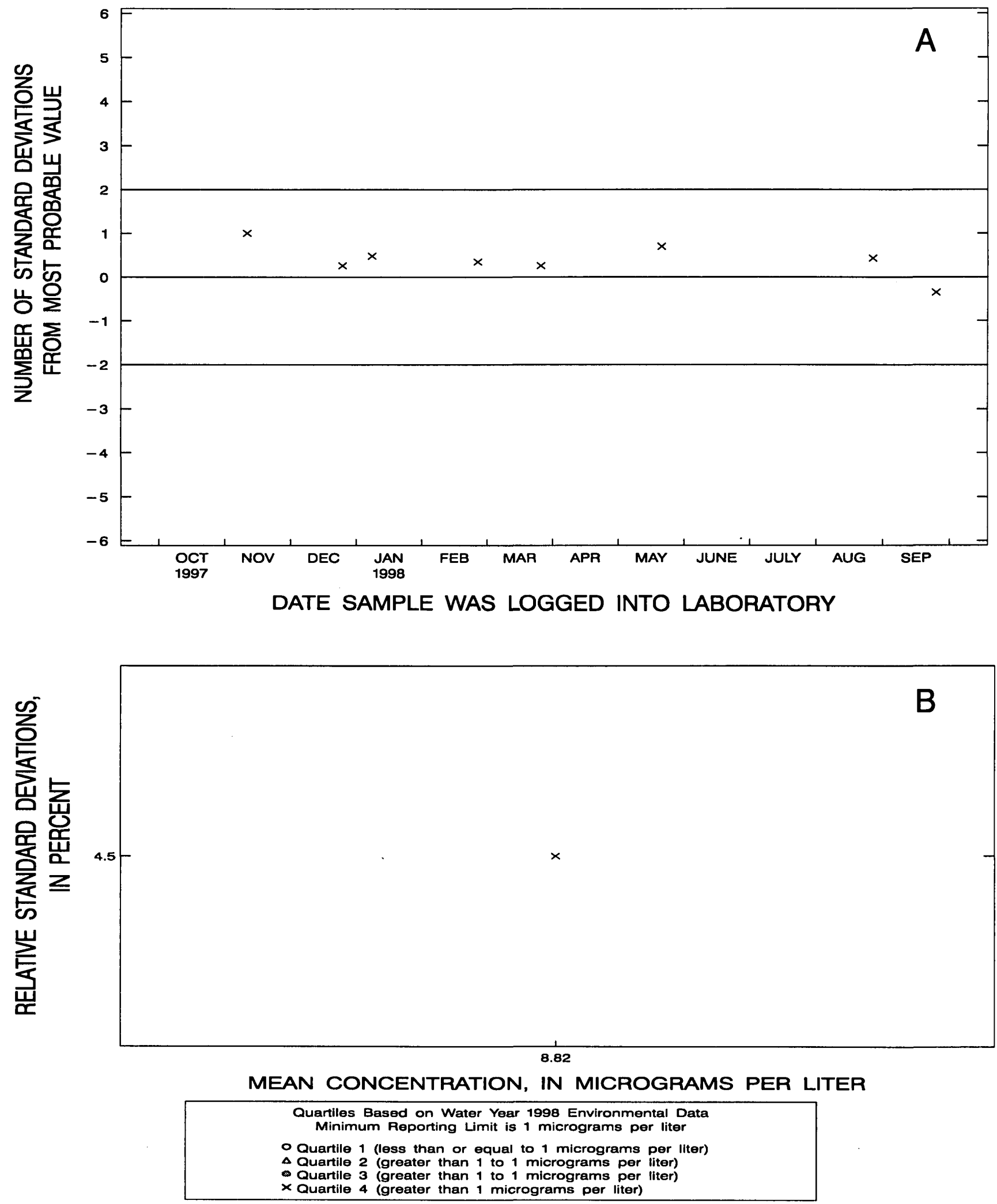

Figure 28. Cobalt, dissolved, (graphite furnace-atomic absorption spectrophotometry) data from the National Water Quality Laboratory. 

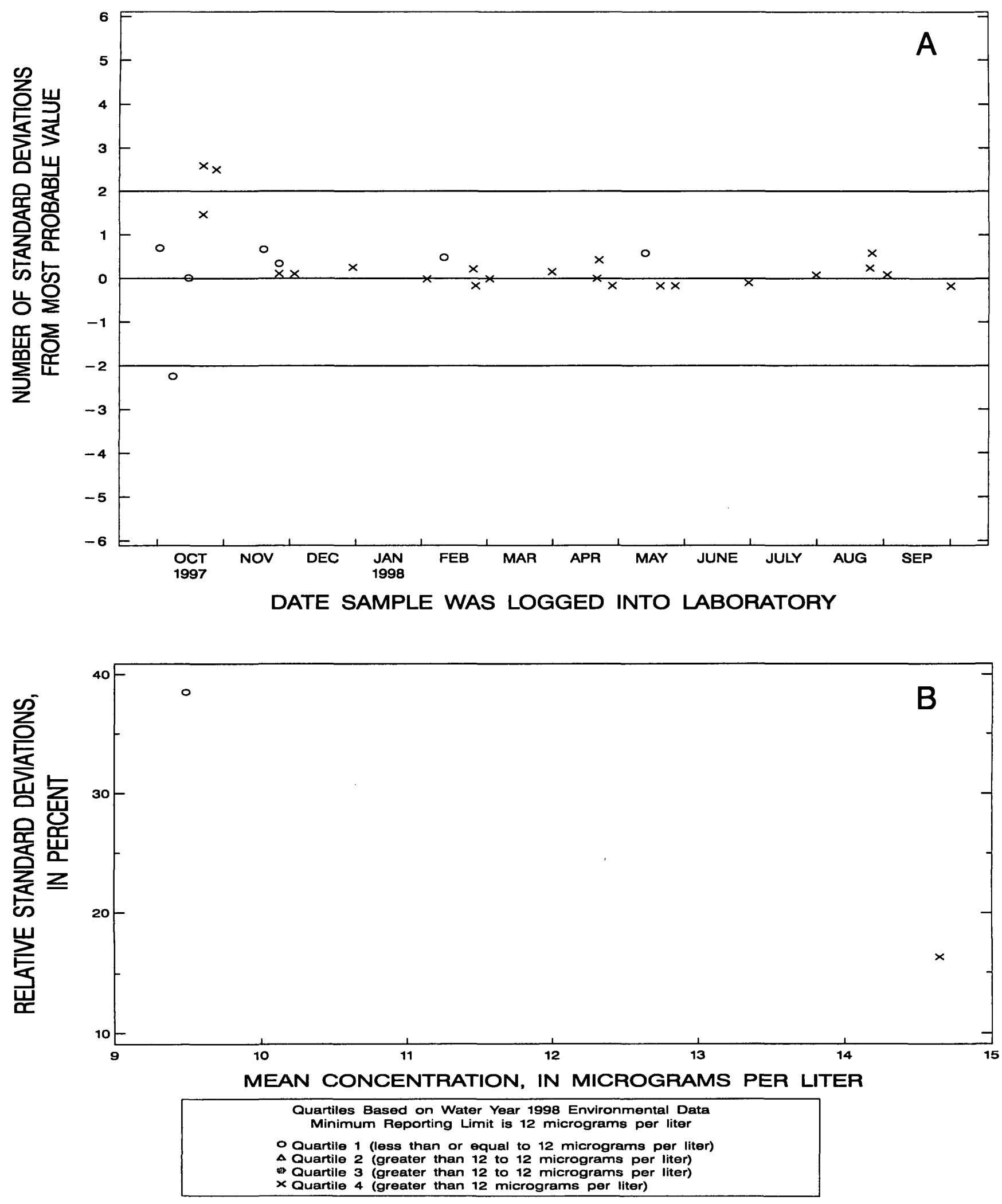

Figure 29. Cobalt, dissolved, (inductively coupled plasma-atomic emission spectrometry) data from the National Water Quality Laboratory. 

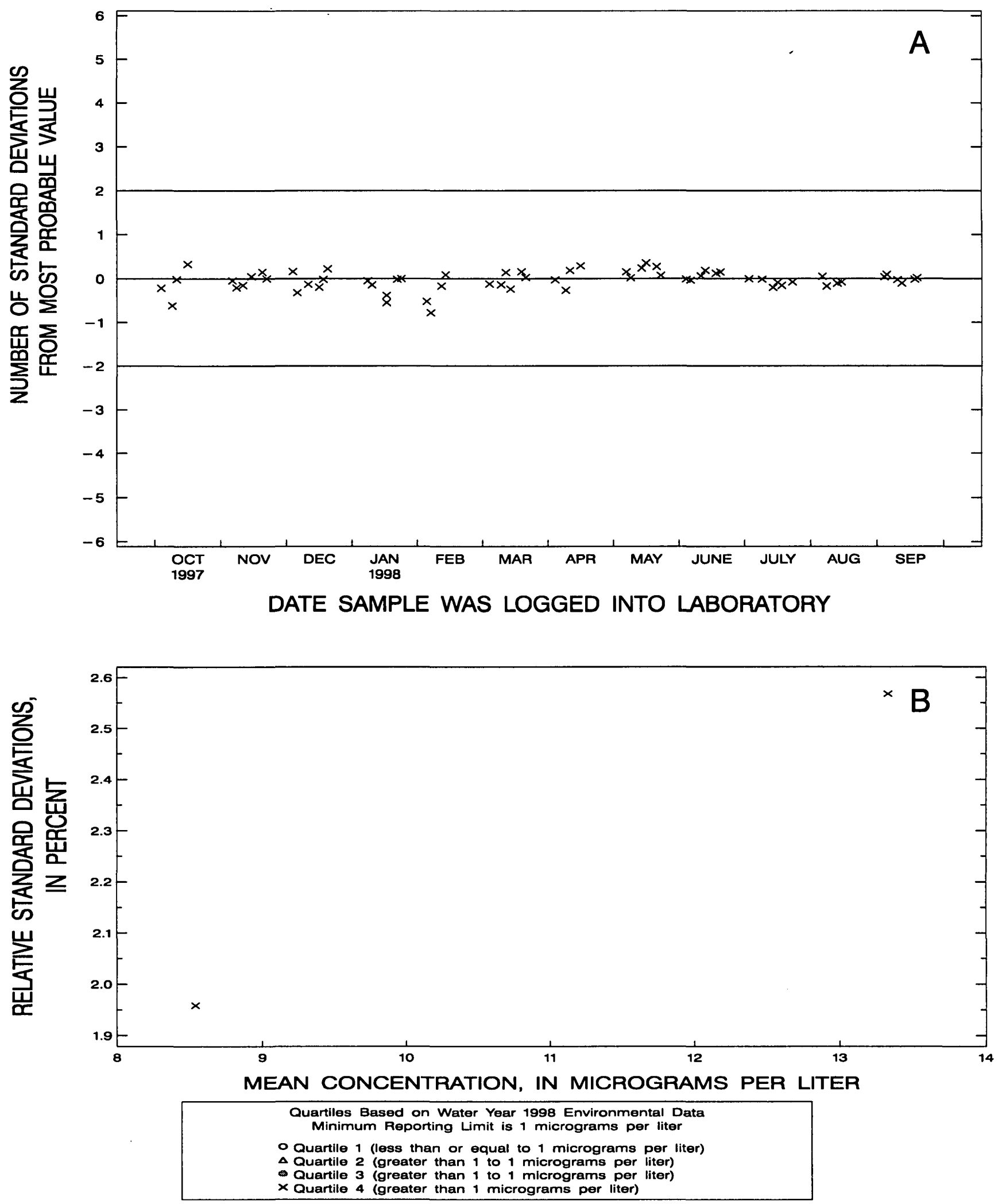

Figure 30. Cobalt, dissolved, (inductively coupled plasma-mass spectrometry) data from the National Water Quality Laboratory. 

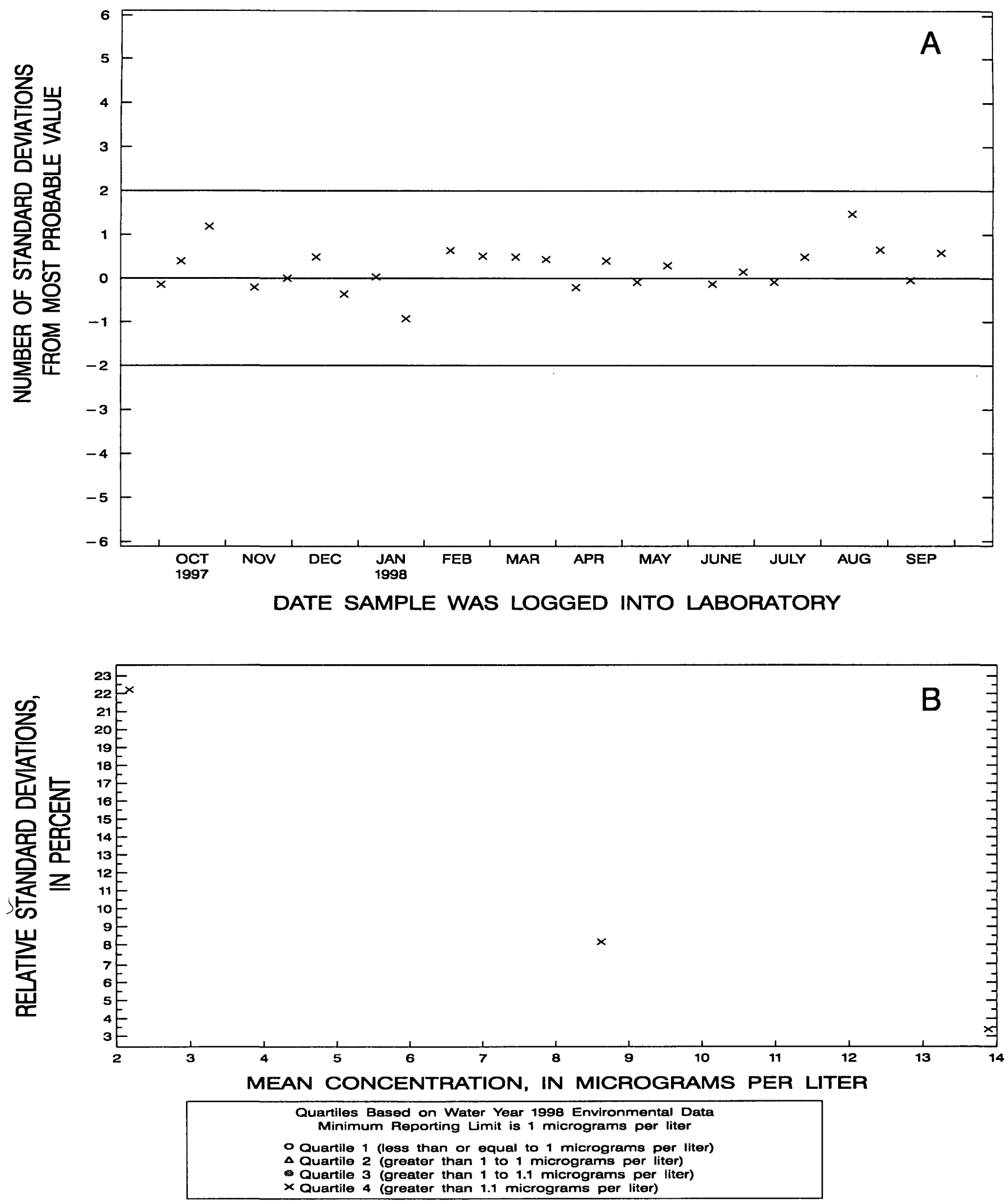

Figure 31. Cobalt, whole-water recoverable, (graphite furnace-atomic absorption spectrophotometry) data from the National Water Quality Laboratory. 

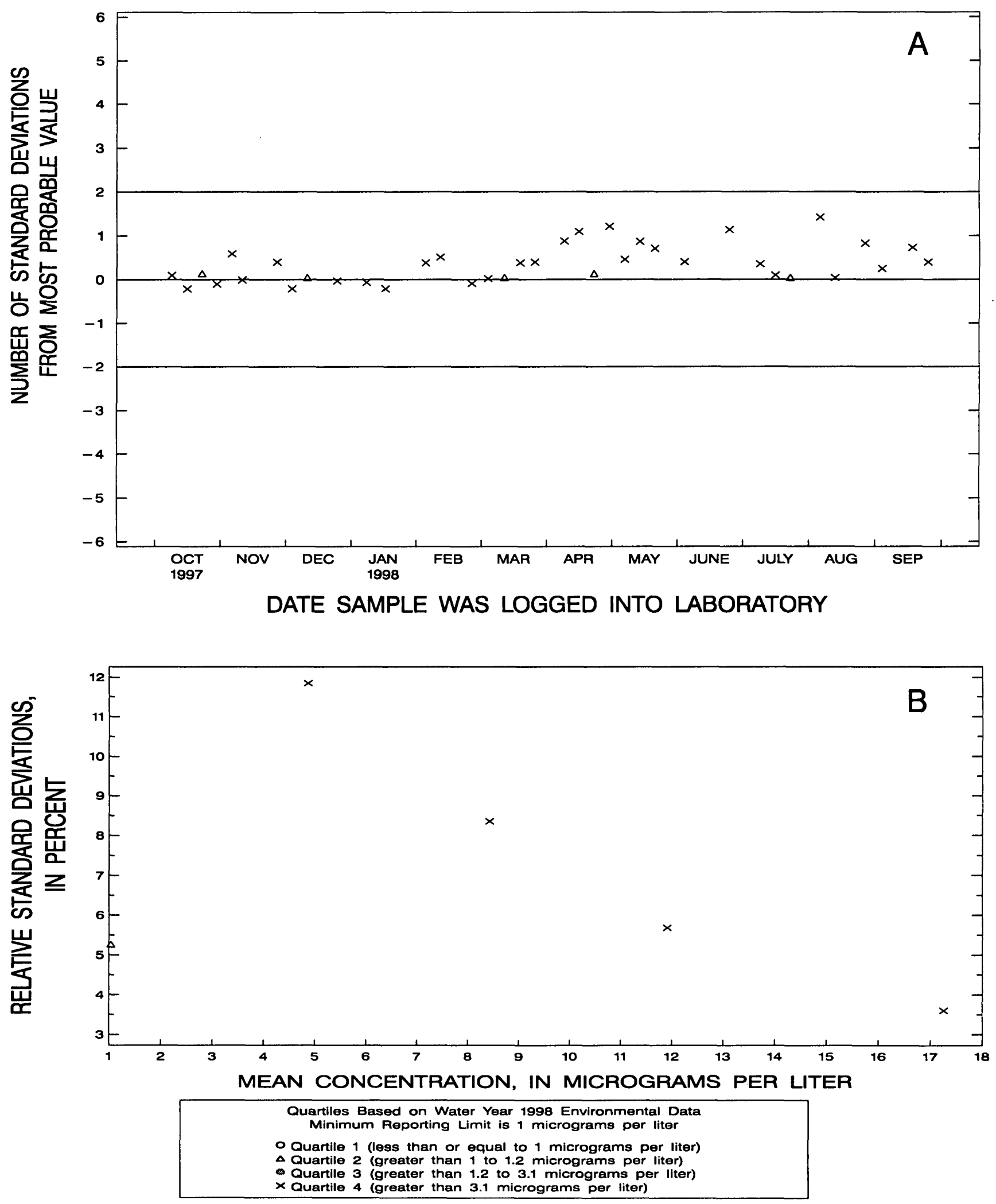

Figure 32. Copper, dissolved, (graphite furnace-atomic absorption spectrophotometry) data from the National Water Quality Laboratory. 

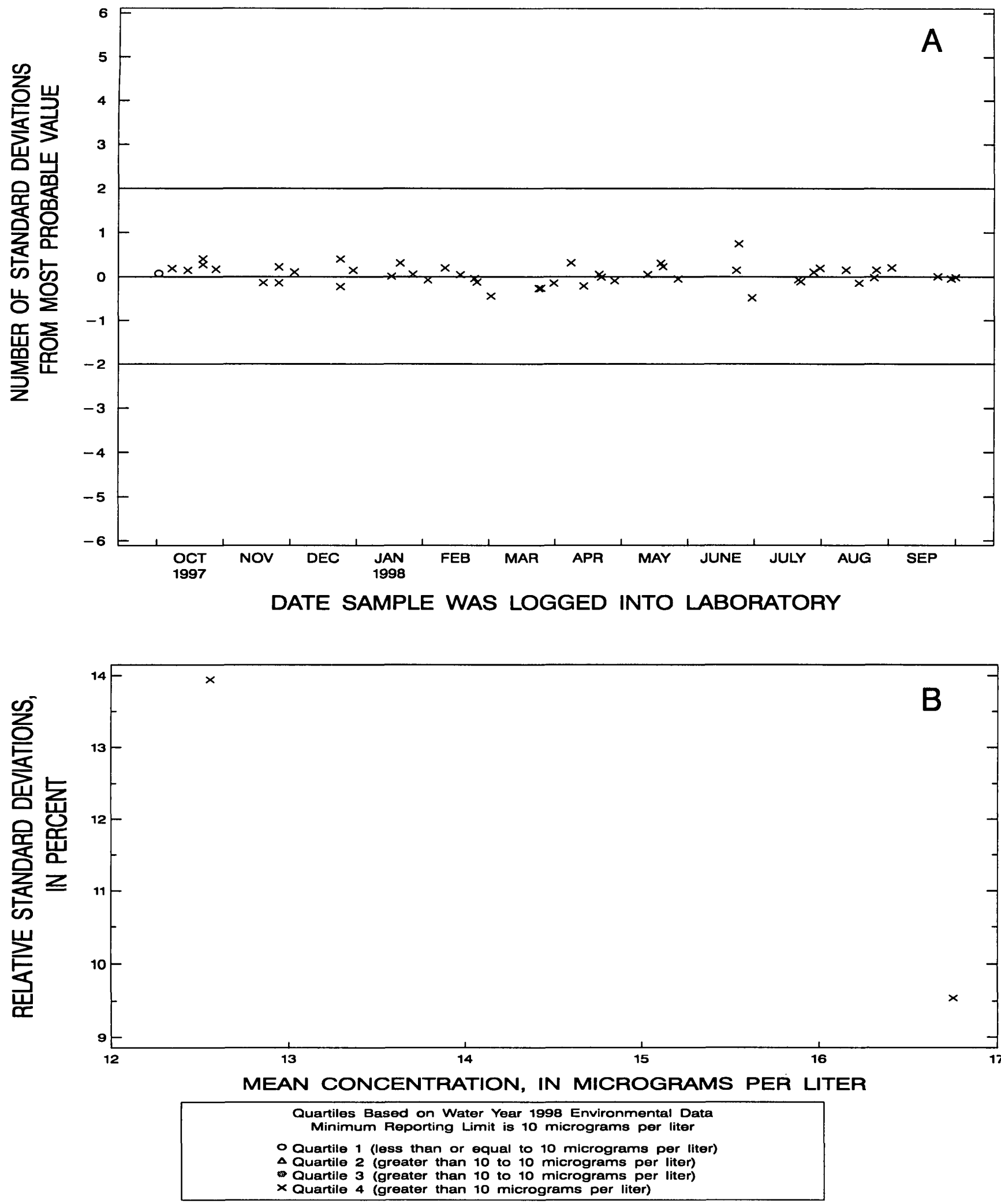

Figure 33. Copper, dissolved, (inductively coupled plasma-atomic emission spectrometry) data from the National Water Quality Laboratory. 

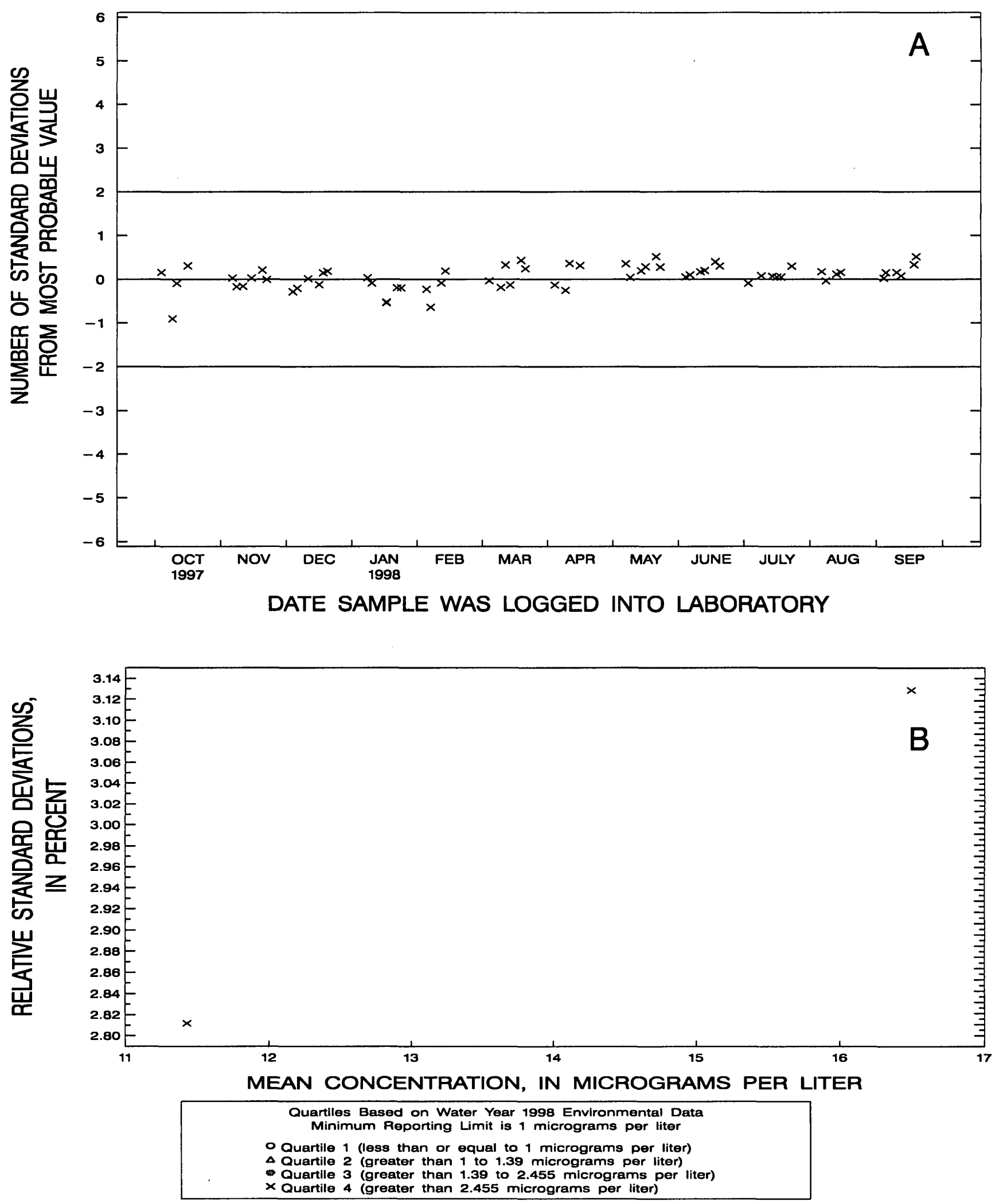

Figure 34. Copper, dissolved, (inductively coupled plasma-mass spectrometry) data from the National Water Quality Laboratory. 

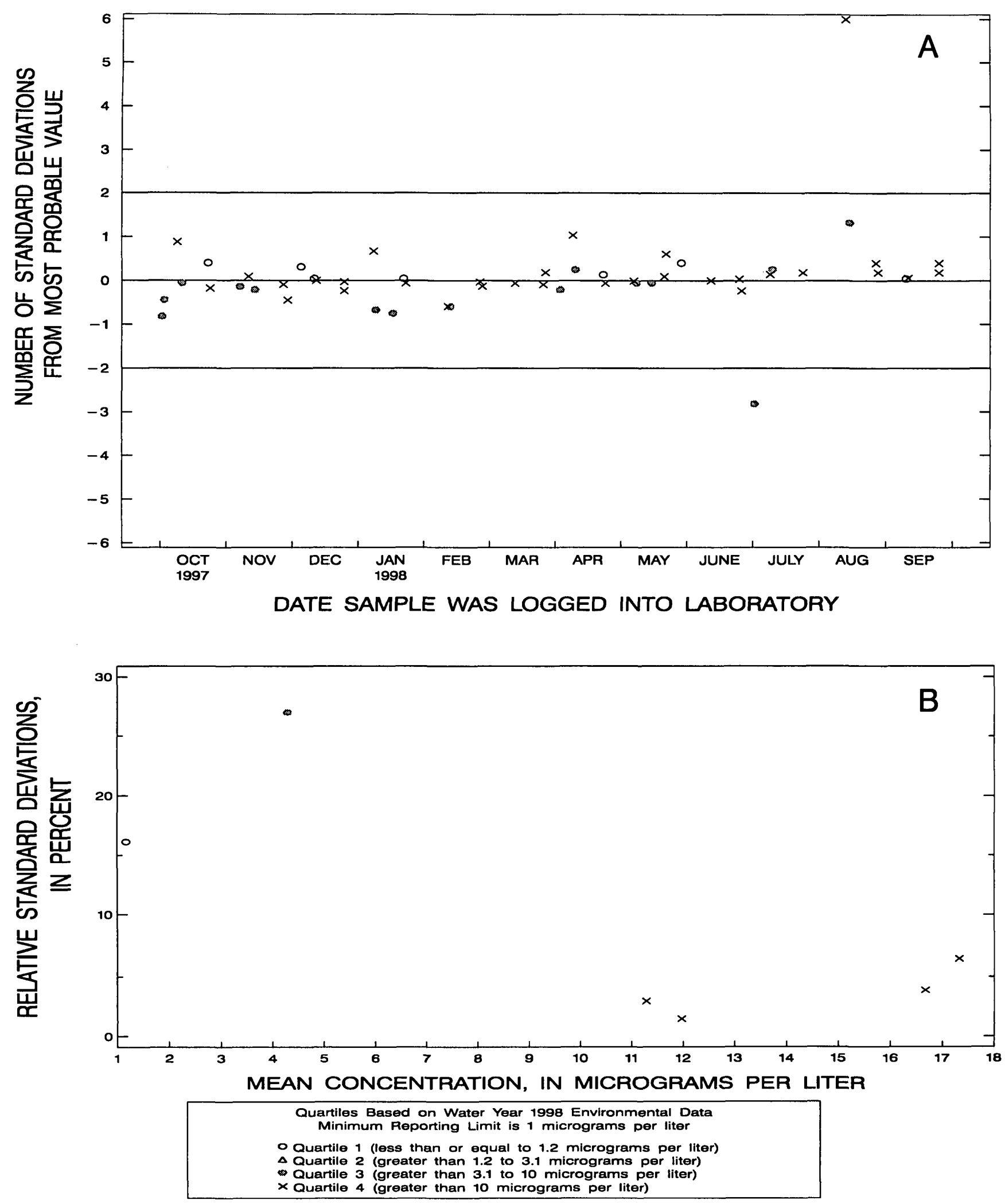

Figure 35. Copper, whole-water recoverable, (graphite furnace-atomic absorption spectrophotometry) data from the National Water Quality Laboratory. 

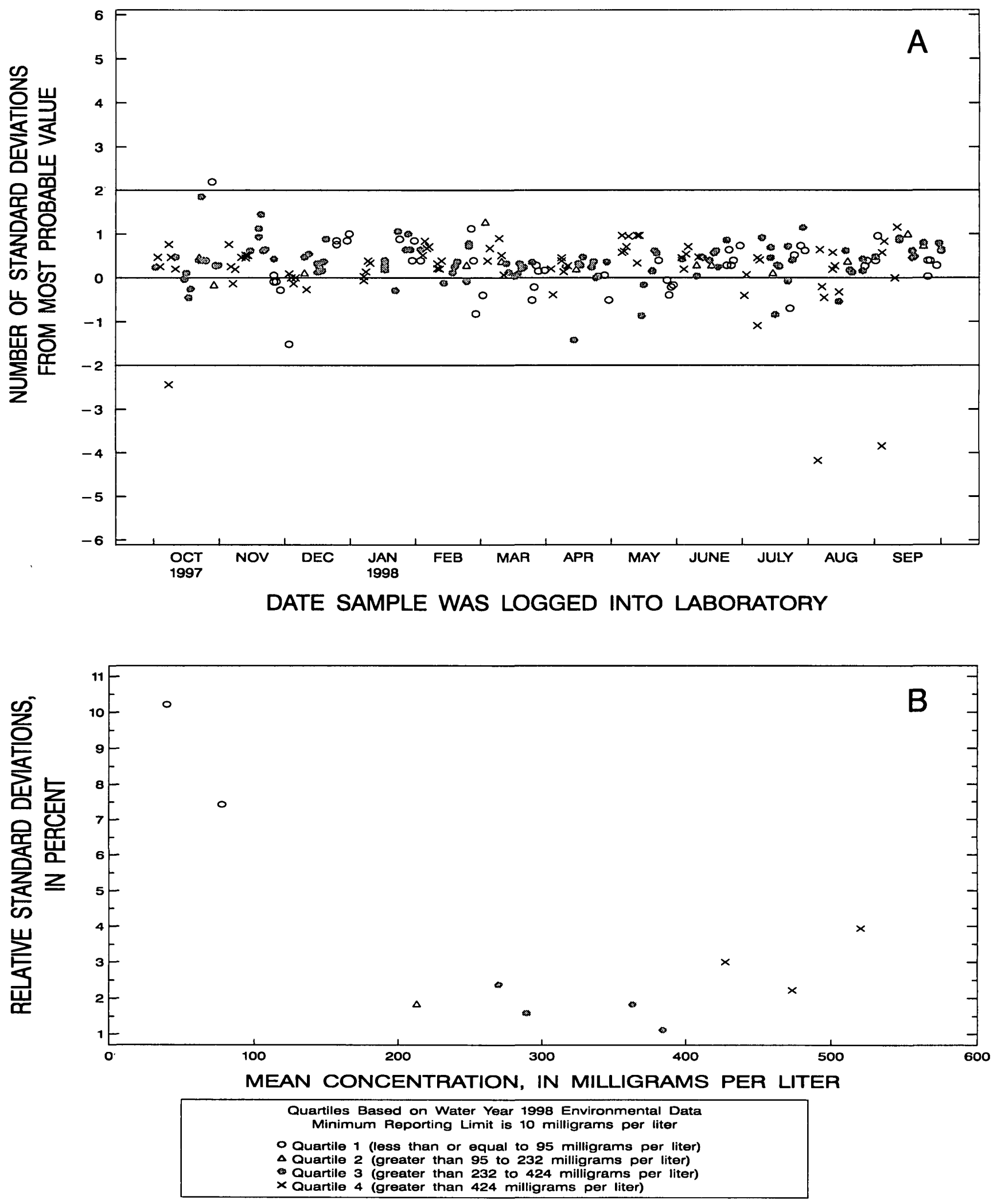

Figure 36. Dissolved solids, dissolved, (gravimetric) data from the National Water Quality Laboratory. 

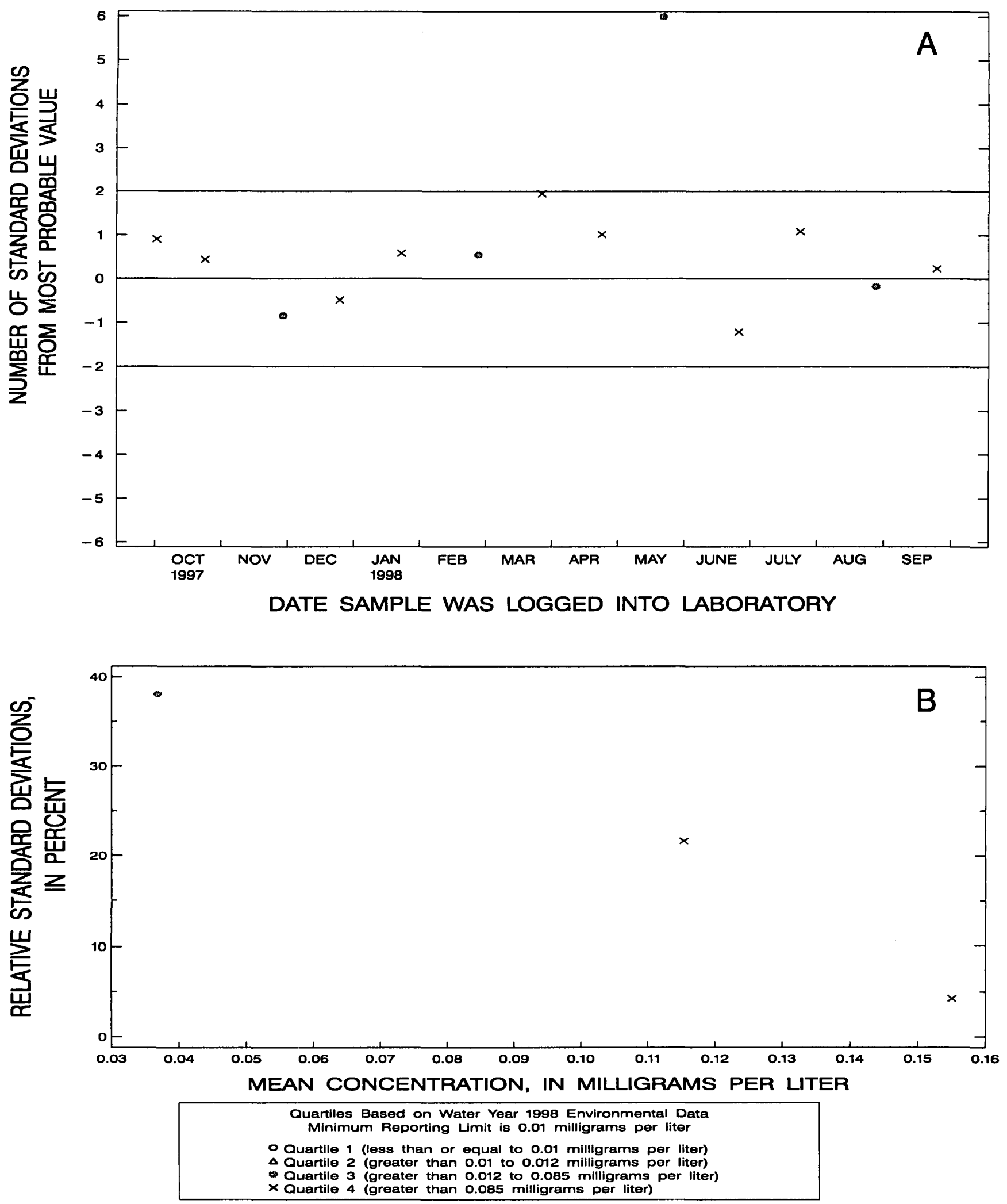

Figure 37. Fluoride, dissolved, (ion chromatography, low level) data from the National Water Quality Laboratory. 


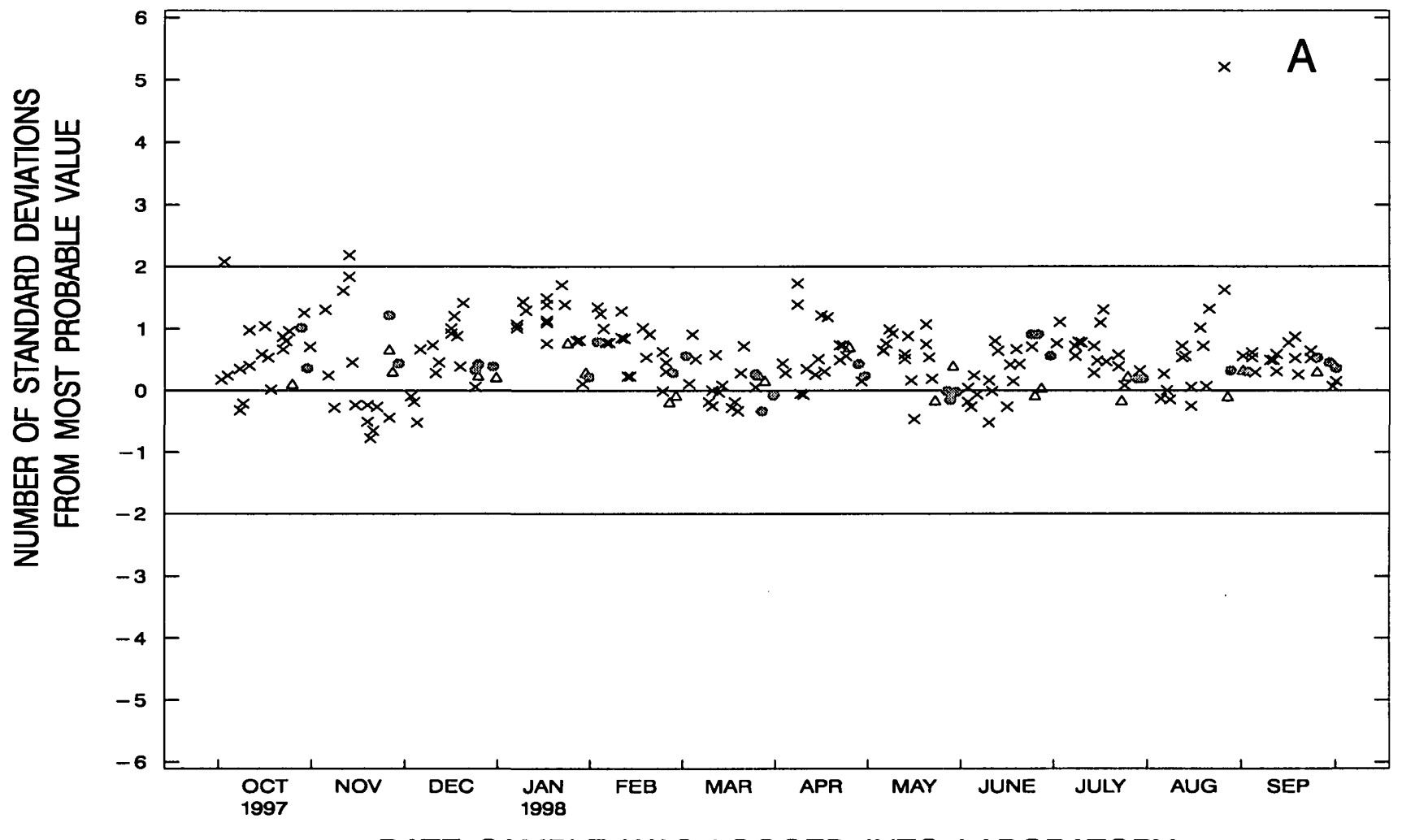

DATE SAMPLE WAS LOGGED INTO LABORATORY

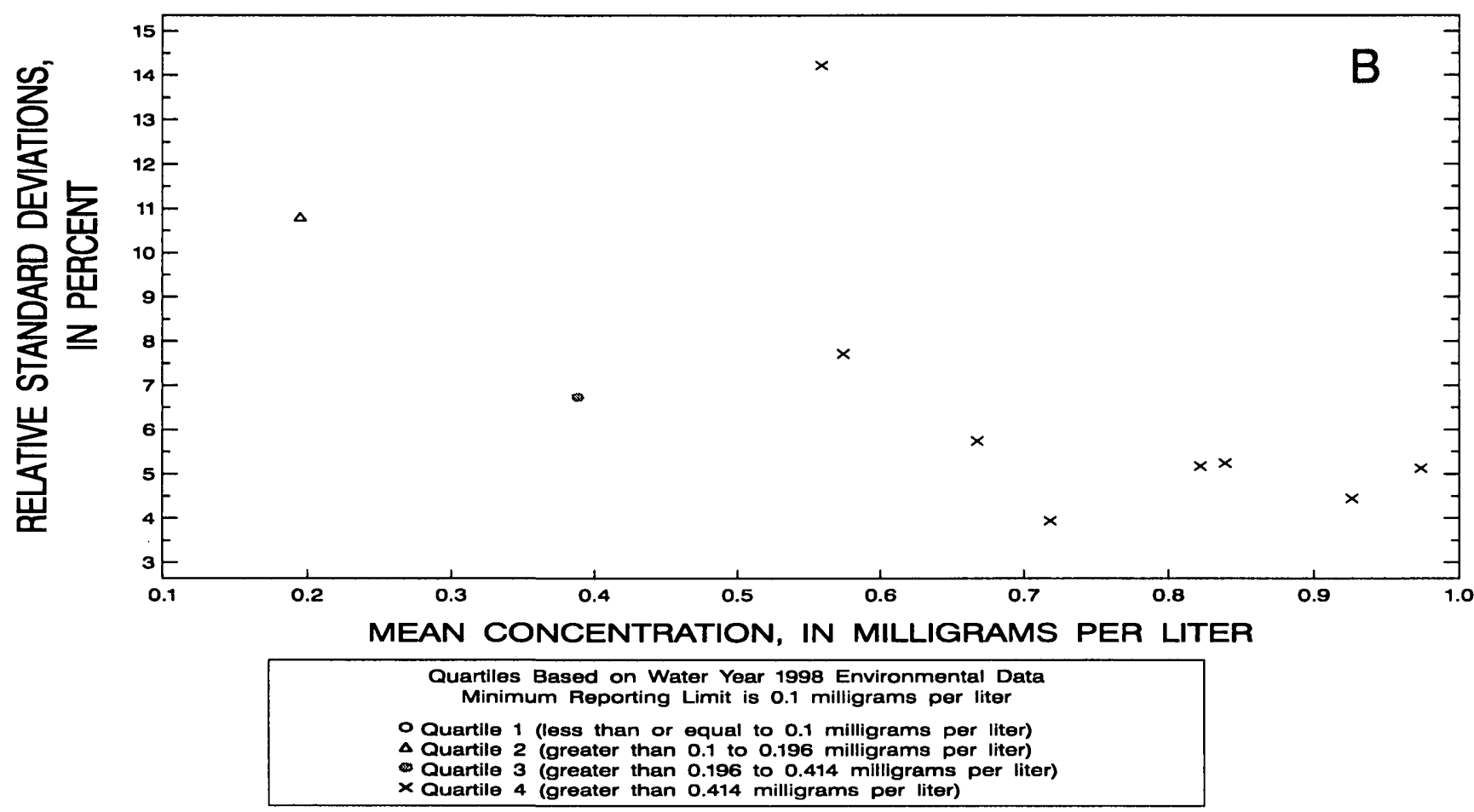

Figure 38. Fluoride, dissolved, (ion-selective electrode) data from the National Water Quality Laboratory. 

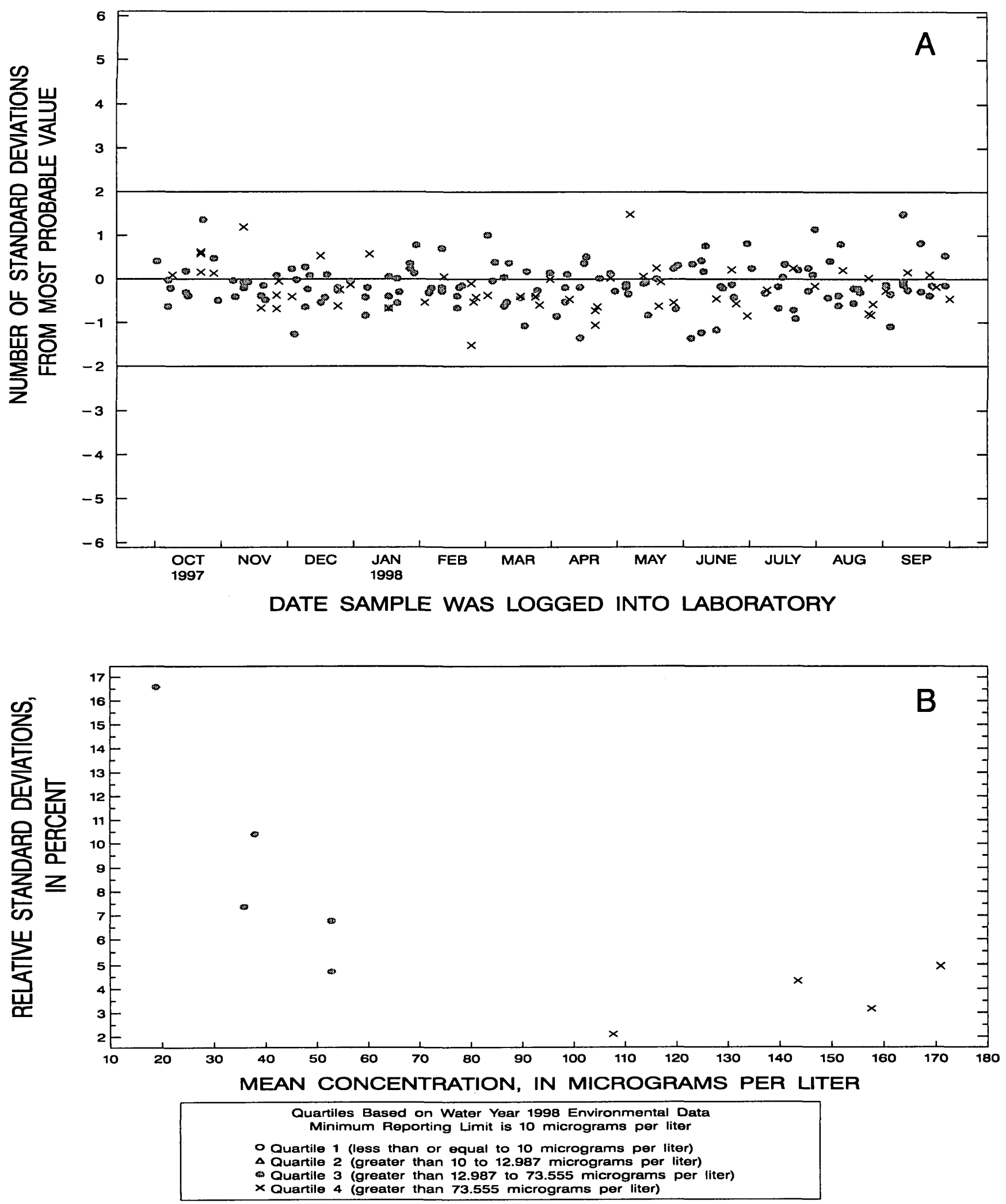

Figure 39. Iron, dissolved, (inductively coupled plasma-atomic emission spectrometry) data from the National Water Quality Laboratory. 

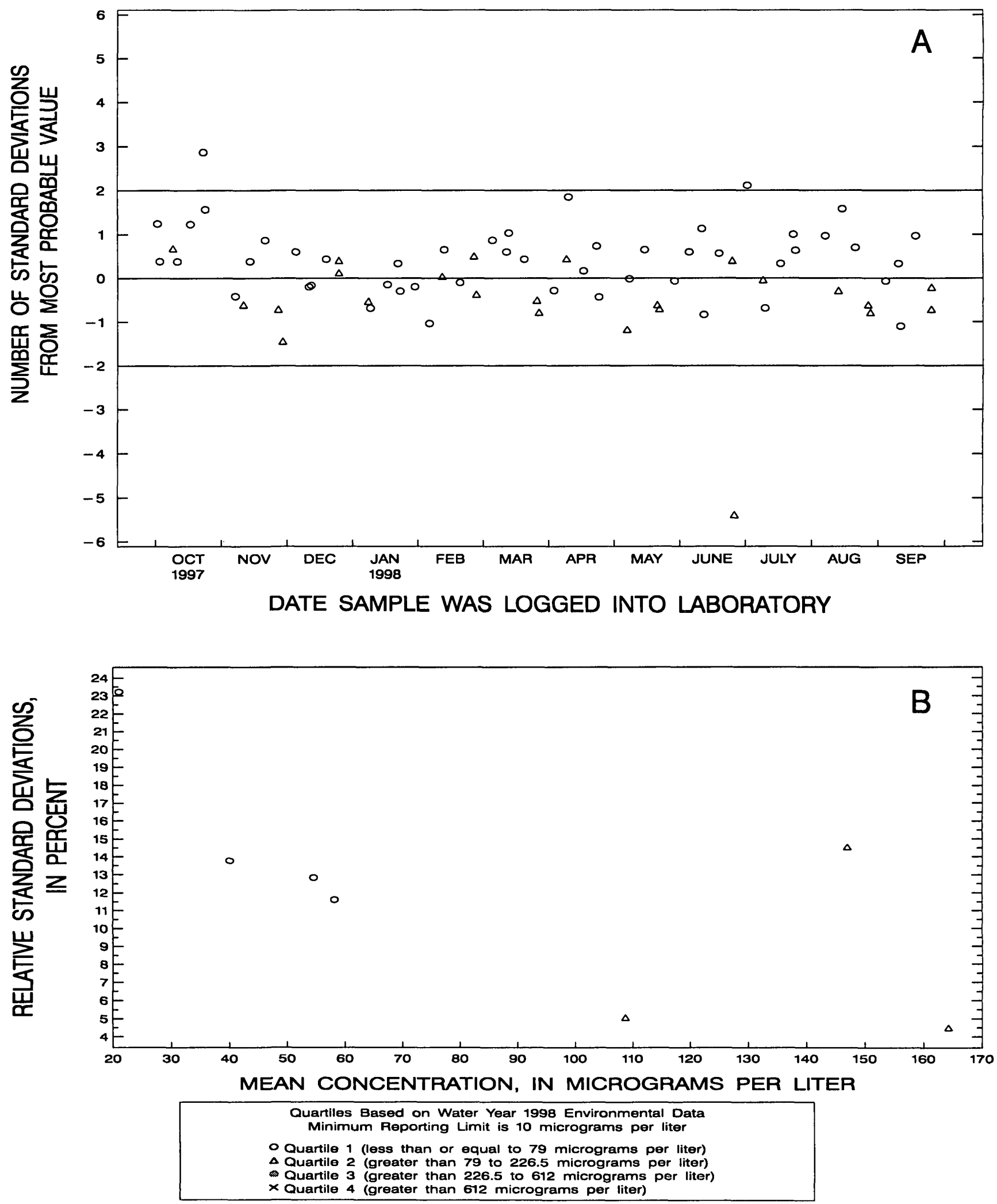

Figure 40. Iron, whole-water recoverable, (flame-atomic absorption spectrophotometry) data from the National Water Quality Laboratory. 

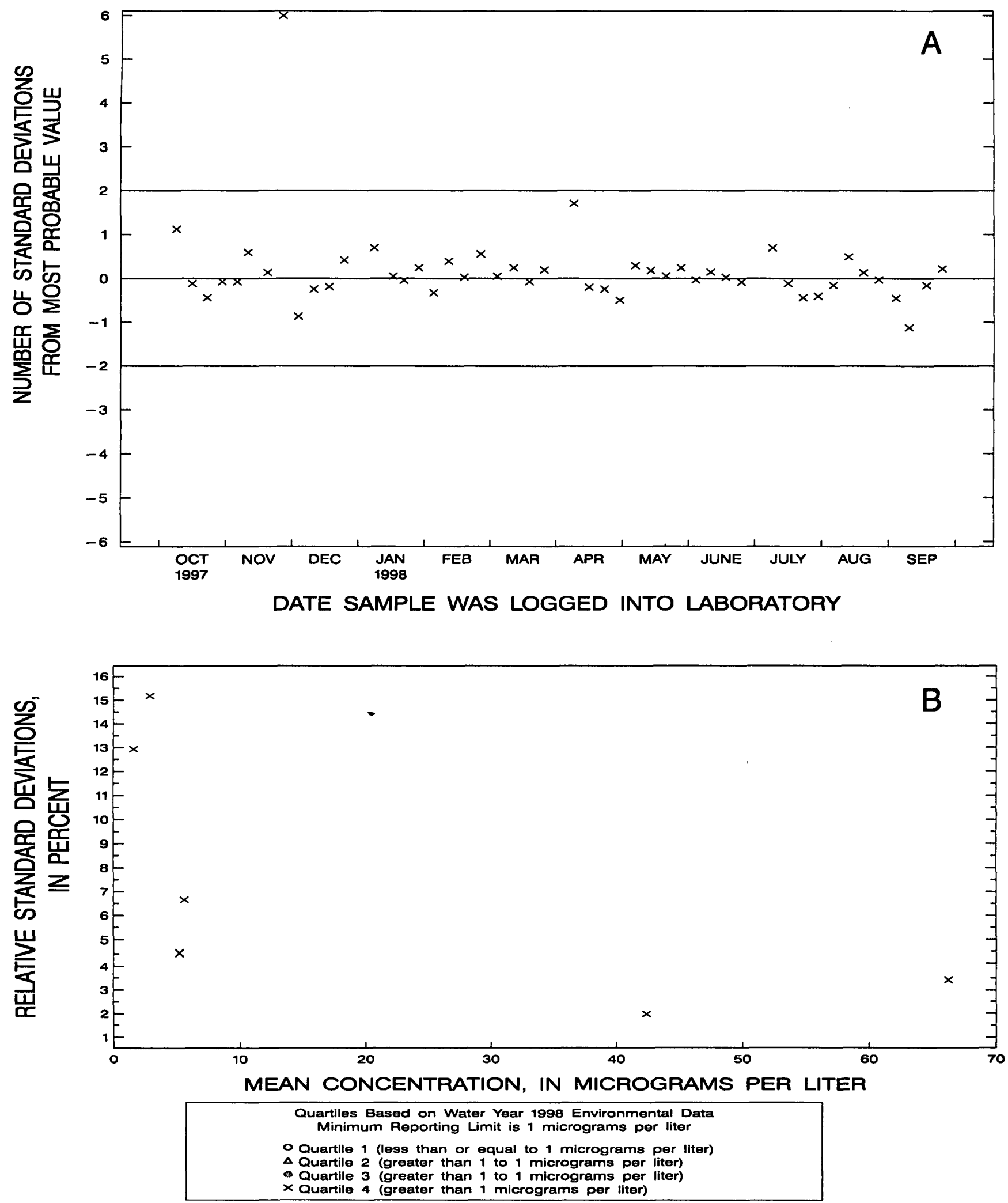

Figure 41. Lead, dissolved, (graphite furnace-atomic absorption spectrophotometry) data from the National Water Quality Laboratory. 

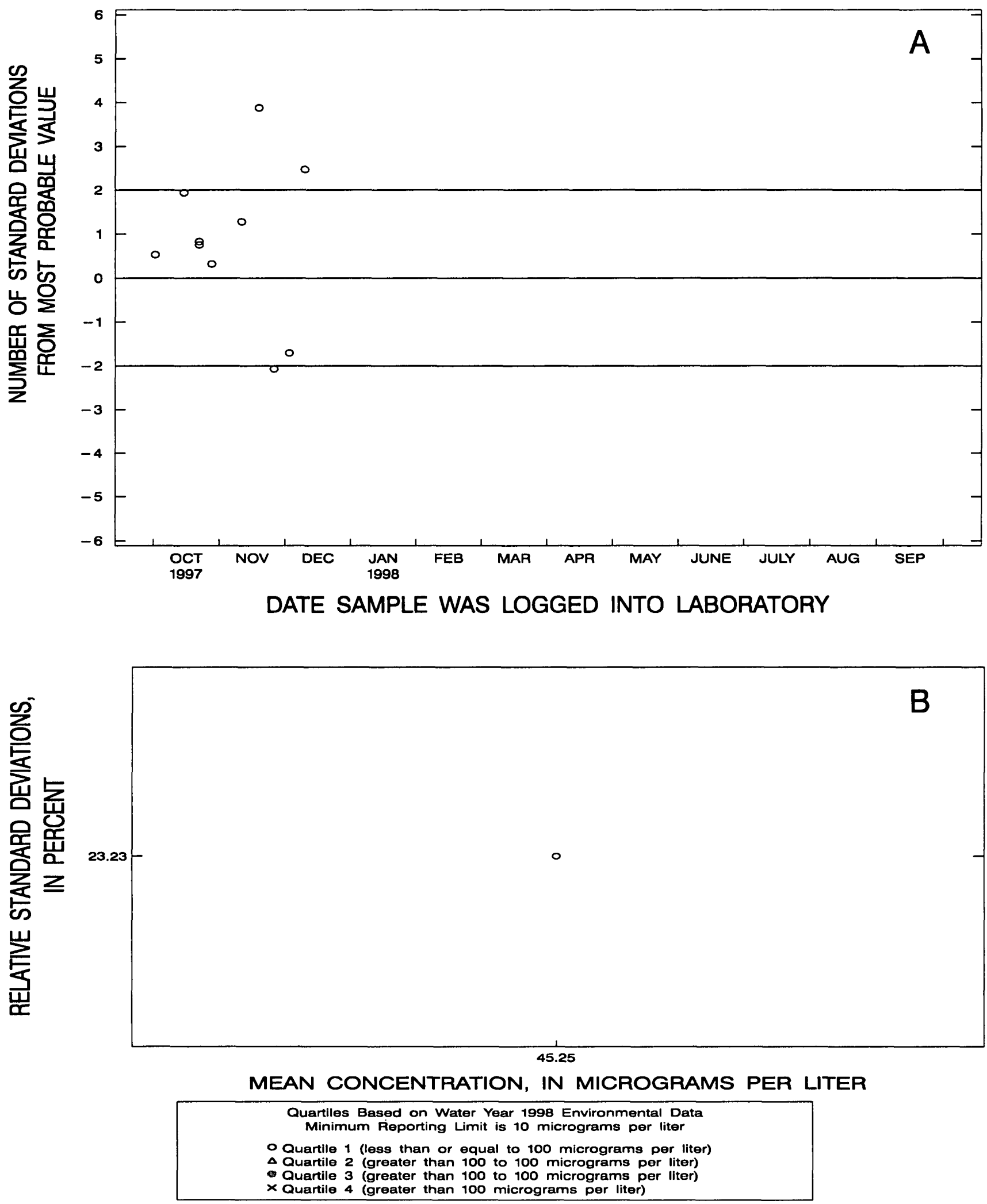

Figure 42. Lead, dissolved, (inductively coupled plasma-atomic emission spectrometry) data from the National Water Quality Laboratory. 

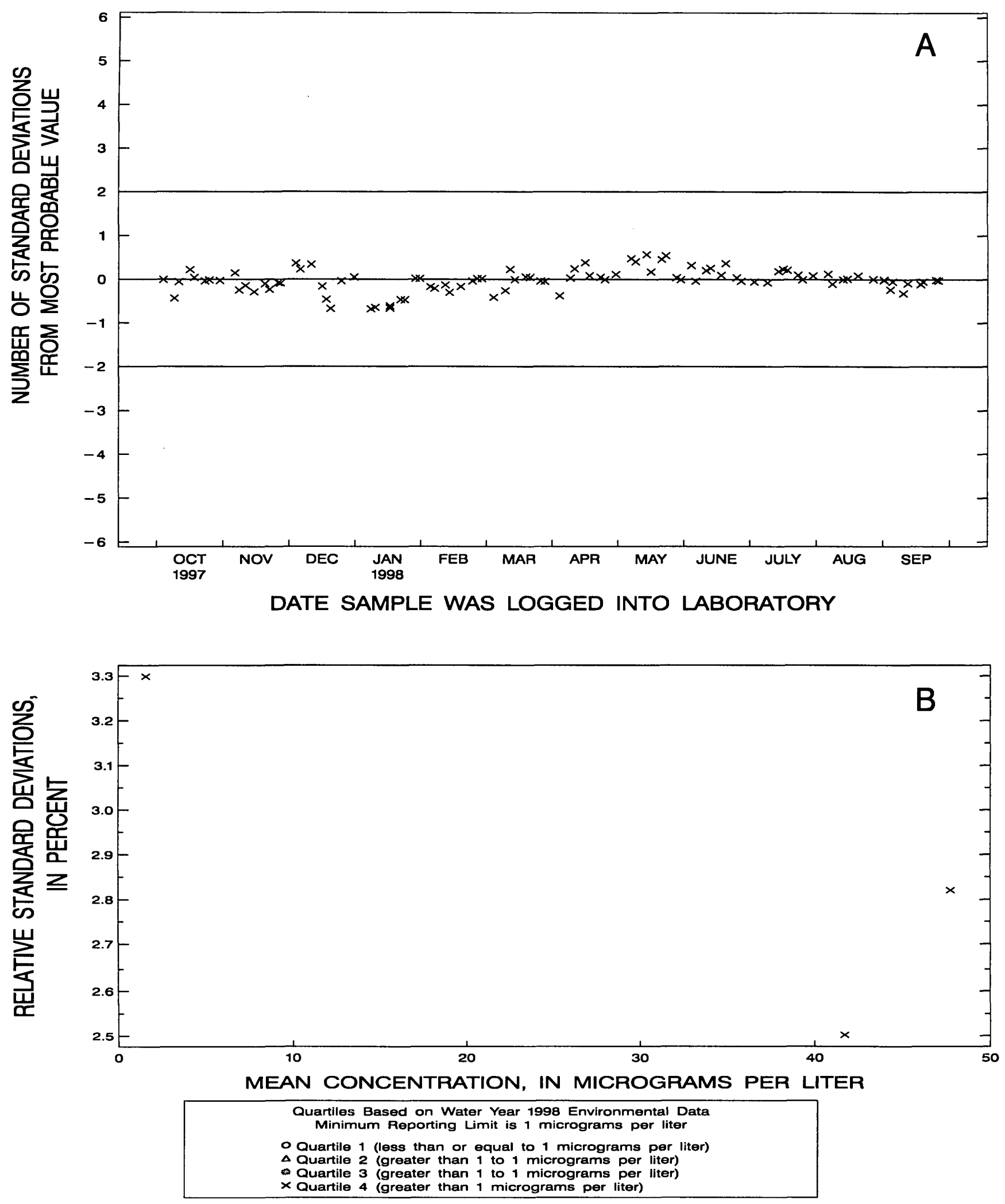

Figure 43. Lead, dissolved, (inductively coupled plasma-mass spectrometry) data from the National Water Quality Laboratory. 

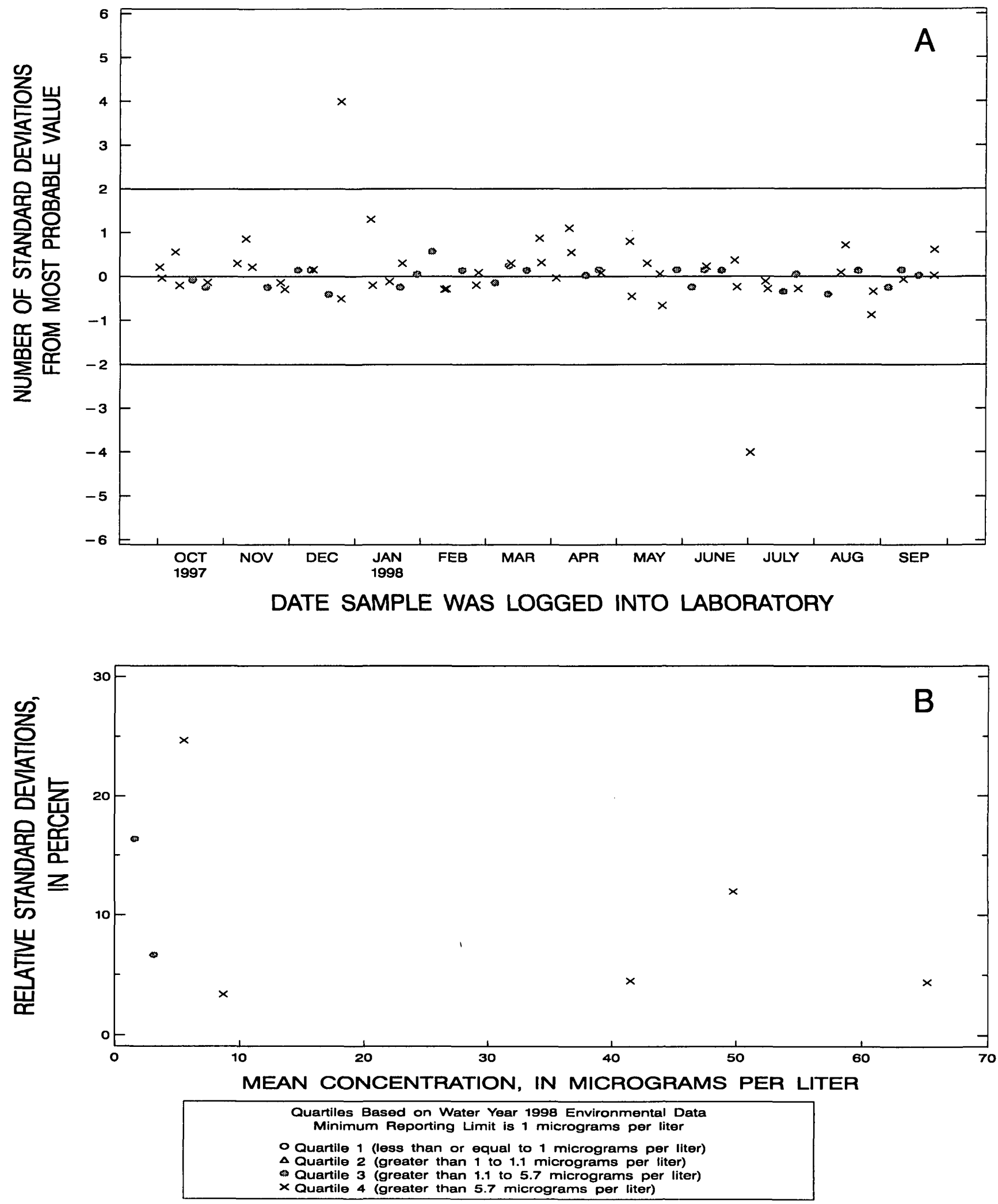

Figure 44. Lead, whole-water recoverable, (graphite furnace-atomic absorption spectrophotometry) data from the National Water Quality Laboratory. 

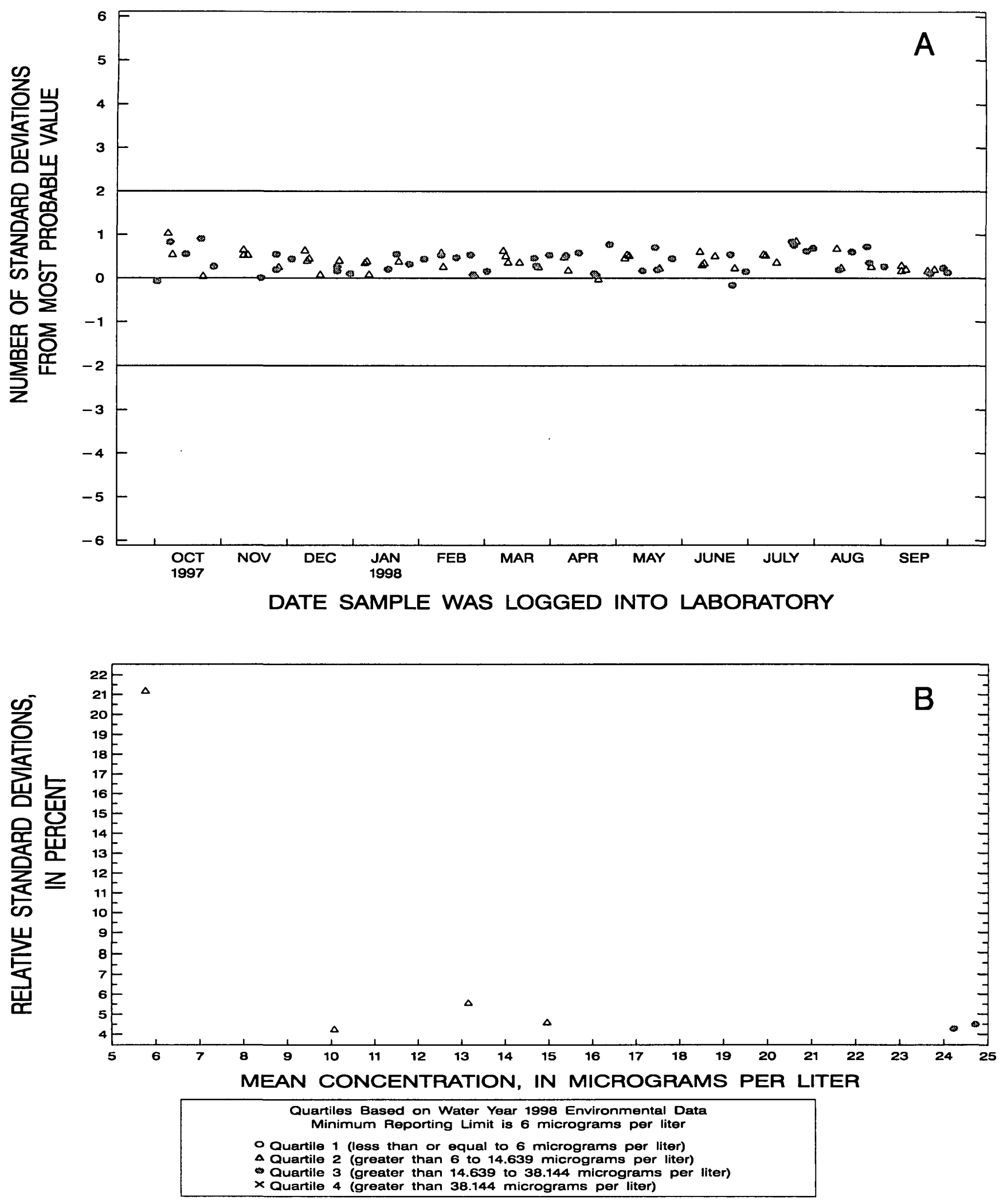

Figure 45. Lithium, dissolved, (inductively coupled plasma-atomic emission spectrometry) data from the National Water Quality Laboratory. 

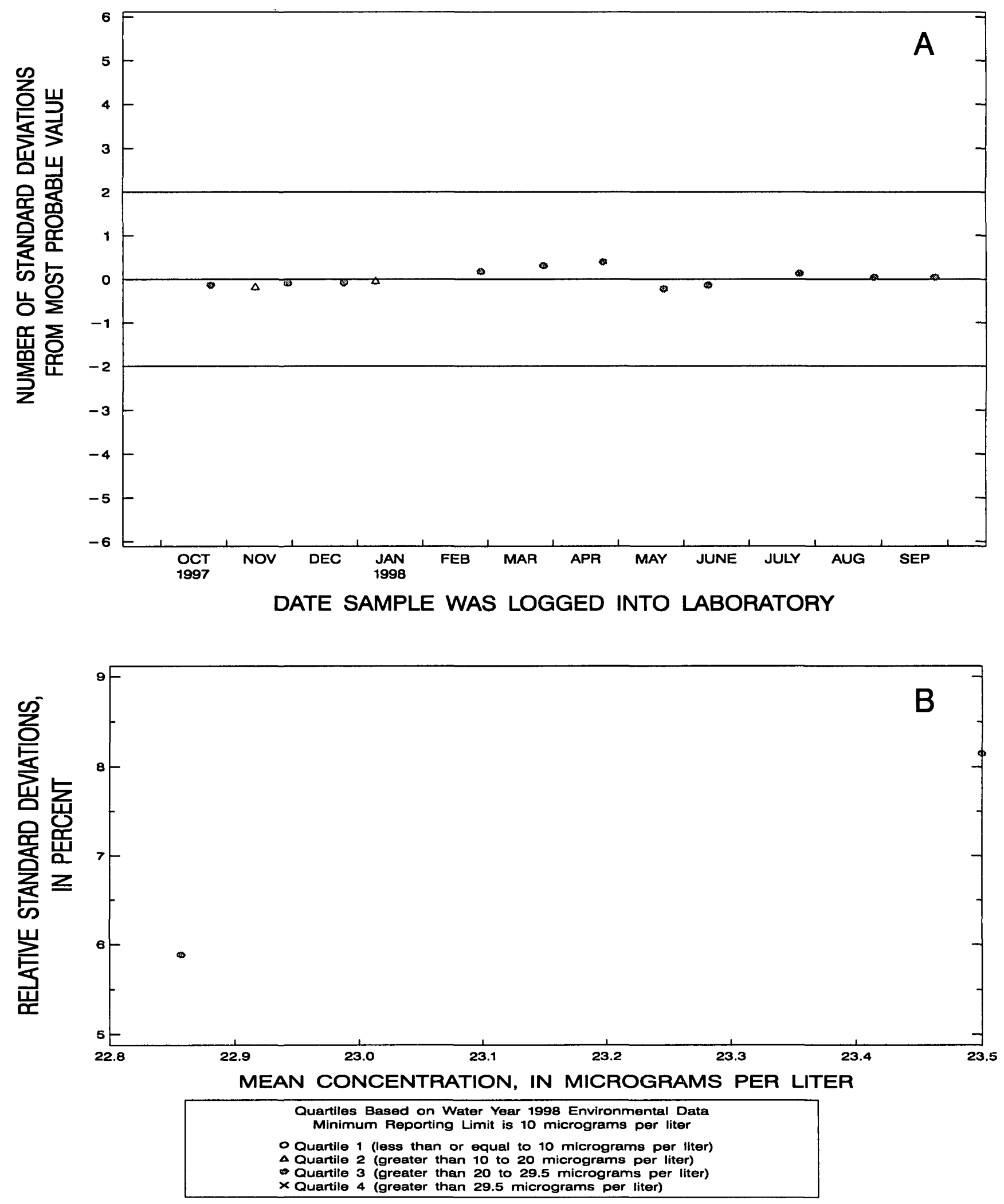

Figure 46. Lithium, whole-water recoverable, (flame-atomic absorption spectrophotometry) data from the National Water Quality Laboratory. 

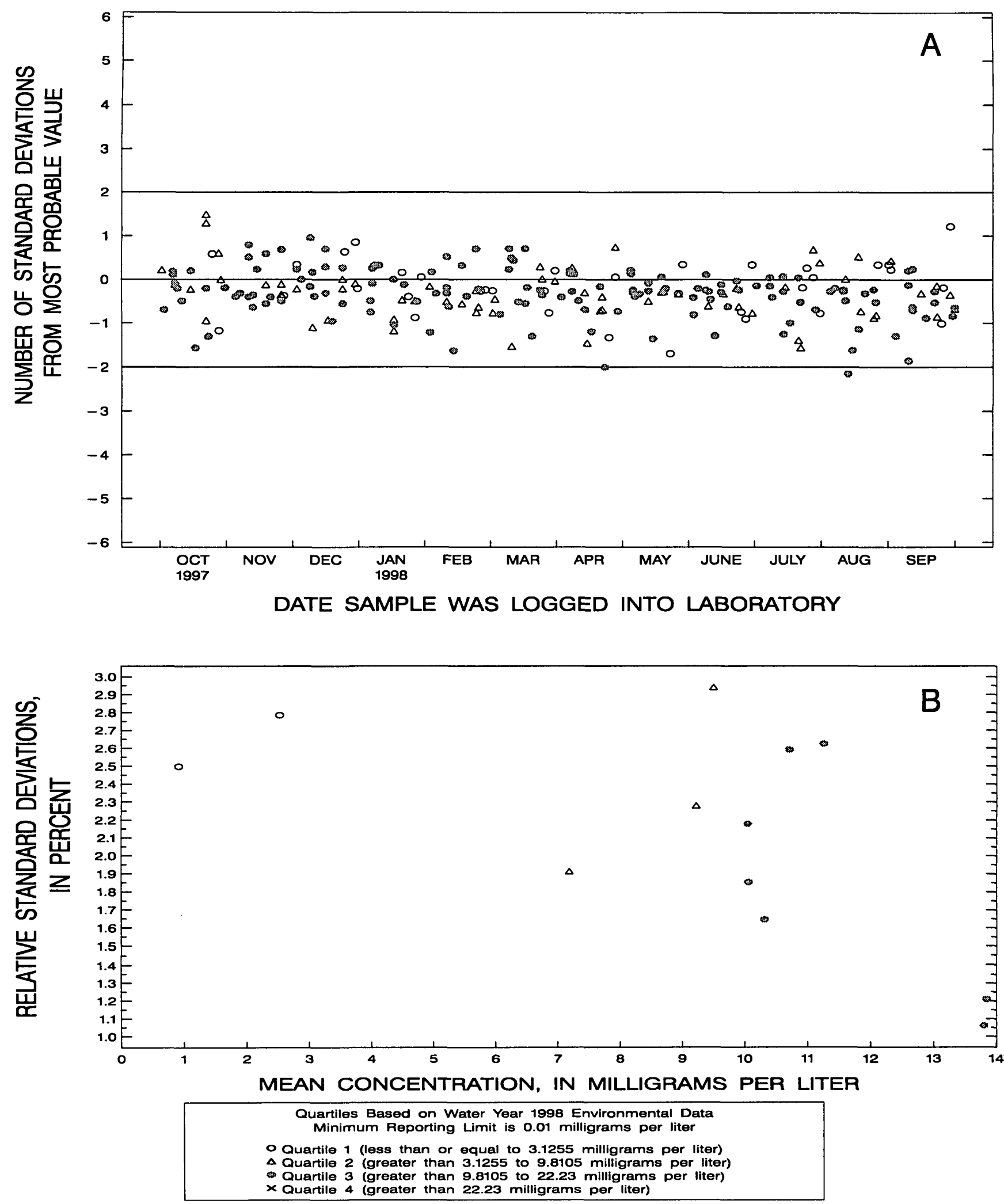

Figure 47. Magnesium, dissolved, (inductively coupled plasma-atomic emission spectrometry) data from the National Water Quality Laboratory. 

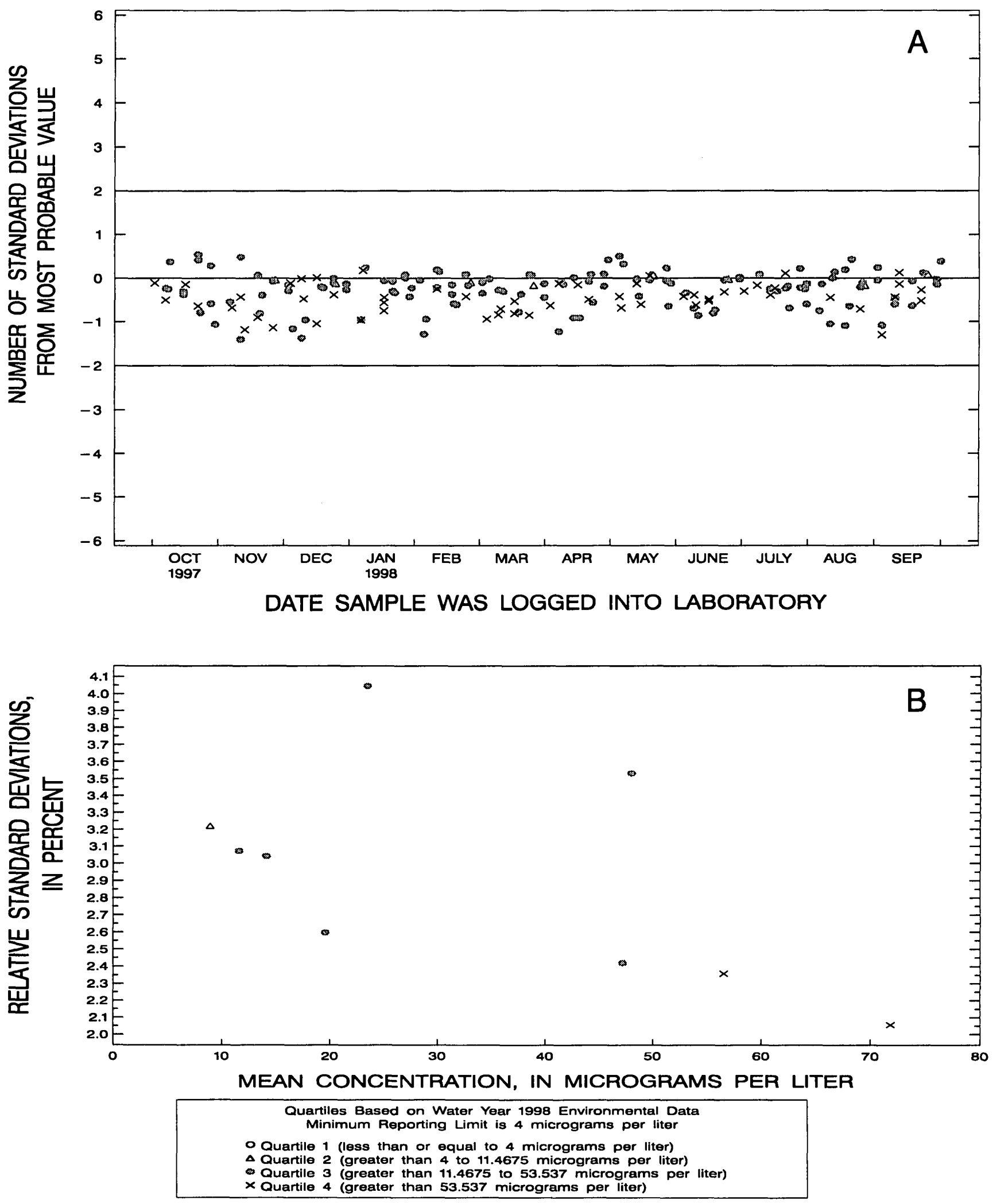

Figure 48. Manganese, dissolved, (inductively coupled plasma-atomic emission spectrometry) data from the National Water Quality Laboratory. 

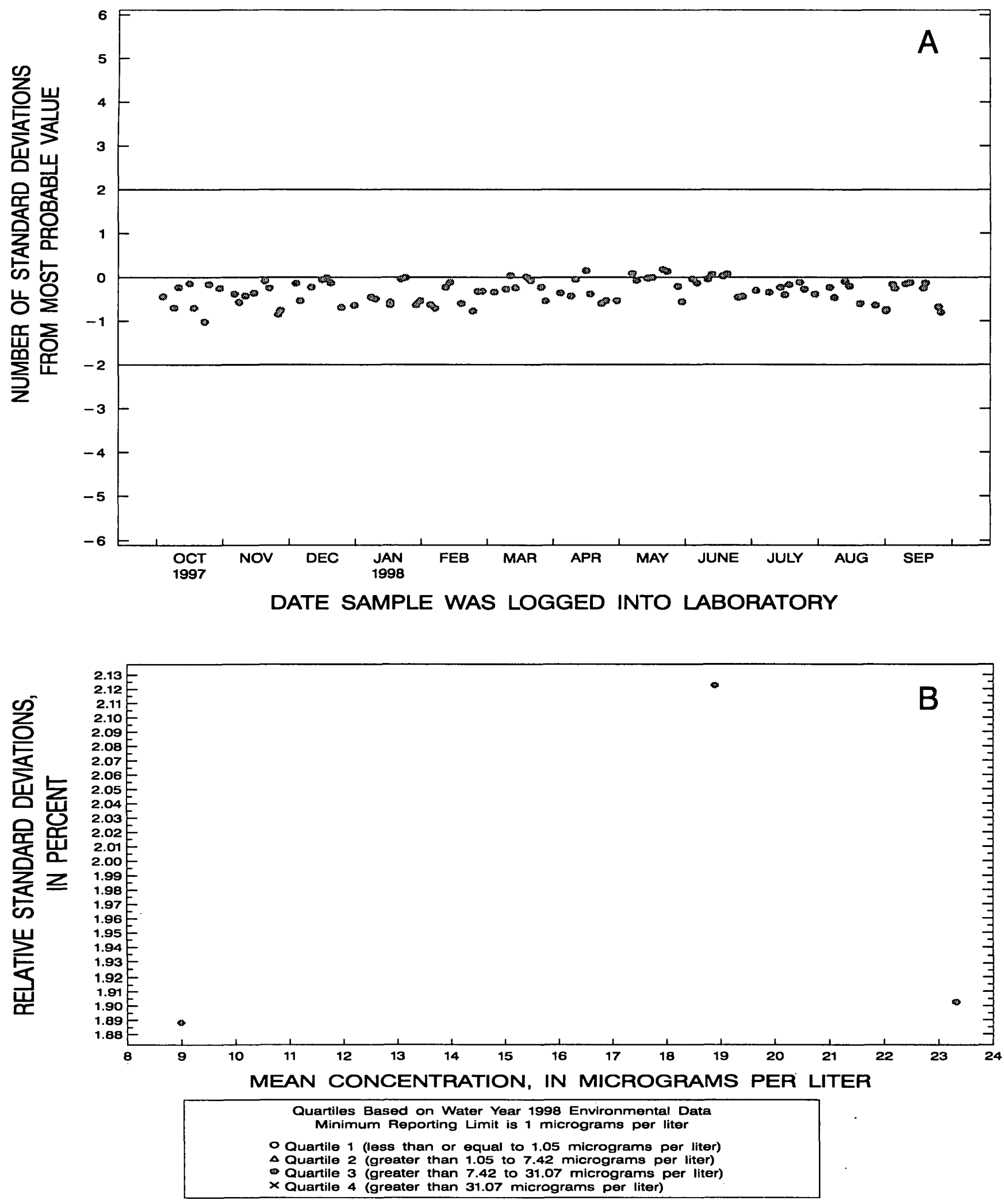

Figure 49. Manganese, dissolved, (inductively coupled plasma-mass spectrometry) data from the National Water Quality Laboratory. 

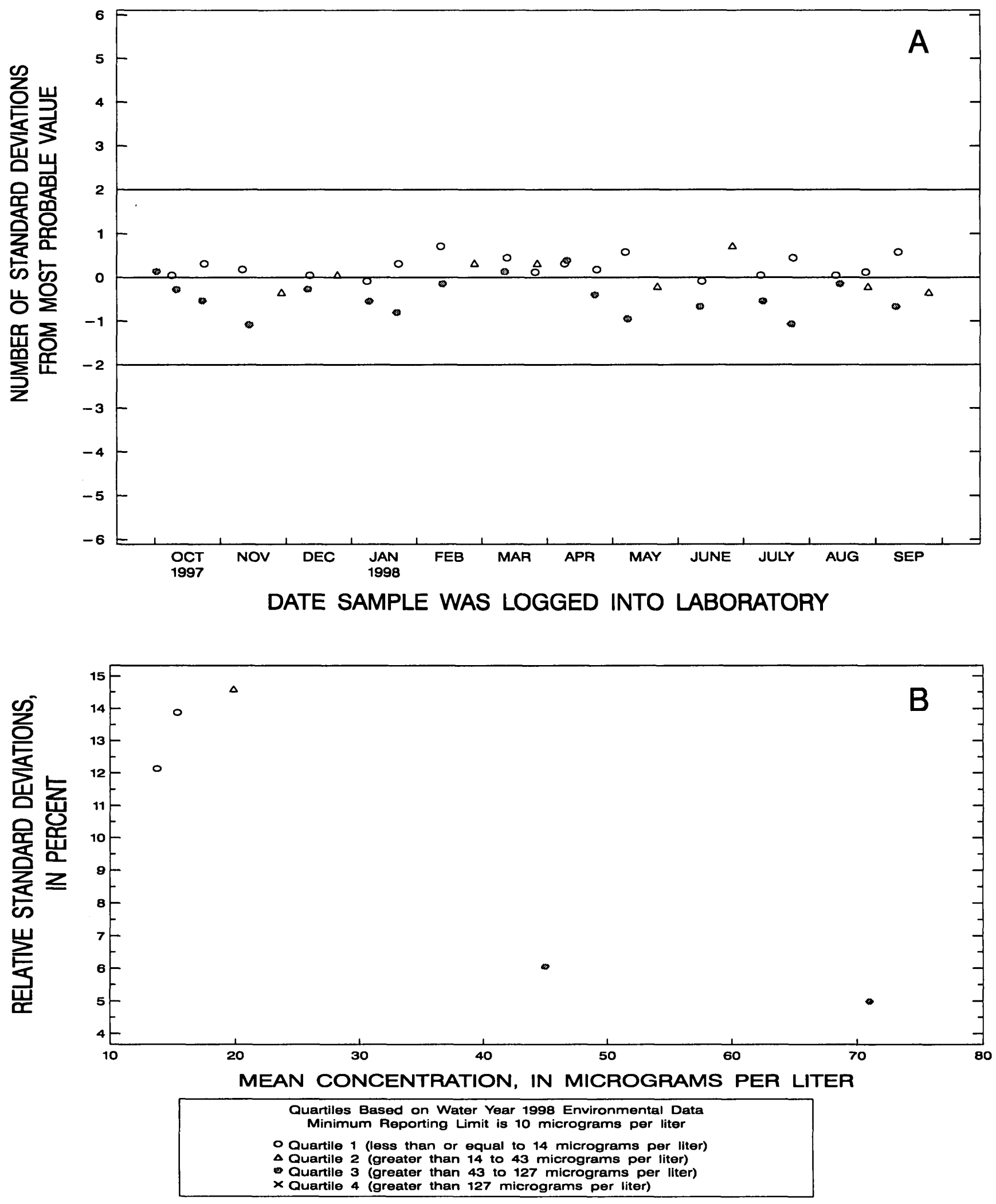

Figure 50. Manganese, whole-water recoverable, (flame-atomic absorption spectrophotometry) data from the National Water Quality Laboratory. 

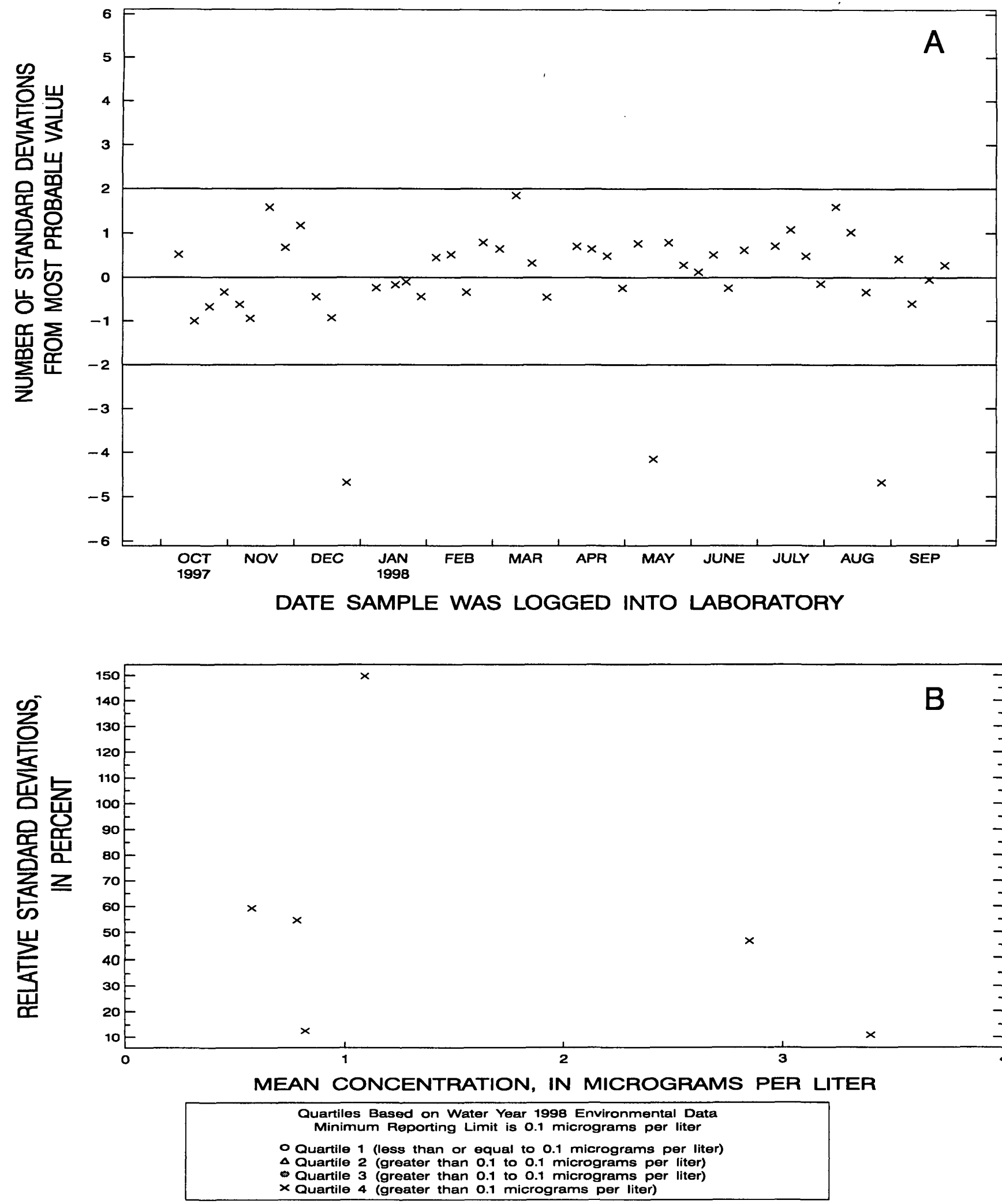

Figure 51. Mercury, dissolved, (cold vapor-atomic absorption spectrophotometry) data from the National Water Quality Laboratory. 

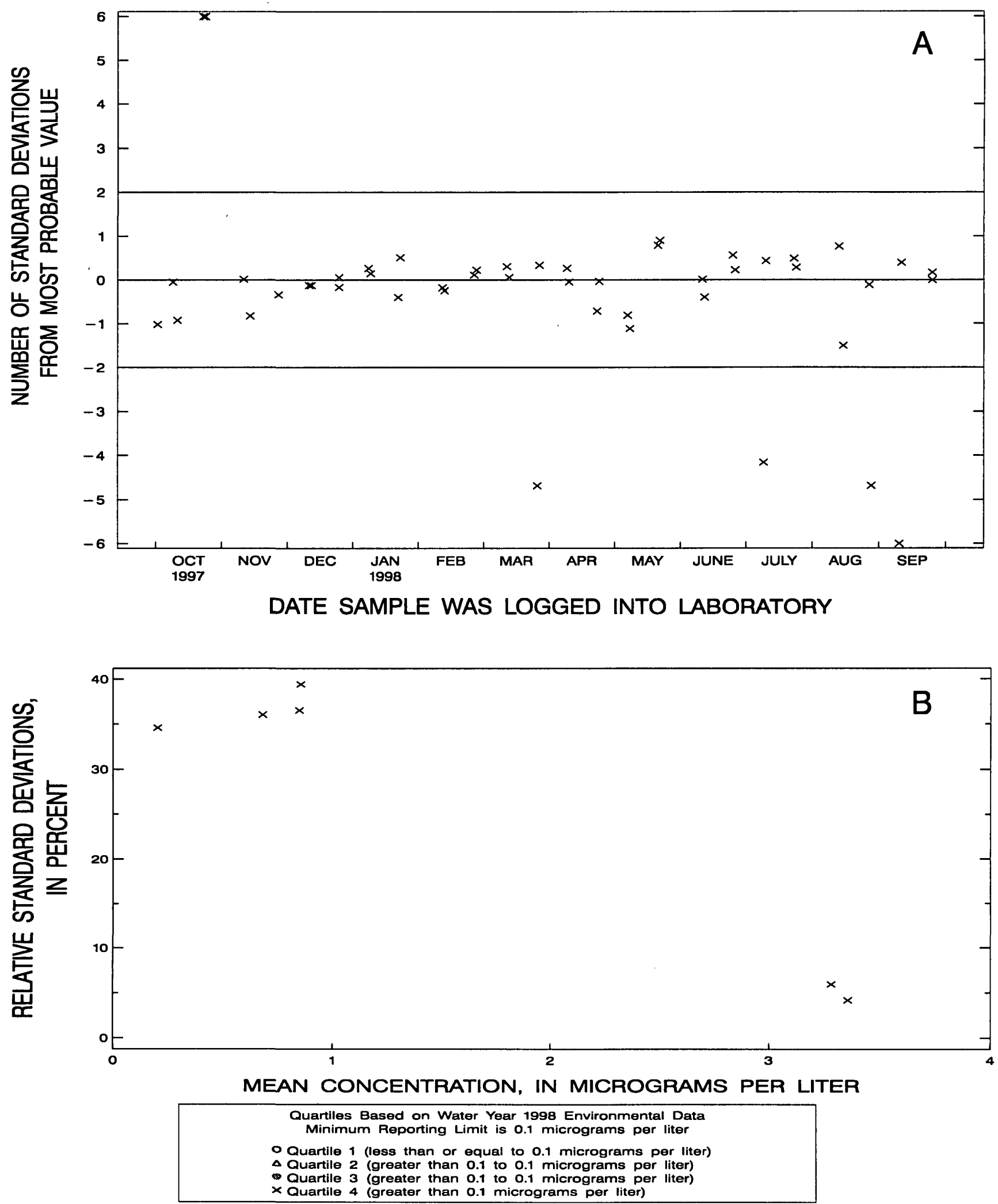

Figure 52. Mercury, whole-water recoverable, (cold vapor-atomic absorption spectrophotometry) data from the National Water Quality Laboratory. 

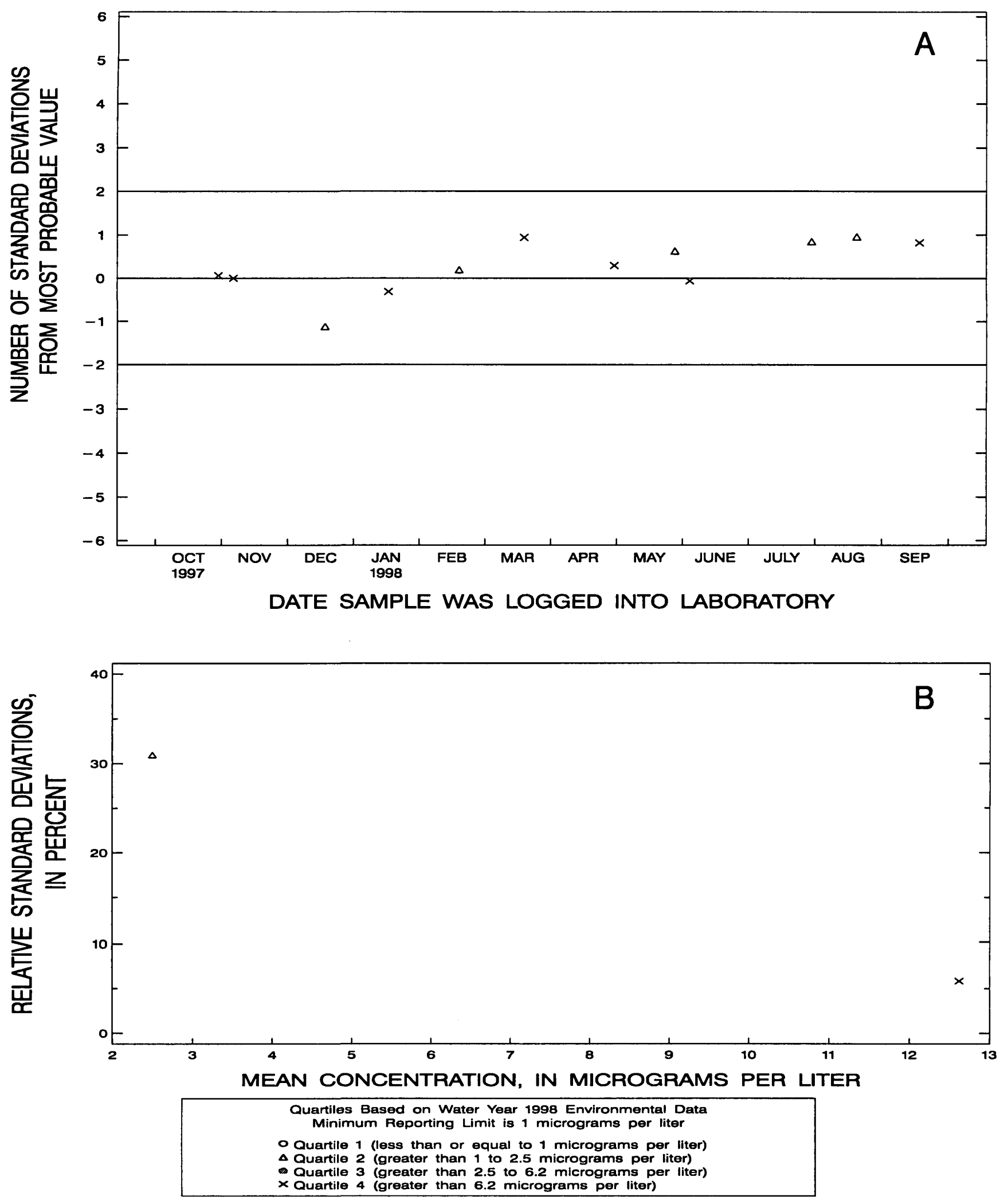

Figure 53. Molybdenum, dissolved, (graphite furnace-atomic absorption spectrophotometry) data from the National Water Quality Laboratory. 


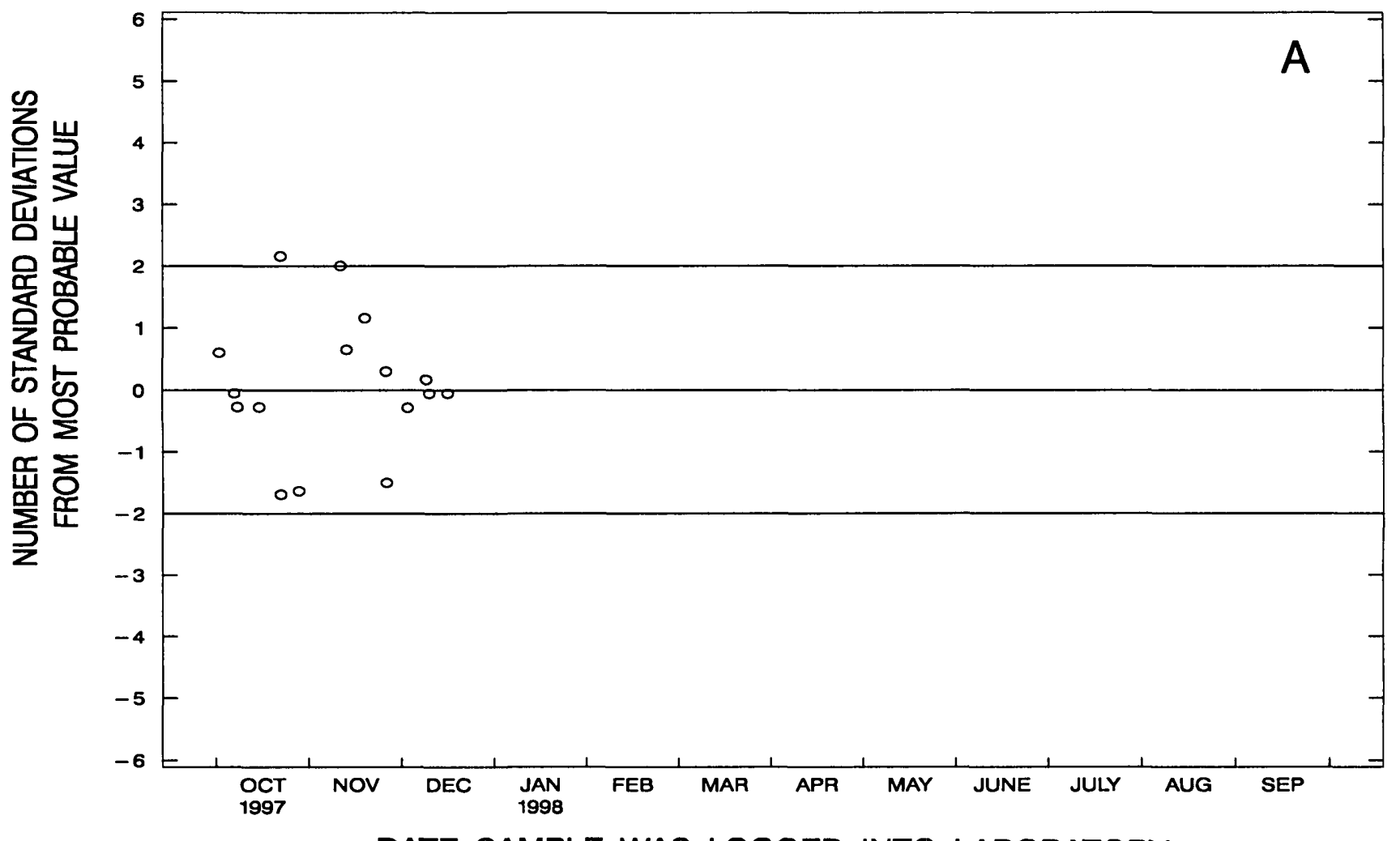

DATE SAMPLE WAS LOGGED INTO LABORATORY

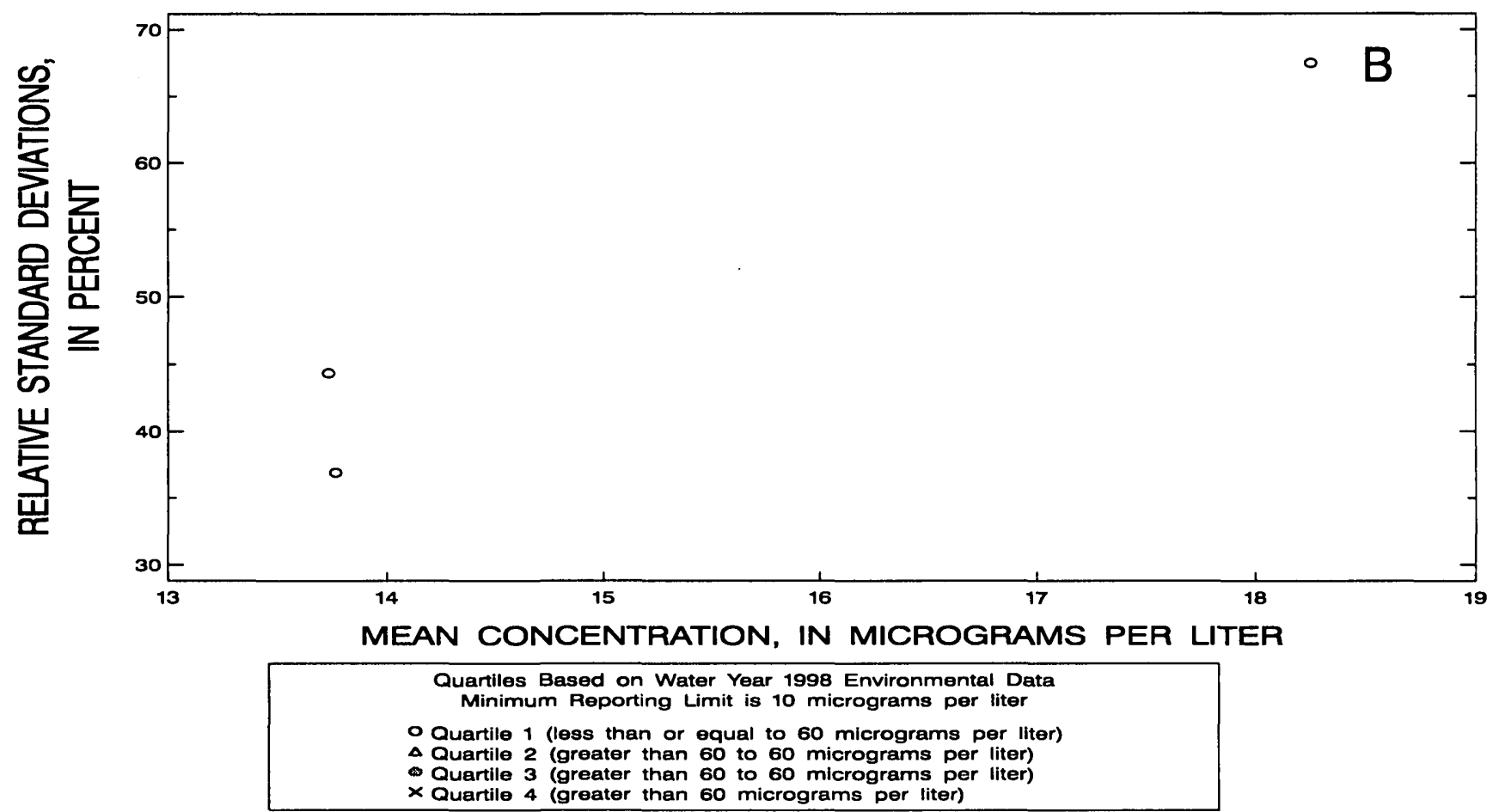

Figure 54. Molybdenum, dissolved, (inductively coupled plasma-atomic emission spectrometry) data from the National Water Quality Laboratory. 

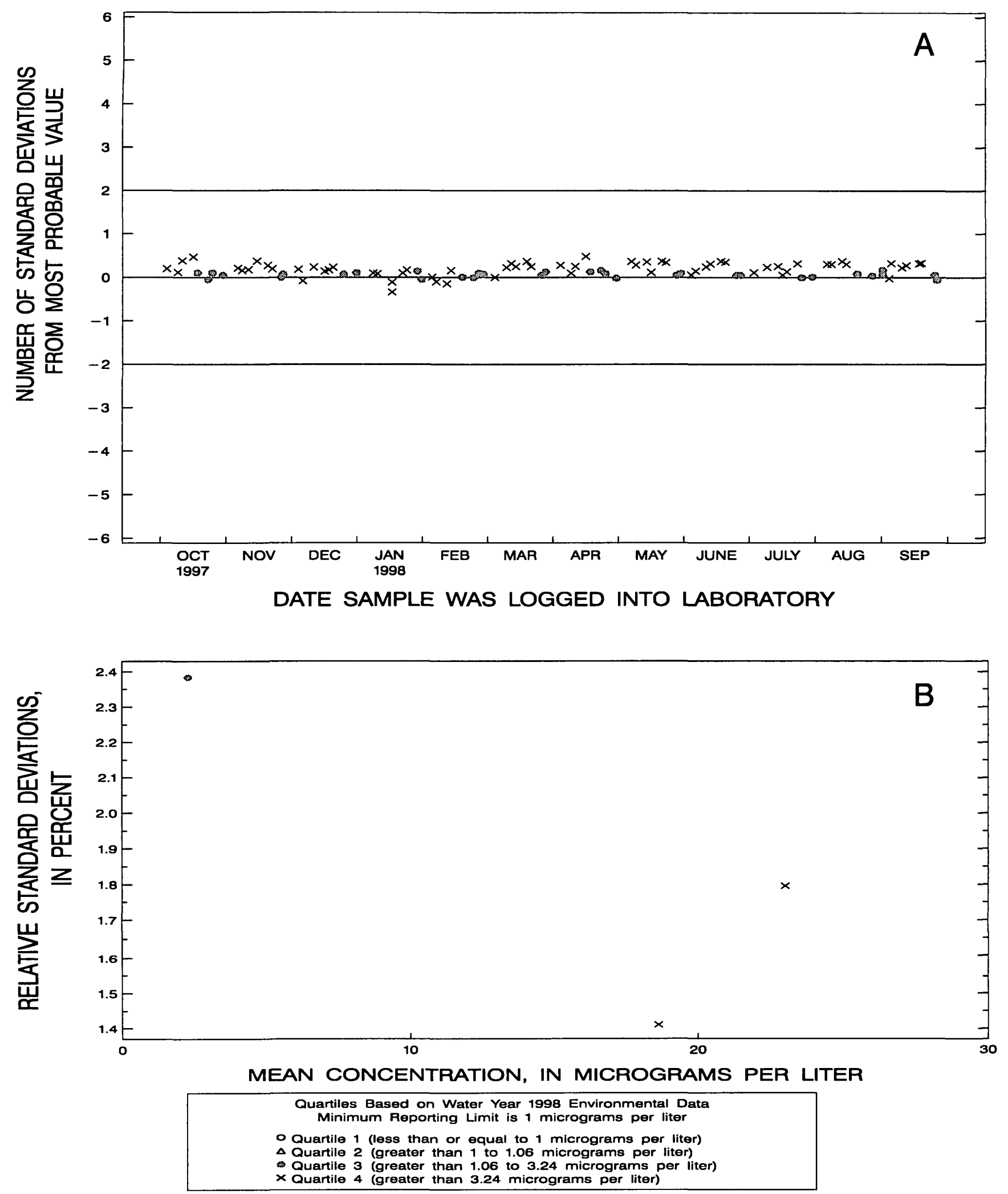

Figure 55. Molybdenum, dissolved, (inductively coupled plasma-mass spectrometry) data from the National Water Quality Laboratory. 

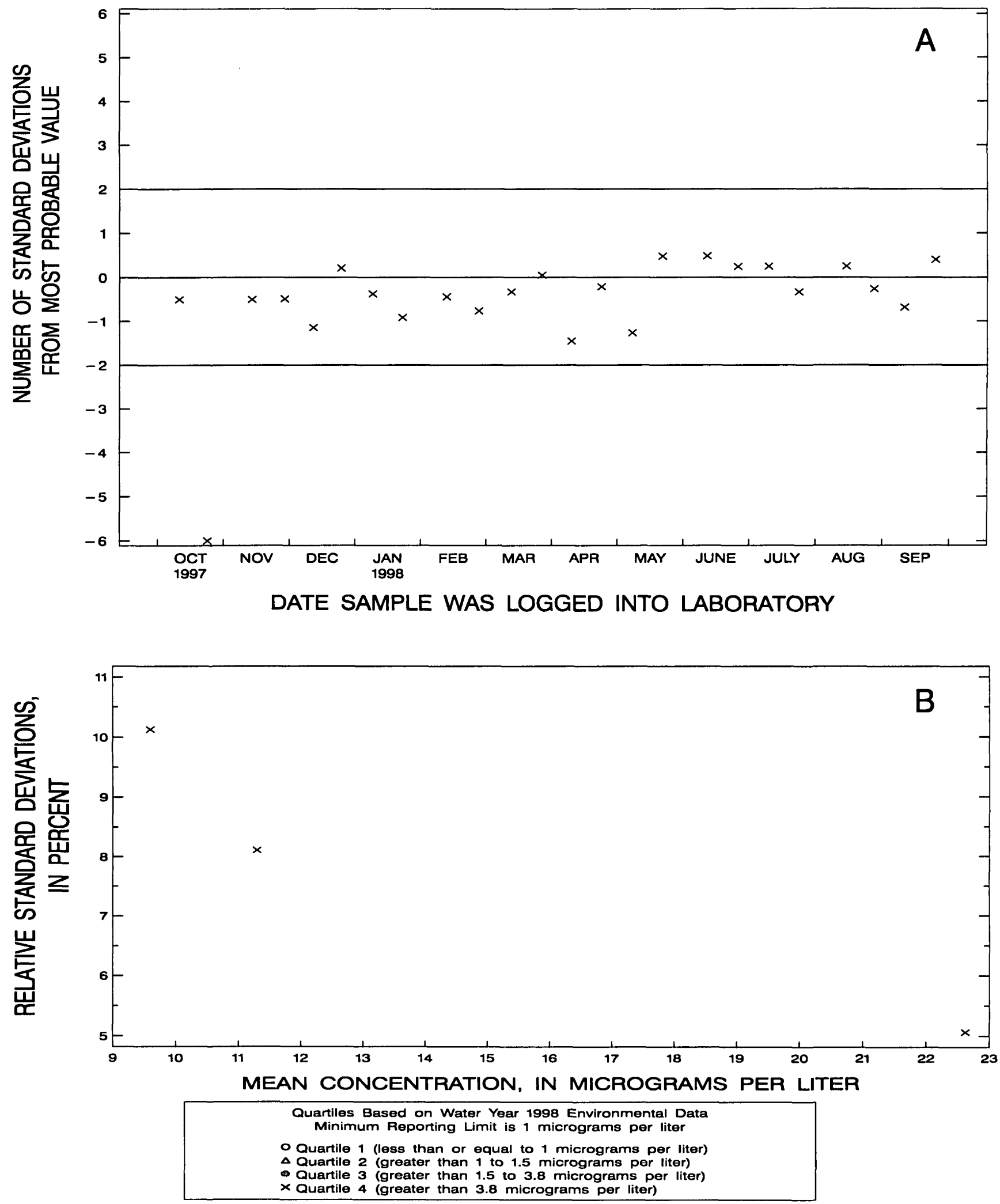

Figure 56. Molybdenum, whole-water recoverable, (graphite furnace-atomic absorption spectrophotometry) data from the National Water Quality Laboratory. 

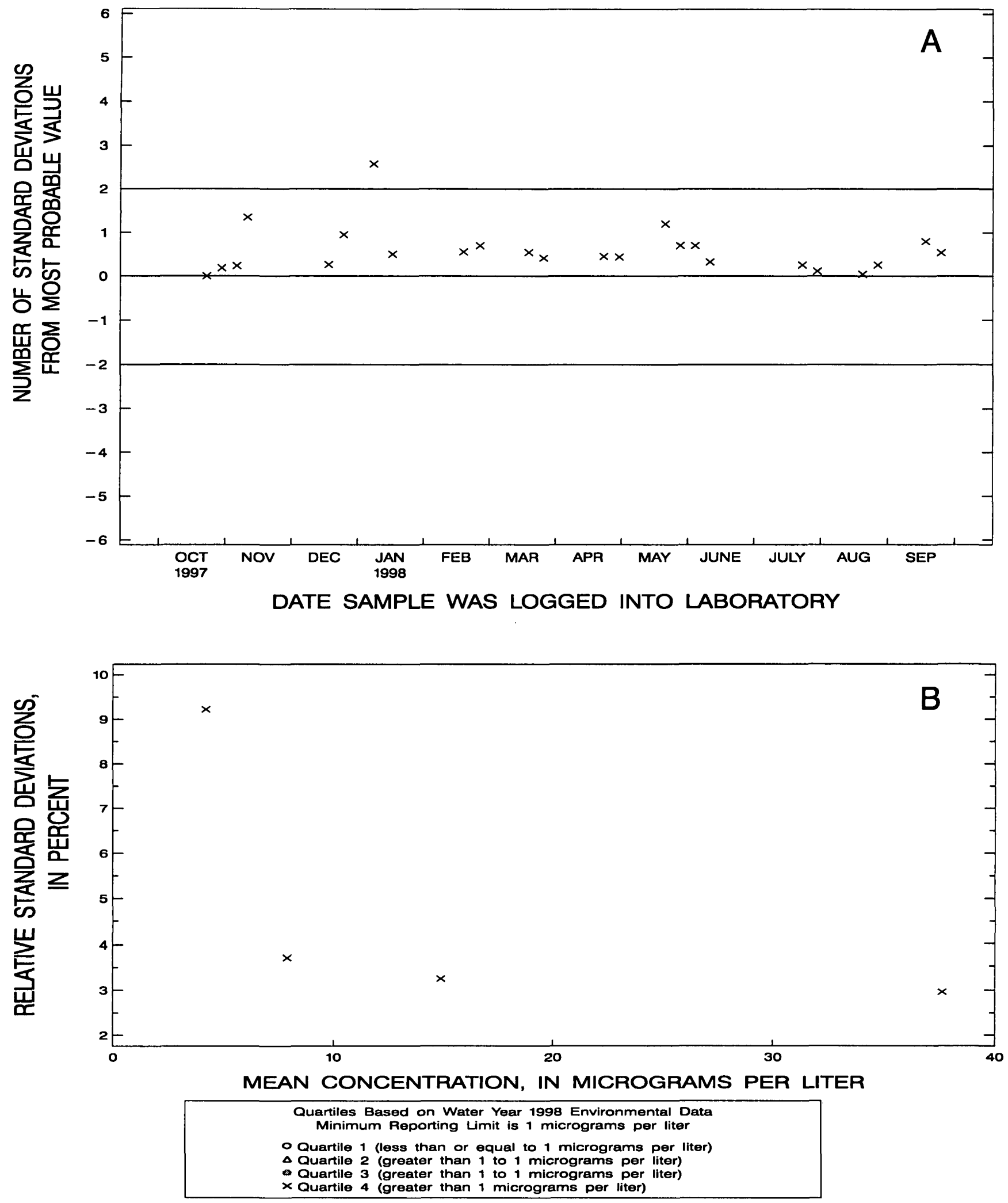

Figure 57. Nickel, dissolved, (graphite furnace-atomic absorption spectrophotometry) data from the National Water Quality Laboratory. 

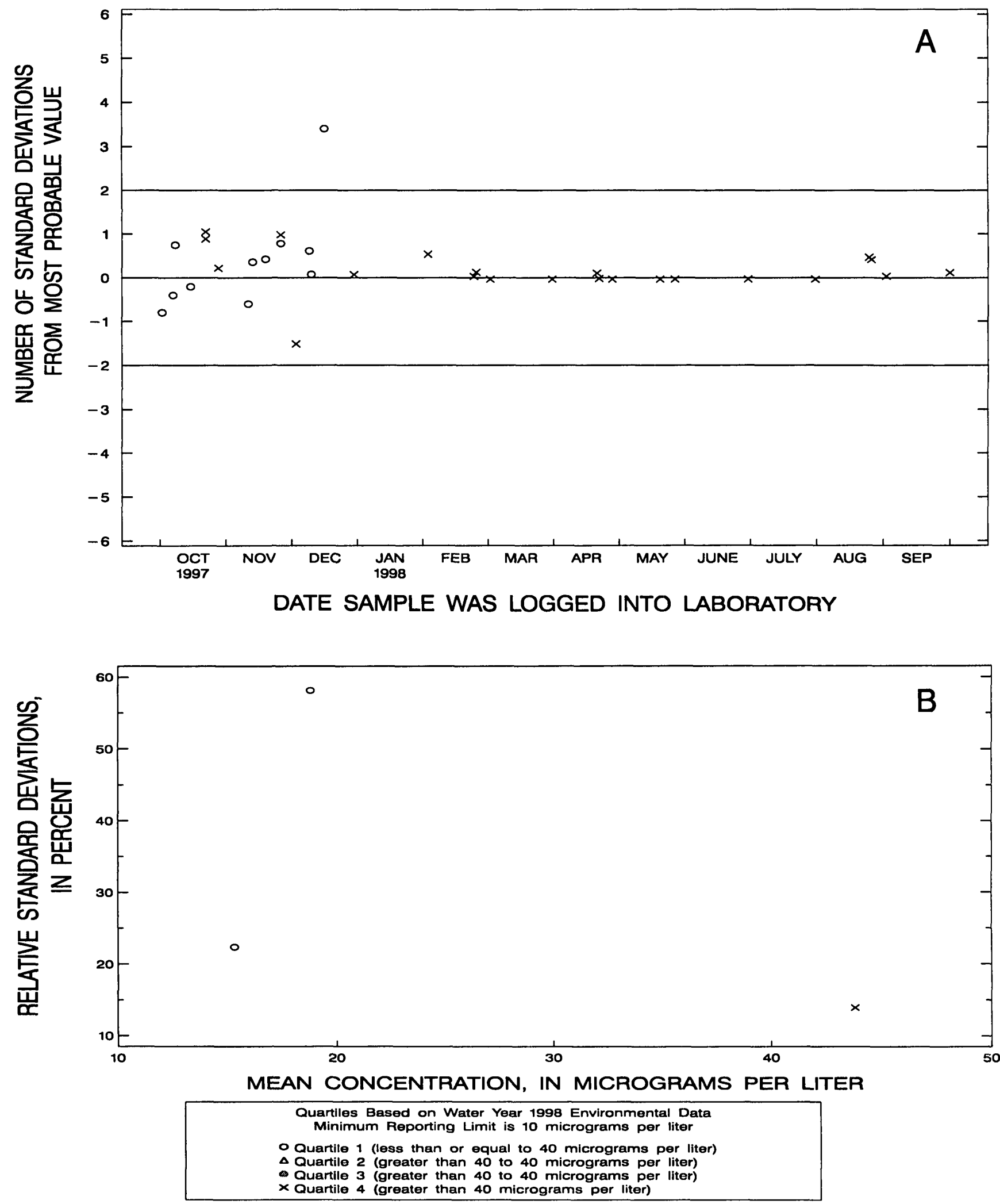

Figure 58. Nickel, dissolved, (inductively coupled plasma-atomic emission spectrometry) data from the National Water Quality Laboratory. 

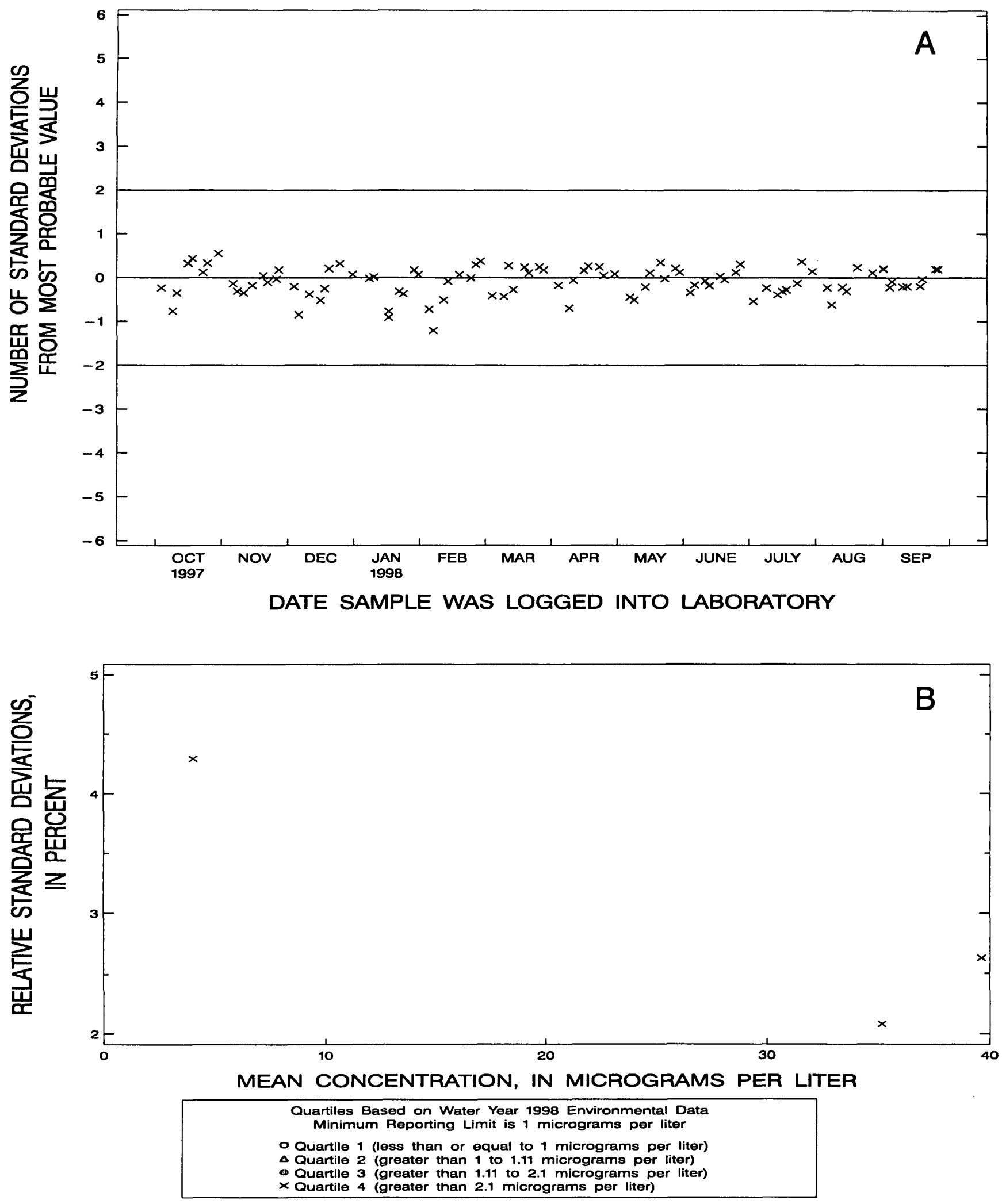

Figure 59. Nickel, dissolved, (inductively coupled plasma-mass spectrometry) data from the National Water Quality Laboratory. 

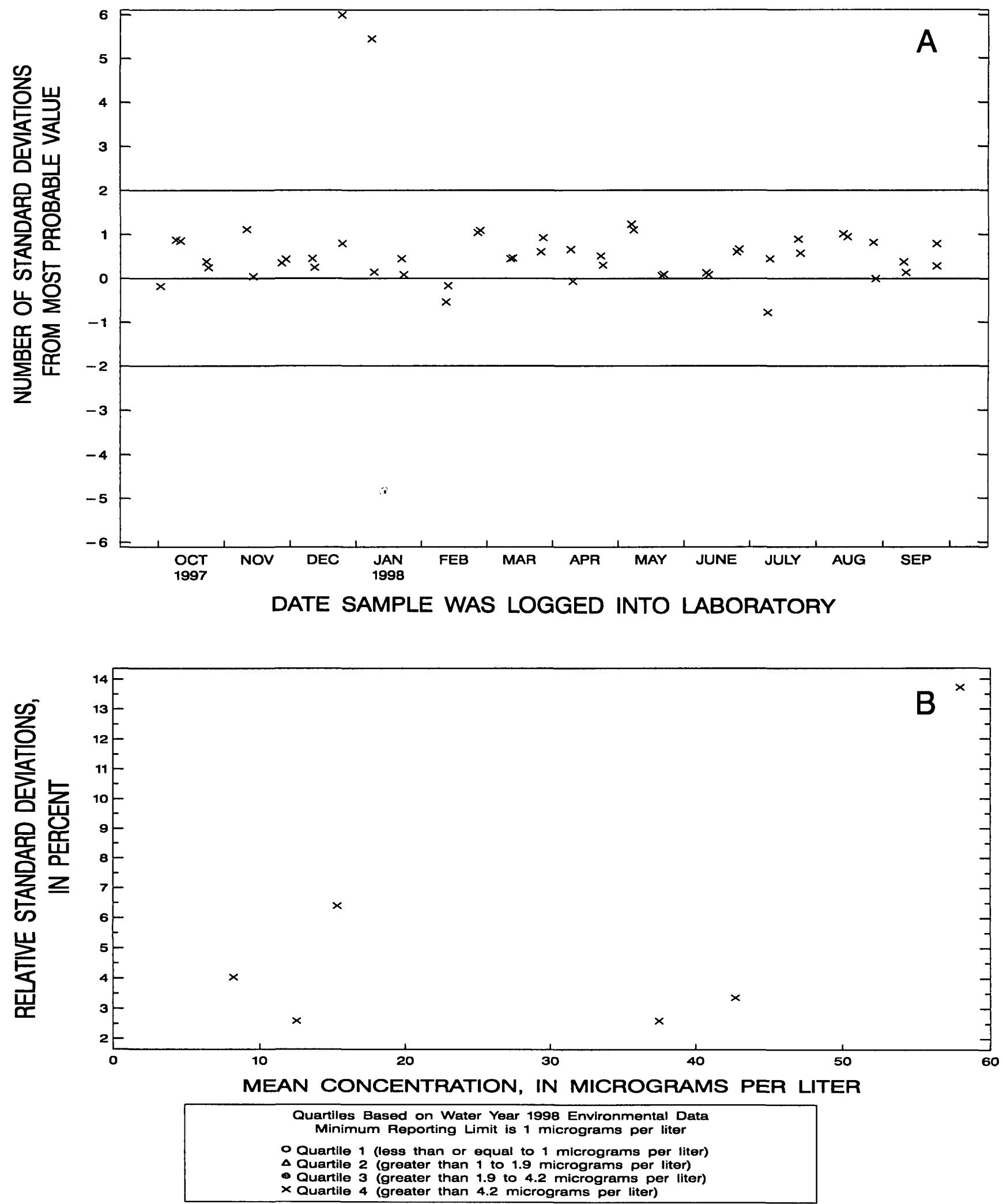

Figure 60. Nickel, whole-water recoverable, (graphite furnace-atomic absorption spectrophotometry) data from the National Water Quality Laboratory. 

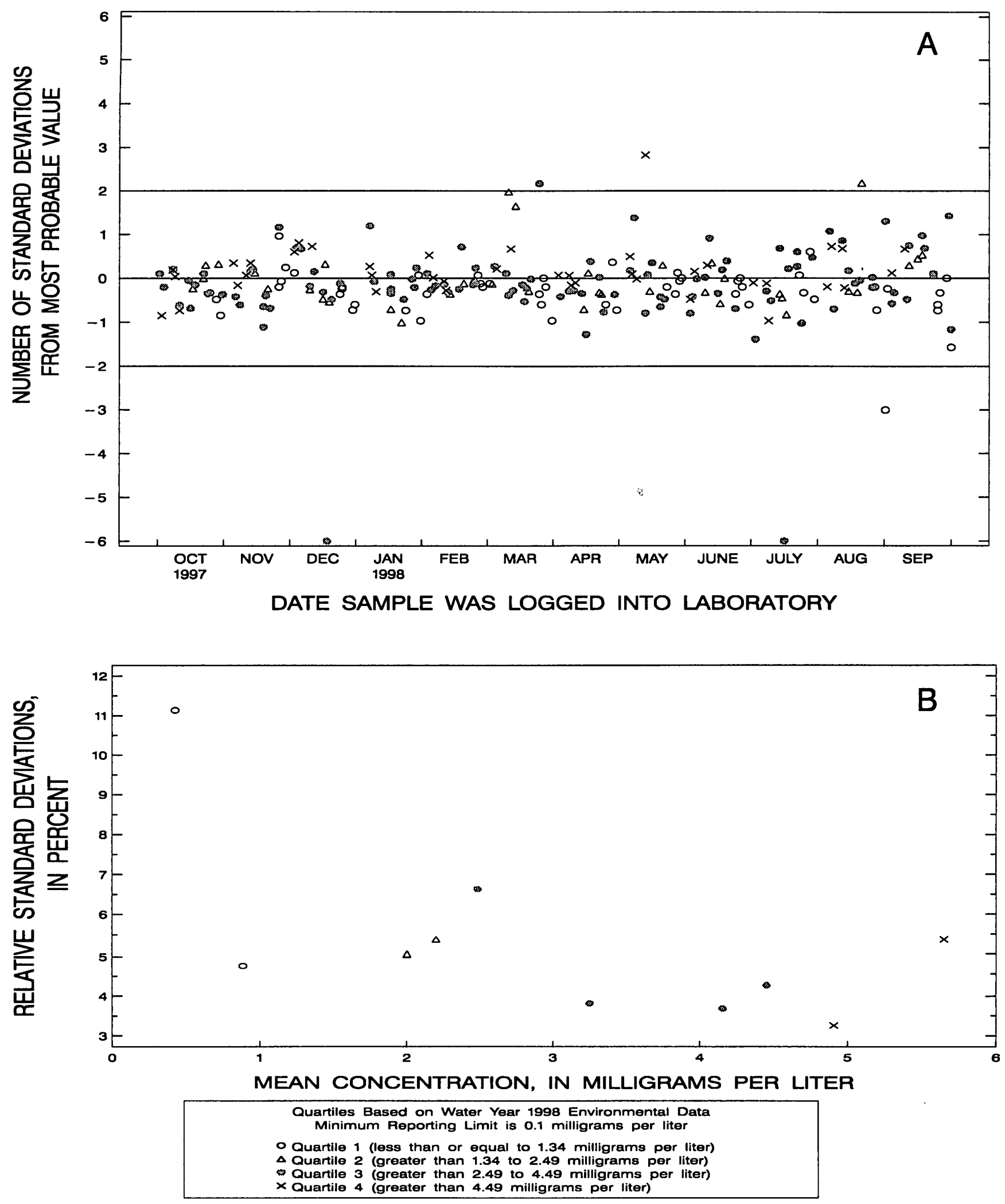

Figure 61. Potassium, dissolved, (flame-atomic absorption spectrophotometry) data from the National Water Quality Laboratory. 

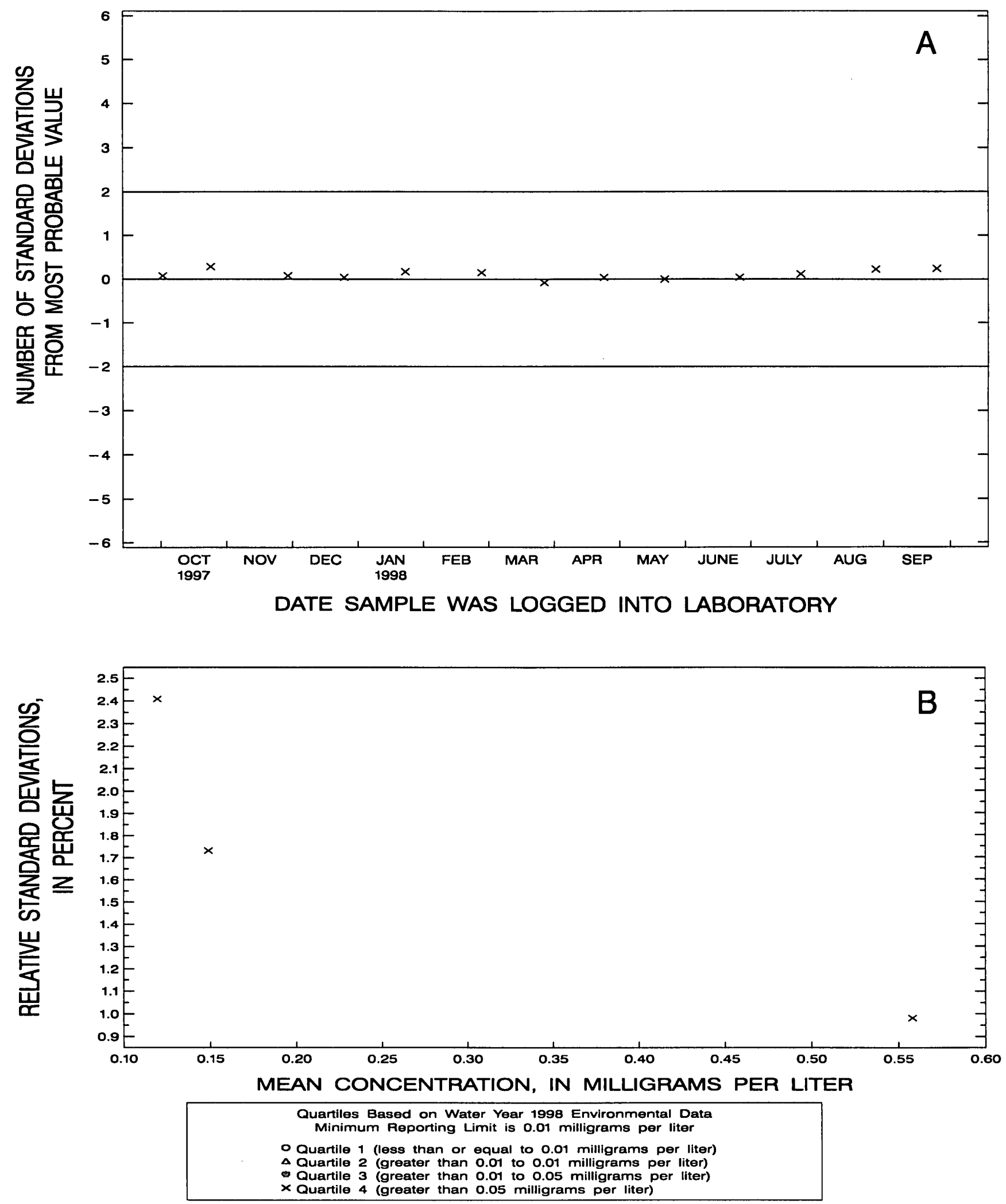

Figure 62. Potassium, dissolved, (flame-atomic absorption spectrophotometry, low level) data from the National Water Quality Laboratory. 

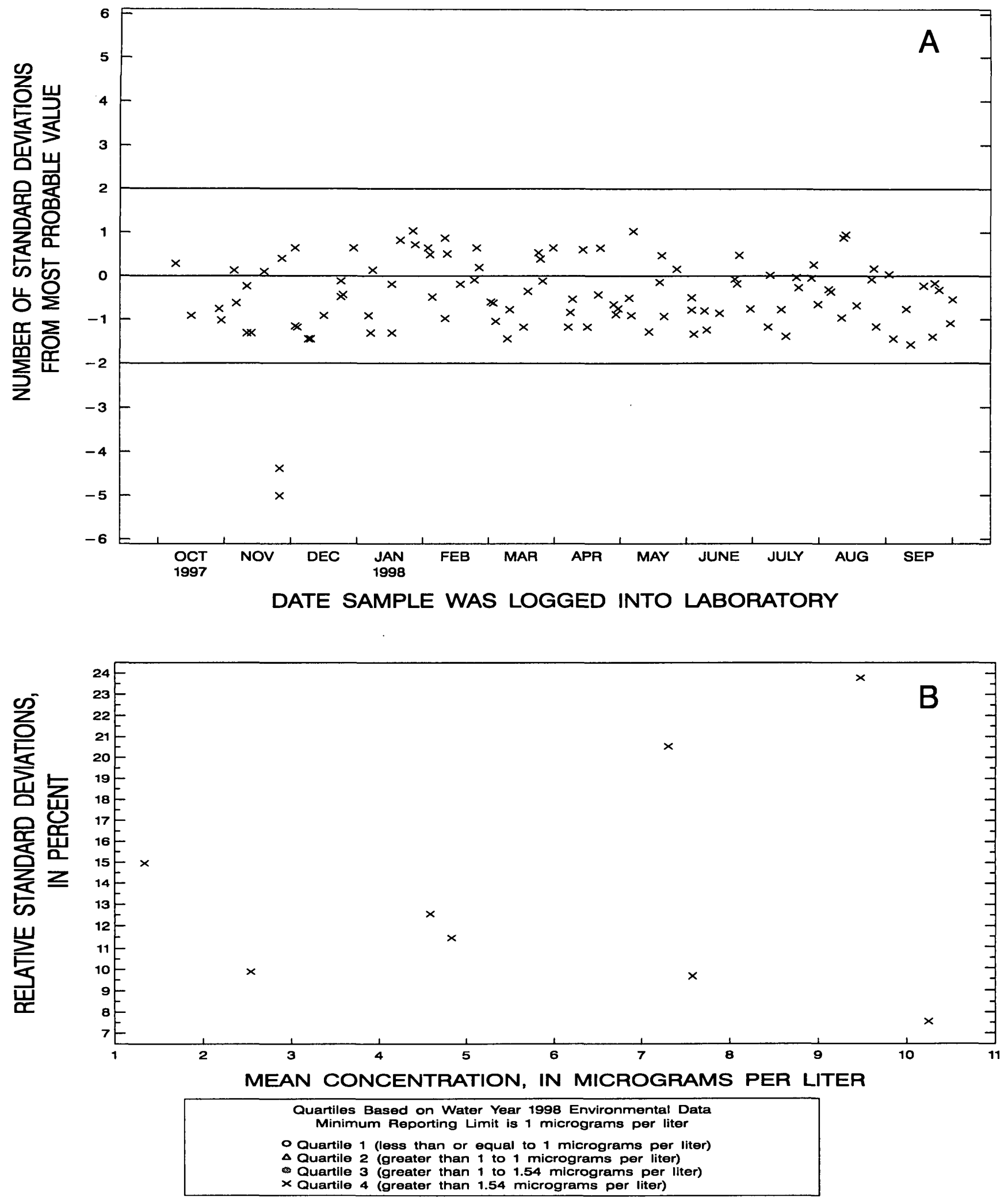

Figure 63. Selenium, dissolved, (hydride generation-atomic absorption spectrophotometry) data from the National Water Quality Laboratory. 

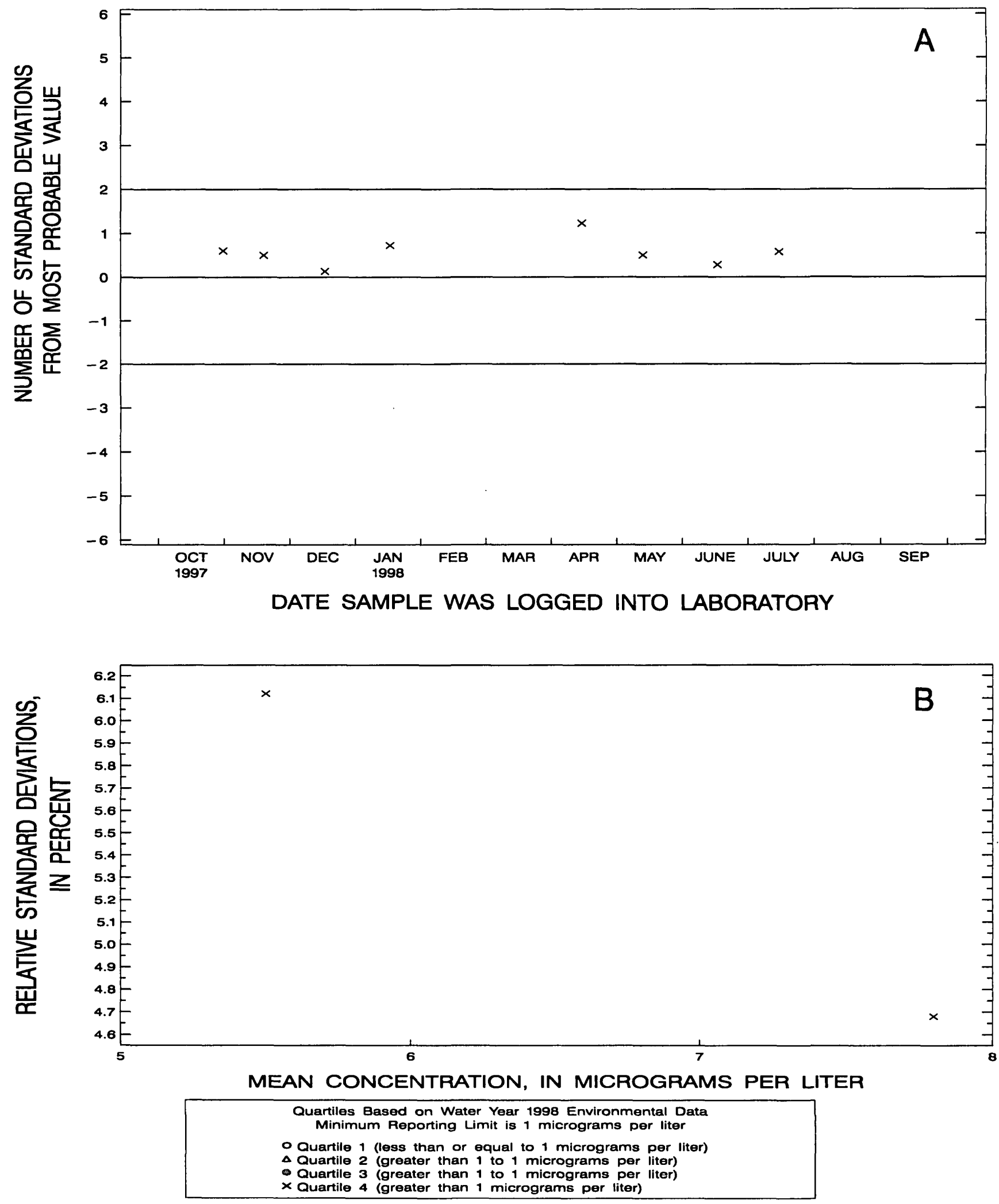

Figure 64. Selenium, whole-water recoverable, (graphite furnace-atomic absorption spectrophotometry, U.S. Environmental Protection Agency) data from the National Water Quality Laboratory. 

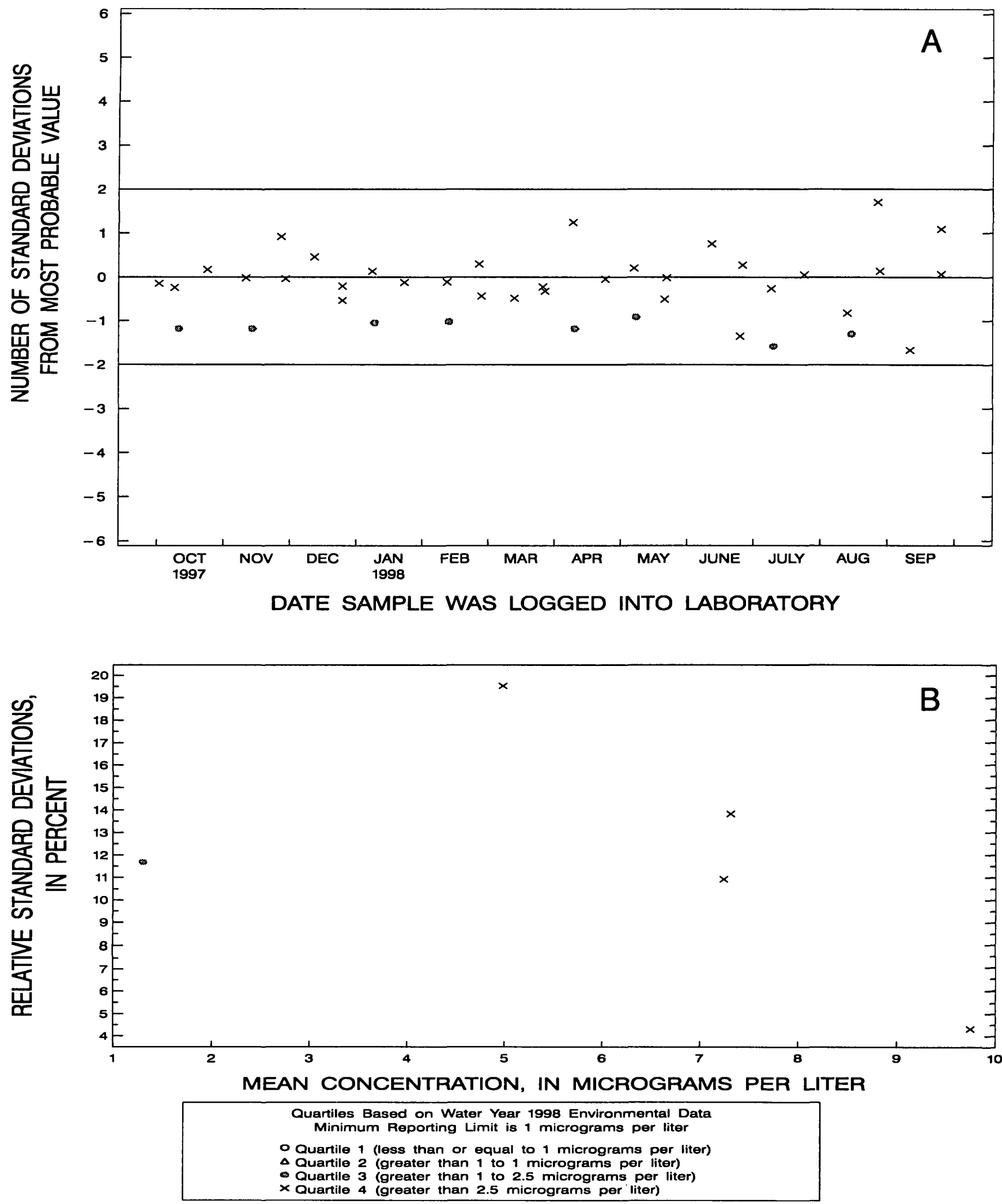

Figure 65. Selenium, whole-water recoverable, (hydride generation-atomic absorption spectrophotometry) data from the National Water Quality Laboratory. 

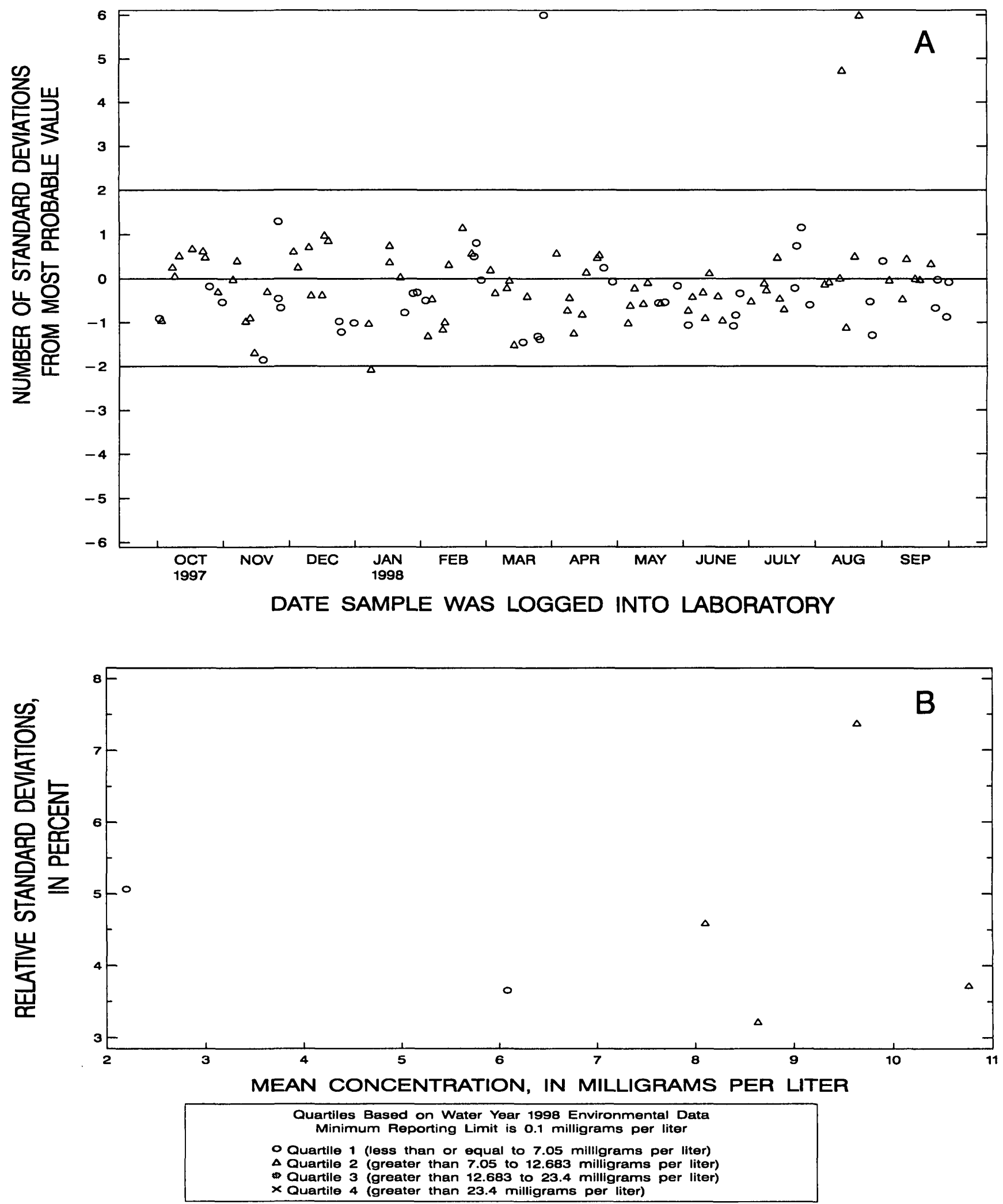

Figure 66. Silica, dissolved, (colorimetric) data from the National Water Quality Laboratory. 

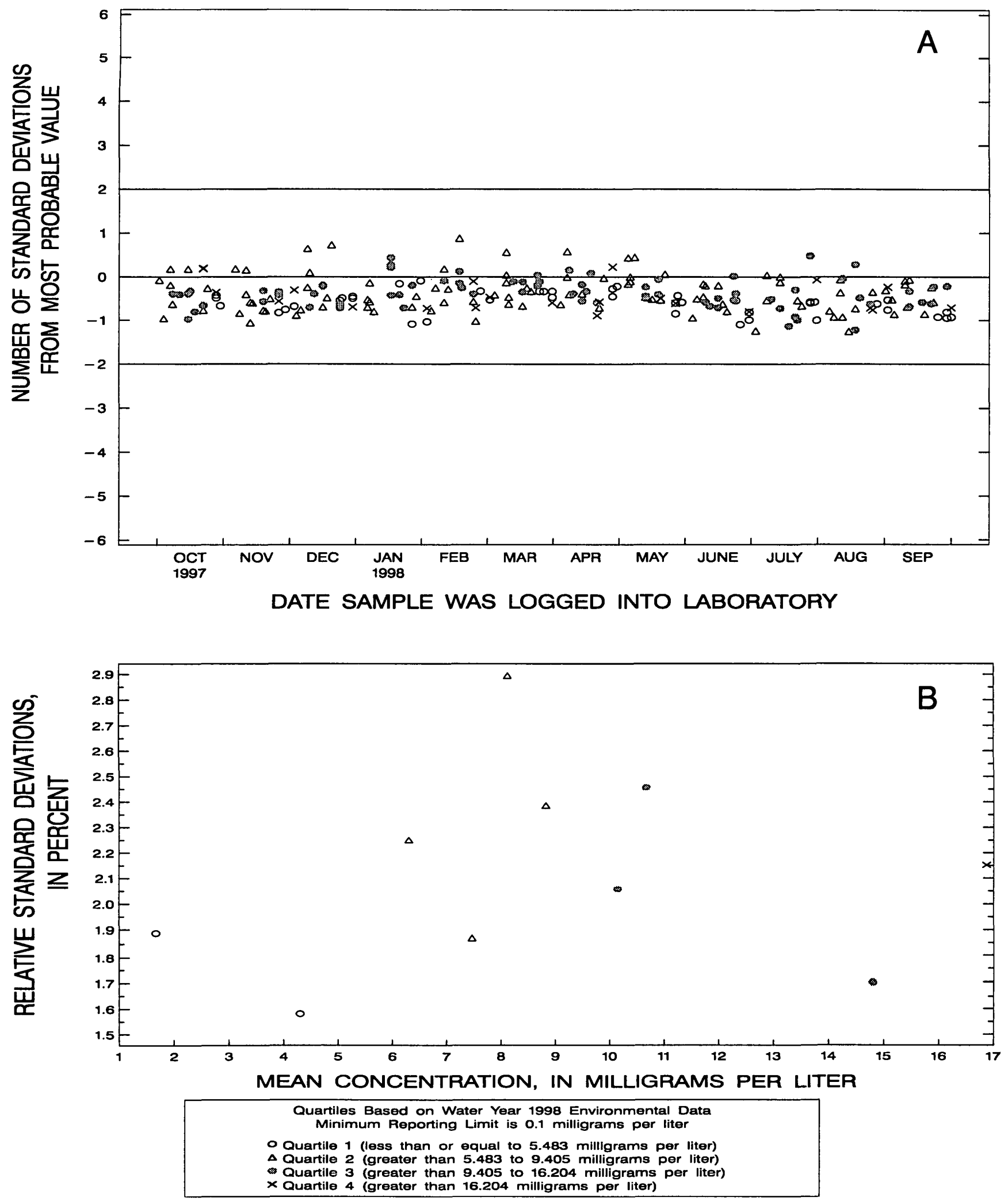

Figure 67. Silica, dissolved, (inductively coupled plasma-atomic emission spectrometry) data from the National Water Quality Laboratory. 

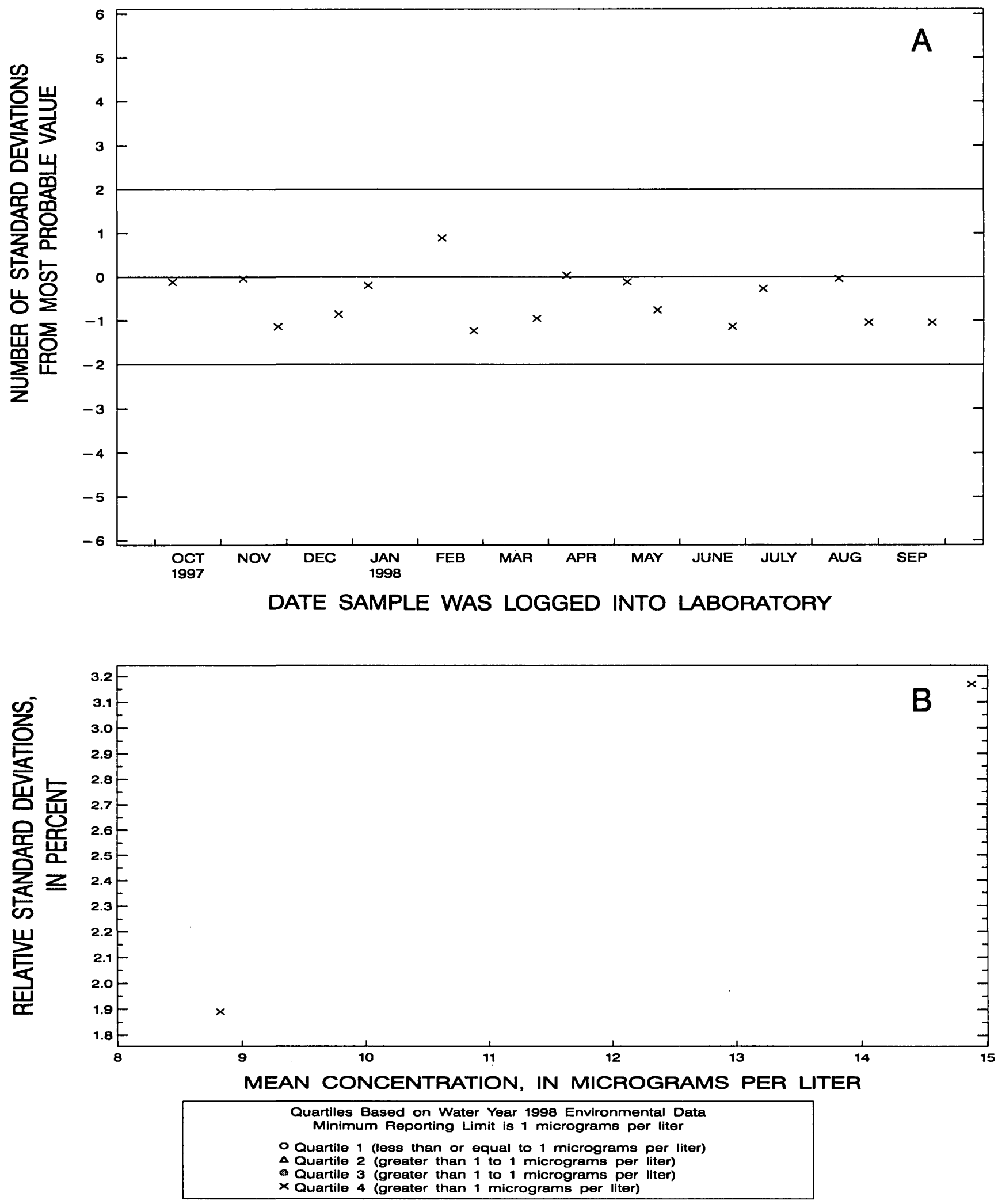

Figure 68. Silver, dissolved, (graphite furnace-atomic absorption spectrophotometry) data from the National Water Quality Laboratory. 

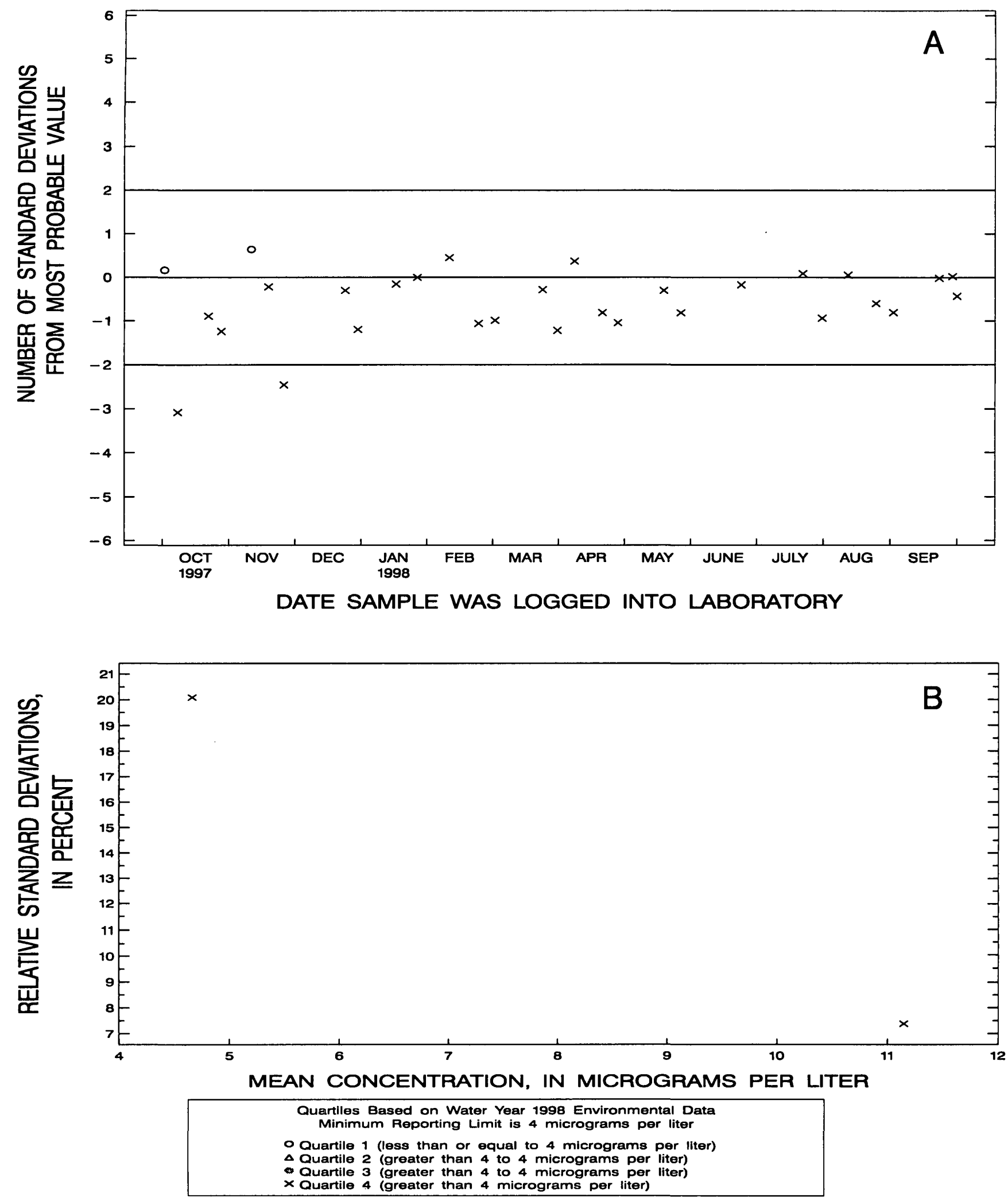

Figure 69. Silver, dissolved, (inductively coupled plasma-atomic emission spectrometry) data from the National Water Quality Laboratory. 

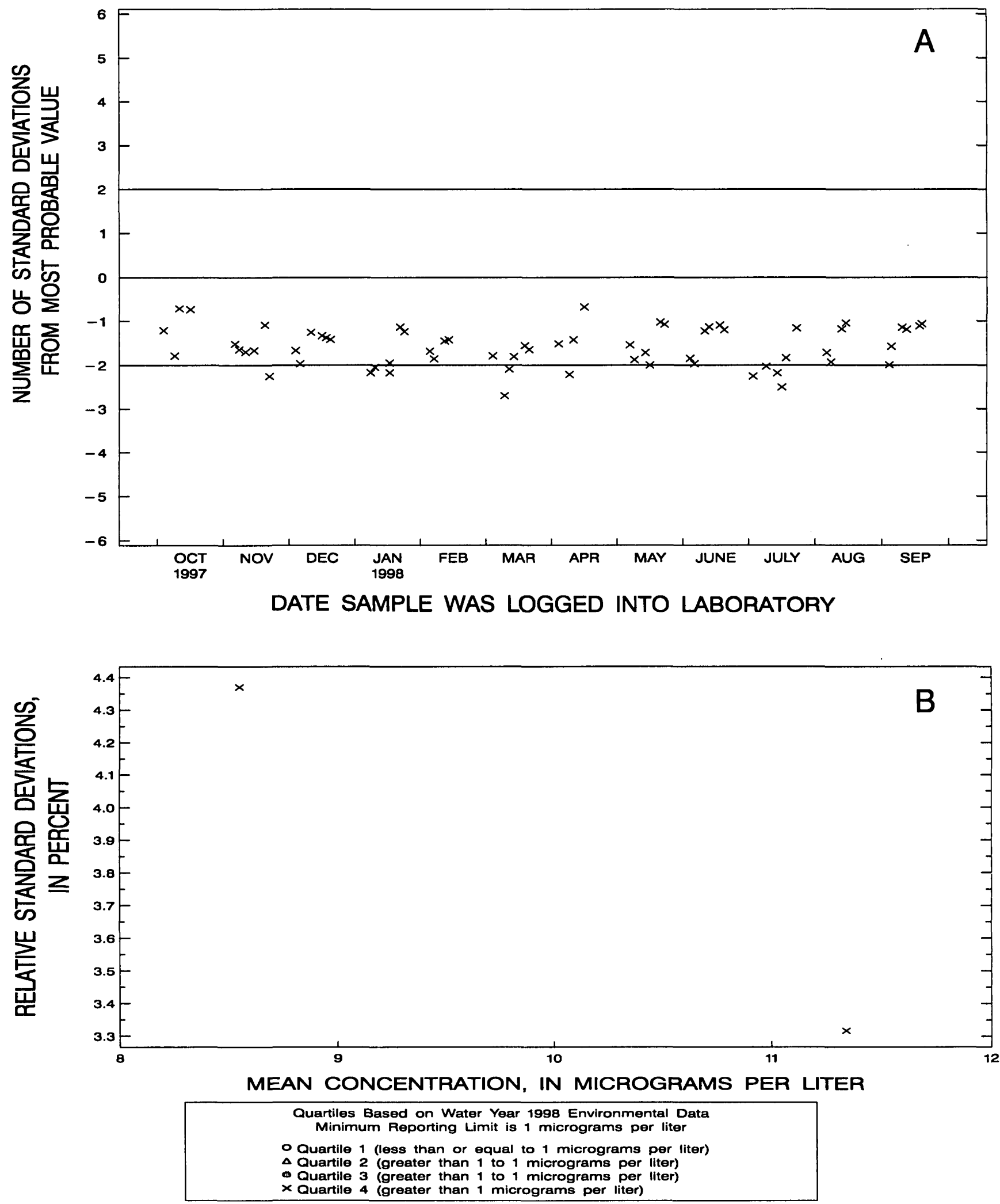

Figure 70. Silver, dissolved, (inductively coupled plasma-mass spectrometry) data from the National Water Quality Laboratory. 

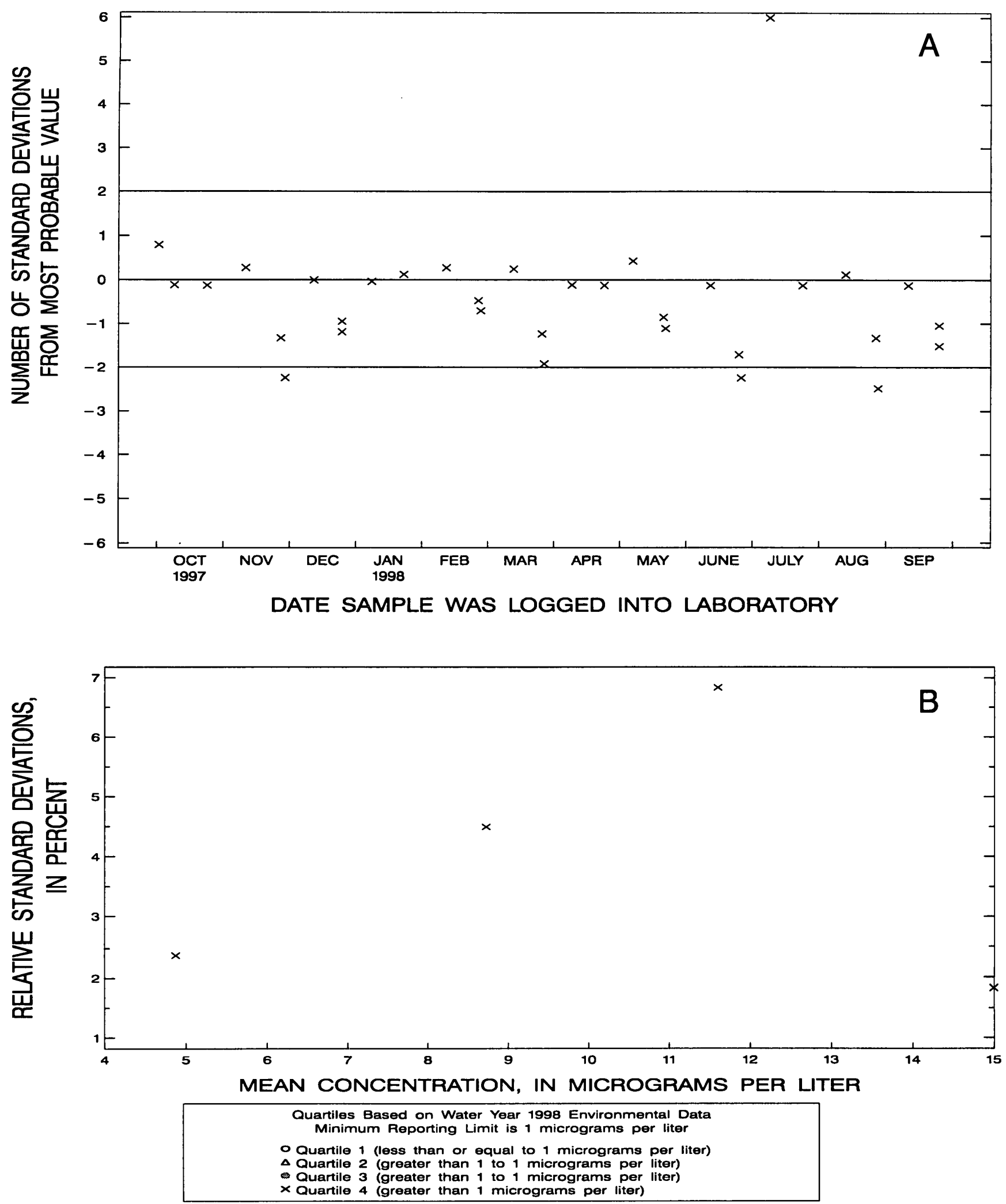

Figure 71. Silver, whole-water recoverable, (graphite furnace-atomic absorption spectrophotometry) data from the National Water Quality Laboratory. 

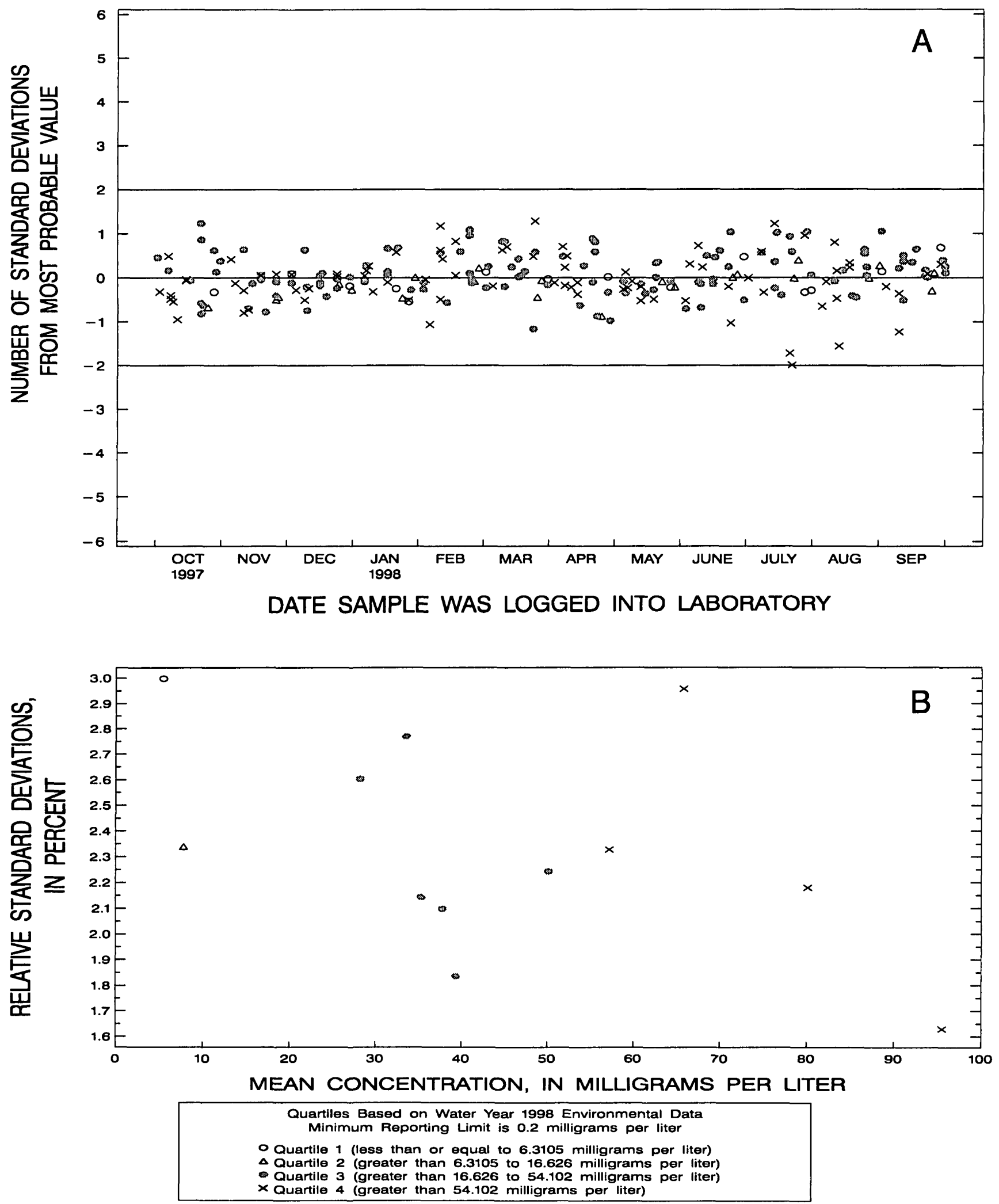

Figure 72. Sodium, dissolved, (inductively coupled plasma-atomic emission spectrometry) data from the National Water Quality Laboratory. 

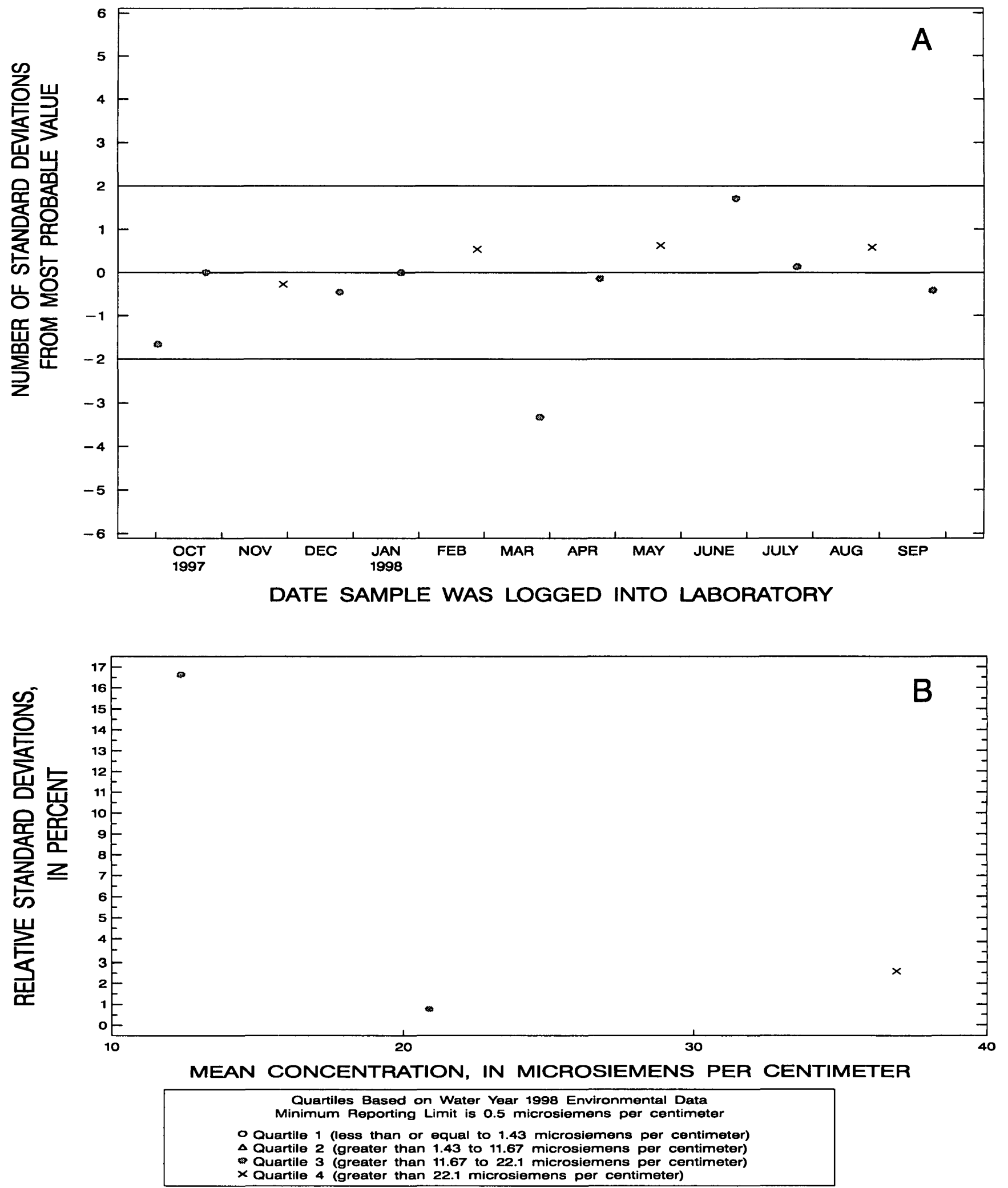

Figure 73. Specific conductance, whole-water recoverable, (electrometric, low level) data from the National Water Quality Laboratory. 

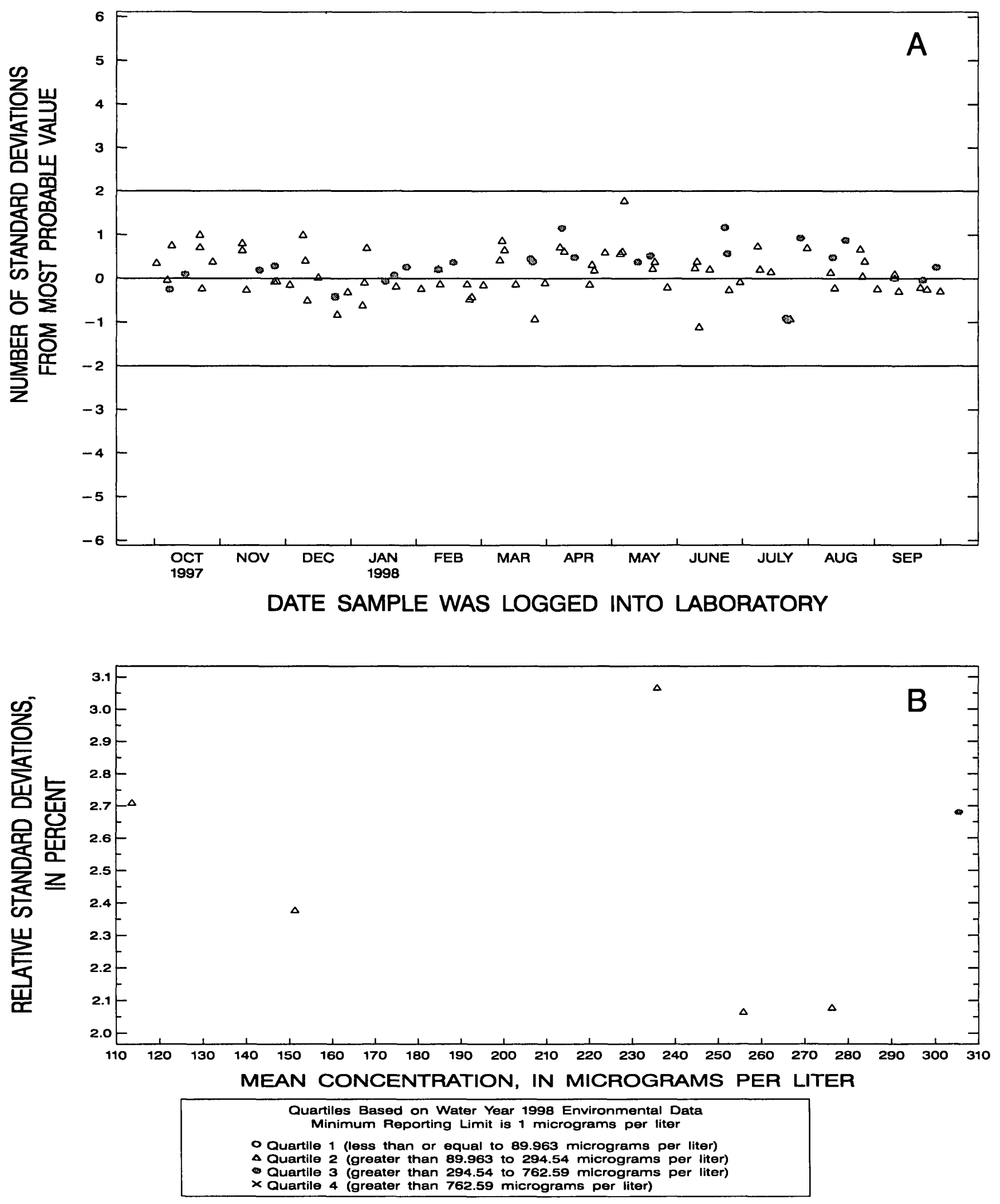

Figure 74. Strontium, dissolved, (inductively coupled plasma-atomic emission spectrometry) data from the National Water Quality Laboratory. 

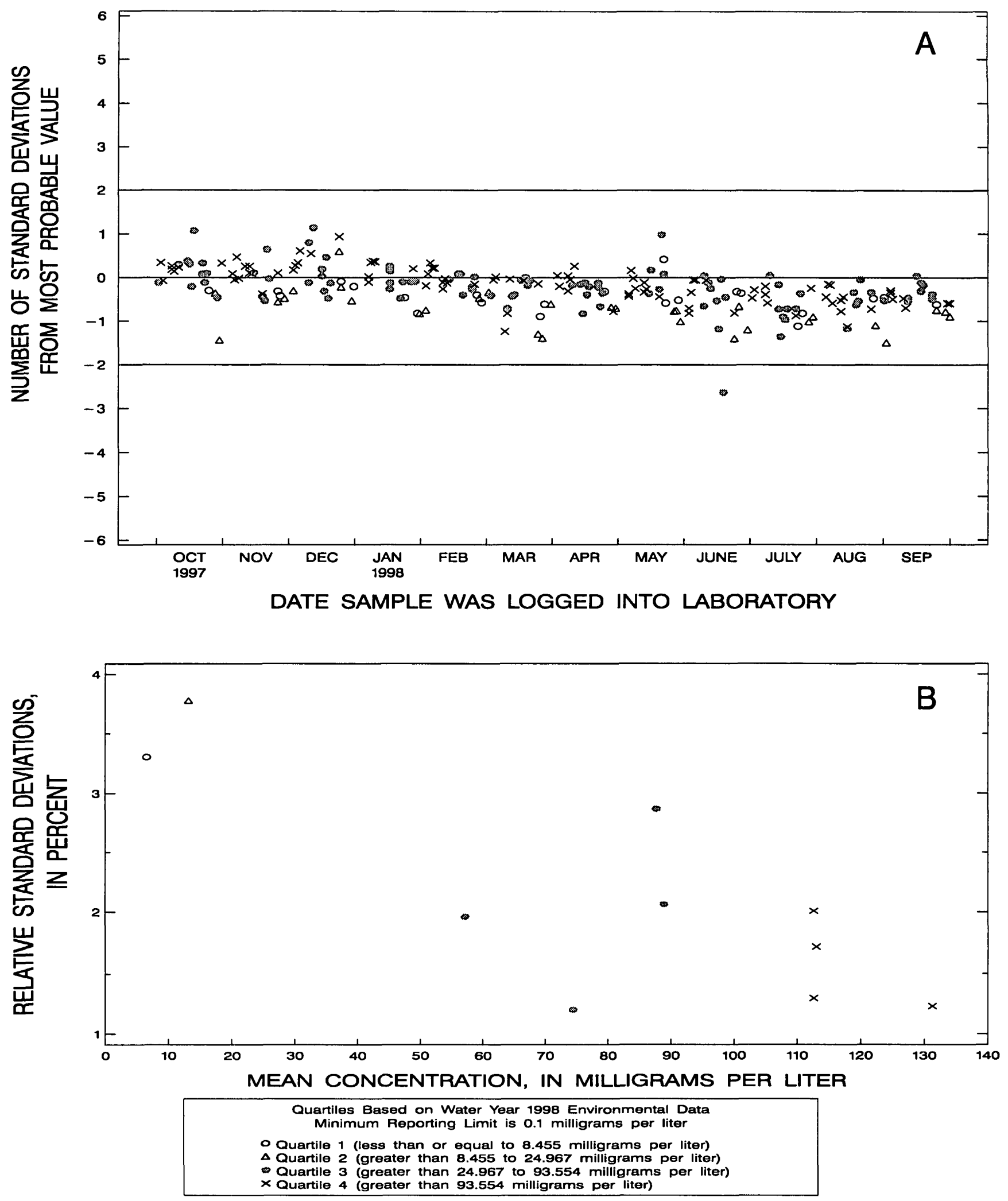

Figure 75. Sulfate, dissolved, (ion chromatography) data from the National Water Quality Laboratory. 

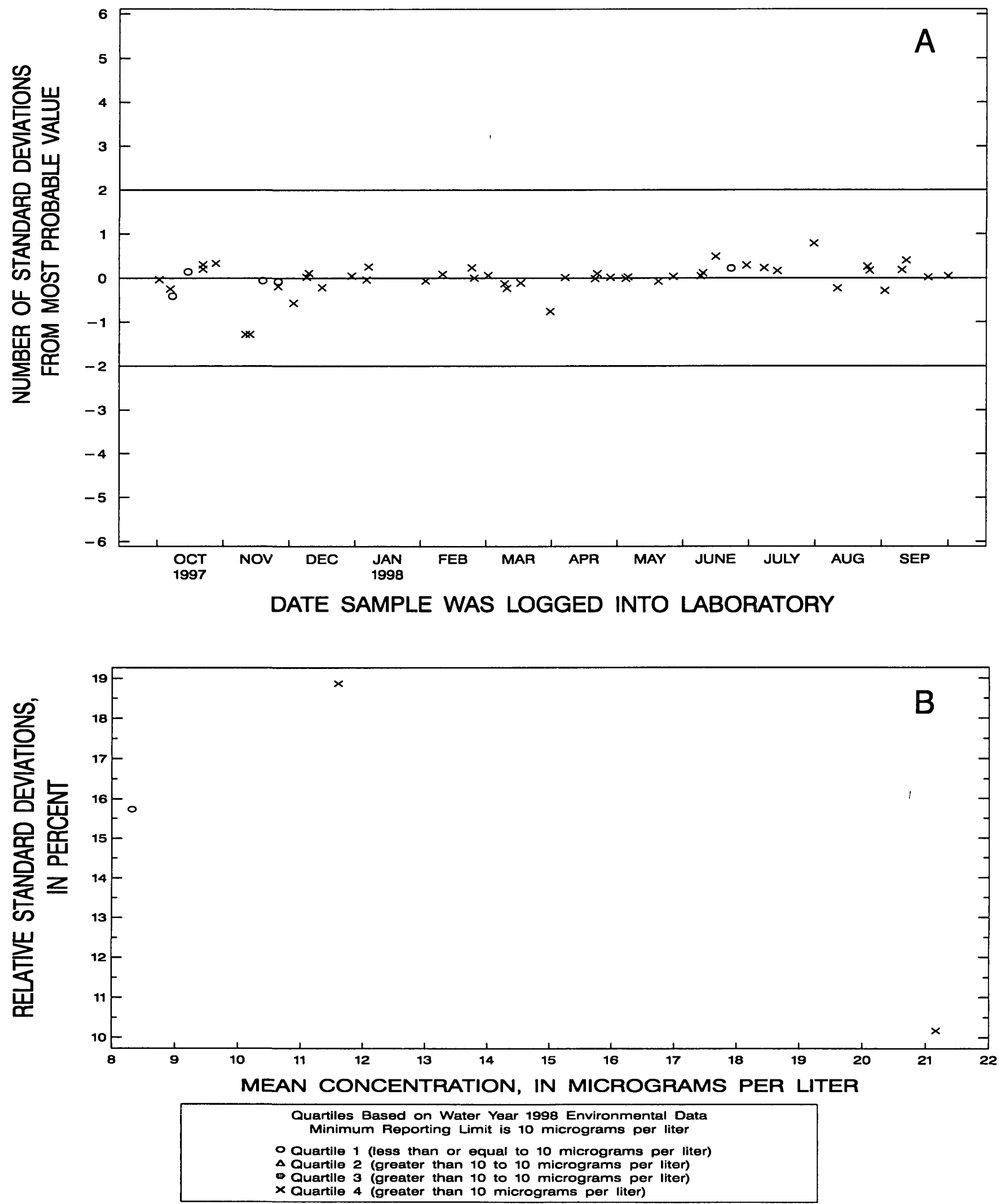

Figure 76. Vanadium, dissolved, (inductively coupled plasma-atomic emission spectrometry) data from the National Water Quality Laboratory. 

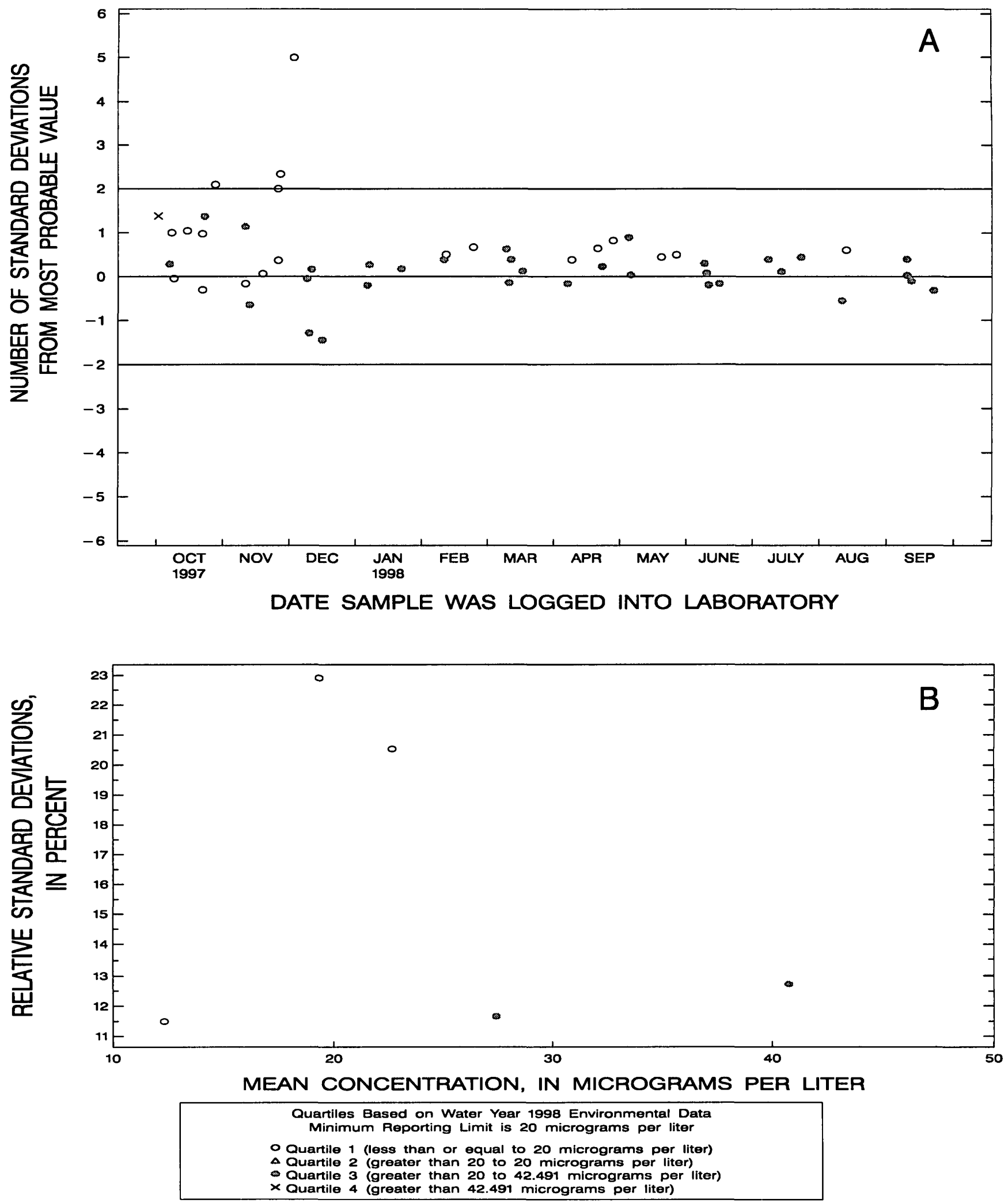

Figure 77. Zinc, dissolved, (inductively coupled plasma-atomic emission spectrometry) data from the National Water Quality Laboratory. 

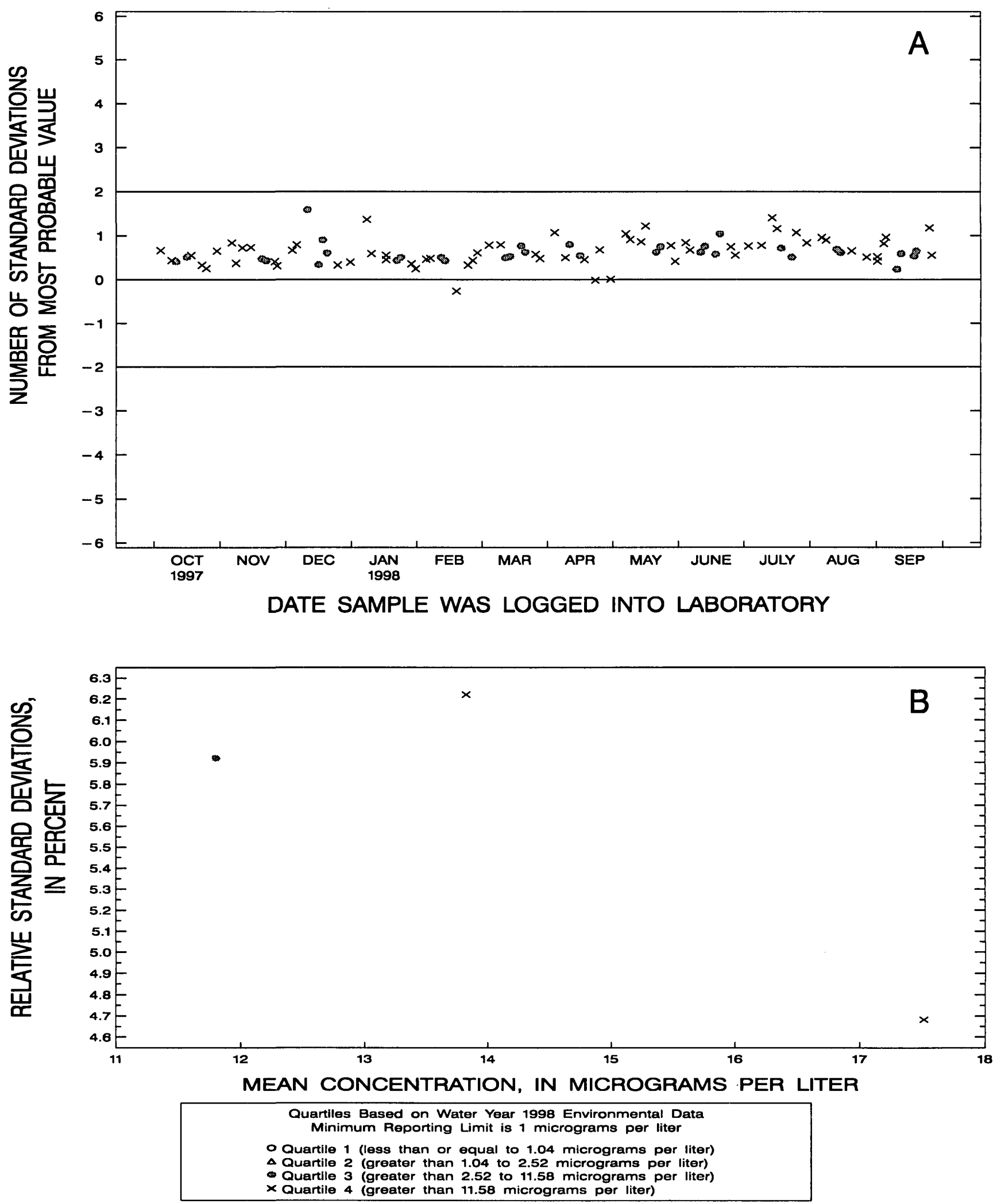

Figure 78. Zinc, dissolved, (inductively coupled plasma-mass spectrometry) data from the National Water Quality Laboratory. 

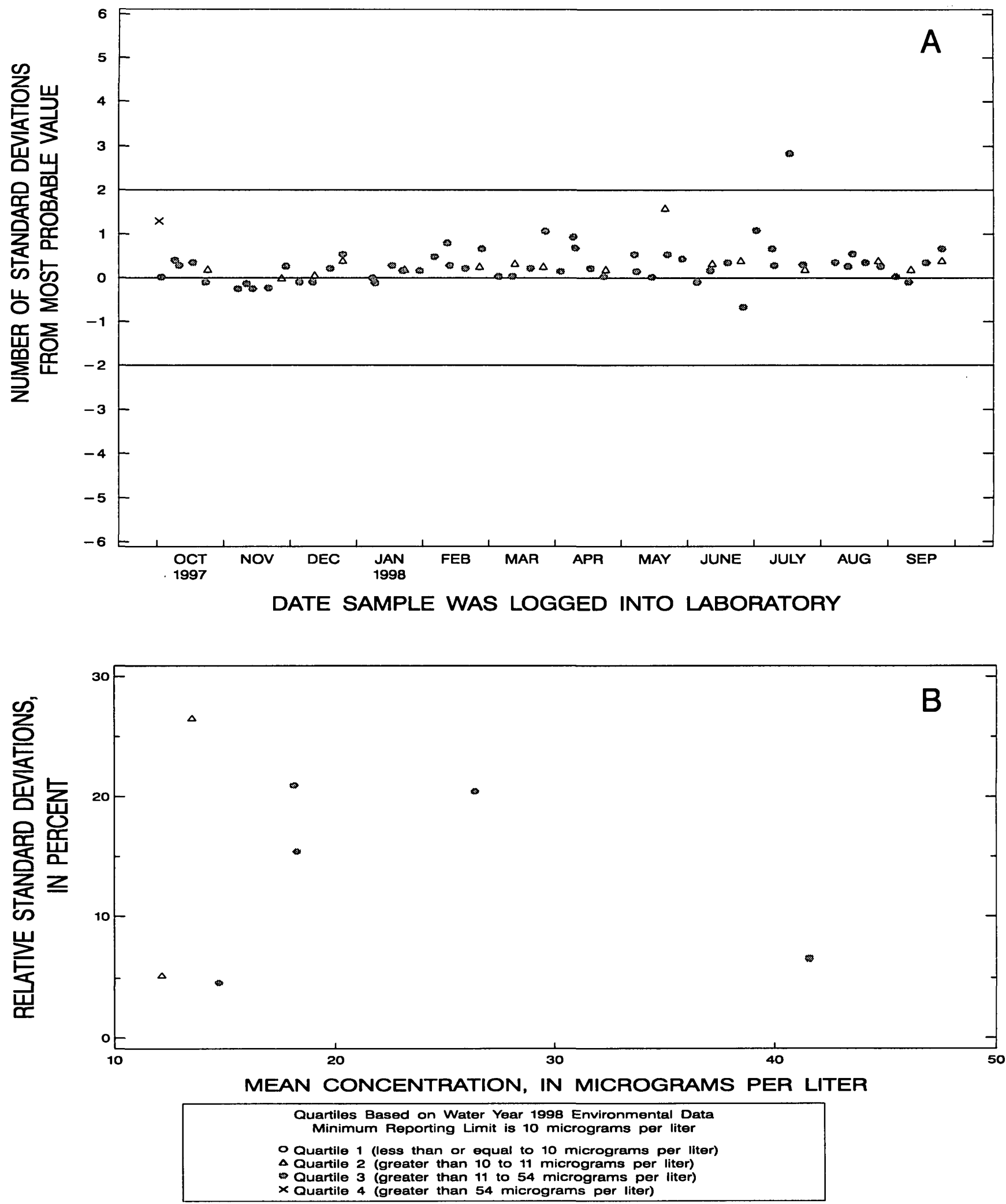

Figure 79. Zinc, whole-water recoverable, (flame-atomic absorption spectrophotometry) data from the National Water Quality Laboratory. 

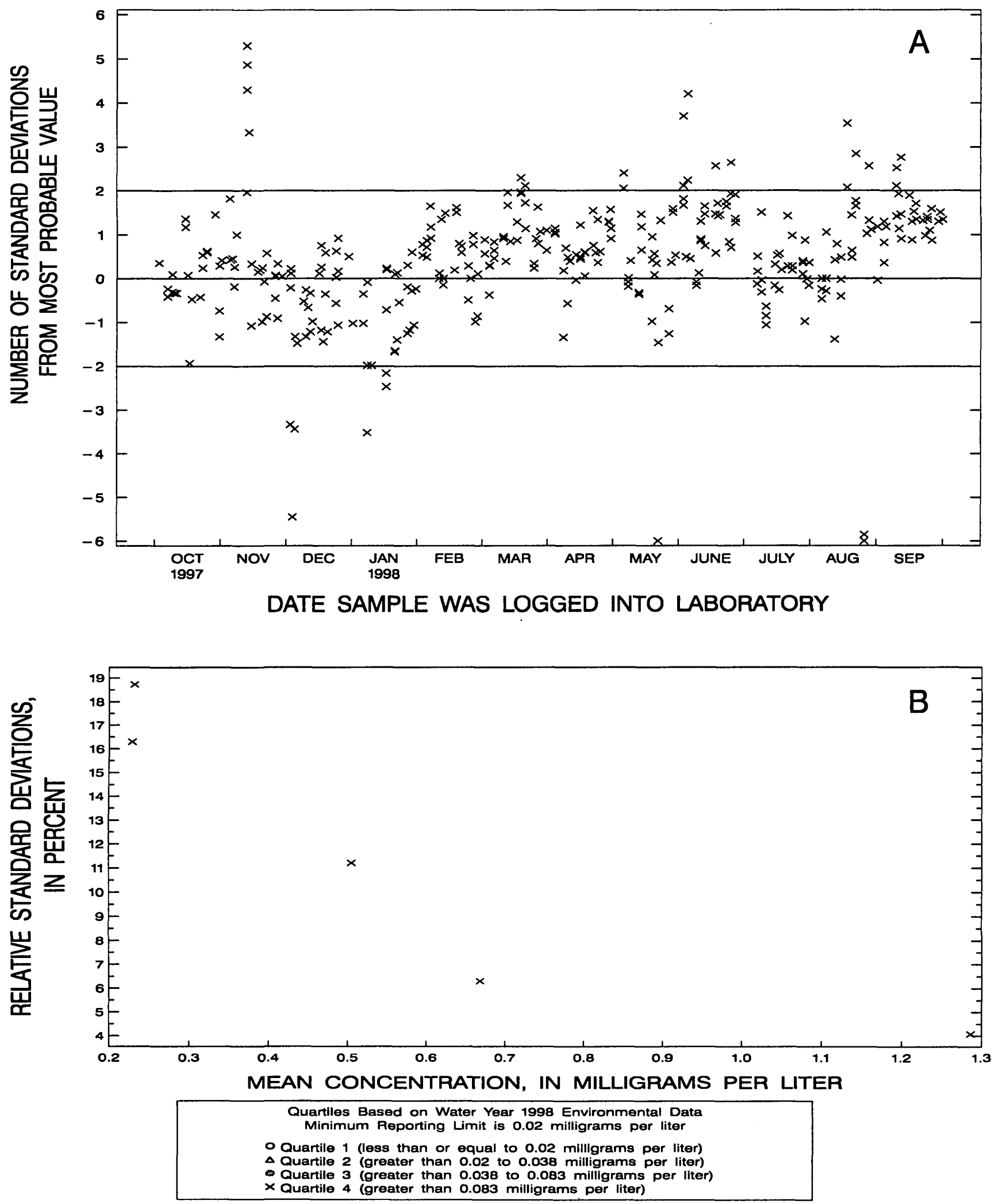

Flgure 80. Ammonia as nitrogen, dissolved, (colorimetric) data from the National Water Quality Laboratory. 

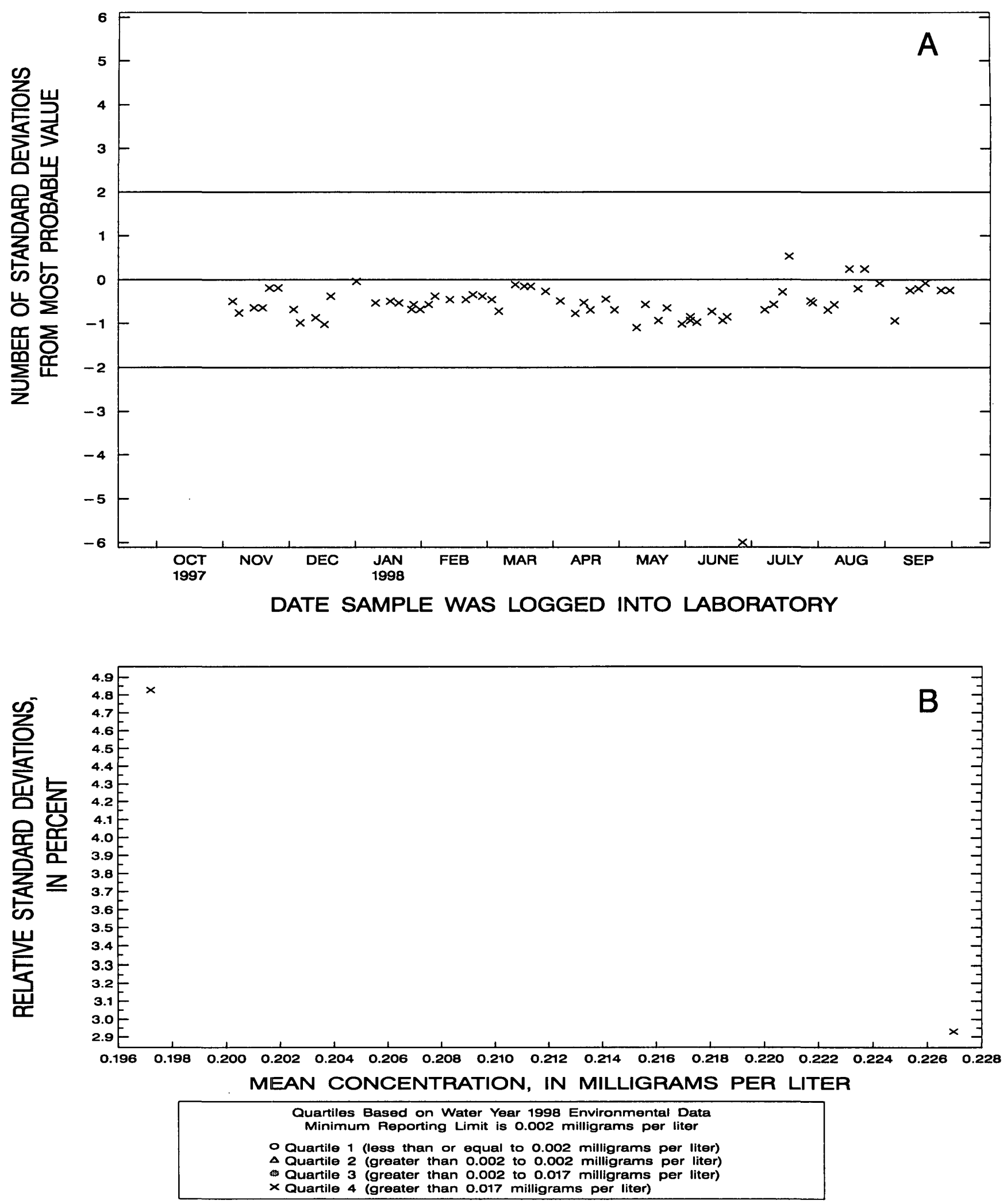

Figure 81. Ammonia as nitrogen, dissolved, (colorimetric, low level) data from the National Water Quality Laboratory. 

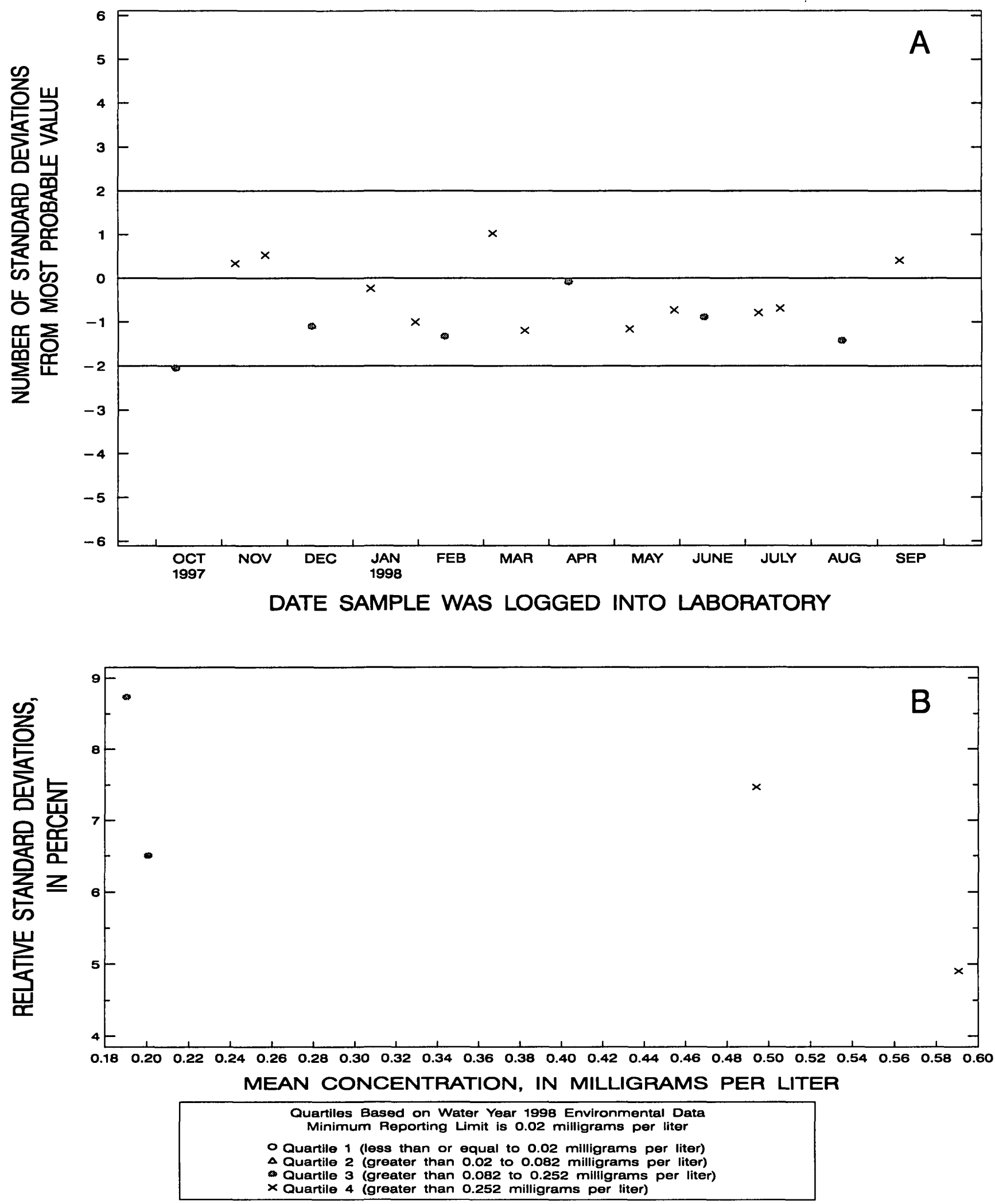

FIgure 82. Ammonia as nitrogen, dissolved, (U.S. Environmental Protection Agency) data from the National Water Quality Laboratory. 

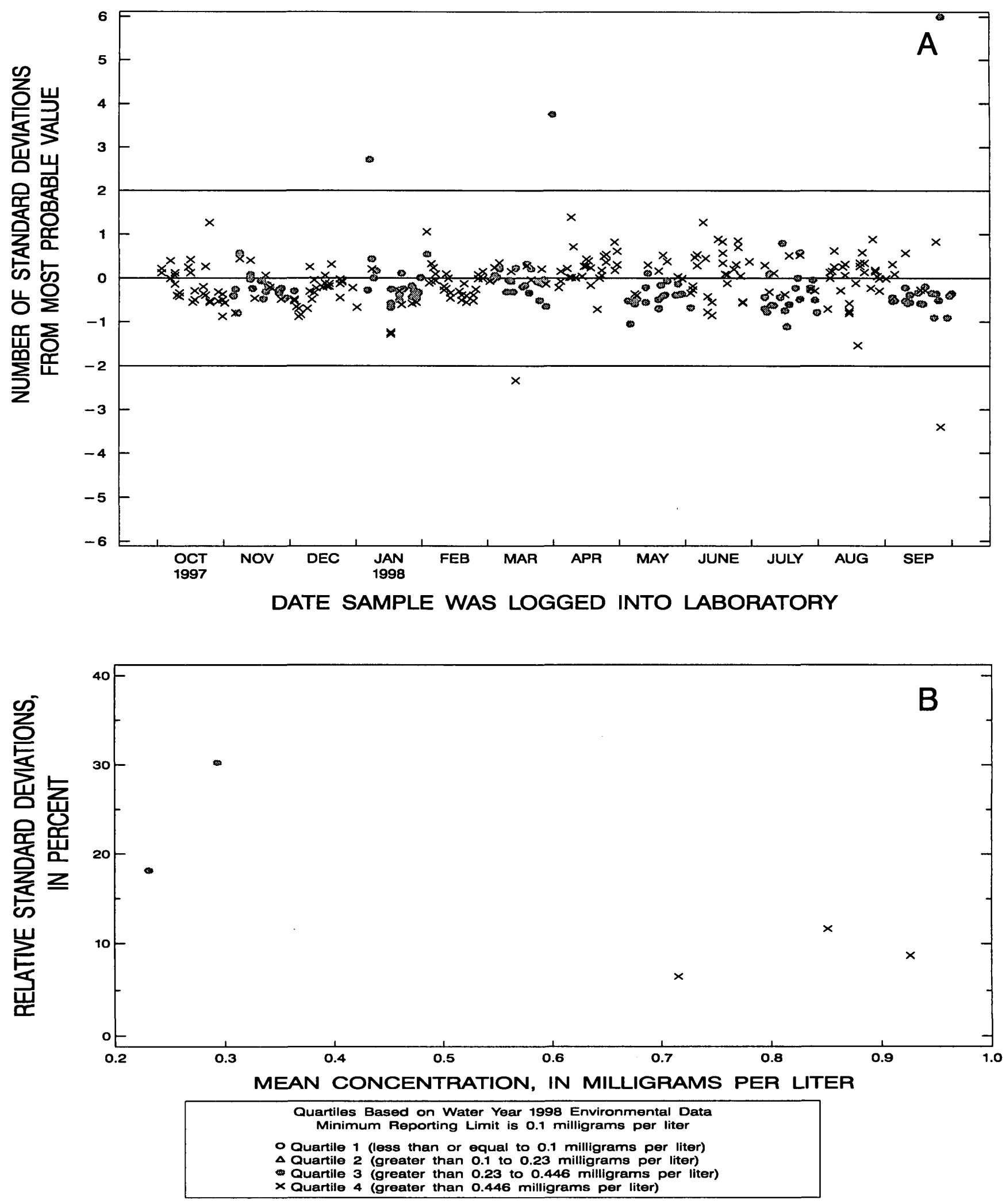

Figure 83. Ammonia plus organic nitrogen as nitrogen, dissolved, (micro-Kjeldahl digestion, automated segmented flow, colorimetric) data from the National Water Quality Laboratory. 

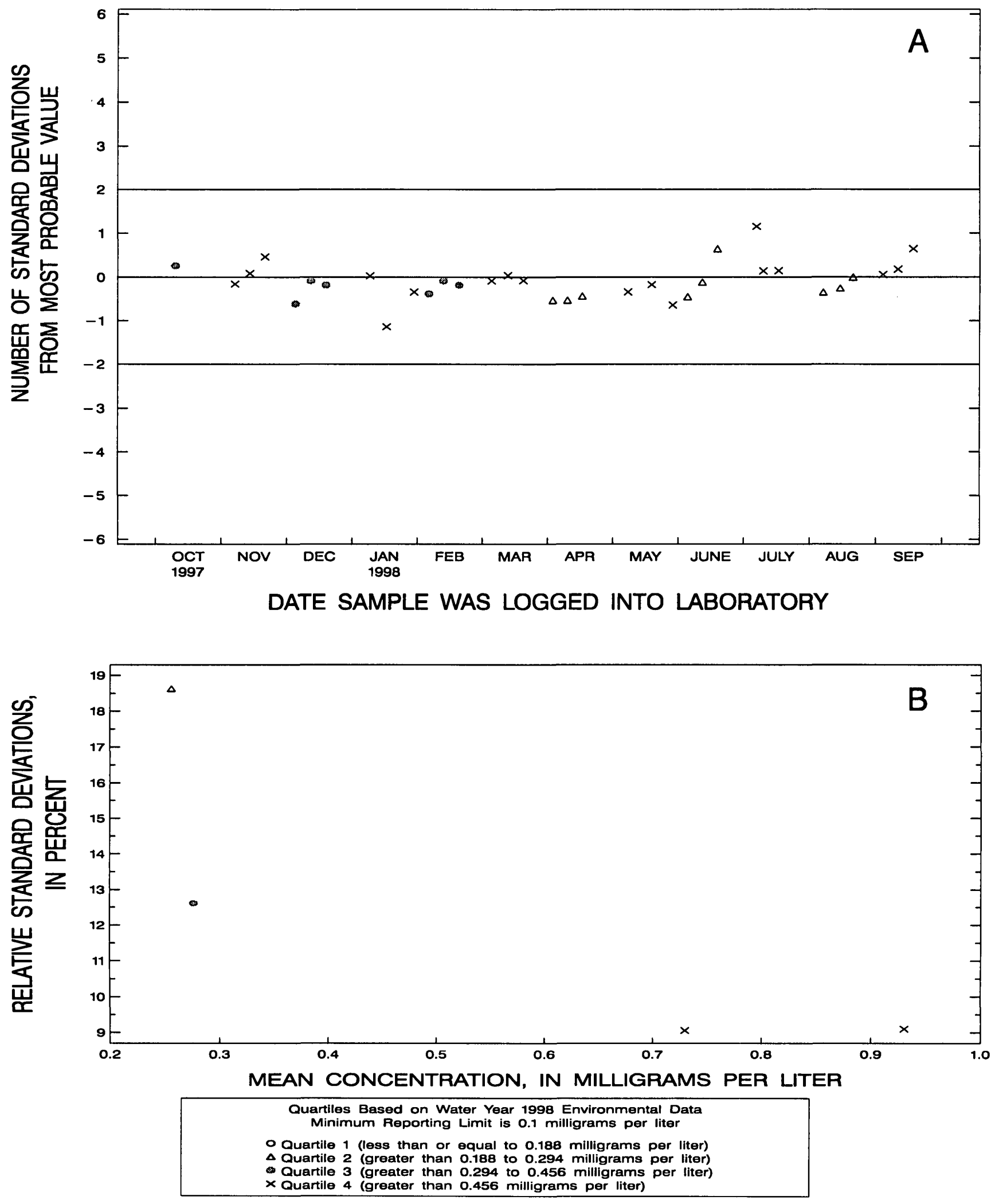

Figure 84. Ammonia plus organic nitrogen as nitrogen, dissolved, (U.S. Environmental Protection Agency) data from the National Water Quality Laboratory. 

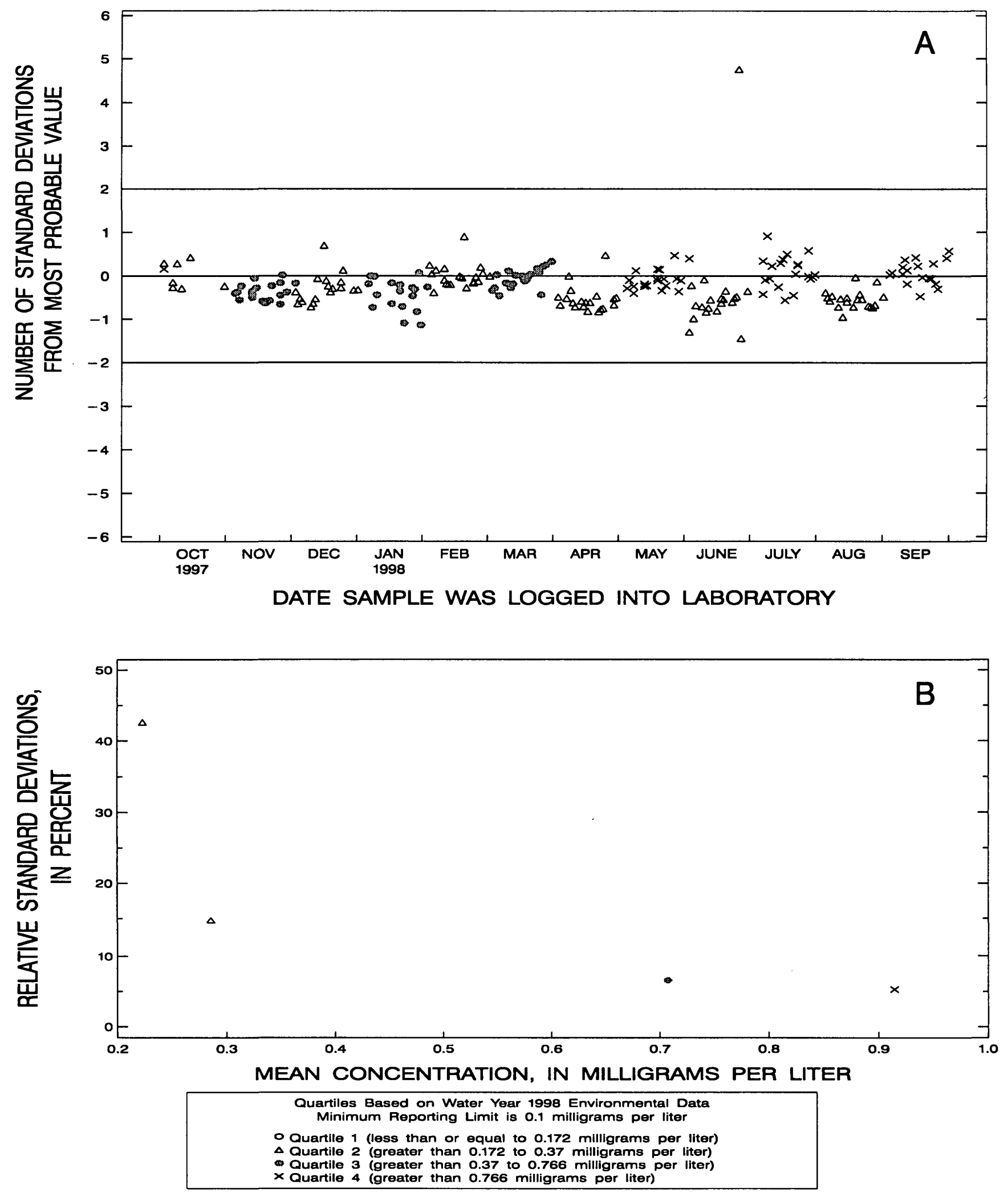

Figure 85. Ammonia plus organic nitrogen as nitrogen, whole-water recoverable, (micro-Kjeldahl digestion, automated segmented flow, colorimetric) data from the National Water Quality Laboratory. 

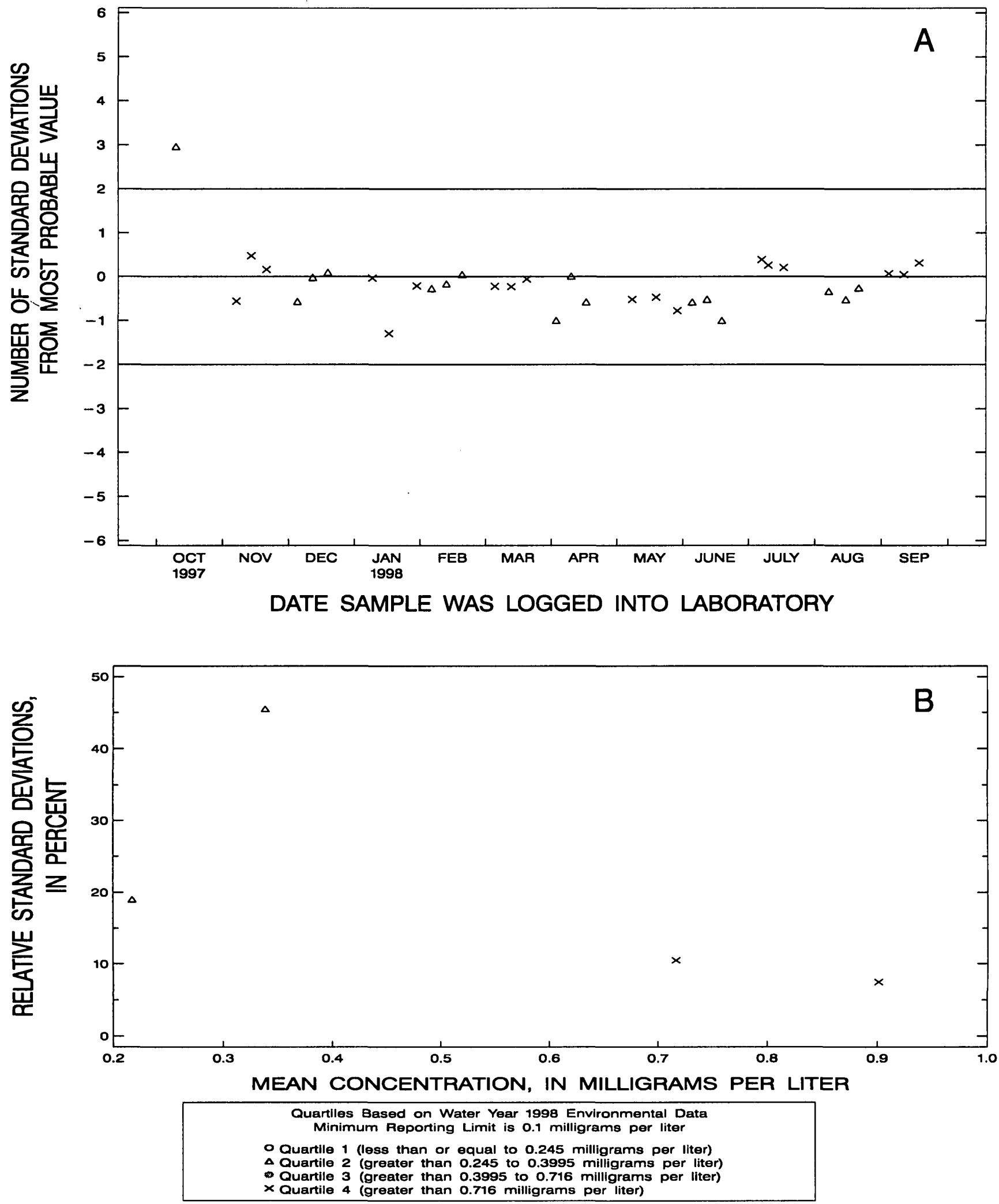

Figure 86. Ammonia plus organic nitrogen as nitrogen, whole-water recoverable, (U.S. Environmental Protection Agency) data from the National Water Quality Laboratory. 

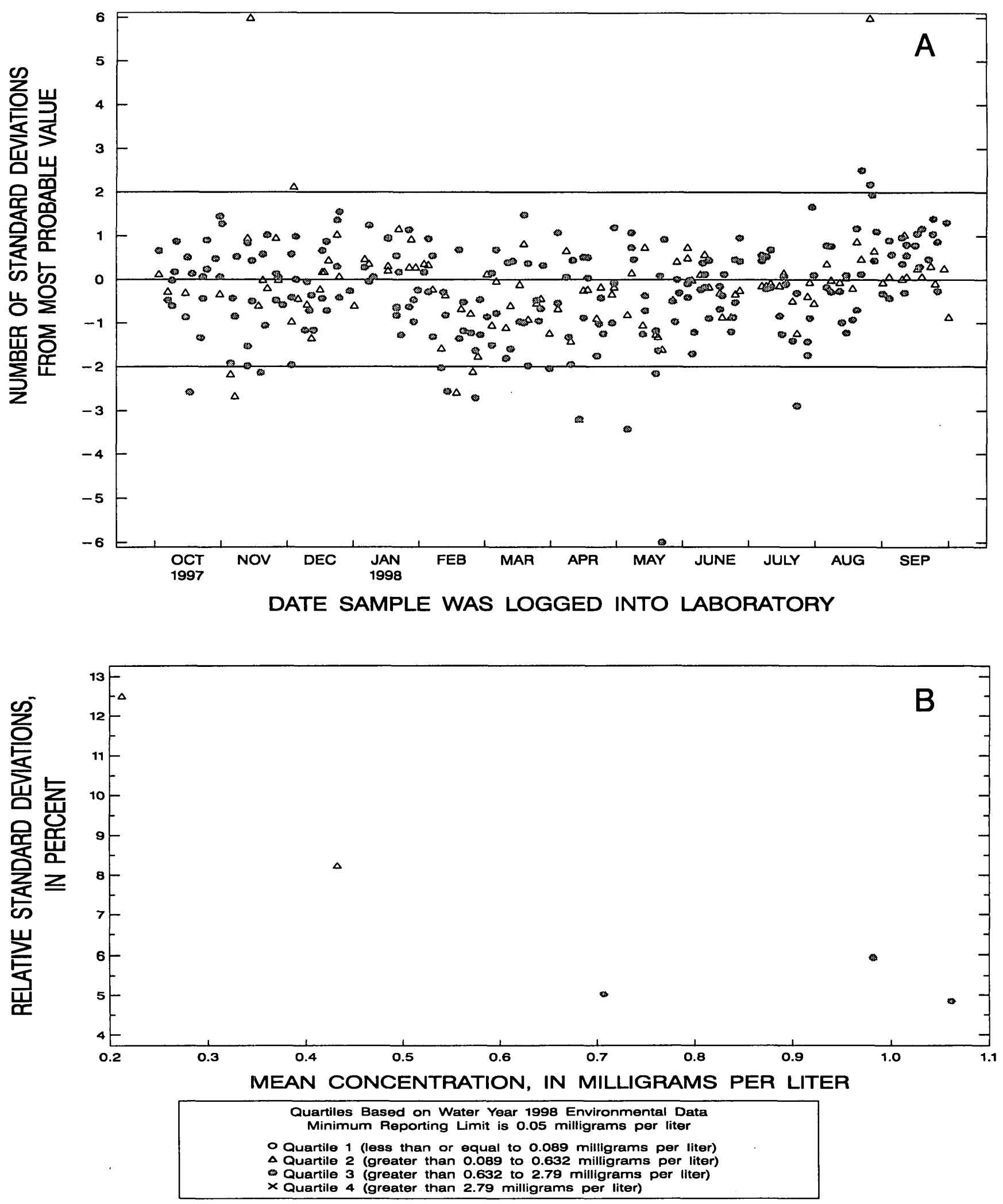

Figure 87. Nitrate plus nitrite as nitrogen, dissolved, (colorimetric) data from the National Water Quality Laboratory. 

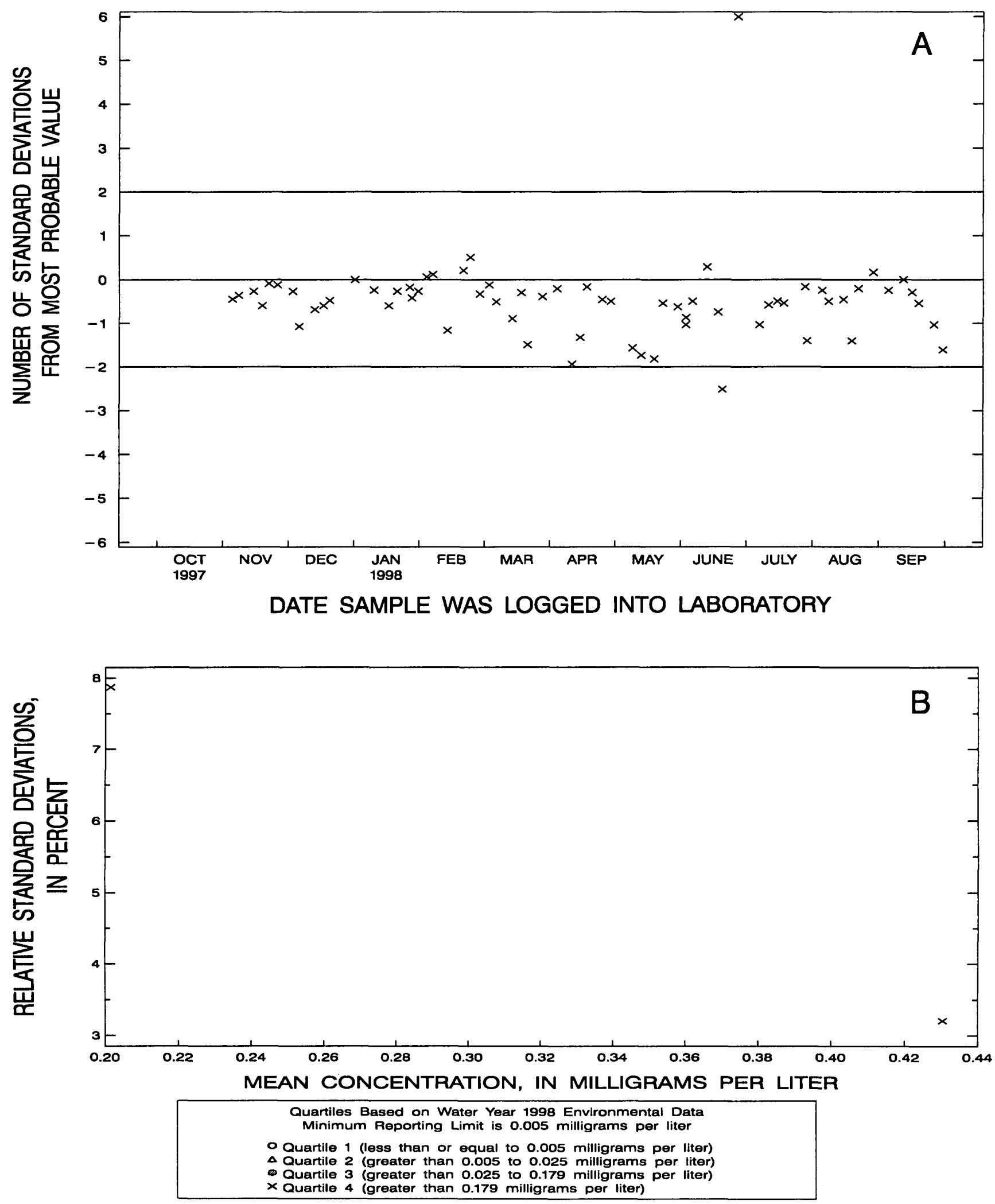

Figure 88. Nitrate plus nitrite as nitrogen, dissolved, (colorimetric, low level) data from the National Water Quality Laboratory. 

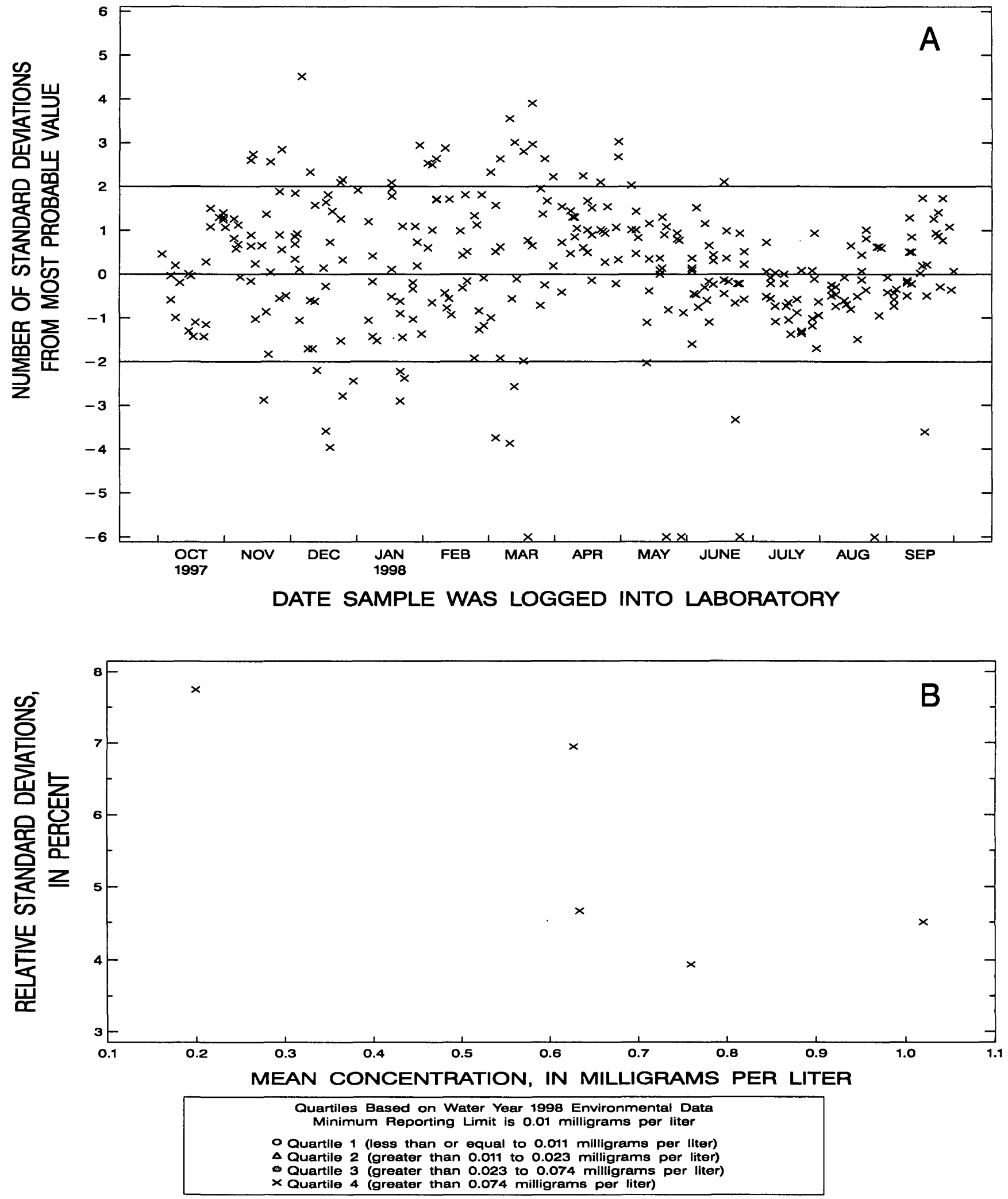

Figure 89. Orthophosphate as phosphorus, dissolved, (colorimetric) data from the National Water Quality Laboratory. 

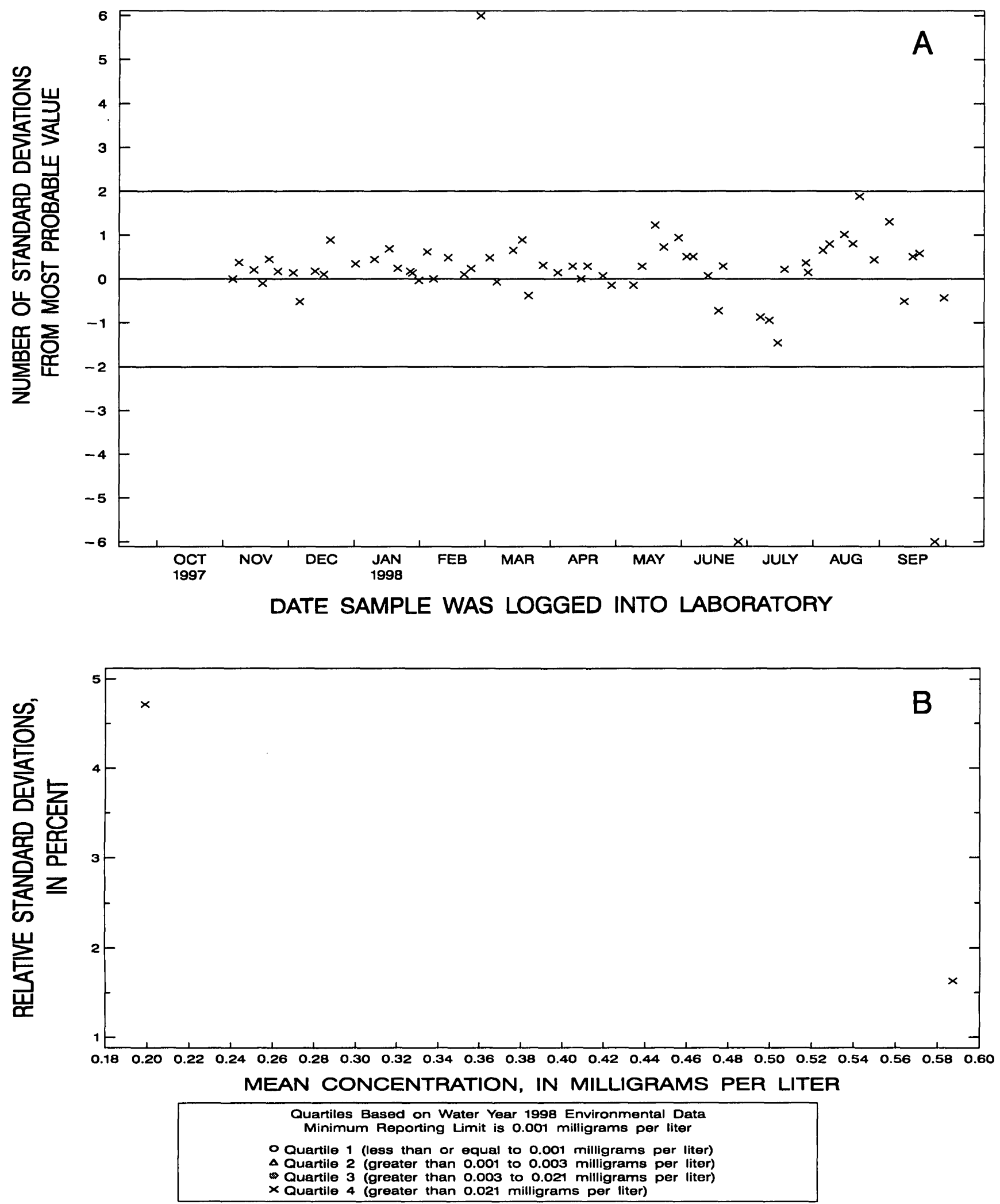

Figure 90. Orthophosphate as phosphorus, dissolved, (colorimetric, low level) data from the National Water Quality Laboratory. 

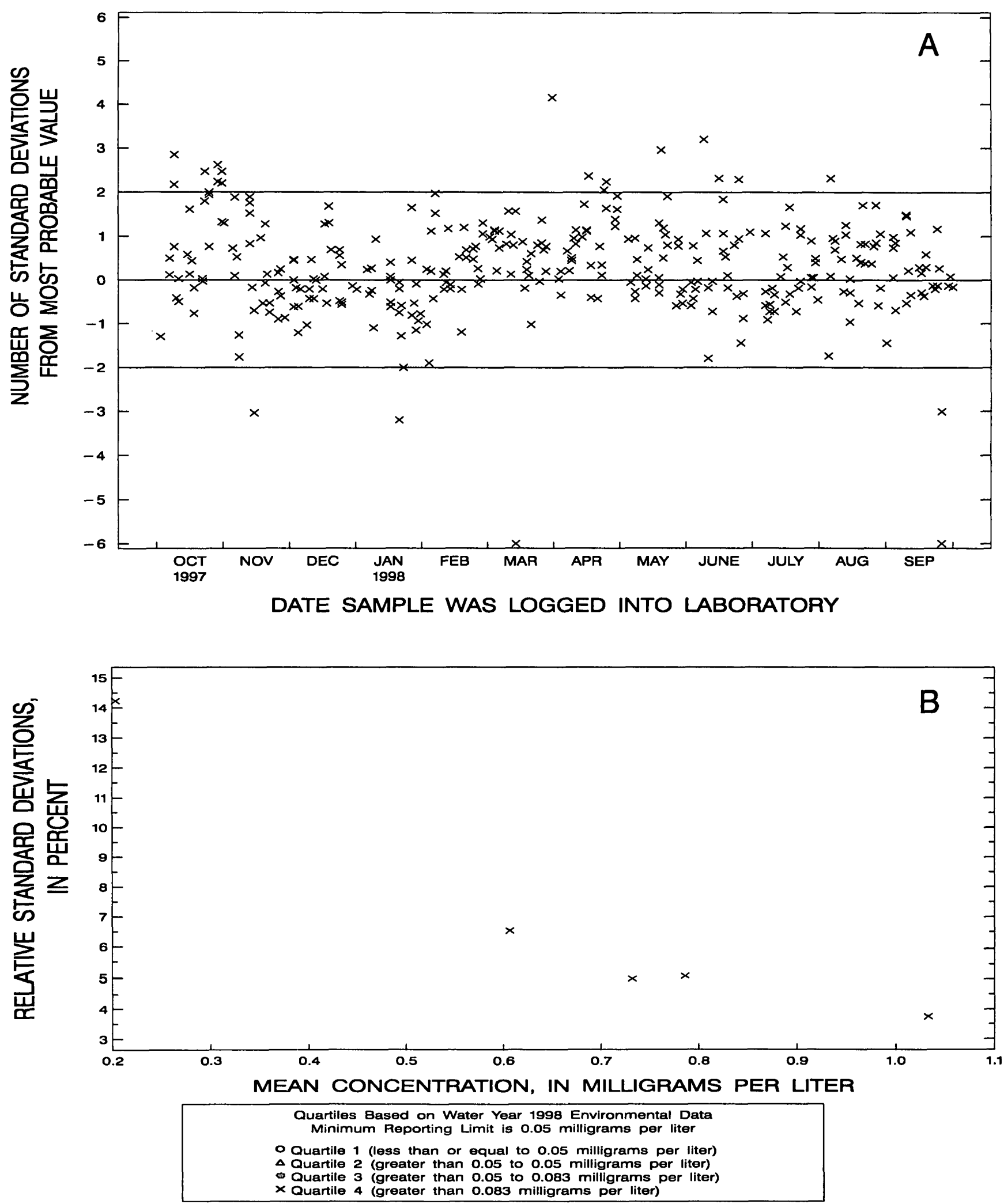

Figure 91. Phosphorus, dissolved, (micro-Kjeldahl digestion, automated segmented flow, colorimetric) data from the National Water Quality Laboratory. 

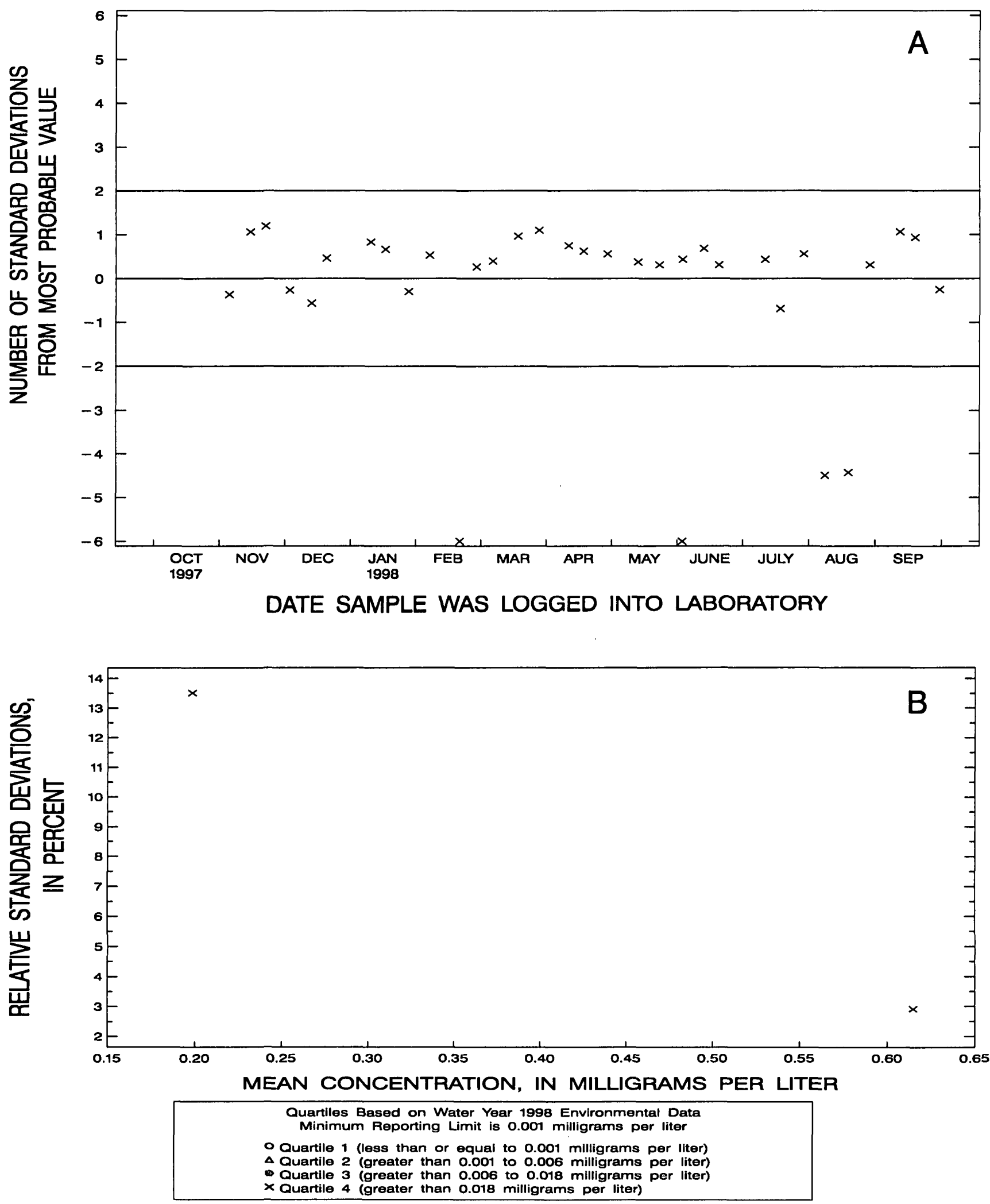

Figure 92. Phosphorus, dissolved, (colorimetric, low level) data from the National Water Quality Laboratory. 

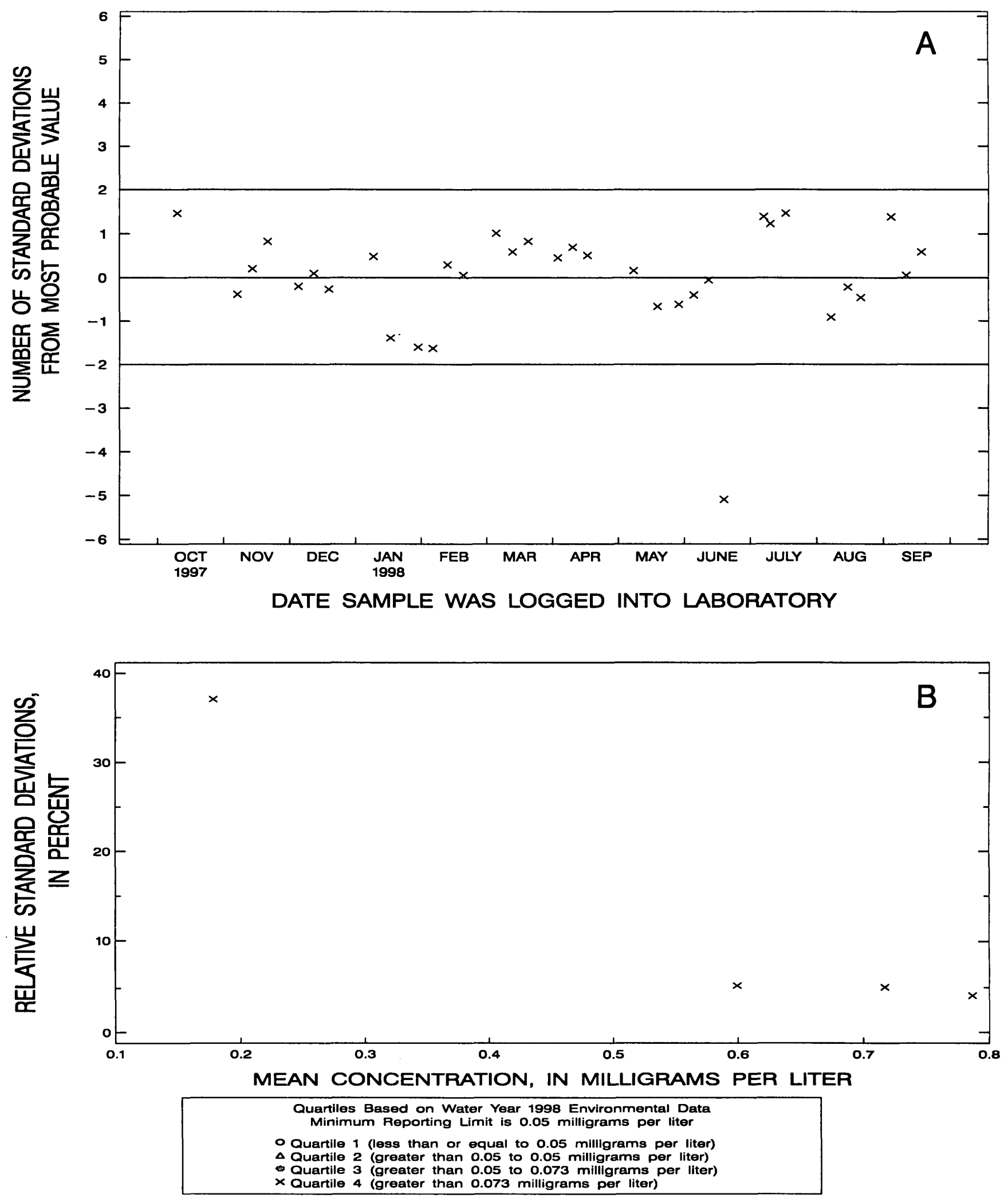

Figure 93. Phosphorus, dissolved, (U.S. Environmental Protection Agency) data from the National Water Quality Laboratory. 

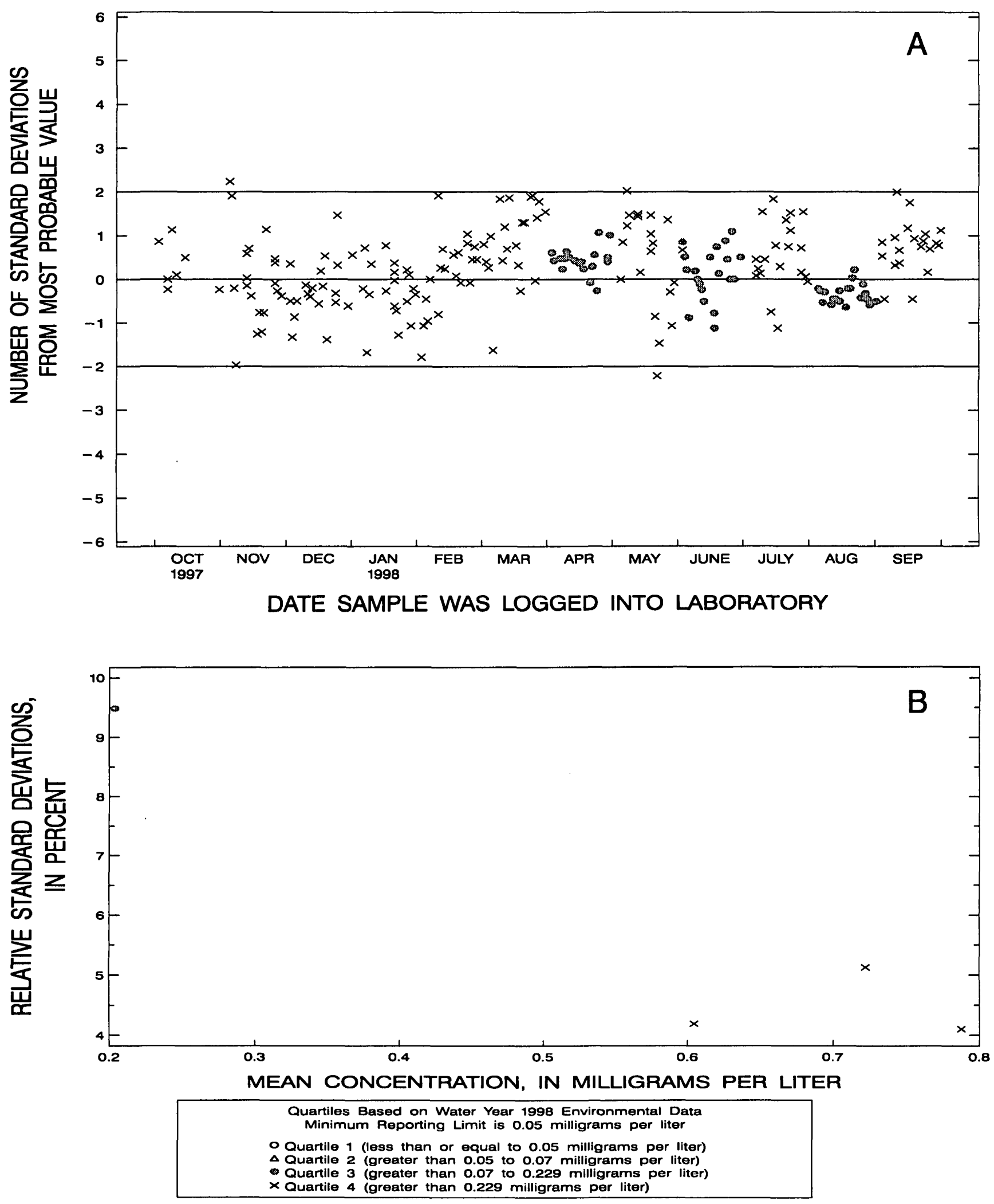

Figure 94. Phosphorus, whole-water recoverable, (micro-Kjeldahl digestion, automated segmented flow, colorimetric) data from the National Water Quality Laboratory. 

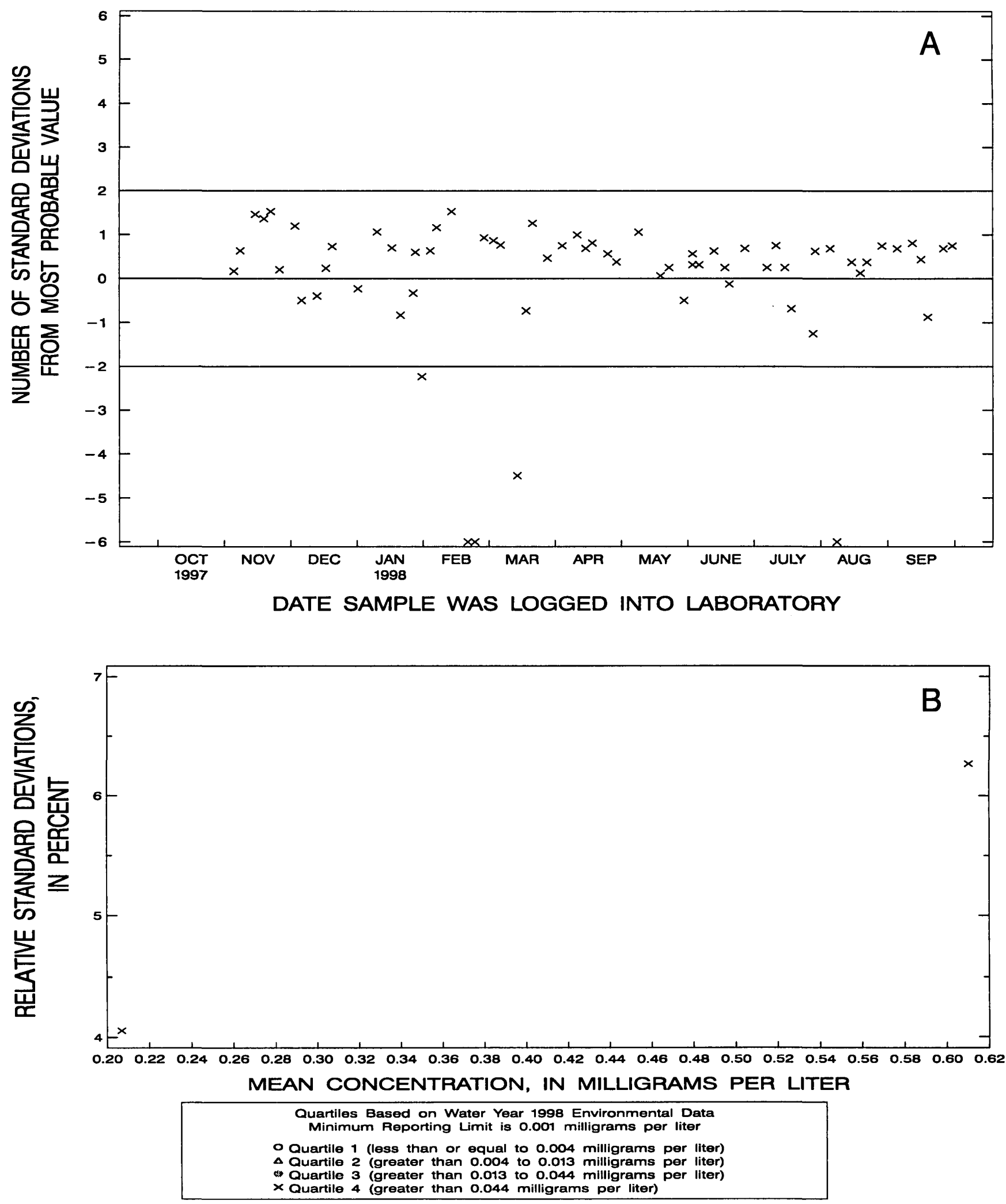

Figure 95. Phosphorus, whole-water recoverable, (colorimetric, low level) data from the National Water Quality Laboratory. 

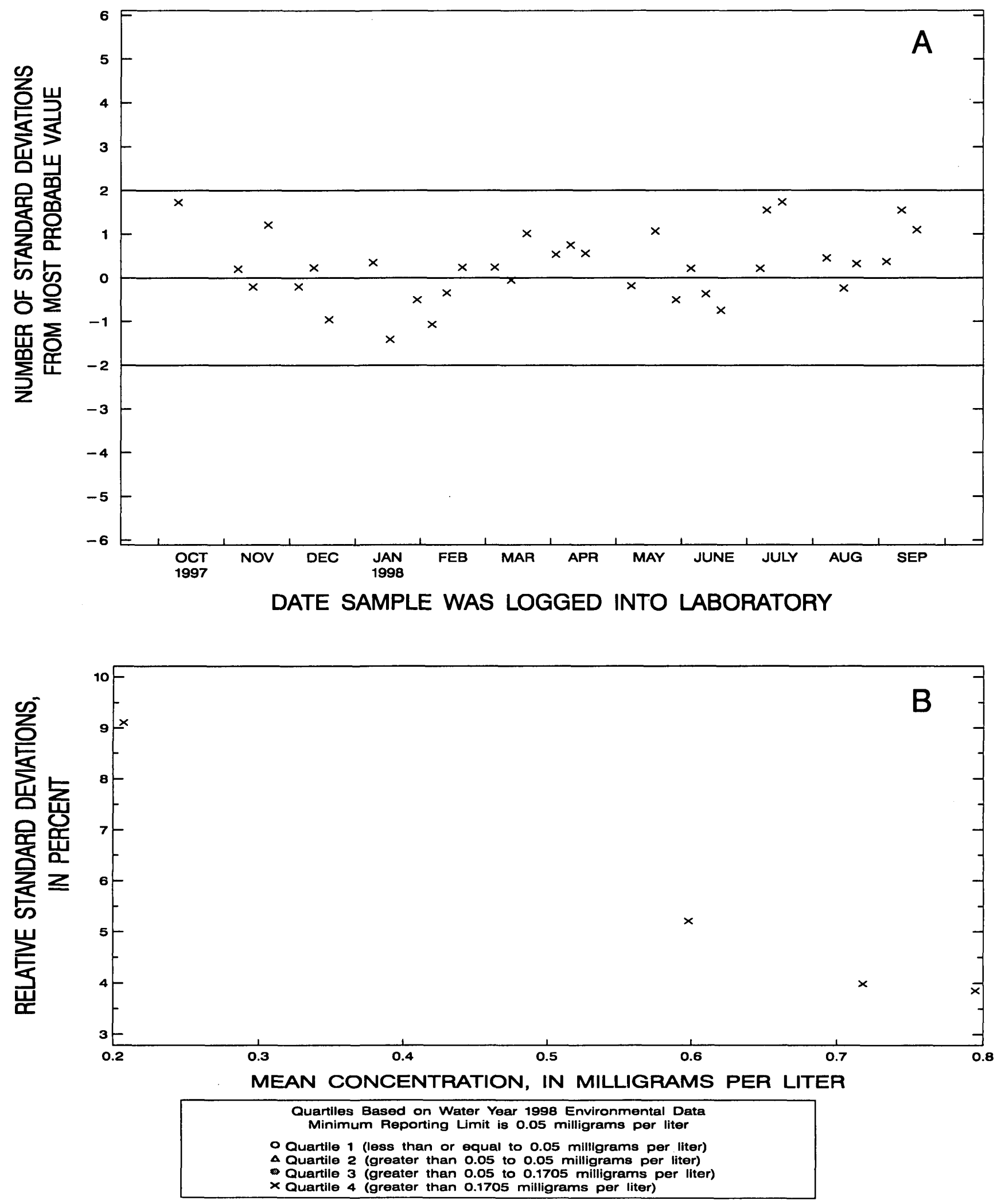

Figure 96. Phosphorus, whole-water recoverable, (U.S. Environmental Protection Agency) data from the National Water Quality Laboratory. 

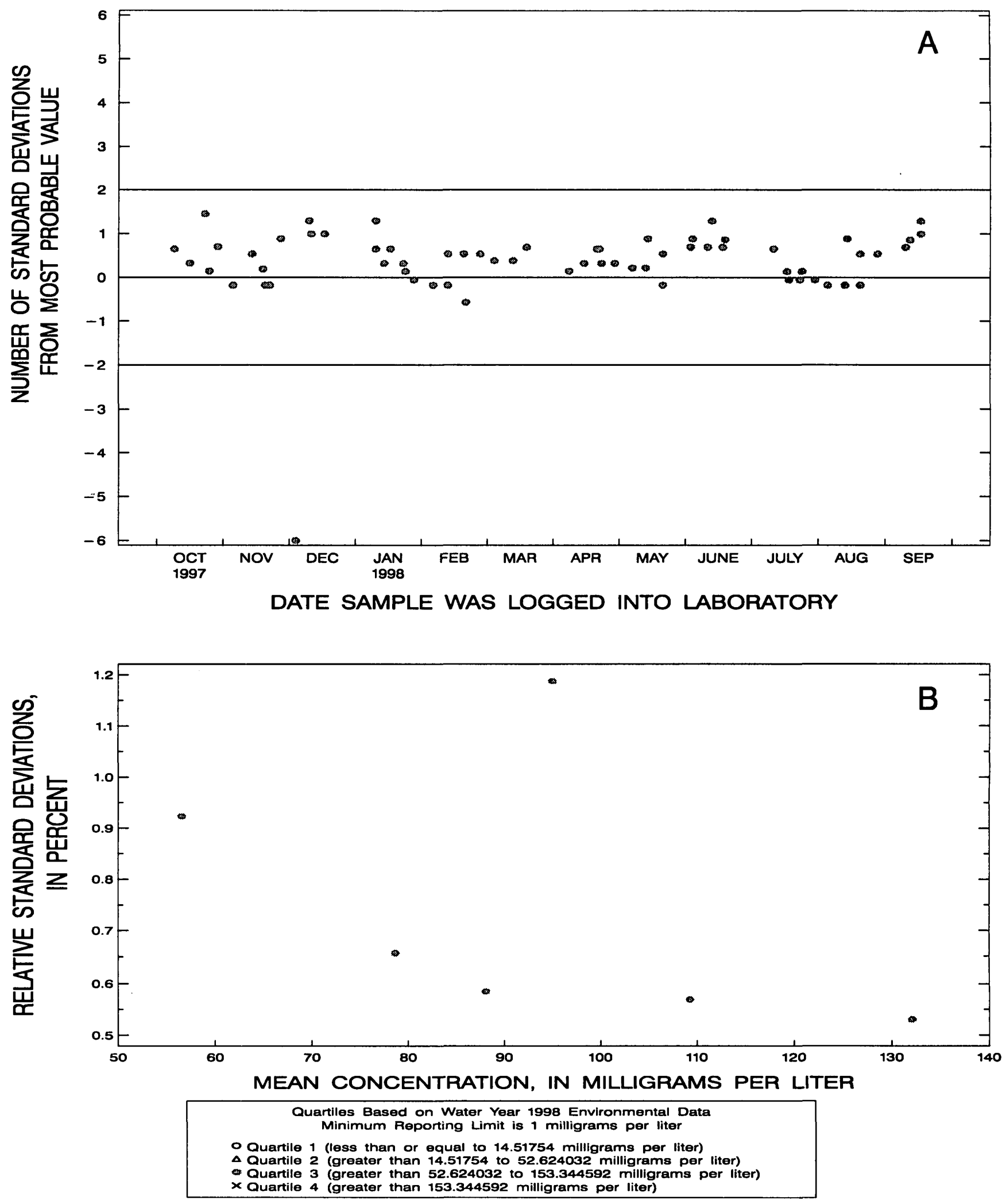

Figure 97. Alkalinity, whole-water recoverable, (electrometric titration) data from the Quality of Water Service Unit laboratory. 

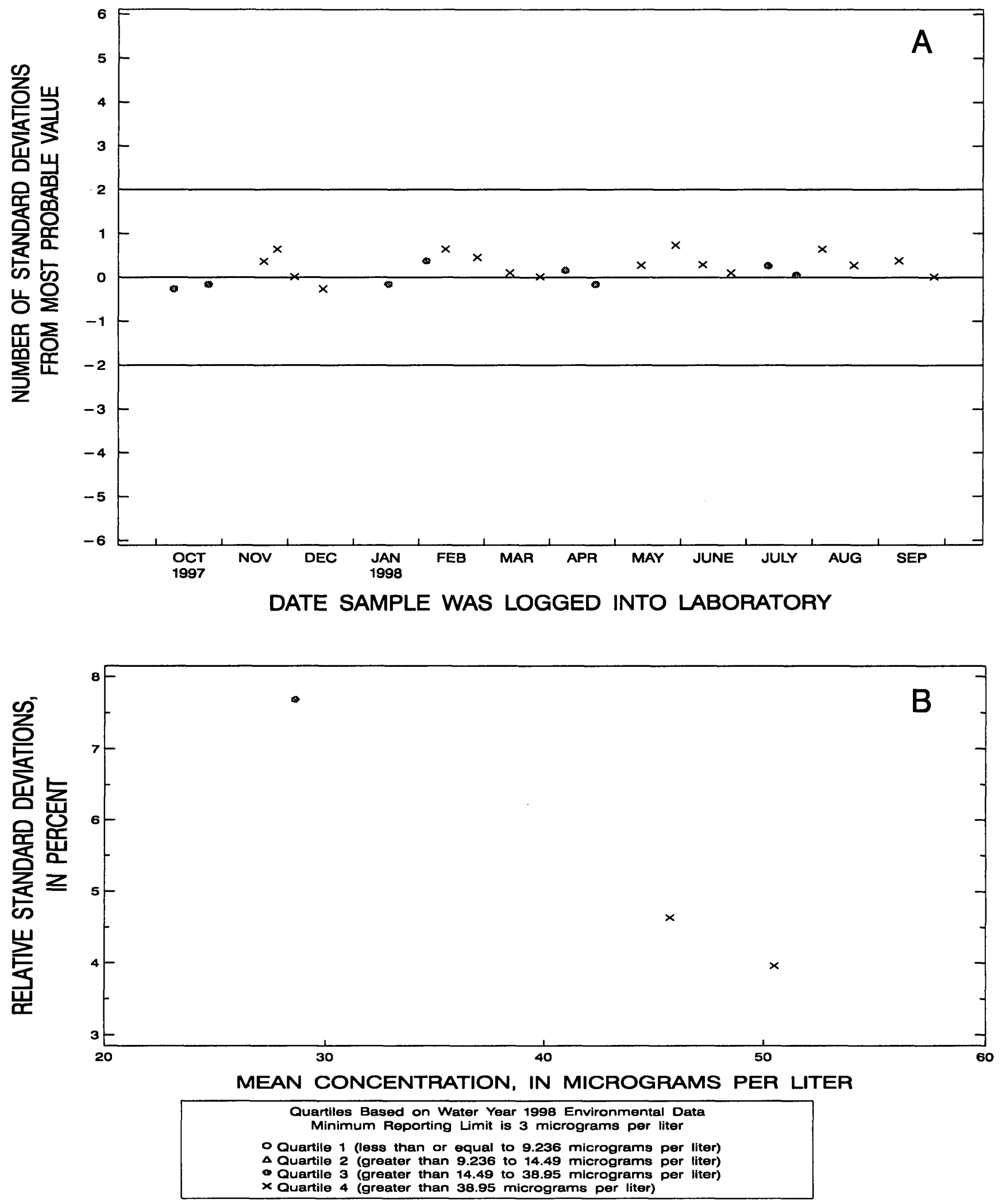

Figure 98. Aluminum, dissolved, (inductively coupled plasma-atomic emission spectrometry, trace) data from the Quality of Water Service Unit laboratory. 

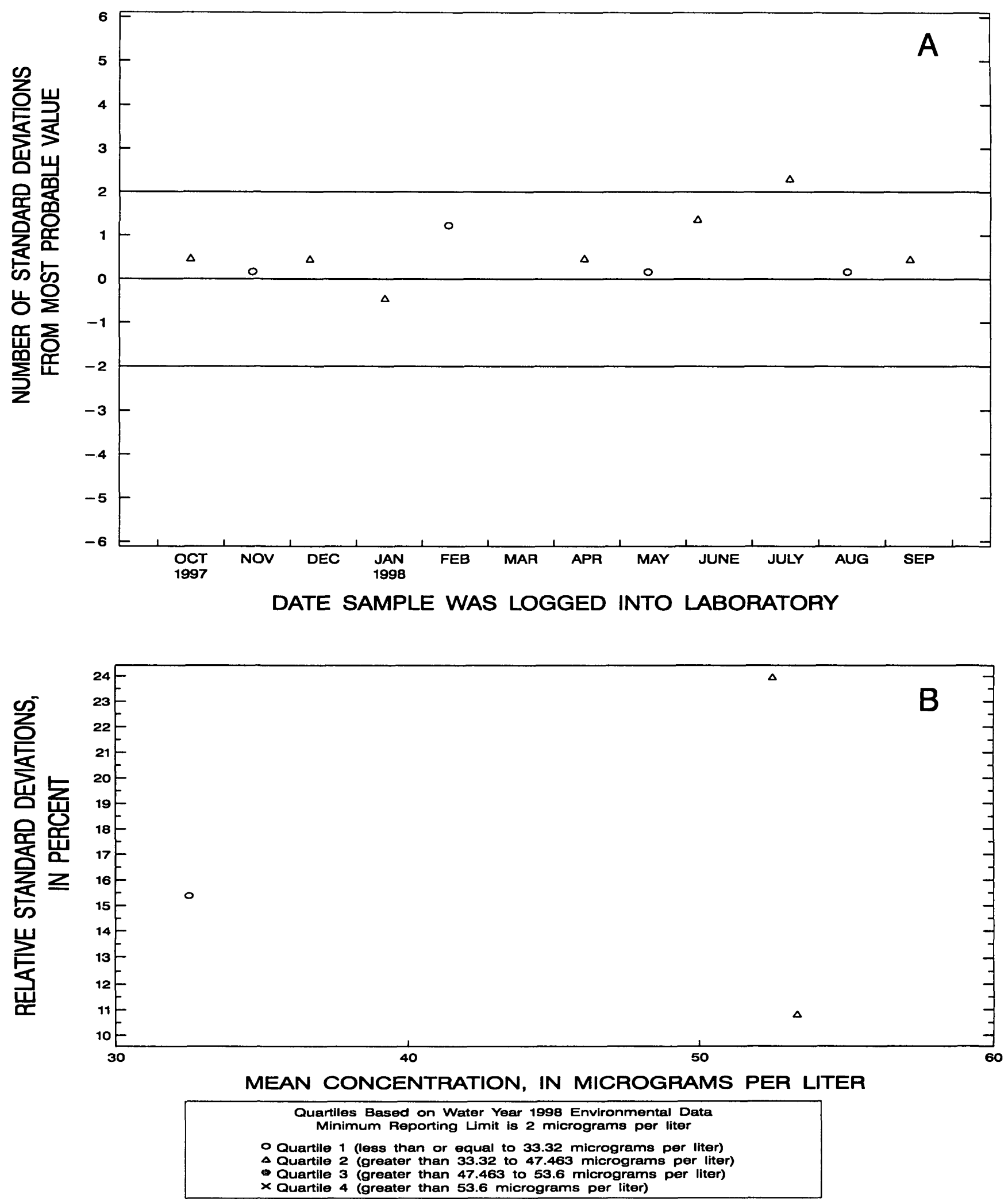

Figure 99. Aluminum, whole-water recoverable, (graphite furnace-atomic absorption spectrophotometry, U.S. Environmental Protection Agency) data from the Quality of Water Service Unit laboratory. 

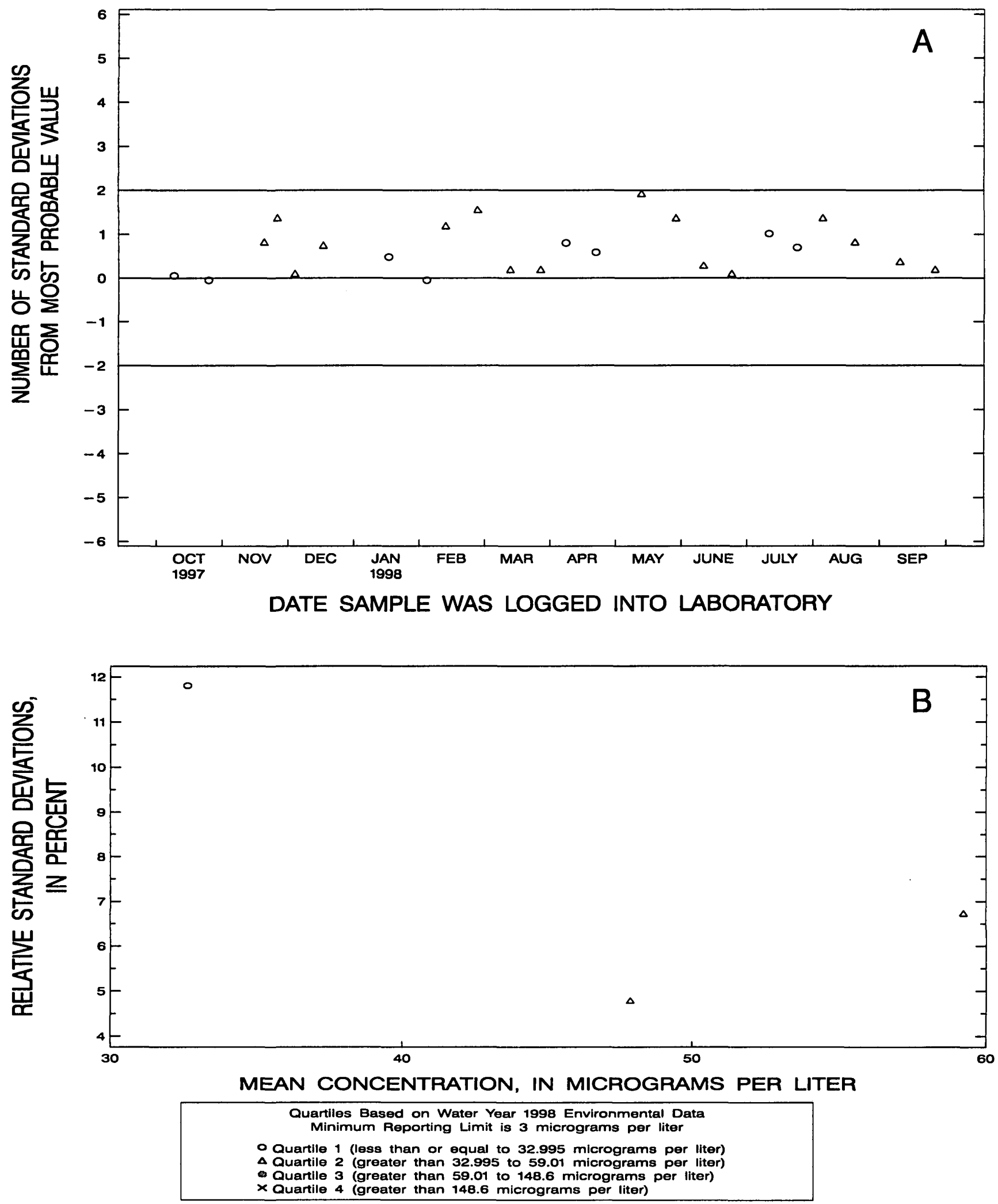

Figure 100. Aluminum, whole-water recoverable, (inductively coupled plasma-atomic emission spectrometry, trace) data from the Quality of Water Service Unit laboratory. 

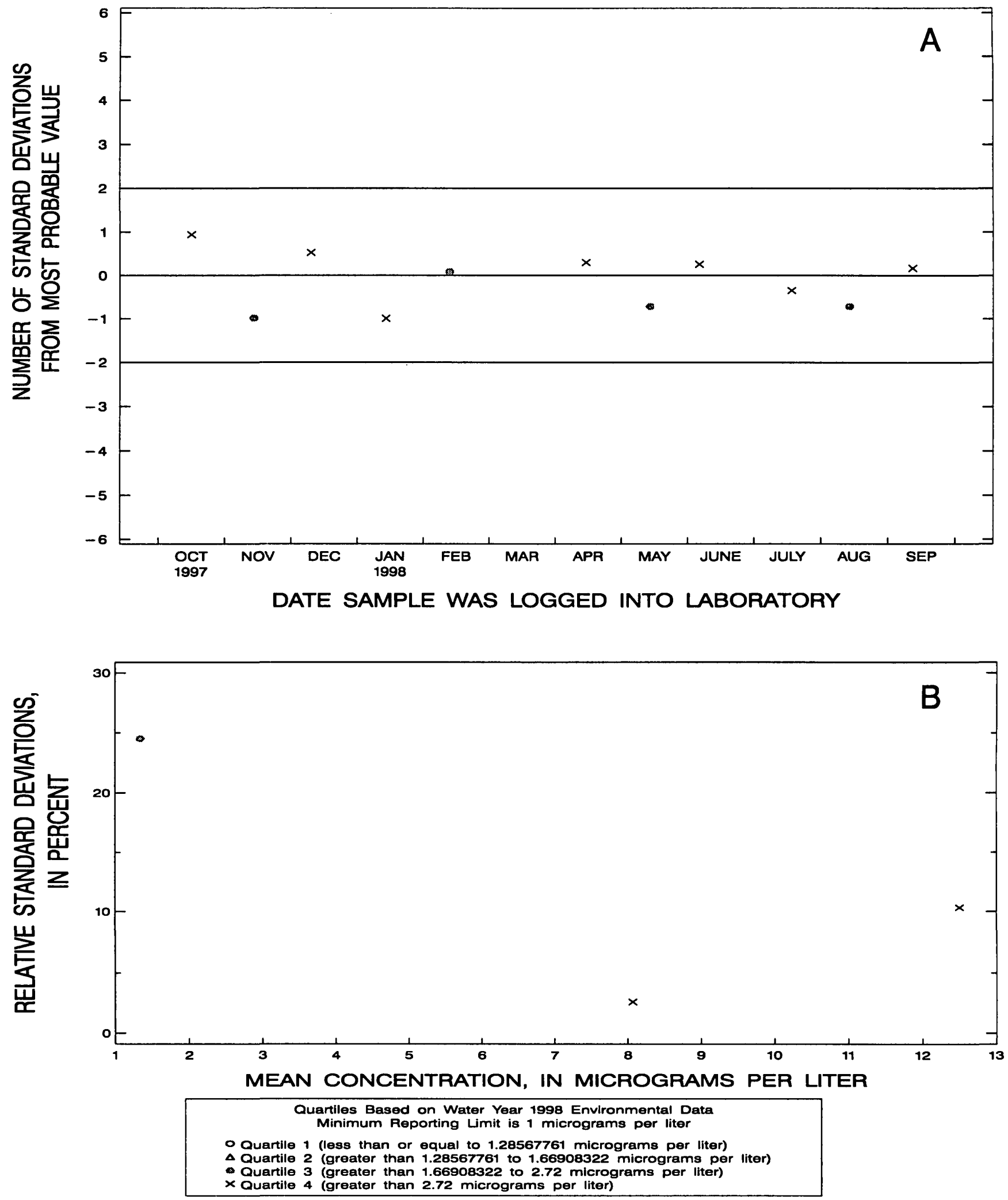

Figure 101. Arsenic, dissolved, (graphite furnace-atomic absorption spectrophotometry) data from the Quality of Water Service Unit laboratory. 

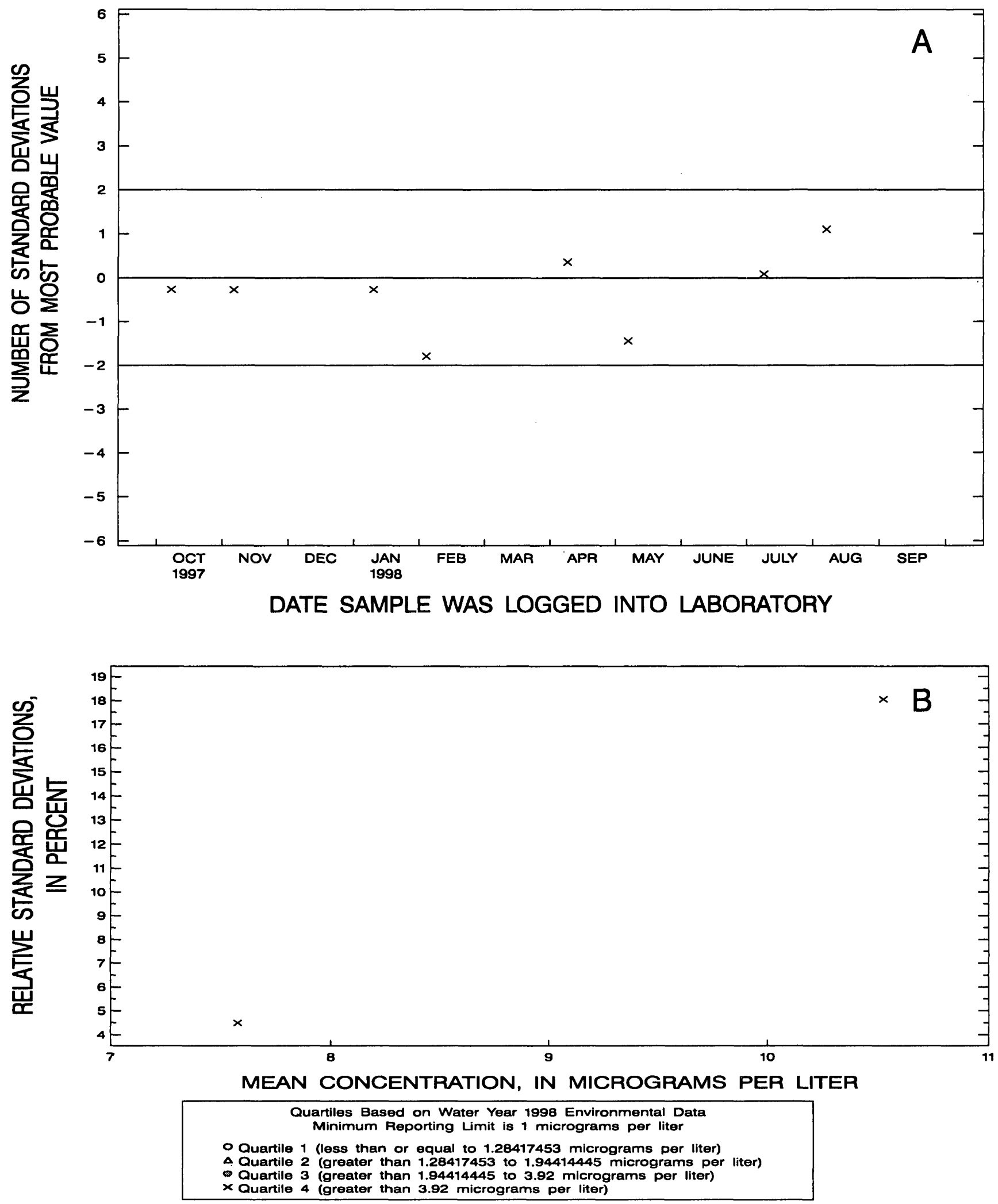

Figure 102. Arsenic, whole-water recoverable, (graphite furnace-atomic absorption spectrophotometry) data from the Quality of Water Service Unit laboratory. 

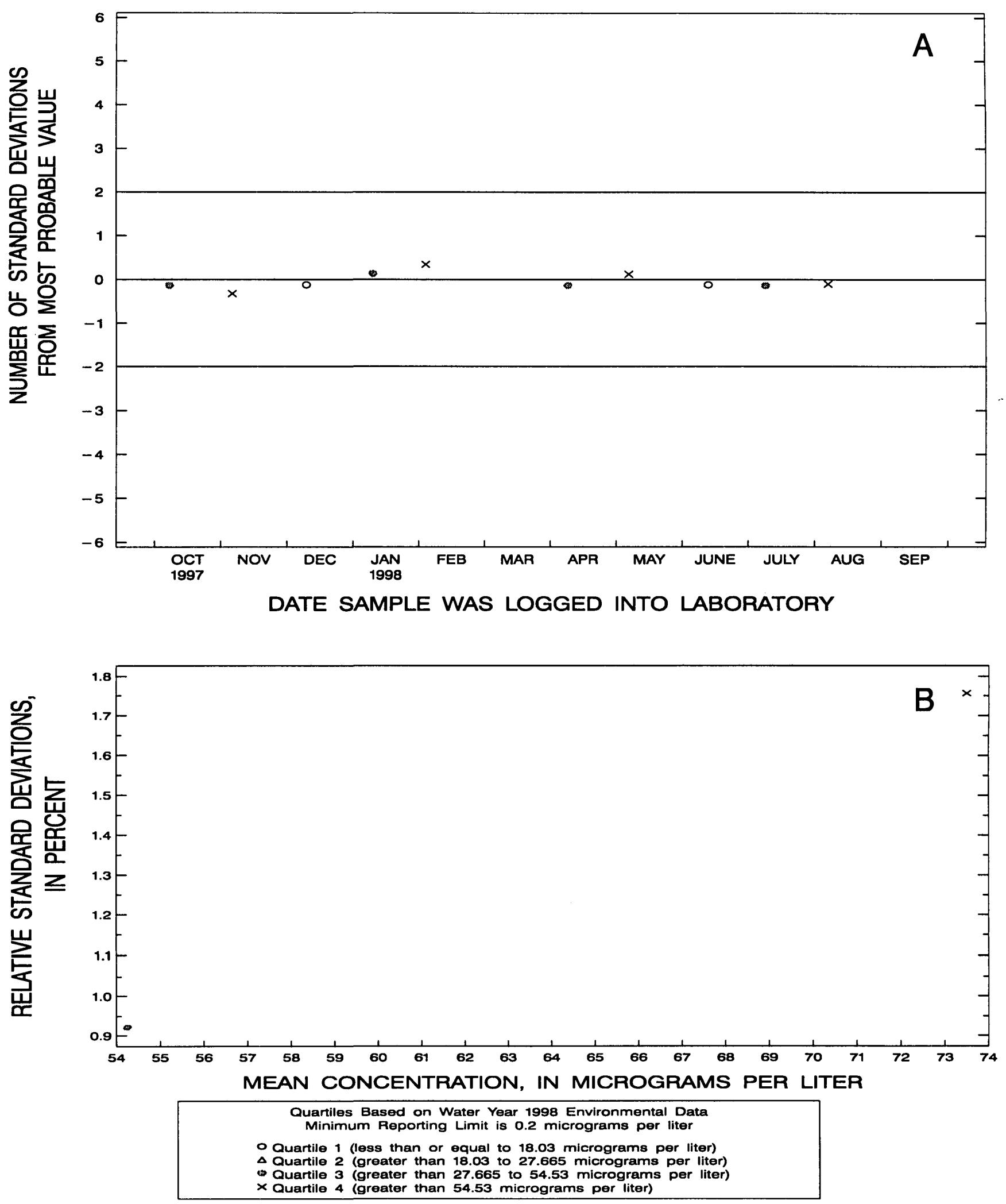

Figure 103. Barium, dissolved, (inductively coupled plasma-atomic emission spectrometry, trace) data from the Quality of Water Service Unit laboratory. 

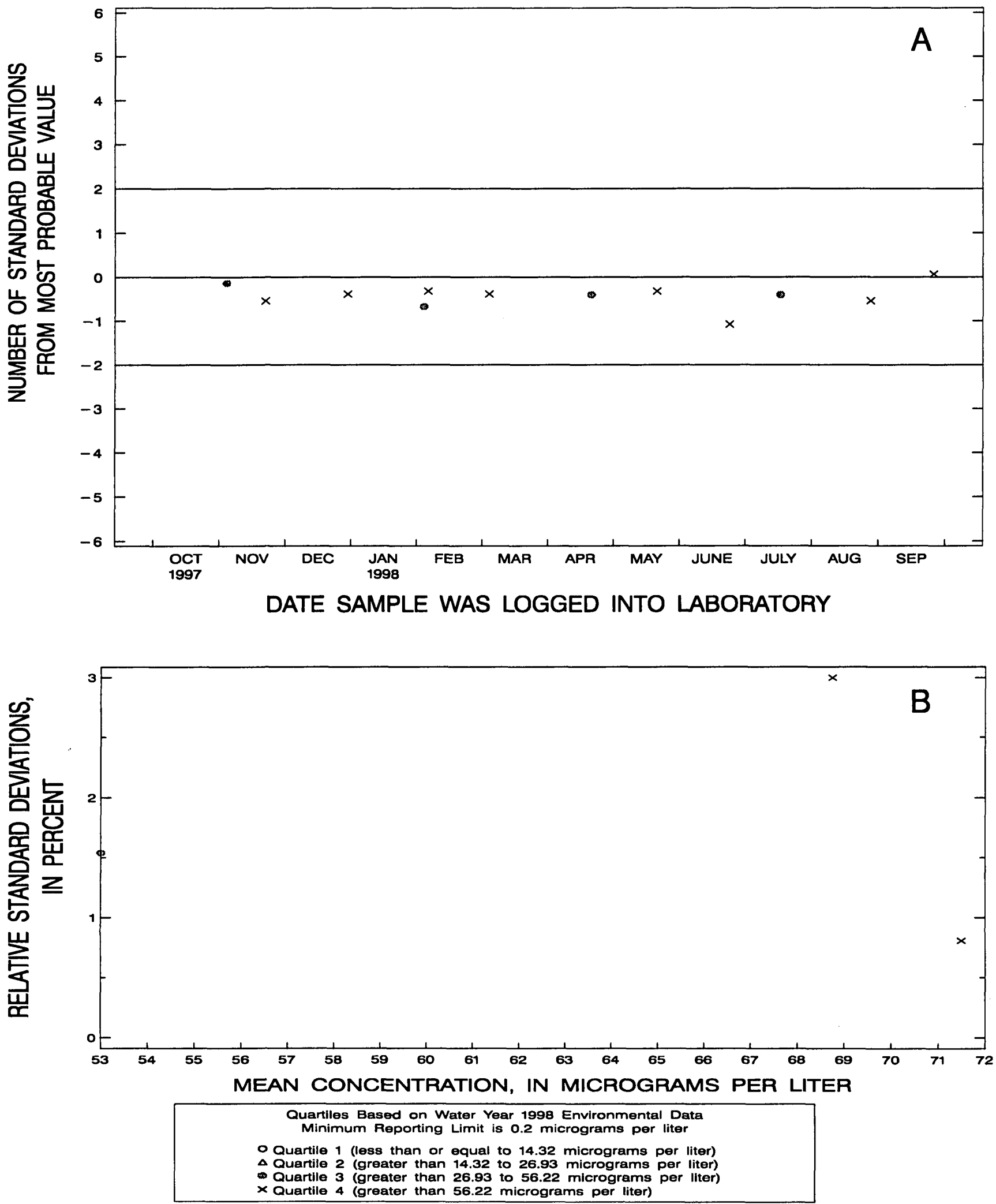

Figure 104. Barium, whole-water recoverable, (inductively coupled plasma-atomic emission spectrometry, trace) data from the Quality of Water Service Unit laboratory. 

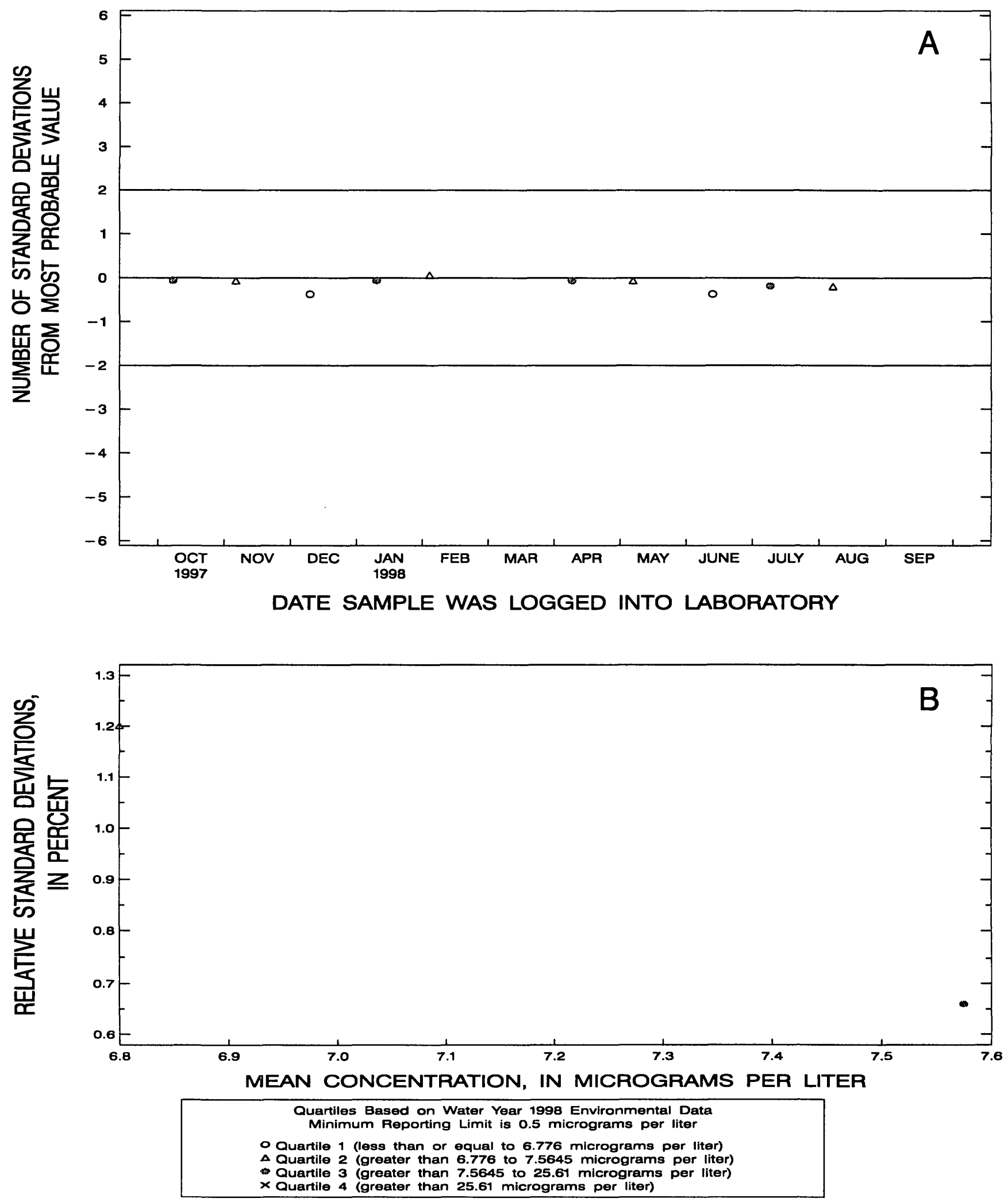

Figure 105. Beryllium, dissolved, (inductively coupled plasma-atomic emission spectrometry, trace) data from the Quality of Water Service Unit laboratory. 

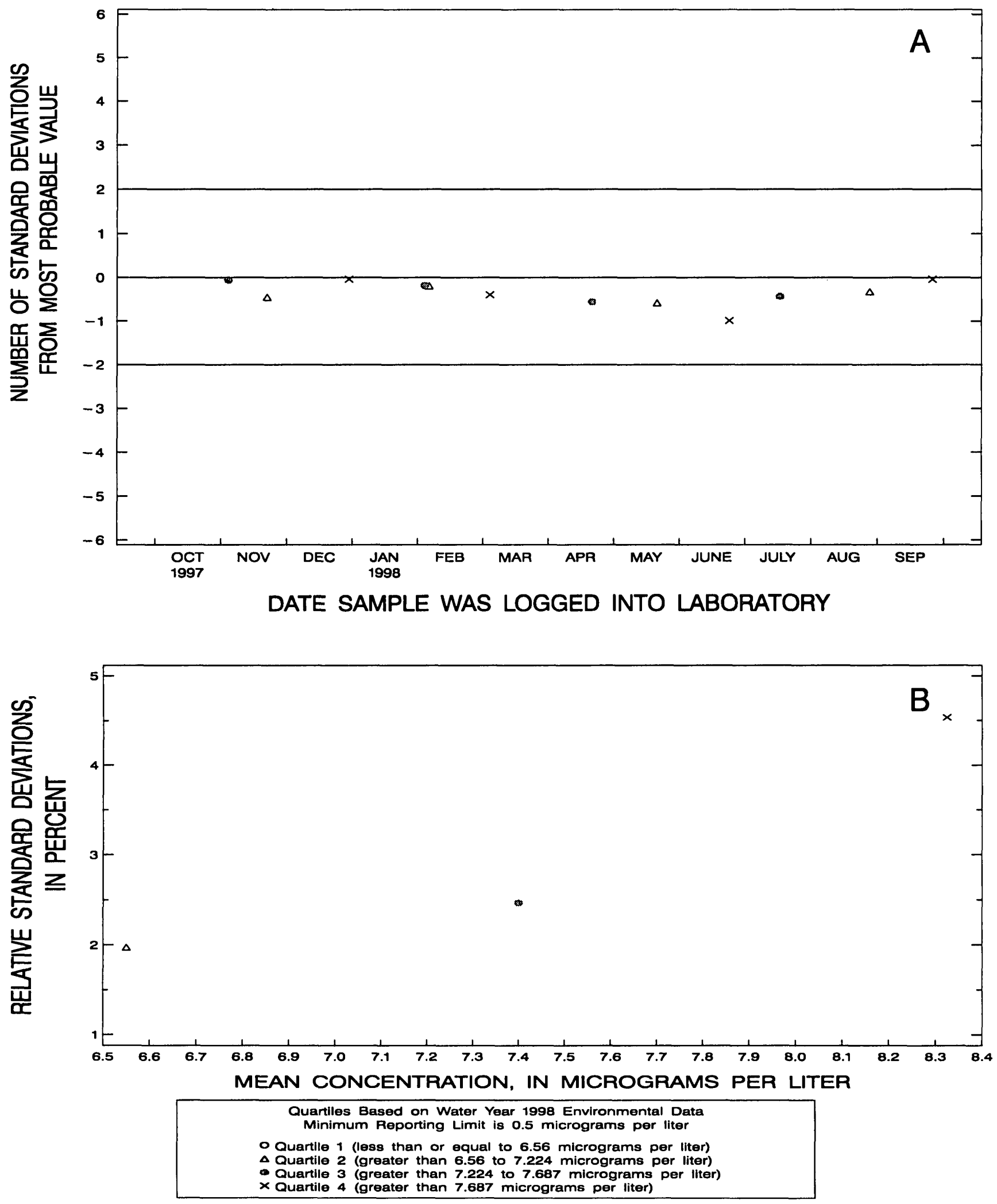

Figure 106. Beryllium, whole-water recoverable, (inductively coupled plasma-atomic emission spectrometry, trace) data from the Quality of Water Service Unit laboratory. 

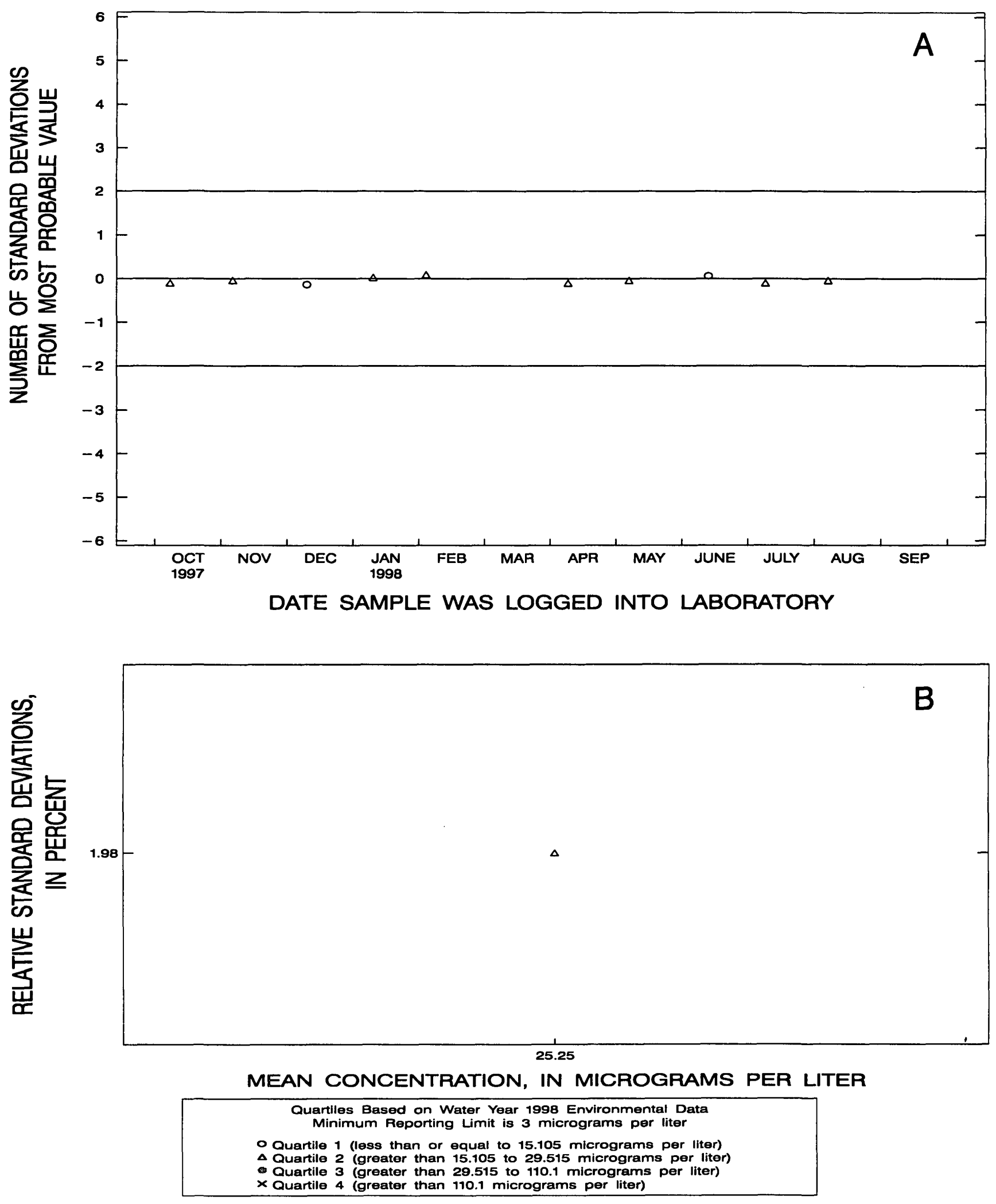

Figure 107. Boron, dissolved, (inductively coupled plasma-atomic emission spectrometry, trace) data from the Quality of Water Service Unit laboratory. 

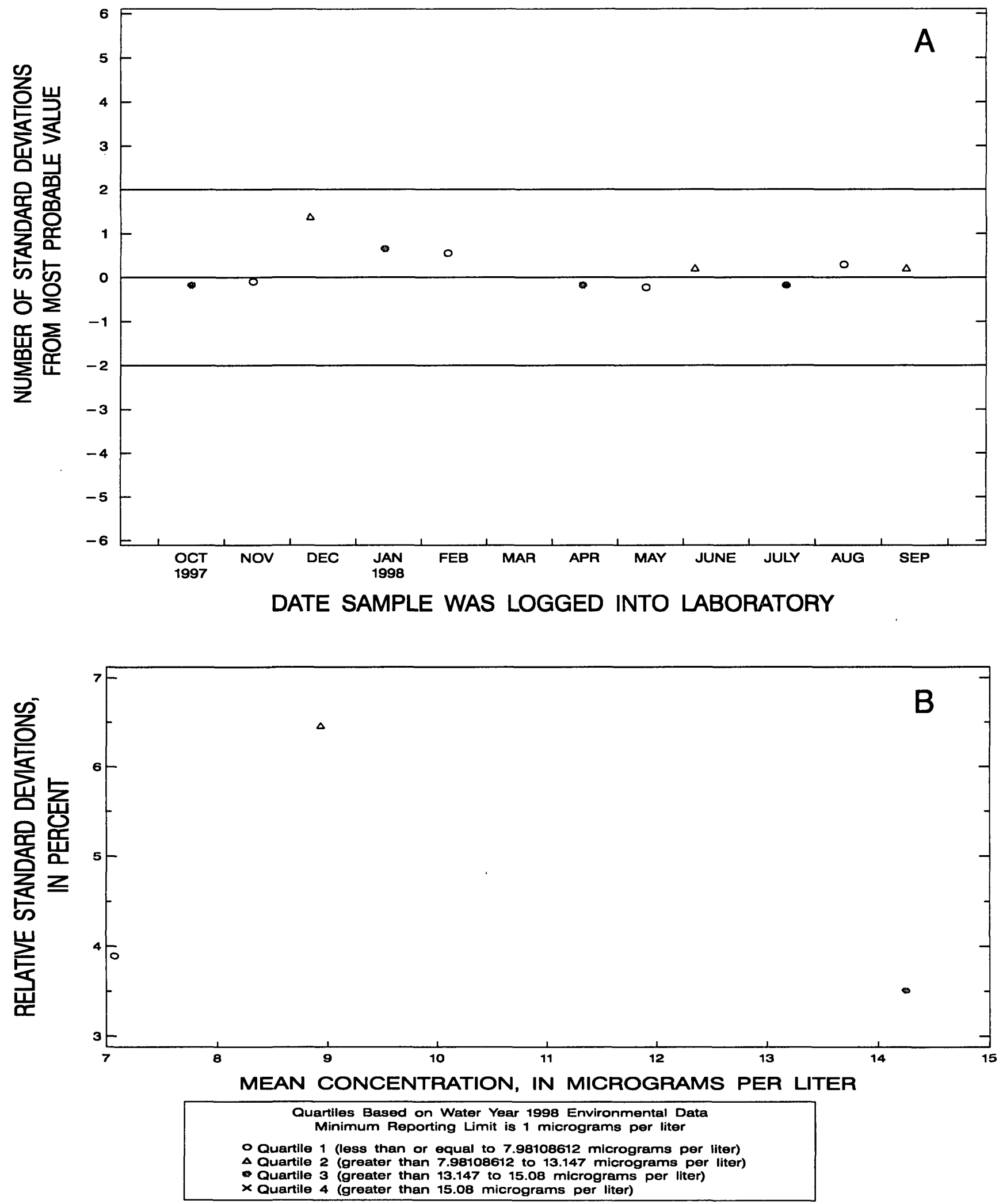

Flgure 108. Cadmium, dissolved, (graphite furnace-atomic absorption spectrophotometry) data from the Quality of Water Service Unit laboratory. 

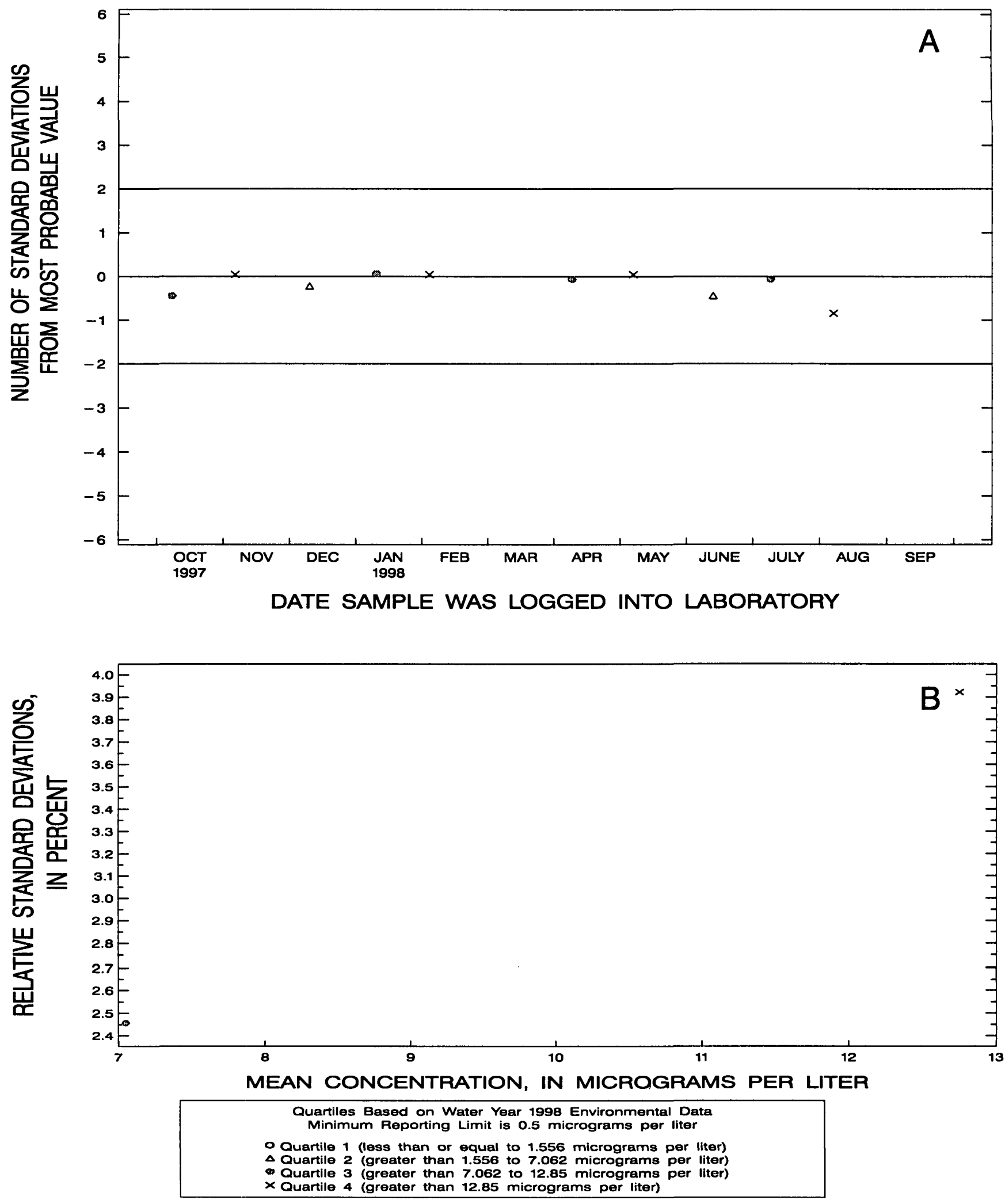

Figure 109. Cadmium, dissolved, (inductively coupled plasma-atomic emission spectrometry, trace) data from the Quality of Water Service Unit laboratory. 

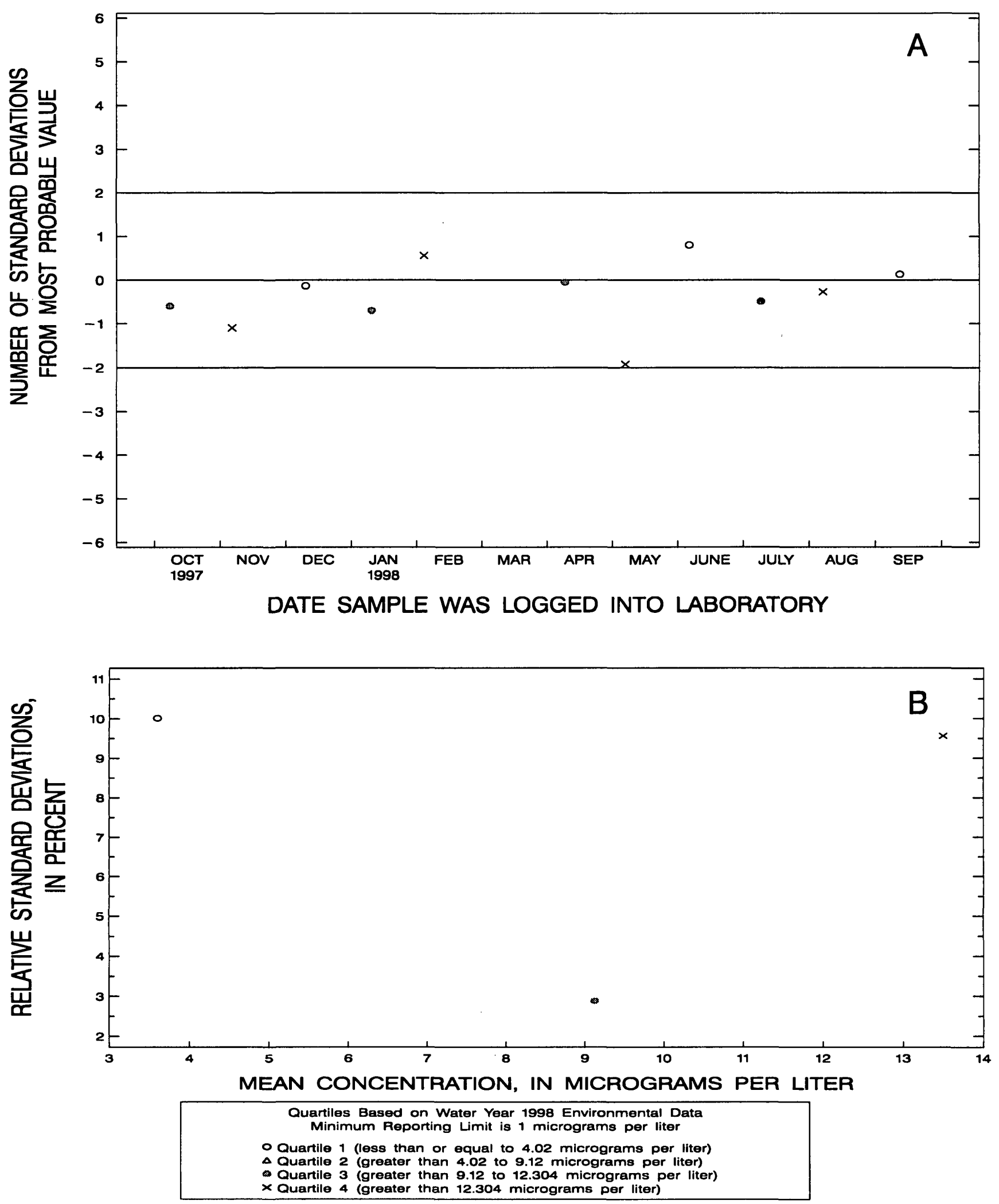

Figure 110. Cadmium, whole-water recoverable, (graphite furnace-atomic absorption spectrophotometry) data from the Quality of Water Service Unit laboratory. 

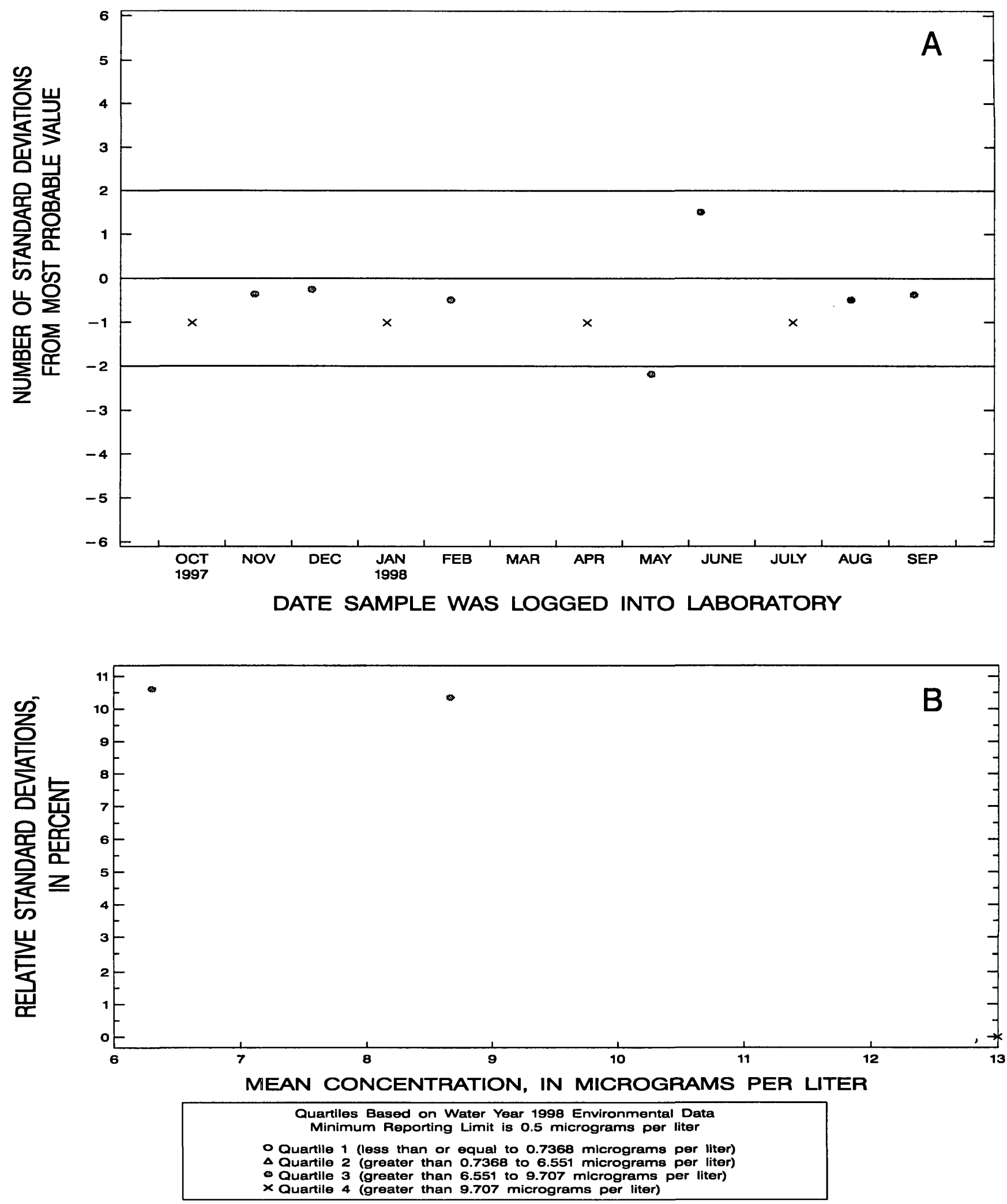

Figure 111. Cadmium, whole-water recoverable, (inductively coupled plasma-atomic emission spectrometry, trace) data from the Quality of Water Senvice Unit laboratory. 

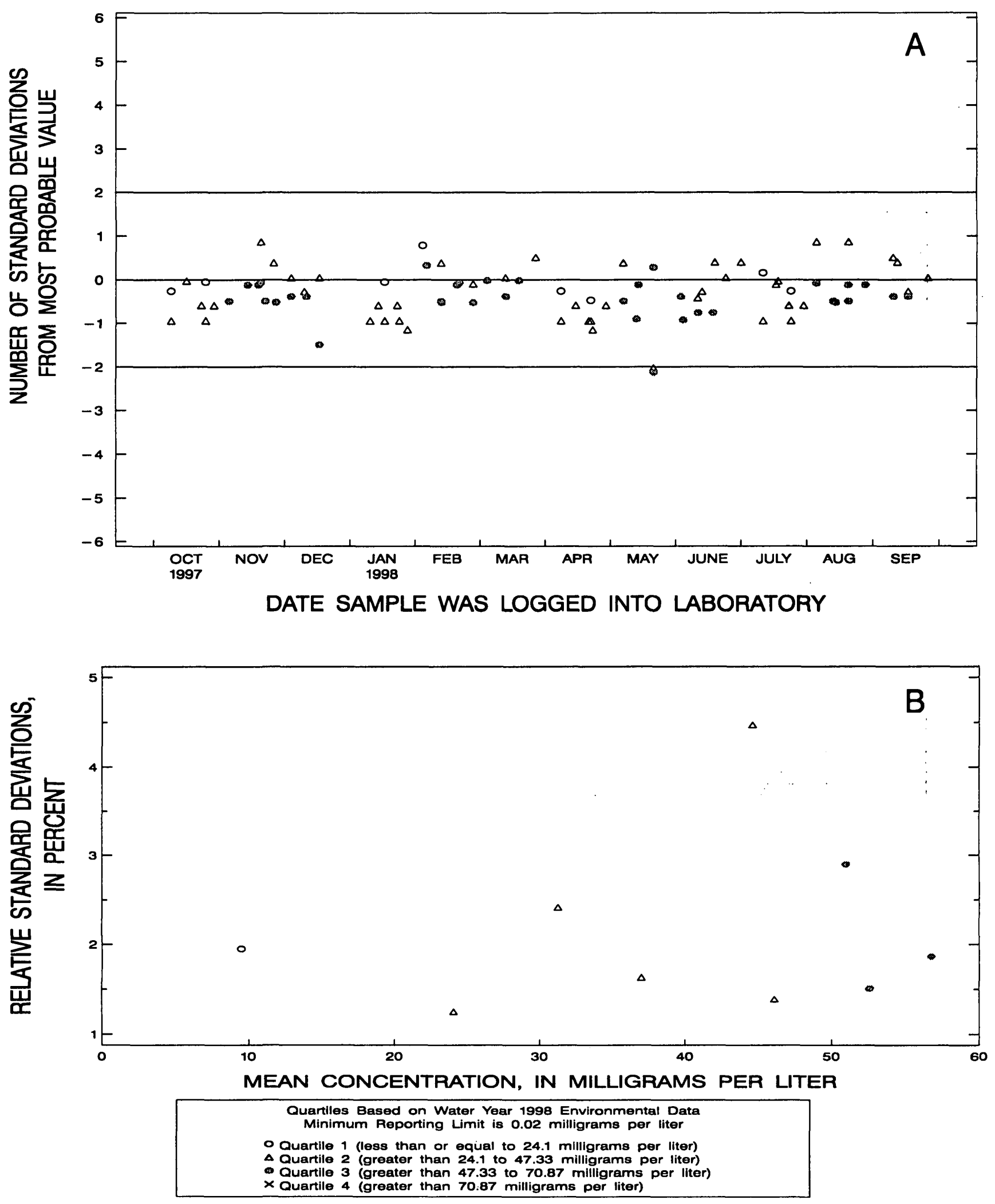

Figure 112. Calcium, dissolved, (inductively coupled plasma-atomic emission spectrometry) data from the Quality of Water Service Unit laboratory. 

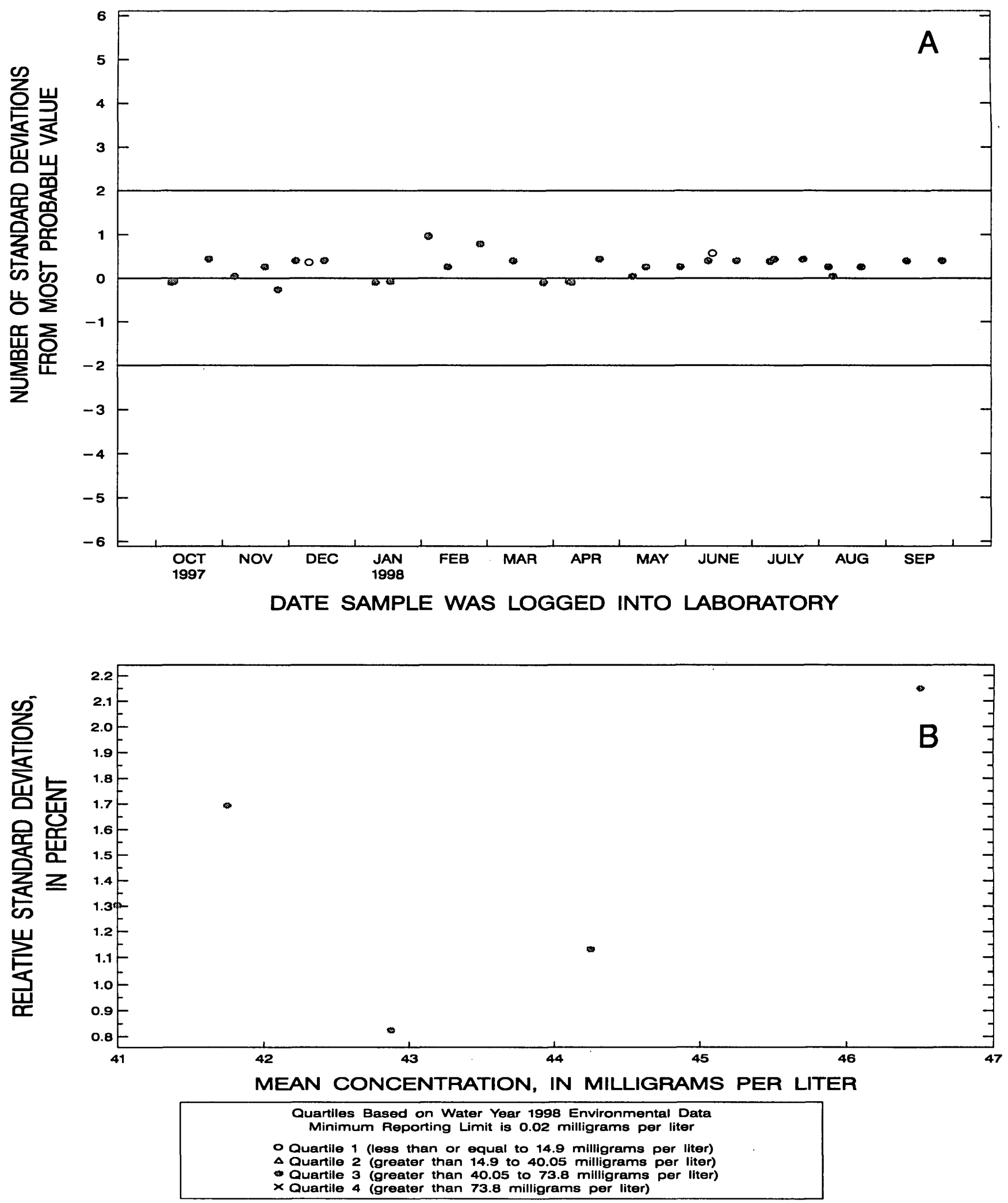

Figure 113. Calcium, dissolved, (inductively coupled plasma-atomic emission spectrometry, trace) data from the Quality of Water Service Unit laboratory. 

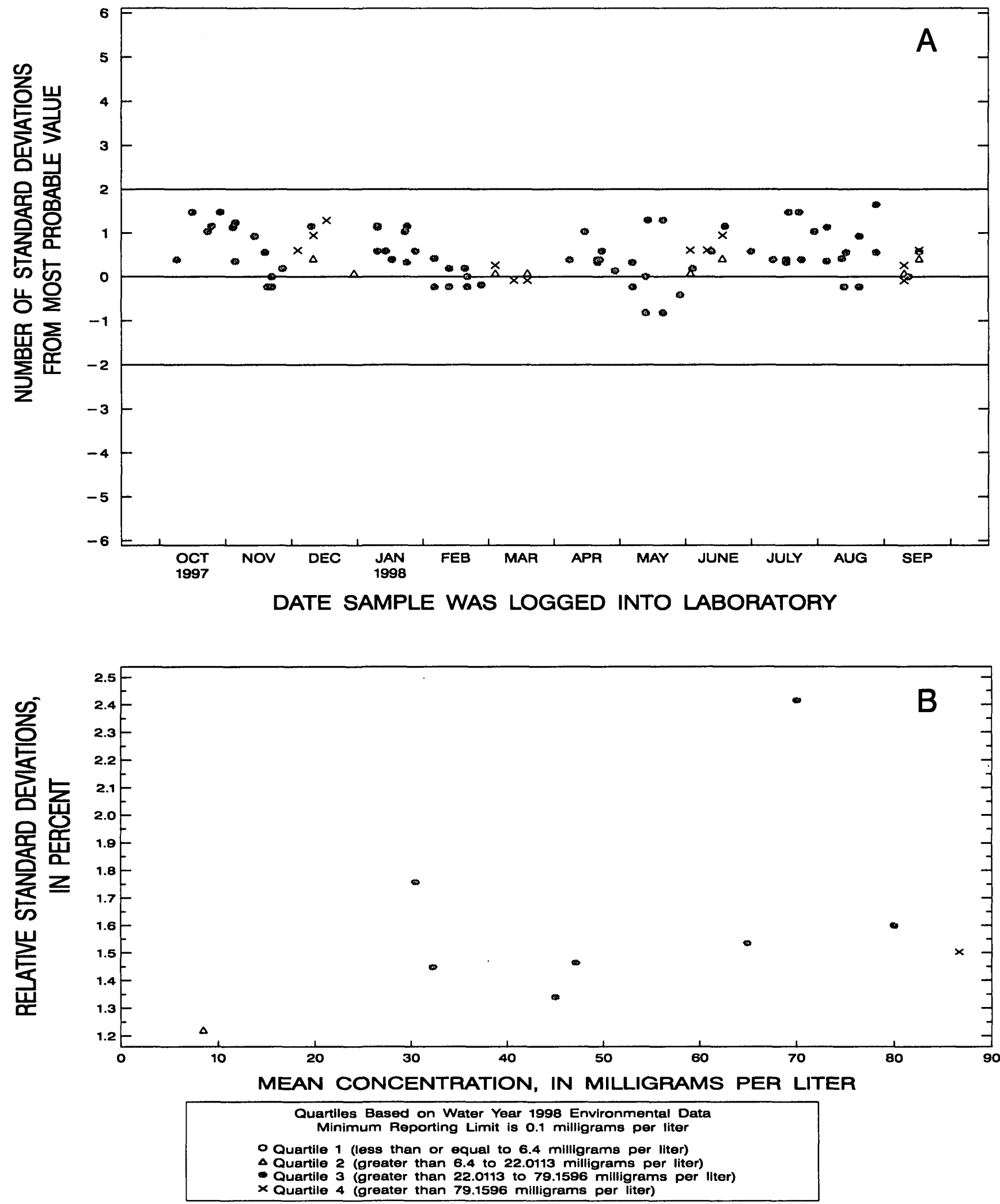

Figure 114. Chloride, dissolved, (ion chromatography) data from the Quality of Water Service Unit laboratory. 

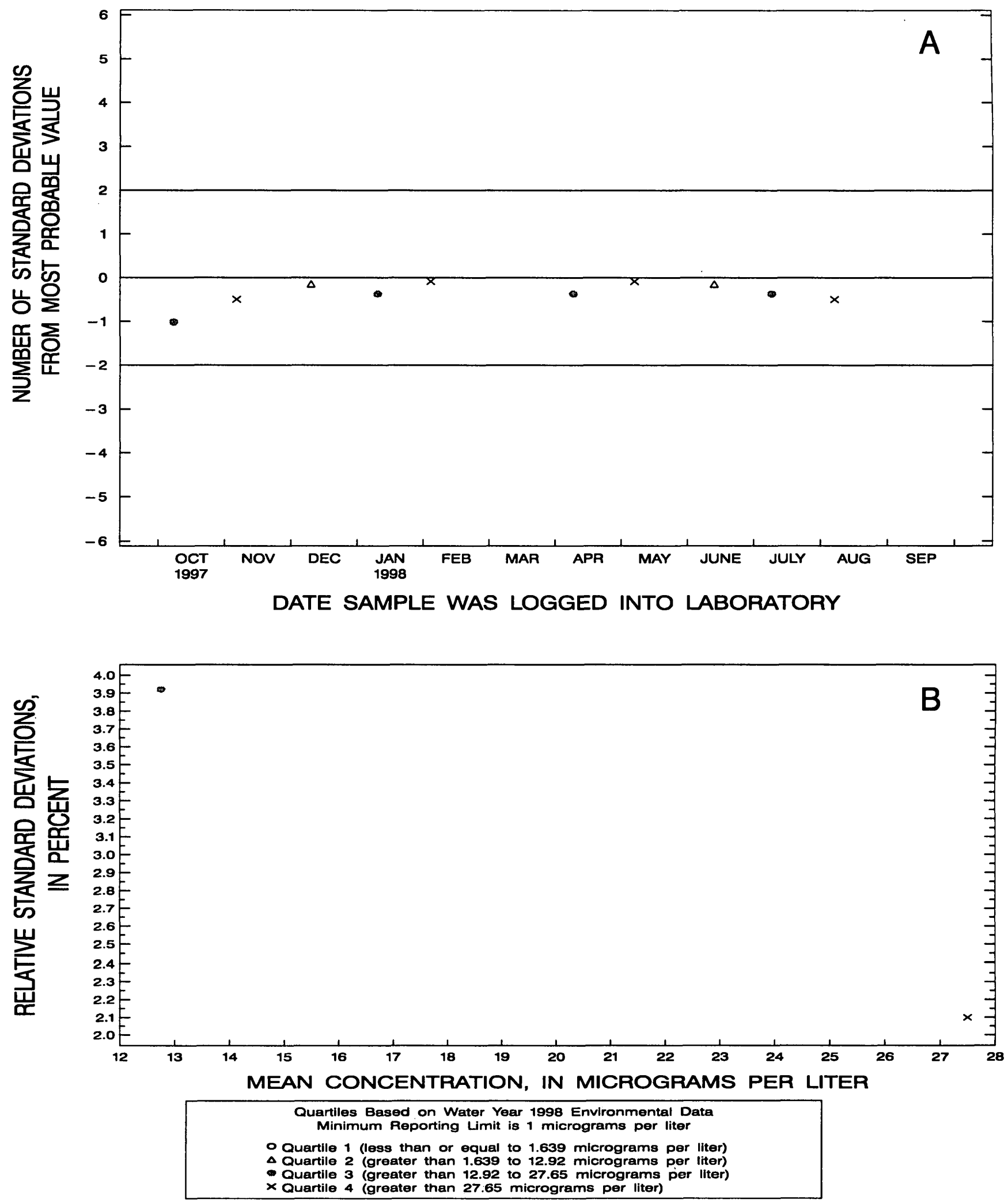

Figure 115. Chromium, dissolved, (inductively coupled plasma-atomic emission spectrometry, trace) data from the Quality of Water Service Unit laboratory. 

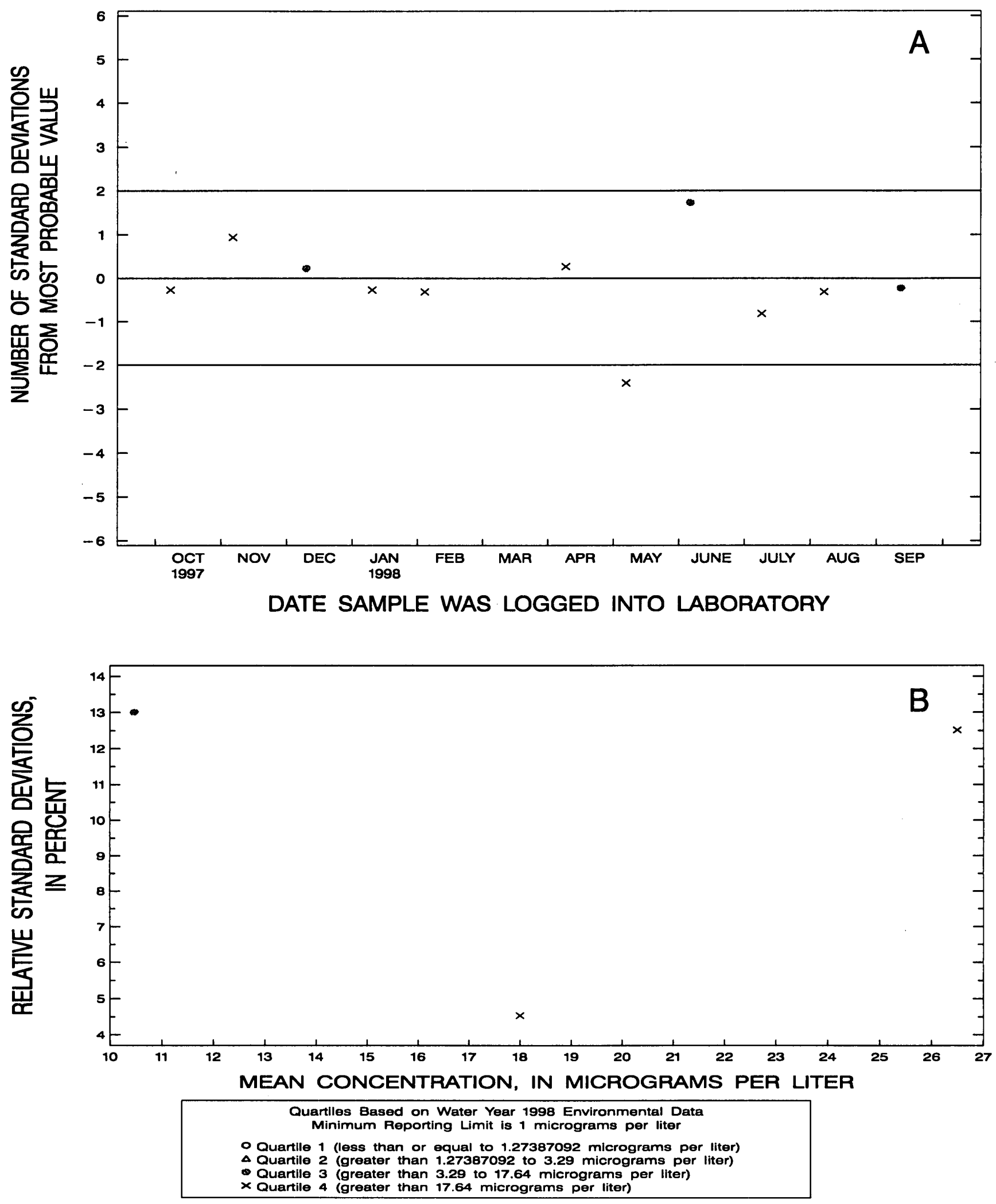

Figure 116. Chromium, whole-water recoverable, (graphite furnace-atomic absorption spectrophotometry) data from the Quality of Water Service Unit laboratory. 

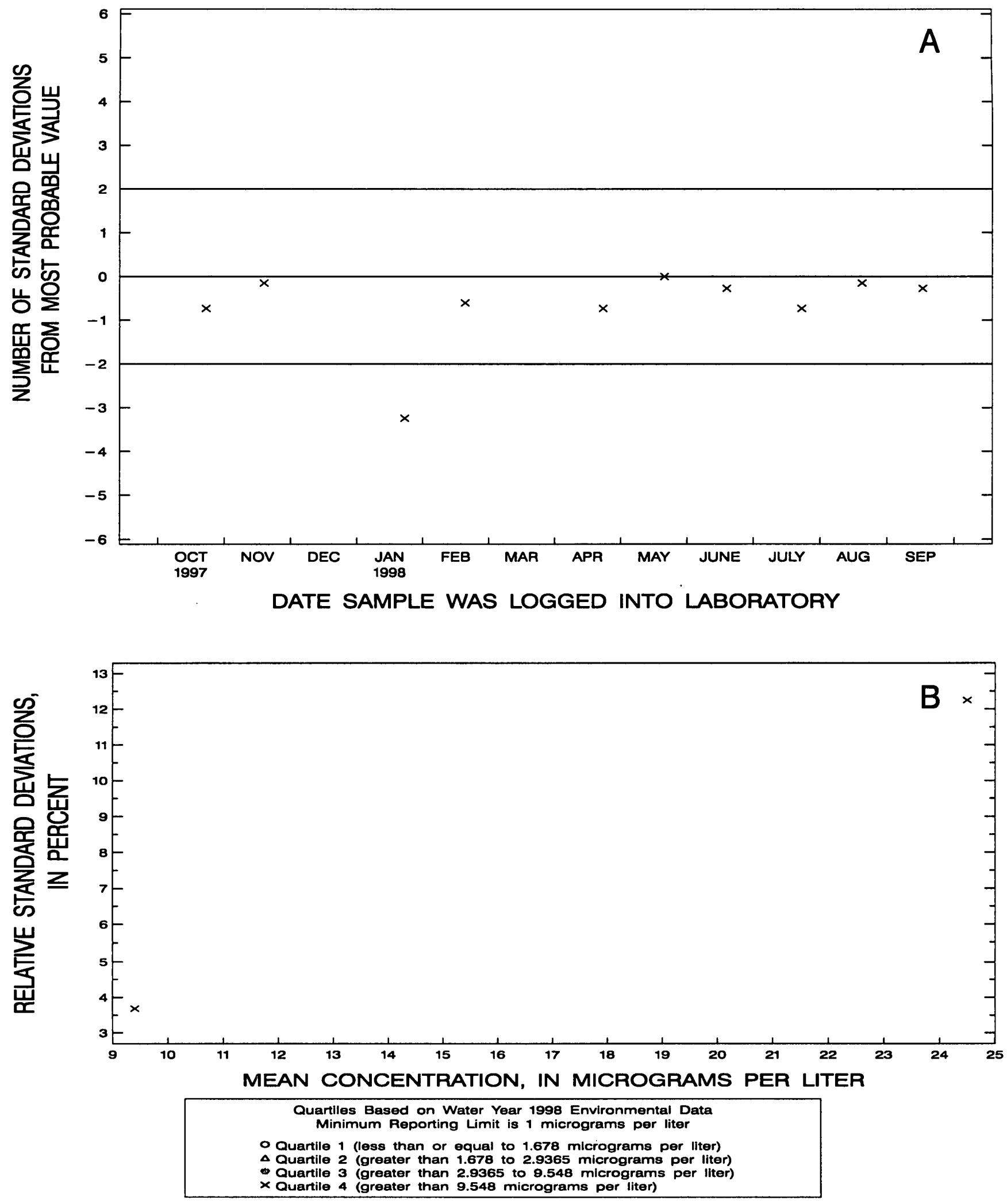

Figure 117. Chromium, whole-water recoverable, (inductively coupled plasma-atomic emission spectrometry, trace) data from the Quality of Water Service Unit laboratory. 

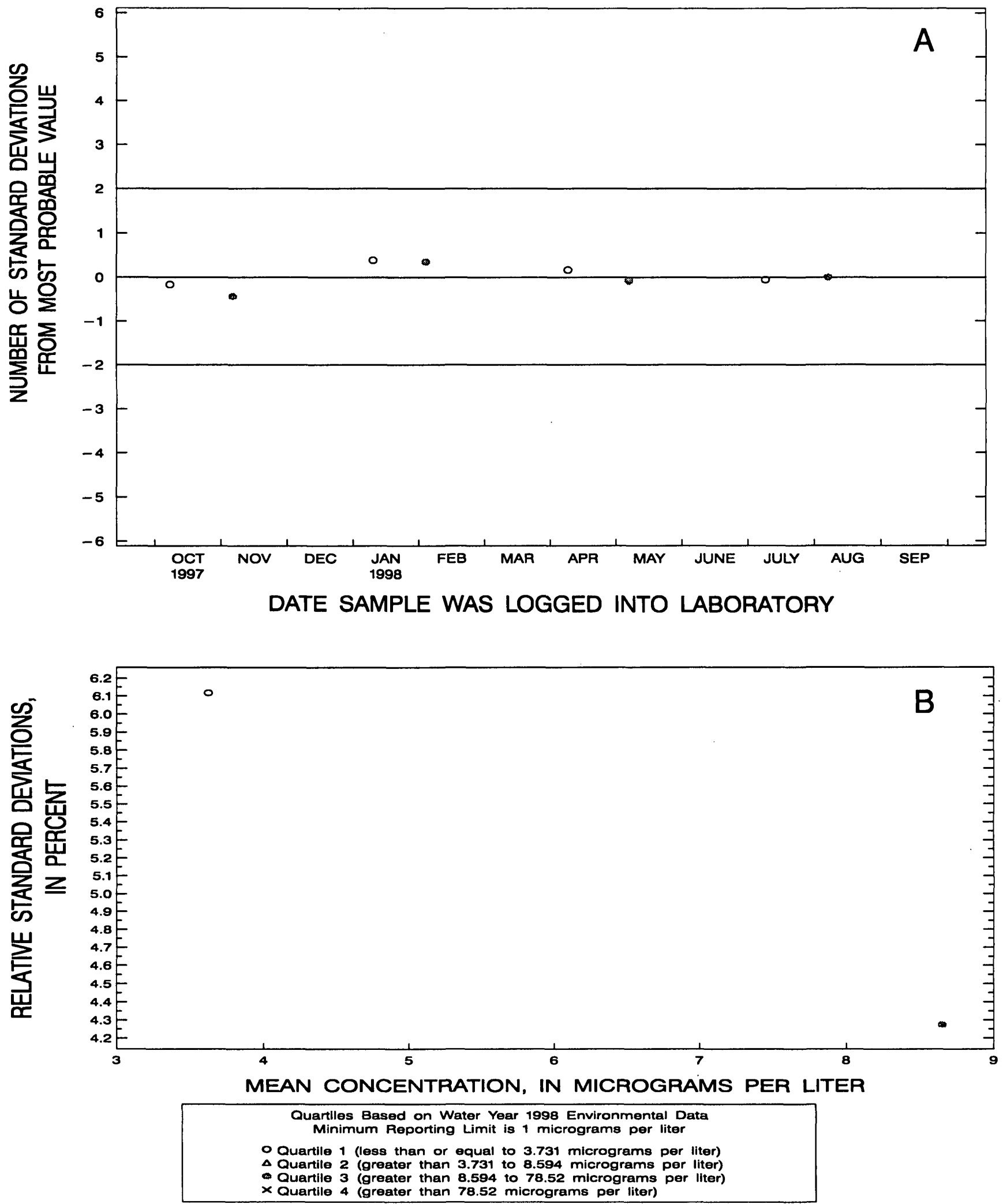

Figure 118. Cobalt, dissolved, (inductively coupled plasma-atomic emission spectrometry, trace) data from the Quality of Water Service Unit laboratory. 

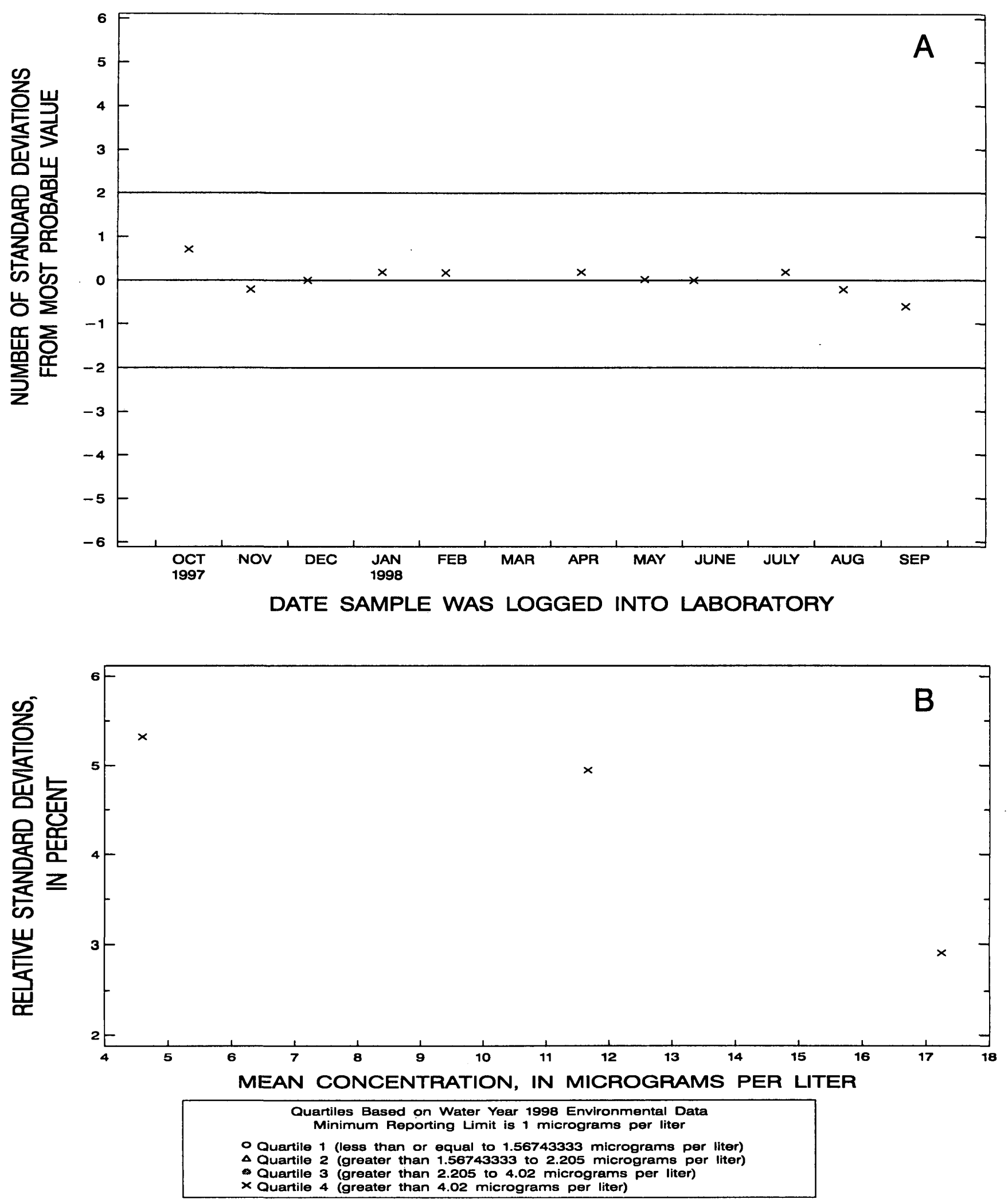

Figure 119. Copper, dissolved, (graphite furnace-atomic absorption spectrophotometry) data from the Quality of Water Service Unit laboratory. 

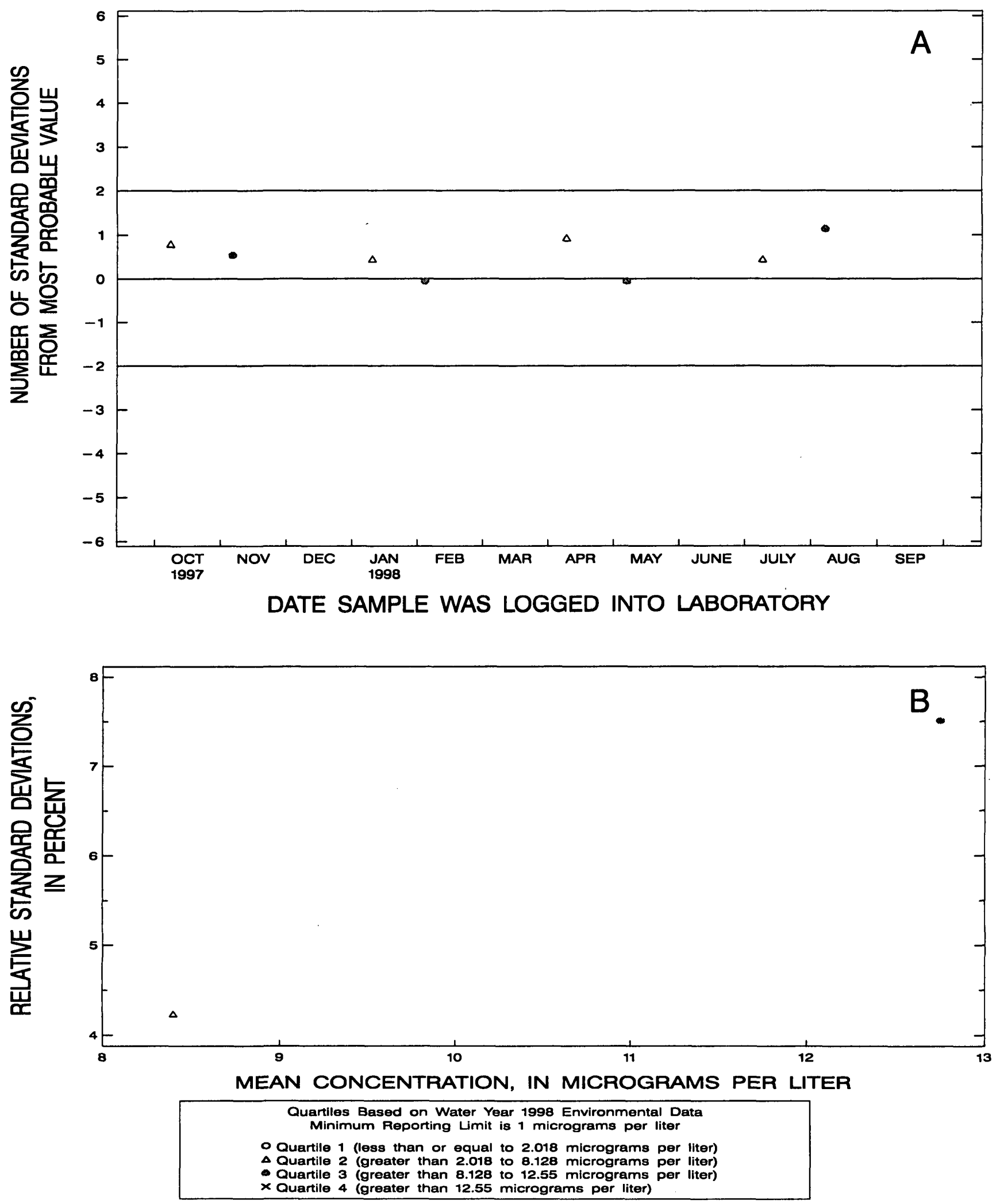

Figure 120. Copper, dissolved, (inductively coupled plasma-atomic emission spectrometry, trace) data from the Quality of Water Service Unit laboratory. 

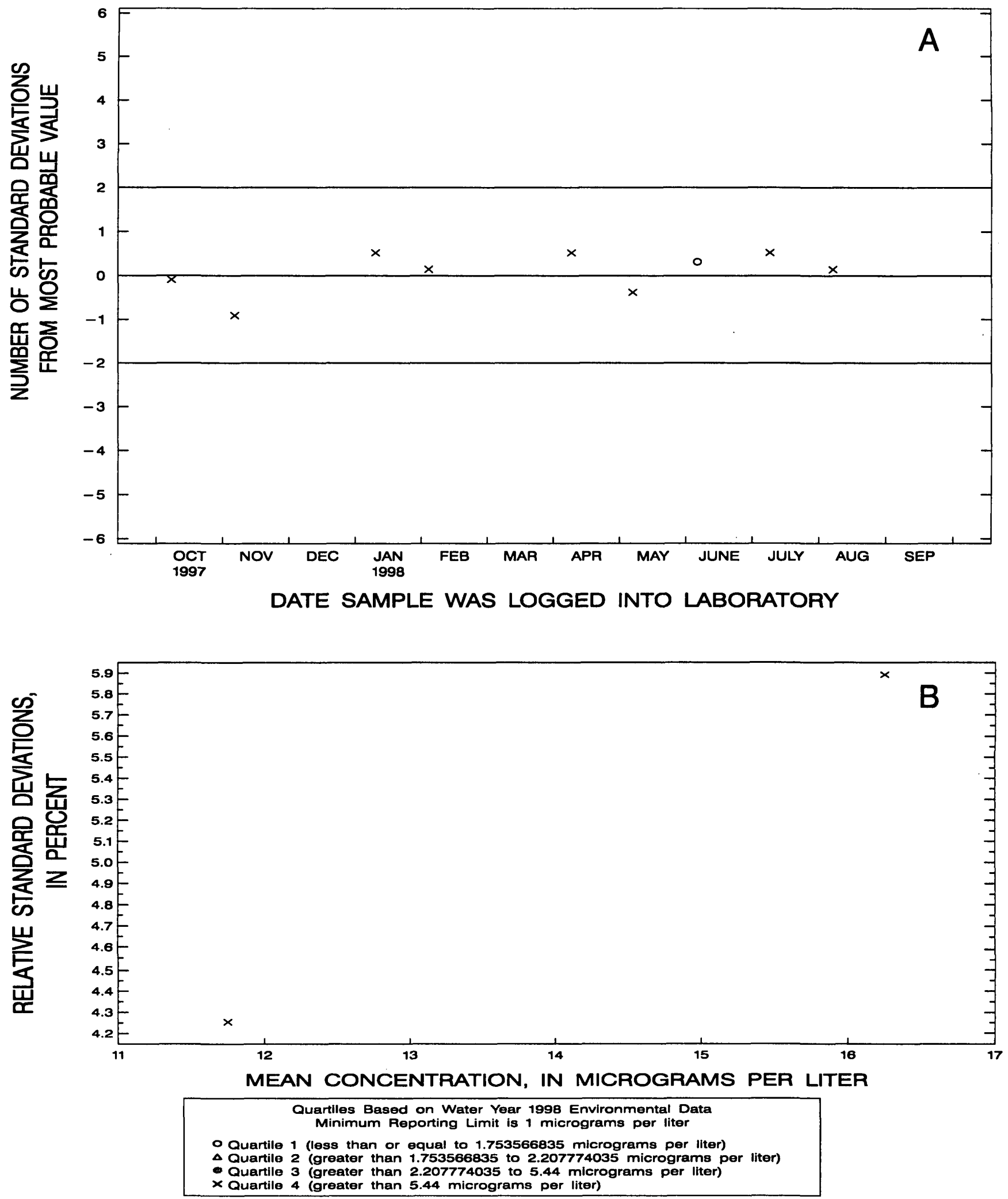

Figure 121. Copper, whole-water recoverable, (graphite furnace-atomic absorption spectrophotometry) data from the Quality of Water Service Unit laboratory. 


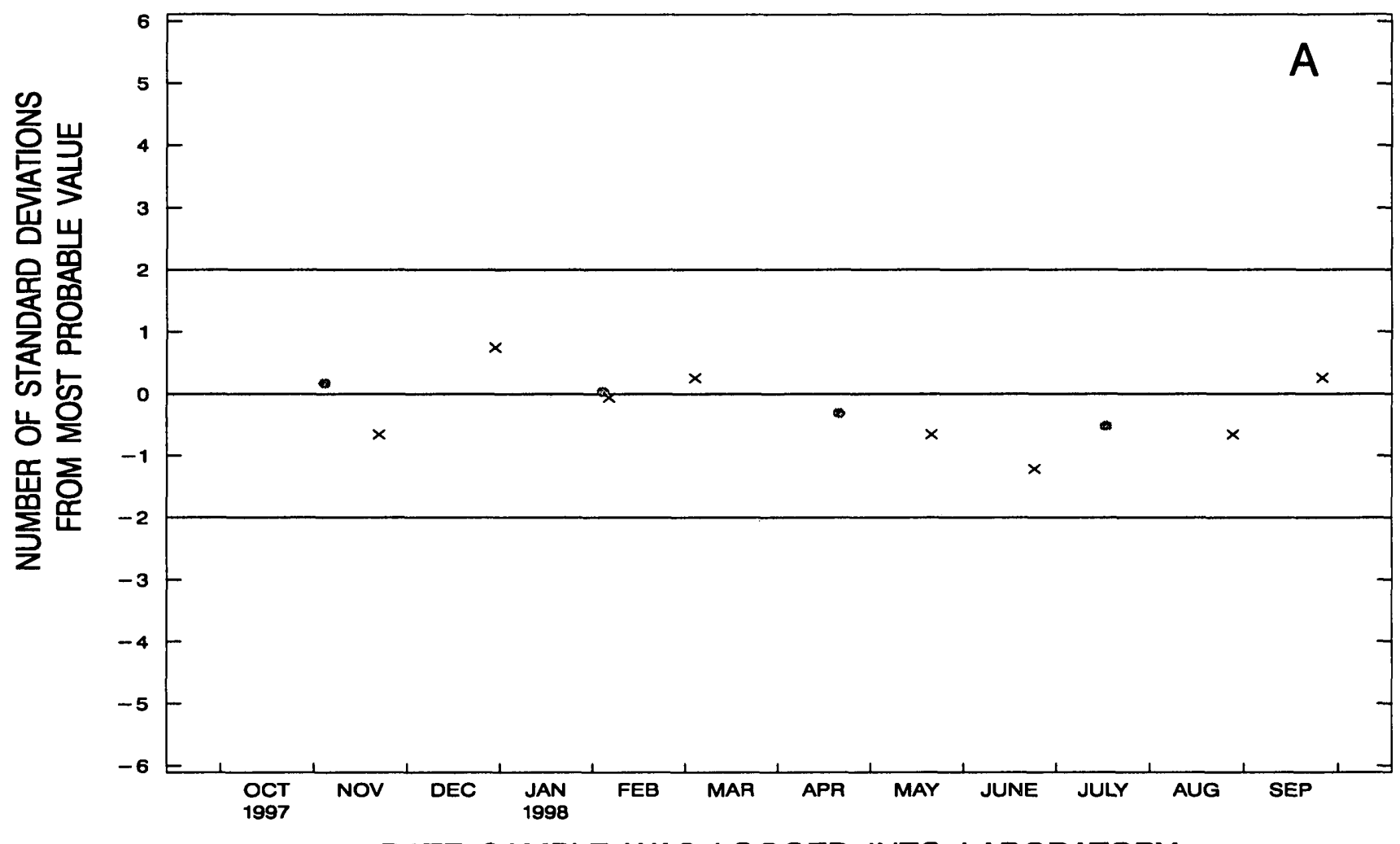

DATE SAMPLE WAS LOGGED INTO LABORATORY

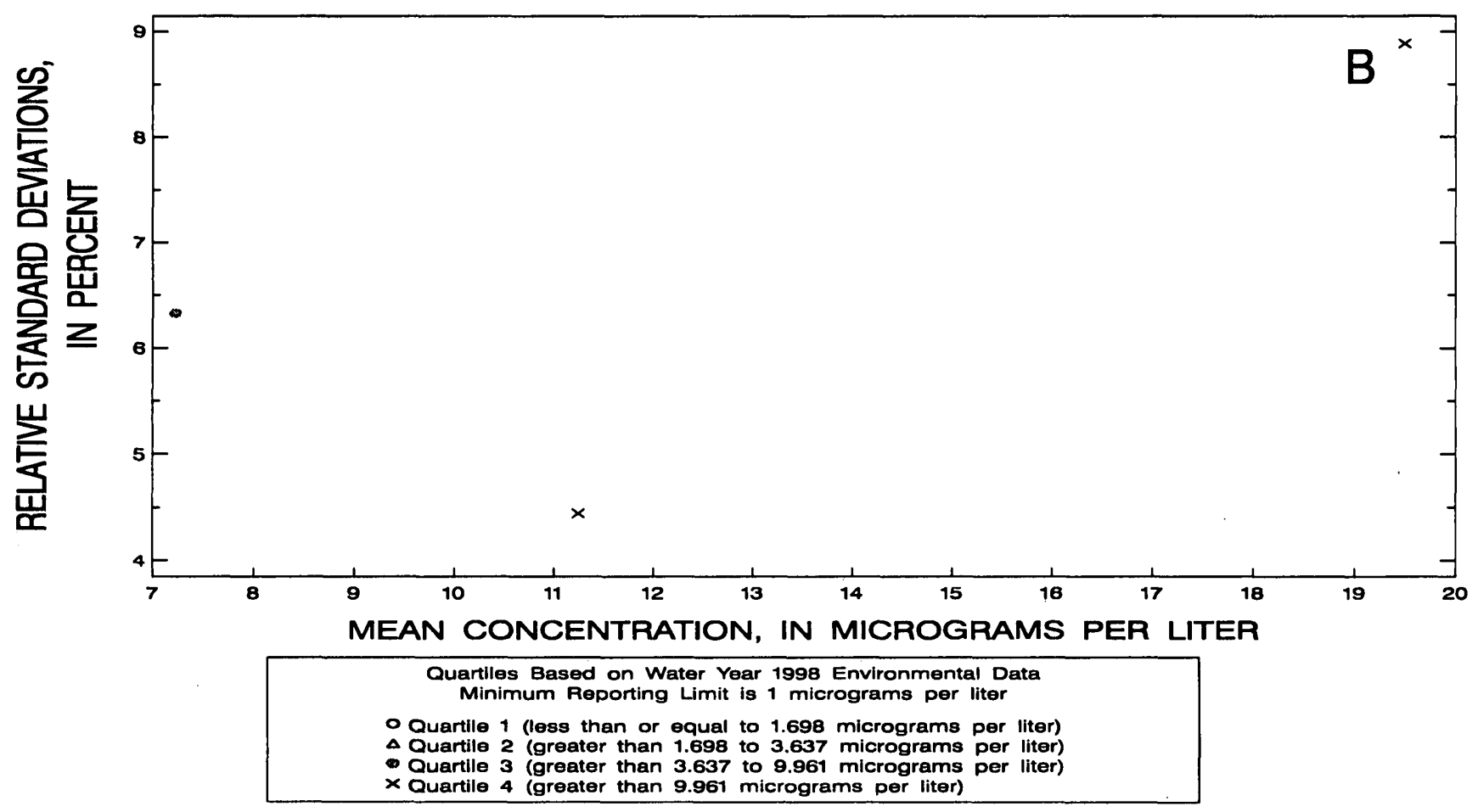

Figure 122. Copper, whole-water recoverable, (inductively coupled plasma-atomic emission spectrometry, trace) data from the Quality of Water Senvice Unit laboratory. 

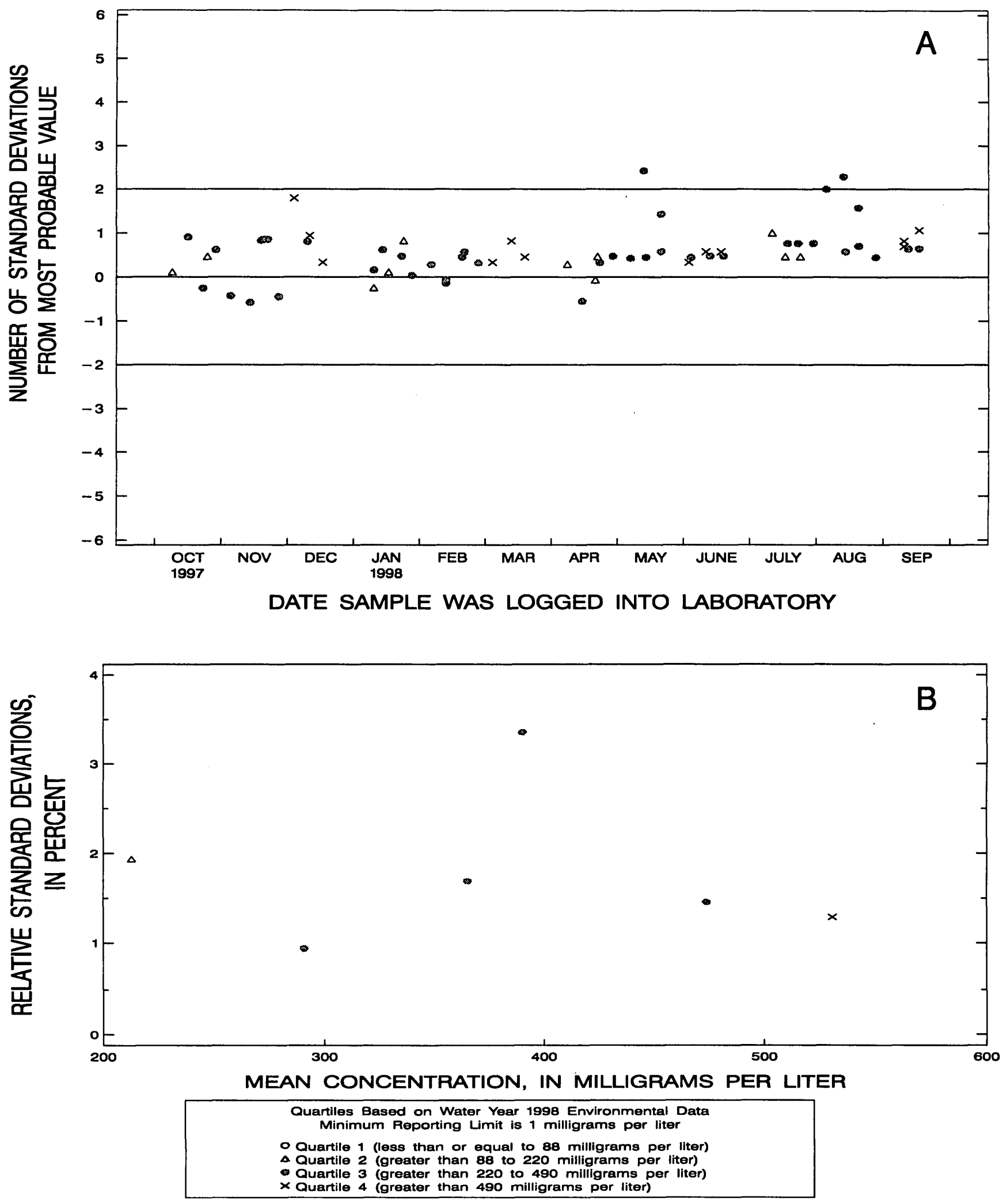

Figure 123. Dissolved solids, dissolved, (gravimetric) data from the Quality of Water Service Unit laboratory. 

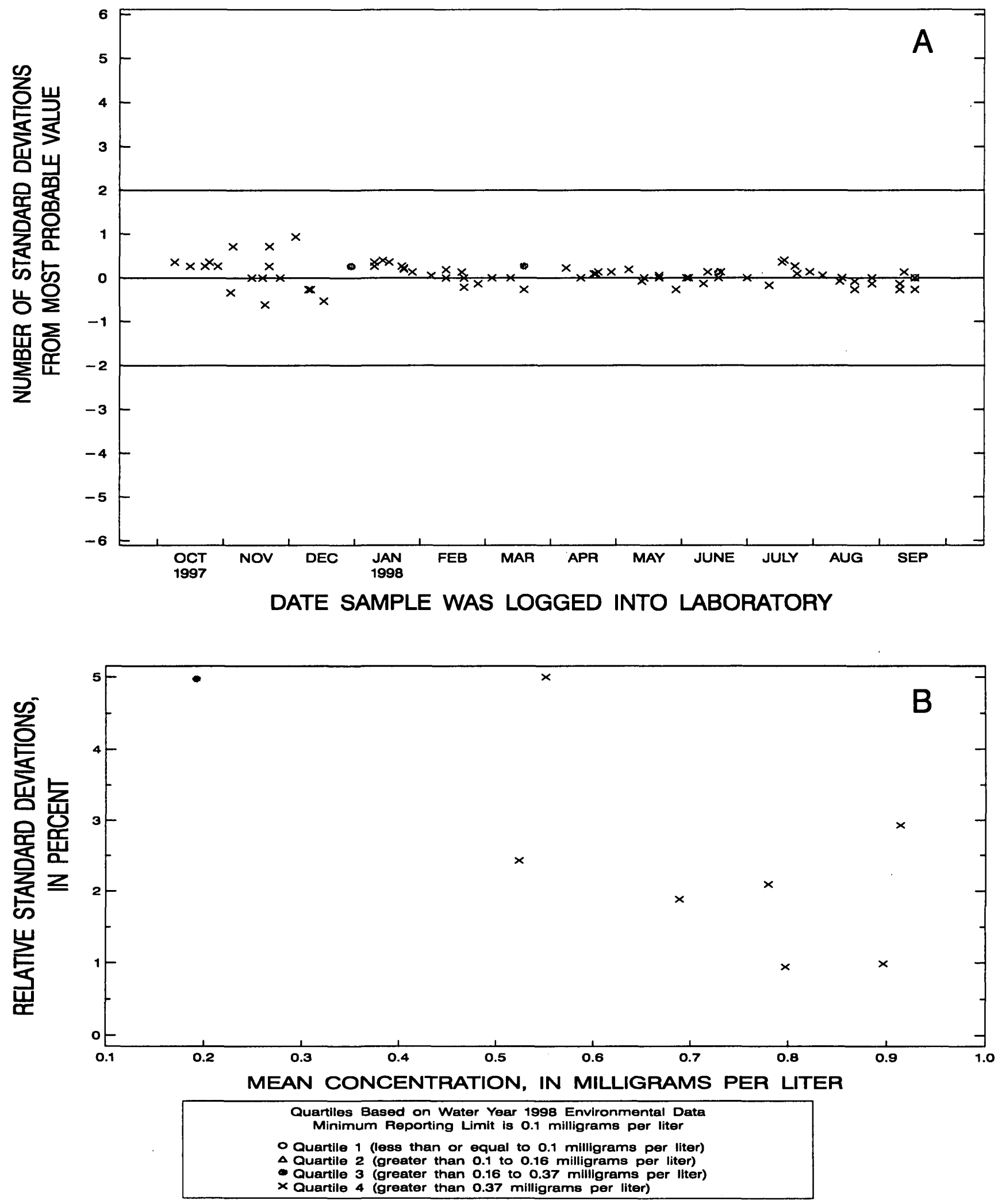

Figure 124. Fluoride, dissolved, (ion-selective electrode) data from the Quality of Water Service Unit laboratory. 

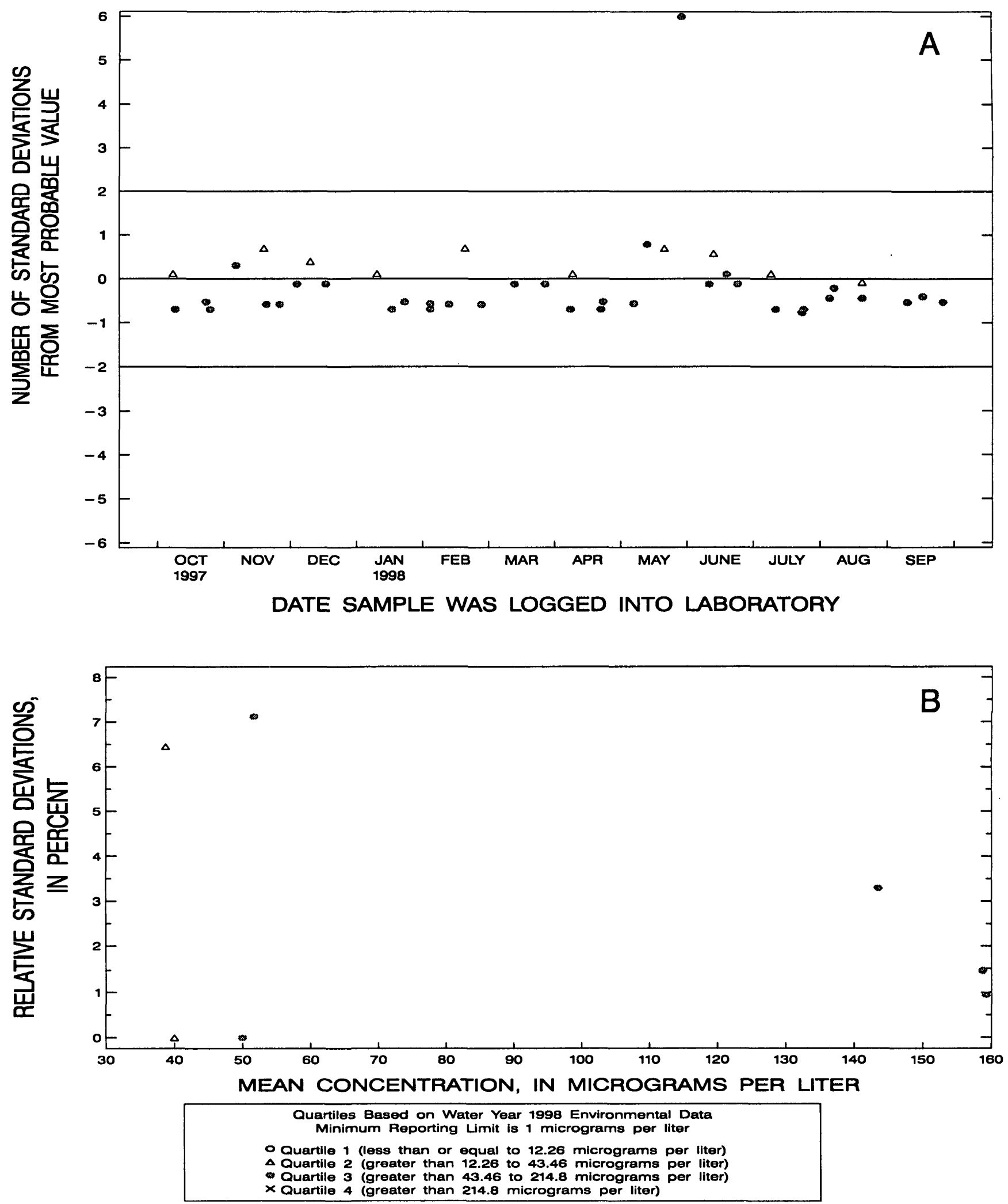

Figure 125. Iron, dissolved, (inductively coupled plasma-atomic emission spectrometry, trace) data from the Quality of Water Service Unit laboratory. 

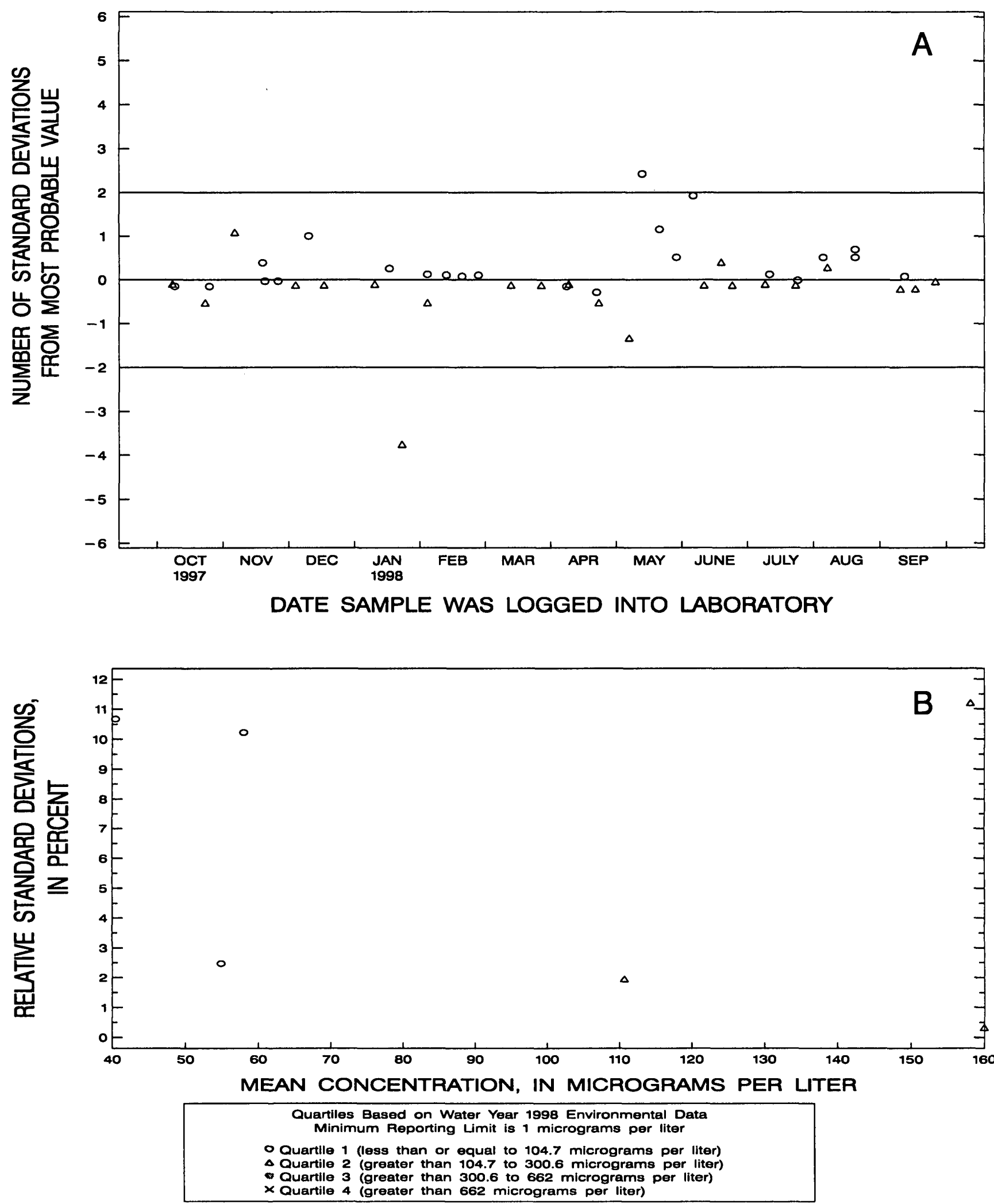

Figure 126. Iron, whole-water recoverable, (inductively coupled plasma-atomic emission spectrometry, trace) data from the Quality of Water Service Unit laboratory. 

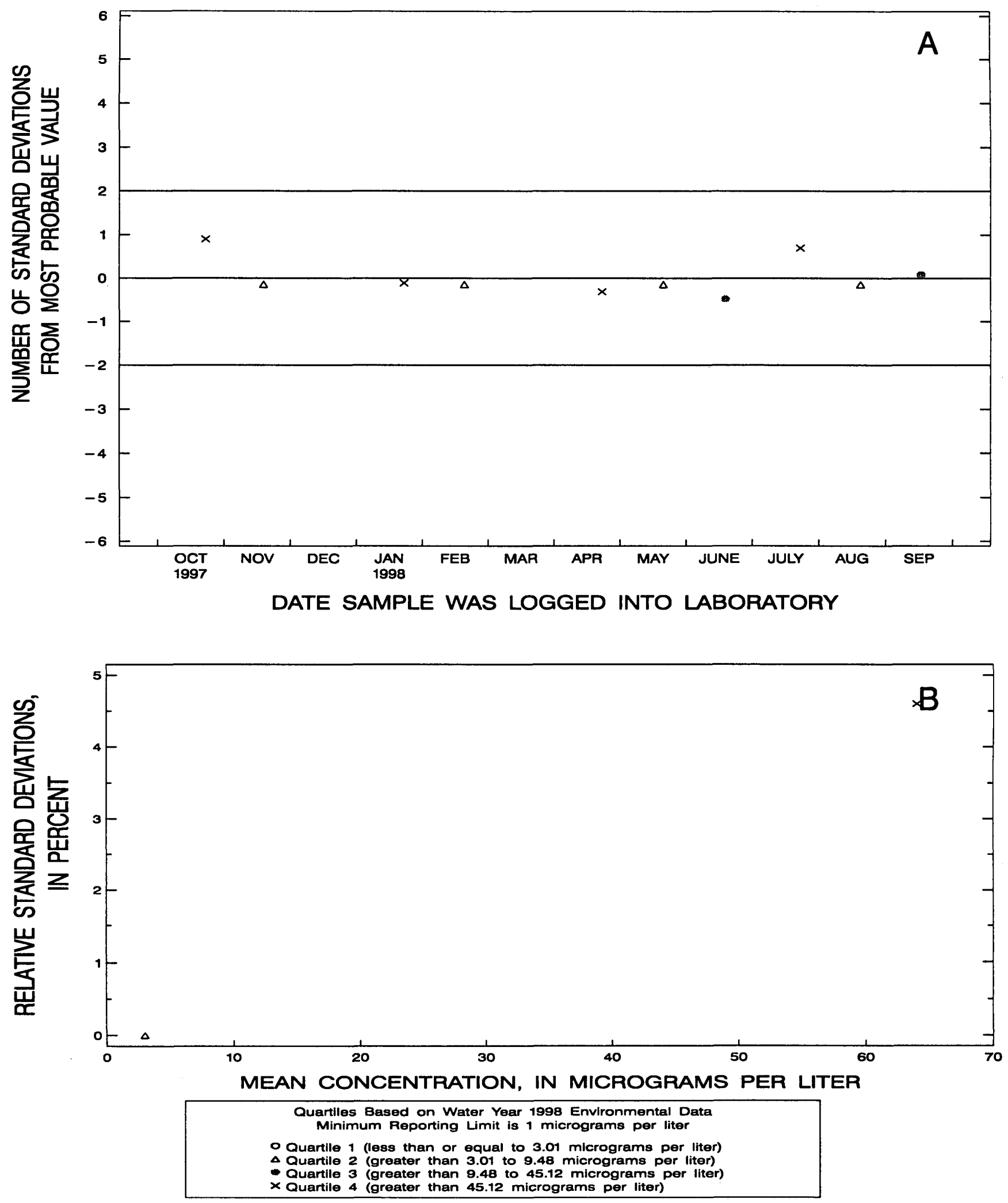

Figure 127. Lead, dissolved, (graphite furnace-atomic absorption spectrophotometry) data from the Quality of Water Service Unit laboratory. 

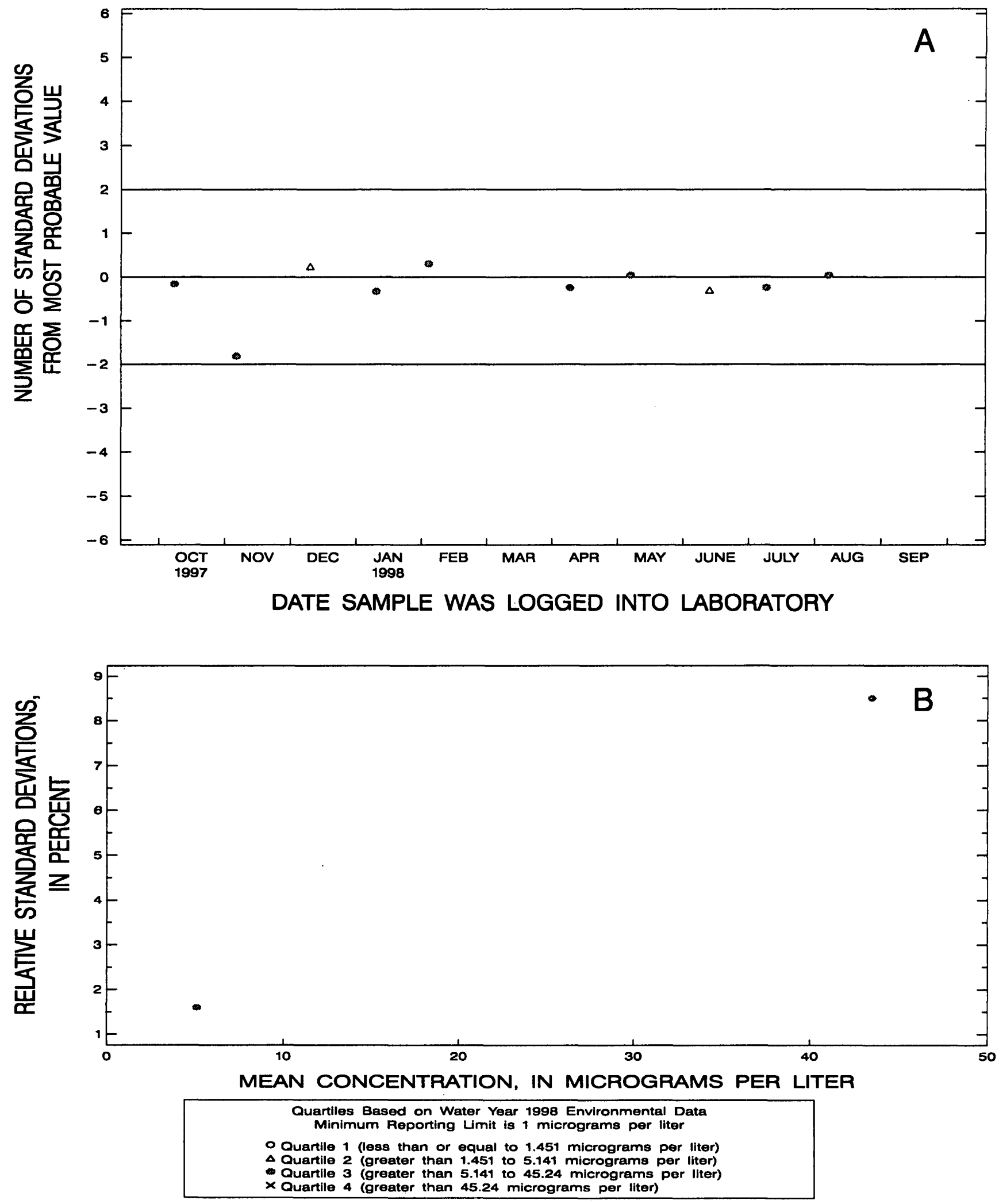

Figure 128. Lead, dissolved, (inductively coupled plasma-atomic emission spectrometry, trace) data from the Quality of Water Service Unit laboratory. 

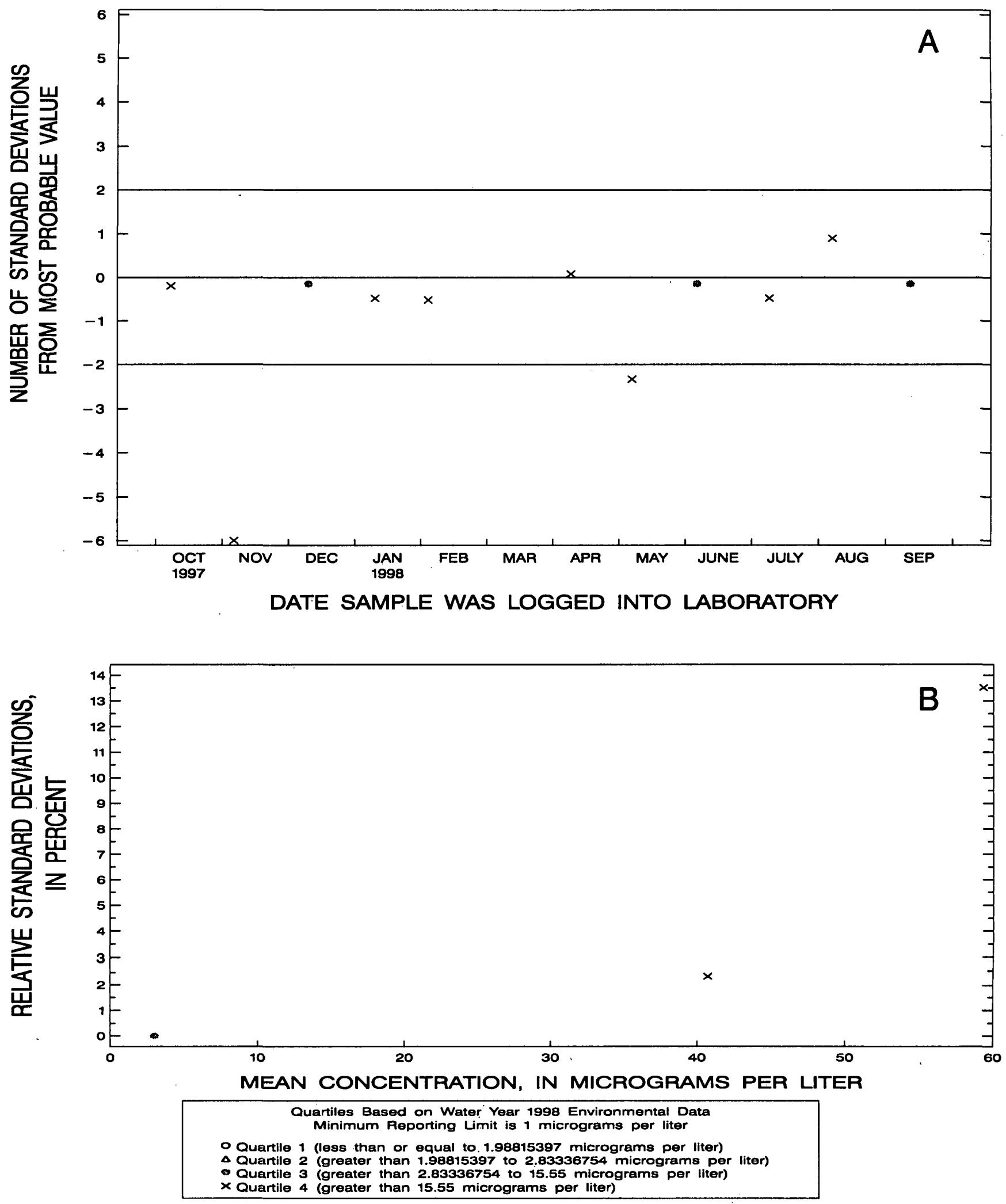

Figure 129. Lead, whole-water recoverable, (graphite furnace-atomic absorption spectrophotometry) data from the Quality of Water Service Unit laboratory. 

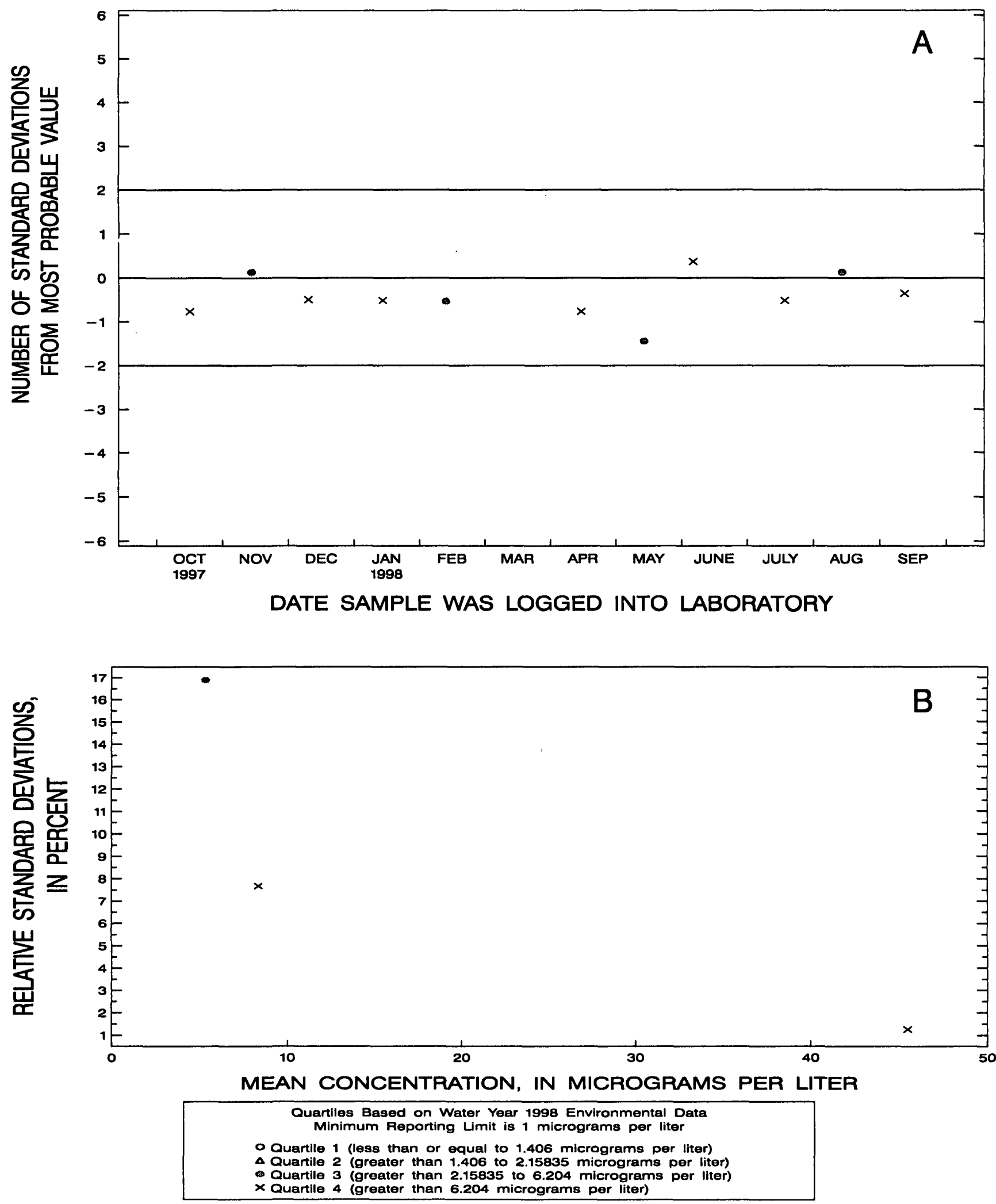

Figure 130. Lead, whole-water recoverable, (inductively coupled plasma-atomic emission spectrometry, trace) data from the Quality of Water Service Unit laboratory. 

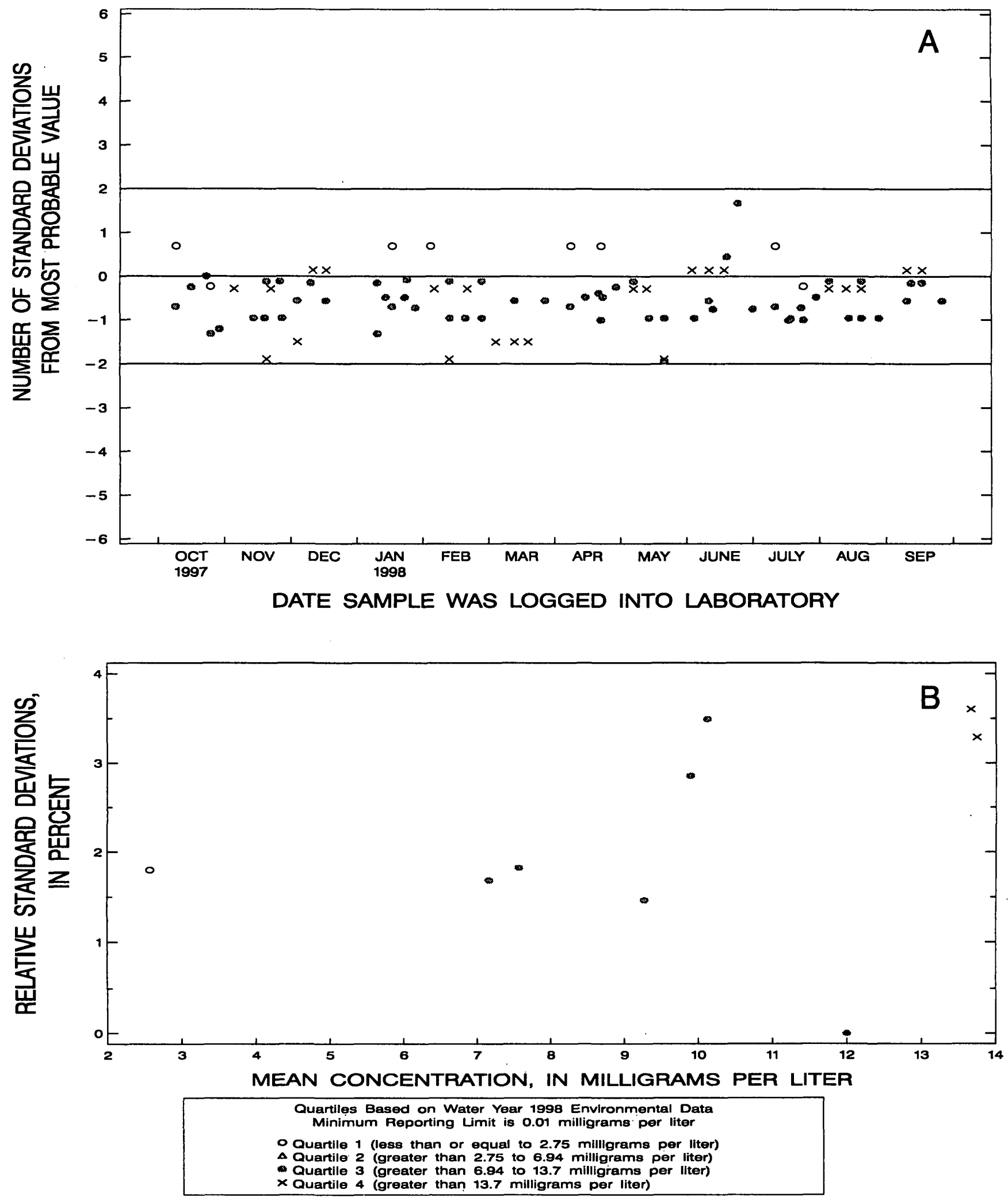

Figure 131. Magnesium, dissolved, (inductively coupled plasma-atomic emission spectrometry) data from the Quality of Water Service Unit laboratory. 

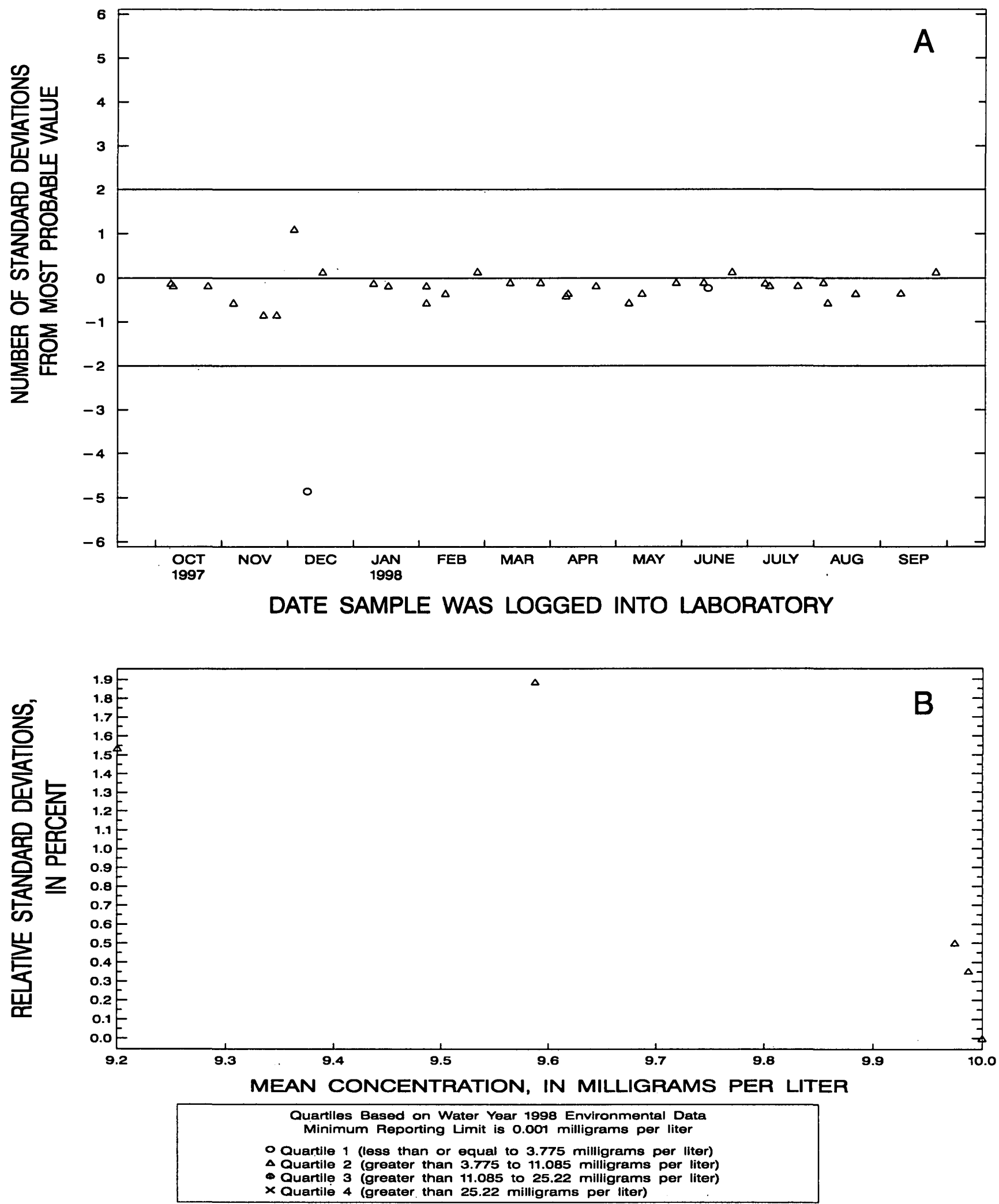

Figure 132. Magnesium, dissolved, (inductively coupled plasma-atomic emission spectrometry, trace) data from the Quality of Water Service Unit laboratory. 

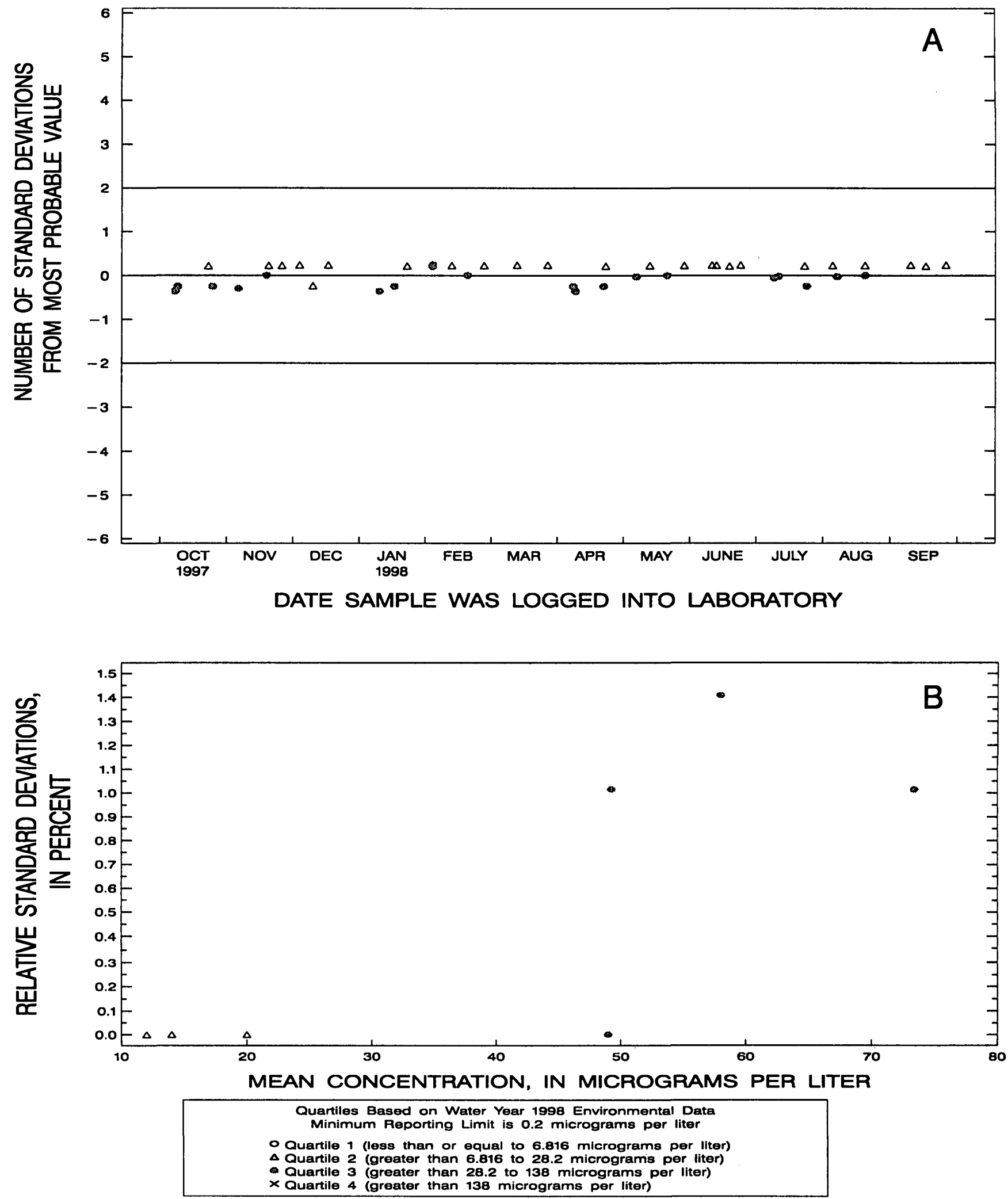

Figure 133. Manganese, dissolved, (inductively coupled plasma-atomic emission spectrometry, trace) data from the Quality of Water Service Unit laboratory. 

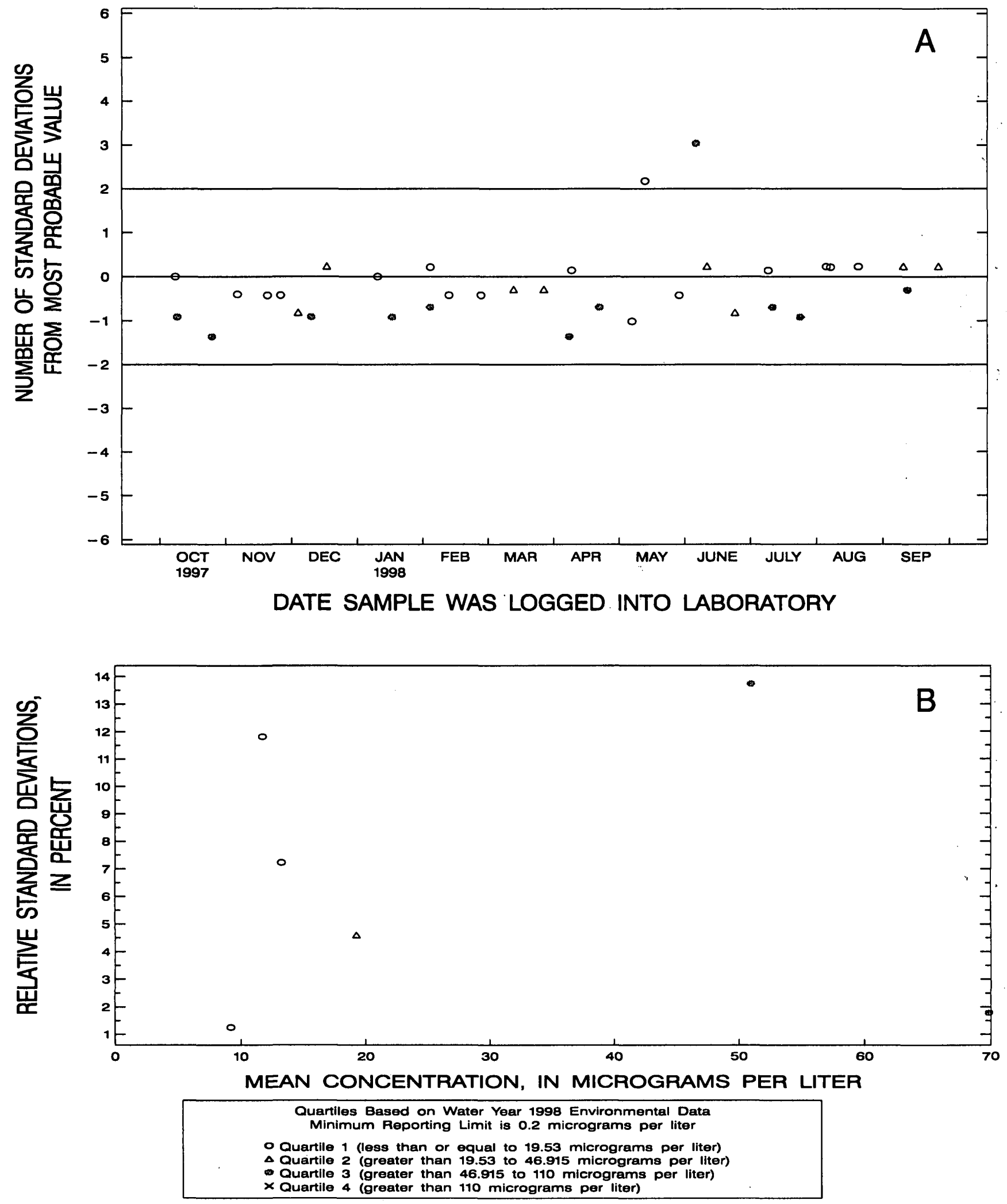

Figure 134. Manganese, whole-water recoverable, (inductively coupled plasma-atomic emission spectrometry, trace) data from the Quality of Water Service Unit laboratory. 

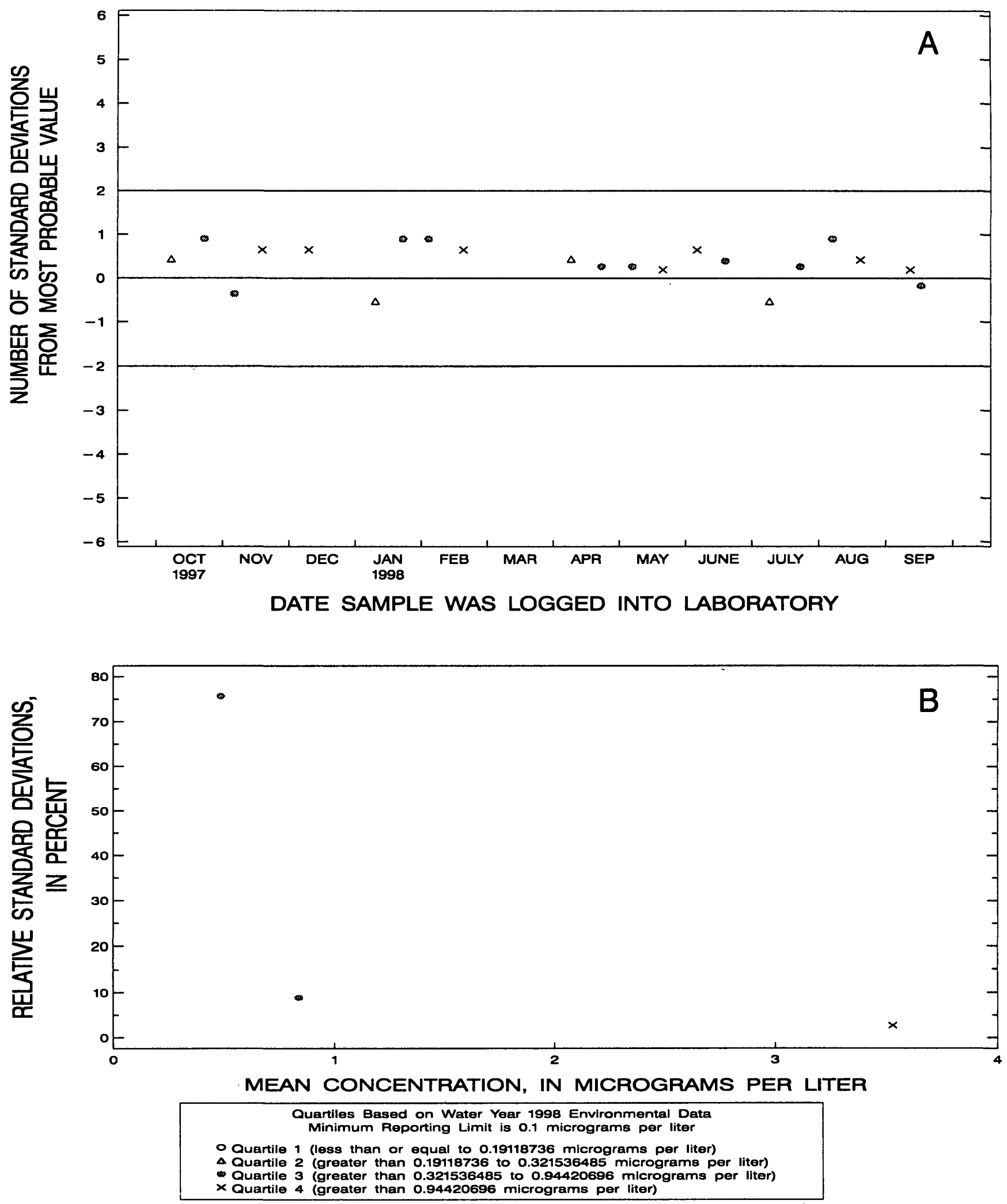

Figure 135. Mercury, whole-water recoverable, (cold vapor-atomic absorption spectrophotometry) data from the Quality of Water Service Unit laboratory. 

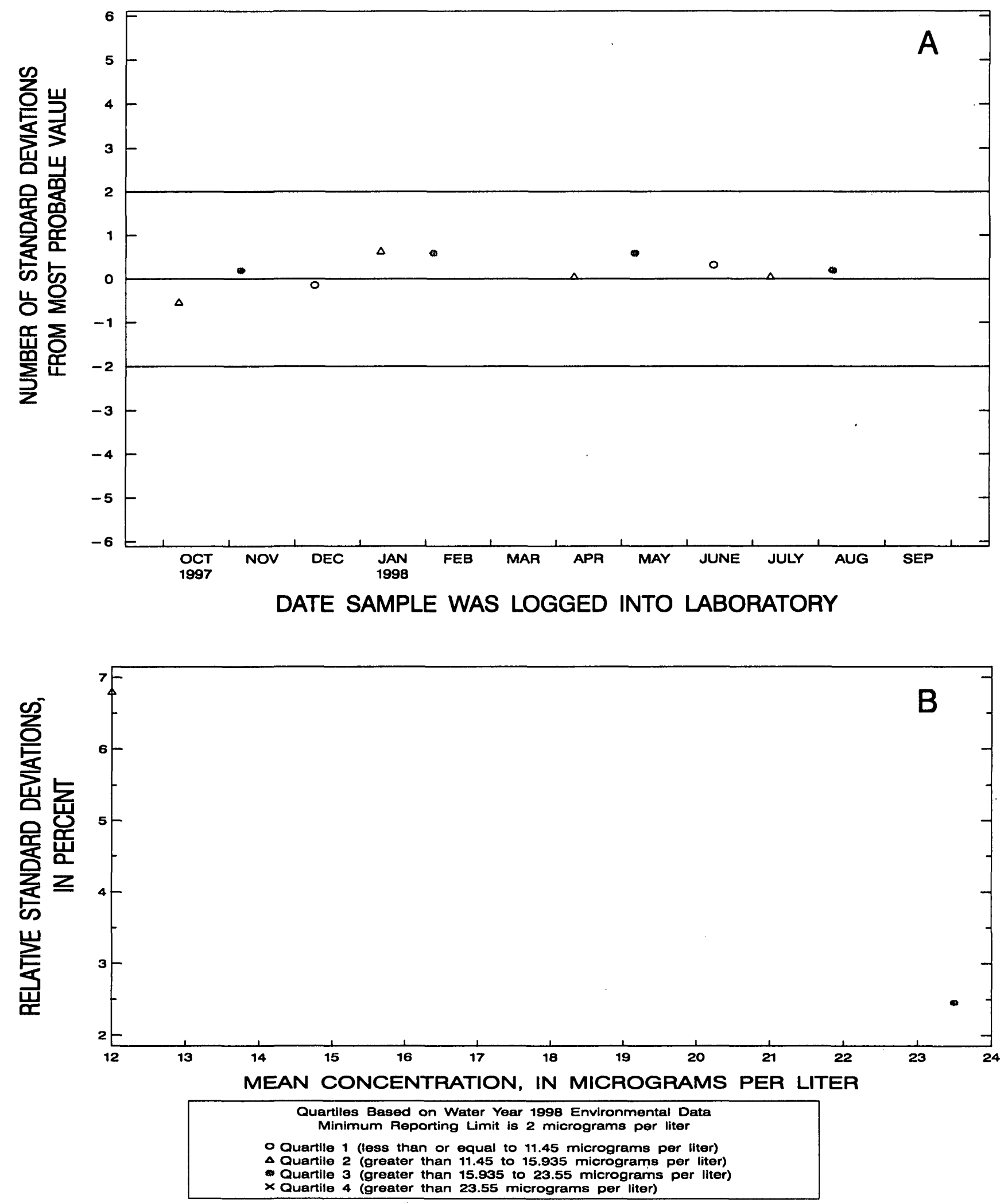

Figure 136. Molybdenum, dissolved, (inductively coupled plasma-atomic emission spectrometry, trace) data from the Quality of Water Service Unit laboratory. 

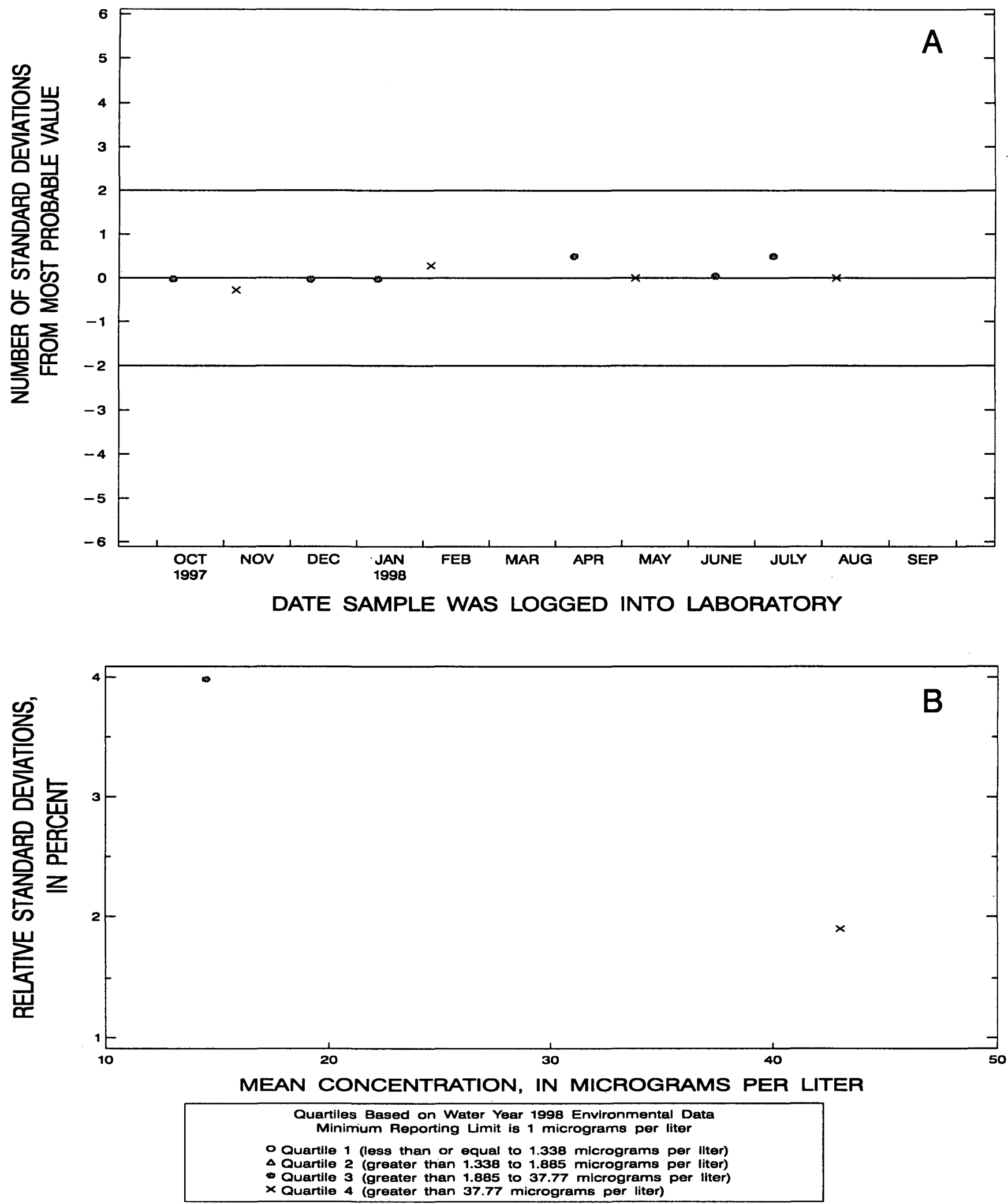

Figure 137. Nickel, dissolved, (inductively coupled plasma-atomic emission spectrometry, trace) data from the Quality of Water Service Unit laboratory. 

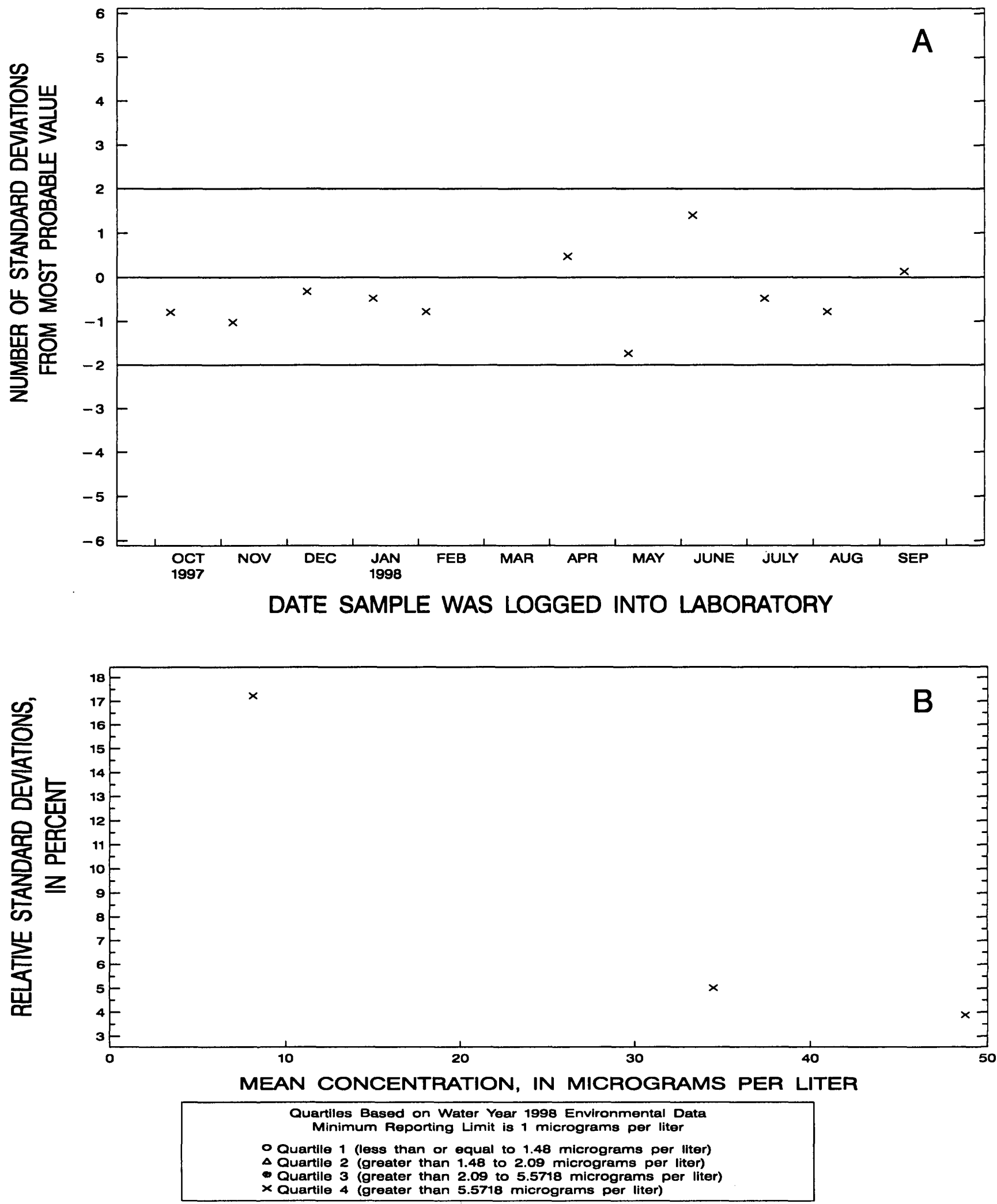

Figure 138. Nickel, whole-water recoverable, (graphite furnace-atomic absorption spectrophotometry) data from the Quality of Water Service Unit laboratory. 

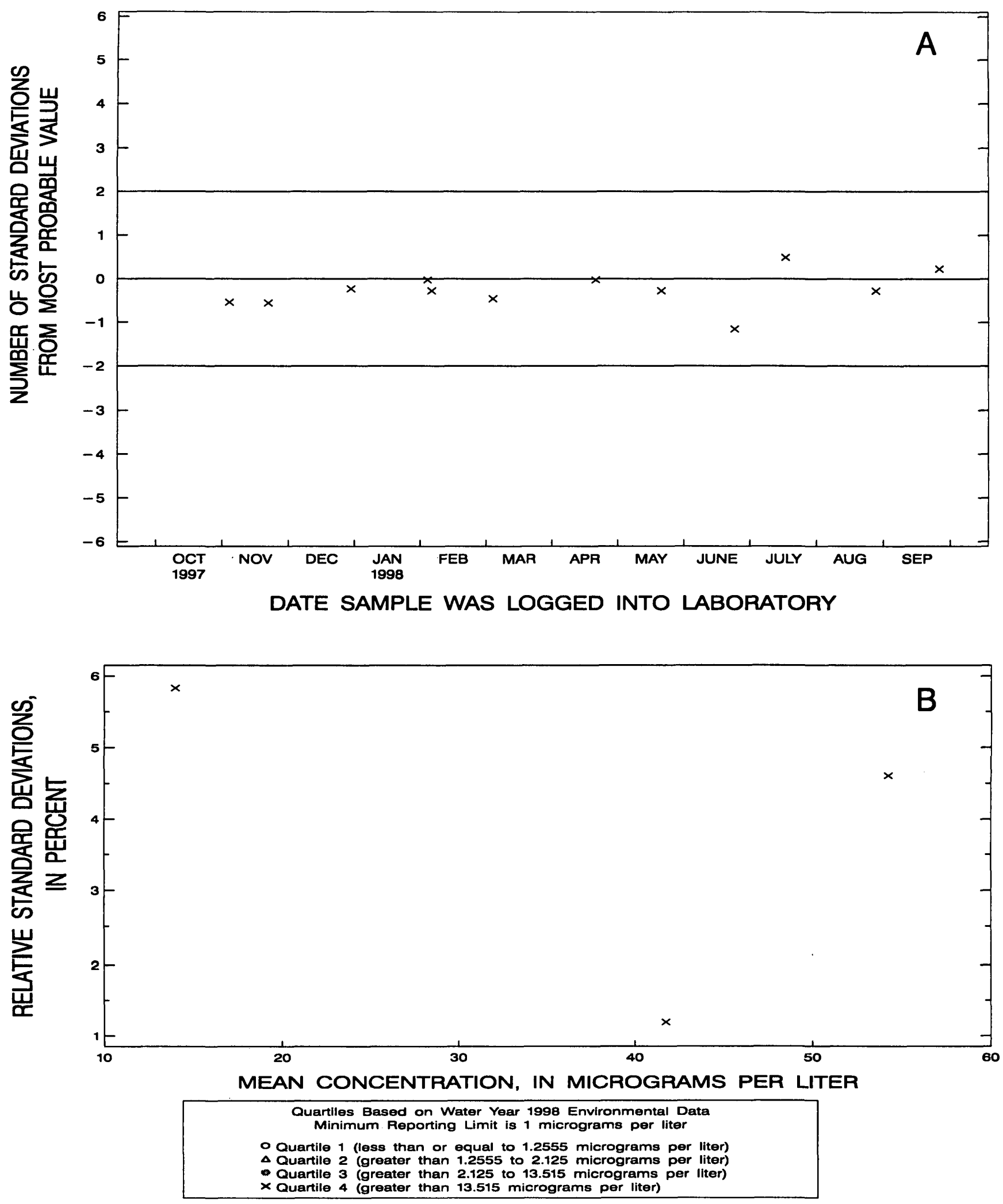

Figure 139. Nickel, whole-water recoverable, (inductively coupled plasma-atomic emission spectrometry, trace) data from the Quality of Water Service Unit laboratory. 

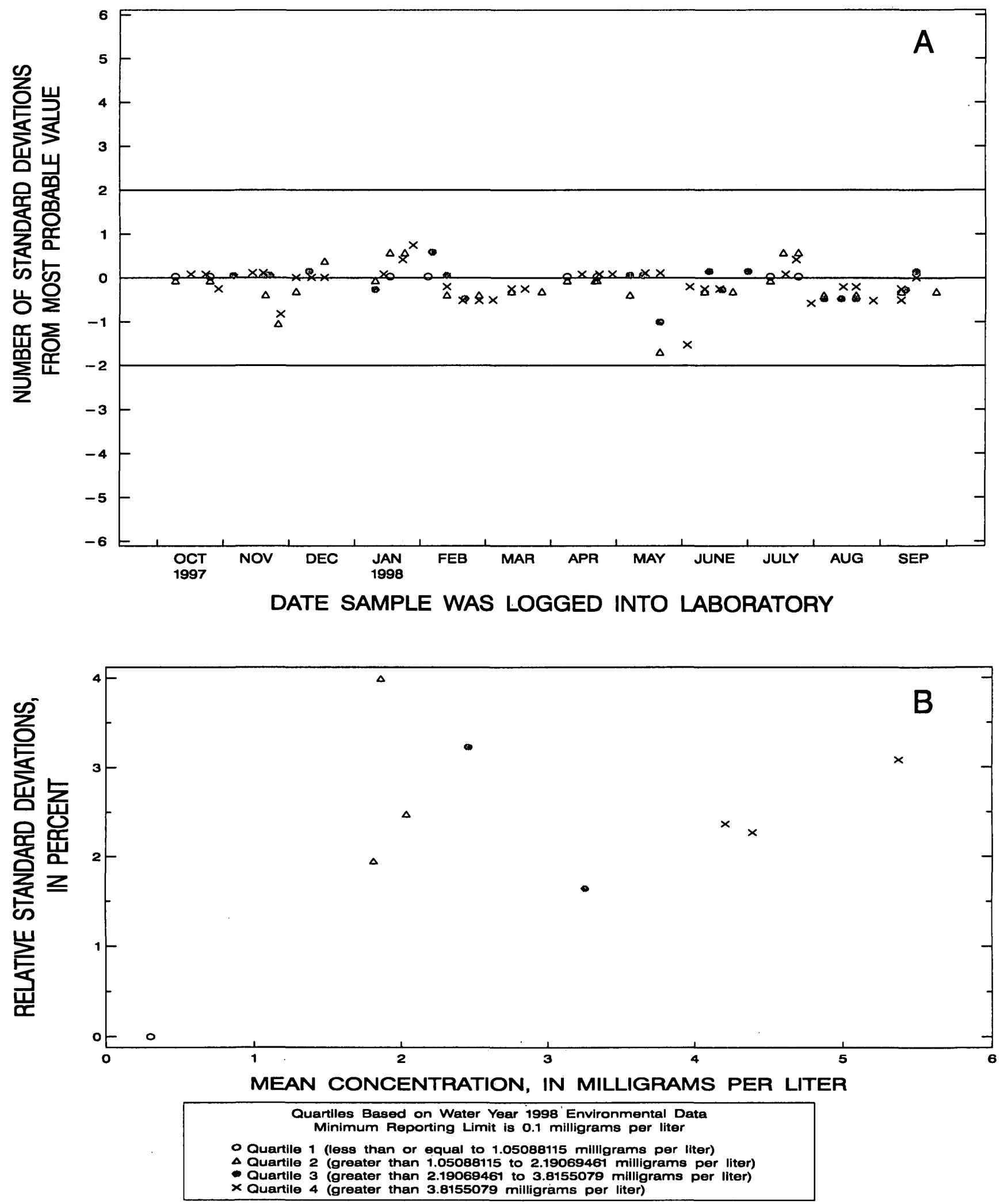

Figure 140. Potassium, dissolved, (flame-atomic absorption spectrophotometry) data from the Quality of Water Service Unit laboratory. 

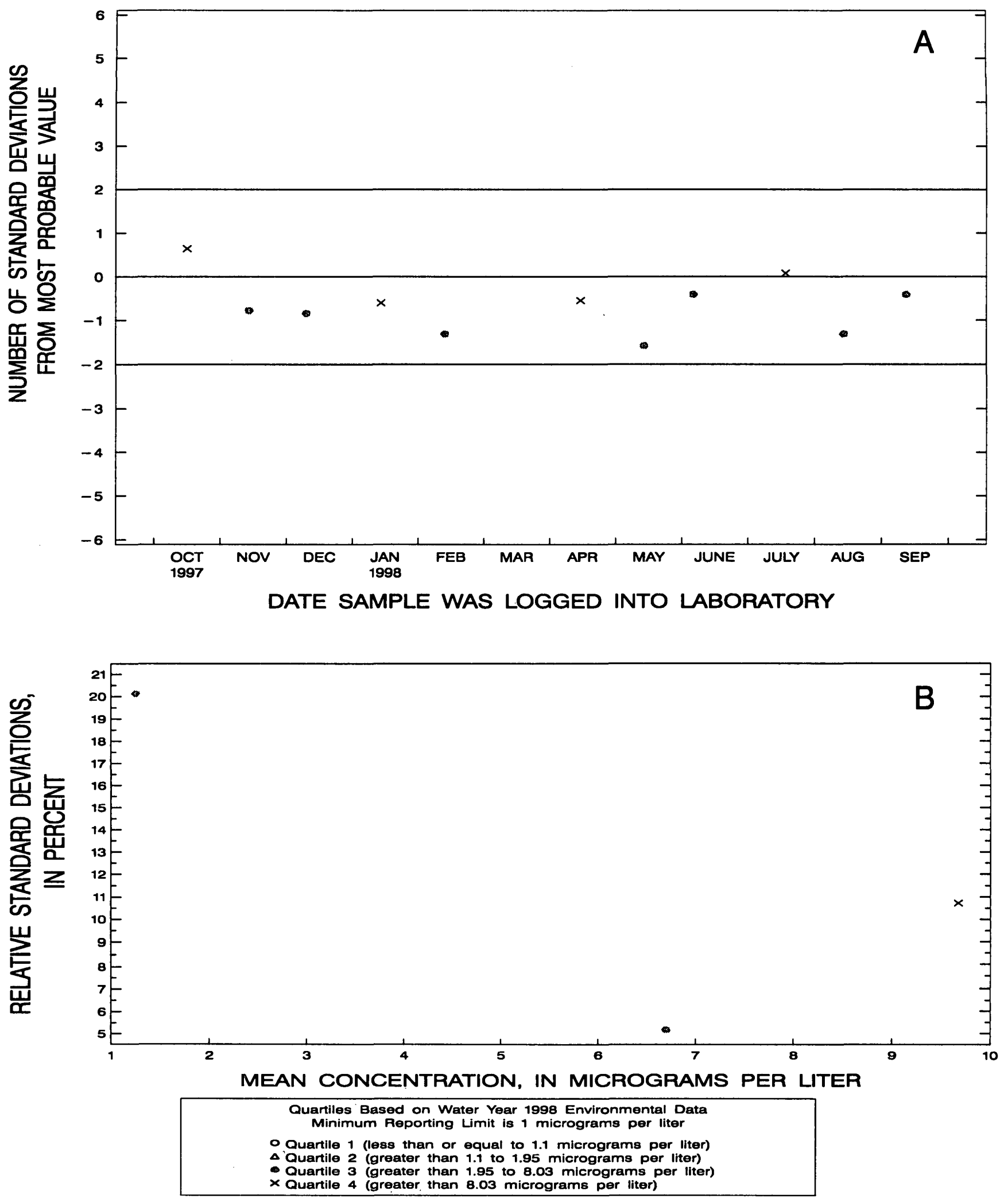

Figure 141. Selenium, dissolved, (graphite furnace-atomic absorption spectrophotometry) data from the Quality of Water Service Unit laboratory. 

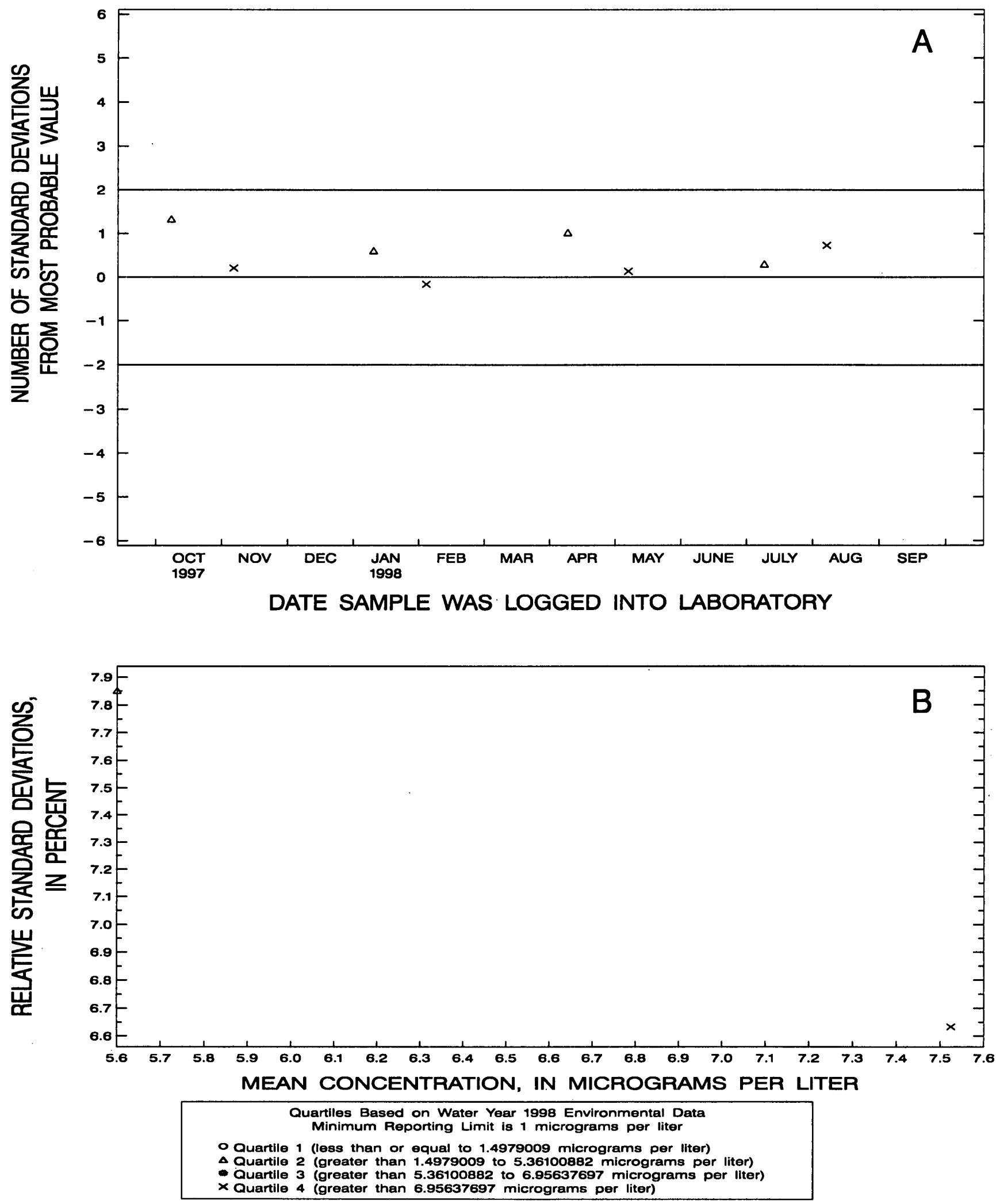

Figure 142. Selenium, whole-water recoverable, (graphite furnace-atomic absorption spectrophotometry) data from the Quality of Water Service Unit laboratory. 

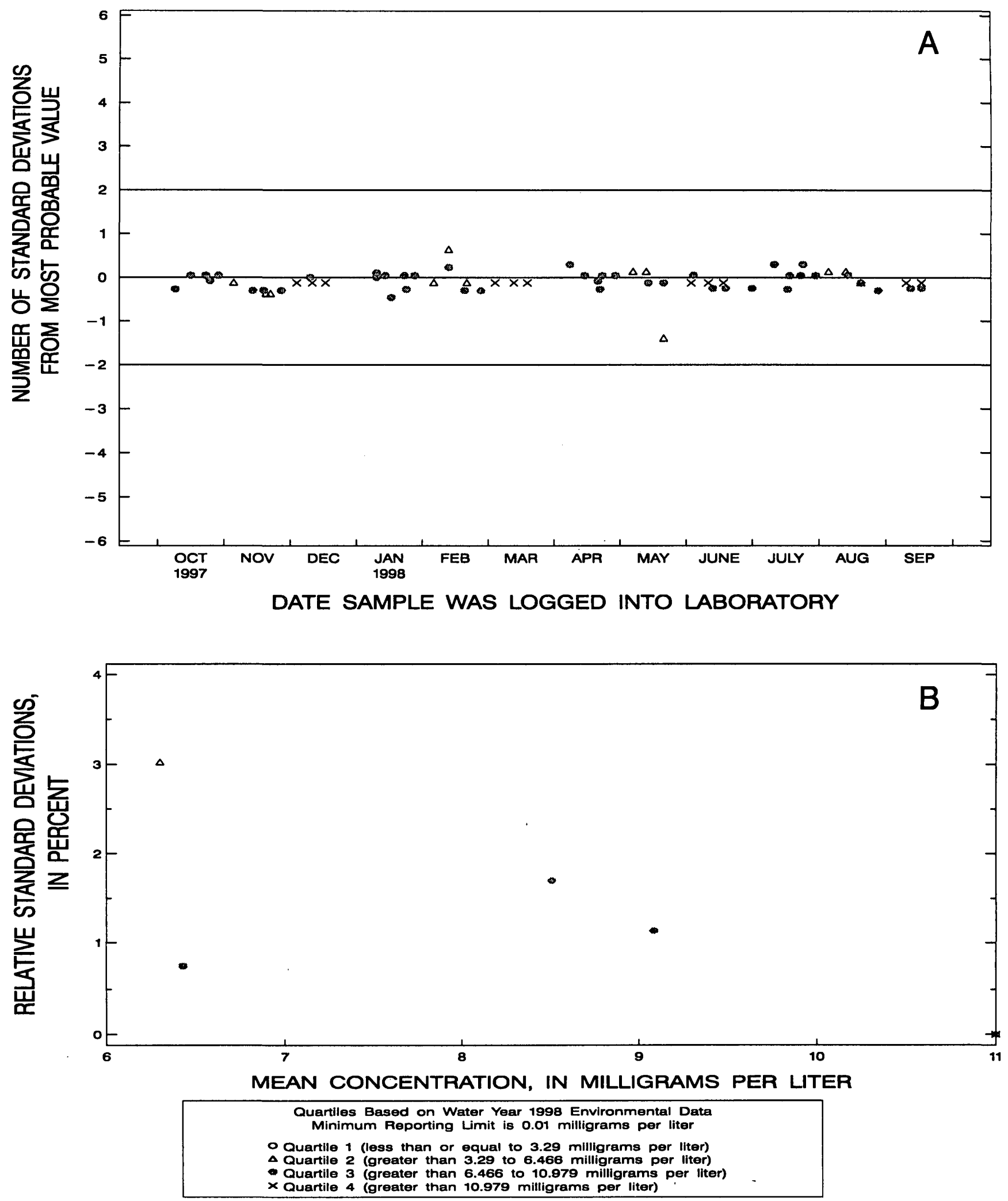

Figure 143. Silica, dissolved, (inductively coupled plasma-atomic emission spectrometry) data from the Quality of Water Service Unit laboratory. 

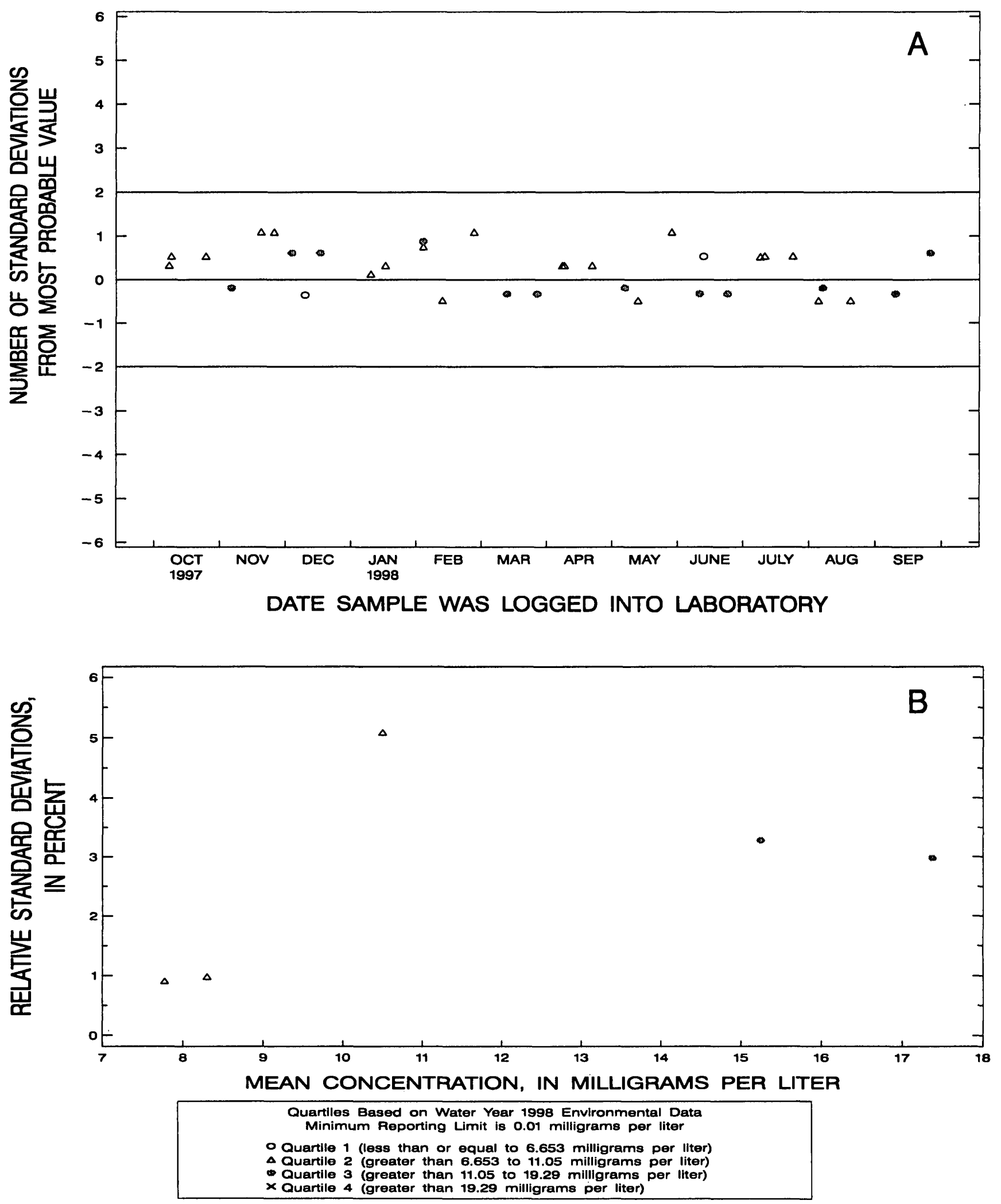

Figure 144. Silica, dissolved, (inductively coupled plasma-atomic emission spectrometry, trace) data from the Quality of Water Service Unit laboratory. 

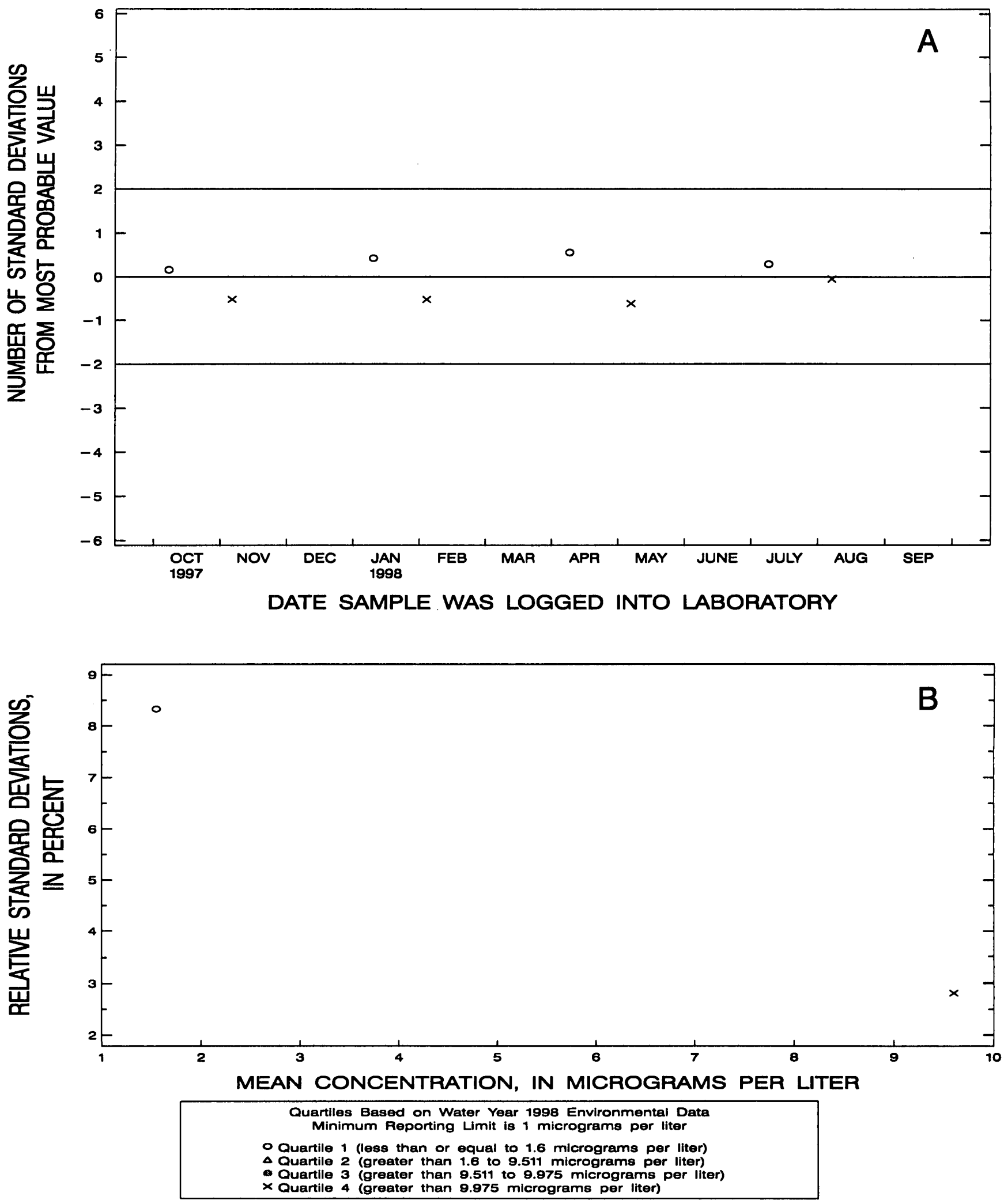

Figure 145. Silver, dissolved, (inductively coupled plasma-atomic emission spectrometry, trace) data from the Quality of Water Service Unit laboratory. 

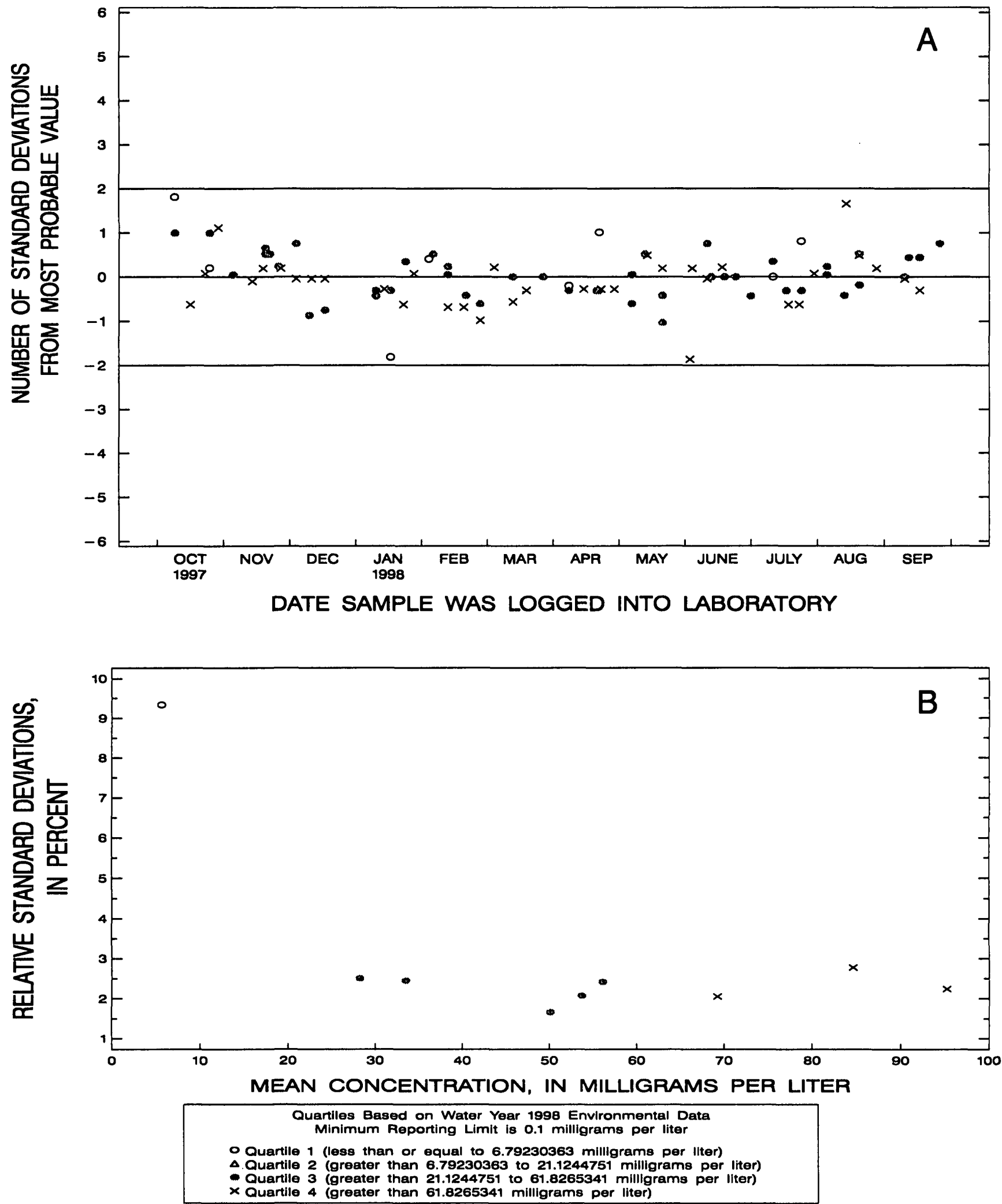

Figure 146. Sodium, dissolved, (flame-atomic absorption spectrophotometry) data from the Quality of Water Service Unit laboratory. 

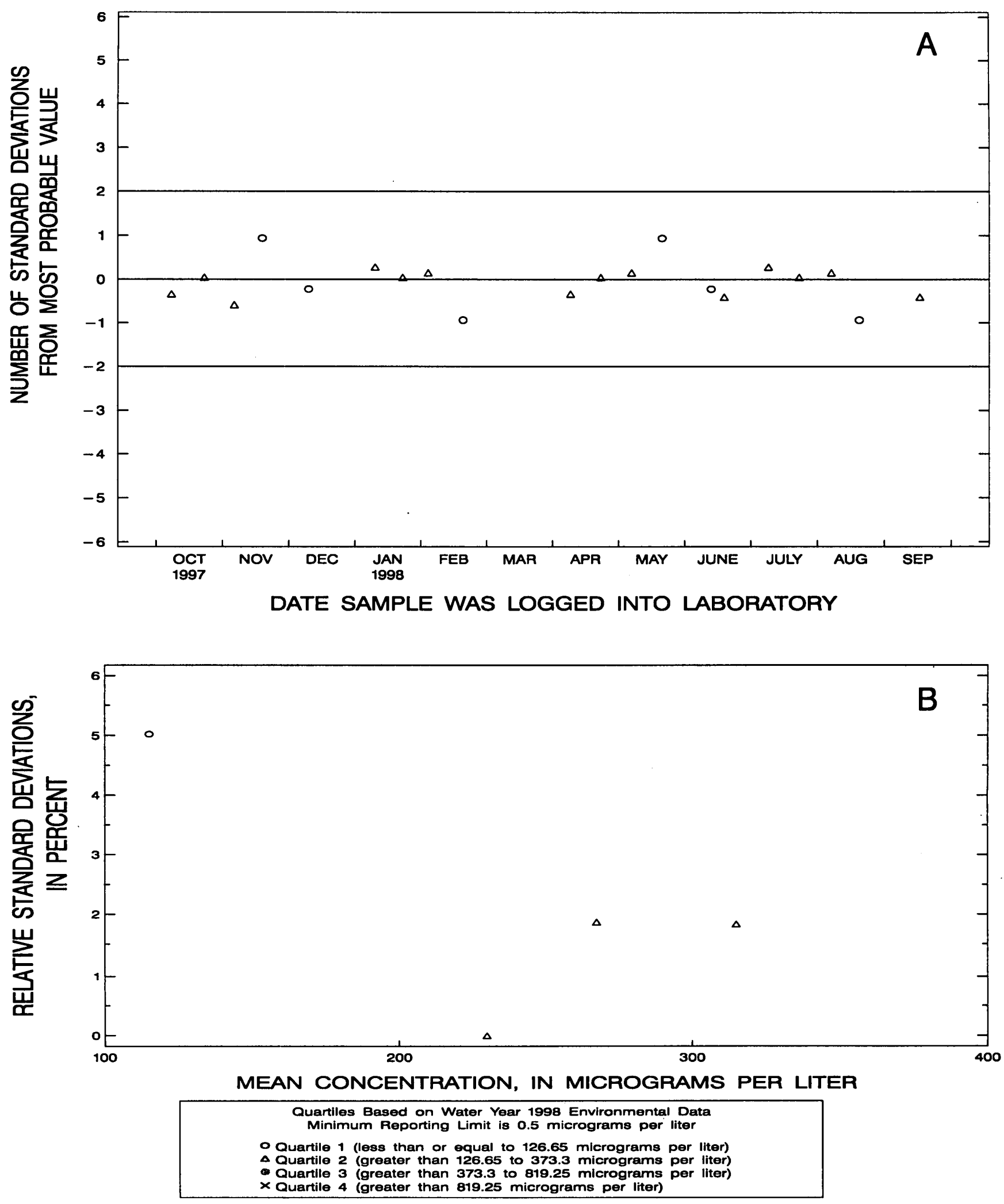

Figure 147. Strontium, dissolved, (inductively coupled plasma-atomic emission spectrometry, trace) data from the Quality of Water Service Unit laboratory. 


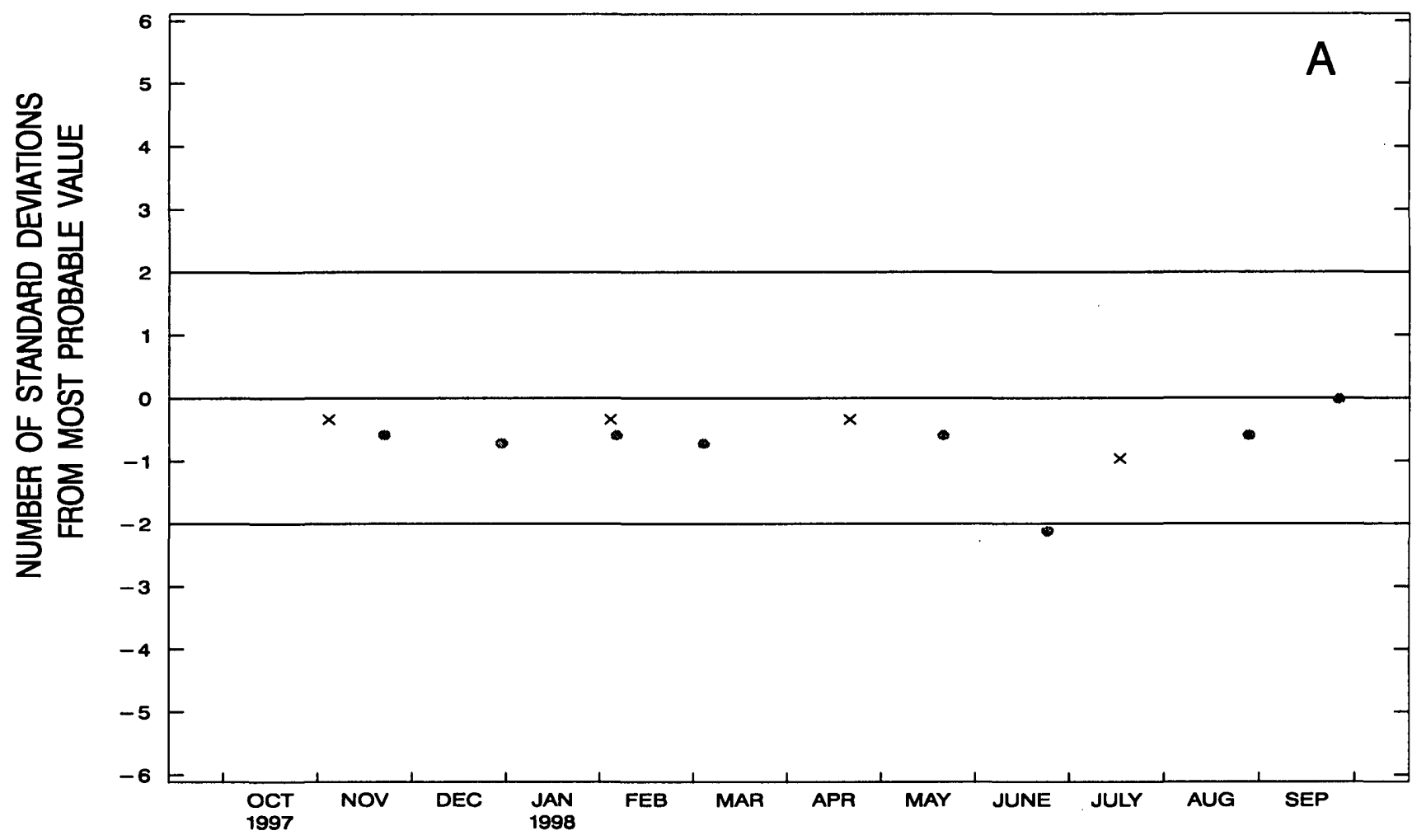

DATE SAMPLE WAS LOGGED INTO LABORATORY

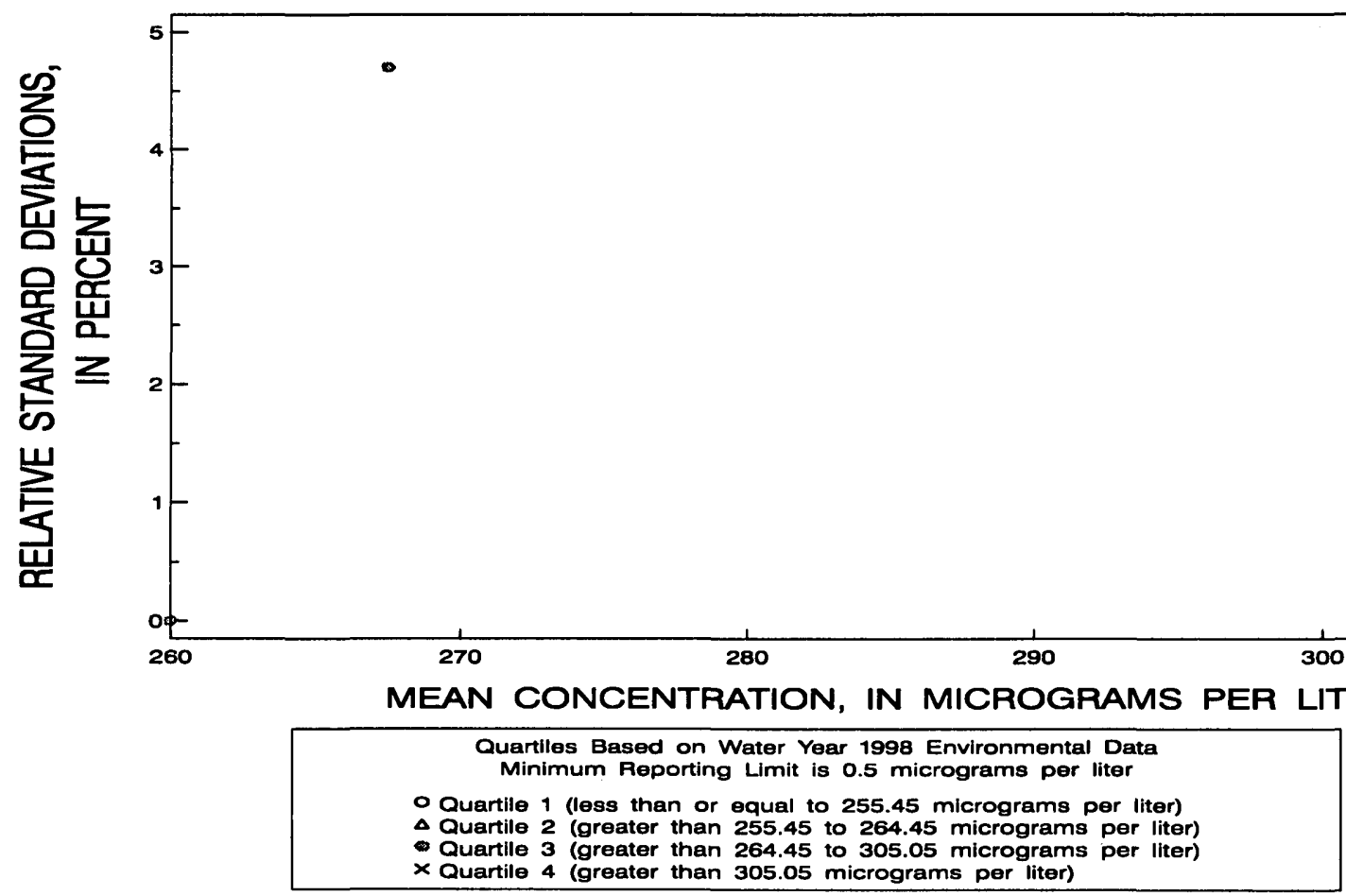

Figure 148. Strontium, whole-water recoverable, (inductively coupled plasma-atomic emission spectrometry, trace) data from the Quality of Water Service Unit laboratory. 

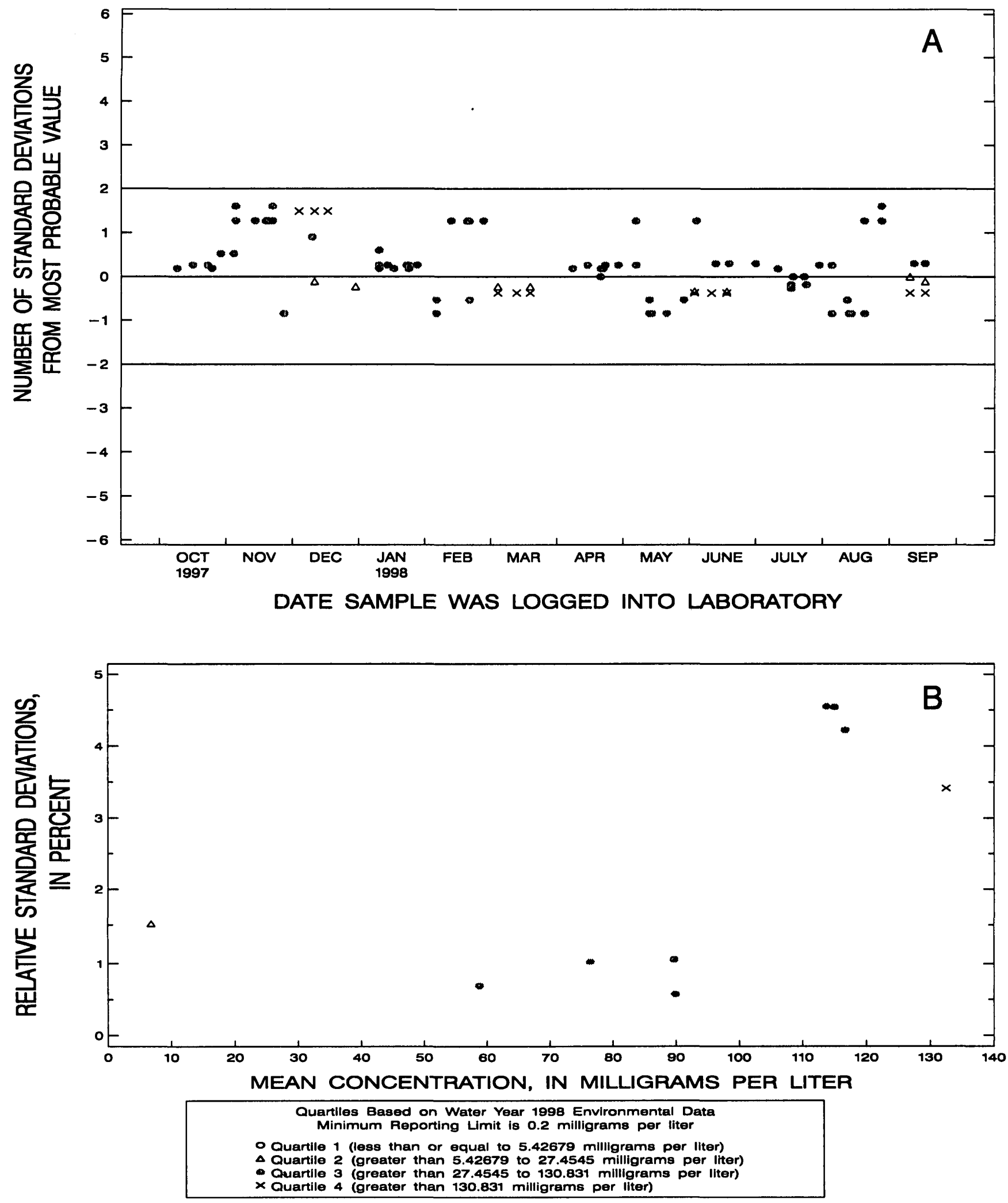

Figure 149. Sulfate, dissolved, (ion chromatography) data from the Quality of Water Service Unit laboratory. 

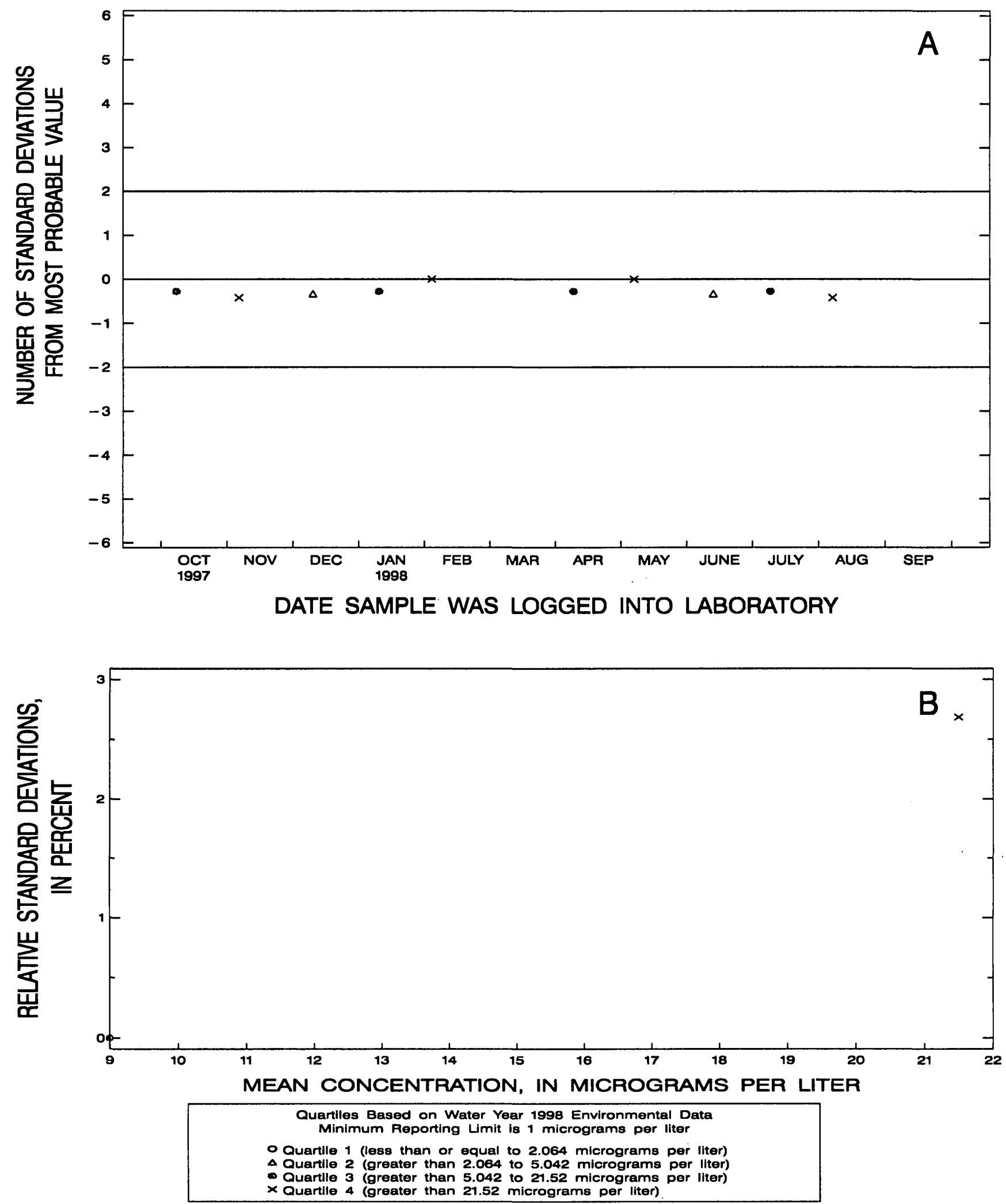

Figure 150. Vanadium, dissolved, (inductively coupled plasma-atomic emission spectrometry, trace) data from the Quality of Water Service Unit laboratory. 

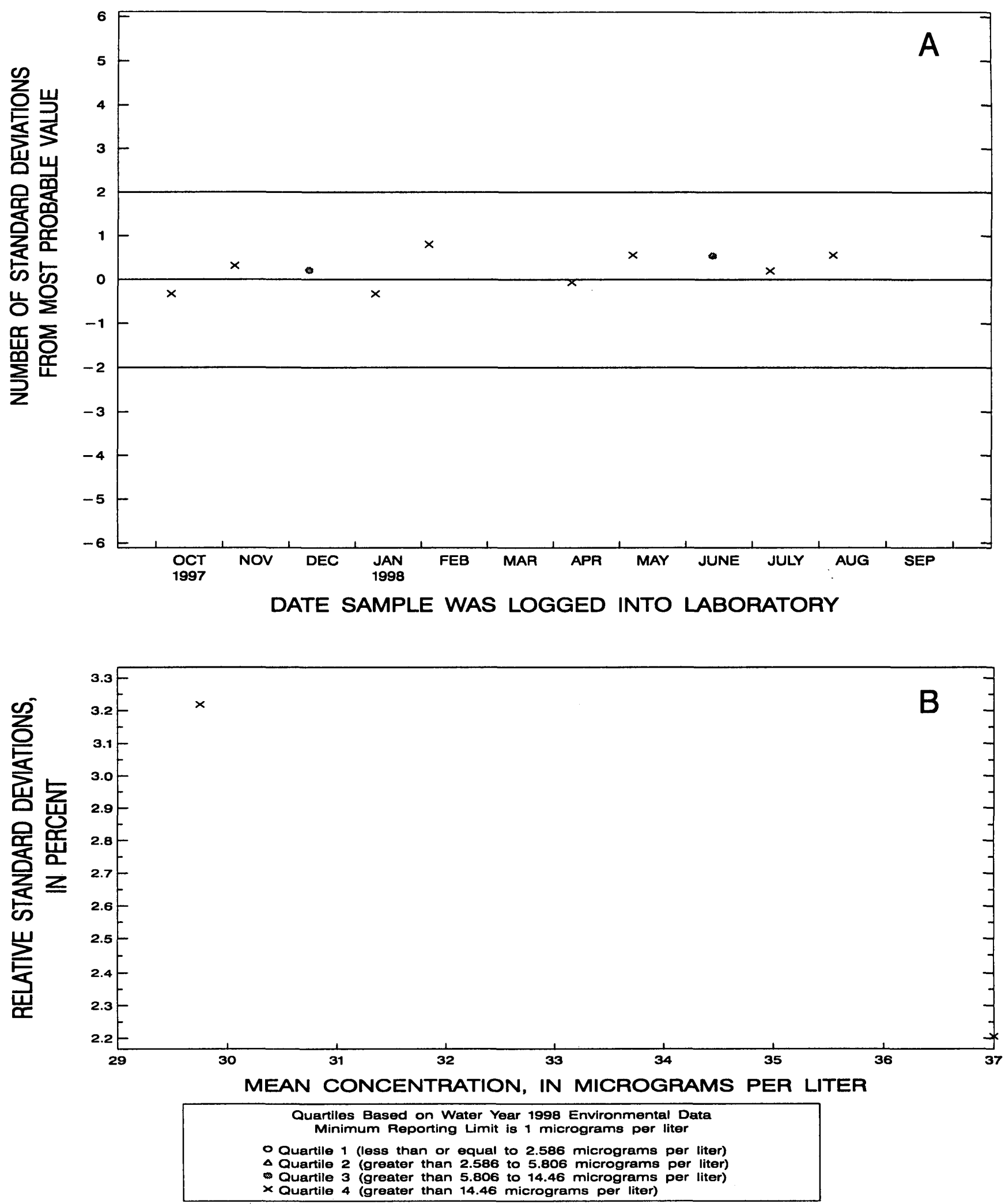

Figure 151. Zinc, dissolved, (inductively coupled plasma-atomic emission spectrometry, trace) data from the Quality of Water Service Unit laboratory. 

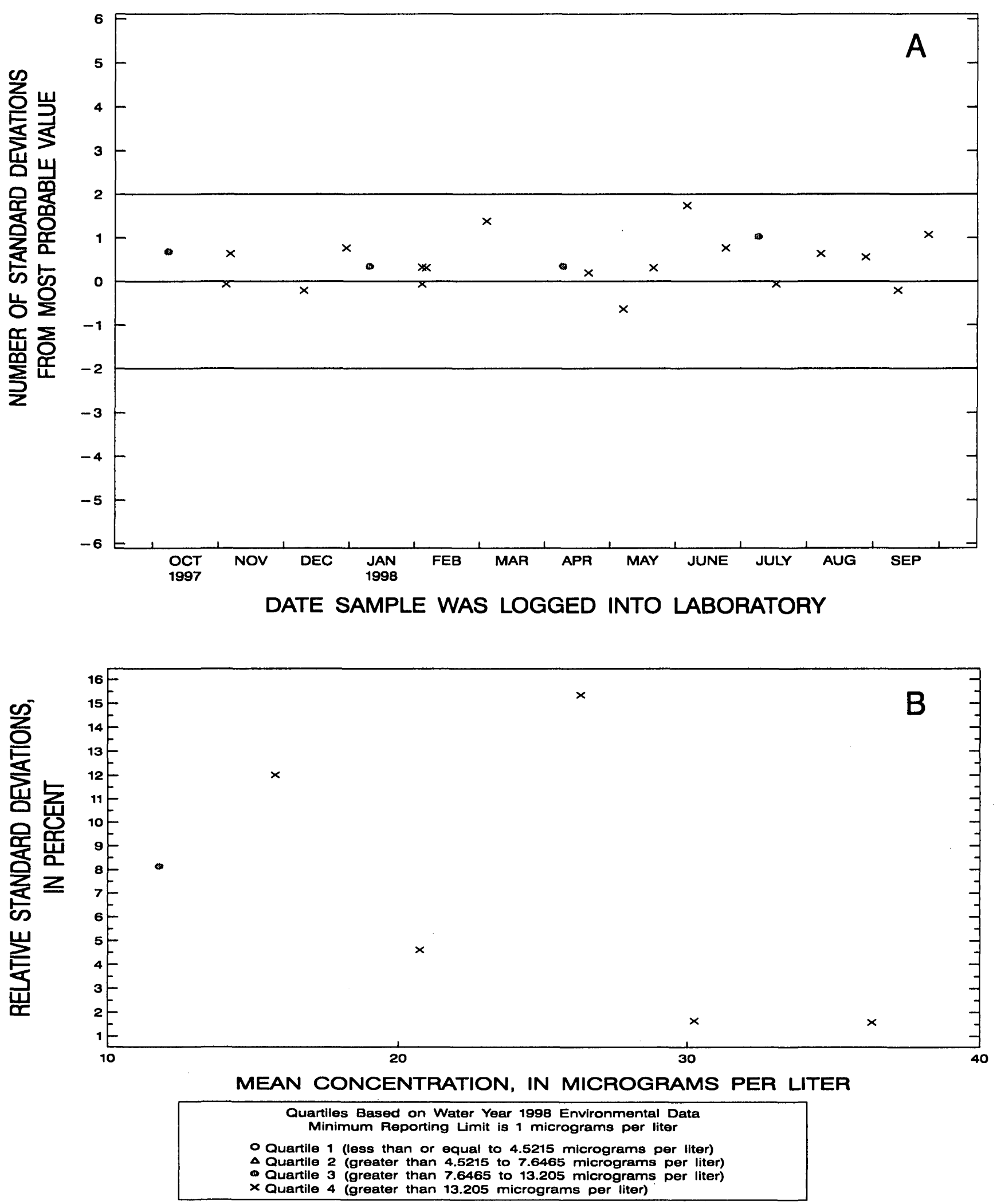

Figure 152. Zinc, whole-water recoverable, (inductively coupled plasma-atomic emission spectrometry, trace) data from the Quality of Water Service Unit laboratory. 

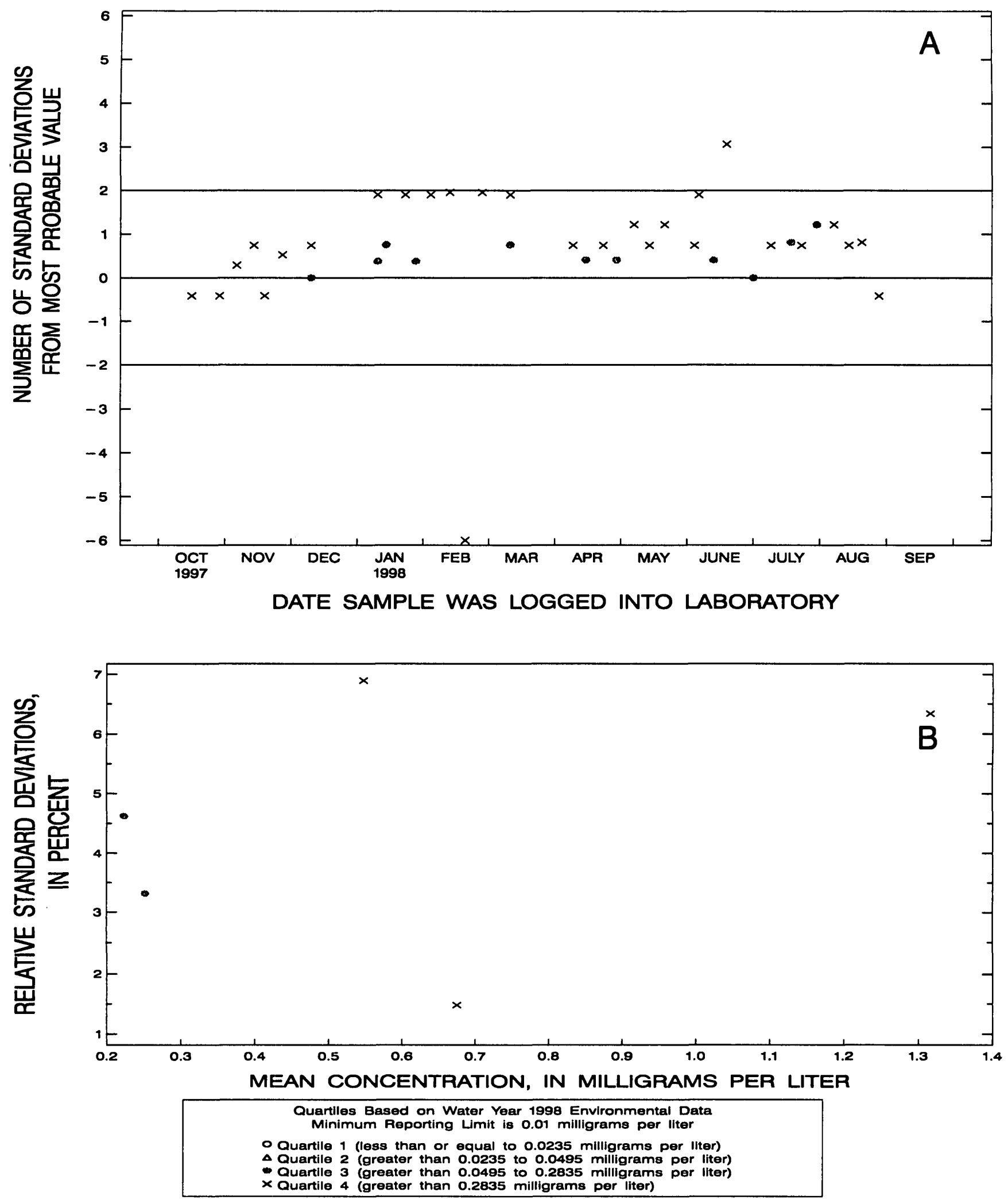

Figure 153. Ammonia as nitrogen, dissolved, data from the Quality of Water Service Unit laboratory. 


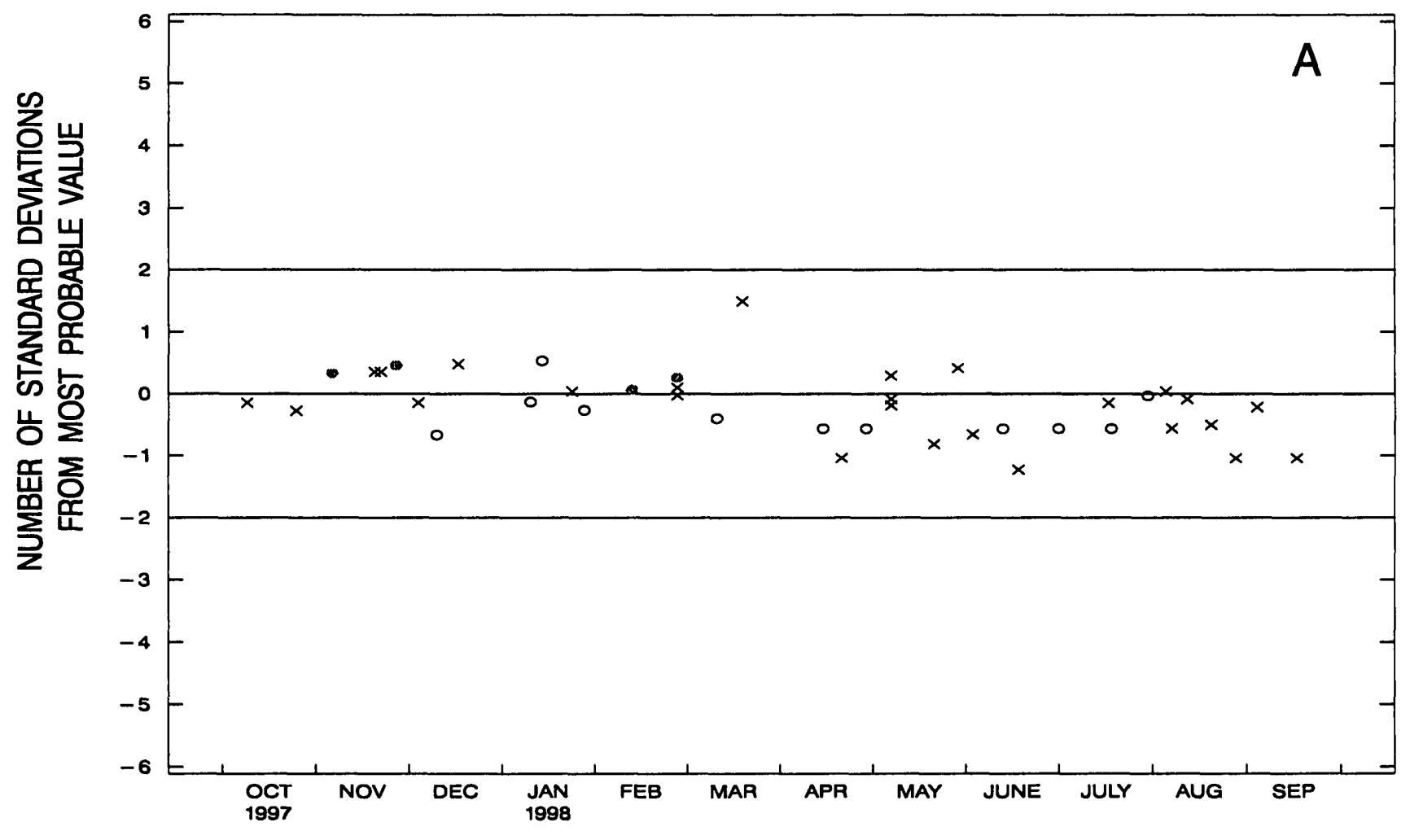

DATE SAMPLE WAS LOGGED INTO LABORATORY

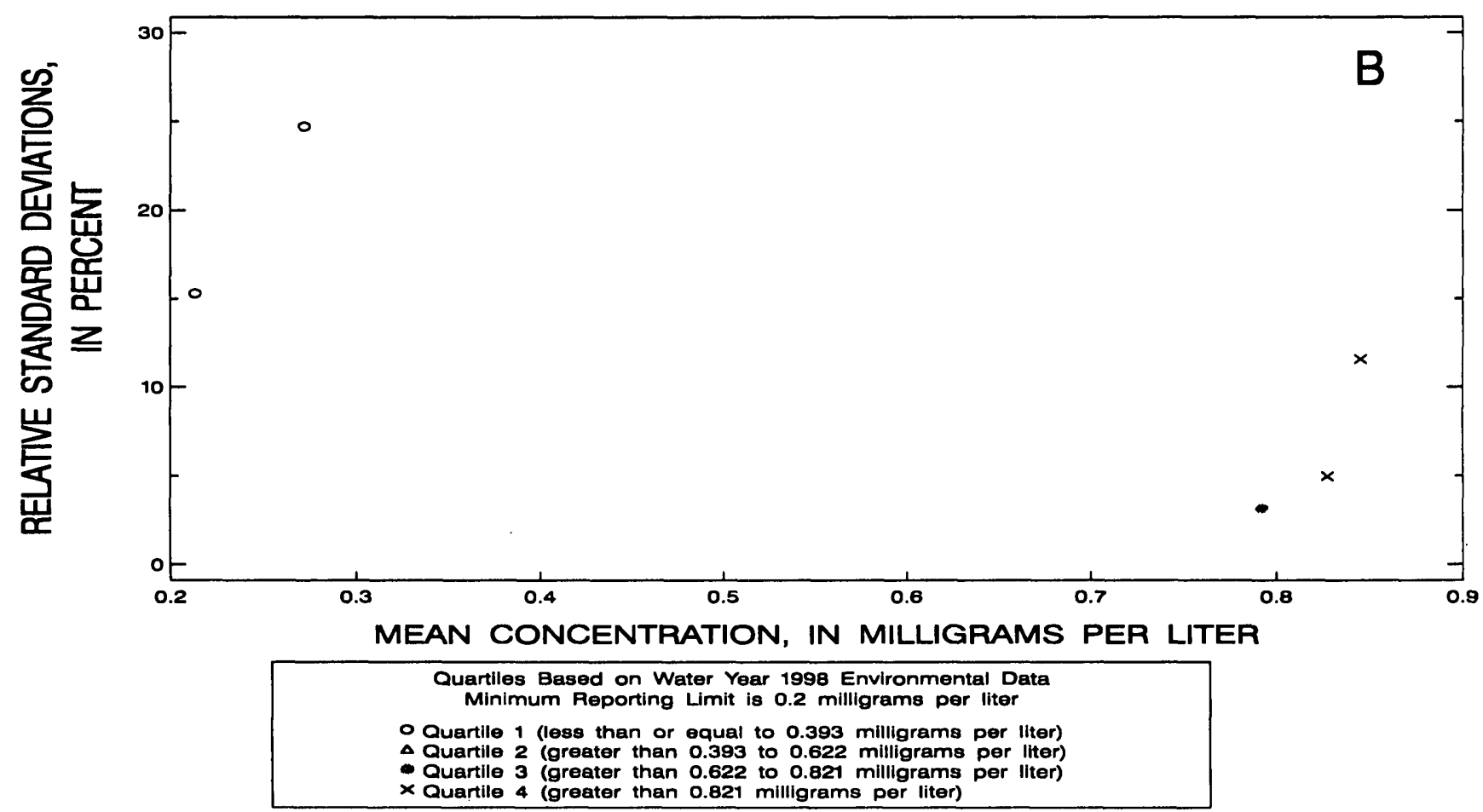

Figure 154. Ammonia plus organic nitrogen as nitrogen, dissolved, data from the Quality of Water Service Unit laboratory. 

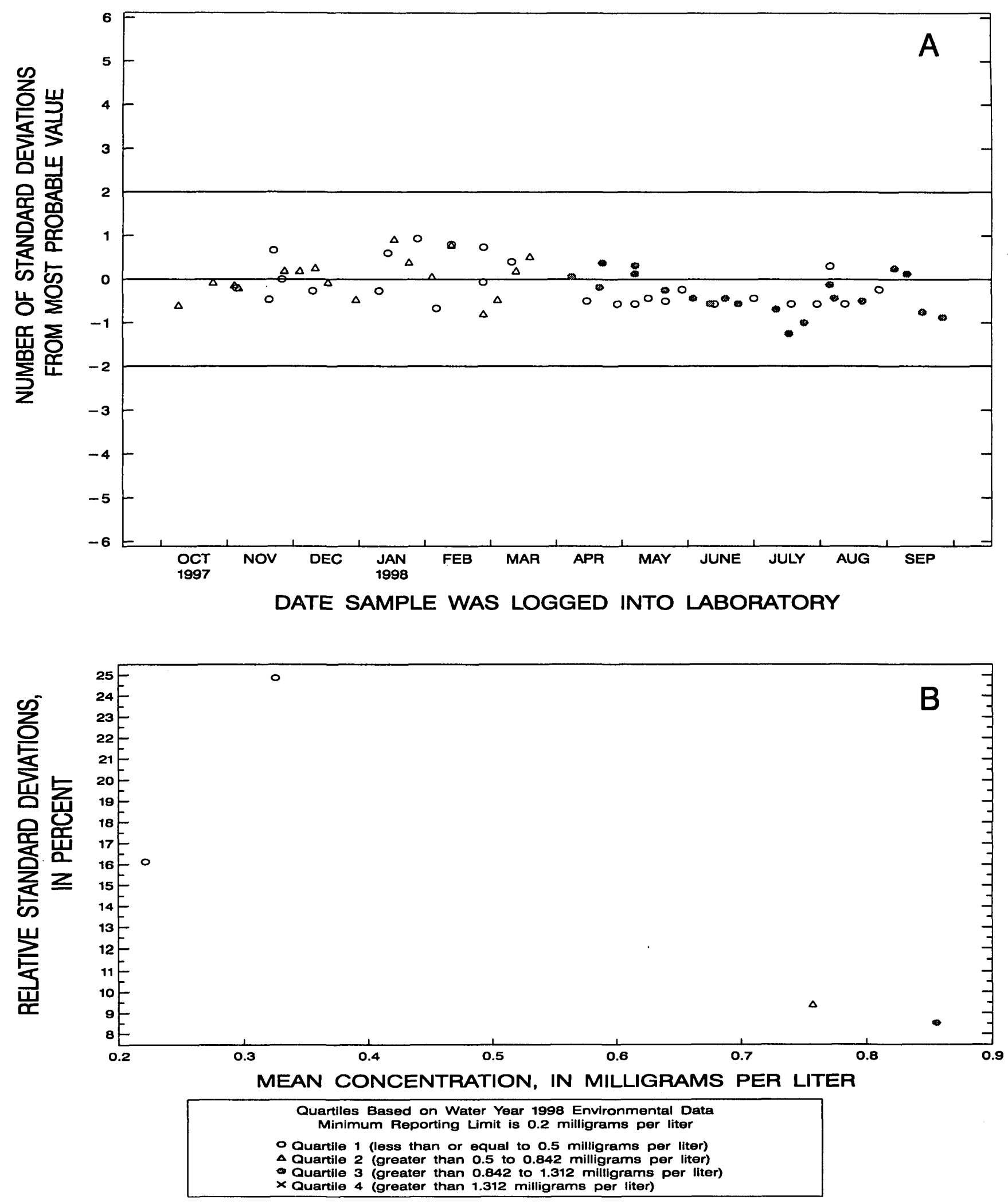

Figure 155. Ammonia plus organic nitrogen as nitrogen, whole-water recoverable, data from the Quality of Water Service Unit laboratory. 

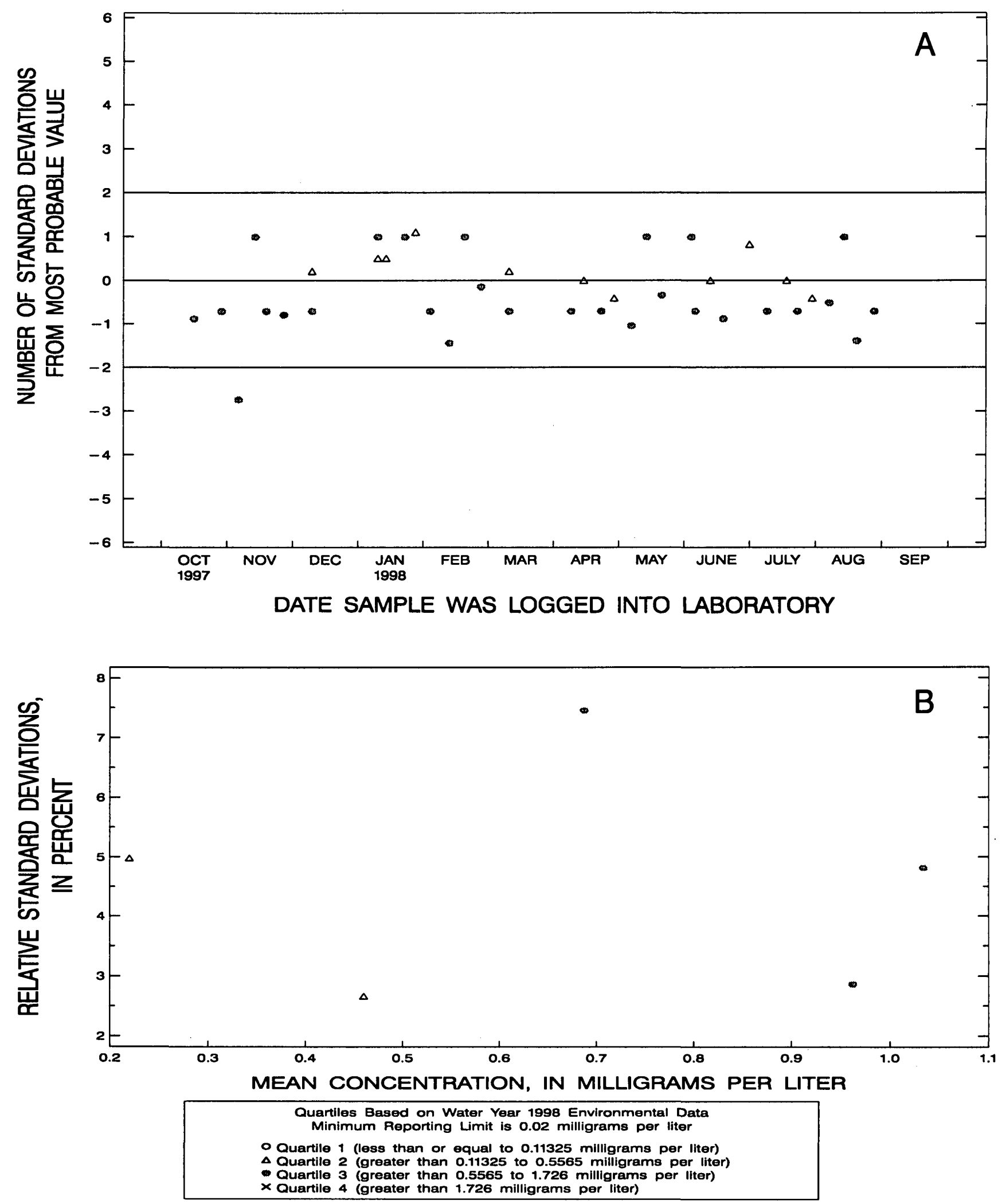

Figure 156. Nitrate plus nitrite as nitrogen, dissolved, data from the Quality of Water Service Unit laboratory. 

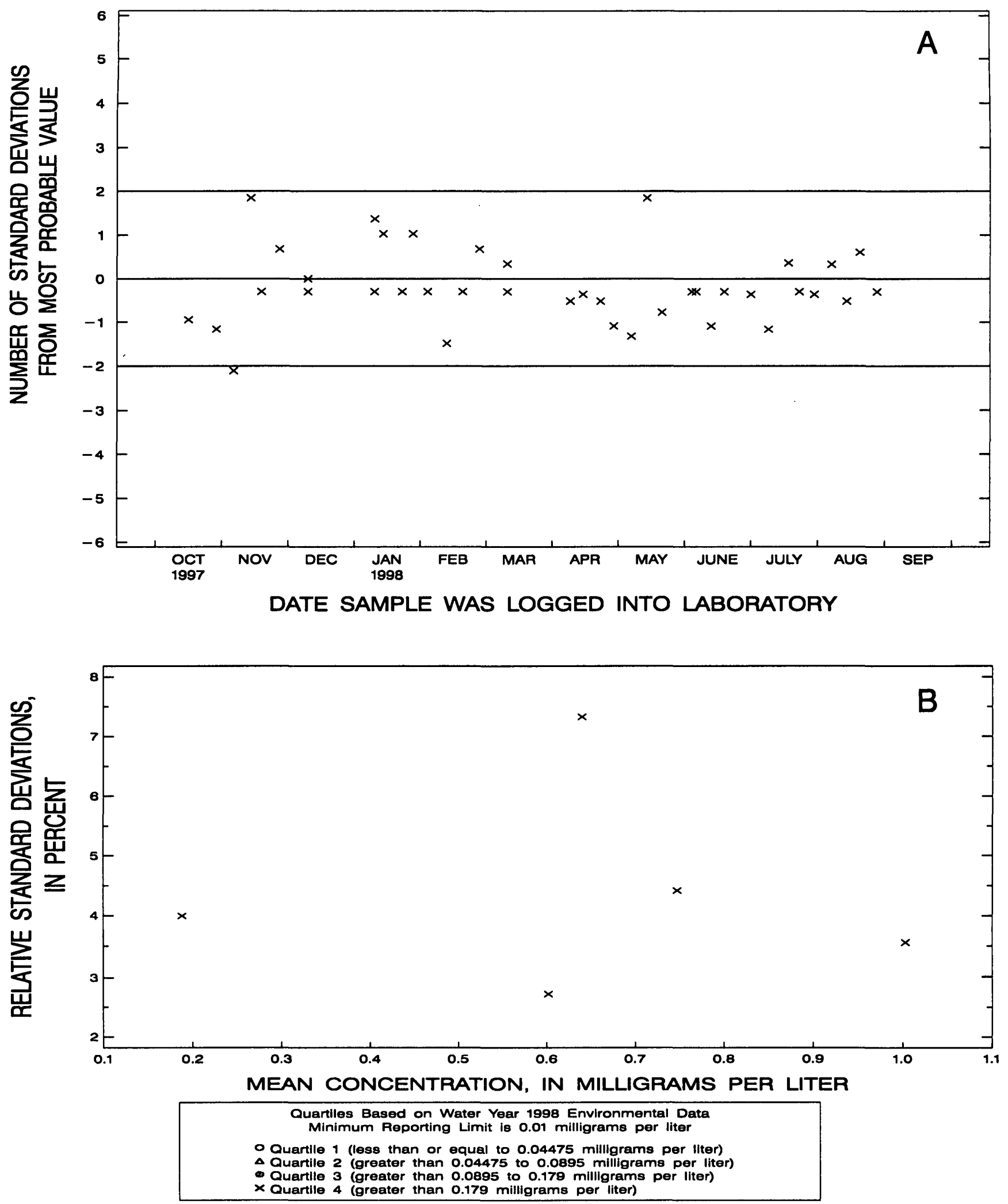

Figure 157. Orthophosphate as phosphorus, dissolved, data from the Quality of Water Service Unit laboratory. 

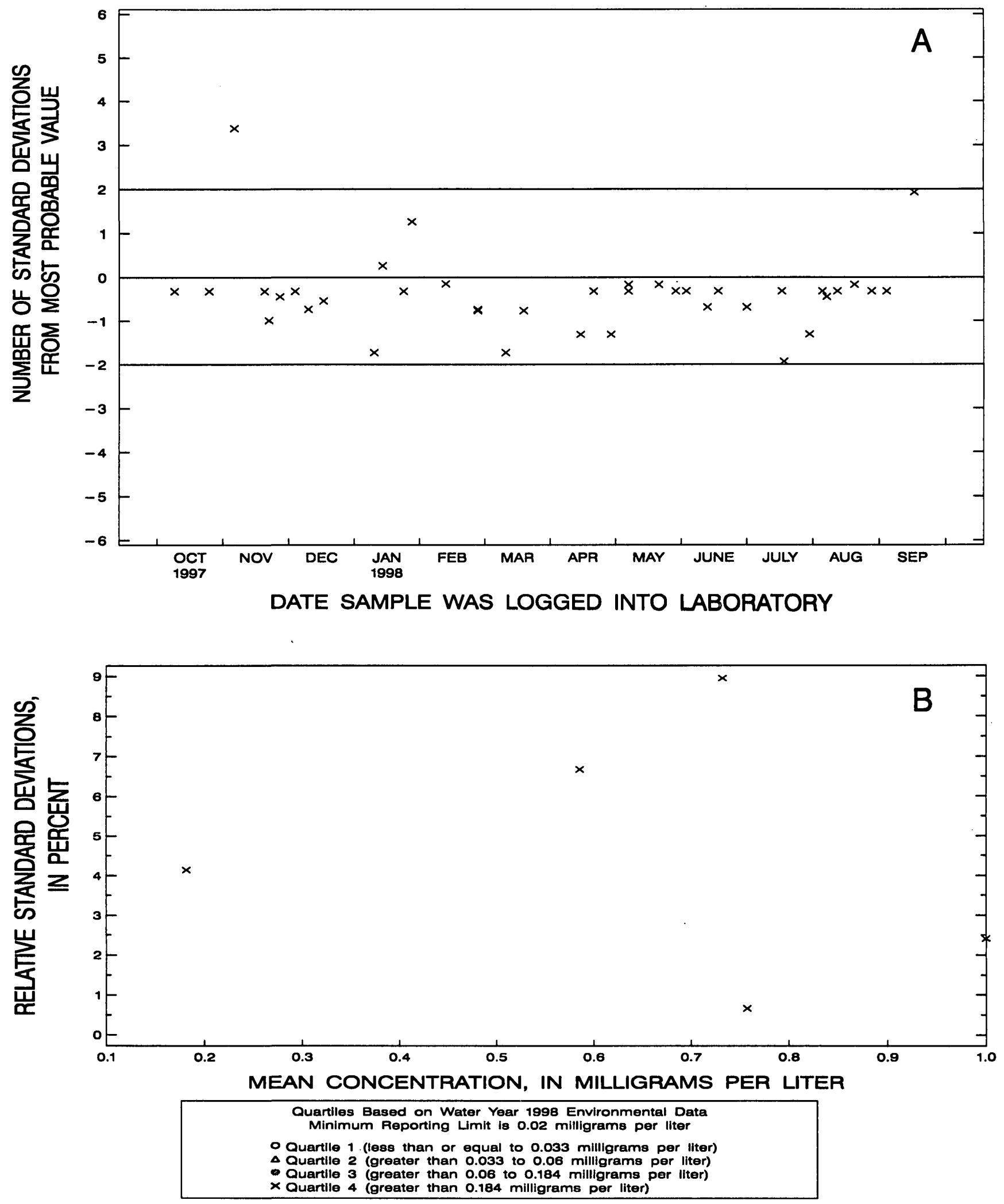

Figure 158. Phosphorus, dissolved, data from the Quality of Water Service Unit laboratory. 

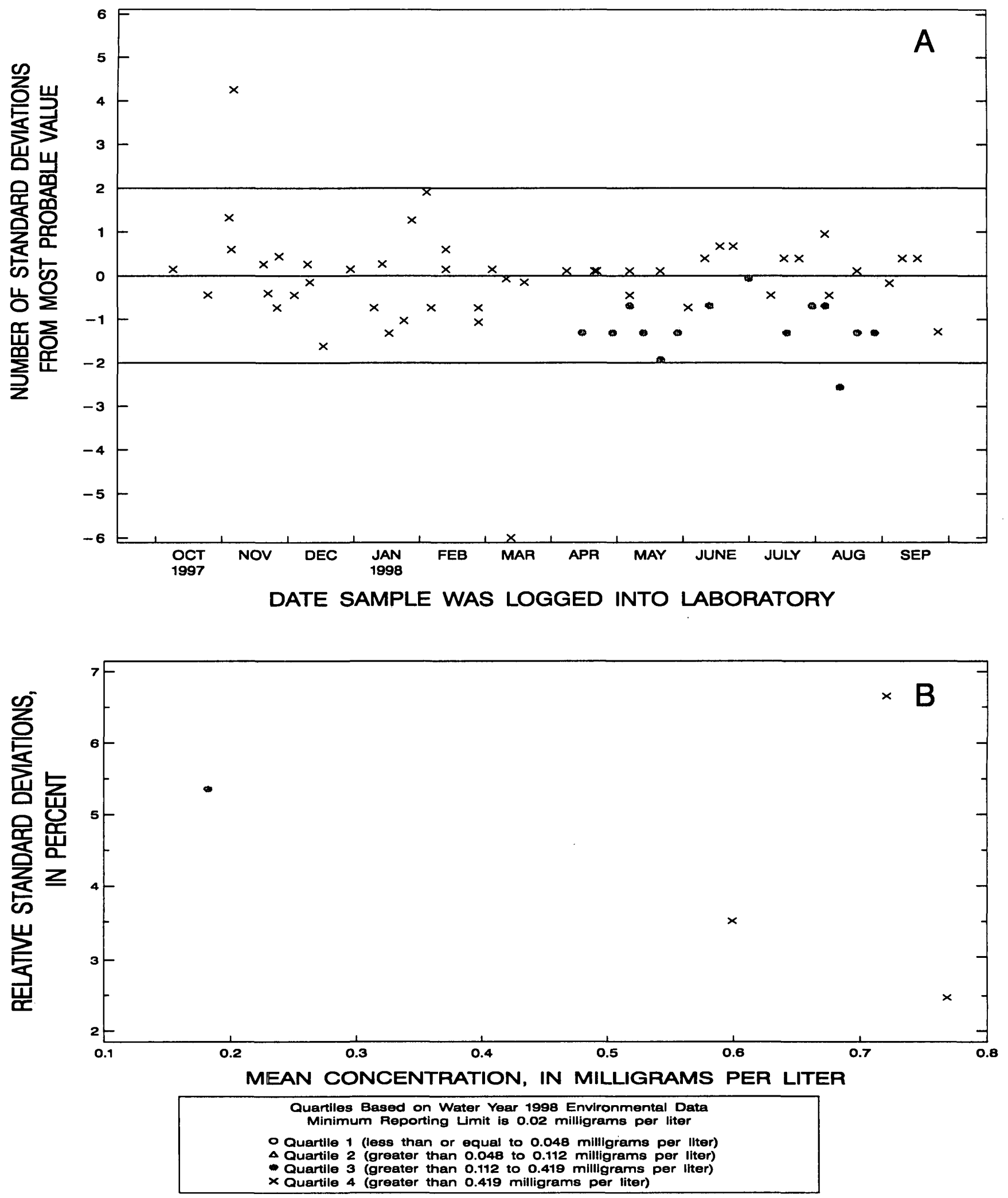

Flgure 159. Phosphorus, whole-water recoverable, data from the Quality of Water Service Unit laboratory. 
